RENATO TOSHIO YAMASSAKI

\title{
UM PROGRAMA DE ELEMENTOS FINITOS EM GPU E ORIENTADO A OBJETOS PARA ANÁLISE DINÂMICA NÃO LINEAR DE ESTRUTURAS
}

\author{
Tese apresentada à Escola Politécnica \\ da Universidade de São Paulo para \\ obtenção do título de Doutor em \\ Ciências
}

São Paulo

2014 

RENATO TOSHIO YAMASSAKI

\title{
UM PROGRAMA DE ELEMENTOS FINITOS EM GPU E ORIENTADO A OBJETOS PARA ANÁLISE DINÂMICA NÃO LINEAR DE ESTRUTURAS
}

\author{
Tese apresentada à Escola Politécnica \\ da Universidade de São Paulo para \\ obtenção do título de Doutor em \\ Ciências \\ Área de Concentração: \\ Engenharia Mecânica de Projeto e \\ Fabricação
}

Orientador: Prof. Livre-Docente Marcílio Alves

São Paulo

2014 
Este exemplar foi revisado e alterado em relação à versão original, sob responsabilidade única do autor e com a anuência de seu orientador.

São Paulo, 28 de maio de 2014

Assinatura do autor

Assinatura do orientador

\section{FICHA CATALOGRÁFICA}

Yamassaki, Renato Toshio

Um programa de elementos finitos em GPU e orientado a objetos para análise dinâmica não linear de estruturas / R. T. Yamassaki. - São Paulo, 2014.

$352 \mathrm{p}$.

Tese (Doutorado) - Escola Politécnica da Universidade de São Paulo. Departamento de Engenharia Mecatrônica e de Sistemas Mecânicos.

1. Método dos elementos finitos 2. Estruturas (Impacto) 3. Sistemas não-lineares 4. Projeto de software orientado a objetos 5. Computação paralela I. Universidade de São Paulo. Escola Politécnica. Departamento de Engenharia Mecatrônica e de Sistemas Mecânicos II.t. 
A Deus, minha mãe, meu irmão e minhas plantas (!) 



\section{Agradecimentos}

Primeiramente, agradeço a Deus pela grande ajuda em tornar este trabalho realidade. Em seguida, duas pessoas foram meus grandes mentores e exemplos que ouvi e segui durante todo este tempo: minha mãe, Amélia, e meu irmão, Ricardo. Durante o doutorado, mesmo quando eu me perdia em devaneios sobre a arquitetura do programa ou contava sobre as ideias malucas que tinha, eles sempre ouviam atentamente, sendo as pessoas com quem mais compartilhei as alegrias e tristezas ao longo do processo. Amélia e Ricardo, muito obrigado por tudo!

Recebi bastante apoio dos meus colegas no GMSIE, o Grupo de Mecânica dos Sólidos e Impacto em Estruturas. Seguem agradecimentos especiais para Rafael Santiago, Rafael Moura, Roberto Oshiro, Leonardo Mazzariol e Miguel Gonzales, pela paciência e oferecerem boas ideias, além de explicar nãolinearidade para um não-engenheiro.

Seguem também agradecimentos à Profa. Larissa Driemeier, pelas explicações iniciais em não-linearidade, e ao Prof. Marco Lúcio Bittencourt, pelas valiosas discussões. E, é claro, não podia faltar agradecimentos ao meu orientador, o Prof. Marcílio Alves, que me ofereceu esta grande oportunidade, para um aluno de computação e me apoiou enquanto eu desvendava a área de Engenharia. Por último, agradeço à CAPES pelo financiamento concedido e à Escola Politécnica e à Universidade de São Paulo, pelo oferecimento das instalações onde foi realizado o trabalho.

Fui excêntrico ao dedicar este trabalho às minhas plantas. O estresse que sofri por causa da demanda por resultados quase me abalou física e mentalmente. Cultivar plantas foi o que me garantiu dias menos estressantes, se tornando uma verdadeira terapia. Aliás, para esclarecer, alguns nomes dos componentes da arquitetura do programa aqui discutido são nomes de plantas que cultivo. 



\section{RESUMO}

É notório que o emprego de unidades de processamento gráfico (GPU) pode acelerar significativamente métodos numéricos de aplicações científicas. Para suportar essa nova tecnologia, é necessário que programas sejam readaptados, exigindo flexibilidade do código. Nesse trabalho, é apresentada a arquitetura de um programa de elementos finitos (MEF) para a análise de estruturas, com suporte ao processamento em GPU. A orientação a objetos é usada para guiar o desenvolvimento e modelar o código em uma estrutura flexível. A escalabilidade do programa é dada pela extensão de suas funcionalidades através de componentes carregados em tempo de execução. Para ilustrar a robustez do código, o software é aplicado para o estudo de dinâmica estrutural, considerando aspectos complexos de não linearidade de material (plasticidade) e geometria (grandes deslocamentos). A acurácia do código é verificada através da comparação com problemas conhecidos da literatura e com as soluções MEF comerciais (ABAQUS). As comparações mostraram uma boa concordância nos resultados. O speedup da GPU é analisado em relação aos tempos de CPU do próprio programa, sendo observado ganhos de desempenho de até 10 vezes.

Palavras-chaves: Método dos Elementos Finitos, estruturas, sistemas não-lineares, projeto de software orientado a objetos, computação paralela. 



\begin{abstract}
It has been recognized that the adoption of graphics processing units (GPU) can significantly boost numerical methods in scientific applications. In order to support such technology, it is necessary to readapt the program, which requires code flexibility. In this work, it is presented the architecture of a finite element (FEM) analysis program for structural analysis with GPU support. Object-oriented design is used to guide development and to build code into a flexible structure. Program scalability is achieved by extensibility of its features, provided by run-time loaded components. In order to demonstrate code robustness, the software is directed to the study of structural dynamics, considering complex non-linear aspects of material (plasticity) and geometry (large displacements). Code accuracy is checked by comparing with known literature problems and with commercial solver packages (ABAQUS). The comparison shows good agreement in the results. The GPU code speedup is analysed against timings of CPU program code, where it is observed performance gain up to 10 times.
\end{abstract}

Keywords: Finite Element Method, structures, non-linear systems, object-oriented software project, parallel computing. 
É autorizada a reprodução e divulgação total ou parcial deste trabalho, por qualquer meio convencional ou eletrônico, para fins de estudo e pesquisa, desde que citada a fonte. As informações contidas nesta obra foram revisadas cuidadosamente e tem como valor principal a sua contribuição científica. Porém, não são garantidas para atender a propósitos específicos, não sendo o autor responsável por quaisquer danos que possam ocorrer pelo seu uso.

O software apresentado neste trabalho faz uso de bibliotecas públicas gratuitas, desenvolvidas por terceiros. Foi empregada e modificada a biblioteca TinyXML 2, desenvolvida por Lee Thomason, Yves Berquin e Andrew Ellerton (licença zlib, disponível em http://www.grinninglizard.com/tinyxml2docs/index.html). O conjunto de bibliotecas Boost, cujo desenvolvimento foi iniciado por Beman Dawes e David Abrahams e é amparada pela licença Boost (http://www.boost.org/LICENSE_1_0.txt), foi empregada em diversas partes do código, principalmente a biblioteca Spirit.

Ao longo deste texto, são citadas várias marcas registradas. Ao invés de identificá-las com o símbolo $\circledR^{\circledR}$ a cada menção, os direitos de propriedades são listados abaixo. Em hipótese alguma, há a intenção de infringir a divulgação ou os direitos autorais sobre essas marcas. Outros nomes de produtos e marcas registradas são propriedades de seus respectivos proprietários.

- Windows, Windows Server, Visual Studio e C++ AMP são marcas registradas da Microsoft Corporation;

- Visual AssistX é marca registrada da Whole Tomato Software, Inc;

- Intel MKL, Pentium, Xeon e Core são marcas registradas da Intel Corporation;

- CUDA, GeForce e Tesla são marcas registradas da nVidia Corporation;

- MATLAB é marca registrada da Mathworks, Inc;

- Hyperworks é marca registrada da Altair Engineering, Inc;

- ABAQUS é marca registrada da Dassault Systèmes. 
Lista de Figuras xxi

Lista de Tabelas $\quad$ xxvii

Tabela de Listagens $\quad$ xxix

Tabela de Algoritmos xxxi

Convenção e Lista de Símbolos $\quad$ xxxiii

\begin{tabular}{ll|}
\hline CAPÍTULO 1 Introdução & 1
\end{tabular}

1.1 O Método dos Elementos Finitos 2

1.2 Dinâmica estrutural 4

1.3 Orientação a objetos aplicada em softwares de elementos finitos 8

1.4 Computação massivamente paralela em processadores gráficos 12

$\begin{array}{lll}1.5 & \text { Cenário nacional de pesquisa } & 15\end{array}$

\begin{tabular}{ll|l}
1.6 & Objetivos & 16
\end{tabular}

$\begin{array}{lll}1.7 & \text { Organização do trabalho } & 18\end{array}$

CAPÍtulo 2 O Método dos Elementos Finitos em análise estrutural 19

2.1 Visão geral do Método dos Elementos Finitos 19

2.2 Discretização do modelo 20

2.3 Procedimento geral de solução 21

2.3.1 Descrição do problema 22

2.3.2 Montagem das matrizes e vetores do sistema 23

2.3.3 Aplicação das condições de contorno 24 
2.4 Solução de problemas de equilíbrio estático linear 24

2.4 .1 Método do gradiente conjugado 25

2.5 Solução de problemas lineares de propagação 27

2.5.1 Método implícito de integração direta 28

2.5.2 Método explícito de integração direta 29

2.6 Tecnologias de elementos para análises lineares 33

2.6.1 Hexaedro linear isoparamétrico (simplex) 35

Matriz de rigidez do elemento 37

Matriz de massa do elemento 39

Matriz de amortecimento do elemento 39

Estado de deformação do elemento 40

Cálculo das forças internas 40

2.6.2 Deficiências e técnicas de melhoramento do elemento 41

Travamento e integração reduzida 41

Controle de hourglass 42

2.7 Materiais lineares 43

2.8 Extensão do MEF para análises não lineares 45

2.8.1 Extensão do método explícito para análises não lineares $\quad 45$

2.8.2 Elemento hexaédrico linear para análises não lineares 46

Atualização da geometria do elemento 46

Cálculo do gradiente de deformação 47

2.9 Tecnologias de materiais não lineares 49

2.9.1 Hiper elasticidade 49

Modelo neo-Hookeano compressível 51

2.9.2 Modelo hipo elástico linear 51

2.9.3 Plasticidade linear isotrópica 52

Componentes do modelo elastoplástico 54

Decomposição da deformação elastoplástica 54

Lei constitutiva elástica 55

Critério de escoamento 55

Regra de escoamento 57

Lei de encruamento 58

Implementação do modelo numérico 59

2.10 Comentários 59 
CAPÍtulo 3 Fundamentos do código de elementos finitos orientado a objetos 63

3.1 Análise orientada a objetos 64

$\begin{array}{lll}3.2 & \text { Objetos e classes } & 67\end{array}$

3.3 Relações entre classes 69

3.3.1 Dependência 70

3.3.2 Associação comum 70

$\begin{array}{lll}3.3 .3 \text { Agregação } & 71\end{array}$

3.3.4 Composição $\quad 72$

3.3.5 Herança ou generalização 72

$\begin{array}{lll}3.4 & \text { Princípios do design orientado a objetos } & 73\end{array}$

3.4.1 Encapsulamento 73

$\begin{array}{lll}3.4 .2 & \text { Polimorfismo } & 73\end{array}$

3.4.3 Design por responsabilidades 74

3.5 Padrões de design para softwares MEF 75

$\begin{array}{lll}3.5 .1 \text { Fachada } & 75\end{array}$

$\begin{array}{lll}3.5 .2 & \text { Fábrica abstrata } & 76\end{array}$

$\begin{array}{lll}3.5 .3 \text { Construtor } & 77\end{array}$

3.5.4 Estratégia 78

3.5.5 Comando 78

$\begin{array}{lll}3.5 .6 & \text { Cadeia de responsabilidades } & 79\end{array}$

3.6 Diagramas UML 80

3.6.1 Vista estática 80

Modelo de domínio 81

Diagrama de classes $\quad 81$

3.6.2 Vista dinâmica $\quad 81$

Diagrama de interação 81

Diagrama de sequência 82

Diagrama de atividades 83

3.7 Outras observações 85

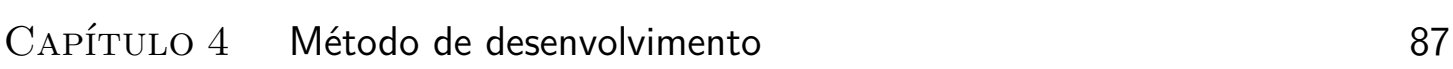

$\begin{array}{lll}4.1 & \text { Problemática } & 88\end{array}$

4.2 Requisitos do método de desenvolvimento 89

4.3 Características da metodologia 90 
4.4 Definições 91

4.5 Fases de desenvolvimento 93

4.5.1 Início da iteração 93

4.5.2 Planejamento 93

Discussão 94

Modelagem inicial e prototipagem rápida $\quad 94$

4.5.3 Modelagem 95

Refinamento e validação 95

Preparação 96

4.5.4 Produção 97

4.5.5 Término da sequência 98

4.6 Ambiente de desenvolvimento 99

4.6.1 Linguagem de programação 99

4.6.2 Plataforma 100

4.6.3 Ferramentas de desenvolvimento 101

4.6.4 Ambiente de testes 102

$\begin{array}{lll}4.7 & \text { Comentários } & 105\end{array}$

\begin{tabular}{lll}
\hline CAPÍtulo 5 & Aspectos gerais do programa & 107
\end{tabular}

5.1 Características do programa 108

5.2 Métricas do projeto 112

$\begin{array}{lll}5.3 & \text { Estrutura geral do programa } & 114\end{array}$

5.3.1 Arquitetura lógica do programa 116

5.3.2 Componentes do software $\quad 117$

5.3.3 Distribuição das funcionalidades 121

5.4 Modelo de domínio: construção básica do núcleo de ele-

mentos finitos 122

5.4.1 Descrição de um elemento finito 123

5.4.2 Modelo numérico 125

5.4.3 Definição genérica do solver 127

5.5 Extensibilidade e robustez do núcleo 129

5.5.1 Carregamento dinâmico de plugins 130

5.5.2 Provedores, localizadores e fábricas de recursos 131

5.5.3 Interpretador sintático do arquivo de entrada 134

$\begin{array}{lll}\text { 5.5.4 Desacoplamento da saída de dados } & 137\end{array}$ 
CAPÍtulo 6 Sistema de solução MEF-OO em CPU

6.1 Sistema de solução para problemas quase estáticos 141

6.1 .1 Inicialização do solver 144

6.1 .2 Execução principal 145

6.1 .3 Pós-processamento 145

6.1.4 Limpeza 145

6.2 Sistema de solução para problemas dinâmicos 147

6.2 .1 Inicialização do solver $\quad 150$

6.2 .2 Execução principal 152

6.2.3 Atualização das condições de contorno 154

6.2 .4 Coleta de resultados 156

6.2 .5 Limpeza 160

6.3 Extensão do solver dinâmico para problemas não-lineares 161

6.4 Comentários 163

CAPÍtulo 7 Sistema de solução MEF-OO em GPU 165

7.1 Visão geral da tecnologia 165

7.2 Limitações do processamento em GPU 168

7.2 .1 Limitações do hardware 168

$\begin{array}{ll}7.2 .2 \text { Limitações da API } & 169\end{array}$

7.3 Organização de memória do programa Axis 171

7.3.1 Sistema de arenas de memória $\quad 171$

7.4 Referência independente de dispositivo: o ponteiro relativo 174

7.5 Yuzu: biblioteca estática para definição dos objetos em GPU 175

7.6 Capsicum: componente de gerenciamento e abstração das operações em GPU 176

7.6.1 Validação do modelo numérico para execução em GPU 178

\begin{tabular}{ll|l}
7.6 .2 Seleção do hardware de execução & 179
\end{tabular}

7.6.3 Coalescência de algoritmos 180

7.6.4 Escalonamento das tarefas de processamento 181

A classe Kernel Scheduler 181

Segmentação da tarefa: classes GPU Task e Kernel

Configuration 


\begin{tabular}{|c|c|c|}
\hline & & Espelhamento de memória: classe Memory Mirror \\
\hline & & Comandos de inicialização de memória: classe Me- \\
\hline & & mory Command \\
\hline & 7.6 .5 & Operações em GPU para classes de domínio: classe \\
\hline & & Kernel Command \\
\hline & 7.6 .6 & Fachadas para as operações em GPU \\
\hline 7.7 & Execuc & ção do solver explícito não-linear em GPU \\
\hline & 7.7 .1 & Inicialização do programa \\
\hline & 7.7 .2 & Carregamento do modelo númerico \\
\hline & 7.7 .3 & Escalonamento do trabalho \\
\hline & 7.7 .4 & Inicialização da memória \\
\hline & 7.7 .5 & Execução do solver \\
\hline 7.8 & Compa & aração do código de elementos finitos em CPU e GPU \\
\hline 7.9 & Com & ios \\
\hline
\end{tabular}

\begin{tabular}{|c|c|c|}
\hline CAPÍtulo 8 & Discussões e avaliação de desempenho & 209 \\
\hline 8.1 & Unidades de teste & 209 \\
\hline 8.2 & Verificação do algoritmo GC do solver quase estático & 212 \\
\hline 8.3 & Validação do elemento finito linear & 212 \\
\hline & 8.3.1 Problema 1: compressão de um cubo unitário & 213 \\
\hline & 8.3.2 Problema 2: compressão de um cubo: modelo discretizad & 215 \\
\hline & 8.3.3 Problema 3: paralelepípedo sob pressão & 217 \\
\hline & 8.3.4 Problema 4: patch test para sólidos & 218 \\
\hline 8.4 & Verificação do solver dinâmico explícito linear (CPU) & 219 \\
\hline & 8.4.1 Problema 5: barra em compressão constante (Cook & \\
\hline & et al. [57]) & 219 \\
\hline & 8.4.2 Problema 6: pulso de compressão & 221 \\
\hline & 8.4.3 Problema 7: Prescrição de deslocamento & 223 \\
\hline & 8.4.4 Problema 8: Prescrição de velocidade & 225 \\
\hline 8.5 & Formulação não-linear: validação do gradiente de deformação & 225 \\
\hline 8.6 & Problemas não-lineares & 227 \\
\hline & 8.6.1 Problema 9: Barra de borracha em tensão & 227 \\
\hline & 8.6.2 Problema 10: Viga sob deformação plástica & 229 \\
\hline 8.7 & Simulações numéricas em GPU & 231 \\
\hline & 8.7.1 Cenário A: Problema dinâmico linear & 231 \\
\hline
\end{tabular}


8.7.2 Cenário B: Problema dinâmico não-linear 238

8.7.3 Comparação de desempenho com software comercial 243

$\begin{array}{lll}8.8 & \text { Outras observações } & 244\end{array}$

\begin{tabular}{ll|}
\hline CAPÍtulo 9 & Conclusão \\
\hline
\end{tabular}

$\begin{array}{lll}9.1 & \text { Perspectivas futuras } & 248\end{array}$

\begin{tabular}{ll}
\hline Referências Bibliográficas & 253
\end{tabular}

ApÊNDICE A Fundamentos de não-linearidade em elementos finitos 273

A.1 Gradiente de deformação 274

A.2 Determinante do gradiente de deformação 276

A.3 Decomposição multiplicativa do gradiente de deformação 276

A.4 Decomposição polar 276

A.5 Medidas de deformação 277

A.5.1 Tensores de deformação de Cauchy-Green 277

A.5.2 Tensor de deformação de Green-Lagrange 278

A.5.3 Tensor de deformação de Hencky ou logarítmico 278

A.6 Gradiente de velocidade, taxa de deformação e giro 279

$\begin{array}{lll}\text { A.7 } & \text { Medidas de tensão } & 280\end{array}$

A.7.1 Tensor de tensão de Cauchy 281

A.7.2 Tensor de tensão de Kirchhoff 281

A.7.3 Primeiro tensor de tensão de Piola-Kirchhoff 281

A.7.4 Segundo tensor de tensão de Piola-Kirchhoff 282

A.8 Princípio da objetividade do material ou da indiferênça do referencial 282

A.8.1 Taxa de tensão de Jaumann 283

\begin{tabular}{lll}
\hline ApÊNDICE B Controle de hourglass & 285
\end{tabular}

B.1 Estabilização de Flanagan-Belytschko 285

B.2 Estabilização por deformação assumida de Puso 289

APÊNDICE C Construção sintática do arquivo de entrada 293

C.1 Introdução rápida à EBNF 293

C.2 Primitivas básicas 295

C.3 Blocos de contexto 295 
\begin{tabular}{lll}
\hline C.4 Extensão da sintaxe & 297
\end{tabular}

APÊNDICE D Arquivos de entrada dos casos de teste 299

D.1 Problema 1: compressão de um cubo unitário 299

D.2 Problema 4: patch test 302

D.3 Problema 5: barra em compressão constante 303

D.4 Problema 8: prescrição de velocidade 305

D.5 Teste não-linear 1: barra de borracha em tensão 306

D.6 Teste não-linear 2: viga sob deformação plástica 307

\begin{tabular}{|lll}
\hline APÊNDICE E & Arquivo de configuração do programa
\end{tabular}

ApÊNDICE F Codificação de kernels para a GPU 311 


\section{Lista de Figuras}

1.1 Aplicações do fenômeno de impacto 4

1.2 Acidentes causados por impacto 5

1.3 Comparação da configuração de penetração da esfera de aço contra

1.4 Tensão de von Mises na seção transversal de um tomate cereja em $\begin{array}{ll}\text { queda livre. } & 7\end{array}$

1.5 Componentes internos do disco rígido e malha do braço atuador. 8

$\begin{array}{lll}1.6 & \text { Abstração em orientação a objetos. } & 10\end{array}$

1.7 Comparativo de desempenho das GPUs e CPUs nos últimos anos. 13

2.1 Descrição do MEF como um conjunto abstrato de atividades. 22

2.2 Método de Rigidez Direto 24

2.3 Elementos sólidos isoparamétricos. 34

2.4 Elemento linear isoparamétrico hexaédrico: elemento de referência $e$ numeração dos nós. 35

2.5 Travamento na análise de flexão de uma viga (deslocamentos exage-

2.6 Hourglassing num problema de flexão de viga. 42

2.7 Modos de hourglass do elemento hexaédrico linear (em vermelho). 43

2.8 Forças de hourglass atuantes num elemento para supressão dos modos instáveis.

2.9 Curva uniaxial idealizada de tensão-deformação para materiais elastoplásticos. 52

2.10 Domínio elástico em uma curva de ensaio uniaxial. $\quad 55$

2.11 Corte da superfície de escoamento multiaxial de von Mises para $\sigma_{3}=0 . \quad 56$ 
2.12 Direção do escoamento. 57

2.13 Encruamento isotrópico, com a expansão da superfície de escoamento. 58

3.1 Decomposição algorítmica da solução de um problema quase estático linear. 64

3.2 Decomposição algorítmica do carregamento de um elemento finito. 65

3.3 Análise orientada a objetos da solução de um problema quase estático linear. 65

3.4 Análise orientada a objetos do carregamento de um elemento finito. 66

3.5 Elementos finitos de uma malha, vistos como objetos com proprie$\begin{array}{ll}\text { dades distintas. } & 68\end{array}$

3.6 Representação de uma classe em UML. 69

3.7 Representação de um objeto em UML. $\quad 69$

$\begin{array}{lll}3.8 & \text { Exemplo de dependência entre classes. } & 70\end{array}$

3.9 Exemplos de associação comum entre classes. 71

3.10 Exemplo de associação do tipo agregação.

3.11 Exemplo de associação do tipo composição.

$\begin{array}{ll}3.12 \text { Exemplo de herança entre classes. } & 72\end{array}$

3.13 Polimorfismo na definição de um modelo de material. 74

3.14 Padrão de design: fachada. 75

$\begin{array}{ll}3.15 \text { Padrão de design: fábrica abstrata. } & 76\end{array}$

$\begin{array}{ll}3.16 \text { Padrão de design: construtor. } & 77\end{array}$

3.17 Padrão de design: estratégia.

$\begin{array}{ll}3.18 \text { Padrão de design: comando. } & 79\end{array}$

3.19 Padrão de design: cadeia de responsabilidade. 80

3.20 Exemplo de modelo de domínio. 81

3.21 Exemplo de diagrama de interação. 82

3.22 Exemplo de diagrama de sequência. 83

3.23 Exemplo de diagrama de atividade. 84

4.1 Relação dos principais itens do método de desenvolvimento. 92

4.2 Fases do método de desenvolvimento. 93

4.3 Sequência de passos da fase de planejamento. 94

4.4 Sequência de passos da fase de modelagem. 95

4.5 Sequência de passos da fase de produção. 97

4.6 Representação da execução dos passos da fase de produção. 98

4.7 Principais atividades realizadas no método de desenvolvimento. 99

$\begin{array}{lll}4.8 & \text { Ferramenta de desenvolvimento adotada. } & 101\end{array}$

$\begin{array}{lll}4.9 & \text { Ferramenta para refatoração de código. } & 102\end{array}$

4.10 Centro de processamento de dados do laboratório. 104

$\begin{array}{lll}5.1 \text { Métricas de qualidade do projeto Axis. } & 114\end{array}$

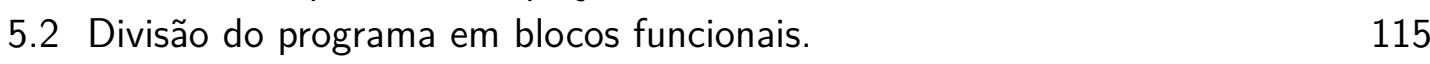


5.3 Arquitetura lógica do programa em camadas.

5.4 Tradução da arquitetura lógica em espaços de nomes no código do software. 118

5.5 Relação entre componentes.

5.6 Componentes principais do Axis.

5.7 Distribuição das funcionalidades através das arquiteturas física e lógica.

121

5.8 Modelo de domínio do software: descrição de um elemento finito.

5.9 Principais operações do elemento finito.

5.10 Modelo de domínio do software: especializações de comportamento.

5.11 Modelo de domínio do software: representação básica de um modelo numérico.

5.12 Modelo de domínio do software: solver genérico.

5.13 Segmentação da análise em fases discretas.

5.14 Operações sobrecarregáveis do solver.

5.15 Esquema de carregamento de plugins no espaço de memória do programa.

5.16 Principais classes e operações envolvidas no carregamento dinâmico

\section{de recursos do Axis.}

5.17 Exemplo de localizador e fábrica de recurso: montagem de clockworks.

5.18 Exemplo de localizador e fábrica de recurso: montagem de materiais.

5.19 Organização básica dos parsers de bloco.

5.20 Entidades principais do sistema de transporte de mensagens.

5.21 Esquema do transporte de mensagens entre as entidades do programa.

6.1 Principais classes para configuração do solver quase estático.

6.2 Encadeamento de mensagens em pseudo-iteração de tempo do solver quase estático.

6.3 Implementação do solver quase estático em dois níveis.

6.4 Implementação do algoritmo GC na classe Conjugate Gradient Solver

6.5 Principais participantes na solução de problemas dinâmicos explícito\$.

6.6 Algoritmo genérico de execução do solver, método Run().

6.7 Sequência de comunicações para a verificação de $\Delta t_{\text {cr }}$ no elemento.

6.8 Operações de distinção da natureza das condições de contorno.

6.9 Construção do vetor máscara e sua influência sobre os vetores de so ução.

6.10 Cálculo do estado de tensão no solver explícito para um elemento finito.

152

6.11 Algoritmo de atualização do estado de tensão na classe Finite Element.

6.12 Cálculo das forças internas no solver explícito.

6.13 Cálculo das forcas internas no solver explícito, com controle de hourglass.

6.14 Interação entre objetos para aplicação da condições de contorno em um grau de liberdade.

6.15 Classes participantes do sistema de coleta de dados. 157

6.16 Classe Finite Element Analysis. 
6.17 Sistema de coleta de dados do programa Axis. 158

6.18 Definicão dos formato de saída Matlab e Hyperworks. 158

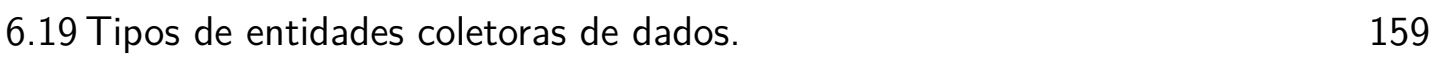

6.20 Algumas entidades coletoras implementadas no programa. 160

6.21 Modificações estruturais nas classes de domínio para o suporte a não-linearidade.

6.22 Modificações estruturais na classe de domínio Infinitesimal State. 163

7.1 Processamento típico de GPU: filtro de imagem. 166

$\begin{array}{lll}7.2 \text { Configuração típica do subsistema de vídeo. } & 167\end{array}$

$\begin{array}{lll}7.3 \text { Latência da transferência de memória GPU-host num problema de } & \\ \text { multiplicação matricial } & 168\end{array}$

$\begin{array}{lll}7.4 & \text { Exemplo de quebra da associação na GPU. } & 169\end{array}$

$\begin{array}{lll}7.5 & \text { Implementação de métodos virtuais em } \mathrm{C}++. & 170\end{array}$

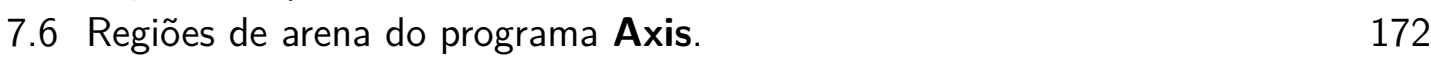

7.7 Organização interna da arena de memória do modelo. 173

$\begin{array}{lll}7.8 & \text { Elasticidade da arena do modelo para novas alocações. } & 173\end{array}$

$\begin{array}{ll}7.9 \text { Ponteiro relativo. } & 175\end{array}$

7.10 Cenário típico de emprego da biblioteca Yuzu. 176

7.11 Dependências mínimas para um sistema com suporte a GPU. 177

7.12 Classes para inspeção da simulação numérica. 178

7.13 Sistema de seleção do ambiente de processamento. 179

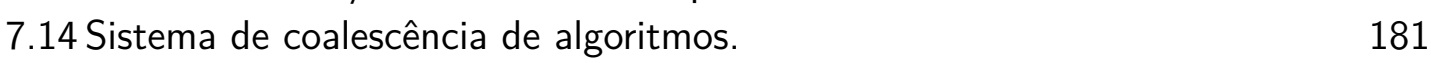

7.15 A classe Kernel Scheduler. 182

7.16 Decomposição de uma tarefa de GPU em múltiplas configurações de kernel.183

$\begin{array}{ll}7.17 \text { Classes de espelhamento de memória. } & 184\end{array}$

7.18 Operações de gerenciamento de par espelhado de memória. $\quad 184$

7.19 Sistema de espelhamento da arena de memória do modelo. $\quad 185$

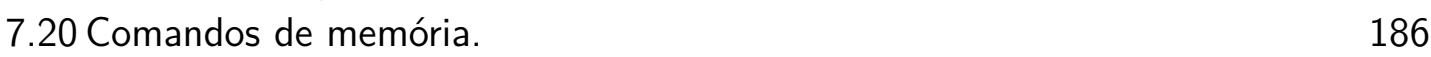

7.21 Comandos de inicialização de segmentos de bloco de memória. 187

$\begin{array}{ll}7.22 \text { Layouts de segmentos de bloco de memória. } & 187\end{array}$

$\begin{array}{ll}7.23 \text { Classes de comando para kernels de um elemento finito. } & 188\end{array}$

7.24 Classes de comando para kernels de condições de contorno e curvas. 188

7.25 Formas de obtenção dos comandos para execução em GPU. 189

7.26 Modificações em Solver para execução em GPU. 189

7.27 Classe Reduced Numerical Model e sistema de operador associado. $\quad 190$

7.28 Solver Facade: fachada para operacõos do solver em GPU. 191

7.29 Exemplo de sincronização da coleta de dados usando semáforo. 192

7.30 Hooking da mensagem GPU ARENA MSG. 195

7.31 Estado das arenas de memória após a leitura do arquivo de entrada. 195

\begin{tabular}{|l|l|l}
\hline 7.32 Sistema de escalonamento de trabalhos do Axis. & 196
\end{tabular} 
$\begin{array}{ll}\text { 7.33 Sistemas de abstração da GPU. } & 197\end{array}$

7.34 Composição da malha do exemplo. 197

7.35 Processo de coalescência de formulações de elementos. 198

7.36 Processo de coalescência de modelos de materiais. 199

7.37 Tarefa de processamento associada a GPU Solver Facade. 199

7.38 Layout de memória do bloco descritor de um elemento finito na GPU. 200

8.1 Modelo de cubo unitário usado no teste. 213

8.2 Modelo de cubo discretizado usado no teste. 216

$\begin{array}{lll}8.3 \text { Descrição do Problema 3. } & 217\end{array}$

\begin{tabular}{|ll|l}
\hline 8.4 & Patch test para elemento hexaédrico [154]. & 218
\end{tabular}

8.5 Propagação de ondas numa barra de aço (baseado em Cook et al. [57]). 220

8.6 Histórico da tensão axial no ponto $x=9,75 \mathrm{pol}(24,765 \mathrm{~cm})$ da barra. Resultado do programa obtido pela média das tensões dos elementos da seção que compreende o ponto.

8.7 Estado da estrutura do Problema 5 em diferentes instantes de tempo. Pós-processamento realizado no programa Altair Hyperworks.

8.8 Descrição do Problema 6. 222

8.9 Comparação dos resultados obtidos no Problema 6. 223

8.10 Deslocamento axial prescrito na extremidade livre da barra. 224

8.11 Comparação dos resultados obtidos no Problema 7. 224

8.12 Velocidade axial prescrita na extremidade livre da barra. 226

8.13 Comparação dos resultados obtidos no Problema 8. 226

8.14 Modelo de elementos finitos para o Problema 9. 227

8.15 Comparação dos resultados obtidos no Problema 9. 228

8.16 Modelo de elementos finitos para o Problema 10. 229

8.17 Comparação dos resultados obtidos no Problema 10.

8.18 Problema dinâmico linear usado para avaliação de desempenho do Axis. 231

8.19 Deslocamento axial de nó da extremidade livre no Cenário A, Teste 3 (CPU e GPU).

8.20 Cenário A: tempo de execução das GPUs em relação à configuração de referência.

8.21 Speedup obtido para o Cenário A. 235

8.22 Cenário A: ocupação dos dispositivos de processamento nos testes de GPU na configuração S1.

8.23 Problema dinâmico não-linear usado para avaliação de desempenho do Axis.

8.24 Deslocamento axial do nó da extremidade livre no Cenário $B$, Teste 3 (CPU e GPU). 
8.25 Cenário B: tempo de execução das GPUs em relação à configuração de referência.

8.26 Speedup obtido para o Cenário B.

8.27 Cenário 2: ocupação dos dispositivos de processamento nos testes de GPU na configuração S1

8.28 Comparação de desempenho do programa Axis (GPU) e o ABAQUS (CPU). 243

A.1 Um infinitesimal de um corpo sofrendo deformação.

A.2 Barra sujeita a uma rotação rígida, alterando seu estado de tensão.

F.1 Processo de compilação usando a plataforma CUDA. 


\section{Lista de Tabelas}

\begin{tabular}{|ll|}
\hline 2.1 & Coordenadas nodais do elemento de referência. \\
\hline 2.2 & $\begin{array}{l}\text { Pesos e pontos de integração de Gauss para até } n=5 \text { (adaptado de } \\
\text { Zwillinger [254]). }\end{array}$ \\
\hline 4.1 Comparativo de desempenho entre implementações de linguagens de \\
\begin{tabular}{|ll} 
programação (adaptado de Fulgham [90]). \\
\hline 4.2 Configuração das estações de desenvolvimento utilizadas.
\end{tabular} \\
\hline 4.3 Configuração dos servidores alocados para os testes de cenário real.
\end{tabular}

5.1 Sistemas de solução implementados no programa.

5.2 Biblioteca de elementos do programa Axis.

5.3 Biblioteca de materiais do programa Axis.

5.4 Métricas da base de código do Axis.

6.1 Inserção do algoritmo gradiente conjugado dentro da arquitetura do programa.

6.2 Inserção do método de integração explícita dentro da arquitetura do programa.

6.3 Operações da coleta de dados disparadas por mensagens. 
7.1 Configurações padrão das arenas. 174

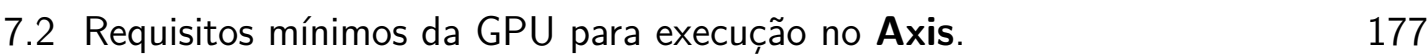

8.1 Distribuição das unidades de teste. 211

8.2 Cobertura dos componentes pelas unidades de teste. 211

8.3 Deslocamento nodal do Problema 1. 214

8.4 Estado de tensão do elemento no Problema 1. 214

8.5 Estado de deformação do elemento no Problema 1. 214

8.6 Deslocamento nodal do Problema 2. 215

8.7 Estado de tensão dos elementos 4, 6 e 7 no Problema 2. 215

8.8 Estado de deformação dos elementos 4, 6 e 7 no Problema 2. 216

8.9 Deslocamento nodal do Problema 3. 217

8.10 Estado de tensão do elemento no Problema 3. 218

8.11 Estado de deformação do elemento no Problema 3. 218

8.12 Configurações gerais da simulação numérica executada no ABAQUS. 222

8.13 Configurações dos testes para o problema linear (Cenário A). 232

8.14 Detalhes dos hardwares gráficos empregados nos testes. 233

8.15 Estatísticas de uso da arena de memória para o Cenário A. 236

8.16 Configurações dos testes para o problema não-linear (Cenário B). 239

8.17 Estatísticas de uso da arena de memória para o Cenário B. 241 


\section{Tabela de Listagens}

5.1 Excerto de estrutura em bloco do arquivo de entrada do programa.

7.1 Exemplo de arquivo de entrada para simulação numérica em GPU.

7.2 Código do modelo de material neo-Hookeano, versão CPU.

7.3 Código do modelo de material neo-Hookeano, versão GPU.

7.4 Atualização do estado de deformação (elemento hexaédrico), versão CPU.

205

7.5 Atualização do estado de deformação (elemento hexaédrico), versão GPU.

C.1 Exemplo de aninhamento de blocos.

C.2 Sintaxes distintas para um mesmo tipo de bloco por influência dos parâmetros do bloco.

C.3 Exemplo de bloco MULTILINE_CURVE.

D.1 Arquivo de entrada do Problema 1.

D.2 Arquivo de entrada do Problema 4.

D.3 Arquivo de entrada do Problema 5.

D.4 Arquivo de entrada do Problema 8.

D.5 Arquivo de entrada do Teste não-linear 1.

D.6 Arquivo de entrada do Teste não-linear 2. 


\section{Tabela de Algoritmos}

2.1 Solução de equilíbrio estático através do Gradiente Conjugado. 26

2.2 Método das diferenças centrais para problemas de integração no tempo. $\quad 32$

2.3 Método das diferenças centrais com extensão para problemas não lineares. $\quad 47$

2.4 Atualização da tensão pelo modelo hipo elástico. 53

2.5 Modelo material hipo elastoplástico (plasticidade de von Mises, encru-

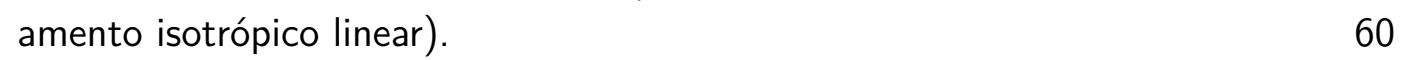

6.1 Método ExecuteStep() usando diferenças centrais. 152

6.2 Método ExecuteStep () usando diferenças centrais, com suporte a nãolinearidade. 163

7.1 Execução do solver de GPU, dinâmico explícito não-linear: lado CPU. 201 



\section{Convenção e Lista de Símbolos}

Sempre que possível, foi adotada a convenção de símbolos mais utilizada para os tópicos abordados neste trabalho, procurando manter a consistência dos formatos, operadores e índices empregados. Contudo, em diversas ocasiões, ocorre conflito das definições, o que leva à adoção de um caractere distinto para a representação ou exceções à convenção definida neste documento.

\section{Convenção geral}

A natureza matemática de uma quantia é caracterizada pela tipografia adotada para sua escrita, conforme especificado nas regras a seguir. Algumas exceções existem, em favor de manter a simbologia consagrada de um termo.

- Letra latina ou grega, tipo serifado, traço regular e itálico $(A, a, \alpha, \Gamma, \ldots)$ : quantias e funções escalares. Exceção: pontos $P, Q, P^{\prime}, Q^{\prime}, Y$ e $Y^{\prime}$;

- Letra latina ou grega minúscula, tipo serifado, negrito $(\mathbf{a}, \mathbf{b}, \boldsymbol{\alpha}, \ldots)$ : quantias e funções vetoriais. Exceção: matriz de coordenadas dos nós $\chi$, matriz de velocidades e de deslocamentos ( $\underset{\sim}{\tilde{\mathbf{u}}}$ e $\underset{\sim}{\tilde{\mathbf{u}}}$, respectivamente) e matriz de velocidades modais de hourglass $(\dot{\mathbf{q}})$;

- Letra latina ou grega maiúscula, tipo serifado, negrito $(\mathbf{A}, \mathbf{B}, \boldsymbol{\Gamma}, \ldots)$ : matrizes. Exceção: $\mathbf{X}$ (vetor da linha infinitesimal na configuração de referência) e o tensor de velocidade angular $\boldsymbol{\Omega}$;

- Letra latina, tipo caligráfico, traço regular e itálico $(\mathscr{A}, a, x, \ldots)$ : quantias e funções escalares definidas no domínio natural (coordenadas isoparamétricas); 
- Letra latina minúscula, tipo caligráfico, negrito $(\boldsymbol{a}, \mathfrak{b}, \ldots)$ : quantias e funções vetoriais definidas no domínio natural (coordenadas isoparamétricas);

- Letra latina maiúscula, tipo caligráfico, negrito $(\mathscr{A}, \mathscr{B}, \ldots)$ : matrizes definidas no domínio natural (coordenadas isoparamétricas). Exceção: vetor das funções de forma do elemento isoparamétrico, $\mathcal{N}$;

- Letra romana maiúscula, tipo sem serifa, negrito-itálico $(\boldsymbol{A}, \boldsymbol{B}, \ldots)$ : Tensores e funções tensoriais de segunda ordem. Exceção: tensor normal de escoamento $\boldsymbol{n}$;

- Letra romana maiúscula, tipo sem serifa, negrito $(\mathbf{A}, \mathbf{B}, \ldots)$ : Tensores de quarta ordem;

- Letra romana maiúscula, tipo manuscrito, traço regular e itálico $(\mathcal{A}, \mathcal{B}, \ldots)$ : conjuntos, grupos, espaços ou configuração de corpos.

\section{Notação de índices}

Eventualmente, um símbolo pode estar acompanhado de índices subscritos ou superscritos, que podem indicar as componentes de um vetor, matriz, tensor ou conjunto. A menos que seja explicitamente indicado o contrário, a convenção a seguir é válida para o presente trabalho:

- Componente escalar de um vetor, matriz ou tensor: é indicado através de índices subscritos, em itálico, como $J_{11}, J_{21}, J_{i j}$ e $J_{2 k}$ (quantia em tipo com traço regular) para uma matriz $\mathbf{J}_{3 \times 3}$, onde o primeiro índice indica a linha e o segundo, a coluna em que o componente está localizado;

- Subvetores de uma matriz: é indicado da mesma forma que componentes escalares, no entanto, a quantia é indicada como usual (tipo em negrito), como $\mathbf{J}_{1}, \mathbf{J}_{2}$ e $\mathbf{J}_{i}$ para uma matriz $\mathbf{J}_{3 \times 3}$. A indicação de decomposição em vetor-coluna ou vetor-linha é dada no texto ou explicitada na equação;

- Indicação da iteração de tempo: é apresentado em índice subscrito à quantia, como em $x_{t}, \mathbf{S}_{t+\Delta t}$ e $\boldsymbol{A}_{t-\Delta t}$. O incremento $\Delta t$ no subscrito referencia o próximo ou o anterior passo de tempo;

- Histórico: o histórico dos valores que uma quantia assume dentro de um algoritmo iterativo é descrito através de um índice subscrito próximo, como em $\mathbf{p}_{1}, \mathbf{p}_{2}$ e $\mathbf{p}_{3}$. Para diferenciar de outros usos, texto próximo à quantia indicam explicitamente este emprego; 
- Ordem de um termo dentro de um conjunto: termos semelhantes dentro de um conjunto, como um elemento finito no conjunto definido pelo modelo numérico, são diferenciados pela sua ordem, dada em superscrito, em tipo sem serifa e entre ângulos, como em $\boldsymbol{\sigma}^{\langle 1\rangle}, p^{\langle 2\rangle}$ e $\boldsymbol{\sigma}^{\langle i\rangle}$.

\section{Adornamentos}

Adornos são usados para modificar a semântica de um símbolo ou representar simplificadamente uma operação. Para um símbolo qualquer, denotado por (·), as seguintes decorações são usadas:

$(\cdot) \quad$ primeira derivada de $(\cdot)$ em relação ao tempo, isto é, $\partial(\cdot) / \partial t$

$(\cdot)$ segunda derivada de $(\cdot)$ em relação ao tempo, isto é, $\partial^{2}(\cdot) / \partial t^{2}$

(.) terceira derivada de $(\cdot)$ em relação ao tempo, isto é, $\partial^{3}(\cdot) / \partial t^{3}$

(·) contribuição da quantia $(\cdot)$, calculada no elemento

$(\cdot) \quad$ indica o valor médio ou equivalente de $(\cdot)$

$(\cdot) \quad$ indica o valor efetivo de $(\cdot)$

$(\tilde{)})$ indica que $(\cdot)$ é escrito em uma organização diferente da usualmente adotada no texto

$\nabla J$
$(\cdot)$ taxa de tensão de Jaumann para a medida de tensão $(\cdot)$

\section{Operadores}

As seguintes operações são usadas ao longo deste documento:

$(\cdot)^{T} \quad$ transposto de um vetor, matriz ou tensor

$(\cdot)^{-1} \quad$ inverso da matriz (ou tensor) $(\cdot)$

$(\cdot)^{-T} \quad$ transposto do inverso da matriz (ou tensor) $(\cdot)$

$\operatorname{det}(\cdot) \quad$ determinante da matriz (ou tensor) $(\cdot)$ 


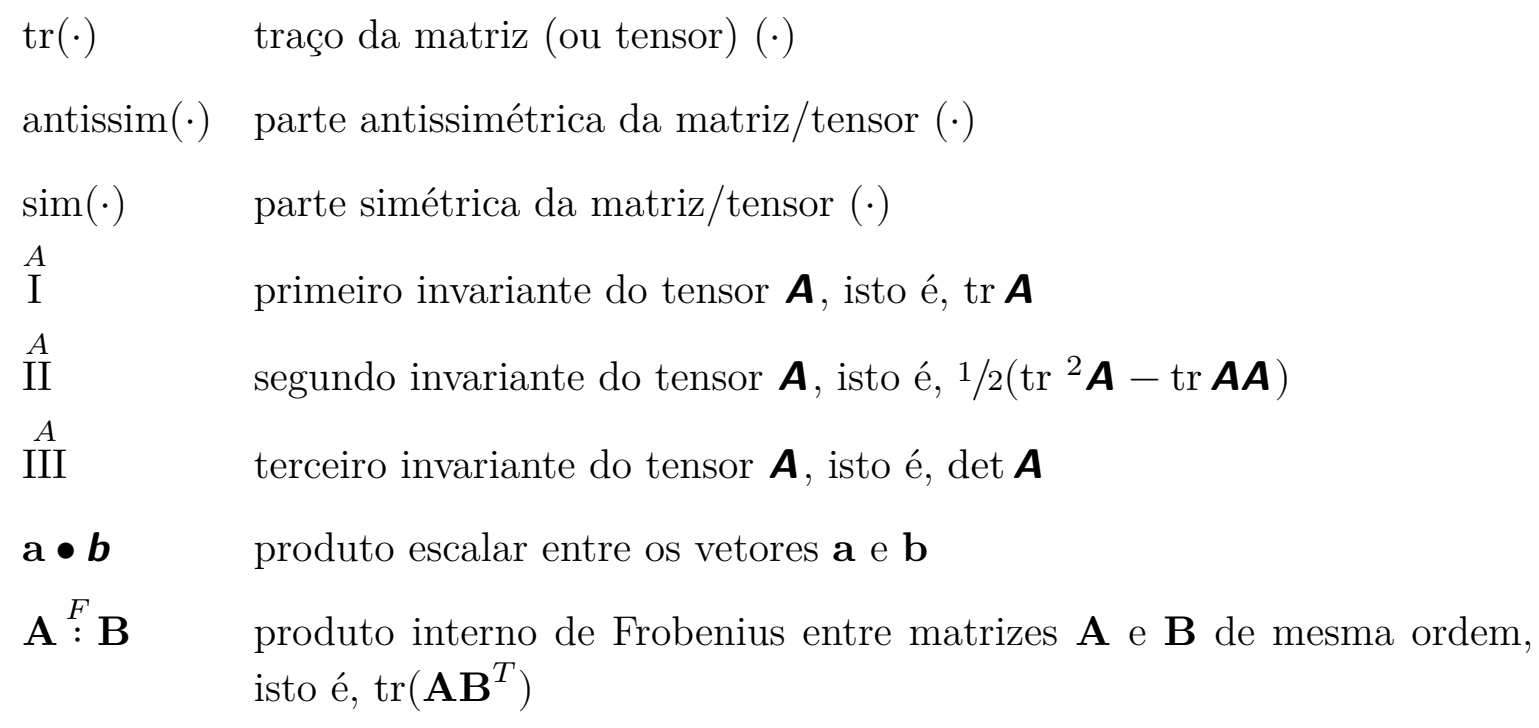

$\boldsymbol{A}: \boldsymbol{B}$ dupla contração do tensor $\boldsymbol{A}$ com o tensor $\boldsymbol{B}$

$\ln (\cdot) \quad$ tensor logarítmo natural de $(\cdot)$

$\sqrt{(\cdot)} \quad$ tensor raiz quadrada de $(\cdot)$

$\sum^{\text {EBE }} \begin{aligned} & \text { denota a soma ap vetor global } \\ & \text { num }\end{aligned}$

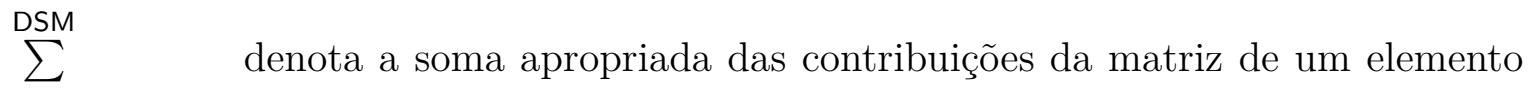
para uma matriz global segundo o Método de Rigidez Direto

\section{Lista de símbolos}

Os símbolos a seguir são utilizados para definir diferentes quantias apresentadas ao longo do texto.

$(\cdot) \quad$ uma quantia vetorial, matricial ou tensorial qualquer

0 vetor, matriz ou tensor nulo

a modo de vibração da estrutura/modelo

$\mathcal{A} \quad$ variáveis internas da plasticidade

B matriz de gradientes das funções de interpolação do elemento 
B matriz de gradiente média das funções de interpolação

$\boldsymbol{B}$ tensor de deformação esquerdo de Cauchy-Green

velocidade do som no meio

C matriz de amortecimento do sistema global

C matriz de amortecimento do elemento (local)

C tensor de deformação direito de Cauchy-Green

$\boldsymbol{D} \quad$ tensor de taxa de deformação

$\boldsymbol{D}^{\mathrm{e}} \quad$ tensor de taxa de deformação elástica

$\boldsymbol{D}^{\mathrm{p}} \quad$ tensor de taxa de deformação plástica

$d_{R} \quad$ diferença relativa

E módulo elástico (módulo de Young)

E representação matricial do tensor de elasticidade do material

E tensor de elasticidade do material

GL tensor de deformação de Green-Lagrange

$\mathscr{E}, c_{i j} \quad$ matriz de elasticidade do material no domínio isoparamétrico

f uma função escalar qualquer

$f_{H} \quad$ função de encruamento plástico

$\boldsymbol{F} \quad$ tensor de gradiente de deformação

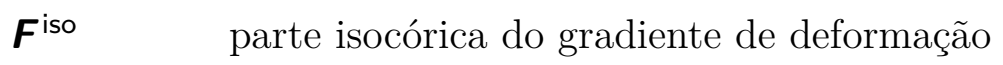

$\boldsymbol{F}^{\text {vol }} \quad$ parte volumétrica do gradiente de deformação

G segunda constante de Lamé (módulo de cisalhamento)

H módulo de encruamento

h vetor de deslocamentos de hourglass

$\boldsymbol{H}^{(\mathrm{M})} \quad$ tensor material de deformação de Hencky

$\boldsymbol{H}^{(\mathrm{E})}$ tensor espacial de deformação de Hencky (deformação logarítmica, natural ou verdadeira) 


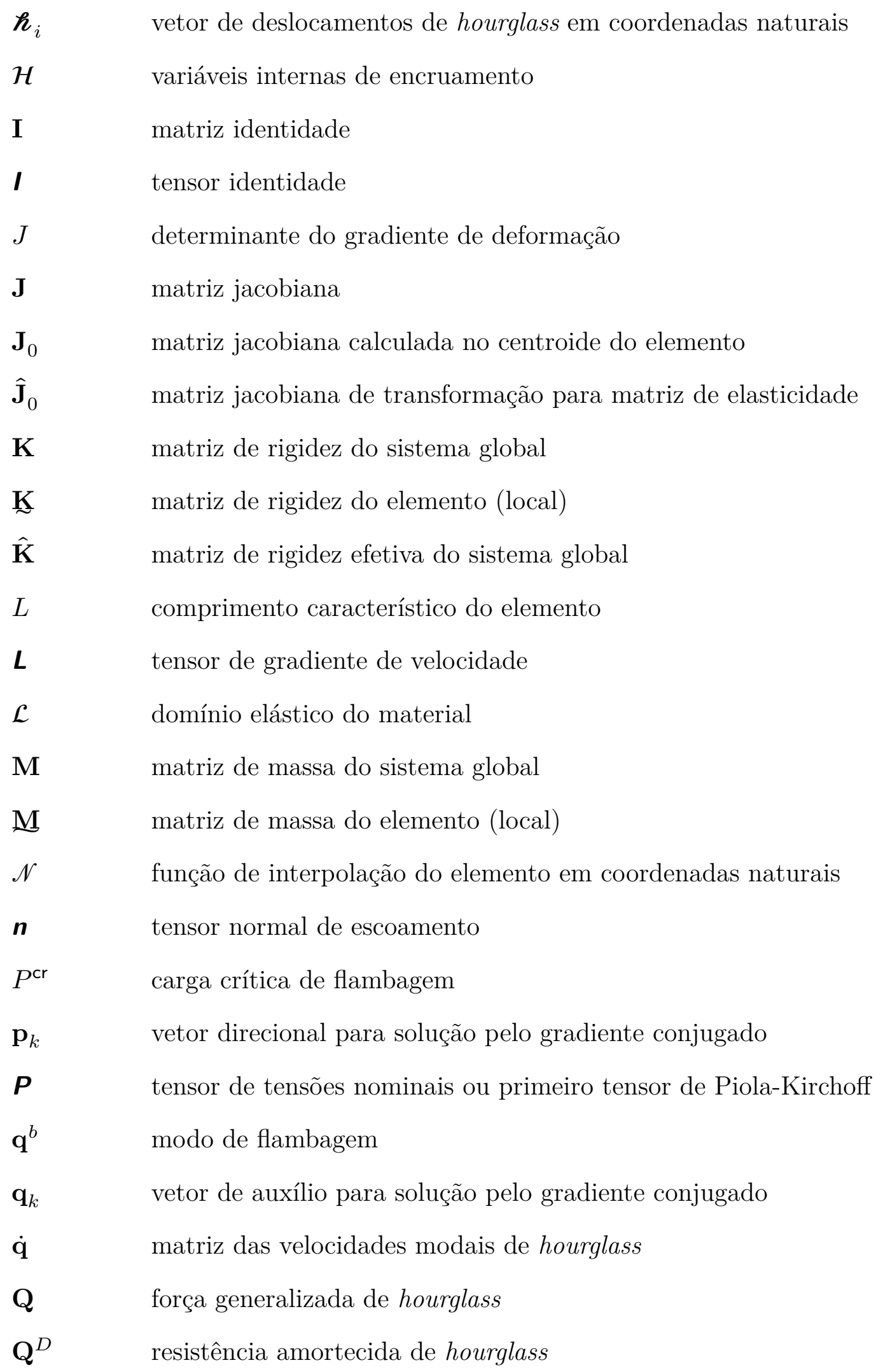




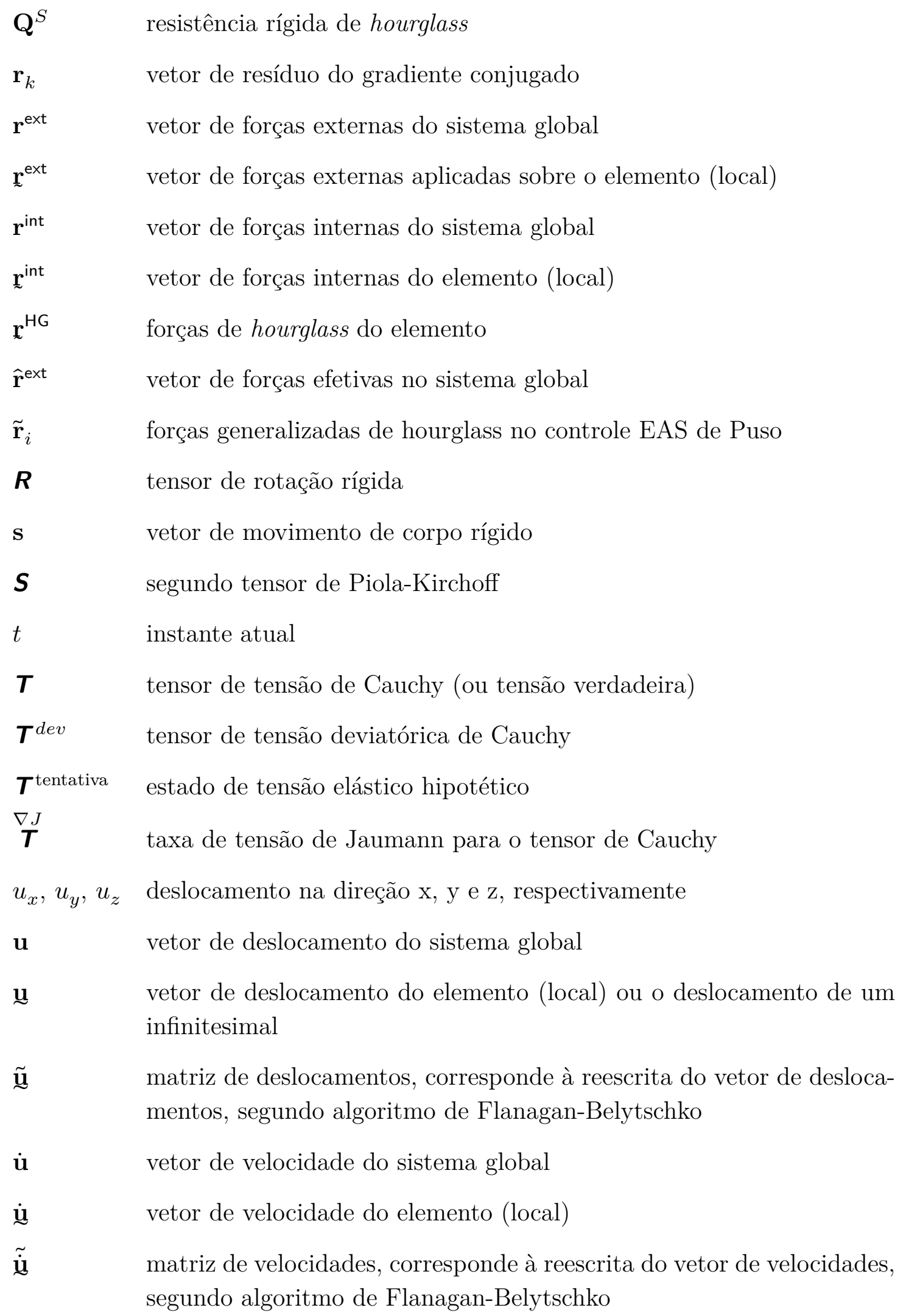



$\dot{\overline{\mathrm{u}}}, \dot{\bar{u}}_{i} \quad$ vetor médio de velocidades

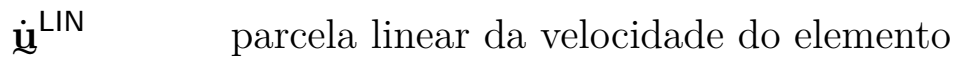
$\dot{\mathrm{u}}^{\mathrm{HG}} \quad$ parcela não-linear da velocidade do elemento, contribuinte para o hourglass
ü vetor de aceleração do sistema global
u vetor de aceleração do elemento (local)
$\boldsymbol{U} \quad$ tensor de alongamento direito
$v \quad$ volume do elemento ou volume final de um infinitesimal
$v_{0} \quad$ volume inicial do elemento ou de um infinitesimal
$\boldsymbol{V} \quad$ tensor de alongamento esquerdo
$w_{i} \quad$ peso associado a um ponto da integração numérica de Gauss
$\boldsymbol{W} \quad$ tensor de giro
$x, y, z \quad$ coordenadas globais de um ponto
$x_{i} \quad$ ponto de integração numérica pelo método de Gauss
x vetor que representa um ponto na configuração deformada
$\mathbf{x}_{k} \quad$ vetor de solução do gradiente conjugado
X vetor que representa um ponto na configuração de referência
$\alpha_{\mathrm{RL}}, \beta_{\mathrm{RL}} \quad$ coeficientes do amortecimento de Rayleigh
$\boldsymbol{\alpha}_{k}, \boldsymbol{\beta}_{k} \quad$ vetores de auxílio para solução pelo gradiente conjugado
$\beta_{\mathrm{NM}} \quad$ primeiro parâmetro de estabilidade de Newmark
$\gamma_{\mathrm{NM}} \quad$ segundo parâmetro de estabilidade de Newmark
$\dot{\gamma} \quad$ multiplicador plástico
$\mathbf{\Gamma} \quad$ matriz dos vetores de hourglass
$\Delta t \quad$ incremento que define o intervalo de tempo entre o instante atual e o próximo instante de tempo a ser calculado
$\Delta t_{c r} \quad$ máximo de incremento de tempo suportado pelo método explícito de integração temporal 


\begin{tabular}{|c|c|}
\hline$\Delta \alpha_{i}$ & variáveis internas de hourglass \\
\hline$\Delta \varepsilon$ & incremento de deformação \\
\hline $\bar{\varepsilon}$ & deformação plástica efetiva \\
\hline$\varepsilon_{i j}, \gamma_{i j}$ & $\begin{array}{l}\text { componentes normal e cisalhante do vetor de deformação infinitesimal, } \\
\text { respectivamente }\end{array}$ \\
\hline$\varepsilon$ & vetor de deformação infinitesimal do elemento \\
\hline$\varepsilon^{e}$ & tensor de deformação elástica logarítmica \\
\hline$\varepsilon^{p}$ & tensor de deformação plástica logarítmica \\
\hline$\vartheta$ & coeficiente de amortecimento de hourglass \\
\hline$\kappa$ & coeficiente de rigidez de hourglass \\
\hline$\lambda$ & primeira constante de Lamé \\
\hline$\Lambda$ & matriz dos vetores volumétricos \\
\hline$\nu$ & coeficiente de Poisson \\
\hline$\xi, \eta, \zeta$ & coordenadas naturais de um ponto \\
\hline$\xi^{D}$ & razão de amortecimento crítico \\
\hline$\xi$ & $\begin{array}{l}\text { vetor que representa um ponto no domínio natural (coordenadas na- } \\
\text { turais) }\end{array}$ \\
\hline$\Xi$ & matriz dos coeficientes das funções de forma de hourglass \\
\hline$\Pi$ & matriz de interpolação de hourglass \\
\hline$\rho$ & densidade volumétrica ou densidade final de um infinitesimal \\
\hline$\rho_{0}$ & densidade inicial do elemento ou de um infinitesimal \\
\hline$\sigma_{y}$ & tensão de escoamento do material \\
\hline$\sigma_{v m}$ & tensão equivalente de von Mises \\
\hline$\sigma$ & vetor de tensão do elemento \\
\hline$\tau$ & tensor de tensões de Kirchoff \\
\hline$\phi$ & função de escoamento plástico \\
\hline
\end{tabular}


$\varphi \quad$ vetor de coordenadas atualizadas do nó

$\bar{\chi}$

vetor das coordenadas do centroide do elemento

$\chi$

matriz das coordenadas dos nós do elemento

$\psi$

energia interna de deformação

$\omega$

frequência de vibração da estrutura/modelo

$\omega_{\max }$

frequência natural máxima em que a estrutura é excitada

$\Omega$ tensor de velocidade angular 


\section{CAPÍTULO I}

\section{Introdução}

Na Engenharia, a aplicação de diversos princípios físicos como conservação de energia e equilíbrio, geralmente culminam em modelos descritos por equações diferenciais parciais (EDP). É possível encontrar na literatura diversos métodos para a solução analítica de diferentes classes de EDPs. Entretanto, na maioria dos casos, são de difícil uso na análise de problemas reais, devido à complexidade das condições iniciais e de contorno, da geometria, do material e do número de variáveis envolvidas no problema [27].

Para a solução desses problemas, é comum o emprego de métodos numéricos que, na definição de Hamming [104], usam números para simular processos matemáticos que, por sua vez, simulam situações do mundo real. Por vezes, matemáticos trabalham juntamente com cientistas e engenheiros para buscar o modelo e o método de solução ideais para um problema. Isso porque, na maioria dos casos, métodos numéricos não produzem uma solução exata. Dessa forma, é necessário saber o que constitui uma solução aceitável [101].

Foi apenas na primeira metade do século XX que o interesse por técnicas numéricas e algorítmicas aumentou expressivamente, motivado pelo surgimento do computador [36]. Os esforços de guerra aceleraram o desenvolvimento da computação na década de 40. Com o tempo, o computador digital programável se tornaria uma ferramenta indispensável nas pesquisas de físicos e engenheiros.

A busca cada vez maior por algoritmos numéricos que pudessem ser utilizados nos computadores culminou na elaboração de diversas ferramentas de análise numérica conhecidas hoje. Abriram-se possibilidades para a solução de diversos tipos 
de problemas, antes impossíveis. Desde então, o uso do computador para o auxílio na solução de problemas de Engenharia, através de programas CAE (Engenharia Assistida por Computador), é de presença marcante nos estudos da área.

\subsection{O Método dos Elementos Finitos}

O Método dos Elementos Finitos (MEF) surgiu na indústria aeroespacial em meados da década de 50 para a análise estrutural de veículos aeroespaciais [192]. Hoje, o método é bastante popular e utilizado como ferramenta para análise na Mecânica dos Sólidos [35, 69, 192], sendo, todavia, também aplicada em outras áreas da Engenharia, como Mecânica dos Fluídos, transferência de calor, acústica ou eletromagnetismo.

Uma grande quantidade de estudos pode ser encontrada a respeito do MEF. Prathap [192] e Clough [50] fazem uma revisão das realizações obtidas nas décadas de estudo sobre o método numérico, apresentando, inclusive, as dificuldade encontradas durante seu desenvolvimento - na construção de uma base científica para o método e no tratamento de erros numéricos.

É creditada a invenção do método aos trabalhos conjuntos de matemáticos, físicos e engenheiros. Atribui-se a Courant [58] a base matemática e a demonstração dos conceitos básicos do método com o problema de torsão de St. Venant. Contudo, o MEF ganhou maior força com o desenvolvimento da técnica pelos engenheiros, aplicando-a em problemas de engenharia civil e aeronáutica. A nomenclatura "elementos finitos" foi adotada a partir do trabalho de Clough [49], em 1960, mesma época em que o método, antes visto como um trabalho fruto de intuição matemática e argumentação física, passou a ser reconhecido como uma forma do método de Rayleigh-Ritz e com uma base matemática mais sólida [199]. Desde então, o número de trabalhos a respeito do método cresceu extensivamente [16, 245]. Zienkiewicz [253], Hughes [115] e Bathe e Wilson [18] são alguns dos trabalhos pioneiros relevantes no tópico.

É também graças a introdução do computador digital que o MEF adquiriu rápida aceitação. Constituído de milhares de operações matemáticas, o método de solução é viável apenas para execução em máquina. Os primeiros computadores digitais com a arquitetura de von Neumann [217], surgidos por volta de 1950, tornavam a sua reprogramação um processo mais simples, com a inclusão de programas armazenados em memória, ao contrário da demorada reprogramação elétrica do equipamento, anteriormente encontrada. Linguagens de programação mais robustas, como as linguagens mnemônicas ou de montagem (1949) [234], segui- 
das pelas linguagens compiladas de alto nível, inicialmente o FORTRAN, em 1957 [210], facilitariam a programação dos computadores digitais, permitindo a construção dos primeiros programas de computador. Notoriamente, as primeiras bases de código de softwares MEF foram escritos em Assembly, seguido pelo Fortran [23, 51, 77, 146, 162, 177, 223, 228].

A rápida evolução dos computadores, com processadores e arquiteturas cada vez mais sofisticados, permitiu uma maior popularização do equipamento. Na década de 70, surgiram os primeiros programas comerciais de elementos finitos de propósito geral e, na década de 80, com memórias de semicondutor mais densas e compactas e dispositivos de entrada e saída mais desenvolvidos [217], foram comercializados os primeiros pacotes de elementos finitos com pré e pós-processamento em monitores gráficos [56]. Com a redução exponencial do preço do hardware, diversas instituições puderam adotar ou desenvolver novos programas baseados no método. Mackerle [146] mostra um levantamento de softwares de análise por elementos finitos existentes até a década de 80, alguns deles, hoje comercialmente bastante conhecidos.

Atualmente, os programas comerciais são dotados de uma extensa biblioteca de modelos de materiais, elementos e algoritmos sofisticados. São produtos de uma extensa linha de estudo que, na segunda metade da década de 90, avaliou-se ser composta por mais de 56000 artigos, 380 livros e 400 anais de congressos [148]. É possível afirmar que o Método dos Elementos Finitos aplicado à análise de estruturas sólidas está em constante evolução, com o desenvolvimento de formulações de elementos mais aperfeiçoadas [79, 86, 89, 105, 135, 182, 197, 203, 232, 246], novos modelos de materiais [14, 67, 168], propostas de algoritmos numéricos [171, 200, 251], otimizações [44, 53, 181], notas de aplicação [3, 206], entre outros tópicos.

No Brasil, os primeiros estudos sobre o MEF surgiram na década de 70, em uma tese de doutorado da UFRJ [230]. Atualmente, é empregado em uma variedade de problemas, como em análise estrutural de máquinas [61, 132], segurança veicular [45], análise de solo [66], construção civil [139], processos de fabricação [26], extração de petróleo e estruturas offshore [42, 191], além de outras áreas, como odontologia [145] e engenharia agrícola [83]. Diversas publicações nacionais são encontradas a respeito do assunto [7, 30, 216, 230], no entanto, poucos programas de elementos finitos para propósitos gerais são desenvolvidos no país, sendo mais comum a elaboração do software para atender a um nicho específico de pesquisa [29, 204]. 


\subsection{Dinâmica estrutural}

O termo dinâmica estrutural para a Engenharia Mecânica engloba uma grande variedade de eventos possíveis, em suas mais diversas variações, de pequenos fenômenos do cotidiano, como o martelar de um prego, a eventos em maior escala, como o impacto de meteoritos na fuselagem de uma aeronave espacial [125], do simples movimento de um objeto numa mesa aos esforços atuantes numa ponte, causados pelo tráfego de veículos.

O impacto é caracterizado pela aplicação súbita de uma quantidade relativamente alta de energia em um corpo, geralmente provinda de um carregamento abrupto, ondas de choque ou de colisões. Apesar da curta duração, é de interesse para o engenheiro os detalhes do comportamento da estrutura durante o evento, como a quantidade de energia absorvida, a resposta da estrutura ou a sua configuração deformada.

Em determinadas ocasiões, o fenômeno é desejado. O assentamento dos alicerces de uma edificação por bate-estacas ou a fixação de um prego na parede são exemplos (Fig. 1.1). No entanto, os efeitos indesejáveis, às vezes com resultados desastrosos, são mais repercutidos devido a sua divulgação em massa pela imprensa. Colisões entre veículos, danos na fuselagem de uma aeronave e explosões são alguns casos (Fig. 1.2). Neste cenário, o estudo de impacto desempenha um importante papel na demanda por veículos e estruturas mais seguras, confiáveis e duráveis.

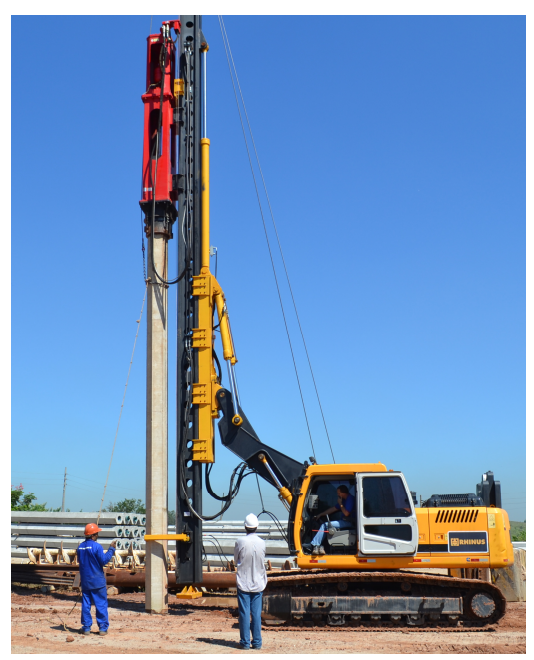

(a) Bate-estacas

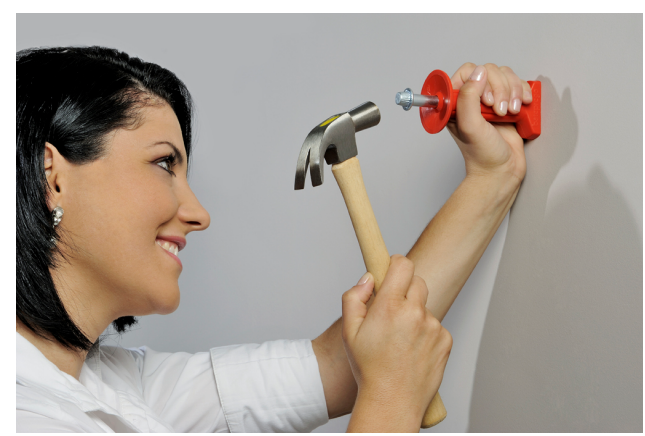

(b) Fixação de prego

Figura 1.1 Aplicações do fenômeno de impacto. Em ambos os casos, a energia de impacto é usada para vencer a fricção e a resistência do meio contra o corpo sendo afixado. 


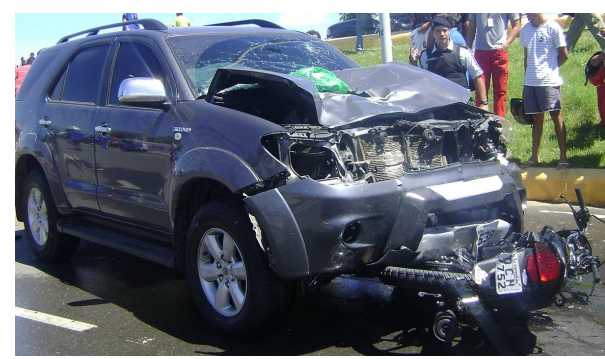

(a)

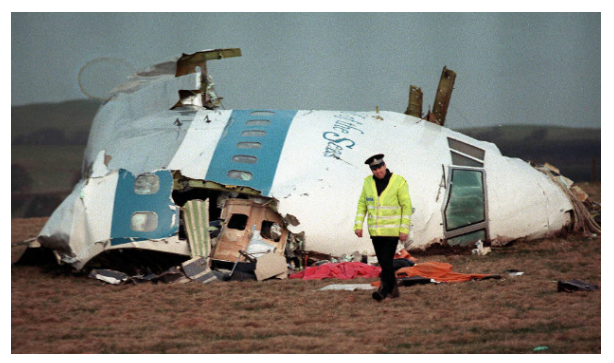

(b)

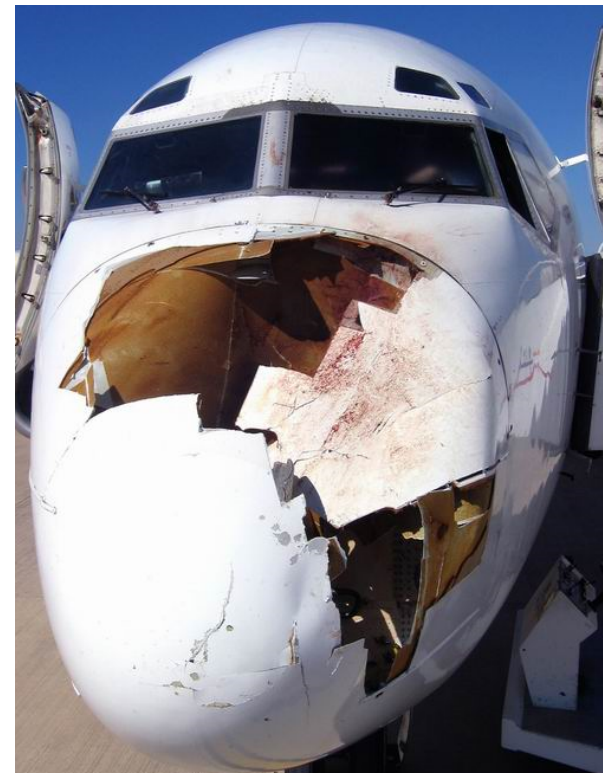

(c)

Figura 1.2 Acidentes causados por impacto. (a) Impacto frontal de motocicleta contra carro [82]; (b) Acidente do voo PanAm 103, catástrofe causada por bomba implantada no compartimento de carga da aeronave [52]; (c) Dano frontal em aeronave causado pelo impacto de pássaro em alta velocidade [71].

Com o desenvolvimento tecnológico, novos tipos de materiais são desenvolvidos e utilizados na indústria, devido a características como baixo custo, facilidade de usinagem, resistência a condições severas de uso, fácil reciclagem, entre outros [165]. Os polímeros, por exemplo, desenvolvidos no início de século XX, são um dos tipos de materiais mais utilizados mundialmente, tendo o volume de produção anual superado apenas pelo volume combinado dos metais [37]. A leveza, a flexibilidade e a resistência a corrosão dos polímeros são algumas das características que culminaram no uso do material com finalidade estrutural. Em sua aplicação como biomaterial [196], são exigidos a níveis críticos de carregamento. Por exemplo, o carregamento médio da articulação do quadril é cerca de 3 vezes o peso do corpo, com picos de até 10 vezes o peso corpóreo. Em automóveis e aeronaves, devido a sua boa relação resistência mecânica e peso, polímeros são usados para compor a estrutura do veículo, reduzindo seu peso final e proporcionando maior eficiência da máquina. Itens de segurança, como absorvedores de impacto e cintos de segurança, são tambem outras aplicações importantes do material.

Cada vez mais polímeros e outros novos tipos de materiais são empregados na fabricação de estruturas que são exigidas em condições críticas, no que se diz a respeito a sua importância para o suporte à vida ou à qualidade final de um produto. 
Dessa forma, é cada vez mais comum a análise dinâmica não linear para a compreensão dos fenômenos mecânicos envolvidos. O estudo muitas vezes é realizado com o auxílio de softwares CAE para análise computacional. Por vezes de natureza destrutiva, como em impacto, dano ou plasticidade, testes experimentais não podem ser conduzidos extensivamente, devido à inviabilidade econômica. Em contrapartida, a simulação numérica oferece ao analista a oportunidade de observar os detalhes do fenômeno sem a construção onerosa de protótipos ou arranjos experimentais. Além disso, a diversidade de conceitos não-triviais envolvidos, como a não-linearidade, plasticidade, contato, falha e a propagação de ondas, tornam os estudos inviáveis sem o auxílio do computador. Na maioria dos casos, o MEF é o método numérico preferido para a análise dinâmica, como é observado em diversos trabalhos.

Micheli [160] estudou a influência da modelagem do comportamento dinâmico de uma chapa de alumínio aeronáutico submetida ao impacto de uma esfera de aço. É demonstrado como a sensibilidade dos resultados está relacionada com os aspectos numéricos do modelo, como tipo de contato, densidade da malha e formulação dos elementos. A utilização de metodologias mais precisas para a caracterização do material e a seleção de um modelo constitutivo adequado também se mostrou relevante para a obtenção de resultados mais realísticos na simulação (Fig. 1.3).
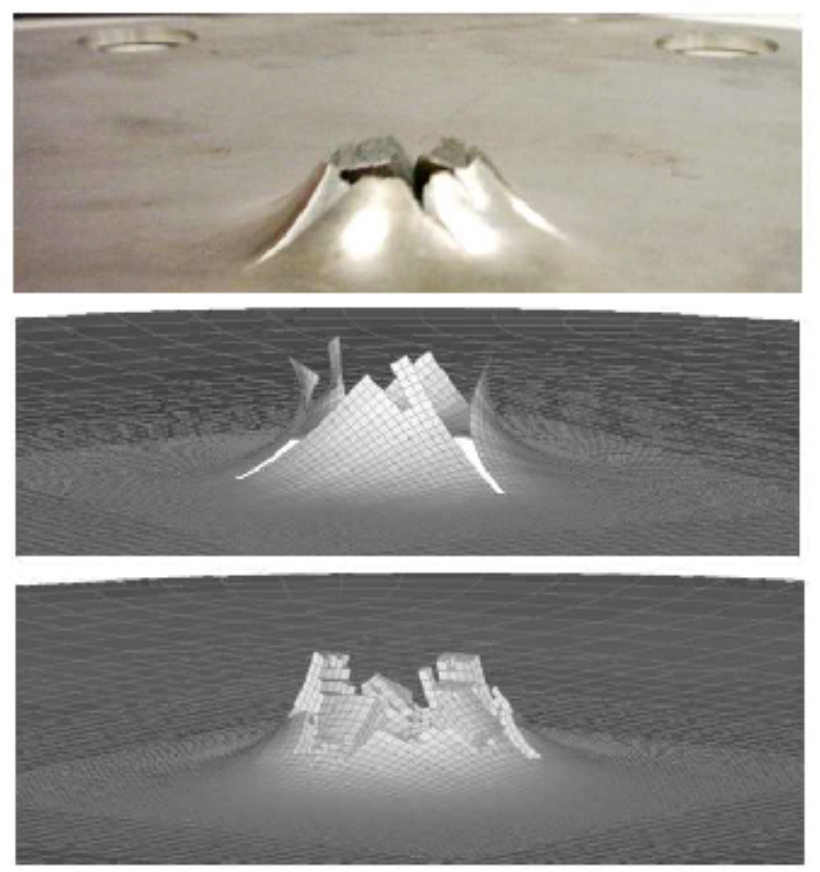

Figura 1.3 Comparação dos casos real e numérico da configuração de penetração da esfera de aço contra chapa de alumínio (de cima para baixo: caso real, malha de elementos de casca e malha de elementos sólidos) [160]. 
Kabas et al. [127] demonstra o uso de MEF para determinar o comportamento de um tomate cereja em queda livre. São demonstrados, de uma forma simplificada, métodos para caracterização do material biológico e são discutidos os procedimentos para a modelagem numérica do corpo de prova e o evento. Nos estudos, é demonstrada a importância das simulações por elementos finitos para a avaliação do comportamento de materiais biológicos, de difícil predição, pois são sujeitos a grandes deformações, devido à natureza mole do tecido (Fig. 1.4).

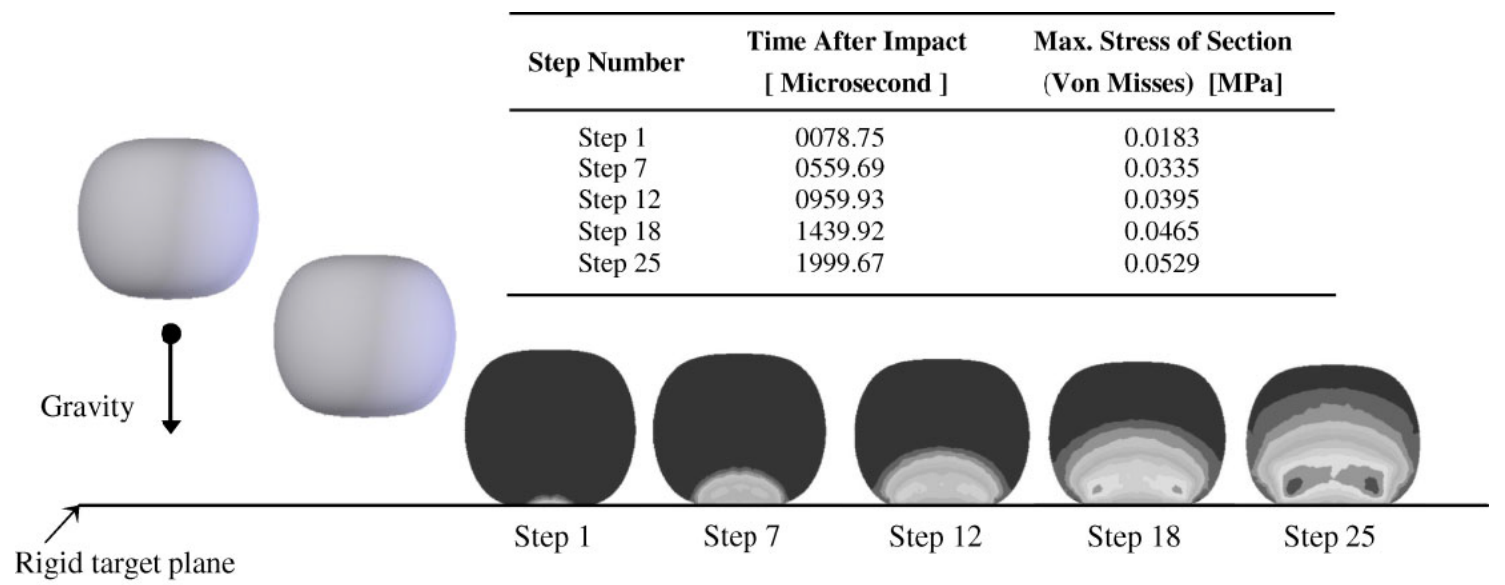

Figura 1.4 Tensão de von Mises na seção transversal de um tomate cereja em queda livre [127.

Existem diversos estudos sobre carregamentos dinâmicos em unidade de disco rígido (HDD) de um computador (Fig. 1.5a). Yu et al. [250] analisa o comportamento do cabeçote de leitura num HDD em operação, situação possível em ambientes hostis, sujeitos a constantes vibrações, tal como um automóvel. O leve e breve toque do cabeçote na mídia em alta rotação, que pode ser descrito como um pulso rápido sobre o disco magnético do dispositivo, pode causar resultados catastróficos, provocando considerável dano à mídia magnética. Estudos de predição do comportamento dos componentes do disco em queda livre também são importantes para o desenvolvimento de dispositivos mais resilientes, principalmente para equipamentos móveis. Shi et al. [211] estuda o comportamento dinâmico do braço de leitura do disco em queda vertical. Nessa situação, ao impactar contra o chão, a cabeça de leitura pode aterrissar na mídia magnética por um curto espaço de tempo, mas suficiente para causar danos àquela área. Demonstra-se quais componentes do braço atuador afetam mais significativamente na resposta dinâmica do componente. A Fig. 1.5b mostra o modelo numérico usado nos estudos. 


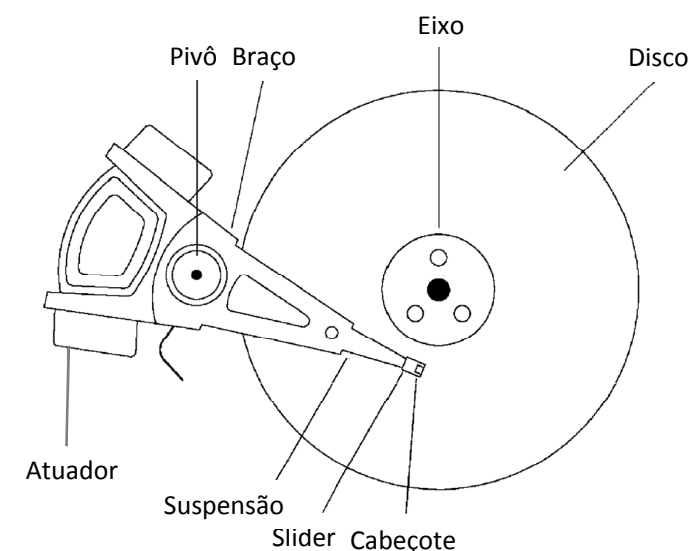

(a)

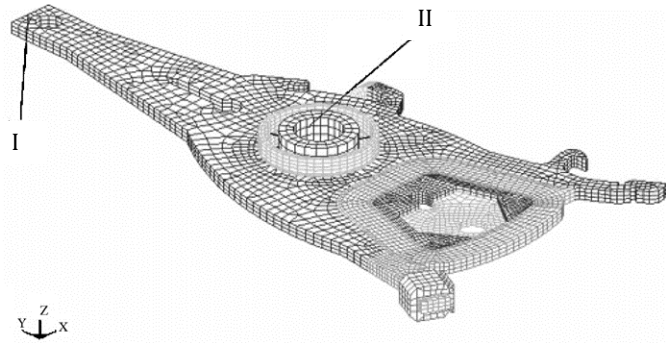

(b)

Figura 1.5 Componentes internos do disco rígido (a) e malha do braço atuador (b), com a interface de contato (I) e a superfície interna do pivô (II) (adaptado de Shi et al. [211]).

\subsection{Orientação a objetos aplicada em softwares de elementos finitos}

Softwares de análise por elementos finitos, ou simplesmente softwares de elementos finitos, são intrinsicamente complexos, devido à grande variedade de problemas que devem atender. O desenvolvimento de um programa para propósitos gerais é bastante custoso e complexo, requerendo uma abordagem bem planejada para a estruturação interna do software, de forma a facilitar futuras intervenções no código com o menor esforço possível, isto é, sem desencadear um processo de recodificação árduo no programa.

Para Dolenc [74], a personalização e a extensibilidade são características desejáveis para um software de elementos finitos. Pode-se dizer que essas são características essenciais para o programa, solicitadas desde os primórdios da ferramenta, como nas especificações originais da NASA para o NASTRAN [243].

As particularidades de cada problema faz requerer do software uma extensa biblioteca de recursos que são intercambiadas em cada situação. Ainda, o MEF passa por constantes revisões, visando suprir deficiências de modelos na representação numérica dos fenômenos físicos, melhorar a precisão numérica ou adicionar métodos de solução mais rápidos e completos. Quando é considerado o universo tecnológico em que reside, há propostas para mudanças no paradigma de uso da ferramenta e a interação com o seu ambiente - acoplamento de sistemas de banco de dados remotos mais eficientes que as tradicionais bases de dados em arquivo [184, 185, 248, 249], instalação como um serviço remoto oferecido por um portal da web [31, 48, 155, 233] ou, ainda, a implementação como um serviço na nuvem [12]. Com tantos 
recursos a serem implementados, não é de causar surpresa que a primeira versão do NASTRAN, na década de 70, tenha mais de 200 mil linhas de código [152]; hoje, os softwares ultrapassam a marca de 1 milhão de linhas [237]. Por essas razões, pode-se classificar o software de elementos finitos como um sistema de grande porte e de alta complexidade.

A complexidade, uma propriedade essencial do software [38], é causada, segundo Booch et al. [33], pela complexidade do domínio do problema, a dificuldade de gerenciar os processos de desenvolvimento e pela dificuldade em caracterizar a flexibilidade necessária para o software e o comportamento do sistema. A interação entre esses componentes, adicionados aos aspectos não-funcionais da ferramenta (tais como usabilidade, confiabilidade e custo), criam a percepção de um sistema de larga escala e requer o uso de paradigmas capazes de decompô-lo em várias partes, com número de objetos e interações limitados, num nível aceitável para a compreensão humana [85].

Em geral, os custos para o desenvolvimento inicial de um programa é baixo. Segundo Lientz e Swanson [138], cerca de 40 a $80 \%$ do custo total são relativos à manutenção do software, isto é, ao período que se inicia após o primeiro lançamento do software. Dessa fração, aproximadamente $50 \%$ corresponde ao tempo de manutenção do código. Códigos de elementos finitos são muito caros para se desenvolver [73], logo, as melhorias no programa devem causar as menores intervenções possíveis no código. Tornando-se tão necessária quanto a eficiência computacional do programa, é importante que seja adotada uma arquitetura robusta (resiliente frente à mudanças) e escalável (capaz de crescer e acomodar novas funcionalidades).

A preocupação com a organização do código perdura desde os primeiros desenvolvimentos de ferramentas MEF para propósito geral [73, 107, 152, 209, 243]. Diferentes formas de organização do código foram discutidas e, ao final da década de 80, o emprego do paradigma de orientação a objetos passa a ganhar destaque no cenário de pesquisa.

Os primódios da orientação da objeto datam da década de 60, com o lançamento da linguagem de programação SIMULA 67, que introduziu os primeiros conceitos de abstração de dados [210]. A disciplina de orientação a objetos em software apenas ganhou força no início da década de 80, com o desenvolvimento da linguagem Smalltalk, a primeira a suportar completamente os conceitos do paradigma.

Uma das formas de simplificação do desenvolvimento, que é adotada pelo paradigma de orientação a objetos, ocorre através do emprego de abstração de dados e encapsulamento da informação. Adotando a terminologia do domínio do problema 
(no caso, elementos finitos), as operações do programa (aritmética sobre números reais, por exemplo) são traduzidas em conceitos e operações mais próximos da realidade do usuário (multiplicação de matrizes). Reduz-se o abismo de comunicação entre o código implementado e a linguagem do desenvolvedor ao ocultar detalhes que não são de seu interesse (no caso, como matrizes são multiplicadas). A Figura 1.6 ilustra o conceito.

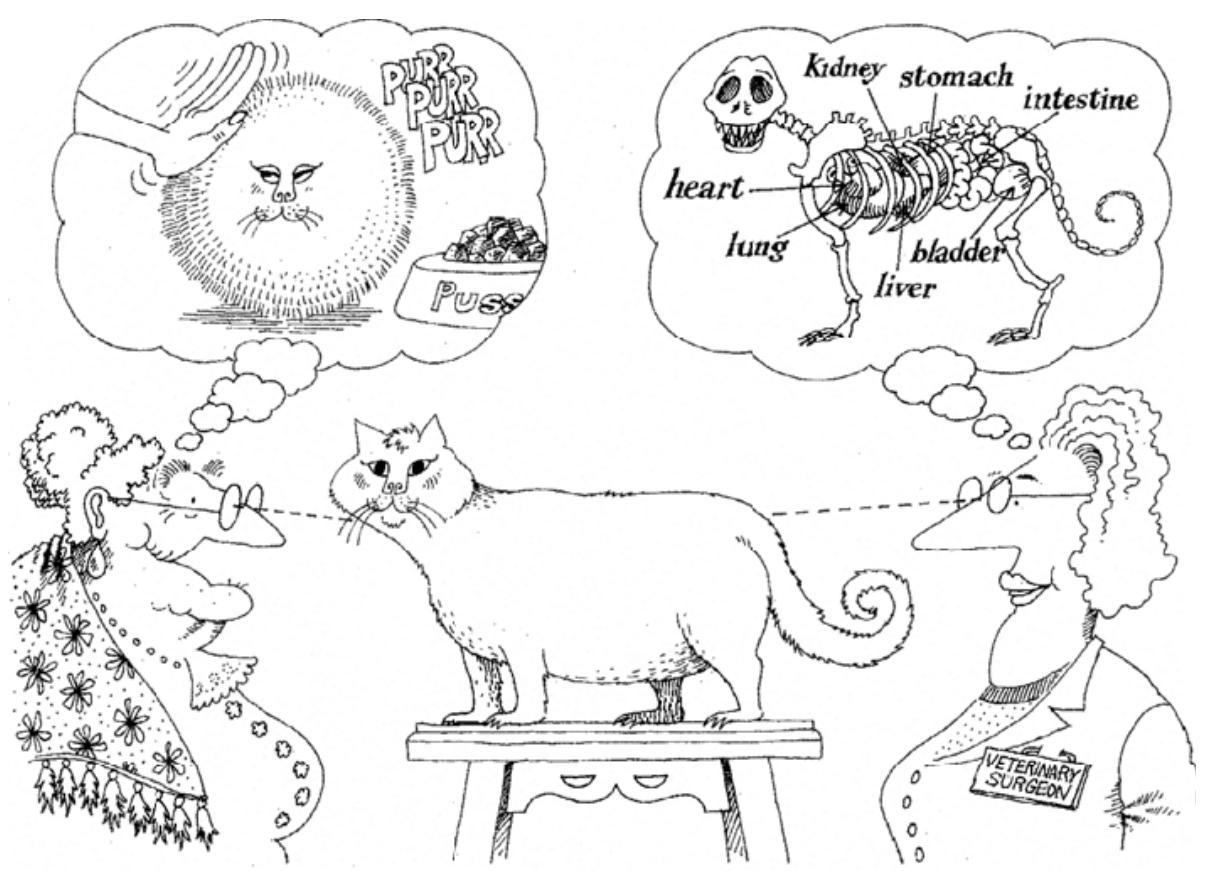

Figura 1.6 Abstração em orientação a objetos: apenas as características relevantes para o usuário de um objeto são reveladas [33].

Analogamente ao exemplo da Figura 1.6, algoritmos de elementos finitos que seguem esse modelo são preferidos. Como afirma MacNeal [153], "pouco sabem ou sequer se importam com o que acontece dentro dele. Na verdade, não é mais necessário saber o que acontece dentro do elemento para poder usá-lo, da mesma forma que não é necessário conhecer o interior de uma motocicleta para dirigíla". De fato, as tecnologias de elementos finitos são construídas sobre uma camada de abstração que as permitem serem trocadas livremente, cada um dos módulos dependendo apenas de características gerais (abstratas) dos demais.

Essa similaridade na abstração de conceitos facilita o emprego da orientação a objetos ao MEF e vem permitindo o refinamento de sua aplicação no desenvolvimento dos softwares de análise. Atualmente, uma grande quantidade de publicações relativas ao assunto pode ser encontrada, como mostrado por Mackerle [149]. Em outro trabalho do autor [150], observam-se diferentes abordagens do uso de orientação a objetos. 
Em sua grande maioria, as implementações usam $\mathrm{C}++$ como linguagem de programação, sendo que, em alguns casos, Java e C\# são também usados, ainda que sejam minoria. Esta predominância na escolha se deve ao fato de $\mathrm{C}++$ obter índices de desempenho bastante próximos à linguagem $\mathrm{C}$ (e ao Fortran). Além disso, o controle granular do poder computacional do hardware abaixo da plataforma de execução do programa não pode ser alcançado nas duas últimas linguagens, devido às limitações da abstração de hardware criada pela sua respectiva máquina virtual.

A criação de um kernel ${ }^{1}$ aberto para extensões é uma das propostas mais frequentes nos trabalhos de orientação a objetos em MEF [2, 11, 74, 95, 142, 151, 183, 187]. A construção de uma arquitetura extensível para o programa é uma tarefa altamente subjetiva e dependente dos objetivos de quem a propõe. Logo, a existência de diversas alternativas para o problema é compreensível.

Patzák e Bittnar 183] destaca necessidades arquiteturais do programa que refletem no desenvolvimento contínuo da ferramenta, onde conceitos como extensibilidade, suporte ao trabalho em equipe, robustez e portabilidade possam emergir. Na solução, são usadas extensivamente classes abstratas para a representação geral de entidades intercambiáveis do problema, tais como elementos, condições de contorno, modelos constitutivos e métodos numéricos.

Por outro lado, Dolenc [74] faz uso de componentes para se alcançar a variabilidade desejada no programa. O sistema é modelado por meio da arquitetura $\mathrm{COM}^{2}$ para expor interfaces que possam ser estendidas por sistemas externos. Da mesma forma que na solução obtida por Patzák e Bittnar [183], essas interfaces permitem a extensão das funcionalidades do programa.

Outras proposições de organização do código, além da apresentação de arquiteturas, podem ser observadas na literatura. Heng e Mackie [106] faz uma revisão dos design patterns ${ }^{3}$, propostos por Gamma et al. [92] no desenvolvimento orientado a objetos, aplicando-os à codificação de softwares MEF. Forde et al. [87] apresenta uma introdução bastante simples e compreensível do uso de orientação a objetos em MEF. Orientações gerais sobre o assunto, aplicadas no ambiente $\mathrm{C}++$, são observadas por Dubois-Pèlerin e Zimmermann [76], enquanto que Besson e Foerch [24] as apresenta no contexto de programação do MEF em larga escala.

\footnotetext{
${ }^{1}$ Kernel (núcleo) é um termo de origem alemã usada para denominar a parte mais importante e essencial de um programa.

${ }^{2}$ Acrônimo para Component Object Model

${ }^{3}$ Design patterns são propostas de estruturação de código orientado a objeto. Maiores detalhes podem ser encontrados em Gamma et al. 92] ou na breve discussão no Capítulo 3.
} 


\subsection{Computação massivamente paralela em processadores gráficos}

O software de MEF pode exigir grande poder computacional dependendo da complexidade do problema. Em alguns casos, devido ao tempo requerido ou aos recursos disponíveis na máquina, uma análise pode se tornar inviável de ser executada em apenas um computador. Simulações numéricas utilizando elementos finitos são tarefas computacionalmente intensas e por isso demandam um hardware preparado para executar o trabalho. Ainda que a era digital atual ofereça abundância de poder de processamento, dirigida pela lei de Moore $^{4}$ e pela integração de cada vez mais núcleos aos processadores, as aplicações de MEF usufrem da oferta usando algoritmos cada vez mais sofisticados (e computacionalmente mais caros), simulando cada vez mais detalhes dos fenômenos. Ao final, permanece a impressão de que é necessário aumentar ainda mais a oferta de processamento para atender às expectativas.

Recentemente, o uso de GPUs (Graphics Processing Unit - processadores gráficos existentes em placas aceleradoras de vídeo) para o cálculo numérico tem ganhado a atenção de pesquisadores e desenvolvedores de software. Esse interesse surgiu no início de 2001 com o lançamento das primeiras GPUs, em específico os chips gráficos das séries GeForce 3 (Nvidia) e Radeon 8500 (ATI) [222]. Diferentemente das gerações anteriores de chips gráficos, esses modelos são altamente programáveis com a introdução dos pixel shaders programáveis, permitindo maior flexibilidade no seu uso.

Devido à competição de mercado entre as principais fabricantes de chips gráficos e o crescente mercado de jogos para PCs, as GPUs hoje alcançam marcas de desempenho aritmético muito superiores que as de uma CPU (Figura 1.7). As GPUs mais sofisticadas conseguem alcançar níveis de desempenho que são de uma ordem de magnitude maior que o de uma CPU em aplicações científicas [208], sendo possível até mesmo alcançar speedups da ordem de 50 vezes ou mais.

O BrookGPU [40] e a extensão Sh para $\mathrm{C}++$ [229] foram alguns dos primeiros trabalhos desenvolvidos para computação de propósito geral em GPUs (GPGPU). Em seu trabalho, Buck [39] mostra o ganho de desempenho utilizando GPU. Para uma CPU Pentium 4, a $3 \mathrm{GHz}$ e com extensões SSE (Streaming SIMD Extensions), é possível obter um desempenho teórico de 6 GFLOPS. Em um chip gráfico NV35 (GeForce FX 5900), dispositivo de mesma geração tecnológica, o ganho observado foi de até 20 GFLOPS.

Em 2006, a Nvidia, uma das maiores fabricantes de chips gráficos do mercado, lançou a plataforma CUDA (Compute Unified Device Architecture) para o

\footnotetext{
${ }^{4} \mathrm{~A}$ lei de Moore é uma estimativa na qual se prevê o desempenho dos processadores dobrar a cada dois anos.
} 


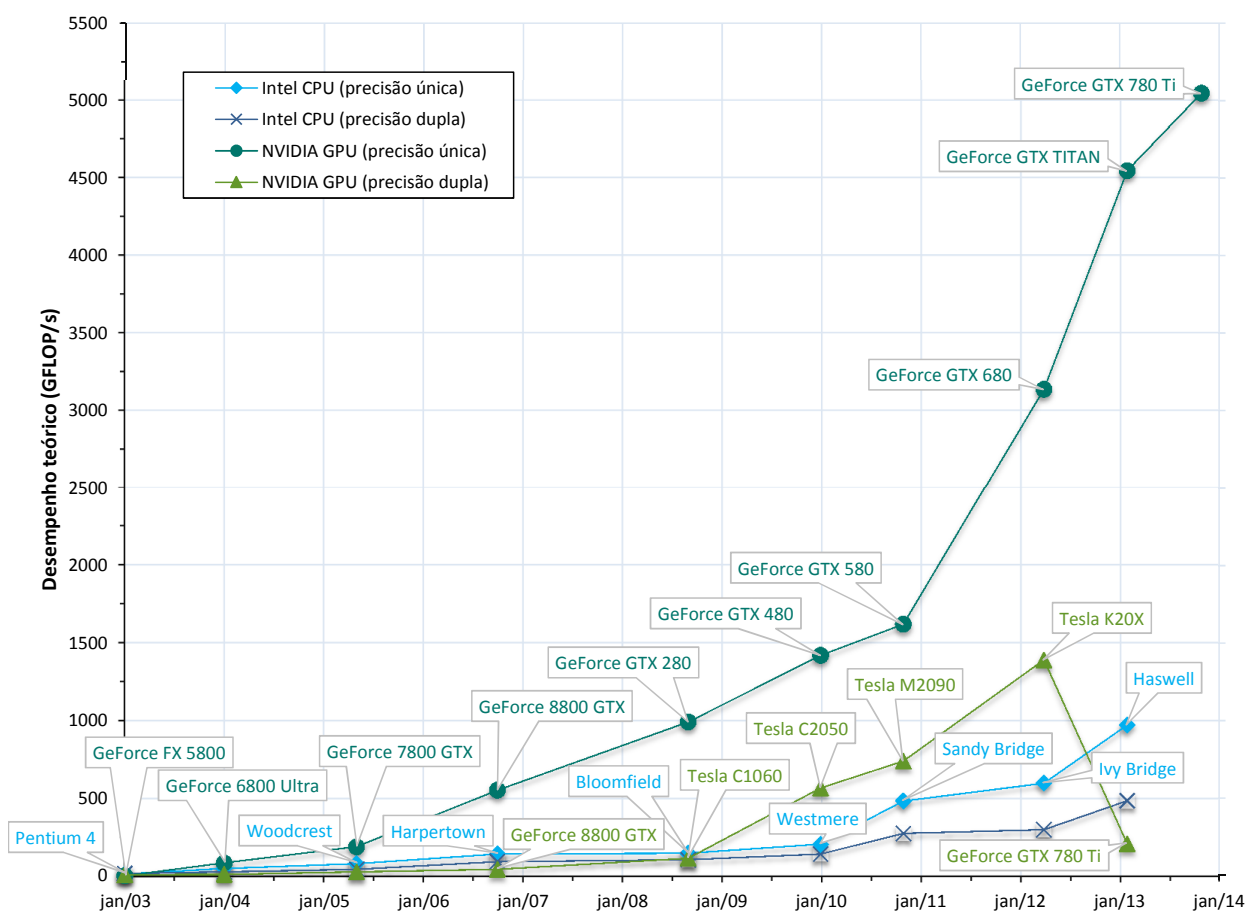

(a) Poder de processamento, GPU vs. CPU

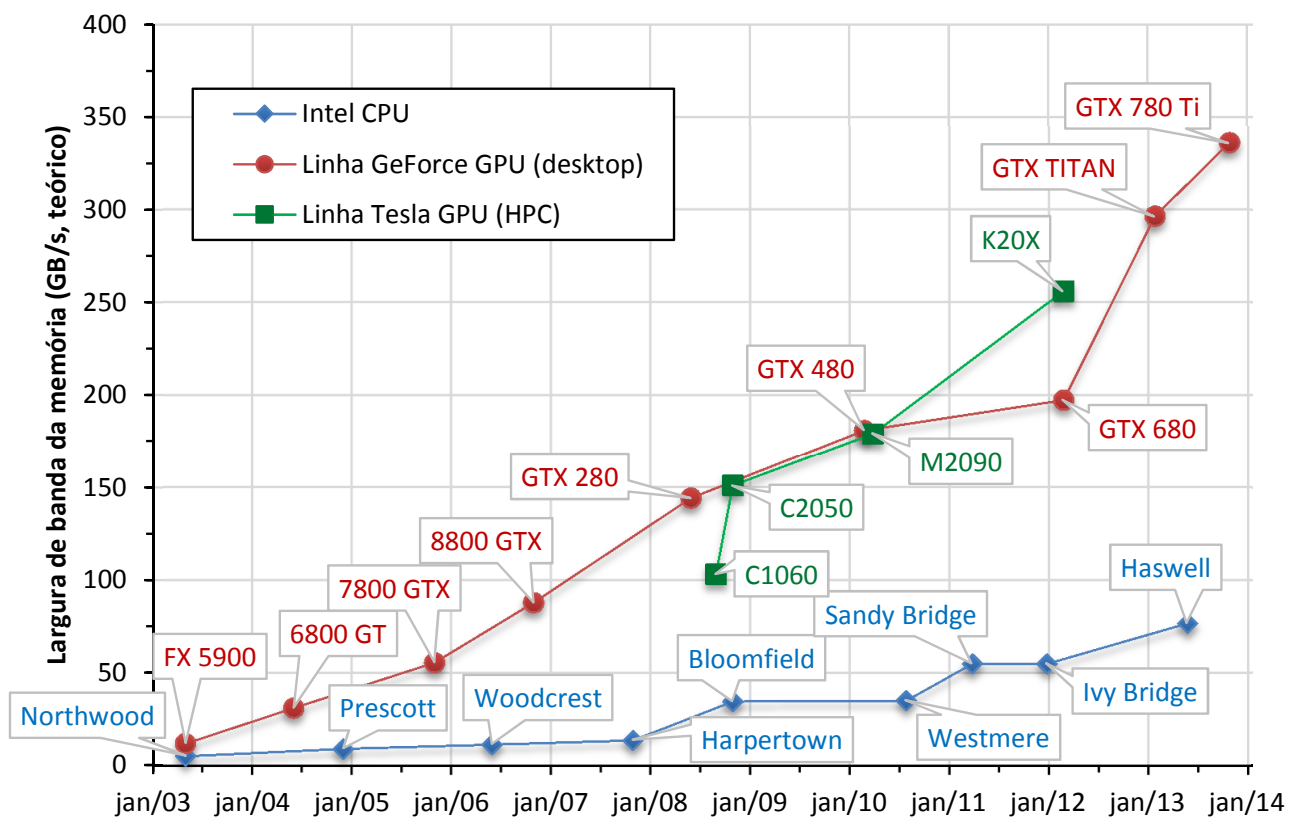

(b) Largura de banda da memória, GPU vs. CPU

Figura 1.7 Comparativo de desempenho das GPUs (Nvidia) e CPUs (Intel) nos últimos anos [70, 113, 175, 189, 214, 235, 236, 238, 239]. 
desenvolvimento de aplicações que possam usufruir do processamento paralelo de suas GPUs. A plataforma está hoje consolidada como uma das mais utilizadas para GPGPU [174, 207]. A arquitetura desenvolvida pela fabricante permite que aplicações executem códigos altamente paralelos nas GPUs. Tomando como exemplo a GPU GeForce 8800 GTX, é possível executar simultaneamente 12288 threads [175], ao passo que esse número é de apenas 20 na CPU com maior número de núcleos disponível até a data da escrita deste trabalho 121.

A capacidade de processamento oferecida pela GPU permite a criação dos chamados cluster commodities, nos quais equipamentos de propósitos gerais (isto é, um computador pessoal comum) são usados para tarefas de processamento intensivo. Diversas placas gráficas de PCs atuais podem ser usadas para essa finalidade. Pelo seu baixo custo, oferecem uma forma barata para uma instituição adquirir um sistema com alto poder de processamento.

Também, no segmento da computação de alto desempenho (HPC), as GPUs são usadas para elevar o poder computacional do sistema. Dentre os 500 supercomputadores mais rápidos do mundo, listados no Top500 224], 7,6\% usam GPU para aumentar o desempenho. Dentre os 10 mais rápidos, 2 usam a aceleradora, sendo que o segundo colocado, por empregá-las, possui melhor relação de desempenho por potência consumida $(2,14$ TFLOPS/kW) que o primeiro colocado, não usuário de GPU (1,90 TFLOPS/kW).

Provedores de serviços em nuvem também disponibilizam a alocação sob demanda de GPUs para um trabalho computacional específico. Serviços como o Amazon EC2 [8], Nimbix [170] e Softlayer [215] são oferecidos para a execução de aplicativos GPGPU. Contudo, até o momento da escrita deste documento, nenhum serviço de GPU em nuvem é disponibilizado para o Brasil.

O uso de aceleradoras gráficas para a construção de computadores massivamente paralelos vem ganhando considerável espaço de destaque na computação de alto desempenho. Na literatura, é possível encontrar diversas experimentações do uso de GPUs em tarefas de alto consumo de processamento, como processamento de imagens 43, 94], cálculo estatístico 194, inteligência artificial [176], análise molecular [143], sequenciamento de DNA [226], problemas computacionais [212], matemáticos [91, 242], de engenharia [54], entre outros.

Göddeke et al. [98] faz um comparativo de diversos sistemas HPC, colocando entre eles os sistemas de cluster com processadores multimídia. Dois aspectos importantes são salientados na discussão: ROI (retorno de investimento) e razão de desempenho por potência consumida do sistema. Sob estas circunstâncias, o uso de 
chips gráficos em processamento massivamente paralelo ganha expressiva notabilidade.

Observa-se, entretanto, que a adoção de chips gráficos para o processamento não se restringe apenas às aceleradoras gráficas de computadores. Clusters compostos de consoles de video games, como o Playstation 3, são também estudados para a construção de sistemas HPC de baixo custo [41, 167].

Em aplicações de MEF, pode-se obter consideráveis marcas de desempenho com o emprego de GPUs. Komatitsch et al. [131] utiliza GPUs para o processamento de análises de terremoto por MEF, com speedups de até 7,1 em uma GTX 280 (Nvidia). Valores de uma ordem de magnitude ou mais podem ser obtidos, dependendo da aplicação e algoritmos utilizados [96, 97]. Turek et al. [227], por exemplo, obtém expressivo speedup de até 35,6 na implementação de um solver multigrid de GPUs em relação à execução em CPU.

\subsection{Cenário nacional de pesquisa}

No Brasil, softwares de elementos finitos têm sido usados em diversas indústrias nos últimos anos, como a automobilística, a aeronáutica e a de extração de petróleo. Avaliar a resistência e absorção de impacto de um automóvel, para garantir a segurança do condutor em diversos tipos de acidentes e colisões [156], determinar a segurança de uma aeronave em colisões de pequenos objetos a altas velocidades 160. e o estudo da integridade das estruturas de uma plataforma petrolífera em cenários críticos de impacto contra navios [157] são alguns dos exemplos de aplicação nesses setores.

Para a simulação numérica desses eventos, recorre-se, geralmente, ao emprego de pacotes comerciais desenvolvidos no exterior, como LS-DYNA [144], ABAQUS [64] ou ANSYS [10], pois não existem no país pesquisas suficientes para o desenvolvimento dessas ferramentas.

São poucos os trabalhos nacionais que relatam a elaboração de uma arquitetura para um software de elementos finitos, englobando não apenas os aspectos inerentes do núcleo de solução do problema (eg. elementos, algoritmos numéricos e modelos constitutivos), mas também a interação desse bloco com os demais pontos do programa (leitura e saída de dados, por exemplo). Augusto [13] descreve uma arquitetura orientada a objetos para o MEF com elementos de alta ordem em análise quasi-estática não-linear. A arquitetura do programa demonstra flexibilidade na capacidade de carregar, analisar e gerar resultados para qualquer tipo de pro- 
blema estrutural dentro das funcionalidades implementadas no software. Contudo, não são discutidas em detalhes as formas de extensibilidade do programa. Em suas funcionalidades, não é oferecido o suporte para a análise de transientes.

O emprego de GPUs em softwares de elementos finitos é relativamente recente e, no Brasil, a adoção do hardware para a análise de fenômenos dinâmicos ainda é pouco comum. Acredita-se que a indisponibilidade de uma arquitetura para programação na aceleradora impeça um maior avanço das pesquisas devido ao custo adicional na elaboração de todo o ambiente.

Observando o atual cenário nacional e as diversas pesquisas e tecnologias disponíveis para o desenvolvimento de programas de elementos finitos, estabelece-se então os objetivos desta pesquisa.

\subsection{Objetivos}

O objetivo principal deste trabalho é a proposta de uma arquitetura para um programa de elementos finitos aplicado à análise dinâmica de estruturas que atenda às seguintes especificações gerais:

1. seja um programa de propósito geral, isto é, capaz de resolver qualquer problemas com diferentes configurações de malha, elementos, condições de contorno, entre outros aspectos;

2. combine satisfatoriamente as disciplinas de Engenharia Mecânica e Engenharia de Software para a construção de uma arquitetura sólida;

3. permita a incorporação facilitada desse núcleo do programa em um sistema maior, estando conectado a uma interface gráfica no sistema local, um serviço web ou aplicação distribuída, por exemplo;

4. ofereça meios para a interface gráfica (ou outro sistema de interface) permitir que o usuário interaja com o sistema de uma forma intuitiva, rápida e fácil;

5. suporte o processamento homogêneo em CPU ou GPU locais;

6. seja robusta (isto é, resistente à mudanças) e escalável (ou seja, permite estender as funcionalidades), permitindo adicionar extensões para uso em CPU e GPU;

7. ofereça, para o desenvolvedor, uma linguagem simples e clara para o desenvolvimento de extensões, de forma a reduzir o abismo entre a linguagem 
de implementação e a linguagem do domínio do problema;

8. seja uma plataforma independente de programas de pré e pós-processamento adotados.

Para tanto, é desenvolvido um programa de elementos finitos para análise de estruturas. De forma a demonstrar a funcionalidade da arquitetura, o programa é aplicado ao estudo de dinâmica estrutural com a presença de fenômenos não lineares, situação em que há maior número de interações entre os componentes, propondo um cenário de testes adequado para o software. Propõe-se para a solução do problema o método explícito de integração temporal, executado na GPU. O desenvolvimento se limita ao programa de elementos finitos propriamente dito, não cabendo a produção de sistemas de pré ou pós-processamento. Essas etapas são desempenhadas por outros softwares especializados.

A construção da arquitetura segue os preceitos da análise e design orientados a objetos (OOAD) [33]. Os princípios OOAD, tais como a decomposição do domínio por objetos e os Princípios de Software Gerais para a Designação de Responsabilidades (GRASP) [134], estão alinhados com os requisitos a serem atendidos neste trabalho. A abstração de dados, a aproximação da linguagem de implementação aos conceitos do domínio do problema e o desacoplamento de tecnologias são alguns dos benefícios inerentes da adoção desta disciplina no desenvolvimento.

A comunicação com o processador gráfico (GPU) é feita através da API middleware CUDA, da Nvidia [174]. Ainda que existam outras plataformas para a comunicação com o dispositivo, tais como OpenCL [9, 129], OpenACC [178] e C++ AMP [102], nesses casos, não são oferecidas formas de acessar o hardware eficientemente, pois requerem generalidade da API. Como resultado, o desempenho obtido é reduzido, como mostra Pennycook et al. 186. No presente estudo, a generalidade ocorre apenas no nível do programa em GPU e o gerenciamento de sua execução. O escopo da pesquisa é restrito ao processamento homogêneo local, isto é, a execução local em um único tipo de hardware (e também a um conjunto restrito de aceleradoras, por consequência do middleware).

Com a finalidade de verificar a precisão dos resultados e demonstrar a aplicabilidade do código, serão conduzidos testes em um ambiente de processamento com ambas as tecnologias de processamento instaladas (CPU e GPU). A partir de testes de speedup da GPU, em relação à CPU, serão avaliados os benefícios que esse hardware pode oferecer a um aplicativo de elementos finitos.

Espera-se, no âmbito nacional, com a proposição desta ferramenta, amparar as pesquisas de métodos computacionais e o desenvolvimento de softwares MEF 
robustos, ao mesmo tempo em que se promove maior acessibilidade ao desenvolvimento em tecnologias de processamento massivamente paralelas através de uma API concisa e que oculte as complexidades de implementação inerentes da plataforma, permitindo ao pesquisador maior foco em seu trabalho.

\subsection{Organização do trabalho}

O presente trabalho é dividido em três grandes partes, a saber: fundamentos, análise e design. Complementa-o ainda uma discussão e finalização.

Os fundamentos presentes nos capítulos 2 e 3 discorrem sobre a base teórica na qual o programa é construído. O Capítulo 2 apresenta os fundamentos do MEF aplicado à mecânica dos sólidos, oferecendo uma breve apresentação do método e sua forma de operação, prosseguindo para os algoritmos para solução de problemas lineares quase estáticos, lineares e não-lineares dinâmicos. A disciplina de orientação a objetos é revisada para a construção de um software de elementos finitos no Capítulo 3, discursando-se sobre orientações gerais no desenvolvimento e padrões comuns para a construção do programa.

A metodologia que orientou todo o desenvolvimento do programa e as motivações para a sua adoção são apresentadas no Capítulo 4, abrindo as discussões sobre a análise e o design do software. O Capítulo 5 apresenta as características gerais do programa e suas dimensões são ilustradas pelas métricas do software. A estruturação geral do código e os sistemas principais são apresentados em seguida. Os detalhes de implementação e a vista dinâmica dos solvers (os mecanismos de solução do problema MEF) são apresentados no Capítulo 6 .

As discussões, iniciadas no Capítulo 8, discorrem sobre os testes de validação dos algoritmos e o teste real do software. Patch tests e outros pequenos testes de validação, abrem a discussão, prosseguindo com a comparação dos resultados contra uma ferramenta comercial (ABAQUS) para avaliar a acurácia da solução e finalizando com testes de speedup da GPU, cujas métricas de desempenho são obtidas em relação aos tempos de execução em CPU do próprio código e do ABAQUS. O Capítulo 9 discursa a respeito dos resultados obtidos no trabalho e oferece linhas de pesquisa possíveis que permitam a sua continuidade.

Apêndices são incluídos para ilustrar conceitos ou partes do programa apresentadas ao longo do trabalho. 


\section{CAPÍTULO 2}

\section{Método dos Elementos Finitos em análise estrutural}

O Método dos Elementos Finitos (MEF) teve seu reconhecimento como técnica numérica viável na década de 60, em análises de estruturas aeronáuticas. Hoje, o método tem sido utilizado com sucesso em outras aplicações, como em análises de fluido-estrutura [34, 128, 164], biomecânica [163, 180], estudos acústicos [147], interações de partículas subatômicas [190], entre outras.

Neste capítulo, são apresentados os conceitos fundamentais da ferramenta quando aplicada no estudo de estruturas sólidas. Com a finalidade de se manter a objetividade, não é proposta deste texto a discussão detalhada dos aspectos do método, sendo possível obtê-la em diversos textos da literatura [16, 17, 27, 69, 108, $199,245,252$.

\subsection{Visão geral do Método dos Elementos Finitos}

O MEF obtém a solução de um sistema de equações diferenciais parciais definidas sob um dado conjunto de restrições (condições de contorno). Nisso, em análise estrutural, três grandes categorias de problemas de valor sobre o contorno são definidas, a saber, problemas de equilíbrio ou estática; problemas de auto-valor e problemas de propagação de ondas ou de transiente [198]. São obtidas como solução, dentre outros, os campos de deslocamento e de tensão; frequências naturais, cargas críticas de flambagem ou modos de vibração; resposta do corpo sob ação de uma carga variável no tempo, etc.

Independentemente da categoria do problema ou da complexidade da estru- 
tura, a análise em elementos finitos se dá através de uma mesma sequência de passos, mostrada a seguir [7, 75, 198]:

Passo 1: Avaliar o problema e levantar hipóteses - nesta etapa, são observadas as características do problema e com base nelas, são definidas as condições de contorno (engastes e carregamento, por exemplo), tipos de materiais e, quando cabíveis, simplificações na análise que não comprometam a qualidade dos resultados (assunção de material linear elástico para estruturas metálicas sujeitas a pequenas deformações, por exemplo).

Passo 2: Dividir a estrutura em unidades menores (discretização) - cabe ao analista subdividir a estrutura ou espaço de solução em unidades menores, denominadas elementos finitos, a partir das quais a solução global é obtida, como resultado da combinação dos resultados individuais dos elementos. A qualidade da malha (forma com que o espaço é discretizado) e os tipos de elementos finitos escolhidos, entre outros fatores, são cruciais para a qualidade do resultado obtido.

Passo 3: Aplicação das condições de contorno - são inseridas no modelo numérico as condições de contorno as quais o modelo está sujeito, inclusive aquelas oriundas de simplificações adotadas na primeira etapa.

Passo 4: Cálculo da solução global - são calculados os resultados individuais dos elementos e, então, combinados a fim de se formar a solução global do modelo. O modo como este procedimento é executado depende da categoria e de outros aspectos intrínsecos do problema.

Passo 5: Avaliação dos resultados - os resultados obtidos através do método devem ser verificados pelo analista a fim de se constatar que a resposta do modelo é fisicamente coerente e plausível. Um resultado infundável é, geralmente, um indicativo de mau-condicionamento ou incompatibilidade do modelo com o problema.

\subsection{Discretização do modelo}

Como foi observado anteriormente, a análise de elementos finitos envolve a subdivisão da estrutura em elementos. Neste sistema discreto, a solução é obtida apenas para pontos específicos do corpo contínuo - os nós, que, em geral, estão localizados nas fronteiras dos elementos e promovem a conexão entre eles. Os deslocamentos nodais são escolhidos como parâmetros para definir o comportamento da estrutura. 
As variáveis de estado, que descrevem o estado de equilíbrio da estrutura, tais como tensão e deformação, são calculadas a partir deles.

Uma vez que não são conhecidos os valores dessas variáveis no contínuo, assume-se que, para um dado elemento, o estado de equilíbrio em um ponto no seu interior pode ser calculado através de funções de interpolação ${ }^{1}$, ou funções de forma, definidas em termos dos valores nodais do elemento [7].

A continuidade do campo de deslocamento na estrutura é dada pela continuidade das funções nodais e a compatibilidade dos deslocamentos. A continuidade das funções de interpolação garantem a consistência dos deslocamentos no interior do elemento e torna capaz a representação dos estados de deformação constantes e os movimentos de corpo rígido possíveis. A compatibilidade dos deslocamentos nos nós assegura a continuidade nas interfaces. Para tanto, o deslocamento de um nó é igualmente percebido em todos os elementos a ele conectado.

Para que possa ser representada qualquer tipo de estrutura, os pacotes comerciais de elementos finitos oferecem uma grande variedade de tecnologias de elementos com geometria e funções de interpolação variadas [10, 55, 64, 144, 166].

\subsection{Procedimento geral de solução}

Uma das vantagens do MEF é a construção do método como uma sequência de atividades auto-contidas. Com isso, é possível desmembrar as etapas de solução em "caixas pretas", que se conectam através de seus dados de entrada e de saída, como é simplificadamente mostrado na Fig. 2.1. Graças à modularidade inerente do método, diferentes procedimentos numéricos podem ser intercambiados sem interferir no bom funcionamento de outras partes do processo de solução.

Neste capítulo, os conceitos do MEF serão explicados fazendo uso da abstração inerente do método. Cada uma das etapas envolvidas no procedimento será discutida como atividade isolada, que se conecta através das informações requeridas e produzidas. Dessa forma, são enfatizados os aspectos de generalização do método, que vão ao encontro das proposições do desenvolvimento orientado a objetos, auxiliando na compreensão dos conceitos que serão explicados no Capítulo 3. Inicialmente, o método é considerado para a solução de problemas lineares, apresentando-se, em seguida, extensões para a solução de problemas não lineares.

\footnotetext{
${ }^{1}$ Variantes do MEF usam artifícios adicionais para melhor representar fenômenos físicos. O Método dos Elementos Finitos Estendido (XFEM), por exemplo, utiliza funções de enriquecimento para melhoria do espaço de aproximação dos elementos [225].
} 


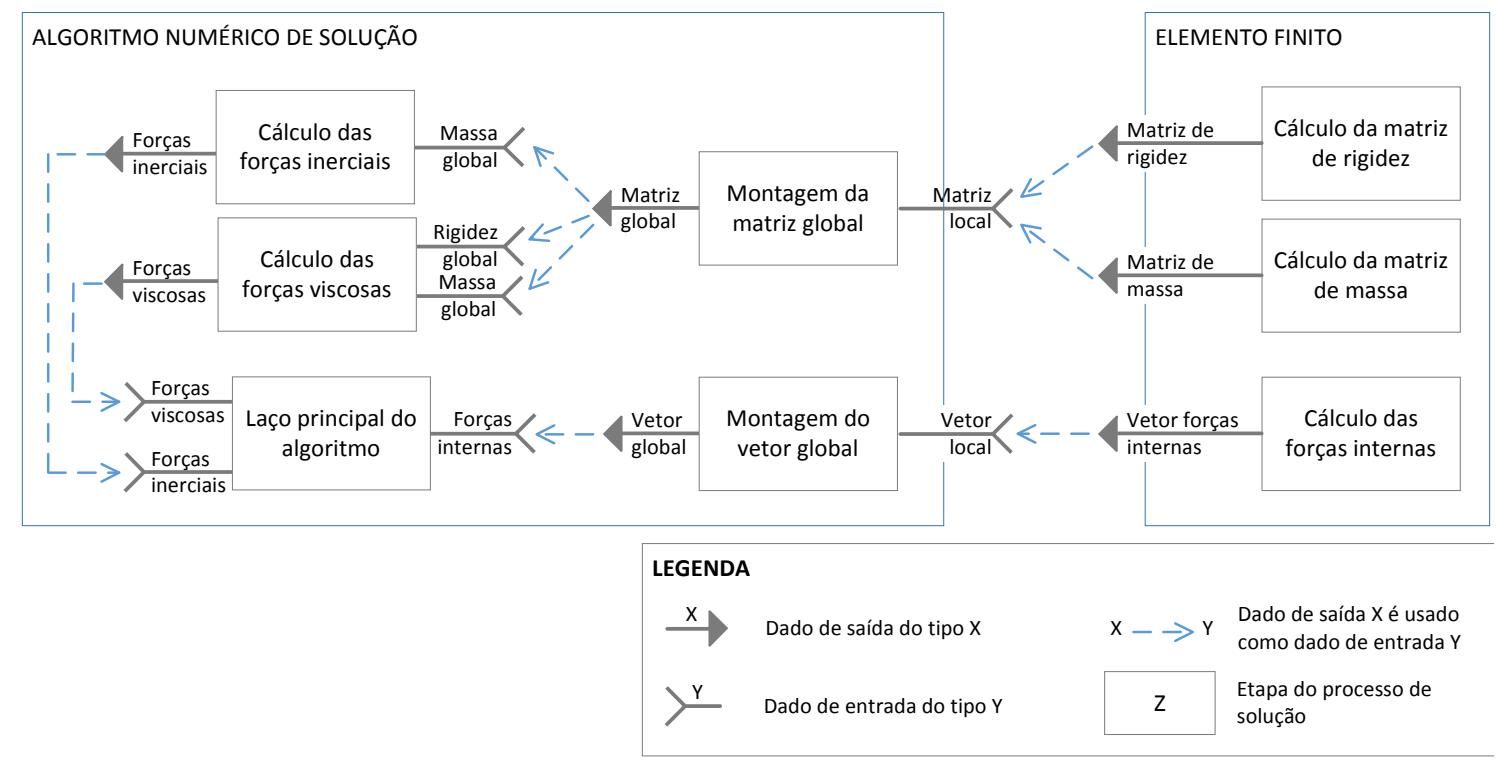

Figura 2.1 Descrição do MEF como um conjunto abstrato de atividades.

\subsubsection{Descrição do problema}

Em Engenharia, algumas classes de problemas consideradas para a solução por elementos finitos são [16, 213]:

$$
\begin{aligned}
\text { Equilíbrio estático: } & \mathbf{r}^{\mathrm{int}}=\mathbf{r}^{\mathrm{ext}} \Rightarrow \mathbf{K u}=\mathbf{r}^{\mathrm{ext}} \\
\text { Análise dinâmica: } & \mathbf{M} \ddot{\mathbf{u}}+\mathbf{C} \dot{\mathbf{u}}+\mathbf{K u}=\mathbf{r}^{\mathrm{ext}} \\
\text { Análise modal: } & \mathbf{K a}-\omega^{2} \mathbf{M a}=\mathbf{0} \\
\text { Flambagem linear: } & \mathbf{K a}-\left(P^{\mathrm{cr}}\right)^{2} \mathbf{M} \mathbf{q}^{b}=\mathbf{0}
\end{aligned}
$$

Em problemas de estática, as forças internas $\mathbf{r}^{\text {int }}$ são dependentes da rigidez da estrutura, representada pela matriz de rigidez global, K. O deslocamento do sistema $(\mathbf{u})$ é calculado resolvendo o sistema linear dado pelos coeficientes de $\mathbf{K}$ e as forças externas $\left(\mathbf{r}^{\mathrm{ext}}\right)$.

Em análises dinâmicas, a Eq. (2.2) é resolvida a cada iteração de tempo. A inércia da estrutura é representada pela matriz de massa global do sistema, $\mathbf{M}$, e a aceleração correspondente, $\ddot{\mathbf{u}}$. A matriz de amortecimento $(\mathbf{C})$ e a velocidade global (ن) representam uma componente contrária ao movimento, atenuando a resposta da estrutura.

Problemas de análise modal podem ser resolvidos através de diversas técnicas, como o método iterativo QR ou os métodos de Lanczos [99], encontrando-se os modos de vibração a e as correspondentes frequências naturais $\omega$. Problemas de 
flambagem linear, no contexto de MEF, resultam em equações de auto-valor, que podem ser resolvidas pelos métodos citados anteriormente, onde os auto-valores são as cargas críticas $\left(P^{\text {cr }}\right)$ e os auto-vetores $\mathbf{q}^{b}$ correspondem aos respectivos modos de flambagem. Flambagem não linear, por outro lado, levam em conta aspectos de não linearidade da estrutura, sendo geralmente resolvido através de análise estática não linear, com o auxílio de métodos iterativos, como os de Newton ou do comprimento do arco, preferencialmente [47, 69].

Para o presente trabalho, são de interesse os problemas governados pelas Eqs. (2.1) e (2.2). As matrizes globais necessárias para a solução desses sistemas são obtidas a partir de sua discretização em elementos, onde a contribuição de cada um desses componentes é devidamente somada à resposta global, conforme apresentado a seguir.

\subsubsection{Montagem das matrizes e vetores do sistema}

$\mathrm{Na}$ discretização da estrutura, cada elemento contribui para a resposta do sistema ao produzir componentes locais que interferem no seu comportamento global. Por exemplo, a rigidez local de um elemento, dada pela matriz $\underset{\sim}{\mathbf{K}}$, participa na determinação da rigidez global, a matriz $\mathbf{K}$.

As matrizes globais do sistema podem ser obtidas a partir da soma direta das contribuições locais dos elementos da estrutura. Nesse procedimento, denominado Método de Rigidez Direto, cada uma das matrizes dos elemento, por exemplo $\underset{\sim}{\mathbf{K}}$, é expandida para a mesma ordem da matriz global do sistema. No caso, os coeficientes de $\underset{\sim}{\mathbf{K}}$ são transportados para a matriz expandida, alinhando-se aos graus de liberdade ao qual se referem na matriz global da estrutura (Fig. 2.2). Em outras palavras,

$$
\mathbf{K}=\sum \sum^{\mathrm{DSM}} \mathbf{K}^{\langle i\rangle}
$$

onde $\sum^{\text {DSM }}$ representa a soma das matrizes de rigidez locais $\underset{\sim}{\mathbf{K}}{ }^{\langle i\rangle}$ a partir do Método de Rigidez Direto. Analogamente, vetores globais podem ser construídos a partir das contribuições locais dos elementos como, por exemplo, na determinação das forças internas da estrutura ou das forças viscosas de amortecimento.

Como comumente ocorre na solução de equações diferenciais parciais, a matriz de coeficientes é grande e esparsa, normalmente em banda (coeficientes não-nulos agrupados próximos à diagonal principal). Dessa forma, é mais eficiente armazenar apenas os valores não-nulos da banda principal. A opção de também armazenar os coeficientes nulos dentro da banda depende do algoritmo ao qual a matriz será 


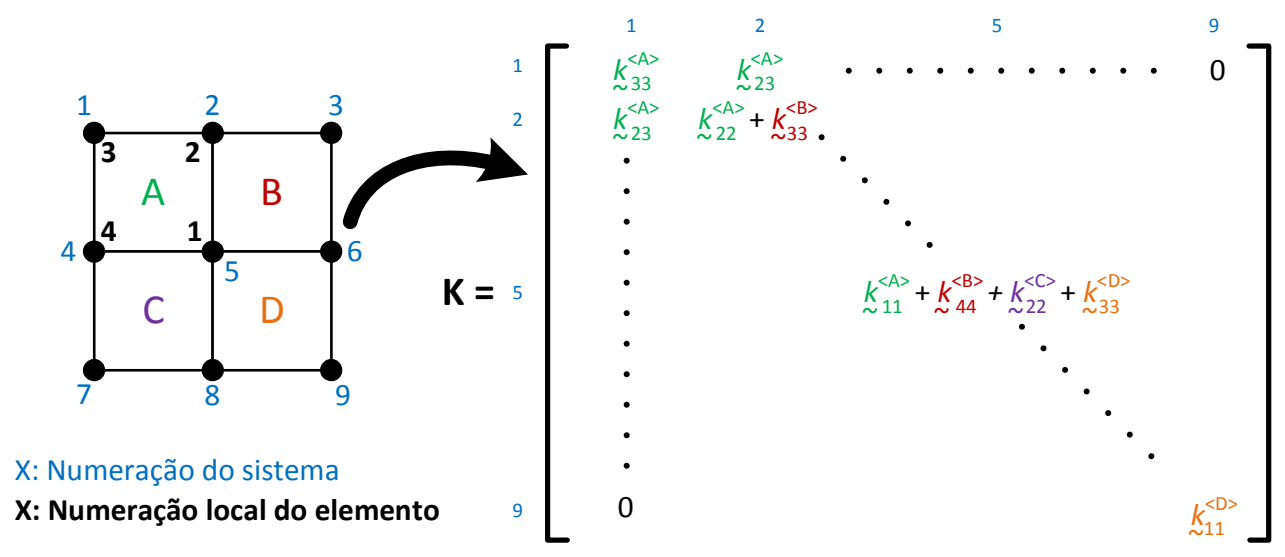

*Neste exemplo, todos os elementos da malha são numerados da mesma maneira.

Figura 2.2 Método de Rigidez Direto. Ao expandir as matrizes de rigidez dos elementos, cada uma das contribuições são transportadas observando a posição que o nó ocupa em relação ao sistema. Apenas algumas contribuições são mostradas.

submetida, conforme será explicado adiante.

\subsubsection{Aplicação das condições de contorno}

Subsequente à montagem das quantidades globais do sistema, as condições de contorno definem as condições de mobilidade e de carregamento da estrutura. É necessário restringir os movimentos da estrutura a fim de se remover a singularidade do sistema linear gerado pelas matrizes globais do sistema. A incorporação das condições de contorno pode se dar de diversas maneiras, como, por exemplo, com a inclusão de um fator de penalidade no grau de liberdade afetado ou "zerando-se" a linha e a coluna correspondente à direção, exceto na diagonal principal (detalhes são fornecidos em [16, 27, 213]). Em qualquer caso, a intenção é remover a singularidade impondo-se o valor de uma ou mais variáveis do sistema.

Nos processos de solução apresentados a seguir, a imposição das condições de contorno não é ilustrada nos algoritmos. No entanto, com base nas técnicas discutidas na literatura, a manipulação dessas variáveis pode facilmente ser deduzida.

\subsection{Solução de problemas de equilíbrio estático linear}

Numa análise de equilíbrio estático, todo o contínuo do sistema deve permanecer em repouso, isto é, a soma de forças e momentos atuantes é nula. No MEF, esta situação é aproximada impondo-se o equilíbrio apenas em pontos específicos do sistema (os nós da malha). 
Como as variáveis do problema não estão em função do tempo, nenhum método de integração temporal é necessário. Tratando-se de um problema puramente linear, $\mathbf{K}$ ou $\mathbf{r}^{\text {ext }}$ independem de $\mathbf{u}$, o que, portanto, se resume na solução do sistema linear da Eq. (2.1).

Existem diversas técnicas que podem ser empregadas para a solução do sistema, entre elas os métodos diretos (eg. decomposição LU, decomposição de Gauss e decomposição Cholesky), nos quais a solução é obtida fatorando-se a matriz de coeficientes (escalonamento), e os métodos iterativos (eg. gradiente conjugado, método generalizados do resíduo mínimo e método de Gauss-Seidel), onde a solução é obtida através de um algoritmo iterativo de convergência [99].

Os métodos diretos de solução se baseiam na decomposição da matriz de coeficientes (no caso, $\mathbf{K}$ ) em uma multiplicação de fatores triangulares, de tal forma que a solução possa ser facilmente obtida através de substituição para trás e para frente. Em geral, esses processos de solução exigem o armazenamento completo da banda da matriz (incluindo valores nulos), o que pode representar um alto custo para problemas maiores com grande quantidade de graus de liberdade [213]. Nessa situação, análises de médio porte, com cerca de 10000 elementos, podem requerer mais de 800 MB para o armazenamento da banda.

Além disso, devido à esparsidade e às dimensões da matriz de rigidez, a busca por fatores de eliminação pode ser prolongada [99]. Nessas ocasiões, normalmente se recomenda o uso de métodos iterativos de solução [16, 213], pois, em diversos casos, não é requerida a montagem da matriz global e as iterações de convergência podem ser aceleradas com o emprego de pré-condicionadores (não discutidos neste trabalho).

\subsubsection{Método do gradiente conjugado}

O método do gradiente conjugado (GC) pertence à família dos métodos iterativos de solução. Nesses algoritmos, a sequência de passos envolvida no processo solicita, no máximo, multiplicações matriz-vetor, o que torna o processo computacionalmente atraente [99].

Descrevendo em termos da Eq. (2.1), a estratégia de resolução do GC se baseia na minimização da função

$$
f(\mathbf{u})=\frac{1}{2} \mathbf{u}^{T} \mathbf{K} \mathbf{u}-\mathbf{u}^{T} \mathbf{r}^{\mathrm{ext}}
$$

Uma vez que $\mathbf{K}$ é simétrico e positivo definido, minimizar $f$ ou resolver o sis- 
tema linear é equivalente. Uma estratégia simples de minimização consiste na busca pela direção em que $f$ decresce mais rapidamente, o que corresponde ao gradiente negativo da função.

O método avança para a solução do sistema na direção dos gradientes calculados a cada iteração. Os vetores são mutuamente ortogonais (ou conjugados, o que dá nome ao método) e, em matemática exata, permite convergência em, no máximo, $n$ iterações, onde $n$ é a ordem de $\mathbf{K}$.

O Algoritmo 2.1 mostra a aplicação do GC para a solução do sistema linear da Eq. (2.1).

Algoritmo 2.1: Solução de equilíbrio estático através do Gradiente Conjugado.

\section{Algoritmo Gradiente Conjugado}

Condições iniciais: $\mathbf{K}$ não-singular, simétrica e positiva-definida; $\mathbf{r}^{\text {ext }}$

\section{Saída: $u$}

1. $k=0$

2. Seja $\mathbf{x}_{0}$ o vetor que guardará a solução do sistema. Atribui-se um valor inicial a partir do qual o algoritmo calculará o gradiente. Por exemplo, $\mathbf{x}_{0}=\mathbf{0}$

3. $\mathbf{r}_{0}=\mathbf{r}^{\mathrm{ext}}-\mathbf{K} \mathbf{x}_{0}$

4. $\mathbf{p}_{1}=\mathbf{r}_{0}$

5. enquanto $\mathbf{r}_{k}$ não é suficientemente pequeno

a. $k=k+1$

b. se $k>1$ então

i. $\boldsymbol{\alpha}_{k}=\left(\mathbf{r}_{k-1}^{T} \mathbf{r}_{k-1}\right) /\left(\mathbf{r}_{k-2}^{T} \mathbf{r}_{k-2}\right)$

ii. $\mathbf{p}_{k}=\mathbf{r}_{k-1}+\boldsymbol{\alpha}_{k} \mathbf{p}_{k-1}$

c. $\mathbf{q}_{k}=\mathbf{K} \mathbf{p}_{k}$

d. $\boldsymbol{\beta}_{k}=\left(\mathbf{r}_{k-1}^{T} \mathbf{r}_{k-1}\right) /\left(\mathbf{p}_{k}^{T} \mathbf{q}_{k}\right)$

e. $\mathbf{x}_{k}=\mathbf{x}_{k-1}+\boldsymbol{\beta}_{k} \mathbf{p}_{k}$

f. $\mathbf{r}_{k}=\mathbf{r}_{k-1}-\boldsymbol{\beta}_{k} \mathbf{q}_{k}$

6. $\mathbf{u}=\mathbf{x}_{k}$ 
A parte mais cara do algoritmo que mais demanda esforço computacional ocorre nas multiplicações matriz-vetor envolvendo K. A multiplicação do passo 5c, no Algoritmo 2.1, não exige que a matriz global seja previamente montada. Isto é,

$$
\mathbf{q}_{k}={\underset{\sim}{\mathbf{K}}}^{\langle 1\rangle} \mathbf{p}_{k}+{\underset{\sim}{\mathbf{K}}}^{\langle 2\rangle} \mathbf{p}_{k}+\underset{\sim}{\mathbf{K}}{ }^{\langle 3\rangle} \mathbf{p}_{k}+\cdots+{\underset{\sim}{\mathbf{K}}}^{\langle\mathrm{n}\rangle} \mathbf{p}_{k}=\sum \sum^{\mathrm{EBE}} \underset{\mathbf{K}^{\langle i\rangle}}{\mathbf{p}_{k}}
$$

onde cada matriz elementar é multiplicada pelos termos de $\mathbf{p}_{k}$ correspondentes aos graus de liberdade daquele elemento. Por esse motivo, o procedimento é classificado como um processo elemento a elemento (denotado por $\sum^{\mathrm{EBE}}$ ), caracterizado pela ausência da matriz global e consequente economia do espaço que por ela outrora seria consumido.

Matematicamente, no passo 5, o critério de parada é definido pela norma nula do vetor resíduo $\mathbf{r}_{k}$, isto é $\left\|\mathbf{r}_{k}\right\|=0$. Contudo, devido a precisão finita do computador, erros de arredondamento e aproximação numérica induzem pequenas variações nos cálculos e, na prática, adotam-se critérios de parada baseados em um valor de tolerância $\delta$, tal como $\|\mathbf{r}\| \leq \delta$.

Devido a essa mesma imprecisão, a convergência da versão computacional do algoritmo pode levar mais que $n$ iterações. No contexto de MEF, algumas formulações de elementos ou condições da malha podem afetar o desempenho do método, devido à super-estimação dos coeficientes de rigidez da matriz do elemento ou ao refinamento pobre da estrutura (fenômeno conhecido pelo nome inglês, locking; maiores detalhes serão fornecidos mais adiante). Como consequência, o método demora demais para convergir ou simplesmente não evolui, devido ao mau-condicionamento de K. O emprego de pré-condicionadores adequados ajudam a mitigar esses problemas $[99]$.

\subsection{Solução de problemas lineares de propagação}

Nos problemas quase estáticos, os efeitos de inércia sofridos pela estrutura são tão pequenos que podem ser convenientemente desprezados. Isto é, a força $\mathbf{r}^{\mathrm{ext}}$, quando aplicada ao sistema (Eq. (2.1)), introduz pertubações mínimas, incapazes de induzir uma variação perceptível na resposta ao longo do tempo.

No entanto, quando as condições de contorno induzem efeitos que excitam consideravelmente os modos de vibração da estrutura, uma análise do seu comportamento ao longo do tempo é requerida, sendo classificada como um problema de propagação de ondas ou então de dinâmica estrutural. 
A solução de problemas de propagação ou dinâmicos, governados pela Eq. (2.2), pode ser obtida por diferentes métodos. Sua escolha depende dos fenômenos que regem o problema, de tal forma que, o emprego incorreto do método pode afetar o desempenho do algoritmo ou a acurácia dos resultados. Existem dois métodos que podem ser adotados na solução: os de superposição de modos e os de integração direta, estes subdivididos em métodos implícitos e explícitos. Devido a sua eficiência limitada no estudo de fenômenos não lineares [16], a superposição de modos não será considerada. Desta forma, são apresentados a seguir os algoritmos de integração direta.

\subsubsection{Método implícito de integração direta}

Os métodos implícitos de integração direta (ou simplesmente métodos implícitos) têm como característica a obtenção do estado do sistema no instante $t+\Delta t$ a partir das condições de equilíbrio nos instantes $t$ e $t+\Delta t$, onde $\Delta t$ representa o incremento de tempo entre os dois instantes. Um dos algoritmos mais conhecidos é o método de Newmark [169], implementado nos pacotes comerciais de elementos finitos [63, 103]. Neste esquema de integração, são adotadas as seguintes relações:

$$
\begin{gathered}
\dot{\mathbf{u}}_{t+\Delta t}=\dot{\mathbf{u}}_{t}+\left[\left(1-\gamma_{\mathrm{NM}}\right) \ddot{\mathbf{u}}_{t}+\gamma_{\mathrm{NM}} \ddot{\mathbf{u}}_{t+\Delta t}\right] \Delta t \\
\mathbf{u}_{t+\Delta t}=\mathbf{u}_{t}+\dot{\mathbf{u}}_{t} \Delta t+\left[\left(\frac{1}{2}-\beta_{\mathrm{NM}}\right) \ddot{\mathbf{u}}_{t}+\beta_{\mathrm{NM}} \ddot{\mathbf{u}}_{t+\Delta t}\right] \Delta t^{2}
\end{gathered}
$$

onde $\beta_{\mathrm{NM}}$ e $\gamma_{\mathrm{NM}}$ são parâmetros de estabilidade do algoritmo. Adotando-se $\beta_{\mathrm{NM}}=1 / 4$ e $\gamma_{\mathrm{NM}}=1 / 2$, isolando $\ddot{\mathbf{u}}_{t+\Delta t}$ em (2.9) e usando a expressão obtida em (2.8), obtém-se que

$$
\begin{gathered}
\ddot{\mathbf{u}}_{t+\Delta t}=\frac{4}{\Delta t^{2}}\left(\mathbf{u}_{t+\Delta t}-\mathbf{u}_{t}+\Delta t \dot{\mathbf{u}}\right)-\ddot{\mathbf{u}}_{t} \\
\dot{\mathbf{u}}_{t+\Delta t}=\frac{2}{\Delta t}\left(\mathbf{u}_{t+\Delta t}-\mathbf{u}_{t}\right)-\dot{\mathbf{u}}_{t} .
\end{gathered}
$$

Por fim, substituindo em (2.2),

$$
\hat{\mathbf{K}} \mathbf{u}_{t+\Delta t}=\hat{\mathbf{r}}_{t+\Delta t}^{\mathrm{ext}}
$$

onde

$$
\hat{\mathbf{K}}=\frac{4}{\Delta t^{2}} \mathbf{M}+\frac{2}{\Delta t} \mathbf{C}+\mathbf{K}
$$

e

$$
\hat{\mathbf{r}}^{\mathrm{ext}}=\mathbf{r}_{t+\Delta t}^{\mathrm{ext}}+\mathbf{M}\left(\frac{4}{\Delta t^{2}} \mathbf{u}_{t}+\frac{4}{\Delta t} \dot{\mathbf{u}}_{t}+\ddot{\mathbf{u}}_{t}\right)+\mathbf{C}\left(\frac{2}{\Delta t} \mathbf{u}_{t}+\dot{\mathbf{u}}_{t}\right) \text {. }
$$


Os valores $\beta_{\mathrm{NM}}=1 / 4$ e $\gamma_{\mathrm{NM}}=1 / 2$ são propostos por Newmark [169] para garantir a estabilidade incondicional do método. Isso significa que a estabilidade numérica do esquema de integração independe do incremento de tempo $\Delta t$ escolhido. Contudo, a acurácia pode ser afetada [35].

O sistema da Eq. (2.12) sempre possui uma única solução, desde que a matriz de massa $\mathbf{M}$ seja positiva definida, ainda que $\mathbf{K}$ permita movimentos de corpo rígido. Em problemas lineares, a equação precisa ser resolvida a cada passo de tempo. Portanto, é recomendável a montagem e fatoração inicial da matriz $\hat{\mathbf{K}}$ (por exemplo, fatoração $L D L^{T}$ [99]). Com isso, a cada iteração, o sistema pode ser resolvido a um custo menor, por substituição para frente e para trás.

No entanto, em problemas de curta duração, onde fenômenos não lineares são predominantes, como no impacto, o método implícito não se mostra vantajoso. $\mathrm{O}$ comportamento não linear do material ou os efeitos de deformação finita, por exemplo, tornam a matriz $\mathbf{K}$ dependente de $\mathbf{u}_{t+\Delta t}$ ou de suas derivadas [57]. Desta forma, a solução da Eq. (2.12) é complexa e precisa ser resolvida por esquemas iterativos, tais como os métodos de Newton ou quase Newton [60]. Em situações de deformação mais severas, um alto número de iterações pode ser requerido, às vezes apresentando problemas de convergência. Nessas ocasiões, técnicas de integração explícita são preferidas para contornar essas deficiências e são preferidas para implementação neste trabalho.

\subsubsection{Método explícito de integração direta}

Os métodos explícitos obtêm a solução a partir do estado de equilíbrio no instante de tempo atual. O algoritmo popular deste grupo é o método das diferenças centrais [57]. Baseado em diferenças finitas, considera-se a Eq. (2.2) como um sistema de equações diferenciais ordinárias com coeficientes constantes [16], $\mathbf{u}_{t+\Delta t}$ e $\mathbf{u}_{t-\Delta t}$ são representados pelas seguintes séries de Taylor:

$$
\begin{aligned}
& \mathbf{u}_{t+\Delta t}=\mathbf{u}_{t}+\Delta t \dot{\mathbf{u}}_{t}+\frac{\Delta t^{2}}{2} \ddot{\mathbf{u}}_{t}+\frac{\Delta t^{3}}{6} \dddot{\mathbf{u}}_{t}+\cdots \\
& \mathbf{u}_{t-\Delta t}=\mathbf{u}_{t}-\Delta t \dot{\mathbf{u}}_{t}+\frac{\Delta t^{2}}{2} \ddot{\mathbf{u}}_{t}-\frac{\Delta t^{3}}{6} \dddot{\mathbf{u}}_{t}+\cdots
\end{aligned}
$$

Ignorando-se os termos maiores que de segunda ordem e subtraindo-se e somandose as Eqs. (2.15)-(2.16), tem-se, respectivamente, as seguintes relações:

$$
\dot{\mathbf{u}}_{t}=\frac{1}{2 \Delta t}\left(\mathbf{u}_{t+\Delta t}-\mathbf{u}_{t-\Delta t}\right)
$$




$$
\ddot{\mathbf{u}}_{t}=\frac{1}{\Delta t^{2}}\left(\mathbf{u}_{t+\Delta t}-2 \mathbf{u}_{t}+\mathbf{u}_{t-\Delta t}\right)
$$

As Eqs. (2.17) e (2.18) possuem precisão quadrática, isto é, as expressões acima possuem erro $O\left(\Delta t^{2}\right)$, o que, ao reduzir pela metade o incremento de tempo $\Delta t$, implica na redução para quase um quarto do erro da aproximação [57].

Combinando-se as Eqs. (2.2), (2.17) e (2.18), obtém-se

$$
\left(\frac{1}{\Delta t^{2}} \mathbf{M}+\frac{1}{2 \Delta t} \mathbf{C}\right) \mathbf{u}_{t+\Delta t}=\mathbf{r}_{t}^{\mathrm{ext}}-\mathbf{K}_{t}+\frac{1}{2 \Delta t} \mathbf{C u}_{t-\Delta t}+\frac{1}{\Delta t^{2}} \mathbf{M}\left(2 \mathbf{u}_{t}-\mathbf{u}_{t-\Delta t}\right)
$$

A primeira iteração do algoritmo requer $\mathbf{u}_{-\Delta t}$, que pode ser calculado através da Eq. (2.16) (novamente, ignorando os termos maiores que segunda ordem), com as condições iniciais, $\mathbf{u}_{0}, \dot{\mathbf{u}}_{0}$ e $\ddot{\mathbf{u}}_{0}$, este último obtido pela resolução da Eq. (2.2):

$$
\mathbf{u}_{-\Delta t}=\mathbf{u}_{0}-\Delta t \dot{\mathbf{u}}_{0}+\frac{\Delta t^{2}}{2} \ddot{\mathbf{u}}_{0}
$$

Se desconsiderado o amortecimento e $\mathbf{M}$ for diagonal, a solução da Eq. (2.19) é trivial. Contudo, para os casos em que $\mathbf{C} \neq \mathbf{0}$, o processo apresenta alto custo computacional, pois, normalmente, $\mathbf{C}$ não é diagonal e depende de $\mathbf{K}$. Para mitigar esse problema, uma implementação alternativa é sugerida na literatura [16, 57, 103], onde a velocidade é artificialmente defasada em meio passo de tempo. Para tanto, define-se a aproximação

$$
\dot{\mathbf{u}}_{t+\frac{1}{2} \Delta t}=\frac{1}{\Delta t}\left(\mathbf{u}_{t+\Delta t}-\mathbf{u}_{t}\right)
$$

Reescrita de outra forma, a relação demonstra uma atualização trivial do deslocamento:

$$
\begin{gathered}
\mathbf{u}_{t+\Delta t}=\mathbf{u}_{t}+\Delta \mathbf{u} \\
\Delta \mathbf{u}=\Delta t \dot{\mathbf{u}}_{t+\frac{1}{2} \Delta t}
\end{gathered}
$$

Usando a Eq. (2.22) em (2.18), obtemos uma nova definição para a aceleração,

$$
\ddot{\mathbf{u}}_{t+\frac{1}{2} \Delta t}=\frac{1}{\Delta t}\left(\dot{\mathbf{u}}_{t+\frac{1}{2} \Delta t}-\dot{\mathbf{u}}_{t-\frac{1}{2} \Delta t}\right)
$$

o que é equivalente dizer que

$$
\dot{\mathbf{u}}_{t+\frac{1}{2} \Delta t}=\dot{\mathbf{u}}_{t-\frac{1}{2} \Delta t}+\Delta t \ddot{\mathbf{u}}_{t-\frac{1}{2} \Delta t}
$$


A equação de equilíbrio (2.2) é modificada, tal que

$$
\mathbf{M} \ddot{\mathbf{u}}_{t}+\mathbf{C} \dot{\mathbf{u}}_{t-\frac{1}{2} \Delta t}+\mathbf{K} \mathbf{u}_{t}=\mathbf{r}_{t}^{\mathrm{ext}}
$$

Podemos, então, definir a atualização da aceleração como

$$
\mathbf{M} \ddot{\mathbf{u}}_{t+\Delta t}=\mathbf{r}_{t+\Delta t}^{\mathrm{ext}}-\mathbf{K} \mathbf{u}_{t+\Delta t}-\mathbf{C} \dot{\mathbf{u}}_{t+\frac{1}{2} \Delta t}
$$

Para início do algoritmo, adota-se $\dot{\mathbf{u}}_{-\frac{1}{2} \Delta t} \approx \dot{\mathbf{u}}_{0}$. A aceleração inicial pode ser obtida através da Eq. (2.26).

Nesta implementação, a eficiência do algoritmo não depende do formato de C. No entanto, devido à defasagem das forças viscosas $\left(\mathbf{C u}_{t-\frac{1}{2} \Delta t}\right)$, a precisão do método é linear [16, 57].

$\mathrm{O}$ termo $\mathbf{K} \mathbf{u}_{t+\Delta t}$ corresponde às forças internas da estrutura no instante $t+\Delta t$. Ao invés de se optar pela montagem da matriz de rigidez global, pode-se recorrer ao cálculo das forças elemento a elemento, isto é,

$$
\mathbf{r}_{t}^{\mathrm{int}}=\mathbf{K} \mathbf{u}_{t}=\sum^{E B E} \int_{v}\left(\mathbf{B}^{\langle i\rangle}\right)^{T} \boldsymbol{\sigma}^{\langle\mathrm{i}\rangle} d v
$$

onde $\sum^{E B E}$ representa a montagem do vetor global, somando-se as contribuições elemento a elemento, em suas respectivas posições, $\mathbf{B}^{\langle i\rangle}$ é a matriz de gradientes, calculada pela formulação do elemento, e $\boldsymbol{\sigma}^{\langle i\rangle}$ é o estado de tensão do i-ésimo elemento, calculado pelo modelo constitutivo do material. Esta alternativa é particularmente interessante ao considerar fenômenos não lineares, evitando a custosa computação de K. A integral em (2.28) é normalmente resolvida numericamente de acordo com os preceitos da tecnologia do elemento. Detalhes do cálculo são fornecidos posteriormente neste capítulo. O Algoritmo 2.2 resume a sequência de passos para a resolução pelo método.

A estabilidade do método explícito depende do incremento de tempo escolhido. A escolha de um valor alto demais pode degradar a solução do sistema rapidamente, na qual os erros numéricos acumulam e predominam sobre a solução. Um limite geralmente aceito para $\Delta t$ baseia-se na condição $\mathrm{CFL}^{2}$, que, desprezando amortecimento, estabelece um limite superior para o incremento de tempo $\left(\Delta t_{c r}\right)$,

$$
\Delta t \leq \Delta t_{c r}=\frac{2}{\omega_{\max }}
$$

onde $\omega_{\max }$ é a maior frequência natural do modelo estrutural. Sua obtenção implica na resolução de um problema de autovalores da equação $\operatorname{det}\left(\mathbf{K}-\omega^{2} \mathbf{M}\right)=\mathbf{0}$.

\footnotetext{
${ }^{2}$ Sigla para Courant-Friedrichs-Lewy, nomes dos autores que propuseram a condição [59].
} 
Algoritmo 2.2: Método das diferenças centrais para problemas de integração no tempo.

\section{Algoritmo Diferenças centrais}

Condições iniciais: $\mathbf{M}, \mathbf{C}, \mathbf{u}_{0}, \dot{\mathbf{u}}_{0}$ e $\ddot{\mathbf{u}}_{0}$

Saída: $\mathbf{u}_{t}, \dot{\mathbf{u}}_{t}$ e $\ddot{\mathbf{u}}_{t}$, a cada instante de tempo $t$

1. $t=0$

2. Calcular passo de tempo $(\Delta t)$ adequado

3. enquanto $t<t_{\text {final }}$

a. $\Delta \mathbf{u}_{t+\Delta t}=\Delta t \dot{\mathbf{u}}_{t+\frac{1}{2} \Delta t}$

b. $\mathbf{u}_{t+\Delta t}=\mathbf{u}_{t}+\Delta \mathbf{u}_{t+\Delta t}$

c. Calcular incremento de deformação $\Delta \varepsilon^{\langle i\rangle}\left(\Delta \underline{u}^{\langle i\rangle}\right)$ dos elementos (formulação do elemento)

d. Atualizar estado de tensão dos elementos (modelo constitutivo do material $),\left(\boldsymbol{\sigma}^{\langle i\rangle}\right)_{t+\Delta t}=\left(\boldsymbol{\sigma}^{\langle i\rangle}\right)_{t}+\Delta \boldsymbol{\sigma}^{\langle i\rangle}\left(\Delta \varepsilon^{\langle i\rangle}\right)$

e. Calcular as forças internas, $\mathbf{r}_{t+\Delta t}^{\text {int }}$, do sistema (ver Eq. (2.28) e texto subsequente)

f. Calcular $\mathbf{r}^{\mathrm{ext}}(t+\Delta t)$

g. $\ddot{\mathbf{u}}_{t+\Delta t}=\mathbf{M}^{-1}\left(\mathbf{r}_{t+\Delta t}^{\mathrm{ext}}-\mathbf{r}_{t+\Delta t}^{\mathrm{int}}-\mathbf{C} \dot{\mathbf{u}}_{t+\frac{1}{2} \Delta t}\right)$

h. $\dot{\mathbf{u}}_{t+\frac{3}{2} \Delta t}=\dot{\mathbf{u}}_{t+\frac{1}{2} \Delta t}+\Delta t \ddot{\mathbf{u}}_{t+\Delta t}$

i. $t=t+\Delta t$

Por representar alto custo computacional, $\omega$ é normalmente calculado por métodos alternativos mais simples. Uma estimativa simples é [57]

$$
\omega_{\max }=\frac{2 c}{L}
$$

onde $L$ é o comprimento característico do menor elemento da malha e $c$ é a velocidade de onda no meio, que, para casos tridimensionais, vale

$$
c=\sqrt{\frac{E(1-\nu)}{\rho(1+\nu)(1-2 \nu)}}
$$

com $E, \nu$ e $\rho$ sendo, respectivamente, o módulo elástico, o coeficiente de Poisson e a densidade do material. 
Por se tratar de uma simplificação, em problemas não lineares de propagação de ondas, o limite do incremento de tempo na Eq. (2.29) é escalonado para uma quantia ainda menor, para garantir que efeitos de alta frequência sejam corretamente representados. Outras soluções para a estimativa de $\Delta t$ são possíveis para o controle da estabilidade do método (eg. Nunes Dias et al. [173], Plešek e Korous [188]).

\subsection{Tecnologias de elementos para análises lineares}

As técnicas abordadas nas seções anteriores descrevem o procedimento geral para solução dos problemas governados pelas Eqs. (2.1) e (2.2). A construção dos sistemas de equação adotados na solução são produzidos a partir da divisão do problema em subdomínios, definidos pelos elementos adotados na discretização do modelo. Cada elemento produz um conjunto de equações que são recombinadas para formar o sistema global usado nas etapas gerais do cálculo.

A divisão do contínuo em subdomínios oferece algumas vantagens, como a melhor representação de geometrias complexas e a captura de efeitos locais. Esses aspectos estão intimamente ligados com as tecnologias de elementos adotadas no problema.

Uma extensa quantidade de elementos é proposta na literatura para diversos casos de aplicação. Os elementos sólidos e de casca são os mais usados em análises tridimensionais. Dentre eles, elementos sólidos são mais versáteis e, por isso, são considerados de propósito geral, podendo ser aplicados na modelagem de diversas estruturas, simples ou complexas. Os elementos tetraédrico e hexaédrico são os mais empregados [23]. Seus primeiros desenvolvimentos ocorreram na década de 60 [231], inicialmente com o uso de funções de interpolação simples, o que corresponde, respectivamente, a elementos de 4 e 8 nós, com 12 e 24 graus de liberdade. Posteriormente, novas versões surgiram, com o aumento do grau das funções de interpolação - e consequente aumento do número de nós, além do uso de mapeamento isoparamétrico ao final dos anos 60. Mais recentemente, com a disponibilidade de computadores cada vez mais potentes, funções de alta ordem e de enriquecimento são usadas em algumas implementações.

Diversas variantes existem para ambos os elementos. A Figura 2.3 mostra as variações mais comuns. Os elementos lineares (Figuras 2.3a e 2.3c), ou simplex, são mais simples de implementar. Os deslocamentos em seu meio são aproximados por funções polinomiais lineares e, portanto, maior refinamento da malha é necessário para a obtenção de resultados mais acurados. Em contrapartida, elementos de ordem segunda ou maior, devido às suas funções de interpolação, necessitam de menor 
refinamento para obtenção de acurácia similar ao linear.

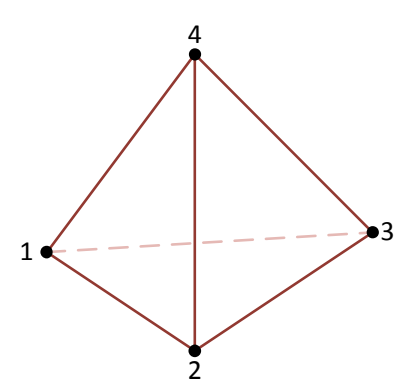

(a) tetraedro linear, 4 nós

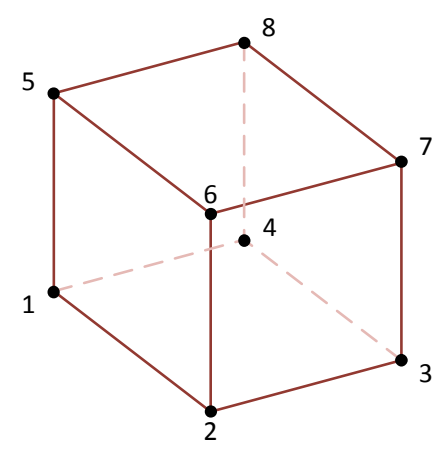

(c) hexaedro linear, 8 nós

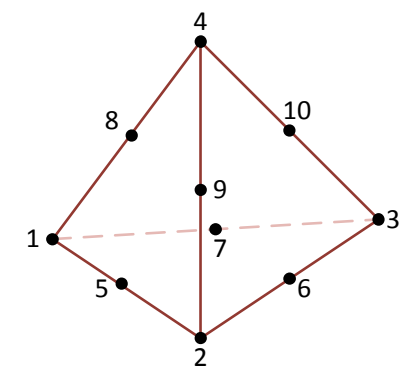

(b) tetraedro segunda ordem, 10 nós

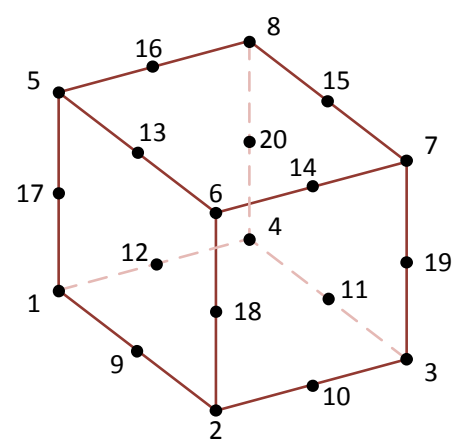

(d) hexaedro segunda ordem, 20 nós

Figura 2.3 Elementos sólidos isoparamétricos.

No entanto, em problemas não lineares, com grandes deformações e distorção considerável da malha - tal como em situações de impacto - a acurácia dos elementos de alta ordem é consideravelmente deteriorada na maioria dos $\operatorname{casos}^{3}$. Segundo Belytschko et al. [23], em problemas de plasticidade ou em interface entre materiais, a acurácia em alta ordem é novamente prejudicada devido às descontinuidades que surgem no domínio.

Outra questão relevante é o desempenho computacional. Problemas não lineares de transientes requerem grande esforço computacional devido a grandes quantidades de iterações de tempo e aos laços (loops) de convergência. O equilíbrio é calculado a cada iteração com o auxílio das formulações dos elementos, responsáveis por uma parcela considerável do processamento. Logo, é crucial que o elemento seja de formulação simples, a fim de reduzir o custo computacional da análise.

Dessa forma, é preferido por alguns autores o uso de elementos lineares em problemas não lineares [23, 114, 136, 202, 221], dada a sua simplicidade, baixo custo

\footnotetext{
${ }^{3}$ Mais especificamente, este problema só ocorre em malhas do tipo Lagrangianas, na qual os nós acompanham a deformação da estrutura, isto é, a malha deforma juntamente com o domínio. Em malhas do tipo Eulerianas, os nós são estáticos, isto é, a malha não muda frente às deformações do domínio. Neste trabalho é considerada apenas a descrição Lagrangiana Total (as equações governantes são descritas em relação ao estado inicial do modelo).
} 
computacional e melhor robustez. Neste trabalho, é adotado o elemento sólido hexaédrico linear para a solução dos problemas. Por questões de simplicidade e também devido às deficiências apresentadas na formulação, elementos tetraédricos não são considerados ${ }^{4}$.

\subsubsection{Hexaedro linear isoparamétrico (simplex)}

O hexaedro simplex é a formulação mais simples para esta geometria de elemento. A numeração dos nós adotada é dada na Figura 2.4. Neste elemento, as funções de interpolação são definidas num domínio de referência, $\boldsymbol{\xi}$, um cubo tri-unitário cujas coordenadas nodais são dadas na Tabela 2.1, com a origem do sistema de coordenadas no centro geométrico do elemento.

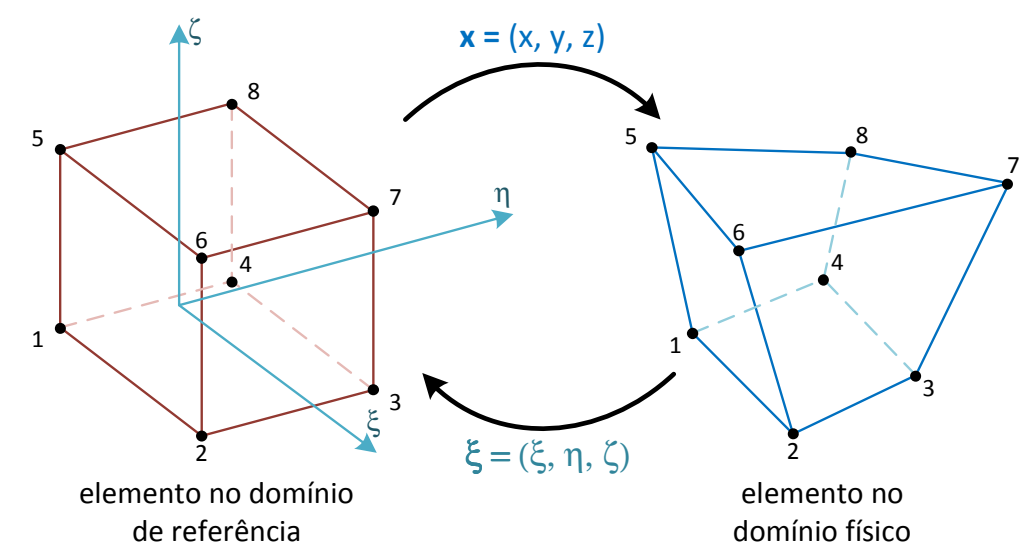

Figura 2.4 Elemento linear isoparamétrico hexaédrico: elemento de referência e numeração dos nós.

Tabela 2.1 Coordenadas nodais do elemento de referência.

\begin{tabular}{ccccccccc}
\hline & 1 & 2 & 3 & 4 & 5 & 6 & 7 & 8 \\
\hline$\xi_{i}$ & -1 & 1 & 1 & -1 & -1 & 1 & 1 & -1 \\
$\eta_{i}$ & -1 & -1 & 1 & 1 & -1 & -1 & 1 & 1 \\
$\zeta_{i}$ & -1 & -1 & -1 & -1 & 1 & 1 & 1 & 1 \\
\hline
\end{tabular}

Um ponto $\boldsymbol{\xi}$ nas coordenadas naturais pode ser mapeado para as coordenadas

\footnotetext{
${ }^{4}$ Ainda que apenas um elemento tenha sido implementado neste trabalho, o software desenvolvido oferece suporte a múltiplos elementos e adição incremental de novas formulações à biblioteca do programa. Esta funcionalidade é explicada no Capítulo 5 .
} 
físicas $(x, y, z)$ correspondentes através das funções de mapeamento

$$
x=\sum_{i=1}^{8} \mathcal{N}_{i}(\boldsymbol{\xi}) x_{i}, \quad y=\sum_{i=1}^{8} \mathcal{N}_{i}(\boldsymbol{\xi}) y_{i}, \quad z=\sum_{i=1}^{8} \mathcal{N}_{i}(\boldsymbol{\xi}) z_{i}
$$

onde $x_{i}, y_{i}$ e $z_{i}$ são as coordenadas físicas do i-ésimo nó e $\mathcal{N}_{i}$ são as funções nodais de interpolação,

$$
\begin{array}{lll}
\mathcal{N}_{1}=1 / 8(1-\xi)(1-\eta)(1-\zeta), & \mathcal{N}_{2}=1 / 8(1+\xi)(1-\eta)(1-\zeta) \\
\mathcal{N}_{3}=1 / 8(1+\xi)(1+\eta)(1-\zeta), & \mathscr{N}_{4}=1 / 8(1-\xi)(1+\eta)(1-\zeta) \\
\mathcal{N}_{5}=1 / 8(1-\xi)(1-\eta)(1+\zeta), & \mathscr{N}_{6}=1 / 8(1+\xi)(1-\eta)(1+\zeta) \\
\mathscr{N}_{7}=1 / 8(1+\xi)(1+\eta)(1+\zeta), & \mathscr{N}_{8}=1 / 8(1-\xi)(1+\eta)(1+\zeta)
\end{array}
$$

Analogamente, valores no interior do elemento, como o deslocamento, podem ser interpolados através das mesmas funções,

$$
u_{x}=\sum_{i=1}^{8} \mathcal{N}_{i}(\boldsymbol{\xi}) \underline{u}_{x i}, \quad u_{y}=\sum_{i=1}^{8} \mathcal{N}_{i}(\boldsymbol{\xi}) \underline{u}_{y i}, \quad u_{z}=\sum_{i=1}^{8} \mathcal{N}_{i}(\boldsymbol{\xi}) \underline{u}_{z i}
$$

onde $u_{x}, u_{y}$ e $u_{z}$ são os deslocamentos de um ponto e $\underline{u}_{x i}, \underline{\sim}_{y i}$ e $\underline{\sim}_{z i}$ são os deslocamentos do i-ésimo nó. Por interpolar o deslocamento (ou outra variável) através das mesmas funções de forma, o mapeamento é denominado isoparamétrico.

Deve-se observar que as funções de interpolação $\mathcal{N}_{i}$ estão definidas no domínio natural. Para as diversas operações que serão realizadas, faz-se necessário o uso das derivadas dessas funções em termos das coordenadas físicas. Logo, é preciso estabelecer uma relação entre os domínios. O operador jacobiano J (ou matriz jacobiana) mapeia as diferenciais dos dois espaços vetoriais [218], tal que

$$
\left[\begin{array}{c}
\frac{\partial}{\partial \xi} \\
\frac{\partial}{\partial \eta} \\
\frac{\partial}{\partial \zeta}
\end{array}\right]=\left[\begin{array}{lll}
\frac{\partial x}{\partial \xi} & \frac{\partial y}{\partial \xi} & \frac{\partial z}{\partial \xi} \\
\frac{\partial x}{\partial \eta} & \frac{\partial y}{\partial \eta} & \frac{\partial z}{\partial \eta} \\
\frac{\partial x}{\partial \zeta} & \frac{\partial y}{\partial \zeta} & \frac{\partial z}{\partial \zeta}
\end{array}\right]\left[\begin{array}{c}
\frac{\partial}{\partial x} \\
\frac{\partial}{\partial y} \\
\frac{\partial}{\partial z}
\end{array}\right]
$$

ou, simplesmente,

$$
\frac{\partial}{\partial \xi}=\mathbf{J} \frac{\partial}{\partial \mathbf{x}}
$$

onde $x, y$ e $z$ são definidos em (2.32). Normalmente, se deseja a relação inversa. Portanto,

$$
\frac{\partial}{\partial \mathbf{x}}=\mathbf{J}^{-1} \frac{\partial}{\partial \xi}
$$


Considera-se que o mapeamento entre os pontos do domínio natural para o físico seja único para cada par. Isso significa que o elemento não sofre distorção excessiva ou não dobra sobre si mesmo [16]. Dessa forma, $\mathbf{J}^{-1}$ sempre existe e a relação acima é válida.

\section{Matriz de rigidez do elemento}

Em elementos estruturais, a matriz de rigidez, $\underset{\sim}{\mathbf{K}}$, estabelece uma relação entre os deslocamentos e as forças de um corpo. Em MEF, ela é geralmente simétrica e positiva-definida [115, 198]. Esses atributos são necessários para o emprego de determinados métodos numéricos.

De uma maneira geral, $\underset{\sim}{\mathbf{K}}$ é calculada no volume do elemento $(v)$ através da integral

$$
\underset{\sim}{\mathbf{K}}=\int_{v} \mathbf{B}^{T} \mathbf{E B} d v
$$

onde $\mathbf{B}$ é a matriz de gradientes das funções de forma (ou simplesmente matriz de gradientes) que, para o hexaedro linear, vale

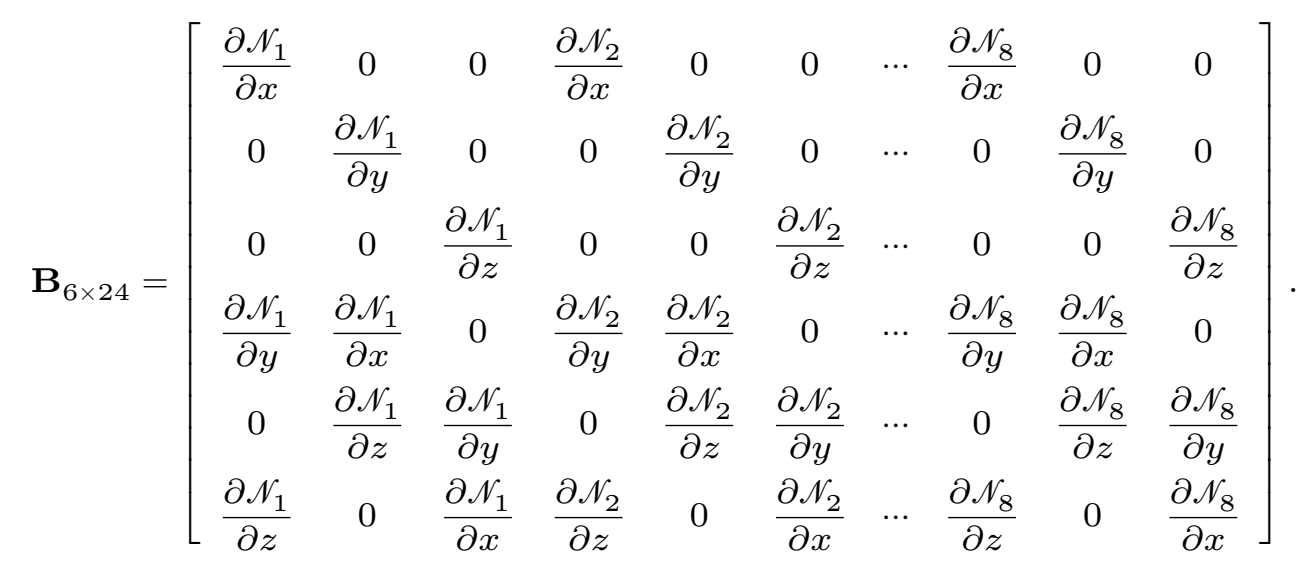

$\mathbf{E}_{6 \times 6}$ é a matriz de elasticidade do material, que relaciona as deformações com as tensões elásticas do elemento, calculada pelo modelo constitutivo adotado. O seu cálculo é apresentado na seção 2.7 .

Para o cálculo das diferenciais de B na Eq. (2.39), é necessário transportar as diferenciais das funções de forma para o domínio físico. Ou seja, pela Eq. (2.37),

$$
\frac{\partial}{\partial \mathbf{x}} \mathcal{N}_{i}=\mathbf{J}^{-1} \frac{\partial}{\partial \xi} \mathcal{N}_{i}
$$

Normalmente, a resolução analítica da integral na Eq. (2.38) é difícil, se possível, principalmente se o elemento sofre maior distorção. Portanto, é comum em 
formulações isoparamétricas a aplicação de métodos numéricos para a resolução da integral.

A integração numérica de Gauss é um dos métodos mais empregados na integração da Eq. (2.38). Nele, considera-se que a integral de uma função polinomial $f$ qualquer pode ser representada pela seguinte soma de funções ponderadas:

$$
\int_{-1}^{1} f(x) d x=\sum_{i=1}^{n} w_{i} f\left(x_{i}\right)
$$

onde $x_{i}$ é o ponto de integração em que $f$ é avaliado, $w_{i}$ é o peso associado e $n$ é o número de pontos de integração, dependente do grau de $f$. Zwillinger [254] fornece uma lista de pontos de integração do método, parcialmente reproduzida na Tabela 2.2. A integração exata ocorre para polinômios de grau até $2 n-1$.

Tabela 2.2 Pesos e pontos de integração de Gauss para até $n=5$ (adaptado de Zwillinger [254]).

\begin{tabular}{ccc}
\hline $\mathrm{n}$ & $x_{i}$ & $w_{i}$ \\
\hline 1 & 0.000000 & 2.000000 \\
2 & \pm 0.577350 & 1.000000 \\
3 & 0.000000 & 0.888889 \\
& \pm 0.774597 & 0.555556 \\
4 & \pm 0.339981 & 0.652145 \\
& \pm 0.861136 & 0.347855 \\
5 & 0.000000 & 0.568889 \\
& \pm 0.538469 & 0.478629 \\
& \pm 0.906180 & 0.236927 \\
\hline & &
\end{tabular}

Antes de avaliar numericamente a integral em Eq. (2.38), é necessário efetuar a mudança de seus limites para torná-la compatível com o método numérico. Para tanto, devemos considerar o volume do elemento de referência,

$$
d v=\operatorname{det} \mathbf{J} d \xi d \eta d \zeta
$$

A Eq. (2.38) é reescrita da seguinte forma:

$$
\underset{\sim}{\mathbf{K}}=\int_{-1}^{1} \int_{-1}^{1} \int_{-1}^{1} \mathbf{B}^{T} \mathbf{E B} \operatorname{det} \mathbf{J} d \xi d \eta d \zeta
$$

Agora é possível avaliar esta integral pelo método de Gauss. Isto é, a integral é finalmente descrita como uma soma ponderada de termos, tal que

$$
\underset{\sim}{\mathbf{K}}=\sum_{i=1}^{2} \sum_{j=1}^{2} \sum_{k=1}^{2}\left[w_{i} w_{j} w_{k} \mathbf{B}\left(x_{i}, x_{j}, x_{k}\right) \mathbf{E B}\left(x_{i}, x_{j}, x_{k}\right) \operatorname{det} \mathbf{J}\left(x_{i}, x_{j}, x_{k}\right)\right]
$$


onde $\mathbf{B}$ é dada em função das coordenadas físicas, $x_{i}, x_{j}$, e $x_{k}$ são as coordenadas dos pontos de integração e $w_{i}, w_{j}$ e $w_{k}$ são seus respectivos pesos.

\section{Matriz de massa do elemento}

A inércia do elemento é quantificada através de sua massa. Usando-se os mesmos métodos para se obter a matriz de rigidez, é possível calcular a matriz de massa $\underline{\mathbf{M}}$ avaliando-se numericamente a integral

$$
\underline{\mathbf{M}}_{c}=\int_{v} \rho \mathscr{N}^{T} \mathscr{N} d v
$$

onde $\rho$ é a densidade do elemento, $\mathcal{N}=\left[\mathcal{N}_{i}\right]^{T}, i=1 \ldots 8$ e o subscrito $c$ denota a matriz de massa consistente, pois é obtida a partir do mesmo método de interpolação dos deslocamentos. Em análises de propagação de ondas, contudo, o seu emprego implica no cálculo de sua inversa (veja Eq. (2.19), por exemplo), o que consome demasiado tempo de processamento.

Alternativamente, na matriz de matriz concentrada (ou diagonal), os deslocamentos de um elemento não são acoplados entre si, resultando na diagonalidade da matriz [198]. Para o elemento hexaédrico considerado neste trabalho, ela pode ser calculada diretamente, através de [245]:

$$
\underline{\mathbf{M}}_{d}=\frac{\rho v}{8} \mathbf{I}_{24 \times 24}
$$

A matriz diagonal $\underline{\mathbf{M}}_{d}$ é apenas uma aproximação dos efeitos de inércia no elemento. No entanto, sua vantagem computacional a torna essencial em análises explícitas. Além da fácil inversão, o seu cálculo é direto e independente de métodos numéricos de integração. Outrossim, Wu [244] demonstra que a adoção da versão simplificada, produz convergência dos resultados dos casos estudados bastante similar à versão completa da matriz. A matriz de massa diagonal é a forma preferida neste trabalho e, por questões de simplicidade, o subscrito $d$ é omitido.

\section{Matriz de amortecimento do elemento}

A matriz de amortecimento oferece uma aproximação para os mecanismos de dissipação dados pelo comportamento do material e geometria da estrutura. Um dos modelos usados para a descrição do fenômeno é o amortecimento proporcional de Rayleigh, onde

$$
\underset{\sim}{\mathbf{C}}=\alpha_{\mathrm{RL}} \underset{\mathbf{M}}{\sim}+\beta_{\mathrm{RL}} \underset{\sim}{\mathbf{K}}
$$


sendo $\alpha_{\mathrm{RL}}$ e $\beta_{\mathrm{RL}}$ constantes definidas para razões de amortecimento crítico, $\xi_{i}^{D}$, em duas frequências de vibração distintas, $\omega_{i}$, tal que

$$
\left\{\begin{array}{c}
\alpha_{\mathrm{RL}} \\
\beta_{\mathrm{RL}}
\end{array}\right\}=2\left[\begin{array}{cc}
\frac{1}{\omega_{1}} & \omega_{1} \\
\frac{1}{\omega_{2}} & \omega_{2}
\end{array}\right]^{-1}\left\{\begin{array}{c}
\xi_{1}^{D} \\
\xi_{2}^{D}
\end{array}\right\}
$$

O modelo simplificado pode não oferecer resultados satisfatórios para diferentes respostas em múltiplas frequências. Por questões de objetividade, o emprego de amortecimento na análise não é contemplado neste trabalho, cabendo a discussão apenas em como ele é inserido no método.

\section{Estado de deformação do elemento}

A deformação infinitesimal $\varepsilon$ é calculada em cada ponto de integração e é dada por

$$
\varepsilon=\left\{\begin{array}{llllll}
\varepsilon_{x x} & \varepsilon_{y y} & \varepsilon_{z z} & \gamma_{x y} & \gamma_{y z} & \gamma_{x z}
\end{array}\right\}^{T}=\mathbf{B}\left(x_{i}, x_{j}, x_{k}\right) \underline{\mathbf{u}}
$$

onde $\varepsilon_{a a}$ são as componentes de deformação normal e $\gamma_{a b}$ são as deformações de cisalhamento de engenharia, que se relacionam com as deformações infinitesimais de cisalhamento através da relação

$$
\gamma_{a b}=2 \varepsilon_{a b}, \quad a \neq b
$$

Em problemas lineares, o estado de deformação pode ser aditivamente decomposto, isto é

$$
\begin{gathered}
\varepsilon=\varepsilon+\Delta \varepsilon \\
\Delta \varepsilon=\mathbf{B}\left(x_{i}, x_{j}, x_{k}\right) \Delta \underline{\mathbf{u}}
\end{gathered}
$$

Para fins de visualização dos resultados, o estado de deformação do elemento é aproximado para a média dos valores percebidos nos pontos de integração. A determinação de $\boldsymbol{\varepsilon}$ em cada ponto é necessária para o cálculo dos respectivos estados de tensão pelo modelo constitutivo e subsequente avaliação das forças internas do elemento.

\section{Cálculo das forças internas}

As forças internas do elemento são definidas pela integral

$$
\stackrel{\sim}{\mathrm{r}}^{\mathrm{int}}=\int_{v} \mathbf{B}^{T} \boldsymbol{\sigma} d V
$$


que é calculada usando os procedimentos numéricos adotados para o cálculo da matriz de rigidez, isto é,

$$
\stackrel{\sim}{\mathrm{rint}}^{\mathrm{in}}=\sum_{i=1}^{2} \sum_{j=1}^{2} \sum_{k=1}^{2}\left(w_{i} w_{j} w_{k} \mathbf{B}\left(x_{i}, x_{j}, x_{k}\right)^{T} \boldsymbol{\sigma}^{(i)} \operatorname{det} \mathbf{J}\left(x_{i}, x_{j}, x_{k}\right)\right)
$$

onde $\boldsymbol{\sigma}^{\langle i\rangle}$ é o estado de tensão do i-ésimo ponto de integração, avaliado pelo modelo constitutivo associado ao elemento.

\subsubsection{Deficiências e técnicas de melhoramento do elemento}

A criação de uma formulação de elemento que consiga representar precisamente todos os fenômenos físicos em qualquer tipo de estrutura, com eficiência computacional aceitável, é demasiadamente complexa e, por isso, programas de MEF oferecem diferentes implementações, mais adequadas para determinados tipos de problemas.

Ainda que o hexaedro linear conte com sua versatilidade, alguns problemas surgem da utilização de suas funções de interpolação lineares. Decorre que técnicas são propostas para amenizar essas questões, discutidas nesta seção.

\section{Travamento e integração reduzida}

Sob determinadas circunstâncias, o elemento hexaédrico pode apresentar o comportamento de travamento. A estrutura exibe uma rigidez adicional fisicamente não explicável, como ilustra a Figura 2.5.

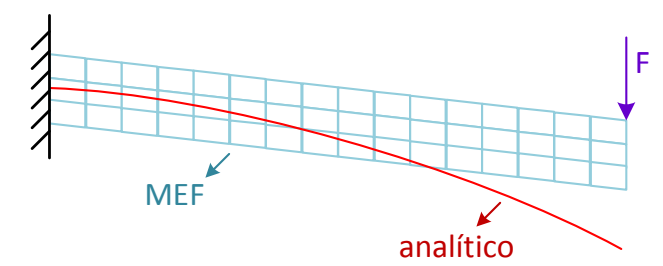

Figura 2.5 Travamento na análise de flexão de uma viga (deslocamentos exagerados para visualização).

O fenômeno pode ocorrer por diversos mecanismos, entre os quais o pobre refinamento da malha e a deficiência da formulação em representar adequadamente os modos de deformação do elemento [35, 193]. Para a solução do segundo caso, as matrizes dos elementos isoparamétricos são integradas uma ordem abaixo do procedimento ótimo da solução numérica. Isto é, tem-se que, para o hexaedro linear, apenas um ponto de integração é usado no método numérico (Tab. 2.2). Com isso, 
as integrais em (2.38) e (2.52) são reduzidas, respectivamente, a

$$
\begin{gathered}
\underset{\sim}{\mathbf{K}}=8 \mathbf{B}(0,0,0) \mathbf{E B}(0,0,0) \operatorname{det} \mathbf{J}(0,0,0) \\
\stackrel{\sim}{\text { int }}^{\text {int }}=8 \mathbf{B}(0,0,0)^{T} \boldsymbol{\sigma} \operatorname{det} \mathbf{J}(0,0,0)
\end{gathered}
$$

Uma outra vantagem que esta abordagem apresenta é a melhoria da eficiência computacional da formulação. A integração reduzida é bastante utilizada em elementos de segunda ordem para torná-los computacionalmente mais baratos, com, inclusive, melhora no seu desempenho numérico [35].

Contudo, a redução da ordem de integração em elementos lineares não é capaz de produzir resultados satisfatórios para qualquer configuração. Sob certas condições, pode causar instabilidades na solução do problema, conforme será discutido a seguir.

\section{Controle de hourglass}

O uso de integração reduzida nas equações do elemento hexaédrico introduzem um fenômeno de instabilidade na solução, conhecido pelo nome inglês, "hourglassing". Causado pelo mau-condicionamento induzido nas matrizes, determinadas configurações de carregamento da malha produzem pertubações espúrias (isto é, não físicas), podendo, num pior caso, crescer rapidamente e degradar completamente a solução do problema. O fenômeno recebe esse nome (ampulheta) devido aos modos de deformação característicos dos elementos afetados, como mostra a Figura 2.6 (às vezes se faz necessário reduzir em algumas ordens de magnitude o deslocamento para se perceber o padrão na malha, devido à instabilidade exponencial produzida).

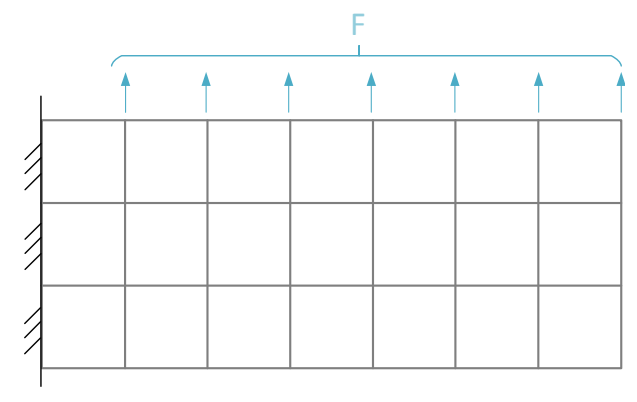

(a) Malha e condições de contorno

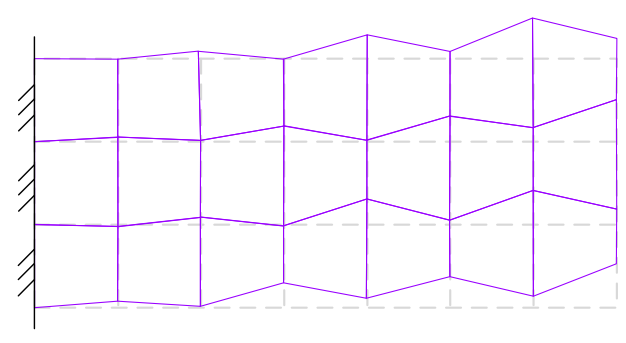

(b) Hourglassing após algumas iterações de tempo

Figura 2.6 Hourglassing em flexão de viga, usando elementos hexaédricos lineares.

No hexaedro linear, existem quatro modos de deformação de hourglass, para cada direção de movimento, conforme ilustra a Figura 2.7. A deformação provocada 
por esses modos não contabilizam na energia total do sistema e, por isso, são também chamados de modo de energia zero.

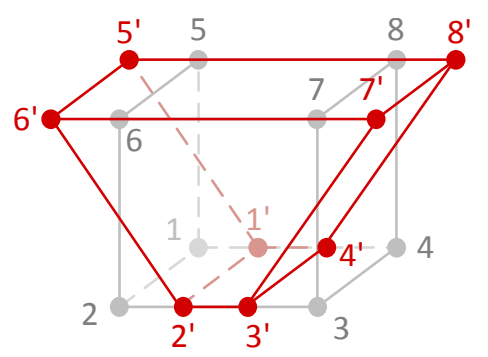

(a) Afunilamento 1 (tapering)

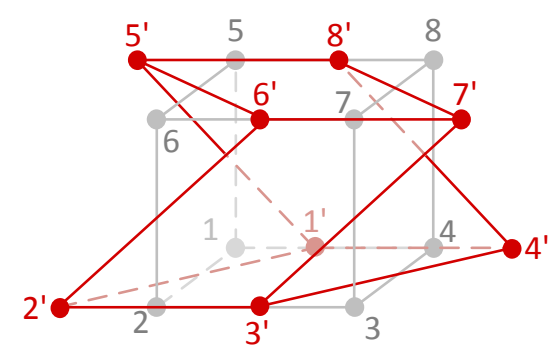

(c) Torção (warping)

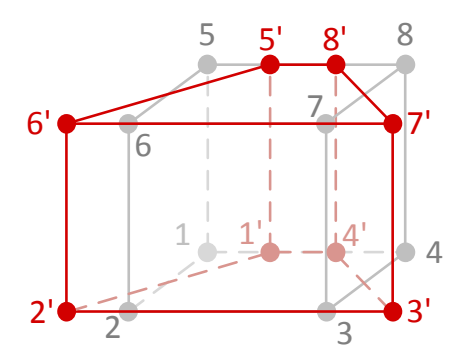

(b) Afunilamento 2 (tapering)

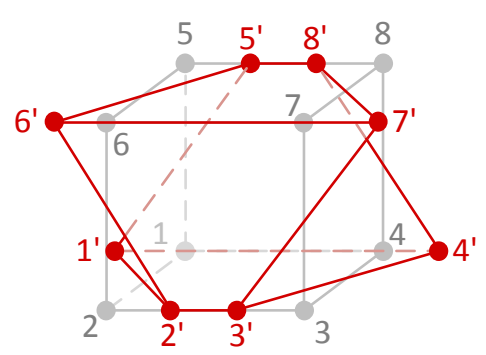

(d) Não-físico

Figura 2.7 Modos de hourglass do elemento hexaédrico linear (em vermelho).

Diversas técnicas para estabilização da malha são propostas na literatura [22, 84, 114, 124, 137, 195, 201. Métodos ad-hoc, aliados ao emprego da integração reduzida, constituem a principal alternativa para a elaboração de formulações que suavizam o problema, pois, na maioria dos casos, são mais eficientes e requerem menor esforço computacional. Para elementos que sofrem o hourglassing, forças internas de hourglass, $\underset{\sim}{\mathrm{HG}}$, são aplicadas para resistir aos modos de deformação instáveis (Figura 2.8).

Duas formas de controle são usuais na literatura: o controle viscoso, cujas forças de hourglass são proporcionais à velocidade atuante no elemento, e o rígido, onde as forças contrárias são formuladas em relação ao deslocamento. No Apêndice $\mathrm{B}$, duas técnicas são discutidas para ilustrar o funcionamento geral do controle de estabilidade para o problema.

\subsection{Materiais lineares}

As relações constitutivas, que modelam o comportamento específico do material componente da estrutura, são implementadas no MEF através de modelos de materiais associados aos elementos discretizantes do contínuo. No método, são geralmente 


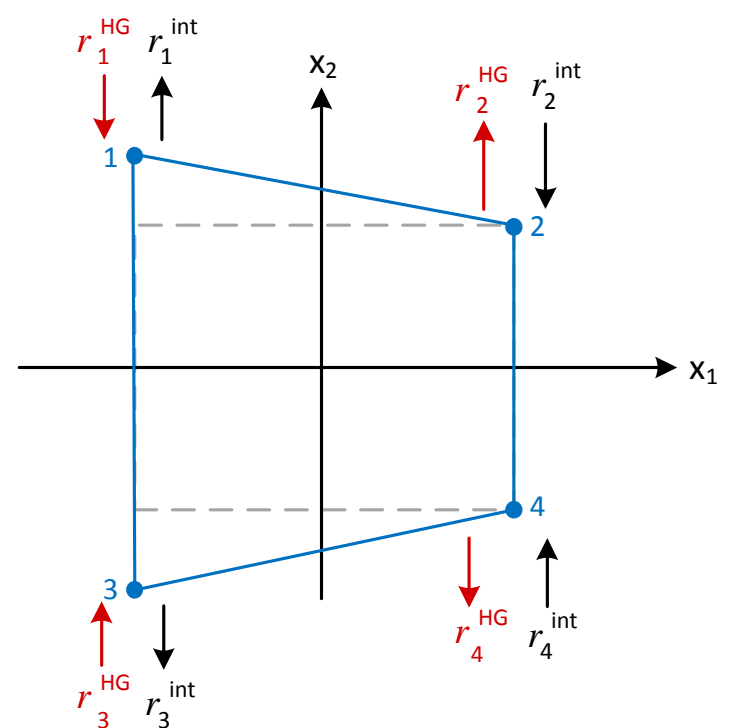

Figura 2.8 Forças de hourglass atuantes num elemento para supressão dos modos instáveis.

descritas como a relação do estado de deformação do elemento com o seu estado de tensão.

É apresentado o modelo isotrópico elástico como único exemplar de relação linear e de interesse para o presente estudo. Outros modelos constitutivos, não lineares, são apresentados na seção 2.9.

O modelo linear elástico isotrópico constitui o caso mais simples de relação constitutiva, estabelecendo a relação entre as quantias de tensão e deformação através da matriz de elasticidade, $\mathbf{E}$, dada por:

$$
\mathbf{E}=\frac{E}{(1+\nu)(1-2 \nu)}\left[\begin{array}{cccccc}
1-\nu & \nu & \nu & 0 & 0 & 0 \\
\nu & 1-\nu & \nu & 0 & 0 & 0 \\
\nu & \nu & 1-\nu & 0 & 0 & 0 \\
0 & 0 & 0 & \frac{1-2 \nu}{2} & 0 & 0 \\
0 & 0 & 0 & 0 & \frac{1-2 \nu}{2} & 0 \\
0 & 0 & 0 & 0 & 0 & \frac{1-2 \nu}{2}
\end{array}\right]
$$

A relação tensão-deformação é

$$
\sigma=\mathbf{E} \varepsilon
$$

Por se tratar de uma relação linear, pode ser estendida para a decomposição aditiva da deformação em cálculos incrementais da tensão. 


\subsection{Extensão do MEF para análises não lineares}

Nesta seção, serão discutidas as modificações necessárias para que as técnicas do MEF, anteriormente apresentadas, possam incorporar os efeitos de deformação finita e não linearidade do material. Com exceção dos modelos constitutivos, será visto que poucas alterações são requeridas para a correta representação desses fenômenos. Não é foco deste estudo a análise não linear quase estática e, portanto, ela não será discutida. Os fundamentos para a análise não linear em elementos finitos são apresentados no Apêndice A.

\subsubsection{Extensão do método explícito para análises não lineares}

Em fênomenos de curta duração, o método explícito, empregado para análises de problemas não lineares, adquire vantagem sobre os demais operadores dinâmicos devido ao fato de que poucas modificações precisam ser feitas ao algoritmo.

Devido aos incrementos de tempo serem muito pequenos, é possível aproximar a não linearidade do fenômeno como uma sequência de passos lineares, onde os deslocamentos nodais, ocorridos no passo anterior, são usados para calcular a nova posição na iteração seguinte.

Uma vez que as deformações podem ser consideravelmente grandes, o comprimento característico dos elementos da malha se altera significativamente ao longo da análise. Caso o incremento de tempo não seja corrigido, poderão haver descontinuidades na propagação de ondas sobre o modelo, levando a resultados incoerentes. Em alguns casos, a escolha de um passo de tempo, um pouco maior do que é necessário para a estabilidade do método, pode levar a uma pequena instabilidade que vai se acumulando ao longo da análise. Em problemas não lineares, isso pode não ser visível, pois acaba se confundindo com erros gerados pela limitação do modelo numérico em representar o fenômeno.

As implementações em pacotes comerciais estimam o valor de $\Delta t_{c r}$ levando em consideração diferentes fatores [5, 63, 103]. A adoção de uma estimativa baseada em atributos gerais do modelo é preferível devido à facilidade de implementação e a menor dependência de tecnologias específicas do método.

Num mecanismo simples, o incremento de tempo pode ser verificado pela condição CFL, como no caso linear (Eq. (2.29)). A cada iteração, $\Delta t$ é revisado contra o valor de $\Delta t_{c r}$, obtido para o passo de tempo atual. Para maior desempenho, a atualização do valor pode ser feita a um número regular de iterações, em detrimento da precisão. Essa abordagem oferece apenas uma estimativa "grosseira" para a es- 
tabilidade do algoritmo. É comum o uso de um fator de escala (ou de penalidade) que reduz proporcionalmente o incremento de tempo calculado para melhor garantir a estabilidade.

O considerável número de variáveis envolvidas no fenômeno, muitas vezes acopladas a propriedades ou comportamentos específicos do material ou elemento escolhido, dificultam a definição de uma estimativa mais precisa para o valor de $\Delta t_{c r}$.

O Algoritmo 2.3 mostra o método modificado. A cada iteração, a geometria dos elementos é atualizada, o que envolve, entre outras computações, a atualização da matriz de gradientes dos elementos, conforme será discutido na próxima seção. O conjunto de parâmetros para o cálculo da deformação e do estado de tensão foi modificado para atender às necessidades das formulações e relações constitutivas de forma generalizada.

As alterações feitas no algoritmo ainda o permitem que seja utilizado em problemas lineares. Nesses casos, a atualização da geometria não provoca modificações nos elementos e a formulação e os modelos constitutivos lineares podem desprezar parâmetros fornecidos (como o $\boldsymbol{F}$ ), restringindo-se apenas aos parâmetros do modelo.

\subsubsection{Elemento hexaédrico linear para análises não lineares}

A formulação do elemento hexaédrico linear permanece a mesma para a inclusão em deformações finitas. As funções de interpolação e a definição das matrizes do elemento permanecem idênticas. Contudo, conforme explicado na seção anterior, o método explícito lineariza o fenômeno, a cada passo de tempo, ao calcular o novo estado a partir do último passo de tempo. Dessa forma, é necessário que alguns aspectos da formulação sejam atualizados a cada iteração.

\section{Atualização da geometria do elemento}

Conhecendo-se a posição atual dos nós, $\boldsymbol{\varphi}$, é possível determinar a geometria do elemento no instante atual. As matrizes elementares e as forças internas são calculadas usando a configuração do elemento no instante atual. Para tanto, a matriz de gradientes (Eq. (2.39) ) é atualizada a cada iteração de tempo, isto é, as funções de mapeamento, dadas na Eq. (2.32),

$$
x=\sum_{i=1}^{8} \mathcal{N}_{i}(\boldsymbol{\xi}) x_{i}, \quad y=\sum_{i=1}^{8} \mathcal{N}_{i}(\boldsymbol{\xi}) y_{i}, \quad z=\sum_{i=1}^{8} \mathcal{N}_{i}(\boldsymbol{\xi}) z_{i}
$$

são calculadas para valores de $\left(x_{i}, y_{i}, z_{i}\right)$ atualizados. Consequentemente, para estas situações, a matriz jacobiana é atualizada a cada iteração de tempo. 
Algoritmo 2.3: Método das diferenças centrais com extensão para problemas não lineares.

Algoritmo Diferenças centrais, não linear

Condições iniciais: $\mathbf{M}, \mathbf{C}, \mathbf{u}_{0}, \dot{\mathbf{u}}_{0}$ e $\ddot{\mathbf{u}}_{0}$

Saída: $\mathbf{u}_{t}, \dot{\mathbf{u}}_{t}$ e $\ddot{\mathbf{u}}_{t}$, a cada instante de tempo $t$

1. $t=0$

2. enquanto $t<t_{\text {final }}$

a. Calcular passo de tempo $(\Delta t)$ adequado

b. Atualizar geometria dos elementos

c. $\Delta \mathbf{u}_{t+\Delta t}=\Delta t \dot{\mathbf{u}}_{t+\frac{1}{2} \Delta t}$

d. $\mathbf{u}_{t+\Delta t}=\mathbf{u}_{t}+\Delta \mathbf{u}_{t+\Delta t}$

e. Atualizar posição dos nós, $\boldsymbol{\varphi}=\boldsymbol{\varphi}\left(\mathbf{u}_{t+\Delta t}\right)$

f. Atualizar estado de deformação $\varepsilon^{\langle i\rangle}\left(\Delta \underline{\sim}^{\langle i\rangle}\right)$ dos elementos (formulação do elemento)

g. Atualizar estado de tensão dos elementos (modelo constitutivo do material), $\left(\boldsymbol{\sigma}^{\langle i\rangle}\right)_{t+\Delta t}=\boldsymbol{\sigma}(\boldsymbol{F}, t, \Delta t)$

h. Calcular as forças internas, $\mathbf{r}_{t+\Delta t}^{\text {int }}$, do sistema (Eq. (2.28))

i. Calcular $\mathbf{r}^{\mathrm{ext}}(t+\Delta t)$

j. $\ddot{\mathbf{u}}_{t+\Delta t}=\mathbf{M}^{-1}\left(\mathbf{r}_{t+\Delta t}^{\mathrm{ext}}-\mathbf{r}_{t+\Delta t}^{\mathrm{int}}-\mathbf{C} \dot{\mathbf{u}}_{t+\frac{1}{2} \Delta t}\right)$

k. $\dot{\mathbf{u}}_{t+\frac{3}{2} \Delta t}=\dot{\mathbf{u}}_{t+\frac{1}{2} \Delta t}+\Delta t \ddot{\mathbf{u}}_{t+\Delta t}$

1. $t=t+\Delta t$

\section{Cálculo do gradiente de deformação}

A medida de deformação infinitesimal, Eq. (2.49), não é adequada para problemas de deformação finita, sendo recomendadas as opções apresentadas na seção A.5. No entanto, a escolha de uma medida de deformação depende da natureza do problema e do modelo constitutivo adotado.

O estado de deformação do elemento é definido pelo gradiente de deformação, ficando a cargo do modelo constitutivo calcular a medida de deformação que lhe é mais conveniente a partir de $\boldsymbol{F}$. 
A partir das Eqs. (A.2) e (A.3), sabe-se que

$$
\boldsymbol{F}=\frac{d \mathbf{x}}{d \mathbf{X}}=\left[\begin{array}{ccc}
\frac{\partial x}{\partial X} & \frac{\partial x}{\partial Y} & \frac{\partial x}{\partial Z} \\
\frac{\partial y}{\partial X} & \frac{\partial y}{\partial Y} & \frac{\partial y}{\partial Z} \\
\frac{\partial z}{\partial X} & \frac{\partial z}{\partial Y} & \frac{\partial z}{\partial Z}
\end{array}\right]
$$

Devido às funções de interpolação serem definidas no domínio de referência, as derivadas presentes em $\boldsymbol{F}$ são calculadas usando a regra da cadeia, tal que, para o primeiro termo, por exemplo,

$$
\frac{\partial x}{\partial X}=\frac{\partial x}{\partial \xi} \frac{\partial \xi}{\partial X}+\frac{\partial x}{\partial \eta} \frac{\partial \eta}{\partial X}+\frac{\partial x}{\partial \zeta} \frac{\partial \zeta}{\partial X}
$$

Combinando com as derivadas em relação a $Y$ e $Z$, obtém-se a seguinte relação matricial:

$$
\left\{\begin{array}{c}
\frac{\partial x}{\partial X} \\
\frac{\partial x}{\partial Y} \\
\frac{\partial x}{\partial Z}
\end{array}\right\}=\left[\begin{array}{ccc}
\frac{\partial \xi}{\partial X} & \frac{\partial \eta}{\partial X} & \frac{\partial \zeta}{\partial X} \\
\frac{\partial \xi}{\partial Y} & \frac{\partial \eta}{\partial Y} & \frac{\partial \zeta}{\partial Y} \\
\frac{\partial \xi}{\partial Z} & \frac{\partial \eta}{\partial Z} & \frac{\partial \zeta}{\partial Z}
\end{array}\right]\left\{\begin{array}{c}
\frac{\partial x}{\partial \xi} \\
\frac{\partial x}{\partial \eta} \\
\frac{\partial x}{\partial \zeta}
\end{array}\right\}
$$

o que equivale a

$$
\left\{\begin{array}{c}
\frac{\partial x}{\partial X} \\
\frac{\partial x}{\partial Y} \\
\frac{\partial x}{\partial Z}
\end{array}\right\}=\mathbf{J}^{-T}\left\{\begin{array}{c}
\frac{\partial x}{\partial \xi} \\
\frac{\partial x}{\partial \eta} \\
\frac{\partial x}{\partial \zeta}
\end{array}\right\}
$$

onde a matriz jacobiana é calculada a partir das coordenadas iniciais dos nós na descrição Lagrangiana Total, adotada ao longo deste trabalho (vide Apêndice A). 
Utilizando-se das relações em (2.32), podemos definir $\partial x / \partial \xi, \partial x / \partial \eta$ e $\partial x / \partial \zeta$, tal que

$$
\begin{aligned}
& \frac{\partial x}{\partial \xi}=\frac{\partial}{\partial \xi}\left(\sum_{i=1}^{n} \mathcal{N}_{i} x_{i}\right) \\
& \frac{\partial x}{\partial \eta}=\frac{\partial}{\partial \eta}\left(\sum_{i=1}^{n} \mathcal{N}_{i} x_{i}\right) \\
& \frac{\partial x}{\partial \zeta}=\frac{\partial}{\partial \zeta}\left(\sum_{i=1}^{n} \mathcal{N}_{i} x_{i}\right)
\end{aligned}
$$

onde $x_{i}$ é a coordenada $x$ atualizada do i-ésimo nó.

Para exemplificar, os termos $F_{11}$ e $F_{13}$ de $\boldsymbol{F}$, são dados por

$$
\begin{aligned}
& F_{11}=\left(J^{-1}\right)_{11}\left(\sum_{i=1}^{n} \frac{\partial}{\partial \xi} N_{i} x_{i}\right)+\left(J^{-1}\right)_{21}\left(\sum_{i=1}^{n} \frac{\partial}{\partial \eta} N_{i} x_{i}\right)+\left(J^{-1}\right)_{31}\left(\sum_{i=1}^{n} \frac{\partial}{\partial \zeta} N_{i} x_{i}\right) \\
& F_{13}=\left(J^{-1}\right)_{13}\left(\sum_{i=1}^{n} \frac{\partial}{\partial \xi} N_{i} y_{i}\right)+\left(J^{-1}\right)_{23}\left(\sum_{i=1}^{n} \frac{\partial}{\partial \eta} N_{i} y_{i}\right)+\left(J^{-1}\right)_{33}\left(\sum_{i=1}^{n} \frac{\partial}{\partial \zeta} N_{i} y_{i}\right)
\end{aligned}
$$

sendo $y_{i}$ a coordenada $y$ atualizada do i-ésimo nó. Os demais termos de $\boldsymbol{F}$ são desenvolvidos de maneira similar.

\subsection{Tecnologias de materiais não lineares}

Este trabalho contempla a implementação de três relações constitutivas não lineares para ilustrar as funcionalidades do programa. Nesta seção, são apresentados os fundamentos teóricos para a implementação desses modelos.

\subsubsection{Hiper elasticidade}

Materiais nos quais a relação constitutiva depende apenas do estado atual de deformação são denominados elásticos. O estado de tensão das partículas do material é calculado apenas em função do seu gradiente de deformação atual.

Quando é possível determinar a energia armazenada durante um processo de deformação apenas através do estado inicial e da configuração final do corpo, o comportamento é independente de caminho e o material é denominado hiper elástico [32]. Em outras palavras, sua função de energia, $\psi$, depende apenas do gradiente de deformação, ou seja, $\psi(\boldsymbol{F})$. 
Pode-se considerar que materiais hiper elásticos são a generalização do caso linear elástico. São materiais que respondem elasticamente a grandes deformações e exibem comportamento não linear, tal como a mudança na forma e na rigidez do componente [35]. Borracha, espuma e materiais poliméricos são alguns dos materiais modelados por esse tipo de relação constitutiva.

Define-se um material hiper elástico através da relação

$$
\boldsymbol{P}(\boldsymbol{F}(\mathbf{X}), \mathbf{X})=\frac{\partial \psi(\boldsymbol{F}(\mathbf{X}), \mathbf{X})}{\partial \boldsymbol{F}}
$$

Contudo, para manter a objetividade do modelo constitutivo, é preferível definí-lo pelo tensor de alongamento, $\boldsymbol{U}$, ao invés de $\boldsymbol{F}$. No entanto, por questões de simplicidade, adota-se $\boldsymbol{C}$, que se relaciona $\operatorname{com} \boldsymbol{U}$ (Eq. (A.16)):

$$
\psi(\boldsymbol{F}(\mathbf{X}), \mathbf{X})=\psi(\boldsymbol{C}(\mathbf{X}), \mathbf{X})
$$

Derivando a Eq. (A.19), encontra-se que $\frac{1}{2} \dot{\boldsymbol{C}}=\dot{\mathrm{G}}$. Então, usando-se desta relação e da Eq. (2.66), é possível reescrever (2.65) usando o par energeticamente conjugado $\boldsymbol{S}$ e $\stackrel{\boldsymbol{E}}{\boldsymbol{E}}[32$,

$$
\frac{1}{2} \boldsymbol{S}(\boldsymbol{C}(\mathbf{X}), \mathbf{X})=\frac{\partial \psi(\boldsymbol{C}(\mathbf{X}), \mathbf{X})}{\partial \boldsymbol{C}}
$$

Neste estudo, será abordado apenas o caso particular de isotropia nesse tipo de material. Em tal cenário, o comportamento do material é idêntico em todas as direções. Logo, é preferível definir a relação constitutiva (Eq. (2.67)) em função dos invariantes, isto é,

$$
\psi(\boldsymbol{C}(\mathbf{X}), \mathbf{X})=\psi(\stackrel{C}{\mathrm{I}}, \stackrel{C}{\mathrm{II}} \stackrel{C}{\mathrm{III}}, \mathbf{X})
$$

$\begin{array}{llll}C & C & C\end{array}$

onde I, II e III são os invariantes de $\boldsymbol{C}$,

$$
\begin{aligned}
& \stackrel{C}{\mathrm{I}}=\operatorname{tr}(\boldsymbol{C}) \\
& \stackrel{C}{\mathrm{II}}=\operatorname{tr}(\boldsymbol{C} \boldsymbol{C})=\boldsymbol{C}: \boldsymbol{C}=\frac{1}{2}\left[\operatorname{tr}^{2}(\boldsymbol{C})-\operatorname{tr}\left(\boldsymbol{C}^{2}\right)\right] \\
& \stackrel{C}{\mathrm{III}}=\operatorname{det} \boldsymbol{C}=J^{2}
\end{aligned}
$$

A Eq. (2.68) permite reescrever (2.67), tal que, usando a regra da cadeia,

$$
\frac{1}{2} S=\frac{\partial \psi}{\partial \mathrm{I}} \frac{\partial \mathrm{I}}{\partial \boldsymbol{C}}+\frac{\partial \psi}{\partial \mathrm{II}} \frac{\partial \mathrm{II}}{\partial \boldsymbol{C}}+\frac{\partial \psi}{\partial \mathrm{III}} \frac{\partial \mathrm{III}}{\partial \boldsymbol{C}}
$$


Sabendo-se que as derivadas dos invariantes são 13

$$
\begin{gathered}
\frac{\partial \stackrel{C}{\mathrm{I}}}{\partial \boldsymbol{C}}=\frac{\partial(\operatorname{tr} \boldsymbol{C})}{\partial \boldsymbol{C}}=\mathbf{I} \\
\frac{\partial \mathrm{II}}{\partial \boldsymbol{C}}=\frac{1}{2}\left[\frac{\partial\left(\operatorname{tr}^{2} \boldsymbol{C}\right)}{\partial \boldsymbol{C}}-\frac{\partial\left(\operatorname{tr}\left(\boldsymbol{C}^{2}\right)\right)}{\partial \boldsymbol{C}}\right]=\operatorname{tr}(\boldsymbol{C}) \mathbf{I}-\mathbf{I} \boldsymbol{C}=\stackrel{C}{\mathrm{I}} \mathbf{I}-\boldsymbol{C} \\
\frac{\partial \mathrm{III}}{\partial \boldsymbol{C}}=\stackrel{C}{\mathrm{III}} \boldsymbol{C}^{-1}
\end{gathered}
$$

substituindo em (2.70), obtém-se a expressão geral para modelos hiper elásticos isotrópicos:

$$
\frac{1}{2} \boldsymbol{S}=\left(\frac{\partial \psi}{\partial \mathrm{I}}+\underset{\partial \mathrm{I}}{\mathrm{I}} \frac{\partial \psi}{C}\right) \mathbf{I}-\frac{\partial \psi}{\partial \mathrm{II}} \boldsymbol{C}+\underset{\mathrm{III}}{\stackrel{C}{\mathrm{II}} \frac{\partial \psi}{C I}} \boldsymbol{C}^{-1}
$$

Por ser independente de caminho e, em geral, não requerer o histórico de variáveis internas, materiais hiper elásticos isotrópicos são relativamente simples de se implementar. Neste estudo, é considerado o modelo neo-Hookeano compressível.

\section{Modelo neo-Hookeano compressível}

O comportamento do modelo neo-Hookeano apresenta características similares aos modelos elásticos em análises lineares. A função de energia nesta relação constitutiva é definida por [32]

$$
\psi=\frac{G}{2}(\stackrel{C}{\mathrm{I}}-3)-G \ln J+\frac{\lambda}{2}(\ln J)^{2}
$$

onde $\lambda$ e $G$ são parâmetros do material, a primeira constante de Lamé e o módulo de cisalhamento, respectivamente.

Substituindo a Eq. (2.73) em (2.72), obtém-se a relação tensão-deformação para o material,

$$
\boldsymbol{S}=G\left(\mathbf{I}-\boldsymbol{C}^{-1}\right)+\lambda J \boldsymbol{C}^{-1}
$$

\subsubsection{Modelo hipo elástico linear}

Modelos hipo elásticos não são usados isoladamente para a caracterização de materiais reais. A equação constitutiva que carrega descreve uma relação linear entre tensão e taxa de deformação para grandes deformações. Geralmente, o modelo é associado a modelos de plasticidade para metais, onde a deformação elástica percebida no material é bastante pequena e praticamente linear. 
Em hipo elasticidade, a elaboração das equações constitutivas é feita em termos de taxas de tensão objetivas para modelar o comportamento reversível do material. A tensão é atualizada incrementalmente a cada passo de tempo. Comumente, elas não são triviais e podem levar a relações complexas. Ainda assim, segundo de Souza Neto et al. [69], esse tipo de modelo é consideravelmente usado na literatura e nos pacotes comerciais de elementos finitos, às vezes como única opção. Dessa forma, para oferecer um método direto para comparação com outros softwares, ele será abordado na implementação de um modelo hipo elasto-plástico. Por questões didáticas, esta seção abordará o modelo hipo elástico isoladamente, reservando a discussão de plasticidade para a próxima seção.

Numa integração temporal explícita, considerando a iteração de tempo $t$, a atualização das tensões para o passo $t+\Delta t$ é feita executando-se os seguintes passos do Algoritmo 2.4.

\subsubsection{Plasticidade linear isotrópica}

A plasticidade é o fenômeno no qual um material, em resposta aos esforços aplicados, exibe deformação e mudança de forma permanentes. Em metais e outros materiais cristalinos, o fenômeno é predominantemente cisalhante, causado pelo rompimento e deslizamento das camadas do arranjo, produzindo deformação permanente no material. Para materiais que exibem este comportamento, como metais, a curva de tensão-deformação é comumente aproximada para o modelo idealizado da Figura 2.9.

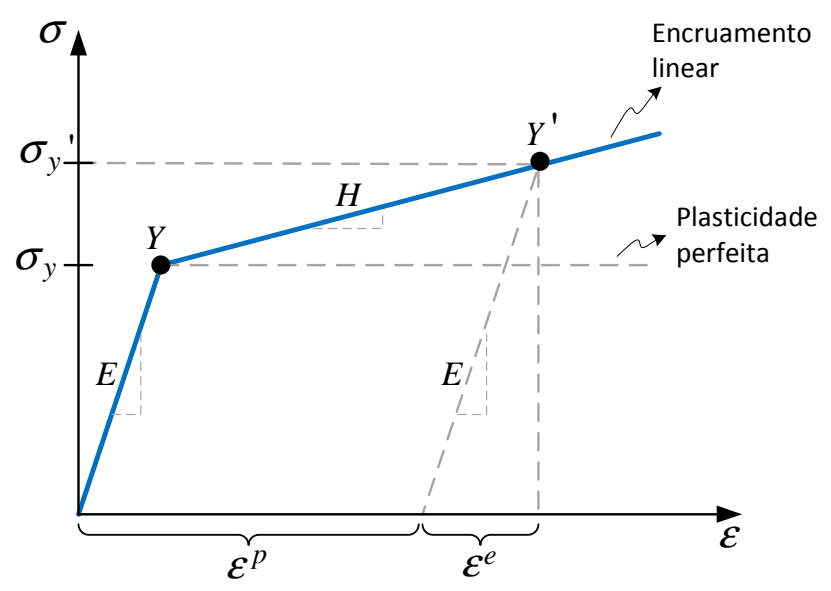

Figura 2.9 Curva uniaxial idealizada de tensão-deformação para materiais elasto-plásticos.

No modelo, o ponto $Y$ denota a tensão de escoamento do material $\left(\sigma_{y}\right)$, que limita o regime elástico e marca o início do escoamento plástico, onde ocorre o acúmulo de distorções permanentes, quantificadas pela deformação plástica $\left(\varepsilon^{p}\right)$. Num 
Algoritmo 2.4: Atualização da tensão pelo modelo hipo elástico.

\section{Algoritmo Modelo hipo elástico \\ Condições iniciais: $\boldsymbol{F}_{t}, \boldsymbol{F}_{t+\Delta t}, \boldsymbol{T}_{t}, \Delta t$}

Saída: $\boldsymbol{T}_{t+\Delta t}$

1. Determinar o gradiente de velocidade, Eq. A.23), onde a derivada temporal de $\boldsymbol{F}$ é aproximada pela relação [165]

$$
\dot{\boldsymbol{F}}_{t}=\frac{\boldsymbol{F}_{t+\Delta t}-\boldsymbol{F}_{t}}{\Delta t}
$$

2. Calcular os tensores de taxa de deformação e de giro, Eqs. A.25) e (A.26);

$$
\boldsymbol{D}_{t}=\frac{1}{2}\left(\boldsymbol{L}_{t}+\boldsymbol{L}_{t}^{T}\right) ; \quad \boldsymbol{W}_{t}=\frac{1}{2}\left(\boldsymbol{L}_{t}-\boldsymbol{L}_{t}^{T}\right)
$$

3. Determinar a taxa de tensão de Jaumann,

$$
\stackrel{\nabla J}{\boldsymbol{T}}_{t}=\mathbf{E}: \boldsymbol{D}_{t}
$$

4. Determinar a taxa de tensão objetiva,

$$
\dot{\boldsymbol{T}}_{t}=\stackrel{\nabla J}{\boldsymbol{T}}_{t}+\boldsymbol{W}_{t} \boldsymbol{T}_{t}-\boldsymbol{T}_{t} \boldsymbol{W}_{t}
$$

5. Determinar o incremento de tensão, integrando-se explicitamente a taxa obtida,

$$
\Delta \boldsymbol{T}_{t}=\Delta t \dot{\boldsymbol{T}}_{t}
$$

6. Determinar novo estado de tensão

$$
\boldsymbol{T}_{t+\Delta t}=\boldsymbol{T}_{t}+\Delta \boldsymbol{T}_{t}
$$

processo de descarregamento, apenas a deformação elástica (e distorção associada), $\varepsilon^{e}$, é recuperada, com o descrescimento linear da tensão (linha paralela à região elástica original do material). O escoamento plástico cessa, mas a deformação plástica acumulada se mantém. Caso o material seja carregado novamente, a deformação elástica e a tensão crescem na mesma razão que anteriormente.

Quando é percebido um aumento da tensão com o avanço do escoamento plástico, diz-se que o material exibe encruamento (no caso, linear), dado pelo módulo 
de encruamento, $H$. Para o caso particular do encruamento isotrópico, à medida que ocorre, a tensão de escoamento acompanha a evolução da tensão, com consequente extensão do domínio elástico, isto é, na eventualidade de um novo ciclo de carregamento, o escoamento será retomado a partir do novo limite, $\sigma_{y}^{\prime}$.

\section{Componentes do modelo elastoplástico}

De uma forma geral, são constituintes para um modelo elastoplástico [25, 69]:

1. Decomposição da deformação elastoplástica - A deformação sofrida pelo material é dividida em componentes elástica e plástica;

2. Lei elástica - Define o comportamento do material na região elástica e a evolução das tensões no corpo;

3. Critério de escoamento - O critério de escoamento é dado geralmente por uma função de escoamento, $\phi$, que define os limites do domínio elástico do material. O núcleo dessa função $(\phi=0)$ define o limite no qual se tem a iminência da plastificação do material, ou seja, a superfície de escoamento;

4. Regra de escoamento - Define a evolução da deformação plástica ou, de forma mais generalizada, a evolução das variáveis internas do material, responsáveis pelo caráter dissipativo do fenômeno;

5. Lei de encruamento - Um subconjunto das variáveis internas, as variáveis de encruamento, definem o limite de escoamento. A lei de encruamento determina a evolução do limite de escoamento do material e dessas variáveis ao longo do processo de plastificação.

O modelo de plasticidade de von Mises é um dos mais utilizados para descrever o comportamento de metais e será abordado neste estudo. A sua simplicidade oferece uma abordagem direta para a compreensão do fenômeno e facilidade para a implementação computacional.

\section{Decomposição da deformação elastoplástica}

Para o modelo em questão, as taxas de deformações elástica e plástica são decompostas aditivamente pela relação,

$$
\boldsymbol{D}=\boldsymbol{D}^{e}+\boldsymbol{D}^{p}
$$

onde $\boldsymbol{D}^{e}$ e $\boldsymbol{D}^{p}$ são a taxa de deformação elástica e plástica, respectivamente, e $\boldsymbol{D}$ é o tensor de taxa de deformação, obtido de $\boldsymbol{L}$ (Eq. A.25). 


\section{Lei constitutiva elástica}

Para a evolução das tensões no corpo, será considerada a lei hipo elástica, que oferece uma extensão da lei de Hooke para o caso de deformações finitas. Conforme anteriormente apresentado, ela é dada por

$$
\stackrel{\nabla J}{\boldsymbol{T}}=\mathbf{E}: \boldsymbol{D}^{e}
$$

\section{Critério de escoamento}

A relação (2.81) estipula uma deformação totalmente elástica. Contudo, a introdução de uma função de escoamento, $\phi$, delimita o domínio elástico do material $(\mathcal{L}$, Fig. 2.10), tal que

$$
\mathcal{L}=\left\{\boldsymbol{\sigma} \mid \phi\left(\boldsymbol{\sigma}, \sigma_{y}\right)<0\right\}
$$

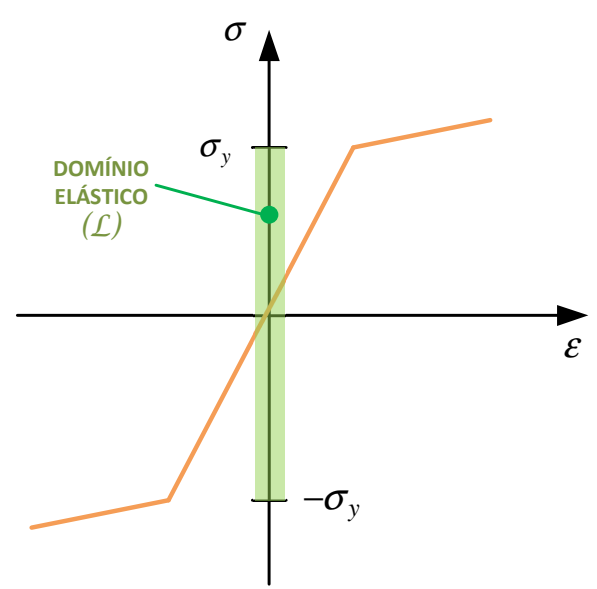

Figura 2.10 Domínio elástico em uma curva de ensaio uniaxial.

O escoamento em materiais cristalinos isotrópicos não-porosos exibe as seguintes características que, por consequência, requer que a função de escoamento atenda a uma série de requisitos [78]:

- o escoamento independe da pressão hidrostática - portanto, $\phi$ é expresso apenas em termos de tensões cisalhantes;

- o fenômeno é isotrópico - $\phi$ é simétrico para qualquer $\boldsymbol{\sigma}_{i}$;

- a tensão de escoamento $\sigma_{y}$ em compressão tem a mesma magnitude que a medida em tração - $\phi$ é par. 
O critério de von Mises atende a esses requisitos e define a função de escoamento como

$$
\phi\left(\boldsymbol{T}, \sigma_{y}\right)=\sigma_{v m}-\sigma_{y}
$$

onde $\sigma_{v m}$ é a tensão equivalente de von Mises, dada por

$$
\sigma_{v m}=\sqrt{\frac{3}{2} \boldsymbol{T}^{d e v}: \boldsymbol{T}^{d e v}}
$$

e $\boldsymbol{T}^{\text {dev }}$ é o tensor de tensões deviatóricas:

$$
\boldsymbol{T}^{\text {dev }}=\boldsymbol{T}-\frac{1}{3} \operatorname{tr}(\boldsymbol{T}) \mathbf{I}
$$

Esta abordagem permite definir o comportamento do material a partir da curva de um ensaio uniaxial, o que simplifica a obtenção dos parâmetros constitutivos. A superfície definida pela função, mostrada na Figura 2.11, é um cilindro centralizado no eixo hidrostático $\left(\sigma_{1}=\sigma_{2}=\sigma_{3}\right)$ com raio $\sqrt{2 / 3 \sigma_{y}}$.

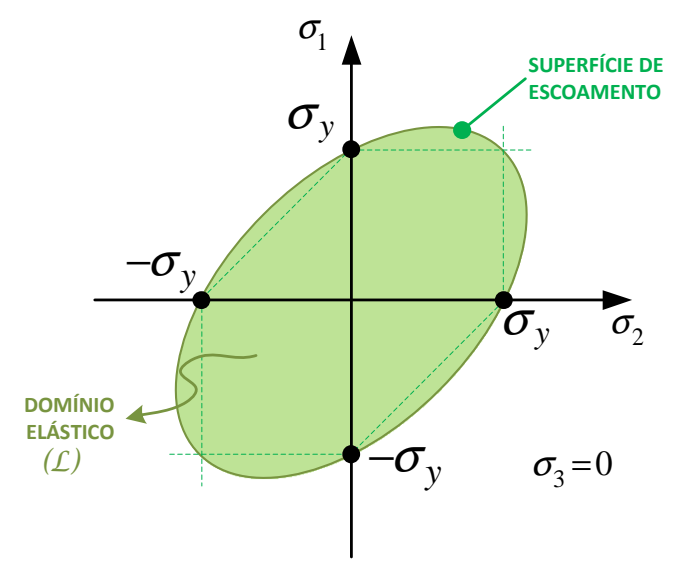

Figura 2.11 Corte da superfície de escoamento multiaxial de von Mises para $\sigma_{3}=0$.

São admissíveis estados de tensão localizados dentro do domínio elástico ou em sua fronteira, definida pela superfície de escoamento. Em outras palavras, o incremento de tensão é dado exclusivamente pelo comportamento elástico do material. Logo, qualquer estado de tensão válido admite a condição

$$
\phi\left(\boldsymbol{T}, \sigma_{y}\right) \leq 0
$$

e assim se estabele o critério de escoamento, que define o estado do material em um determinado instante:

$$
\begin{aligned}
& \text { Se } \phi\left(\boldsymbol{T}, \sigma_{y}\right)<0 \Rightarrow \boldsymbol{D}^{p}=\mathbf{0} \text { para carregamento elástico } \\
& \text { Se } \phi\left(\boldsymbol{T}, \sigma_{y}\right)=0 \Rightarrow\left\{\begin{array}{l}
\boldsymbol{D}^{p}=\mathbf{0} \text { para descarregamento elástico } \\
\boldsymbol{D}^{p} \neq \mathbf{0} \text { para carregamento plástico }
\end{array}\right.
\end{aligned}
$$




\section{Regra de escoamento}

A regra de escoamento define a evolução das variáveis internas durante a plastificação, que caracterizam o efeito dissipativo do fenômeno. Num modelo associativo, a evolução das variáveis é dada pelo multiplicador plástico, $\dot{\gamma}$, e a função de escoamento, tal que

$$
\boldsymbol{D}^{p}=\dot{\gamma} \frac{\partial \phi}{\partial \boldsymbol{T}}
$$

O multiplicador plástico também define a deformação plástica efetiva, $\bar{\varepsilon}$, um escalar que representa a deformação plástica acumulada,

$$
\dot{\bar{\varepsilon}}=\dot{\gamma}
$$

Para a função de escoamento definida em (2.83),

$$
\frac{\partial \phi}{\partial \boldsymbol{T}}=\frac{3}{2 \sigma_{v m}} \boldsymbol{T}^{d e v}=\boldsymbol{n}
$$

onde $\boldsymbol{T}^{d e v}$ é a tensão deviatórica calculada no passo de predição elástico e $\boldsymbol{n}$ é o tensor de escoamento, normal à tangente da superfície de escoamento no ponto definido pelo estado de tensão atual, conforme mostra a Fig. 2.12 para o caso bidimensional.

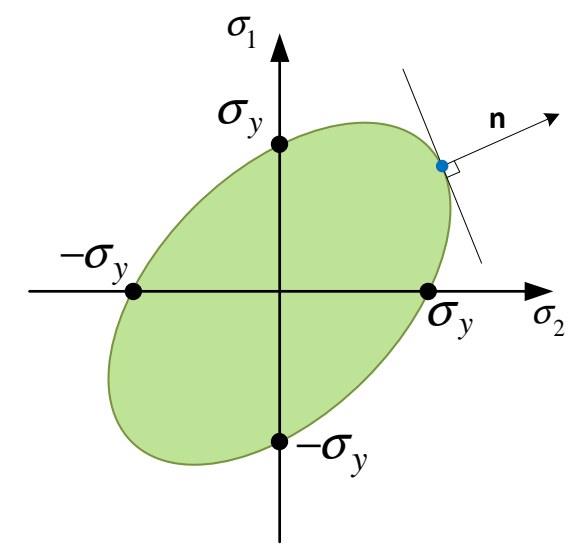

Figura 2.12 Direção do escoamento.

O tensor $\boldsymbol{n}$, unitário, determina a direção na qual a deformação plástica e as variáveis internas evoluem, enquanto que a magnitude é fornecida pelo multiplicador plástico.

Para todos os efeitos, durante o escoamento,

$$
\dot{\gamma} \geq 0
$$

e satisfaz a condição de complementariedade [69]

$$
\phi \dot{\gamma}=0
$$


o que implica nas seguintes condições:

- como estipulado pelo critério de escoamento na Eq. (2.87), em vista das relações constitutivas (2.88) e (2.92), a taxa de deformação plástica é nula no domínio elástico, ou seja,

$$
\phi<0 \Rightarrow \dot{\gamma}=0 \Rightarrow \boldsymbol{D}^{p}=\mathbf{0}
$$

- durante o escoamento plástico, $\boldsymbol{D}^{p} \neq \mathbf{0}$ e, portanto,

$$
\boldsymbol{D}^{p} \neq \mathbf{0} \Rightarrow \dot{\gamma}>0 \Rightarrow \phi=0
$$

Desta forma, define-se o que é chamado de condição de carregamento/descarregamento, que estabelece quando ocorre o escoamento plástico:

$$
\phi \leq 0, \quad \dot{\gamma} \geq 0, \quad \dot{\gamma} \phi=0
$$

\section{Lei de encruamento}

A maioria dos metais, durante o escoamento, exibe uma evolução de seu estado de tensão, à medida que deformam plasticamente. Esse corportamento é definido pela lei de encruamento do material e geralmente é dado em função da deformação plástica acumulada. Durante o encruamento, a superfície de escoamento é expandida (encruamento isotrópico) ou transladada (encruamento cinemático, não abordado neste trabalho) à medida que o processo evolui. Quando a expansão é uniforme em todas as direções e não há translação da superfície, denomina-se que o encruamento é isotrópico. A Figura 2.13 ilustra o processo.

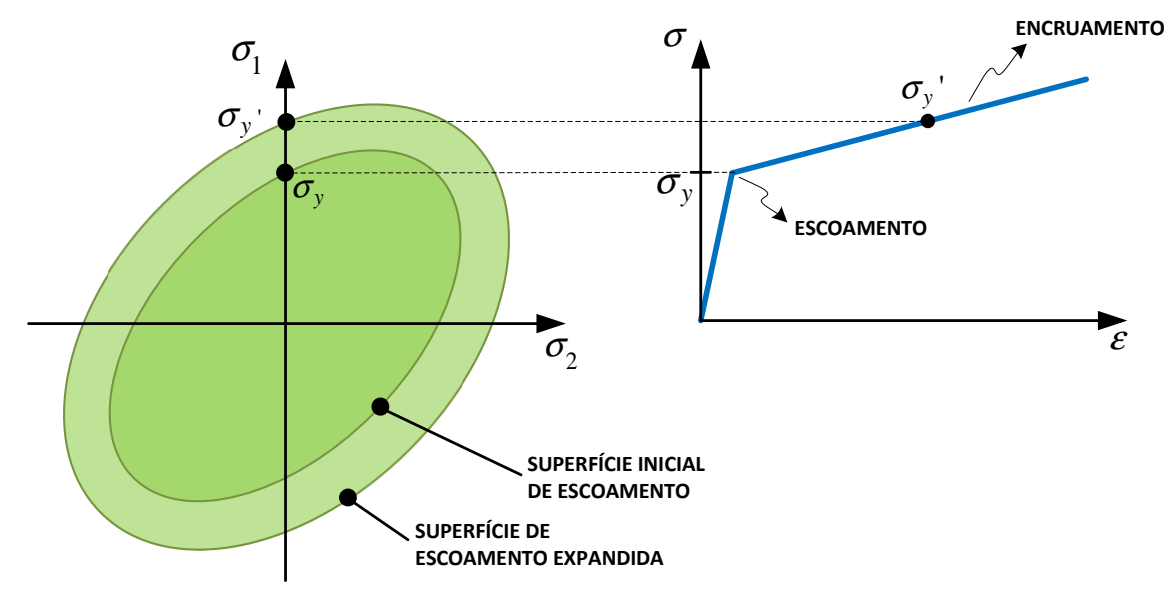

Figura 2.13 Encruamento isotrópico, com a expansão da superfície de escoamento. A curva uniaxial de tensão-deformação é oferecida para comparação. 
De forma similar à Eq. (2.88), as variáveis de encruamento, $\mathcal{H}$, evoluem segundo o multiplicador plástico,

$$
\dot{\mathcal{H}}=\dot{\gamma} f_{H}(\boldsymbol{T}, \mathcal{A})
$$

onde $f_{H}$ é a função de encruamento, dependente do estado de tensão e de um conjunto $\mathcal{A}$ de variáveis internas do modelo.

Para o encruamento isotrópico na plasticidade de von Mises, o multiplicador plástico é [23]

$$
\dot{\gamma}=\frac{\boldsymbol{n}: \mathbf{E}: \boldsymbol{D}}{\boldsymbol{n}: \boldsymbol{D}+H}
$$

onde $H$ é o módulo de encruamento, que define a inclinação do encruamento linear, mostrado na Fig. 2.9.

\section{Implementação do modelo numérico}

Com base nas informações apresentadas, é possível descrever e organizar os procedimentos para implementação computacional, apresentados no Algoritmo 2.5, onde as relações constitutivas são calculadas por integração explícita de suas equações. A vantagem de adotar este esquema consiste na simplicidade e menor custo computacional que o algoritmo resultante apresenta, não requerendo métodos de correção da tensão, como o retorno radial.

Devido ao método de integração usado, para a acurácia numérica do modelo, é necessário que os incrementos de tempo sejam mantidos pequenos o suficiente para garantir a estabilidade numérica. Além disso, o multiplicador plástico (Eq. 2.97) é obtido para garantir a condição de escoamento apenas para o instante $t$. Valores maiores de $\Delta t$ poderão provocar desvios na solução, deslocando a tensão para fora da superfície de escoamento. Por estas razões, este tipo de implementação se torna mais vantajoso quando usado em conjunto com métodos dinâmicos explícitos.

\subsection{Comentários}

O Método dos Elementos Finitos oferece a modelagem para diversos aspectos da Mecânica dos Sólidos. Nas indústrias aeronáutica e aeroespacial, onde se consagrou, o método ganhou base matemática sólida. Atualmente, contam-se diversos algoritmos e procedimentos numéricos para a modelagem de estruturas complexas e comportamentos não lineares. O desacoplamento das técnicas envolvidas para a solução do problema fornecem-lhe a adaptabilidade para a simulação e o estudo de diferentes eventos com características particulares. 
Algoritmo 2.5: Modelo material hipo elastoplástico (plasticidade de von Mises, encruamento isotrópico linear).

\section{Algoritmo Plasticidade de von Mises com encruamento isotrópico linear}

Condições iniciais: $\boldsymbol{L}_{t}, \boldsymbol{T}_{t}, \Delta t, H, \boldsymbol{\varepsilon}_{t}^{p}, \bar{\varepsilon}_{t}$ e $\sigma_{y_{t}}$

Saída: $\boldsymbol{T}_{t+\Delta t}, \boldsymbol{\varepsilon}_{t+\Delta t}^{p}, \bar{\varepsilon}_{t+\Delta t}$ e $\sigma_{y_{t+\Delta t}}$

1. Calcular taxa de deformação a partir do gradiente de velocidade,

$$
\boldsymbol{D}=\frac{1}{2}\left(\boldsymbol{L}+\boldsymbol{L}^{T}\right) ; \quad \boldsymbol{W}=\frac{1}{2}\left(\boldsymbol{L}-\boldsymbol{L}^{T}\right)
$$

2. Definir estado de tensão de tentativa pela lei hipo elástica

$$
\begin{gathered}
\stackrel{\nabla J}{\boldsymbol{T}}=\mathbf{E}: \boldsymbol{D} \\
\Delta \boldsymbol{T}=\Delta t\left(\stackrel{\nabla J}{\boldsymbol{T}}+\boldsymbol{W} \boldsymbol{T}_{t}-\boldsymbol{T}_{t} \boldsymbol{W}\right) \\
\boldsymbol{T}^{\text {tentativa }}=\boldsymbol{T}_{t}+\Delta \boldsymbol{T}
\end{gathered}
$$

3. Determinar função de escoamento

$$
\begin{gathered}
\phi=\sigma_{v m}-\left(\sigma_{y}\right)_{t} \\
\sigma_{v m}=\sqrt{3 / 2 \boldsymbol{T}^{d e v}: \boldsymbol{T}^{d e v}} ; \quad \boldsymbol{T}^{d e v}=\boldsymbol{T}-1 / 3 \operatorname{tr}(\boldsymbol{T}) \mathbf{I}
\end{gathered}
$$

4. se $\phi>0$ então

a. Determinar a direção de escoamento e o multiplicador plástico

$$
\boldsymbol{n}=\frac{3}{2 \sigma_{v m}} \boldsymbol{T}^{\text {dev }} ; \quad \dot{\gamma}=\frac{\boldsymbol{n}: \mathbf{E}: \boldsymbol{D}}{\boldsymbol{n}: \boldsymbol{D}+H}
$$

b. Determinar taxas de deformação plástica e elástica

$$
\boldsymbol{D}^{p}=\dot{\gamma} \boldsymbol{n} ; \quad \boldsymbol{D}^{e}=\boldsymbol{D}-\boldsymbol{D}^{p}
$$

c. Calcular tensão corrigida

$$
\begin{gathered}
\stackrel{\nabla J}{\boldsymbol{T}}=\mathbf{E}: \boldsymbol{D}^{e} \\
\Delta \boldsymbol{T}=\Delta t(\stackrel{\nabla J}{\boldsymbol{T}}+\boldsymbol{W} \boldsymbol{T}-\boldsymbol{T} \boldsymbol{W}) \\
\boldsymbol{T}_{t+\Delta t}=\boldsymbol{T}_{t}+\Delta \boldsymbol{T}
\end{gathered}
$$

d. Atualizar variáveis internas

$$
\begin{gathered}
\varepsilon_{t+\Delta t}^{p}=\varepsilon_{t+\Delta t}^{p}+\Delta t \boldsymbol{D}^{p} ; \quad \bar{\varepsilon}_{t+\Delta t}=\bar{\varepsilon}_{t}+\Delta t \dot{\gamma} \\
\left(\sigma_{y}\right)_{t+\Delta t}=\left(\sigma_{y}\right)_{t}+H \Delta t \dot{\gamma}
\end{gathered}
$$

5. senão

a. Atualizar estado de tensão

$$
\boldsymbol{T}_{t+\Delta t}=\boldsymbol{T}^{\text {tentativa }}
$$


A modularidade inerente do MEF possibilita uma implementação computacional mais simples e direta ao utilizar paradigmas de abstração de dados, como a orientação a objetos. O Capítulo 3 inicia a abordagem a respeito deste assunto. 



\section{Fundamentos do código de elementos finitos orientado a objetos}

O desenvolvimento orientado a objetos é estudado para aplicação em MEF há mais de duas décadas. As pesquisas são motivadas pelas ferramentas que o padrão oferece, usando um idioma mais próximo do domínio para descrever o problema. Consequentemente, diminui-se consideravelmente o abismo entre a linguagem de programação e a especificação do problema, tornando mais simples a elaboração de sistemas complexos, como softwares de MEF. O grande número de variáveis que se inter-relacionam aumentam a dificuldade de se estabelecer um ambiente de desenvolvimento adequado. A necessidade de grandes dicionários de dados, para associar um conceito de alto nível (do problema) com variáveis de dados do programa, apenas agravam o cenário.

Em orientação a objetos, os mecanismos fornecidos buscam descrever o programa, sempre que possível, através de uma terminologia mais próxima do problema, inserindo uma camada de abstração de dados entre os aspectos tecnológicos e o problema em questão. O assunto é extensamente abordado na literatura [33, 88, 92, 100, 123, 205], dado que é um dos principais paradigmas de desenvolvimento, atualmente. Neste capítulo, os principais aspectos do desenvolvimento orientado a objetos são apresentados, com ênfase na aplicação em softwares de elementos finitos. É também oferecida uma breve introdução à linguagem de modelagem UML (Unified Modeling Language). Maiores detalhes podem ser obtidos em Eriksson et al. [80], Larman [134]. 


\subsection{Análise orientada a objetos}

Uma das formas mais comuns de se analisar um sistema complexo é a partir da sua decomposição em partes menores, observando-as isoladamente e examinando o funcionamento entre elas. Isso se deve ao fato da limitação da cognição humana ser incapaz de analisar simultaneamente um grande número de fatos interrelacionados [33, 85].

Toma-se de exemplo o procedimento de solução de um problema quase estático linear, cujas atividades dependentes são simplificadamente ilustradas na Fig. 3.1. Uma das formas de estudar o processo é através de sua decomposição em tarefas e subtarefas até se alcançar o detalhamento desejado. Conhecida como decomposição algorítmica, o foco desta técnica são as operações e suas dependências, conforme mostra a figura.

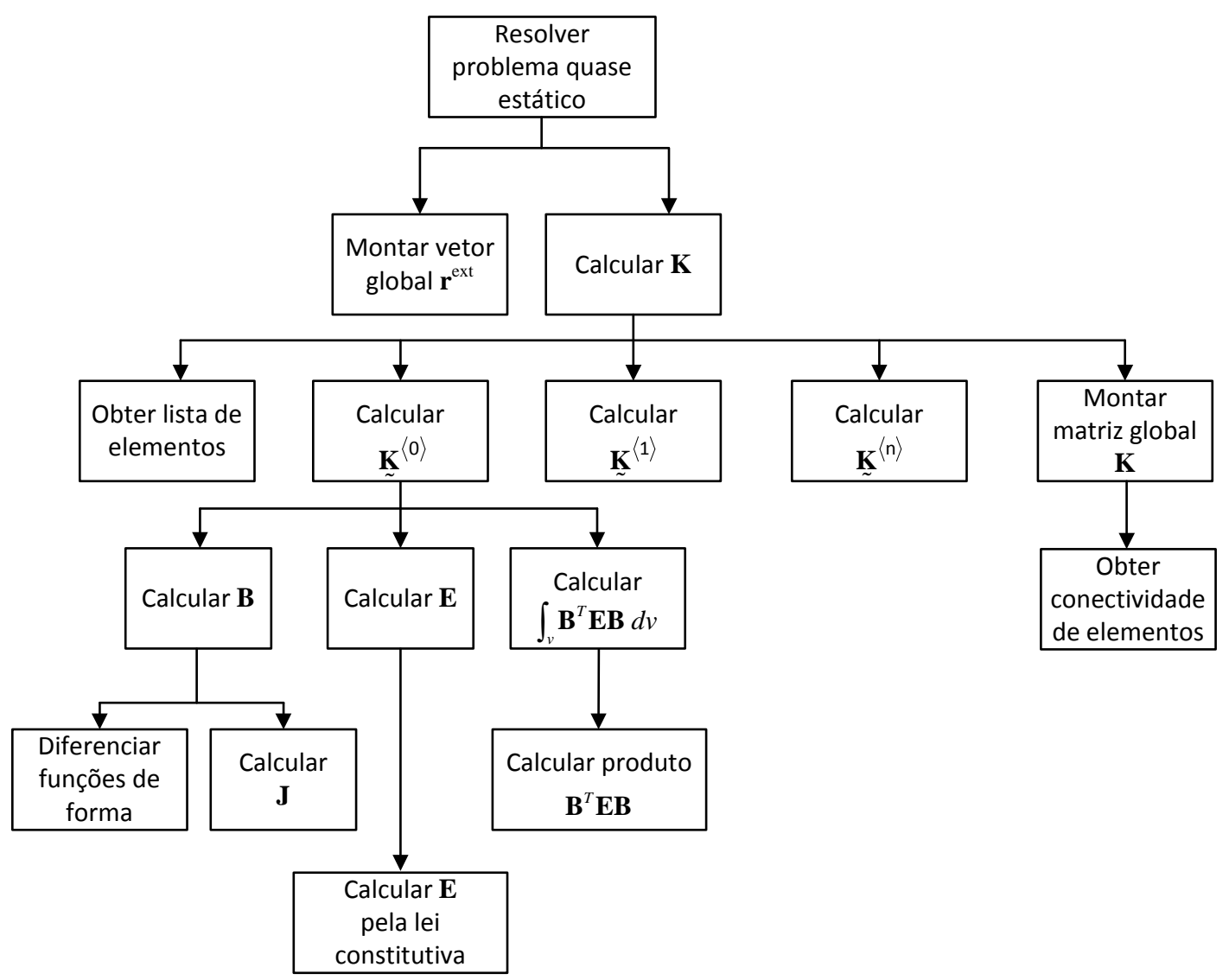

Figura 3.1 Decomposição algorítmica da solução de um problema quase estático linear.

A abordagem não define claramente os limites estruturais de um programa. É sugerido, apenas, a ordem em que as funções precisam ser implementadas, além de que, em muitos casos, a descrição das funções faz uso de terminologias que não 
são pertinentes ao problema. Na Figura 3.2, por exemplo, o processo de leitura do elemento finito é carregado de termos tecnológicos, o que distancia da representação dos conceitos relativos ao domínio.

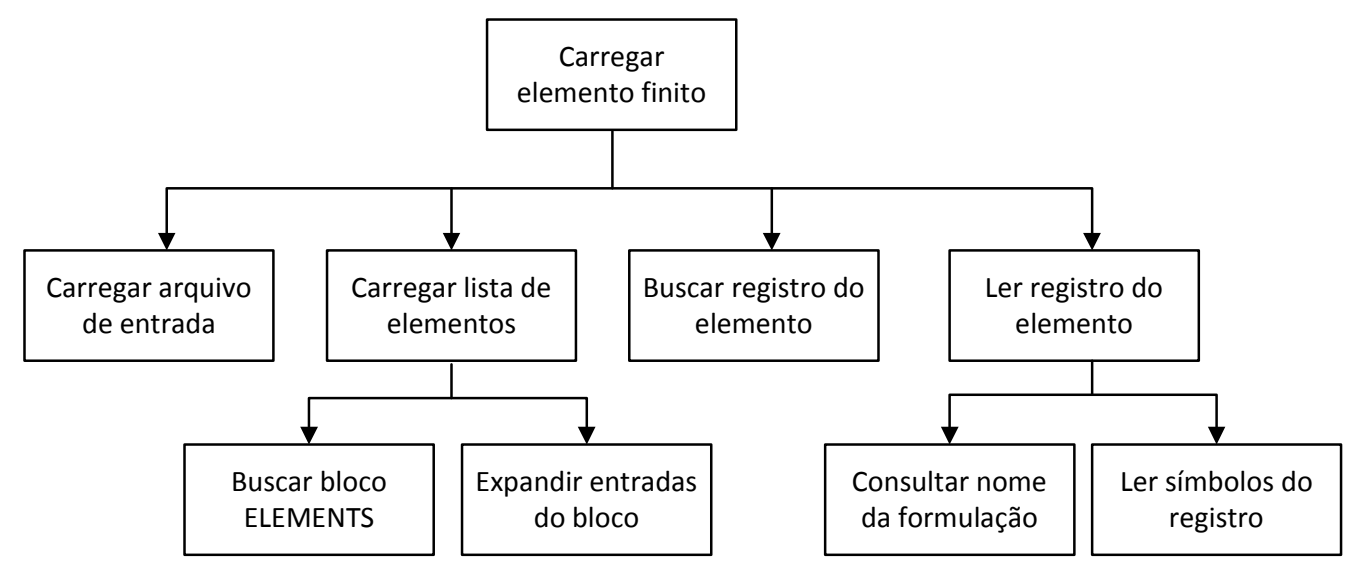

Figura 3.2 Decomposição algorítmica do carregamento de um elemento finito.

Num segundo método de decomposição, termos chaves são utilizados para analisar o sistema, extraídos do vocabulário do problema. Entidades autônomas são definidas, que colaboram entre si para completar a computação solicitada, ilustradas nas Figs. 3.3 e 3.4. Neste procedimento, denominado análise orientada a objetos, as entidades e as comunicações são modeladas através de conceitos do domínio, tornando o modelo mais intuitivo.

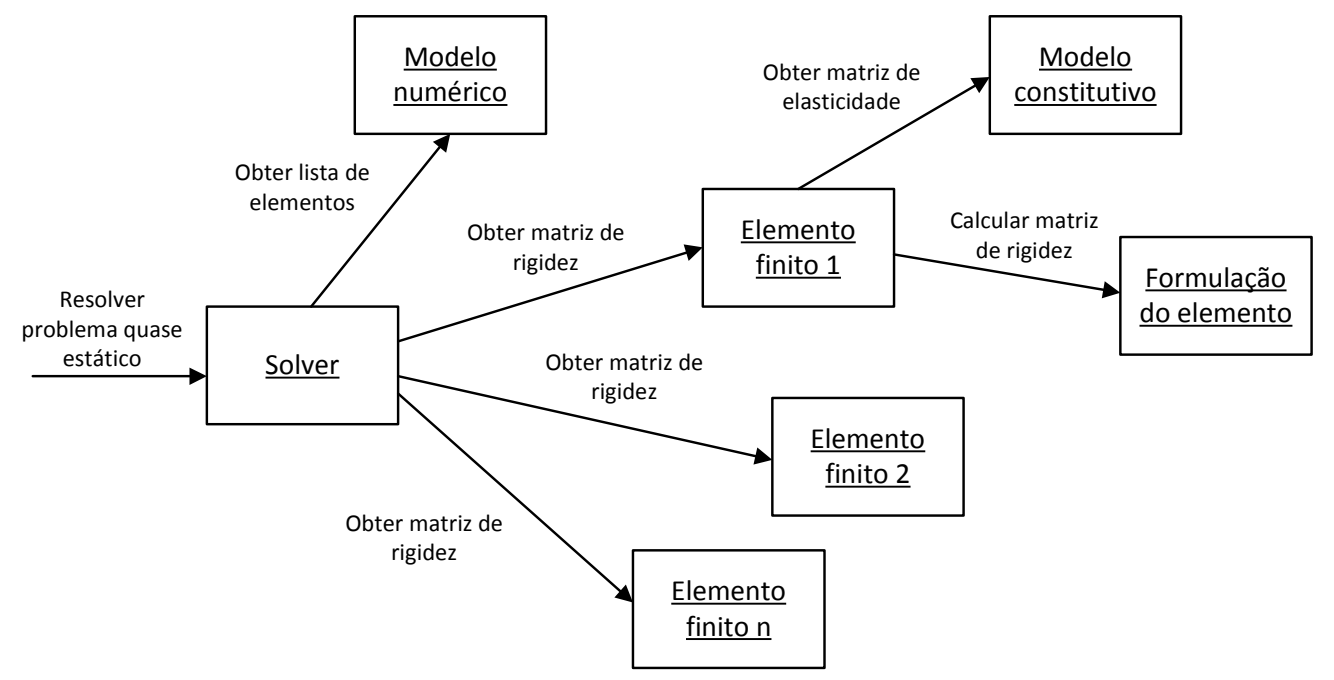

Figura 3.3 Análise orientada a objetos da solução de um problema quase estático linear.

Aspectos tecnológicos são omitidos e encapsulados dentro das entidades, como é o caso da Fig. 3.4. Em diversas ocasiões, no desenvolvimento orientado a objetos, mostra-se a preocupação apenas em quais comunicações são realizadas para executar 


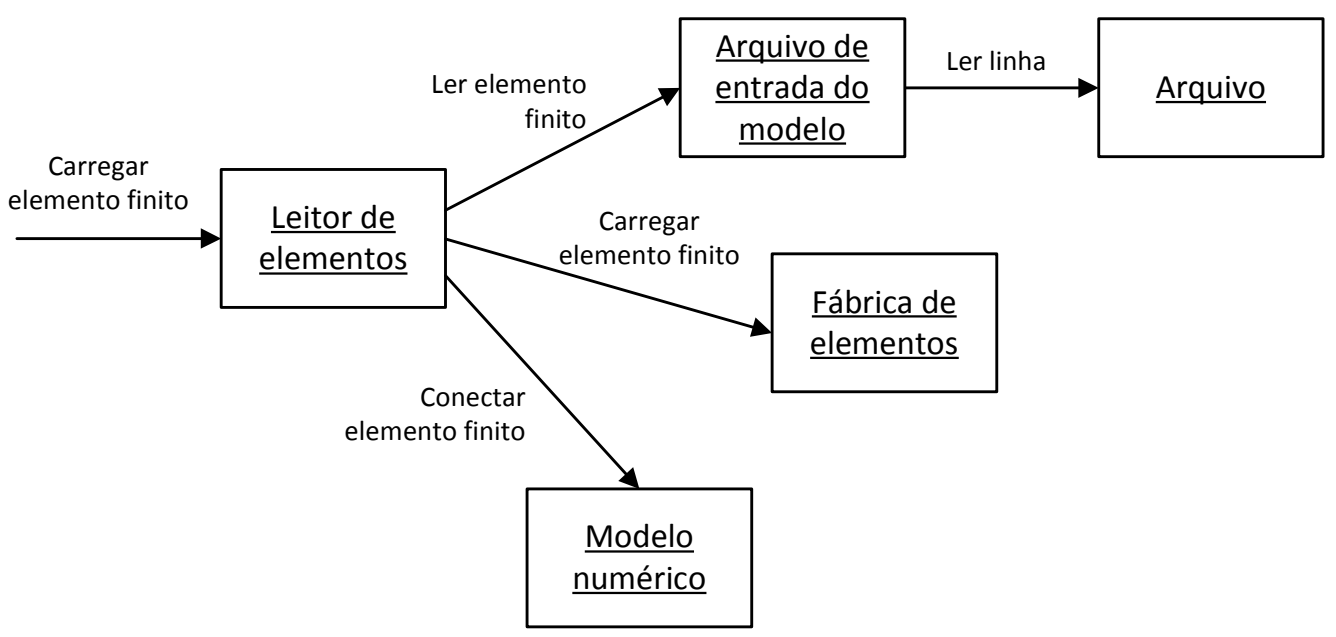

Figura 3.4 Análise orientada a objetos do carregamento de um elemento finito.

a tarefa; a forma com que é desempenhada não é relevante. Na mesma figura, o encadeamento das comunicações 'Ler elemento finito' e 'Ler linha' remove uma dependência direta do Leitor de elementos com a tecnologia específica de leitura do arquivo de entrada (no caso, lê-lo linha por linha).

Assim, definem-se então as principais preocupações da orientação a objetos [80]:

- modelagem de um sistema que reflita o domínio em questão, usando uma linguagem mais natural, de terminologia específica do problema;

- decomposição do domínio em entidades - os objetos, que representam uma instância ${ }^{1}$ de um conceito do problema, e as classes, onde são alocadas e distribuídas as responsabilidades (isto é, computações) para o cumprimento dos objetivos do programa;

- promoção de uma arquitetura flexível e capaz de responder rapidamente a mudanças;

- favorecimento de reuso do código através de componentes reutilizáveis, reduzindo a carga de programação;

- construção de um modelo de software que promova fácil comunicação e permita mudanças, expansões e verificações;

- adoção de uma linguagem orientada a objetos para implementar os conceitos e responsabilidades descritos no modelo projetado.

\footnotetext{
${ }^{1}$ Aqui, instância denota exemplar ou caso particular de um protótipo. Ainda que este não seja o termo apropriado para designar esta qualidade, ele será utilizado em favor do seu uso já consolidado em Engenharia de Software.
} 
É importante observar que o desenvolvimento orientado a objetos não se restringe apenas ao uso de uma linguagem de programação como tal. Dá-se maior ênfase na abordagem do problema e na forma como ele é descrito. Essa visão é compartilhada entre diversas disciplinas de desenvolvimento de software, nas quais, geralmente, há maior ênfase nas etapas de análise do problema e elaboração do modelo do software [80, 134]. Para a descrição do modelo ao longo dessas etapas, uma ferramenta de modelagem padronizada é comumente adotada, a Linguagem de Modelagem Unificada (UML).

A UML é uma linguagem de modelagem visual que provê mecanismos padronizados para a visualização, especificação, construção e documentação do software, através da descrição das interações dentro do sistema por meio de um conjunto de elementos gráficos bem-definidas Eriksson et al. [80]. Os diagramas que a linguagem oferece permite a representação de diferentes aspectos de um programa, como sua estrutura estática, a dinamicidade de uma computação ou a sua organização lógica. Os principais digramas UML usados neste trabalho são discutidos na seção 3.6.

\subsection{Objetos e classes}

Em orientação a objetos, a definição mais comum para um objeto é qualquer elemento do mundo real que possa ser manipulado ou facilmente compreendido. De fato, a definição tem abrangência suficiente para cobrir os conceitos numa aplicação usual - terminal, pedido, produto e cliente são objetos pertinentes para um domínio comercial, por exemplo. Contudo, para aplicações científicas, muitas vezes essa definição não é suficiente, pois o próprio domínio do problema não trata apenas com assuntos concretos da realidade - em MEF, por exemplo, os elementos finitos, que fazem parte do domínio conceitual do software, são conceitos abstratos.

Considera-se suficiente, para este estudo, a definição de Booch et al. [33] para objetos, onde "um objeto é uma entidade que tem estado, comportamento e identidade. A estrutura e comportamento de objetos similares são definidos pela sua classe em comum. Termos 'instância' e 'objeto' são considerados sinônimos".

Em MEF, cada elemento finito de uma malha pode ser representado por um objeto, conforme ilustra a Figura 3.5. O estado de cada elemento é definido pelo seu conjunto de atributos, como funções de interpolação, estado de deformação e estado de tensão. A alteração de seu estado, ou seja, a modificação de seus atributos, induz a uma mudança no comportamento do objeto, dado pelas suas operações. Por exemplo, o acréscimo de tensão induzido pelo incremento de deformação sofrido depende do estado anterior de tensão do elemento. 
Ainda que detenham estados idênticos (mesmo conjunto de atributos e valores), múltiplos objetos são tratados como entidades distintas. No exemplo da Figura 3.5, elementos da malha que detenham o mesmo conjunto de atributos, pois compartilham a mesma formulação, e detenham o mesmo valor (deformação e tensão nulos, como no estado inicial do modelo), tem sua identidade preservada, uma vez que são alocados em endereços distintos na memória do sistema.

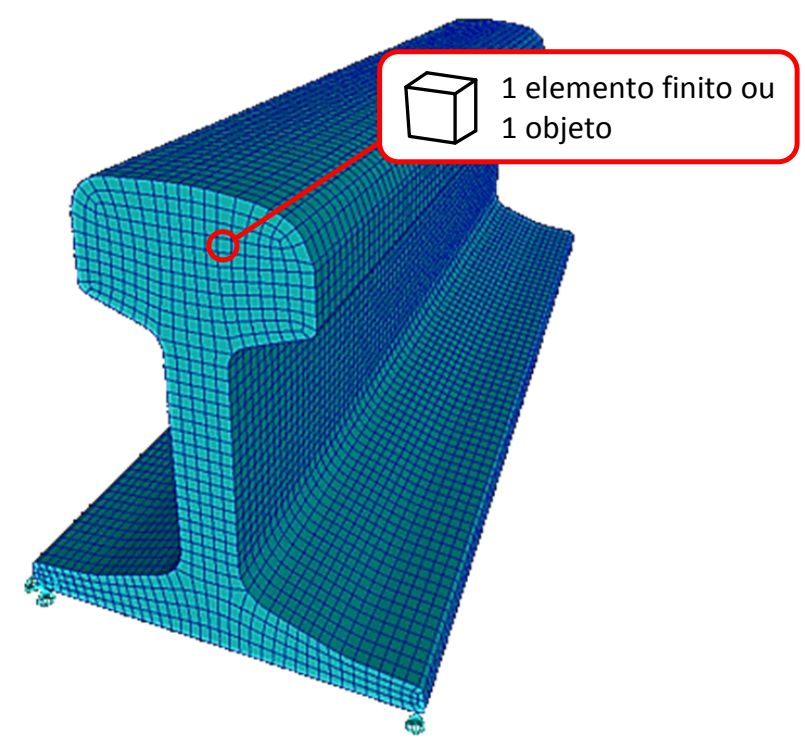

Figura 3.5 Elementos finitos de uma malha, vistos como objetos com propriedades distintas.

Todos os elementos finitos da malha da Figura 3.5 que detém características comuns, como número de nós, as funções de interpolação adotadas e também a forma como seu comportamento se modifica - em outras palavras, as operações e atributos oferecidos são igualmente definidos. A definição de todas essas características e a descrição das ações desses objetos é dada pela classe - por exemplo, a classe Elemento Hexaédrico, a partir da qual são gerados objetos com essas características. Objetos com características distintas são considerados instâncias de classes diferentes.

Na Figura 3.6a, é mostrada as possíveis representações de uma classe. O nome, os atributos e as operações da classe são organizados e agrupados em compartimentos distintos (Fig. 3.6a). Por questões de clareza ou simplicidade, um ou mais compartimentos podem ser omitidos (Figs. 3.6b e 3.6c). A representação UML de um objeto é dada na Figura 3.7. A identificação de um objeto é dada através de seu nome, seguido pelo nome da classe de origem e separados por dois-pontos (:), com ambos os termos sublinhados. O compartimento inferior da representação exibe o estado atual do objeto (atributos e respectivos valores). 


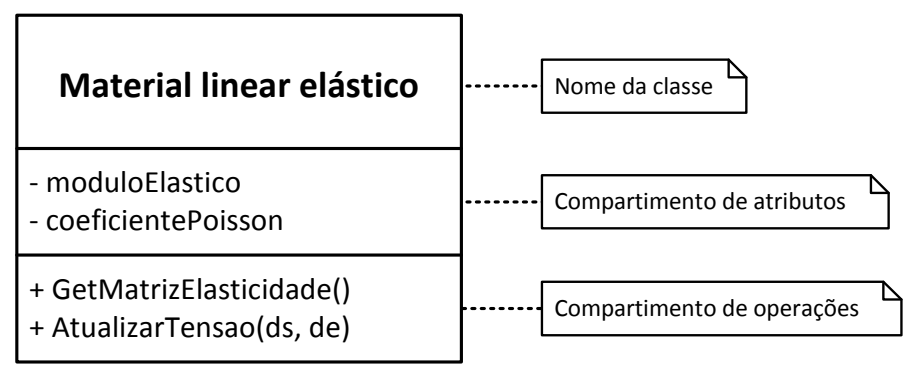

(a) Completo

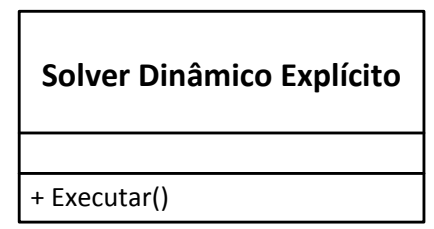

(b) Simplificado

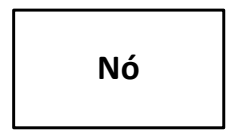

(c) Mínimo

Figura 3.6 Representação de uma classe em UML.

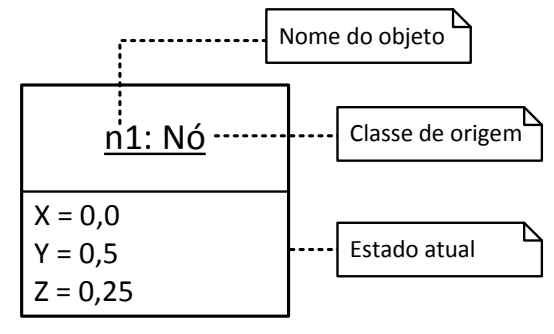

(a) Completo

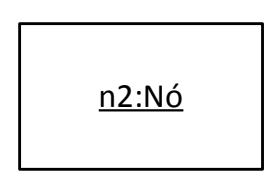

(b) Reduzido

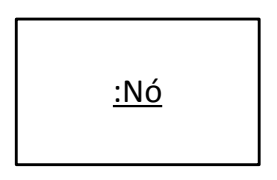

(c) Objeto anônimo

Figura 3.7 Representação de um objeto em UML.

\subsection{Relações entre classes}

Em um sistema computacional, as computações realizadas pelo programa são distribuídas entre os objetos, com responsabilidades bem-definidas dentro do sistema. De uma forma coordenada, mensagens são trocadas entre eles, solicitando o serviço de outro participante, cuja operação é de sua responsabilidade.

Uma associação é a conexão semântica entre as classes, que permite suas instâncias operarem cooperativamente com o resto do sistema por meio da troca de mensagens. Diversas formas de associação existem, sendo algumas delas discutidas a seguir. 


\subsubsection{Dependência}

Uma dependência indica uma relação transitória entre instâncias de duas classes. Ela é representada por uma linha tracejada orientada, como mostra a Figura 3.8.

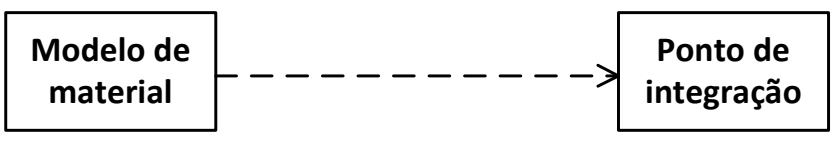

Figura 3.8 Exemplo de dependência entre classes.

A orientação aponta para a classe independente, isto é, no exemplo da figura, lê-se que "o modelo de material depende do ponto de integração". Neste caso, o modelo de material requer serviços do ponto de integração (por exemplo, saber seu estado de deformação) apenas em momentos específicos (somente ao calcular o novo estado de tensão do ponto).

\subsubsection{Associação comum}

A associação comum é uma conexão ordinária e duradoura entre classes. Sua representação gráfica em UML é mostrada na Figura 3.9. Denotada por um traço sólido conectando as classes, os seguintes elementos opcionais podem estar presentes na notação:

- Navegabilidade. Dada pela orientação do segmento, a visibilidade da associação ocorre apenas naquela direção. No caso da Figura 3.9b, apenas instâncias de Elemento finito são capazes de acessar serviços de Modelo de material, não sendo possível o contrário. Bidirecionalidade é assumida na ausência de orientação (Fig. 3.9a);

- Multiplicidade. Localizada na extremidade próxima à classe a que se refere, a multiplicidade de uma classe B define com quantas de suas instâncias um único objeto da classe A pode se relacionar. Esse valor pode ser fixado em um valor ou definido num intervalo. Na Fig. 3.9c, um elemento de viga se associa a dois nós, enquanto um nó se associa a, pelo menos, um elemento de viga;

- Rótulo. O rótulo auxilia a entender a natureza da relação entre as classes e é colocado sobre a associação, indicando o sentido da associação a que se refere, como ilustra as Figuras 3.9b e Fig. 3.9c;

- Papel. Posicionado próximo à classe a que se refere, o papel de uma classe B indica como uma de suas instâncias (ou a coleção delas, no caso 


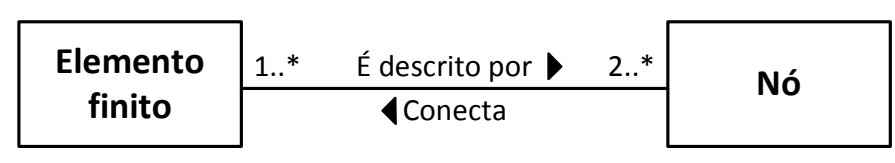

(a) Associação bidirecional

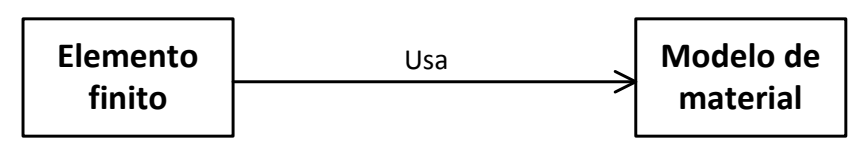

(b) Associação unidimensional

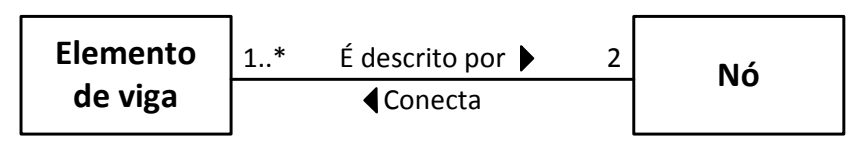

(c) Exemplo de multiplicidade definida

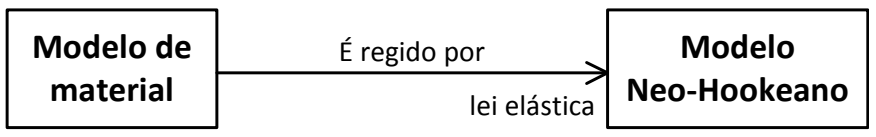

(d) Associação com papel definido

Figura 3.9 Exemplos de associação comum entre classes.

de relações com múltiplos elementos) é identificada pelo objeto da classe A. Numa outra leitura, a associação da Fig. 3.9d define que, "um modelo de material é regido por uma lei elástica, dada pelo modelo Neo-Hookeano".

\subsubsection{Agregação}

A agregação é um tipo específico de associação, cuja semântica carrega uma relação de contêiner e conteúdo. É denotada por um losango vazado no lado próximo à classe contêiner, como mostra a Figura 3.10. No exemplo, a associação define o nó como um objeto contido dentro do modelo numérico. Normalmente, a relação é unidirecional, como mostrado na figura.

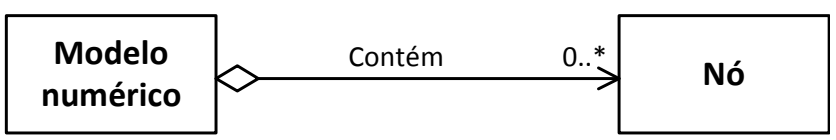

Figura 3.10 Exemplo de associação do tipo agregação. 


\subsubsection{Composição}

Uma outra particularidade de associação, a composição carrega a semântica de parte integrante de uma classe. Um losango preenchido identifica a classe composta da relação, como ilustra a Figura 3.11.

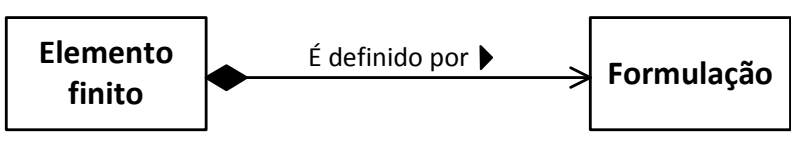

Figura 3.11 Exemplo de associação do tipo composição.

Como parte integrante de um todo, o objeto componente, representado pela classe no lado oposto do losango, se associa somente a uma única instância da classe composta, não sendo compartilhado com qualquer outra. Do ponto de vista de implementação, a associação comum, a agregação e a composição são idênticas. Sua diferenciação se dá no impacto que causam durante o design do programa.

\subsubsection{Herança ou generalização}

A herança especifica que duas classes carregam similaridades quanto ao seus aspectos construtivos e de implementação. Semanticamente, é uma relação "é um tipo de" e representada graficamente por uma seta cheia no lado da classe genérica, como mostra a Figura 3.12.

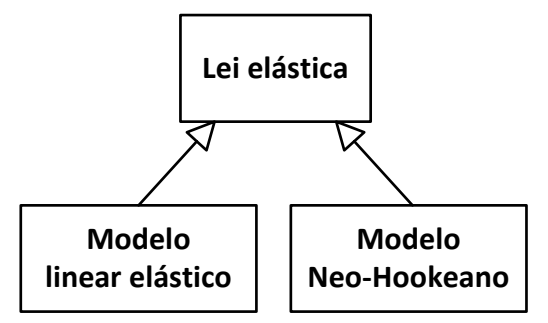

Figura 3.12 Exemplo de herança entre classes.

Na figura, tanto o modelo linear elástico como o modelo neo-Hookeano (isto é, as subclasses) podem ser classificados como leis elásticas (contudo, o oposto não é verdadeiro). Do ponto de vista estrutural, a classe lei elástica define uma interface comum para todas as suas especializações. Com efeito transitivo, propriedades e operações definidas nela também ocorrem em suas subclasses.

O mecanismo de herança também oferece um método de estabelecer uma interface genérica, similar a um contrato, cuja estrutura é herdada pelas subclasses, responsáveis pela implementação das operações. 


\subsection{Princípios do design orientado a objetos}

Durante o desenvolvimento do modelo de software, alguns princípios são estipulados para auxiliar na construção de classes com baixo nível de acoplamento (isto é, que dependam ao mínimo de outras e de seus aspectos construtivos), mas, ainda assim, atuando de forma coesa. Três considerações importantes são apresentadas a seguir.

\subsubsection{Encapsulamento}

O princípio de encapsulamento estipula que os atributos de uma classe (e, portanto, seu estado) não sejam expostos para clientes (isto é, as entidades que a utilizarão). Por exemplo, no elemento finito, para a quantidade de energia produzida por forças de estabilização (como as de anti-hourglass) é preferível que o atributo seja exposto apenas através de operação de acesso. A modificação de seu valor ocorre apenas internamente, pois é dependente da formulação. Outros objetos podem apenas ler o valor, evitando alterações acidentais que invalidariam o estado do elemento.

Linguagens de programação orientadas a objetos realizam o encapsulamento definindo os seguintes níveis de acessibilidade para os membros, indicados em UML por um prefixo antes do nome do membro (exemplo na Figura 3.6a):

- Acesso público (prefixo UML: +). o membro da classe é acessível interna e externamente, por objetos de outras classes;

- Acesso protegido (prefixo UML: \#). membros são acessíveis apenas internamente ou por instâncias de subclasses;

- Acesso privado (prefixo UML: -). membros deste nível são acessíveis apenas por instâncias da própria classe.

\subsubsection{Polimorfismo}

O mecanismo de herança permite que diversas classes detenham uma estrutura geral e comum a todas elas, especificada na superclasse. Objetos que se relacionam com instâncias da superclasse podem estabelecer ligação com suas subclasses, uma vez que essas são instâncias equivalentes da primeira. O fato de ser possível apontar um conjunto de instâncias de classes distintas através de um único nome (o da superclasse) é denominado polimorfismo.

A Figura 3.13 mostra um exemplo de aplicação do conceito. A classe Lei elástica é abstrata e especifica uma interface modelo, a partir da qual outros objetos 
se relacionam. Subclasses implementam as operações abstratas, oferecendo variabilidade do comportamento da classe abstrata. No exemplo, diferentes leis elásticas implementam um tipo de cálculo para as tensões do elemento, através da operação AtualizarTensao().

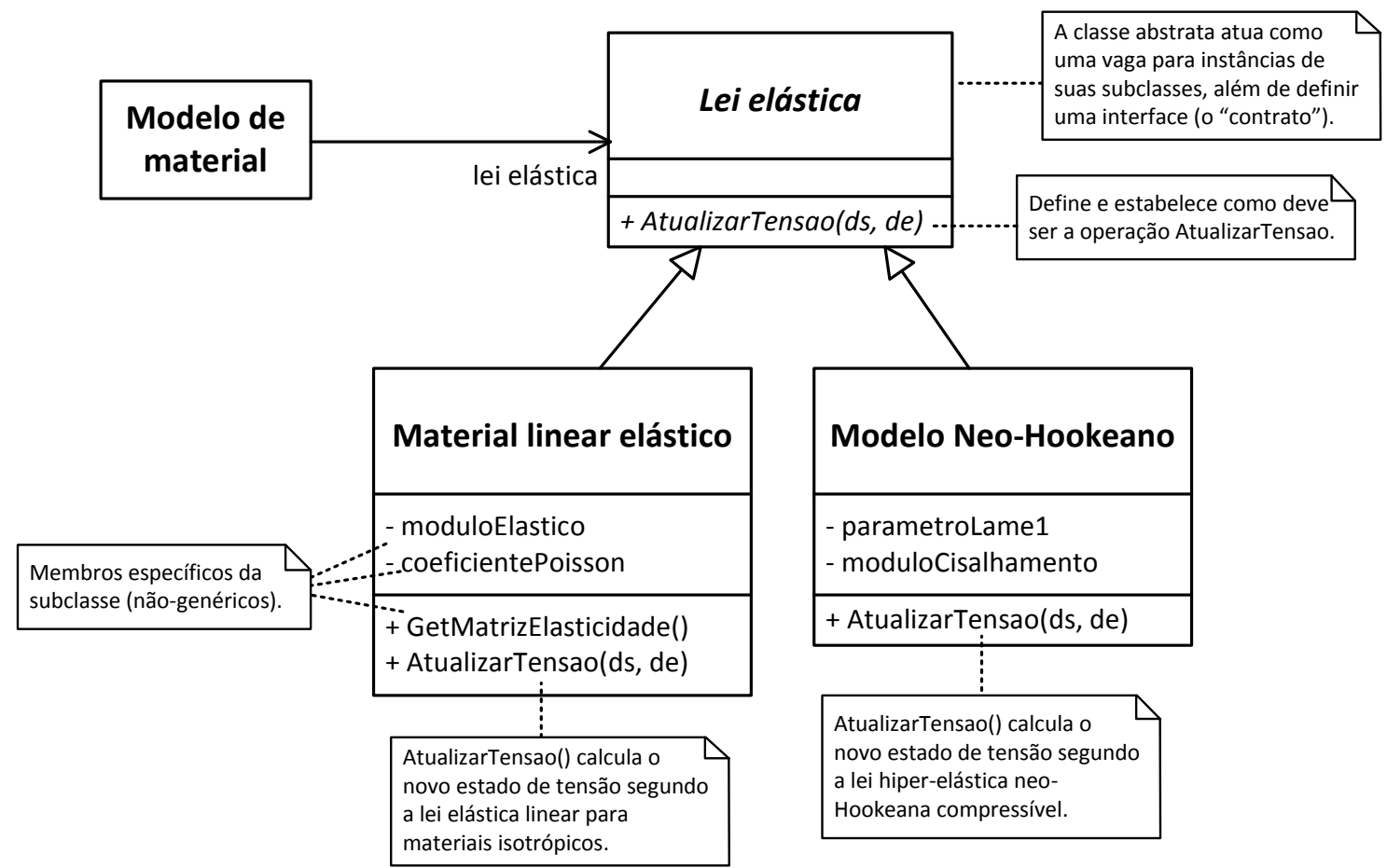

Figura 3.13 Polimorfismo na definição de um modelo de material.

\subsubsection{Design por responsabilidades}

Classes definem contratos ou responsabilidades a serem cumpridos, em outras palavras, o papel de um objeto dentro do programa. Definir um conjunto de classes coeso e com baixo acoplamento não é uma tarefa trivial. Na maioria dos casos, não é desejável que uma única classe detenha múltiplas responsabilidades, pois isso reduz a clareza de seu papel nas diversas computações do programa.

Por vezes, para garantir coerência, consideram-se ferramentas e práticas para a distribuição de responsabilidades entre as entidades e a definição adequada do encapsulamento das informações. Larman [134] e Booch et al. [33] abordam algumas dessas possibilidades, tais como o $\mathrm{GRASP}^{2}$, o $\mathrm{RDD}^{3}$ e as abstrações chaves.

\footnotetext{
${ }^{2}$ Sigla inglesa para Princípios Gerais de Designação de Responsabilidades em Software.

${ }^{3}$ Sigla inglesa para Design Digirido por Responsabilidades.
} 


\subsection{Padrões de design para softwares MEF}

Durante o desenvolvimento, o engenheiro de software faz uso de um conjunto de técnicas e princípios que são estruturadas em um formato que descreve um problema típico e uma solução alinhada com os princípios do desenvolvimento orientado a objetos. A essas técnicas, dá-se o nome de padrões de design ${ }^{4} 134$.

Heng e Mackie [106] estende a aplicação dos padrões de design para a implementação de softwares de elementos finitos, principalmente na construção de interface com o usuário. Na mesma linha de discussão, esta seção apresenta padrões de design, inicialmente definidos por Gamma et al. [92], que foram aplicados na construção do software MEF deste trabalho.

\subsubsection{Fachada}

O padrão fachada (do original facade, em inglês), ilustrado na Figura 3.14, é usado quando se deseja obter uma interface mais simples para um determinado subsistema do programa. Da mesma forma que uma fachada de edificação, o padrão oferece um conjunto de operações mais simples que, ao serem executadas, coordenam classes ocultadas pela fachada. Deve-se observar que a intenção deste padrão é apenas simplificar a interação com um sistema. Alterar o seu comportamento ou ligar interfaces distintas são problemas resolvidos por outros padrões.

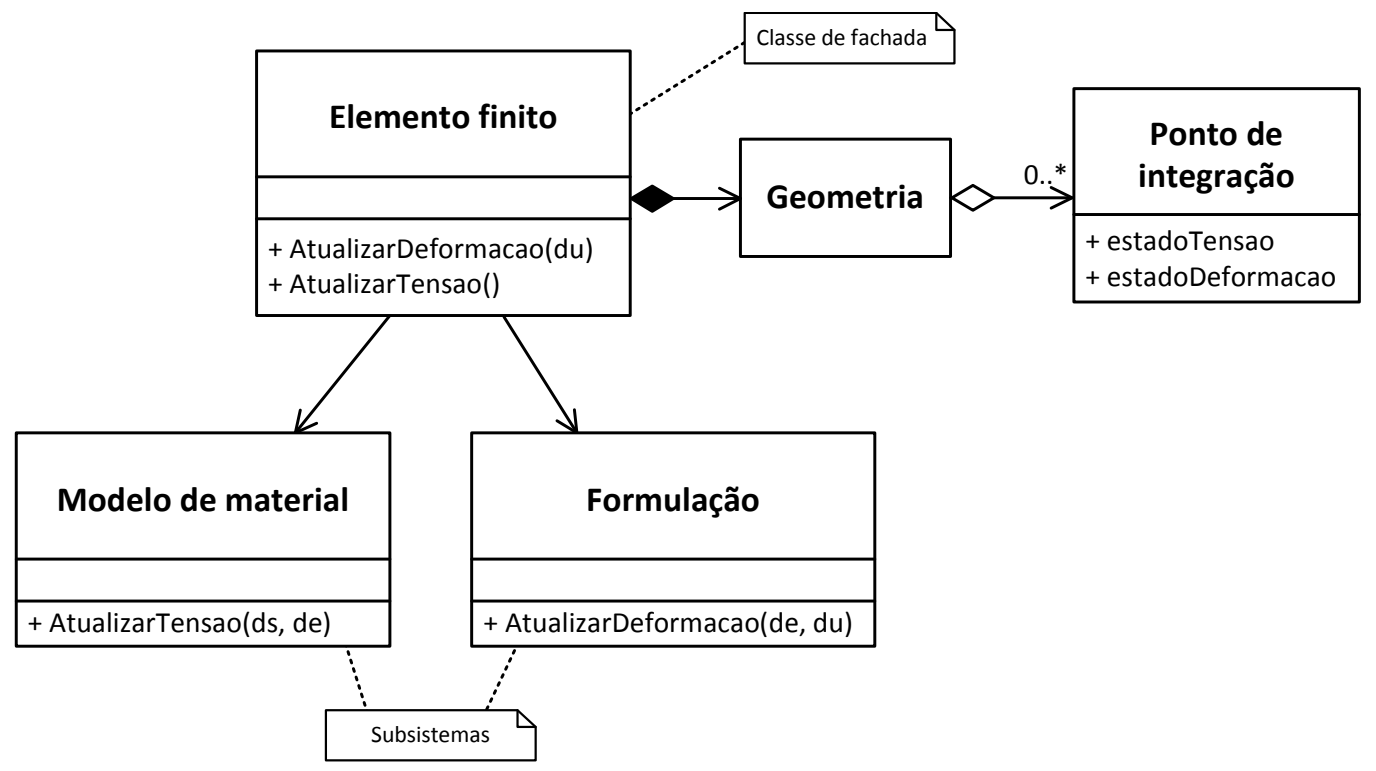

Figura 3.14 Padrão de design: fachada.

\footnotetext{
${ }^{4}$ Do inglês, design patterns.
} 
Os objetos clientes da classe Elemento finito, apresentada na Figura 3.14, não podem acessar diretamente o modelo de material ou a formulação do elemento, devendo ser requisitadas as operações através da fachada. Ao mesmo tempo em que impede o acesso direto aos subsistemas (e, assim, impedindo de acoplamentos com essas classes sejam criados), Elemento finito oferece uma simplificação das comunicações. A atualização da deformação, por exemplo, é feita em todos os pontos de integração, armazenados através das classes Geometria e Ponto de integração. A própria fachada se incumbe de verificar a existência dos pontos e atualiza conforme necessário. Analogamente, a tensão é atualizada através do modelo de material, tal que o estado de tensão de cada ponto é atualizado, informando o estado de deformação correspondente.

\subsubsection{Fábrica abstrata}

Uma fábrica é uma classe especializada em criar instâncias de uma determinada classe. O padrão fábrica abstrata (do inglês, abstract factory) sugere uma solução para problemas quando se torna necessário criar objetos de múltiplas classes, mas todos tem um tema em comum (isto é, uma superclasse comum). A Figura 3.15 oferece um exemplo para demonstrar o problema.

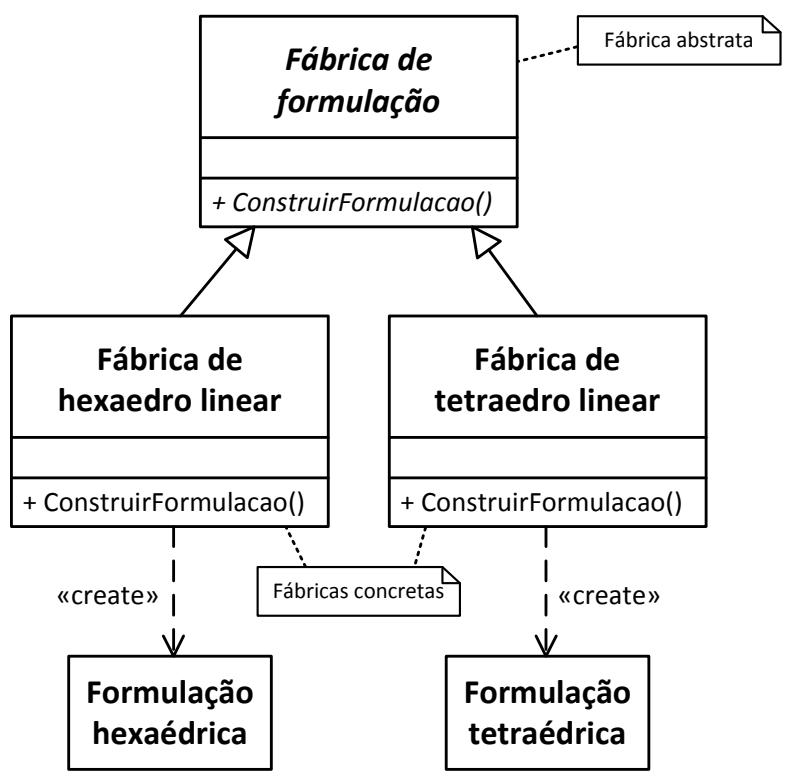

Figura 3.15 Padrão de design: fábrica abstrata.

No processo de leitura de um elemento finito, supondo sua composição dada pelas classes da Fig. 3.14, a construção da formulação do elemento não deve ser desempenhada pelas classes de leitura de dados e tampouco pela própria formulação, 
pois é uma tarefa distinta e de nível de abstração diferente das responsabilidades que já detém. Assim, uma fábrica é designada para a criação das intâncias de uma formulação em particular. A fábrica abstrata define uma interface comum, permitindo que clientes tenham compatibilidade para uso de qualquer fábrica concreta descendente.

\subsubsection{Construtor}

No problema apresentado anteriormente, ainda é necessário remover do sistema de leitura do modelo numérico a responsabilidade de escolher qual fábrica concreta utilizar, de acordo com as informações obtidas no arquivo de entrada. Para tanto, o padrão Construtor (do inglês, Builder) fornece uma solução plausível (Fig. 3.16).

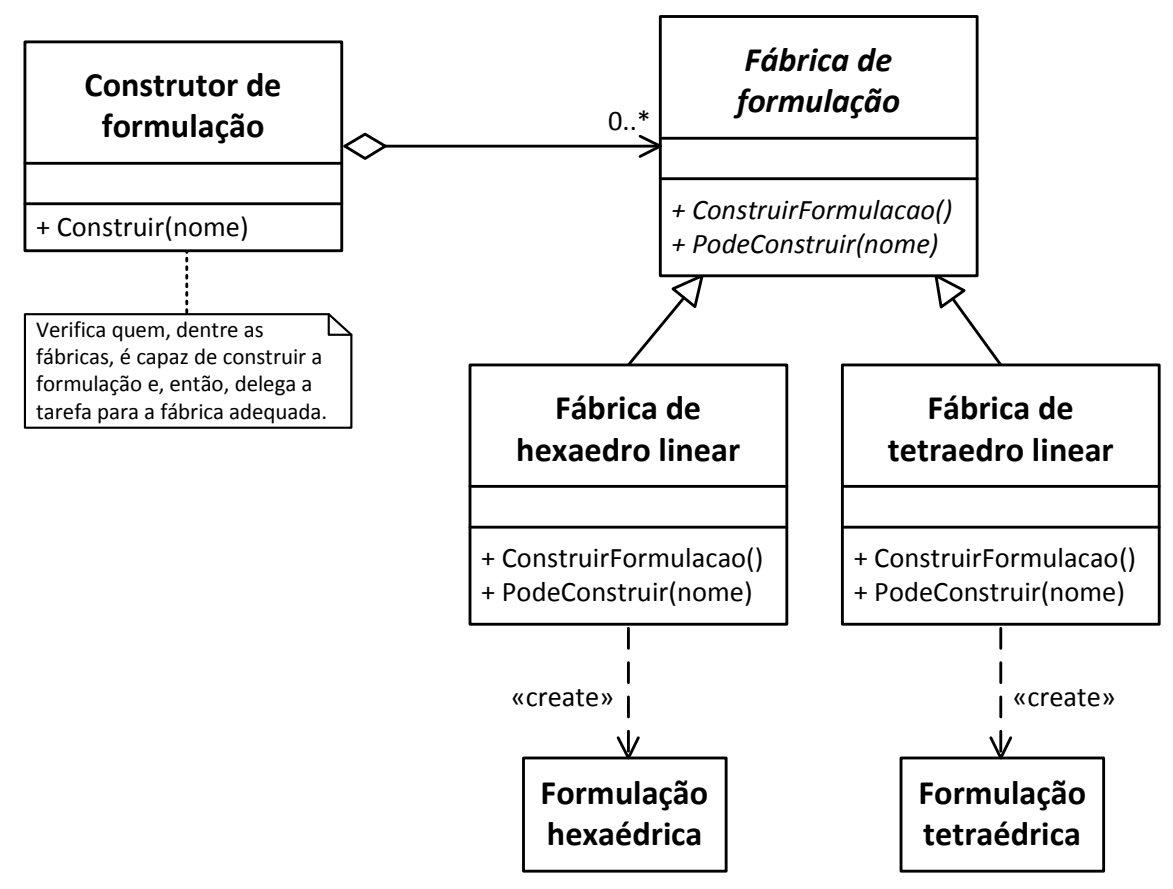

Figura 3.16 Padrão de design: construtor.

Para a solução, a fábrica abstrata (e, consequentemente, as versões concretas) foi modificada, incluindo a operação PodeConstruir(), que retorna se a fábrica pode construir a formulação especificada pelo parâmetro nome. A classe construtora, Construtor de formulação, detém uma lista de referências para todas as fábricas de formulação suportadas pelo programa. Quando lhe é solicitada a criação de uma formulação, identificada por um nome, é feita uma pesquisa sobre qual fábrica concreta é capaz de atender ao pedido e, assim, encaminhar o processamento para a instância correta. 


\subsubsection{Estratégia}

O padrão estratégia (do original, strategy) oferece uma forma de variar o algoritmo de uma classe sem que, para isso, seja criada uma extensa lista de subclasses para cada possibilidade de variação. Um modelo de material, por exemplo, pode ser descrito como uma combinação de diferentes relações constitutivas. A multiplicidade de leis elásticas, plásticas e critérios de falha remetem a um número considerável de possibillidades de modelos.

Empregando-se o padrão estratégia, como mostra a Figura 3.17, um modelo de material é descrito por um conjunto de algoritmos abstratos. As classes abstratas Lei elástica, Lei de plasticidade e Critério de falha definem, em conjunto, as relações constitutivas do modelo de material. A interface abstrata comum é herdada e implementada nas estratégias concretas (as subclasses).

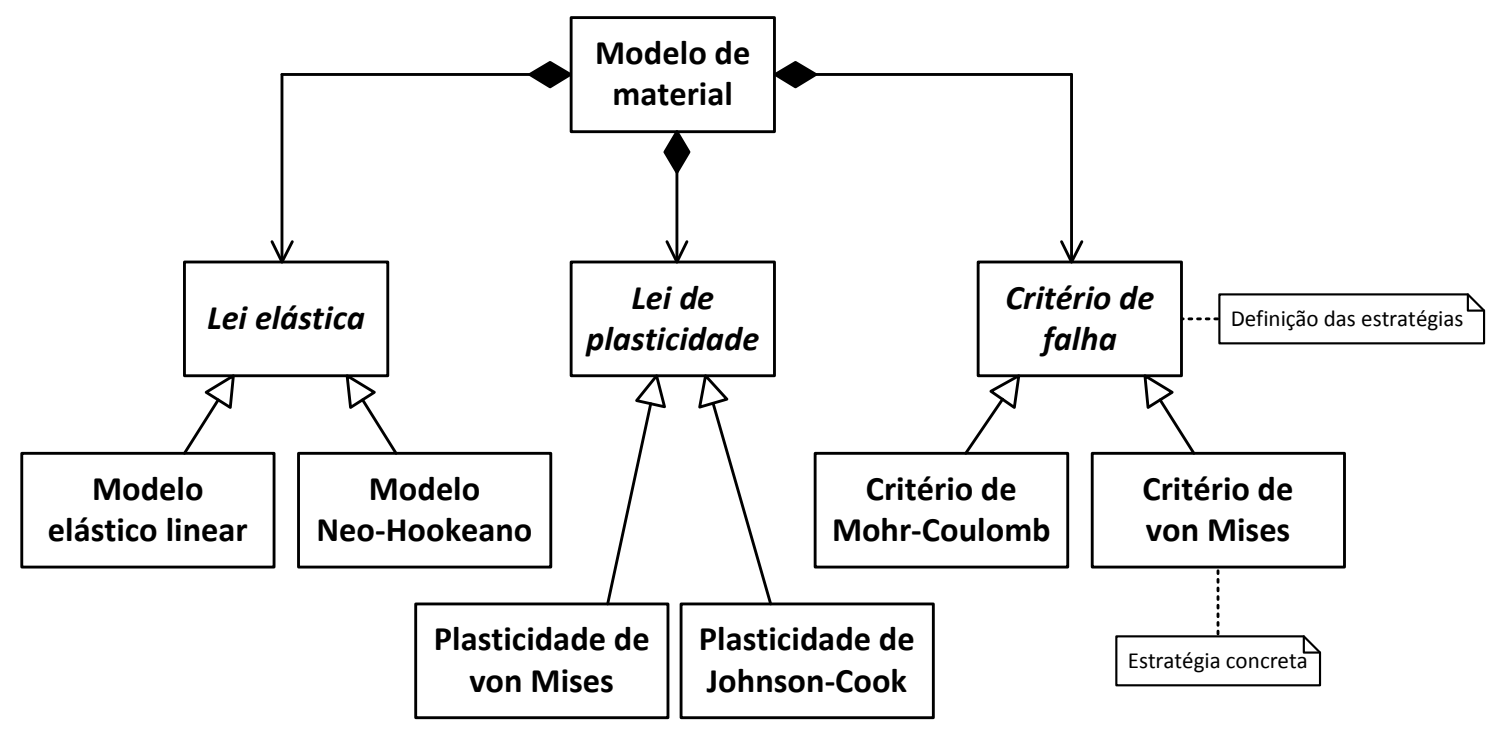

Figura 3.17 Padrão de design: estratégia.

\subsubsection{Comando}

O padrão comando (do inglês, command) descreve o encapsulamento de uma ação em um objeto, juntamente com as informações necessárias para concretizá-la. Esta abordagem é útil quando se deseja que ela seja disparada por um objeto cuja natureza de sua responsabilidade o impede que detenha informações a respeito da operação.

Por exemplo, suponha a execução do algoritmo de um solver em GPU. Antes que as computações na aceleradora gráfica tenham efeito, é necessário inicializar os 
dados na memória do dispositivo. Para evitar que o solver detenha conhecimento sobre a manipulação do hardware, os parâmetros e instruções para sequência de inicialização são fornecidos numa instância da classe de comando, conforme ilustra a Figura 3.18 .

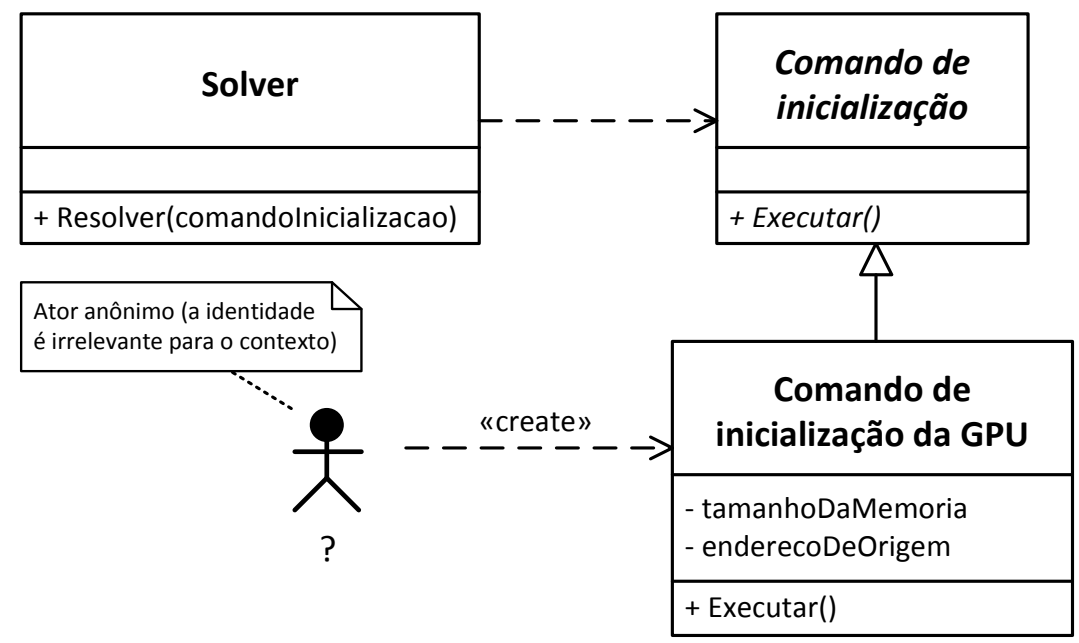

Figura 3.18 Padrão de design: comando.

Na figura, o comando é criado e tem seus parâmetros inicializados por um terceiro objeto, cuja responsabilidade é coordenar a utilização do hardware gráfico (representado pelo ator anônimo na figura). Ao executar o solver através do método Resolver(), o comando de inicialização lhe é passado como parâmetro. Como todo o processo de configuração do comando foi realizado anteriormente, a classe Solver não está sujeita a acoplamentos que poderiam ser causados pela dependência tecnológica da GPU.

\subsubsection{Cadeia de responsabilidades}

Na coleta de resultados de uma análise de elementos finitos, as opções de saída selecionadas pelo usuário torna o sistema de gravação do arquivo de saída relativamente complexo. Por exemplo, num dado momento, o usuário analista pode optar gravar apenas os resultados de tensão e deformação da malha. Para um programa que define uma classe coletora para essas e outras variáveis, é necessário verificar a quem interessa os resultados obtidos do modelo numérico, sem se atrelar ao conhecimento prévio da identidade da classe (pois isto é uma informação relativa à estrutura do programa, indesejável para as práticas de OO). A Figura 3.19 promove uma solução através do padrão cadeia de responsabilidade (do inglês, chain of responsibility). 


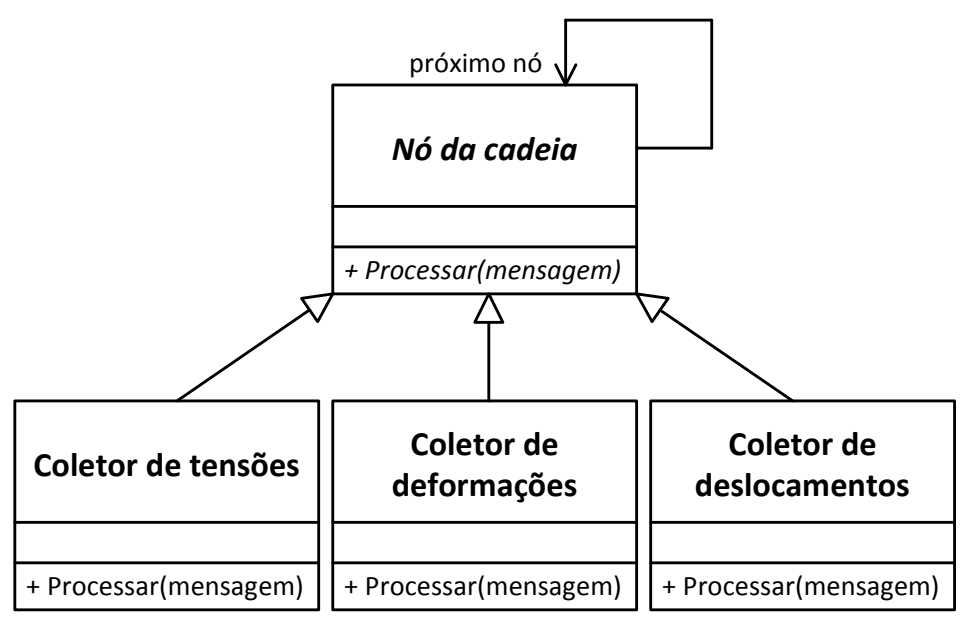

Figura 3.19 Padrão de design: cadeia de responsabilidade.

Na solução apresentada, cada tipo de coletor é definido como descendente da classe Nó da cadeia. Diversas subclasses podem ser conectadas entre si, como elos de uma corrente, denotado pela associação recursiva na superclasse.

Quando são obtidos os resultados do modelo numérico, o solver dispara uma mensagem que atinge o primeiro nó da cadeia, através do método Processar(), que, por sua vez, verifica se é de seu interesse o processamento da informação. Em caso positivo, a mensagem é processada localmente e a execução da coleta é encerrada ali. Do contrário, a mensagem é encaminhada para o próximo nó e o processo se repete.

\subsection{Diagramas UML}

Através do UML, o desenvolvedor pode destacar um trecho específico do programa e representá-lo através de diagramas. De acordo com a intenção, diferentes tipos de diagramas enfatizam determinados aspectos do software. A seguir são brevemente comentados os mais utilizados neste trabalho. Uma discussão mais detalhada é apresentada em Eriksson et al. [80].

\subsubsection{Vista estática}

A visão estática do programa, dada pelas classes e conceitos do domínio, mostram como o software é organizado e como as responsabilidades são distribuídas e conectadas. Dois diagramas são importantes nesta categoria, o modelo de domínio e o diagrama de classes. 


\section{Modelo de domínio}

O modelo de domínio ofere uma representação visual dos conceitos do domínio do problema e as interações entre eles, estando ausente, qualquer aspecto tecnológico de implementação. Denotados por classes conceituais e respectivas associações, as informações presentes no diagrama ilustram o que poderia ser especificado textualmente e, por isso, recebe o nome de "dicionário visual".

A Figura 3.20 oferece um pequeno exemplo do diagrama. Exemplos mais completos podem ser vistos para o modelo de domínio do programa proposto neste trabalho, ilustrado nas Figuras 5.85.11.

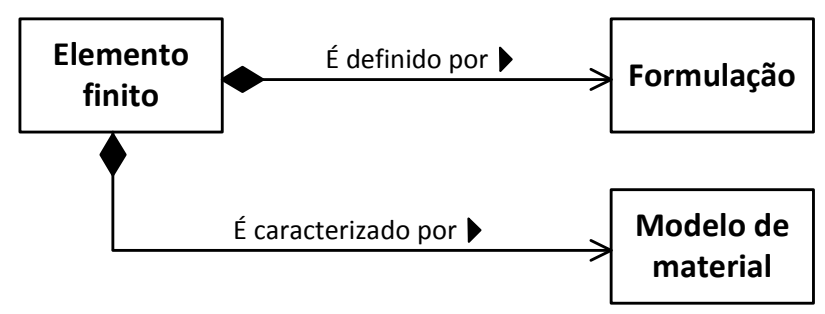

Figura 3.20 Exemplo de modelo de domínio.

\section{Diagrama de classes}

O diagrama de classes é a principal representação da visão estática do programa, onde são representadas as diversas entidades que participam da computação e suas relações. No desenvolvimento de um software, múltiplos diagramas são usados para dar ênfase a diferentes aspectos do software. As Figuras 3.14 3.19 apresentam alguns exemplos.

\subsubsection{Vista dinâmica}

A visão dinâmica do programa é dada pelos objetos e suas interações. Diagramas UML, como o de interação, sequência e de atividadades, ilustram as comunicações entre os objetos e a ordem em que elas ocorrem. A seguir, cada um deles é brevemente apresentado.

\section{Diagrama de interação}

O diagrama de interação oferece uma forma de representação para computações simples e sequenciais, normalmente envolvendo poucos objetos. A Figura 3.21 traz um exemplo. 


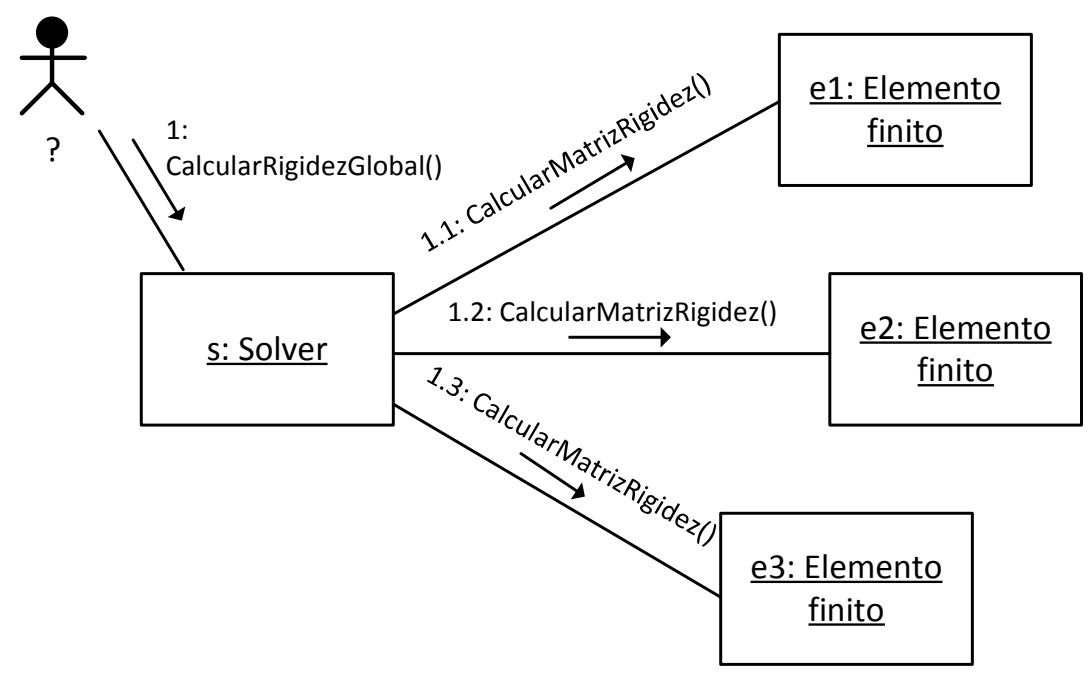

Figura 3.21 Exemplo de diagrama de interação.

Na figura, as ligações entre os objetos são representadas por segmentos de reta sólidos. As comunicações disparadas são denotadas pelas setas acima das ligações, com origem no solicitante e apontando para o executor da ação. Juntamente, é identificado o nome da operação solicitada e o seu número de ordem, que mostra a sequência em que as operações ocorrem. Por exemplo, na Figura 3.21, a comunicação 1.2 ocorre após a 1.1 e ambas são executadas em função do disparo da operação 1 , CalcularRigidezGlobal().

\section{Diagrama de sequência}

Diagramas de sequência podem ser aplicados da mesma forma que os diagramas de interação, mas oferecem uma visão mais clara do tempo de vida de cada operação e quais operações estão pendentes num determinado instante de tempo. A Figura 3.22 oferece um exemplo.

No diagrama, o tempo ocorre de cima para baixo. Os objetos são posicionados verticalmente no instante em que eles passam a existir (isto é, são criados). No caso da figura, todos os objetos existem desde um momento anterior não representado. A duração da vida de um objeto é identificada pela linha de vida, tal que o objeto é destruído quando ela termina e é marcada com um "x". Do contrário, o tempo de vida é indefinido (ou seja, o objeto não é destruído na situação representada pelo diagrama).

O cenário é identificado pelo rótulo da moldura externa do diagrama. A computação tem início a partir da mensagem CacularForcasInternas (mais ao topo da figura), disparada por um ator desconhecido. A duração dessa mensagem é mar- 


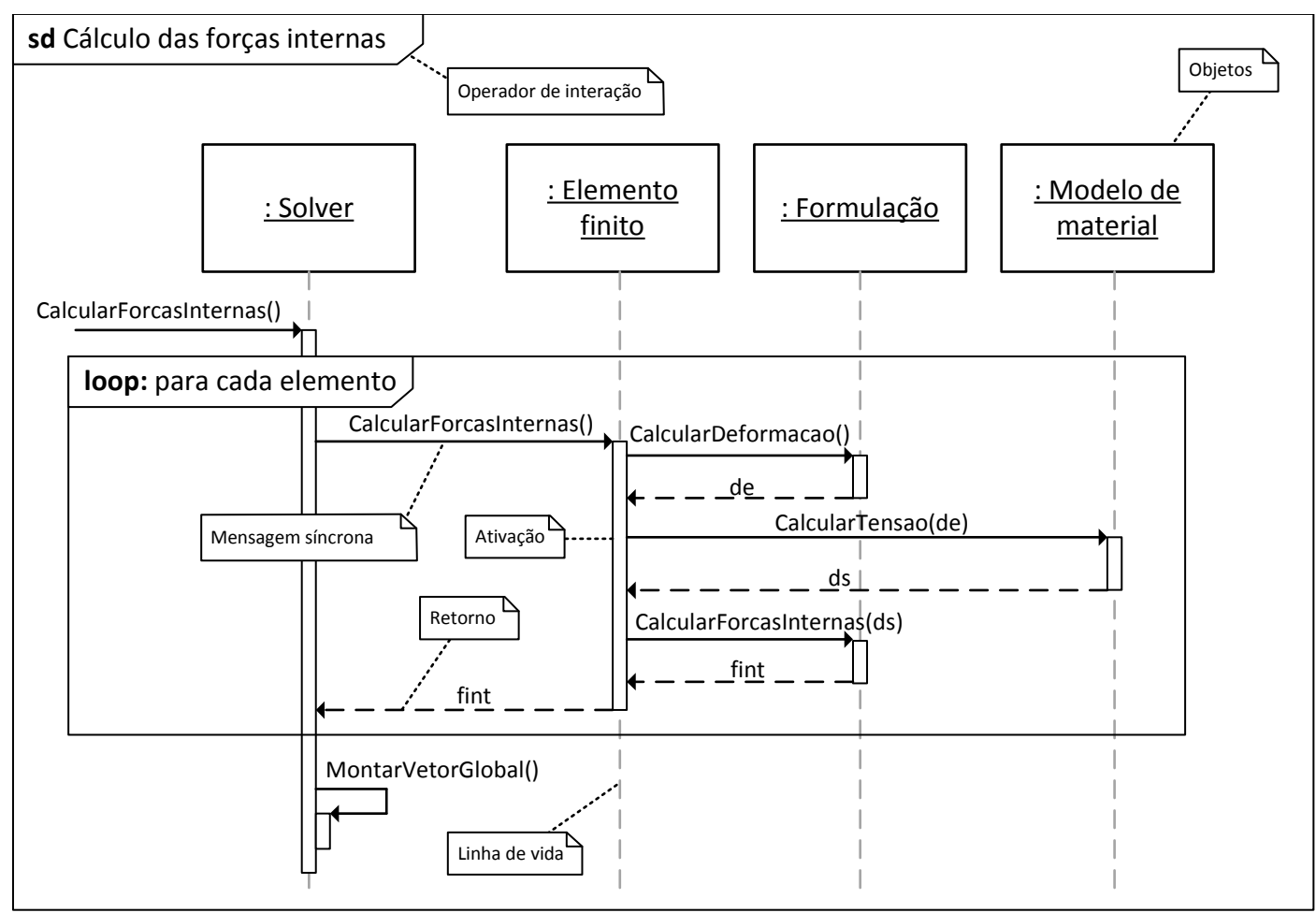

Figura 3.22 Exemplo de diagrama de sequência.

cada por um retângulo logo abaixo dela, na linha de vida do objeto de Solver, a caixa de ativação. O seu comprimento é determinado pelo tempo que leva para a execução da mensagem ser concluída (sem escala).

No exemplo da Figura 3.22, a solicitação do cálculo das forças internas resulta num encadeamento de mensagens disparadas a outros objetos. Enquanto essas computações não terminam, a mensagem original é mantida pendente. Quando a execução é concluída, marca-se o retorno do controle, isto é, a execução é retomada para o objeto que a seta de retorno aponta, naquele instante de tempo. Opcionalmente, alguma informação pode ser devolvida juntamente com o controle.

Operandos podem denotar uma execução condicionada a determinados critérios. No exemplo, um laço que percorre todos os elementos da malha faz com que o objeto de Solver calcule as forças internas de todos os elementos, a fim de serem usadas para o cálculo do vetor global.

\section{Diagrama de atividades}

Diagramas de atividade (Figura 3.23) apresentam informações a respeito de uma execução e suas consequências. Podem ser empregados em diferentes propósitos, 
como na descrição detalhada de uma operação, demonstrar a operação geral de um objeto, ilustrar a execução de um subsistema do programa, entre outros.

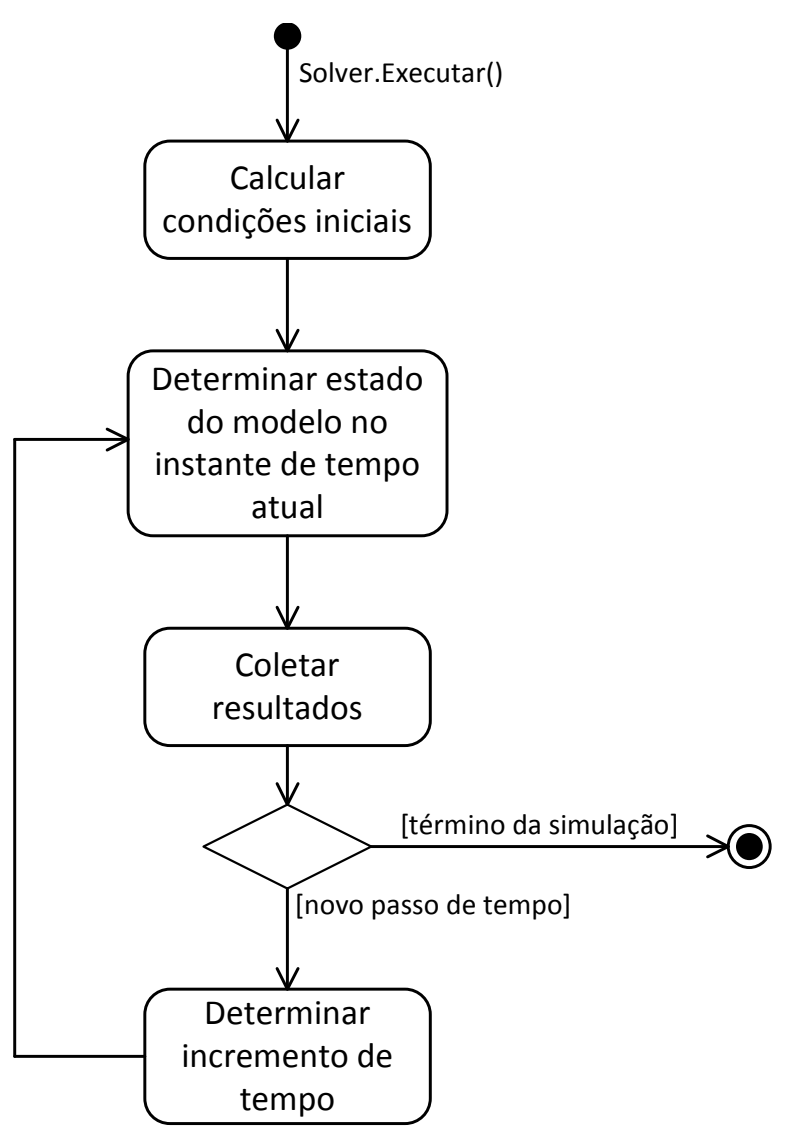

Figura 3.23 Exemplo de diagrama de atividade.

No exemplo, a execução tem início com a invocação da operação Executar() da instância de Solver. A partir de então, as atividades descritas no diagrama são executadas de acordo com o fluxo dado pelas setas. A execução pode ser modificada através de condições, representadas pelo losango e pelos critérios entre colchetes ([ ]). Na figura, o término da atividade ocorre quando se atinge a condição "término da simulação".

Deve-se observar que apesar da similaridade, um diagrama de atividades não tem a mesma função que o fluxograma. Ao contrário deste, são descritas apenas as operações gerais e estados pelos quais um objeto (ou sistema) atravessa. Detalhes de implementação (como, por exemplo, a condição exata que determina o término da simulação) não são o foco da representação. 


\subsection{Outras observações}

Entender os principais conceitos de orientação a objetos permite a elaboração de uma estrutura sólida para o desenvolvimento de um programa de elementos finitos. No entanto, a aplicação da ferramenta não implica na obtenção direta de aspectos tão desejáveis no sistema, como flexibilidade, escalabilidade e robustez. Oferece-se, sim, meios pelos quais o engenheiro de software consegue decompor o problema em estruturas mais simples e, utilizando da linguagem própria do domínio, compreender e determinar uma arquitetura de solução em direção a esses quesitos.

O uso de linguagens de modelagem, como o UML, permite a representação gráfica dessas estruturas e discursar sobre seu funcionamento, usando um idioma padronizado e aceito por todos os desenvolvedores de software. As ferramentas oferecidas permitem o compartilhamento de ideias, fornecem instruções sobre o funcionamento do programa, expressam requisitos e modelam contratos de utilização das funcionalidades do sistema. Para uma metodologia de desenvolvimento, o UML é um típico artefato essencial para as etapas de análise e design do problema. 



\section{CAPÍTULO 4}

\section{Método de desenvolvimento}

Em sua análise sobre projetos de software, Brooks Jr. [38] aborda dois tópicos que representam tarefas essenciais na elaboração do sistema: o levantamento de requisitos de software e a necessidade de crescimento orgânico do programa, isto é, permitir que ele seja desenvolvido adicionando-se, aos poucos, cada vez mais funções à medida que são executadas, usadas e testadas. Essas são necessidades comuns a todos os projetos de software, cuja modo de abordagem influenciará o sucesso do desenvolvimento.

Além disso, no desenvolvimento de um software, há a necessidade da adoção de políticas que permitam a construção do sistema em tempo e custo razoáveis. Para sistemas maiores, isso também significa o emprego estratégico de equipes de desenvolvimento equilibradas e ferramentas que estimulem maior e melhor comunicação entre elas. Por último, tem-se também a necessidade de oferecer suporte e estender a vida útil do programa, que deve então ser de fácil manutenção. Mesmo no desenvolvimento solo, é importante que seja adotado um conjunto mínimo de metodologias para delimitar o domínio do problema, obter melhor controle sobre o processo e fazer emergir os resultados de forma rápida e planejada.

Neste capítulo é apresentado o método de desenvolvimento adotado para a implementação do software de elementos finitos, quais mecanismos foram usados para a obtenção de resultados e a influência da análise dos resultados na dinâmica do desenvolvimento. A definição do ambiente de desenvolvimento, importante para a realização das atividades propostas no método, é comentada ao final. 


\subsection{Problemática}

Adotar uma estratégia de desenvolvimento mantém o ciclo de desenvolvimento do programa estável, previsível e sob o controle do desenvolvedor. Não há uma regra geral ou padrão pré-estabelecida que garanta o sucesso do projeto, cunhado por Brooks Jr. [38] como a "bala de prata". A estratégia adotada deve estar alinhada com as necessidades latentes do projeto.

É comum que projetos falhem pela escolha incorreta de metodologias, ou pela total ausência de uma. Em certos casos, o desenvolvimento se torna extretamente burocrático, com grande quantidade de documentação a ser gerada; ou ele é prático demais, com uma situação contrastante com a anterior [38, 205]. Em aplicações de maior porte, tal como é o caso de softwares de elementos finitos, a adoção de uma metodologia adequada evita que uma série de problemas ocorram, apresentados a seguir.

Código caduco. Em aplicações maiores, é comum que aquilo que foi codificado nas primeiras iterações do desenvolvimento sejam esquecidas pelo programador à medida que se avança sobre o programa. Para algumas funcionalidades, nem sempre documentação inline nos arquivos-fontes do software são suficientes para esclarecer o seu funcionamento.

Código monolítico. Em certas ocasiões, a forma como a aplicação é desenvolvida impede que ela seja desmembrada em partes. Como consequência, com o decorrer do tempo, a codificação torna-se consideravelmente difícil, uma vez que, para testar uma funcionalidade, faz-se necessário concluir a priori outras funções do programa. Num pior caso, essas funções dependem da implementação antecipada de outros serviços da aplicação (efeito em cadeia).

Ilha de conhecimento. Algumas vezes intensificado pela ocorrência de códigos monolíticos, o efeito de ilha de conhecimento surge quando apenas um conjunto restrito de programadores da equipe é responsável pela maior parte da implementação das funcionalidades do programa [111]. Na programação solo, são consequências deste efeito a impossibilidade de estender o código produzido por um programador anterior e a dificuldade em transmitir a ideia expressa no código (algoritmo), gerando produções dúbias e desnecessariamente complexas.

Código estático. Não prever modificações ou extensões do programa é um erro comum no desenvolvimento. Nesta situação, é custosa a recodificação e, em alguns casos, impossível [111]. As extensões não necessariamente ocorrem após o lançamento da versão de produção do software. Elas também surgem ao longo do desenvolvimento, conforme um melhor entendimento da aplicação (e do problema) é 
obtido, ou mesmo quando surge um requisito importante esquecido ou não previsto nas etapas preliminares de planejamento.

Paralisia na etapa de análise. Em contraste com os itens anteriores, quando se adota um método de desenvolvimento no qual existe um excesso de requisitos a serem cumpridos e documentações a serem geradas, ocorre a paralisia na etapa de análise [205]. Neste cenário, o desenvolvimento entra aos poucos em colapso, devido a quantidade de processos a serem cumpridos, atrasando entregas de funcionalidades, desmotivando a equipe e gradativamente reduzindo o tempo gasto no desenvolvimento efetivo do programa.

\subsection{Requisitos do método de desenvolvimento}

Para o contexto deste trabalho, a adoção de uma metodologia possui grande relevância para promover um melhor direcionamento do desenvolvimento do programa aos objetivos da pesquisa, garantindo o rastreamento da evolução do projeto e assegurando um melhor controle do processo.

Observa-se que é importante o atendimento a uma série de requisitos, de forma que o papel da metodologia como orientação para o desenvolvimento seja atingido. A seguir, são apresentados os requisitos estabelecidos para a modelagem do método.

Revisão periódica do problema. É importante que no método hajam oportunidades para se rever o modelo conceitual sendo seguido. Em especial nos problemas maiores, é comum que novos conceitos sejam aprendidos e que ocorram enganos ao longo do projeto. Ainda, a dinâmica do desenvolvimento científico requer que conceitos sejam atualizados ao longo do tempo e, como consequência, reestruturações tornam-se comuns. Laços de feedback e pausas no desenvolvimento para debates são alguns dos mecanismos que auxiliam a guiar o método de desenvolvimento nessa direção.

Flexibilidade. A flexibilidade é outro mecanismo facilitador para o dinamismo da pesquisa. A estratégia adotada deve possuir mais caráter de orientação do que uma política ou lei governante [205]. Em certas ocasiões, etapas do processo podem ser omitidas quando seu propósito de existência não pode ser bem definido, como na codificação de funcionalidades triviais. No entanto, omitir etapas com a única finalidade de acelerar a codificação e entrega de resultados pode ser prejudicial ao desenvolvimento e, portanto, a escolha pela redução de etapas exige cautela. Em fases mais delicadas do processo, onde o desenvedor possui pouca aptidão para a modelagem do sistema, o método deve permitir que mudanças sejam feitas a 
pequenos passos, de forma que permita o desenvolvedor reestabelecer a sua segurança e controle sobre o projeto.

Rastreabilidade. Resultados de testes, confronto dos requisitos e métricas de software são alguns exemplos de métodos de rastreio que identificam a qualidade do código e permitem observar a presença de um correto direcionamento aos objetivos. A sequência de passos sugeridos pelo método deve mostrar, de forma clara, que é possível apresentar resultados concretos após a execução das etapas e que, então, a verificação da qualidade do software, o confrontamento com os requisitos de software e a validação dos conceitos do problema é praticável e simples. Do ponto de vista da gestão, a rastreabilidade do projeto gera motivação no desenvolvimento, pois é simples verificar o que já foi realizado, gerando satisfação, torna o abstrato (o software enquanto ideia) em concreto (resultados) e oferece perspectiva ao projeto, proporcionando motivação, fechando um ciclo positivo.

Eficiência. Define-se a eficiência do método como a sua capacidade de orientar o desenvolvimento, de forma clara e objetiva, com a menor sequência possível de passos e artefatos (documentações). É desejável que o método requira uma produção mínima de artefatos para rastreamento e documentação, de forma concisa e autosuficiente.

\subsection{Características da metodologia}

Atendendo aos requisitos estabelecidos, o método elaborado encoraja o desenvolvimento do sistema usando apenas um conjunto mínimo e suficiente de documentações, evitando paralisações na etapa de análise. O fluxo de trabalho se divide em fases de análise (o que fazer), design do projeto (como fazer) e produção, buscando promover a conexão do domínio do problema com os aspectos tecnológicos da pesquisa. A seguir, são apresentadas as principais características do método.

Processo iterativo com feedback $O$ método elaborado aborda o problema de forma iterativa, permitindo que ele seja decomposto em partes menores e apenas pequenas operações sejam analisadas por vez. Dessa forma, a introdução de mudanças, causadas pela melhor compreensão do problema ou pela inclusão de novas tecnologias, por exemplo, ocorre mais cedo, aumentando o dinamismo do projeto;

Convergência e desenvolvimento ativo Durante uma iteração, apenas um objetivo principal é observado ao longo dos procedimentos de planejamento, modelagem e implementação. Isso auxilia a manter o foco no desenvolvi- 
mento, acelerando a finalização da iteração. Contudo, durante a iteração, podem ocorrer dúvidas, sugestões ou outras questões relativas a alguma outra funcionalidade fora do objetivo, mas relacionada à atividade atual. Neste caso, faz-se uso de listas de tarefas, que evitam que essas percepções sejam esquecidas, sendo então mais tarde analisadas;

Prototipagem rápida Iterações para prototipagem rápida e unidades de teste são usadas para a verificação rápida de conceitos e de código. Ambos os mecanismos tem como finalidade acelerar as etapas críticas do desenvolvimento. Em específico, as unidades de testes provêm a validação de resultados obtidos no projeto.

\subsection{Definições}

Para o entendimento da estratégia adotada, faz-se necessário apresentar a terminologia adotada para representar as diversas ações que ocorrem no método. Os principais termos e relações são ilustrados na Figura 4.1.

Fase é o conjunto de atividades relacionadas que delineiam um estado no método.

Iteração é o ato de se avançar por todas as fases do método, ligadas em um ciclo, até se alcançar novamente a fase inicial ou a condição de término (normalmente a entrega de algum resultado esperado).

Passo é a subdivisão de uma fase, que contém, pelo menos, uma atividade a ser realizada. Dentro de uma fase, não é possível a execução simultânea de passos diferentes ou várias instâncias de um mesmo.

Corrida é a execução cíclica e sequencial de passos de uma mesma fase.

Característica primária é um recurso do programa de grande relevância para o seu funcionamento ou que, com a sua ausência, a cobertura dos objetivos estabelecidos é reduzida.

Característica secundária é um recurso do programa cuja ausência não causa impacto significativo ao programa, quando observado isoladamente.

Checkpoint é um conjunto de resultados previamente estabelecidos que precisam ser atingidos em um determinado ponto da iteração. Normalmente, é um conjunto reduzido (em relação ao objetivo da iteração) e se restringe a resolver questões relacionadas a características secundárias. 


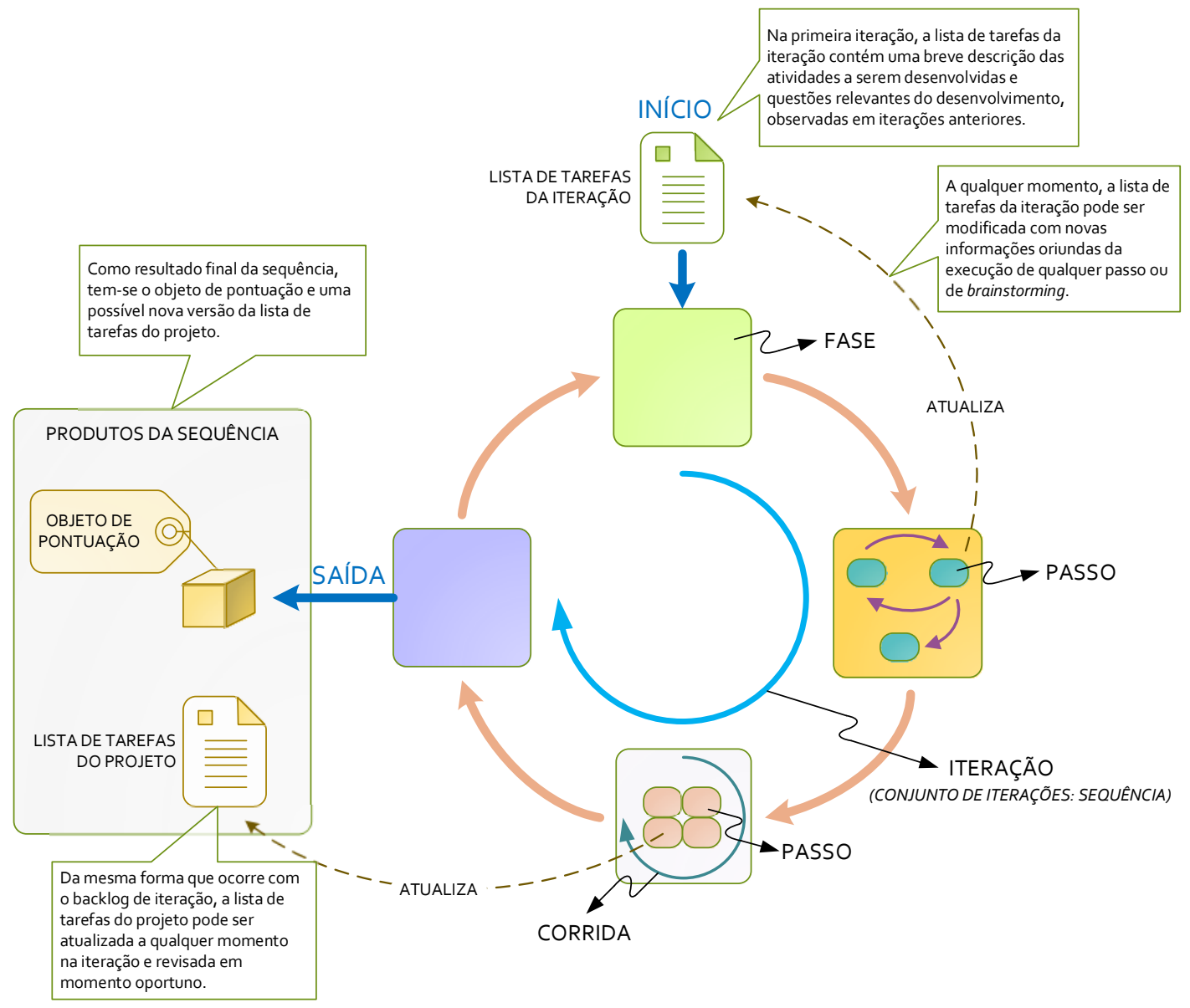

Figura 4.1 Relação dos principais itens do método de desenvolvimento.

Milestone é o nome dado a um estado do desenvolvimento geral da aplicação, determinado pela realização de um conjunto de atividades bem definidas.

Sequência é o conjunto de iterações sucessivas efetuadas para a entrega de um objeto de pontuação.

Objeto de pontuação é qualquer conjunto de checkpoints que precisam ser atingidos para o término da sequência de iterações.

Lista de tarefas da iteração é uma lista de rascunho para enumeração de atividades a serem cumpridas até a conclusão de um objeto de pontuação. Um item concluído não é removido (apagado) da lista, mas desabilitado (riscado), para permitir o rastreio posterior de eventuais falhas.

Lista de tarefas do projeto é uma outra lista de rascunho, com os mesmos critérios de uso, onde são enumeradas questões do projeto que precisam ser discutidas durante a fase de planejamento. 


\subsection{Fases de desenvolvimento}

A iteração do método de desenvolvimento é composta de três fases gerais (Figura 4.2), que dinstinguem as diferentes etapas do desenvolvimento: planejamento, modelagem e produção. Nesta seção, são descritas as atividades de cada uma dessas fases.

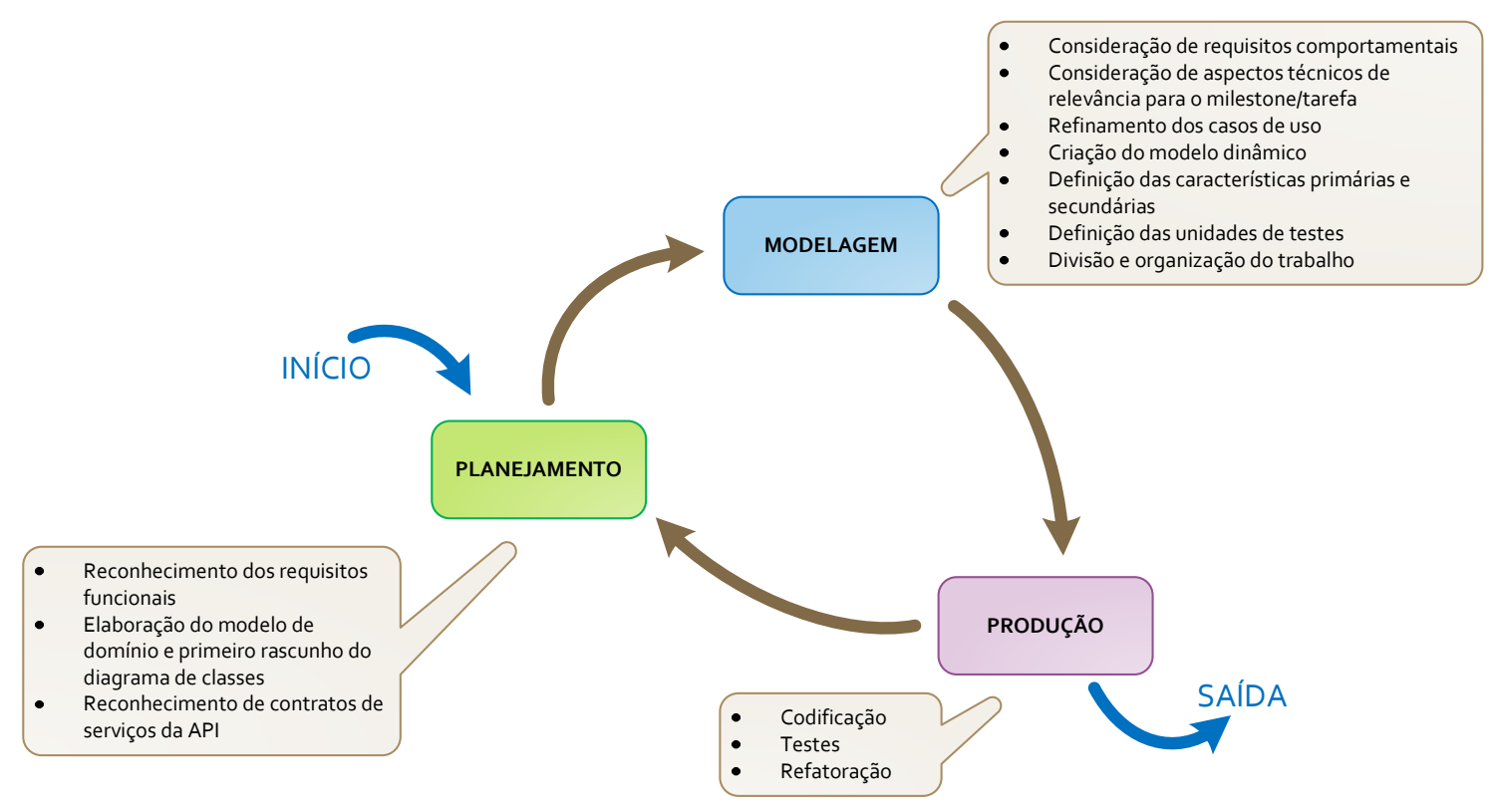

Figura 4.2 Fases do método de desenvolvimento.

\subsubsection{Início da iteração}

No início da iteração, retira-se da lista de tarefas do projeto as informações relevantes para a realização do objeto de pontuação. Essas informações são inseridas no lista de tarefas da iteração e devem ser verificadas ao longo da sequência.

\subsubsection{Planejamento}

O objetivo da fase de planejamento é fornecer uma análise de domínio dos requisitos funcionais e da estrutura da API do programa para que o software possa atender às especificações do objeto de pontuação. Os passos desta fase são ilustrados na Figura 4.3 e discutidos a seguir. 


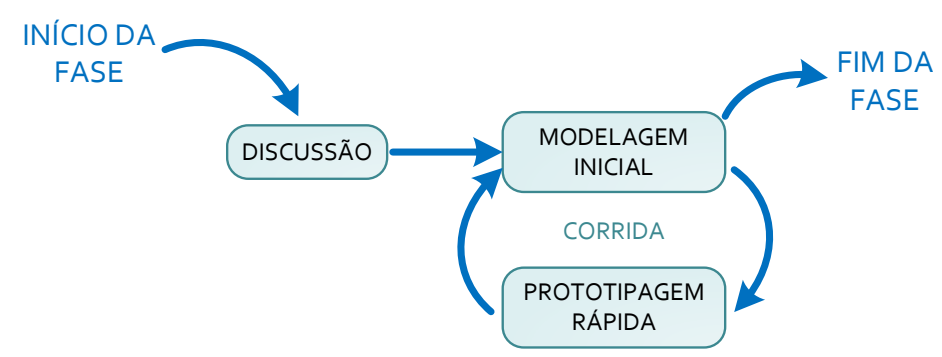

Figura 4.3 Sequência de passos da fase de planejamento.

\section{Discussão}

As informações relevantes para discussão na fase são apresentadas na lista de tarefas da iteração. Obrigatoriamente, o objeto de pontuação é um dos itens da lista. Outras anotações provenientes de iterações anteriores ou de percepções previamente anotadas na lista de tarefas do projeto também são enumeradas. A partir desta entrada, são verificados os requisitos que devem ser cumpridos nesta etapa, declarados usando apenas termos do domínio do problema. Aspectos operacionais, tais como tipo de algoritmo, eficiência ou termos de APIs, não devem ser utilizados. Caso não seja possível declarar um requisito usando apenas termos do domínio, isso implica que se trata de um requisito operacional e deve ser abordado em atividades posteriores da iteração.

A lista de requisitos é utilizada como orientação geral para o progresso da iteração. Opcionalmente, pode ser necessário validar a correta compreensão do problema através de análise de especificação, elaborando, por exemplo, uma descrição narrativa das atividades, diagramas de processo, casos de uso ou mapa mental.

Espera-se obter como produtos finais deste passo:

- versão inicial ou atualização do modelo de domínio,

- lista de requisitos,

- ideia geral sobre as operações necessáras no programa para que seja cumprido o objeto de pontuação.

\section{Modelagem inicial e prototipagem rápida}

No passo de análise, são refinadas as operações enumeradas no passo anterior. São verificados, para cada operação enumerada no passo anterior, os dados de entrada e de saída de cada operação. Como nenhum aspecto tenológico foi abordado até então, as operações são analisadas como "caixas-pretas", isto é, apenas sua responsabilidade 
é importante, sendo irrelevante a forma como ela é desenvolvida.

A partir dos dados de entrada e de saída das operações, com o auxílio dos critérios de estruturação de objetos (por exemplo, os critérios GRASP ${ }^{1}$ [134]), são descobertos outros objetos participantes das operações e seus relacionamentos. Ao mesmo tempo, tem-se uma ideia geral dos objetos que poderão ser expostos para extensão na API do programa. Se, em algum momento do refinamento, os conceitos envolvidos nas operações não se mostram bem entendidos, então é realizado um protótipo rápido para auxiliar na compreensão dos conceitos e requisitos.

Desta forma, ao final da fase, são obtidos como produtos:

- refinamento do modelo de domínio,

- criação ou atualização do diagrama de classes, contendo as primeiras classes do modelo de negócio para o objetivo específico da iteração, e

- primeira versão dos contratos de serviço da API do programa (relativos às funcionalidades em desenvolvimento).

\subsubsection{Modelagem}

A fase de modelagem introduz os primeiros aspectos operacionais e tecnológicos do problema na análise efetuada na fase de planejamento, além de preparar o ambiente de desenvolvimento para a etapa de design da aplicação (codificação). Na Figura 4.4, são apresentados os passos que compõem a fase.

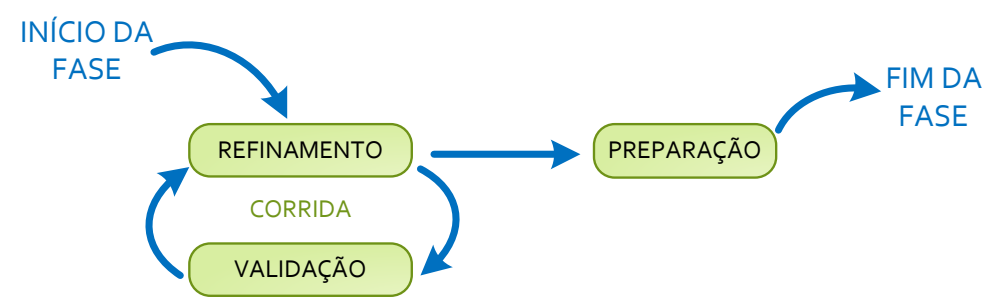

Figura 4.4 Sequência de passos da fase de modelagem.

\section{Refinamento e validação}

No passo de refinamento, são introduzidos aspectos tecnológicos e operacionais relevantes para as operações analisadas na fase anterior. Com o auxílio desses aspectos,

\footnotetext{
${ }^{1}$ Acrônimo para General Responsibility Assignment Software Patterns of Principles
} 
cada operação é detalhada, levando em consideração, por exemplo:

- uso de APIs de terceiros,

- alocação das classes em bibliotecas (componentes),

- escalabilidade necessária para a API do programa, e

- limitações técnicas (de hardware, por exemplo).

Neste passo, busca-se resolver redundâncias no projeto, identificar e eliminar entidades desnecessárias para a aplicação (código morto) e resolver as questões tecnológicas levantadas, por vezes adaptando o modelo desenvolvido. Protótipos ou testes rápidos no passo de validação auxiliam na compreensão de conceitos complexos, quando necessário.

O ciclo de corrida na fase é usado para refinar o modelo conforme necessário para a implementação e os testes. Otimizações globais mais simples são aplicadas nesta fase. Otimizações locais são adiadas para a fase posterior, quando há uma melhor visualização da estrutura do software.

\section{Preparação}

Neste passo, é estipulada a ordem de implementação das operações na fase de produção. Para auxiliar nesta tarefa, são elaborados os seguintes itens:

- lista de checkpoints (atividades de curta duração e de pouca relevância individual), que serão usadas para organizar o desenvolvimento,

- lista de milestones (atividades longas, dependentes de outras atividades para concluir), caso outras atividades fora da sequência precisam ser cumpridas para melhores resultados, e

- lista com propostas de unidades de testes.

A organização lógica do programa em pacotes [80] ou camadas 134 auxiliam na divisão de atividades. Essa forma de organização é comentada no Capítulo 5.

Quando muitas atividades são geradas, o objeto de pontuação é alterado para fragmentá-las em grupos menores, permitindo maior foco no desenvolvimento. Uma nova sequência é criada para esses objetos, incluindo as devidas modificações da lista de tarefas do projeto.

Ao final desta fase, são apresentados os seguintes itens para a fase de produção: 
- modelo de domínio,

- diagrama de classes,

- descrição dinâmica do problema (diagramas de robustez e de sequência),

- análise da estrutura, contendo diagramas de pacotes e de camadas lógicas,

- lista ordenada de checkpoints e milestones a serem cumpridos, e

- definições das unidades de testes.

\subsubsection{Produção}

A fase de produção é composta de três passos recorrentes, ilustrados na Figura 4.5.

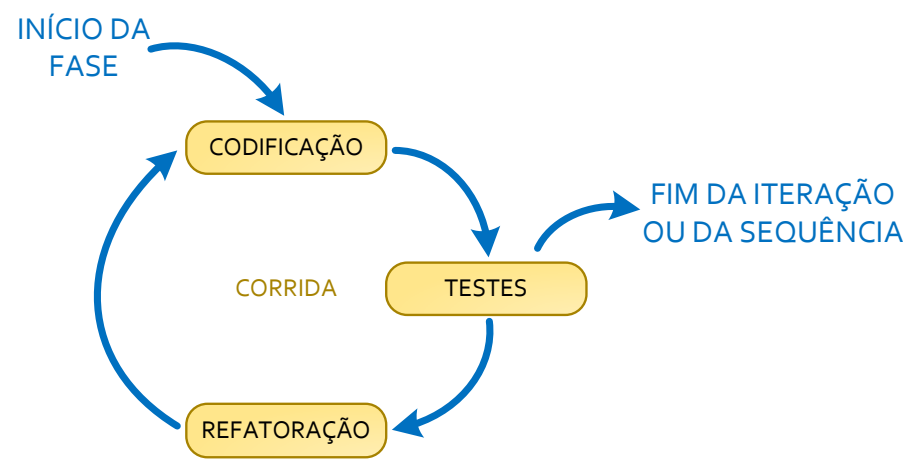

Figura 4.5 Sequência de passos da fase de produção.

Os passos da fase de produção são de curta duração e executados ciclicamente. Cada checkpoint é completado em uma corrida pelos passos da fase. A quantidade de ciclos determina o quão curta será a duração dos passos. O tempo levado está relacionado com a confiança do desenvolvedor em suas habilidades para lidar com o problema em questão. Ainda, passos curtos de codificação auxiliam na escrita de testes mais curtos e com maior cobertura de código, além de adiantar a execução dos testes, permitindo que erros desta ou de fases anteriores sejam detectados mais cedo.

Ainda que as fases de análise e de construção do modelo foram concluídas, deve-se notar que, durante a fase de produção, o modelo da aplicação pode sofrer pequenos refinamentos. A menos que seja encontrado algum erro considerável no modelo, estas modificações podem ocorrer "on the fly", bastando manter o modelo do software atualizado.

Para acelerar o desenvolvimento, pode-se recorrer a implementações falsas Beck [20], unidades de código que imitam, de uma forma controlada, o compor- 
tamento de um sistema, similarmente a um boneco de testes em testes de impacto de veículos. As funcionalidades implementadas são então validadas e corrigidas através da execução das unidades de teste no passo de testes. No passo de refatoração, o código implementado é aprimorado, removendo redundâncias de código e dados usando técnicas de refatoração discutidas por Fowler [88]. As implementações falsas são removidas à medida que as versões verdadeiras são concluídas. A Figura 4.6 ilustra como ocorre a execução dos passos desta fase. Conforme é feita a codificação, a cobertura sobre o conjunto de funcionalidades avança. Após a etapa de refatoração, a robustez e escalabilidade do código é melhorada em detrimento dessa cobertura, redução causada principalmente pela remoção das implementações falsas.

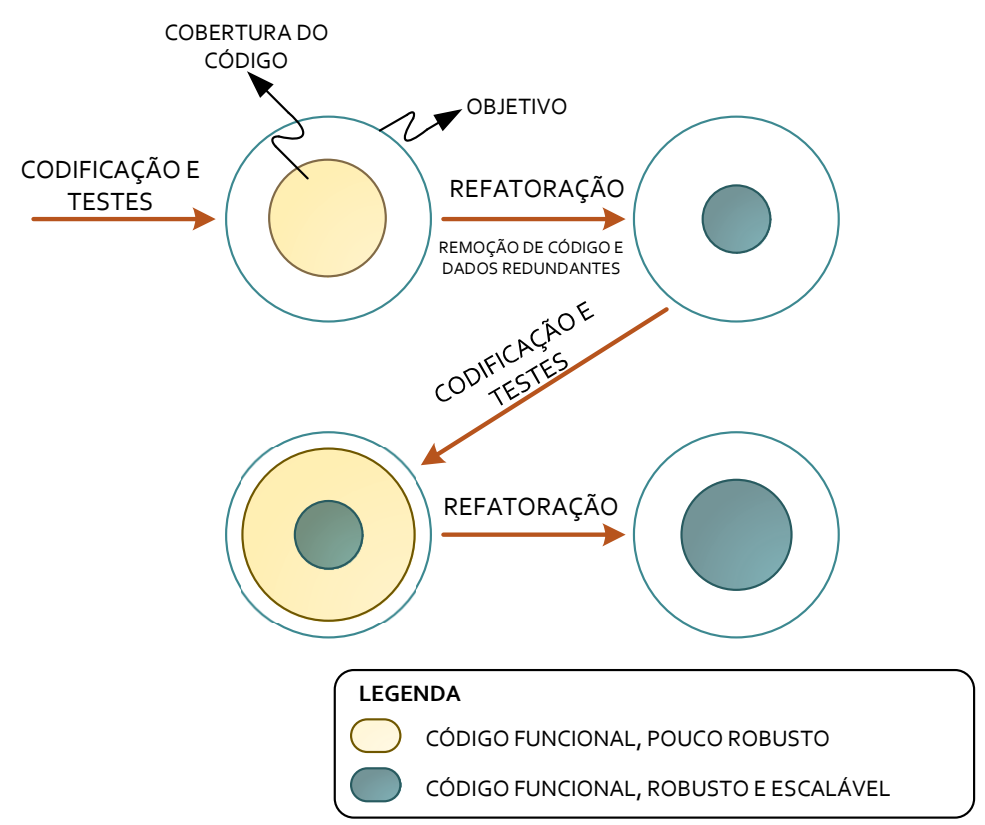

Figura 4.6 Representação da execução dos passos da fase de produção.

\subsubsection{Término da sequência}

O térmimo da sequência ocorre assim que é alcançado o objeto de pontuação. Caso isso não se mostre possível ao término da iteração, o conjunto de funcionalidades restantes e considerações emergentes da execução atual são levadas para uma nova rodada na fase de planejamento.

Ao final da sequência, considerações importantes resultantes da sua execução são anotadas na lista de tarefas do projeto para que sejam revistas em momento oportuno, isto é, durante a execução de sequência para funcionalidades a que dizem respeito. A Figura 4.7 fornece um resumo da sequência de atividades realizadas ao longo do processo. 


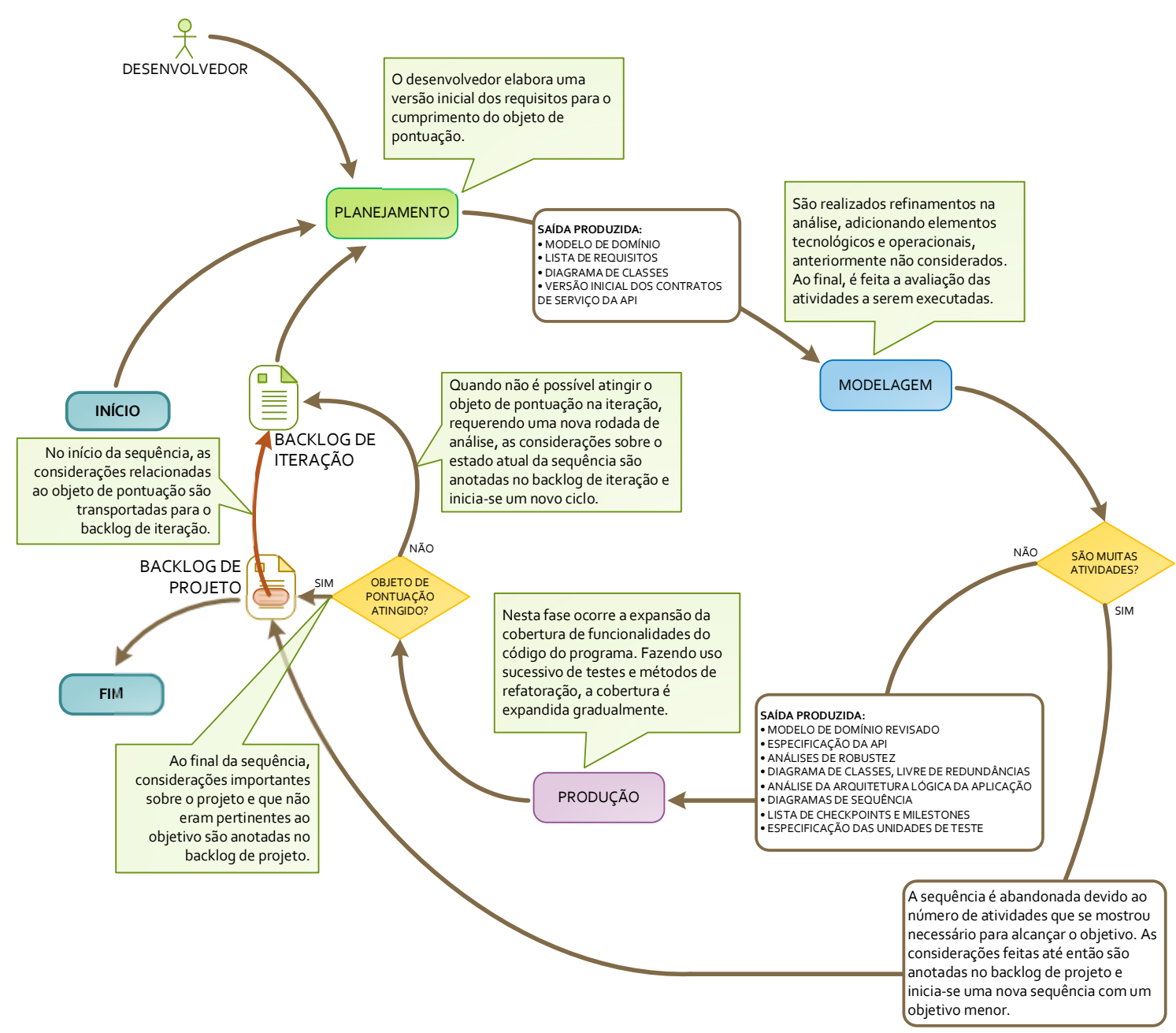

Figura 4.7 Principais atividades realizadas no método de desenvolvimento.

\subsection{Ambiente de desenvolvimento}

A configuração do ambiente de desenvolvimento interpõe-se entre o método de desenvolvimento e a sua prática, atuando como mecanismo de realização das proposições do método. Nesta seção, são apresentadas as escolhas dos componentes que definem o ambiente de desenvolvimento deste trabalho.

\subsubsection{Linguagem de programação}

Para a escolha da linguagem, o desempenho foi tomado como uma das características mais importantes para aplicações MEF, aliada à flexibilidade de desenvolvimento, isto é, a possibilidade de diferentes formas de codificação de uma mesma computação. São também de considerável relevância a diversidade de materiais de apoio presentes 
na literatura e a disponibilidade de APIs, que serão usadas para a implementação de recursos importantes do programa, como a computação em GPU, e em recursos periféricos, como a entrada de dados.

A linguagem ISO C ++11 122 foi escolhida para a implementação do software deste trabalho. $\mathrm{C}++$ é uma linguagem multi-paradigma bastante flexível. Em seus primórdios, assim como a linguagem $\mathrm{C}$, a quem sucedeu, foi desenvolvida para a construção de sistemas [210]. Sendo a versão oficial mais recente, $\mathrm{C}++11$, oferece uma considerável variedade de recursos que viabilizam uma grande variedade de construções, como sobrecarga de operadores, gabaritos, tratamento de exceções, funções lambda e outros [126, 140, 219].

Existe uma boa literatura a respeito da linguagem e uma grande variedade de APIs disponíveis, a citar algumas mais conhecidas, como Boost [65] (biblioteca de uso geral com especificações TR1), Qt [172] (desenvolvimento de interface com o usuário), Intel MKL [117] (biblioteca de álgebra linear) e CUDA [174] (computação em GPU).

Devido a sua flexibilidade, $\mathrm{C}++$ habilita a escrita de programas com maior desempenho, frente a outras linguagens. A Tabela 4.1 ilustra um comparativo do desempenho de diversas linguagens. Salienta-se aqui que a comparação é meramente ilustrativa, pois não se apresentou como critério suficiente para a escolha da linguagem, dada a grande dependência de outros fatores externos aos testes e especificidade do cenário de teste.

Tabela 4.1 Comparativo de desempenho entre implementações de linguagens de programação (adaptado de Fulgham [90]).

\begin{tabular}{lccc}
\hline Linguagem & Implementação & Desempenho médio & Nota \\
\hline C & GNU gcc & 1,00 & $(2)$ \\
C ++ & GNU g++ & 1,08 & $(2)$ \\
Ada 2005 & GNAT & 1,18 & $(2)$ \\
Java 7 & Java HotSpot 1.7 .0 & 1,42 & $(3)$ \\
Fortran & Intel Compiler & 1,68 & $(2)$ \\
\hline
\end{tabular}

Cenário de teste: Ubuntu x64, processador Intel Q6600, operação em single-core.

Notas: (1) Tempo de execução dos testes realizados, normalizados para o melhor desempenho medido; (2) Linguagem compilada; (3) Linguagem interpretada

\subsubsection{Plataforma}

O programa desenvolvido neste trabalho é executado na plataforma Windows. A opção foi feita devido a existência de ferramentas elaboradas e integradas para o desenvolvimento em GPU, um dos temas da pesquisa. 
Existem diversas formas de se melhorar o desempenho da aplicação, através da otimização do código do programa, escolha de compiladores mais sofisticados ou, ainda, otimizando a execução para uma família específica de processadores, por exemplo. Em razão disso, desempenho não é considerado mérito suficiente de escolha para uma plataforma. Neste sentido, cenários de testes de desempenho serão controlados de forma que a plataforma não seja um fator de influência.

\subsubsection{Ferramentas de desenvolvimento}

Foi utilizado o compilador Microsoft Visual C++ (Toolset 2012 v11, x64). Na plataforma Windows, esse é um dos compiladores suportados pela API de desenvolvimento em GPU escolhida (veja seção posterior). Para lidar com grandes volumes de dados em memória e aproveitar as vantagens oferecidas pelas arquiteturas de processadores mais recentes, a aplicação é desenvolvida para sistemas 64-bits [161], usando a versão mais recente do compilador (até a data da escrita deste documento), com suporte às instruções SSE [118] e AVX [119].

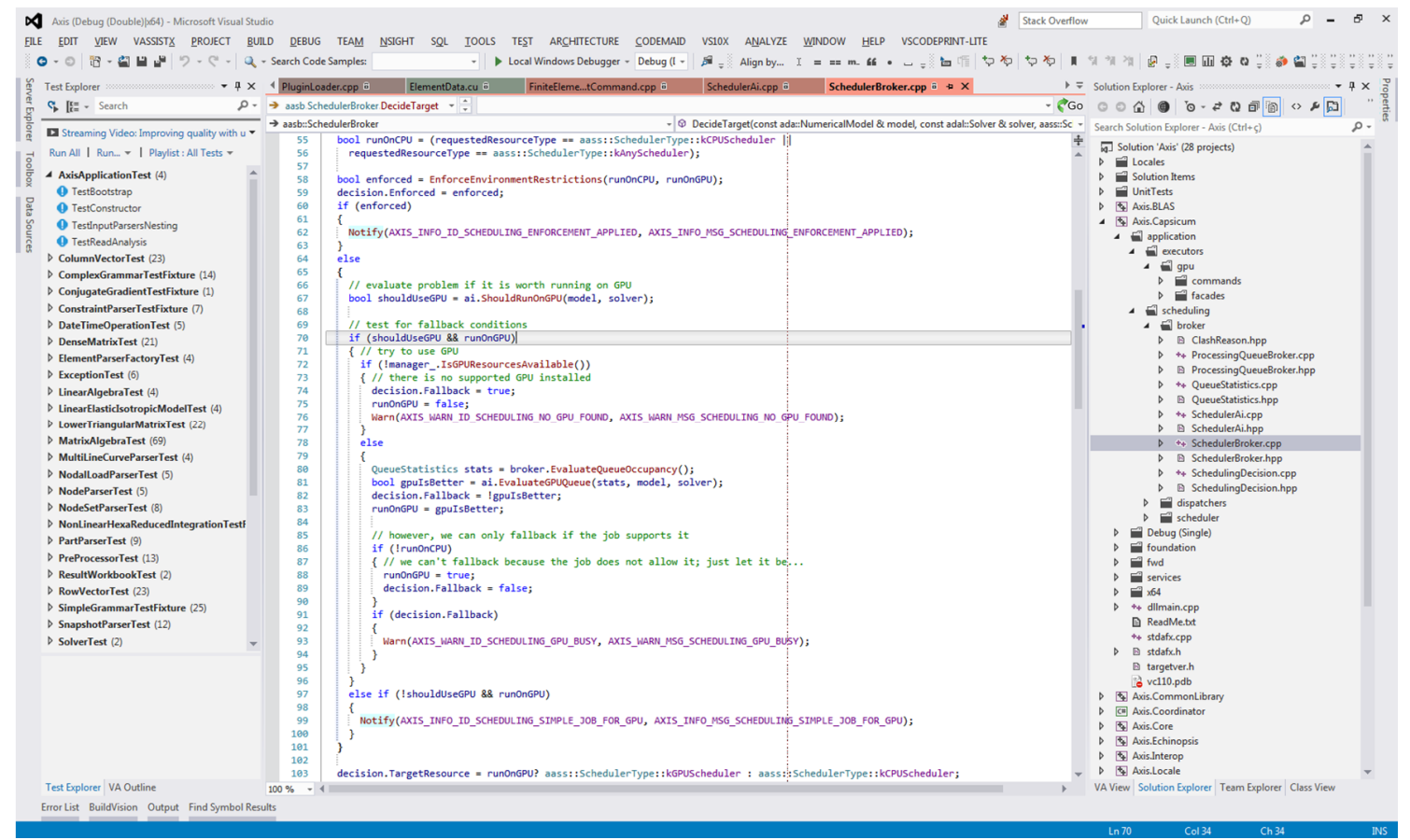

Figura 4.8 Ferramenta de desenvolvimento adotada.

A aplicação foi desenvolvida utilizando o Microsoft Visual Studio 2012 Ultimate (Update 3), Fig. 4.8. A escolha da ferramenta se deu pela variedade de recursos de auxílio ao desenvolvimento, tais como fácil manipulação de unidades de testes, ferramentas de análise de código e sistema de depuração inteligente, extensibilidade 


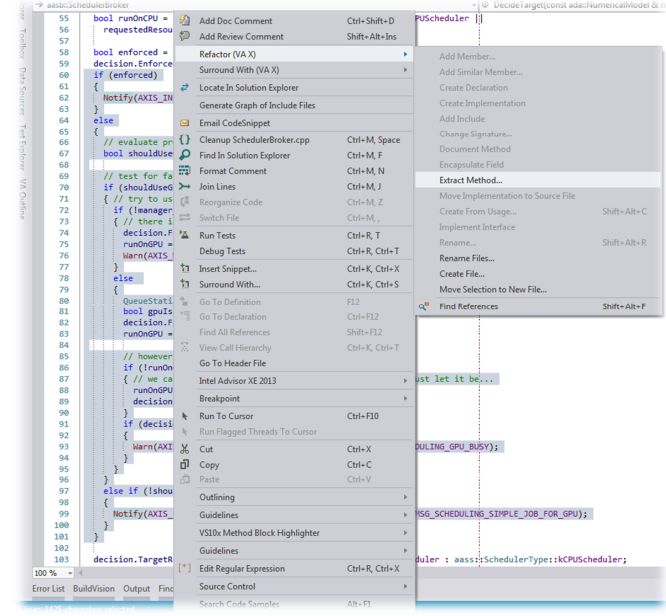

(a) Opções de refatoração disponíveis

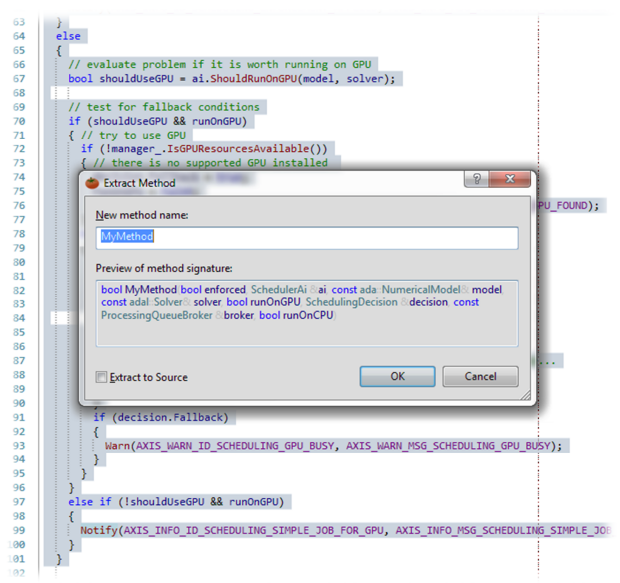

(b) Exemplo de aplicação

Figura 4.9 Ferramenta para refatoração de código.

permitida a partir de add-ins e, por ter considerável reconhecimento da comunidade de desenvolvedores, possui uma grande variedade de informações a seu respeito.

Para extensão das capacidades de refatoração, foi utilizada a extensão Whole Tomato Visual Assist X 10.7 (Fig. 4.9). A ferramenta adiciona ao Visual Studio recursos de refatoração, dando maior velocidade à codificação e facilitando a limpeza, reuso e claridade do código.

Foi escolhida a API CUDA da Nvidia 174 para o processamento de GPU. Uma maior variedade de materiais de apoio disponíveis na literatura e o amparo de programas de softwares para o desenvolvimento de aplicações na plataforma contribuíram para a escolha.

Um sistema de controle de versão foi usado no desenvolvimento para auxiliar no controle de mudanças e nas etapas de prototipagem do código. Juntamente com o sistema, mecanismos para rastreamento de tarefas e bugs foram adotados para amparar no acompanhamento de mudanças no software.

\subsubsection{Ambiente de testes}

A princípio, todos os testes foram executados nas estações de desenvolvimento cujas configurações estão descritas na Tabela 4.2. O uso de múltiplas estações é justificado unicamente pelo desenvolvimento ter ocorrido em locais físicos distintos.

Para a avaliação de seu desempenho em um cenário real, um hardware mais robusto foi utilizado, mostrado na Tabela 4.3. Os computadores instalados para os 
testes estão ligados à rede de informática do laboratório (Fig. 4.10) e dispõem de sistemas de refrigeração monitorado, controle de acesso ao ambiente, monitoramento e gerenciamento dos serviços e sistema ininterrupto de alimentação (no-break).

Tabela 4.2 Configuração das estações de desenvolvimento utilizadas.

\begin{tabular}{|c|c|c|}
\hline & Configuração D1 & Configuração D2 \\
\hline \multirow{2}{*}{ Processador } & Intel Core i7-2600 (8 CPUs & Intel Core i5-750 (4 CPUs \\
\hline & lógicas, 3,4 GHz) & lógicas, 2,67 GHz) \\
\hline Memória & 16 GB DDR3-1333 & 16GB DDR3-1333 \\
\hline Disco rígido & 1,25 TB total & $500 \mathrm{~GB}$ total \\
\hline Placa gráfica & MSI GeForce 560GTX Ti & EVGA GeForce 780 GTX \\
\hline \multirow{2}{*}{ Sistema operacional } & Microsoft Windows 7 & Microsoft Windows 7 Enterprise \\
\hline & Professional SP1, x64 & SP1, x64 \\
\hline Ferramenta de desenvolvimento & \multirow{2}{*}{\multicolumn{2}{|c|}{$\begin{array}{c}\text { Microsoft Visual Studio } 2012 \text { U3 + Whole Tomato Visual AssistX } 10.7 \\
\text { nVidia CUDA Toolkit 5.5 }\end{array}$}} \\
\hline GPU API & & \\
\hline Versão do driver de GPU & 332.21 & 332.21 \\
\hline Modo de computação da GPU & WDDM$^{*}$ & WDDM* \\
\hline
\end{tabular}

*Sigla para Windows Display Driver Model

Tabela 4.3 Configuração dos servidores alocados para os testes de cenário real.

\begin{tabular}{lc}
\hline & Configuração S1 \\
\hline Processador & Intel Xeon E5620 (x2) (8 CPUs lógicas por pastilha, 2,4 GHz) \\
Memória & 12 GB DDR3-1333 \\
Disco rígido & 500 GB total \\
GPU & nVidia Tesla M2050 \\
Sistema operacional & Microsoft Windows Server 2012 Datacenter, x64 \\
GPU API & nVidia CUDA Toolkit 5.5 \\
Versão do driver de GPU & 332.50 \\
Modo de computação da GPU & TCC* $^{*}$ \\
\hline
\end{tabular}

*Sigla para Tesla Compute Cluster 


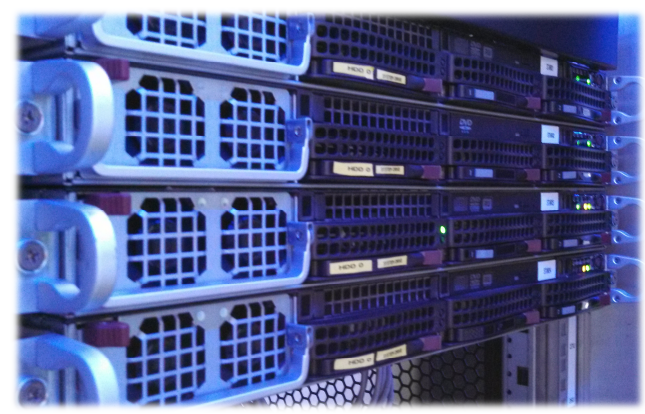

(a) Cluster utilizado
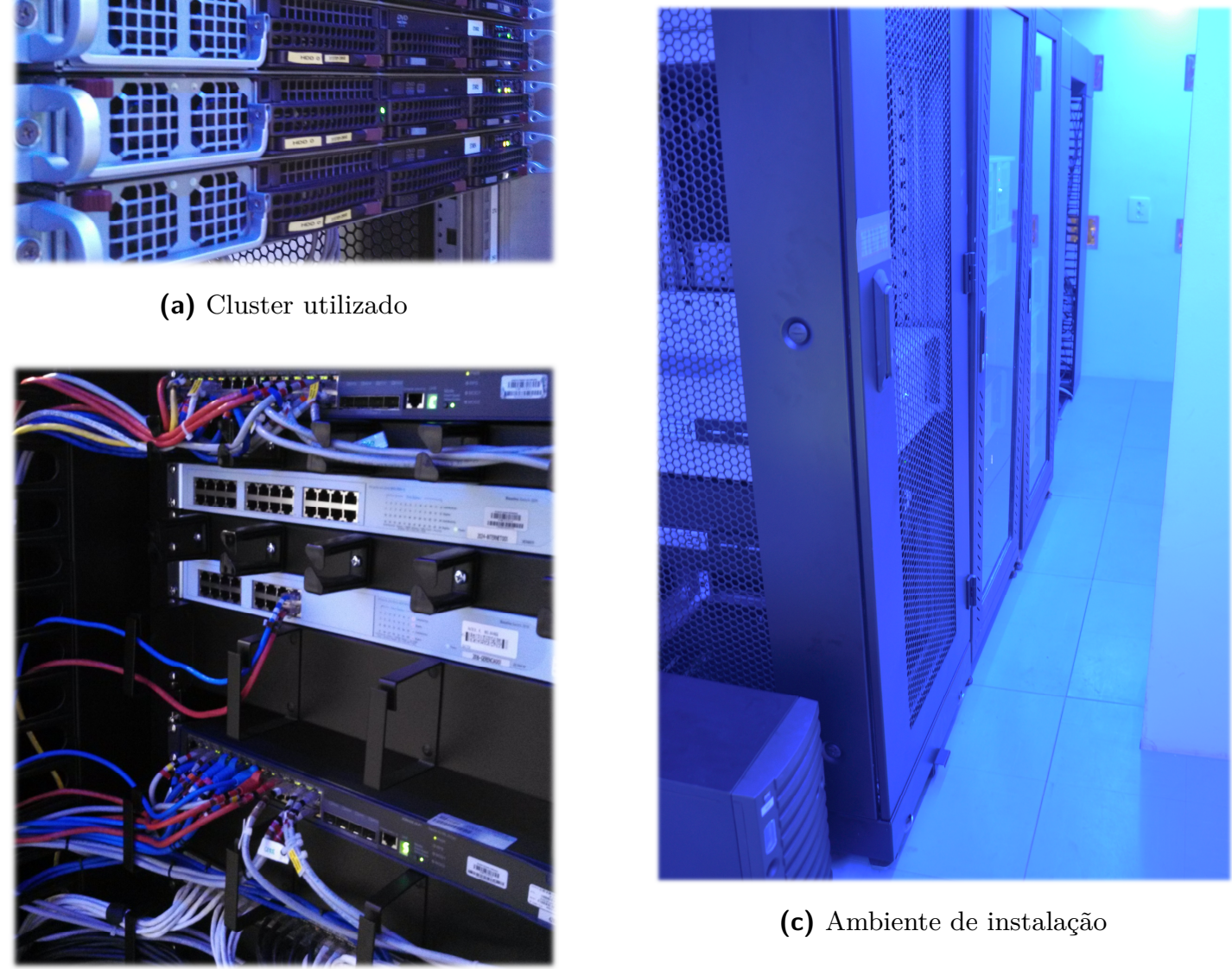

(c) Ambiente de instalação

(b) Cabeamento estruturado

Figura 4.10 Centro de processamento de dados do laboratório, onde foram executados os testes de cenário real. 


\subsection{Comentários}

As etapas de análise e design de um software constituem as fases mais importantes no desenvolvimento. A correta avaliação dos objetivos e requisitos aos quais o programa deve atender é essencial para o seu sucesso.

Torna-se importante adotar uma metodologia que promova o crescimento orgânico do software e proponha técnicas flexíveis para o desenvolvimento, permitindo que o problema seja atacado por etapas, à medida que o programa e o conhecimento da equipe de desenvolvimento sobre o domínio evoluem. O estabelecimento de políticas são igualmente importantes para controlar o processo e definir metas para a construção do sistema em tempo e custo hábeis.

Para este trabalho, as estratégias empregadas para o desenvolvimento mostraramse suficientes para o controle da qualidade do código e o atendimento dos requisitos definidos na etapa de análise. A adoção de um método de desenvolvimento revelou-se importante para o controle de um sistema de dimensões e complexidade consideráveis, conforme será apresentado no próximo capítulo. 



\section{CAPÍTULO 5}

\section{Aspectos gerais do programa}

Sistemas computacionais são construídos com a intenção de habilitar o computador para uso em em tarefas específicas, visando facilitar processos. Para que um sistema se comporte desta forma, diversas computações são realizadas e combinadas de forma harmônica.

Entretanto, desde os primórdios da computação, a descrição de um sistema computacional acaba se mostrando muito maior do que o breve relato do seu papel a cumprir. O problema no desenvolvimento de softwares, segundo Dijkstra [72], tem seus fundamentos na inabilidade do ser humano em avaliar corretamente sistemas de grandes dimensões. Na classificação de Klir [130], sistemas tecnológicos são, em sua maioria, de complexidade organizada, isto é, há um grande número de variáveis que interferem no sistema e potencialmente podem alterar significativamente o seu comportamento. Logo, não é possível obter um modelo analítico determinístico ou sistema estatístico que possa representá-los satisfatoriamente. É comum que ocorram simplificações e interpretações durante o processo de análise do sistema, levando a diferentes soluções. A solução é gradativamente simplificada até um nível de complexidade satisfatório para o engenheiro de sistemas [85, 130].

O software é um produto abstrato de complexidade inerente. Produzí-lo requer a sua representação em termos mais concretos para facilitar a compreensão de seu funcionamento. Sendo assim, é comum que sejam usados substantivos concretos e metáforas para denominar sistemas e subsistemas da aplicação [38, 134, 205], enquanto que, geralmente, suas interações são representadas através de formas geométricas, por exemplo UML [80]. 
Softwares de elementos finitos também apresentam a mesma complexidade. Como é possível observar da teoria apresentada nos capítulos anteriores, há diversos mecanismos na ferramenta que são interdependentes ou que interferem significativamente no comportamento da outra parte. A variabilidade de problemas que o programa deve ser capaz de ler, analisar e solucionar é grande e, com os diversos avanços no desenvolvimento da teoria, com a proposta de novos algoritmos e melhoramentos, é cada vez mais exigido a elaboração de um software que possa agregar rapidamente essas mudanças. Hoje, pode-se dizer que flexibilidade e modularidade são qualidades desejáveis em qualquer solução de elementos finitos. Nesse contexto, a qualidade da arquitetura do software é um fator importante para permitir que essas constantes modificações sejam realizadas, para que características como modularidade, reusabilidade e extensibilidade possam emergir convenientemente [133].

Neste capítulo, é descrita a arquitetura do programa aqui desenvolvido, utilizandose de diversas vistas de sua estrutura para uma melhor compreensão de seu funcionamento. A discussão é iniciada apresentando-se as principais funcionalidades e características do software, prosseguindo na descrição de seus principais módulos, levando à descrição da arquitetura do programa e à elaboração do núcleo de elementos finitos desenvolvido. A discussão sobre essa estrutura-base ocorre sob diversas perspectivas, para que se torne mais clara a interação de suas partes e os aspectos de robustez e extensibilidade atingidos.

\subsection{Características do programa}

O programa desenvolvido, denominado Axis, foi concebido para a resolução de programas de impacto estrutural. Suas funcionalidades abrangem:

- solução de problemas quasi-estáticos lineares através de método iterativo, o gradiente conjugado;

- solução de problemas dinâmicos através de esquema explícito de integração temporal, o método das diferenças centrais;

- suporte a problemas dinâmicos não-lineares, o que inclui suporte a:

— não-linearidade geométrica (grandes deslocamentos e grandes deformações);

— não-linearidade do material (modelo constitutivo não-linear).

- formulação de elemento sólido hexaédrico, permitindo a modelagem de praticamente qualquer estrutura tridimensional; 
Ainda que não seja necessário o suporte à solução de problemas quasi-estáticos para se alcançar os objetivos do trabalho, a funcionalidade foi adicionada durante o desenvolvimento para permitir a depuração da formulação do elemento e modelos de materiais implementados, além de se examinar a exatidão das interações entre os diversos componentes do sistema.

Em termos de ambientes de processamento, é suportado:

- processamento CPU, com paralelização nos processadores lógicos locais. Disponível para qualquer tipo de análise;

- processamento em GPU, com paralelização interna no dispositivo, suporte a um único dispositivo local. Disponível apenas para análises dinâmicas.

As características anteriormente descritas são resumidas na Tabela 5.1. Aliada a essas funcionalidades, o programa Axis oferece uma biblioteca de elementos e de materiais extensíveis que, em sua implementação básica, oferecem as tecnologias descritas nas Tabelas 5.2 e 5.3, respectivamente.

Tabela 5.1 Sistemas de solução implementados no programa.

\begin{tabular}{lccccccc}
\hline \multirow{2}{*}{ Solver } & \multirow{2}{*}{ Algoritmo base } & \multicolumn{3}{c}{$\begin{array}{c}\text { Recursos suportados* } \\
\text { Linearidade }\end{array}$} & Não-linearidade & \multicolumn{2}{c}{ Ambientes de } \\
& & processamento suportados \\
\cline { 3 - 7 } & & G & M & G & M & CPU & GPU \\
\hline Quasi-estático linear & Gradiente conjugado & $\times$ & $\times$ & & & $\times$ & \\
Dinâmico linear & Diferenças centrais & $\times$ & $\times$ & & & $\times$ & $\times$ \\
Dinâmico não-linear & Diferenças centrais & $\times$ & $\times$ & $\times$ & $\times$ & $\times$ & $\times$ \\
\hline
\end{tabular}

${ }^{*}$ G: linearidade/não-linearidade geométrica; M: linearidade/não-linearidade do material

A arquitetura elaborada para o programa lhe confere características computacionais significativas que corroboram sua robustez e extensibilidade, tais como:

- arquitetura única para todos os solvers, quasi-estático e dinâmico (outros podem ser implementados pelo usuário), o que facilita o aprendizado sobre o código e simplifica os mecanismos envolvidos na execução da simulação numérica;

- divisão do programa em componentes, com o objetivo de facilitar a manutenção do programa, reduzir o tempo de compilação, modularizar e reaproveitar o código, oferecendo mais enfoque e clareza à implementação dos algoritmos propriamente ditos; 


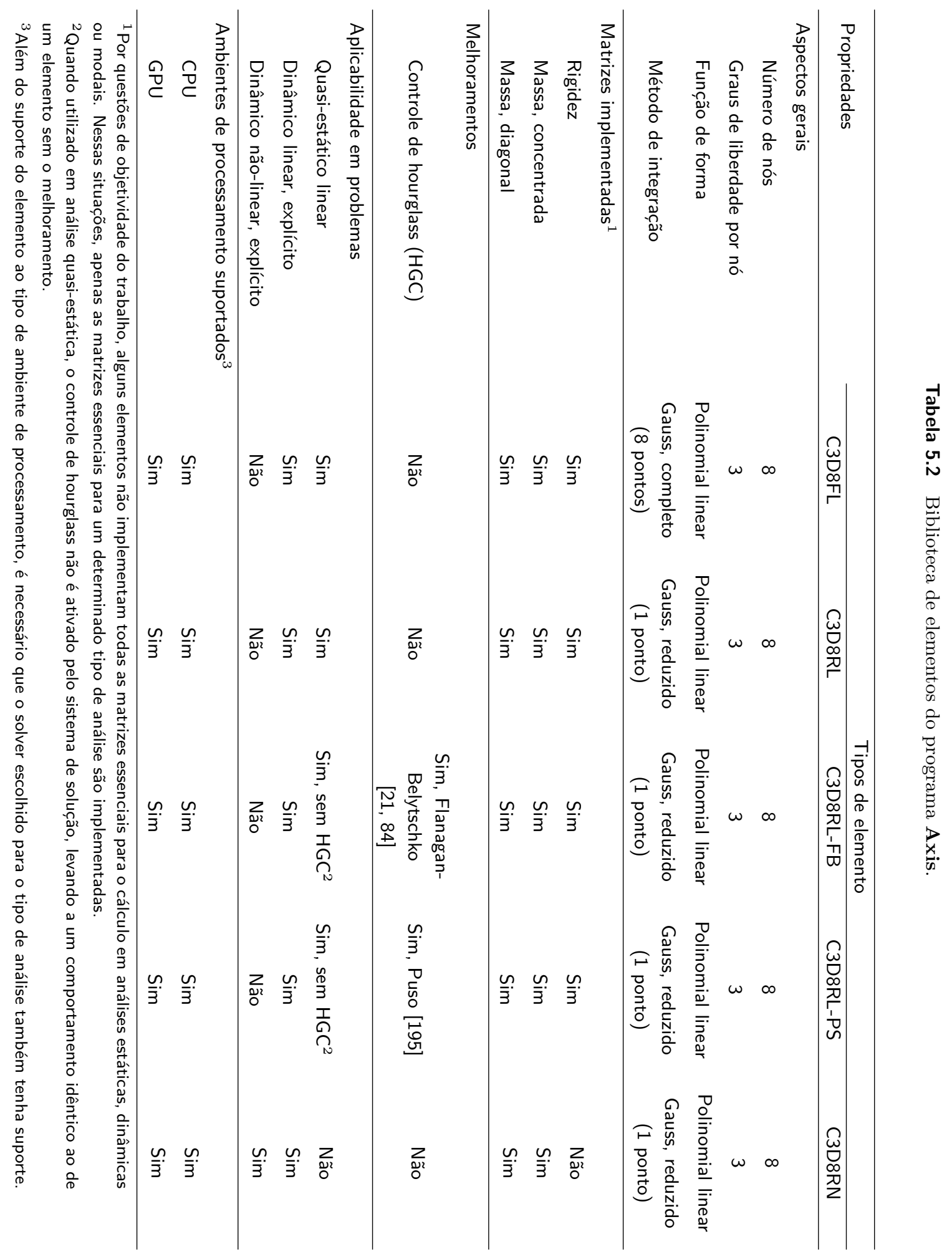


Tabela 5.3 Biblioteca de materiais do programa Axis.

\begin{tabular}{|c|c|c|c|c|}
\hline \multirow{2}{*}{ Propriedades } & \multicolumn{4}{|c|}{ Modelos de materiais } \\
\hline & Elástico & Neo-Hookeano & Hipoelástico & Bilinear plástico \\
\hline \multicolumn{5}{|l|}{ Aspectos gerais } \\
\hline Isotropia & Sim & Sim & Sim & $\operatorname{Sim}$ \\
\hline Elasticidade & Linear & Hiperelástica & Hipo-elástica & Hipo-elástica \\
\hline Plasticidade & Não & Não & Não & $\operatorname{Sim}$ \\
\hline Encruamento plástico & - & - & - & $\begin{array}{r}\text { Isotrópico } \\
\text { (von Mises) }\end{array}$ \\
\hline Grandes deformações & Não & Sim & $\operatorname{Sim}$ & $\operatorname{Sim}$ \\
\hline \multicolumn{5}{|c|}{$\begin{array}{l}\text { Ambientes de processamento } \\
\text { suportados }^{1}\end{array}$} \\
\hline CPU & $\operatorname{Sim}$ & $\operatorname{Sim}$ & $\operatorname{Sim}$ & Sim \\
\hline GPU & Sim & Sim & Sim & Sim \\
\hline
\end{tabular}

${ }^{1}$ Além do suporte do material ao tipo de ambiente de processamento, é necessário que o solver escolhido para o tipo de análise também tenha suporte.

- código totalmente desacoplado de tecnologias de interface com o usuário, permitindo que a base do programa possa ser reaproveitada na escrita de softwares com interface textual, gráfica ou serviços web, por exemplo;

- exposição de uma $\mathrm{API}^{1}$ de extensibilidade que permite ao analista (ou terceiros) a escrita e incorporação de novas funcionalidades ao programa, tais como solvers, elementos e materiais, sem a necessidade de acesso ao códigofonte ou recompilação total do software, empacotadas em um componente externo e carregado dinamicamente - os plugins de personalização;

- similaridade na maioria das estruturas de dados em código compilado para CPU ou GPU. As operações em ambos os ambientes são funcionalmente idênticas, reduzindo a curva de aprendizado para a implementação de funcionalidades com suporte a GPU;

- definição de uma linguagem estruturada em blocos, de fácil compreensão, para o arquivo de entrada do programa. Plugins posteriormente adicionados ao programas podem estendê-la, incluindo novas construções sintáticas que definem, no arquivo de entrada, as funcionalidades oferecidas. A descrição sintática da linguagem é dada no Apêndice C, enquanto exemplos de arquivos de entrada são apresentados no Apêndice D.

\footnotetext{
${ }^{1}$ Uma API (Application Programming Interface) é a descrição de como interagir com um componente. Em termos computacionais, é o conjunto das interfaces de métodos e estruturas de dados de um componente, exposto para interação com outras entidades externas.
} 


\subsection{Métricas do projeto}

As métricas da base de código do programa Axis são apresentadas na Tabela 5.4. Para referência, é demonstrada a evolução do código conforme determinados milestones do software foram atingidos ao longo do desenvolvimento.

Tabela 5.4 Métricas da base de código do Axis.

\begin{tabular}{lccc}
\hline \multirow{2}{*}{ Parâmetro } & \multicolumn{3}{c}{ Milestones } \\
\cline { 2 - 4 } & $\mathrm{M} 1$ & $\mathrm{M} 2$ & $\mathrm{M} 3$ \\
$(\mathrm{abr} / 2013)$ & $(\mathrm{jul} / 2013)$ & $($ out $/ 2013)$ \\
\hline Dimensões & & & \\
Linhas de código $^{1}$ & 86902 & 111543 & 114260 \\
Total de arquivos & 1137 & 1461 & 1476 \\
Total de classes & 617 & 762 & 769 \\
Total de Instruções $_{\text {Total de funções }}$ & 41500 & 54256 & 55476 \\
Qualidade & 208 & 416 & 440 \\
Razão de comentários (\%) & & & \\
Métodos/classe & 27,0 & 23,1 & 23,4 \\
Razão de desvios (\%) & 9,13 & 10,18 & 10,16 \\
Complexidade média & 9,5 & 9,4 & 9,6 \\
Complexidade máxima & 1,79 & 1,72 & 1,73 \\
Profundidade média & 38 & 38 & 38 \\
Profundidade máxima & 1,08 & 0,98 & 1,00 \\
\hline
\end{tabular}

\section{Milestones:}

M1: Implementação base, solver quase-estático e dinâmico, lineares e em CPU concluídos; hexaedro linear, integração completa e reduzida; formulações com controle de hourglass; material isotrópico linear elástico.

M2: Adição do suporte à execução em GPU para os solvers implementados em M1; apenas hexaedro linear com integração reduzida o material linear elástico são suportados no hardware; compatibilidade com CPU se mantém.

M3: Última versão. Suporte a não-linearidade de geometria e de material incluído para análises dinâmicas pelo método explícito; hexaedro linear com integração reduzida para grandes deformações, modelo de material neo-Hookeano e de plasticidade bilinear de von-Mises são incluídos para o suporte em CPU e em GPU.

\footnotetext{
${ }^{1}$ Não são consideradas linhas em branco; comentários inclusos.

${ }^{2}$ Valor superior a 9 . Por questões práticas, valores acima do limite denotam degradação considerável do código, requerendo correção para manter a qualidade.
}

São oferecidas métricas que ilustram as dimensões do código produzido e parâmetros que mensuram a sua qualidade, no que se refere a sua legibilidade, flexibilidade e facilidade para testes, entre outros aspectos. Cada uma delas é brevemente explicada a seguir:

- Linhas de código: total de linhas de código do programa, incluindo comentários e diretivas de pré-processamento. Exclui-se linhas em branco; 
- Total de arquivos: total de arquivos nos quais o código C++é distribuído, como arquivos-cabeçalho e unidades de tradução;

- Total de classes: número total de classes definidas no programa;

- Total de instruções: número total de instruções C++ declaradas;

- Total de funções: número total de funções livres definidas;

- Razão de comentários: razão de comentários por total de linhas de código. Uma proporção muito baixa pode implicar numa documentação deficiente, enquando que valores altos denotam código pouco expressivo;

- Métodos/classe: quantidade média de métodos declarados por classe. Idealmente, a classe deve ter relevância no código (ou seja, a responsabilidade atribuída tem importância no domínio do problema), ao mesmo tempo que não concentra múltiplas atividades dissidentes, o que estabelece uma faixa de aceitabilidade para este valor;

- Razão de desvios: razão de instruções de desvio, como condicionais, laços e tratamento de exceção, por total de instruções. Códigos com demasiada proporção de desvios tendem a ser pouco legíveis e com lógica pouco dedutível;

- Complexidade ${ }^{2}$ : valor escalar que mensura a quantidade de caminhos de execução de uma função ou método, tal que códigos com maior número de desvios e lógica de condicionais complexas são considerados altamente complexos (valor maior). A complexidade média é definida pela média aritmética da métrica sobre todos os métodos e funções declarados;

- Profundidade: número de blocos aninhados em uma função ou método, dados por condicionais, laços, tratamento de exceções e o próprio corpo da função, por exemplo. A profundidade média é definida pela média aritmética da métrica sobre todos os métodos e funções.

A medida da qualidade de código é uma tarefa subjetiva e dependente dos aspectos do projeto, tais como o propósito do programa, os requisitos e às vezes, a fase do desenvolvimento. Para este trabalho, foram adotados os limites apresentados no gráfico da Figura 5.1 para a última versão da base de código. A área destacada representa os limites desejáveis para as métricas.

\footnotetext{
${ }^{2}$ Existem diversas medidas de complexidade de código. Para este trabalho, é adotada a métrica definida por McConnell [158].
} 
Para os limites estabelecidos no projeto, a base de código atende aos requisitos mínimos de qualidade. A complexidade máxima do código ultrapassa consideravelmente o limite devido a uma classe protótipo usada na leitura das informações do arquivo de entrada. Excluindo-se esta entidade, todas as demais atendem aos limites de qualidade da métrica. Em razão da mesma classe, a profundidade máxima é excedida. A única penalidade que é sofrida é dada pela profundidade média. No entanto, como a extrapolação ocorreu no limite inferior, o impacto na qualidade do código é menor e é mais facilmente corrigido o problema.

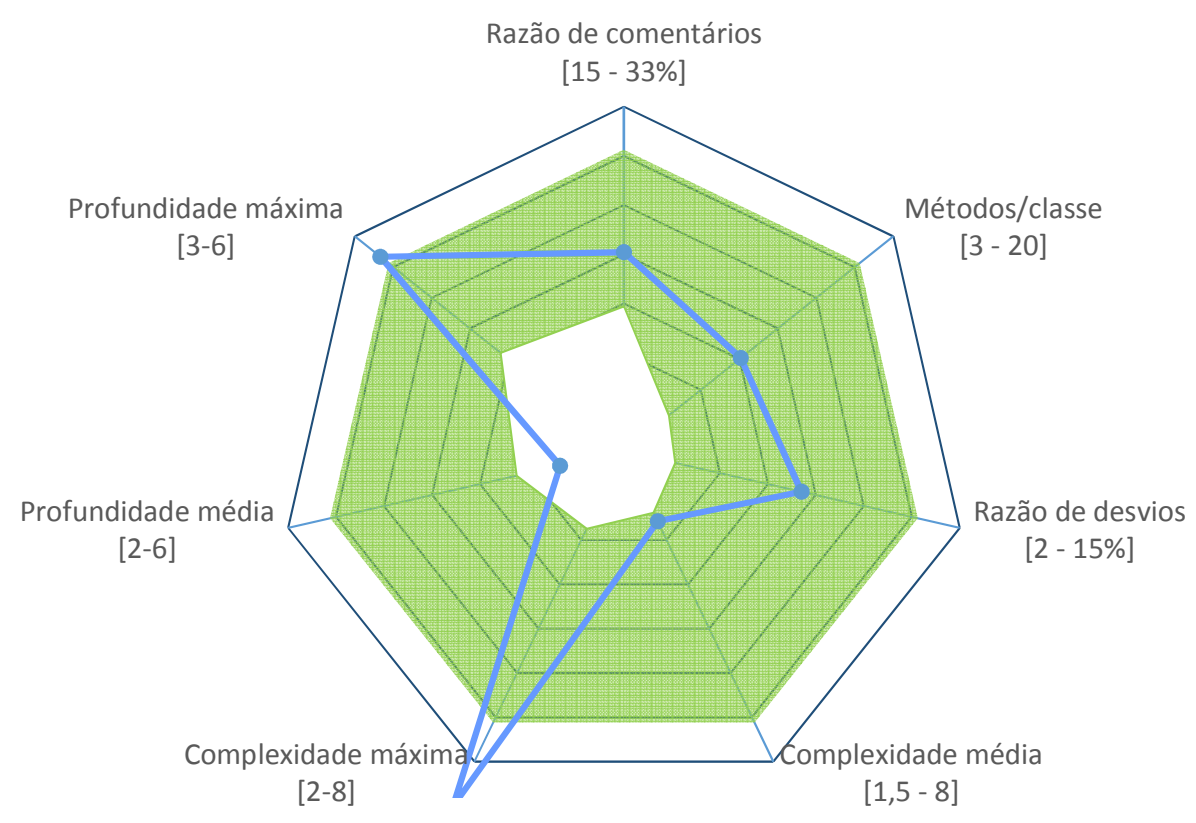

Figura 5.1 Métricas de qualidade do projeto Axis.

\subsection{Estrutura geral do programa}

É possível dividir o programa em seis grandes subsistemas, conforme ilustra a Figura 5.2. Cada bloco denota um conjunto fechado de funcionalidades a serem desempenhadas durante o ciclo de execução do software:

Coordenador Atua sob todo o programa orquestrando as operações dos diversos blocos. Também oferece uma interface de comunicação a partir da qual pode-se estabelecer a interface com o usuário ou interações com agentes computacionais externos.

Analisador sintático de entrada Lê as informações contidas nos arquivos de entrada da análise, traduzindo-as em uma sequência de símbolos que, após a interpretação sintática (de uma maneira similar a um compilador de 


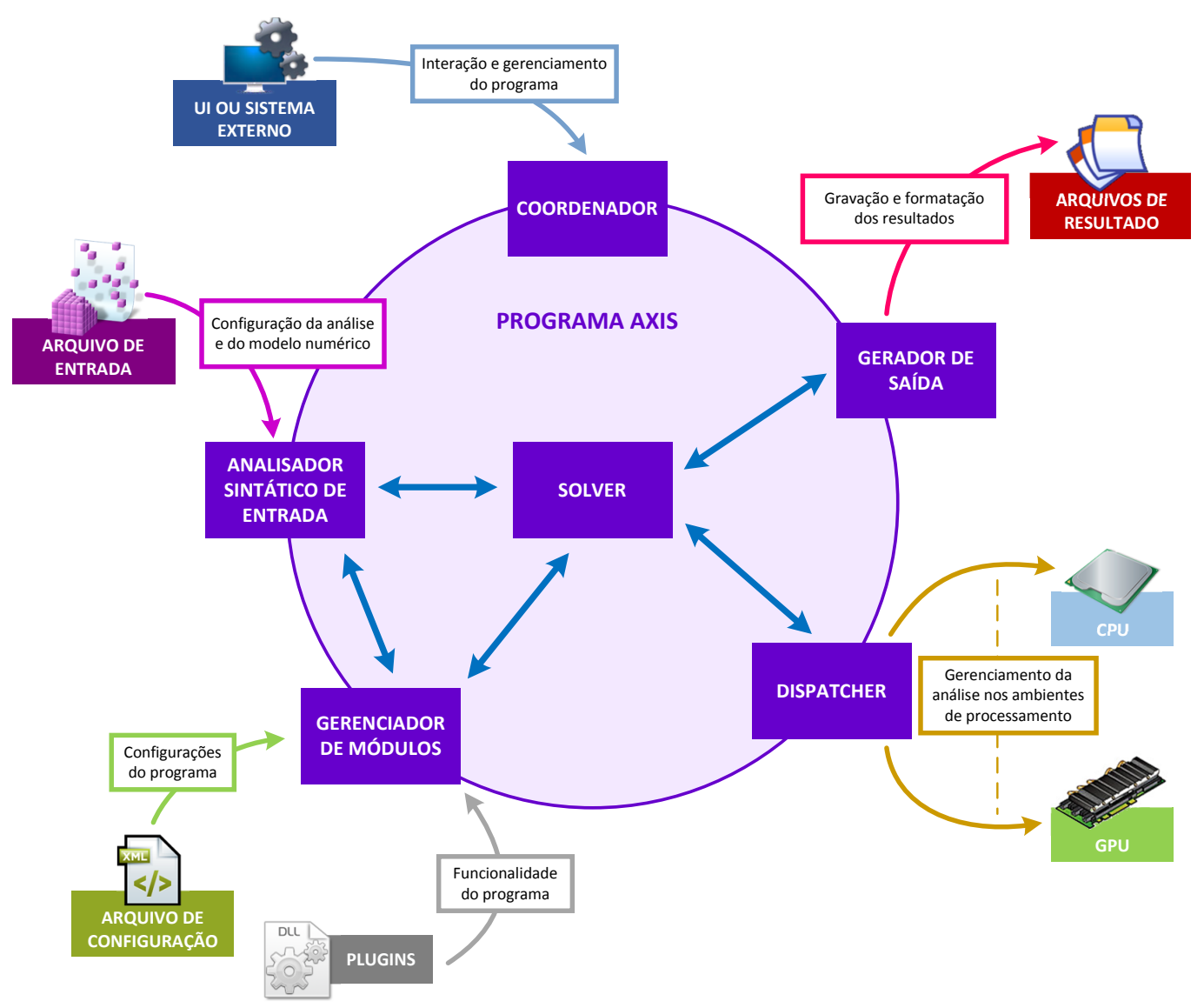

Figura 5.2 Divisão do programa em blocos funcionais.

linguagem de programação [1, 112]), constrói o modelo numérico proposto e as configurações da análise (duração do evento simulado, frequência de gravação de dados, configuração da saída de dados, entre outros).

Gerador de saída Grava os resultados gerados pelo solver numa base de dados de formato previamente configurado através das definições no arquivo de entrada. Os dados podem ser gravados em mais de uma base dados com formatos distintos. A leitura dos dados da análise é feita em um programa de pós-processamento compatível com o formato escolhido.

Solver Executa efetivamente a simulação numérica, usando o modelo carregado a partir dos arquivos de entrada.

Dispatcher Gerencia a execução da análise em um dos ambientes de processamento suportados, cabendo-lhe selecionar o ambiente adequado de acordo com propriedades da análise e o suporte da implementação de elementos, materiais e solvers selecionados para os ambientes disponíveis. 
Gerenciador de módulos Carrega e gerencia as bibliotecas de extensão do programa (os plugins). Cada plugin carregado pode agregar um conjunto de novas funcionalidades ao sistema, como bibliotecas de elementos, materiais, novos algoritmos de solução, entre outros.

A visão modular do programa oferece uma perspectiva simples e concisa para a compreensão das partes do programa. No entanto, ela não oferece detalhes de funcionamento e tampouco permite delimitar precisamente as responsabilidades das entidades do código, pois é abrangente demais para definir grupos de classes especializadas. Para tanto, recorreu-se a uma organização de dois níveis, dada pela arquitetura lógica do software e pela divisão física do código em componentes.

\subsubsection{Arquitetura lógica do programa}

A arquitetura lógica define um dos primeiros níveis de organização das classes do programa. No Axis, a estruturação ocorre através da separação em camadas [134]. Cada camada define um aspecto principal do sistema; internamente, contêineres organizados hierarquicamente (pacotes) separam as classes em funcionalidades cada vez mais específicas. A Figura 5.3 mostra a organização lógica do software.

São permitidas apenas interações entre classes localizadas na mesma camada ou em níveis inferiores. Essa regra de primeiro nível dificulta a criação de acoplamentos indesejáveis, tal como a dependência direta das classes de MEF com o formato do arquivo de entrada. Vale observar que apenas interações intercamadas unidirecionais são válidas, pois, do contrário, violariam a regra.

A organização em camadas promove a decomposição das tarefas em diferentes níveis de abstração, movendo operações mais intrinsicamente ligadas a elementos tecnológicos para camadas inferiores, enquanto que conceitos intimamente ligados com o propósito da aplicação localizam-se em níveis superiores.

Aplicar uma política de separação provê maior claridade do código porque a responsabilidade das classes são reduzidas a tarefas menores e mais especializadas, prevenindo programação monolítica, reduzindo o tamanho geral da classe e melhorando a clareza do código. Além disso, classes menores permitem melhor granularidade no desenvolvimento e divisão de tarefas entre membros do time de desenvolvimento. A presença desses fatores no projeto automaticamente induzem a uma disciplina de desenvolvimento orientada a pequenas iterações, tal como a discutida no Capítulo 4 .

No código, as camadas são representadas por espaços de nomes (namespace) 
Camadas

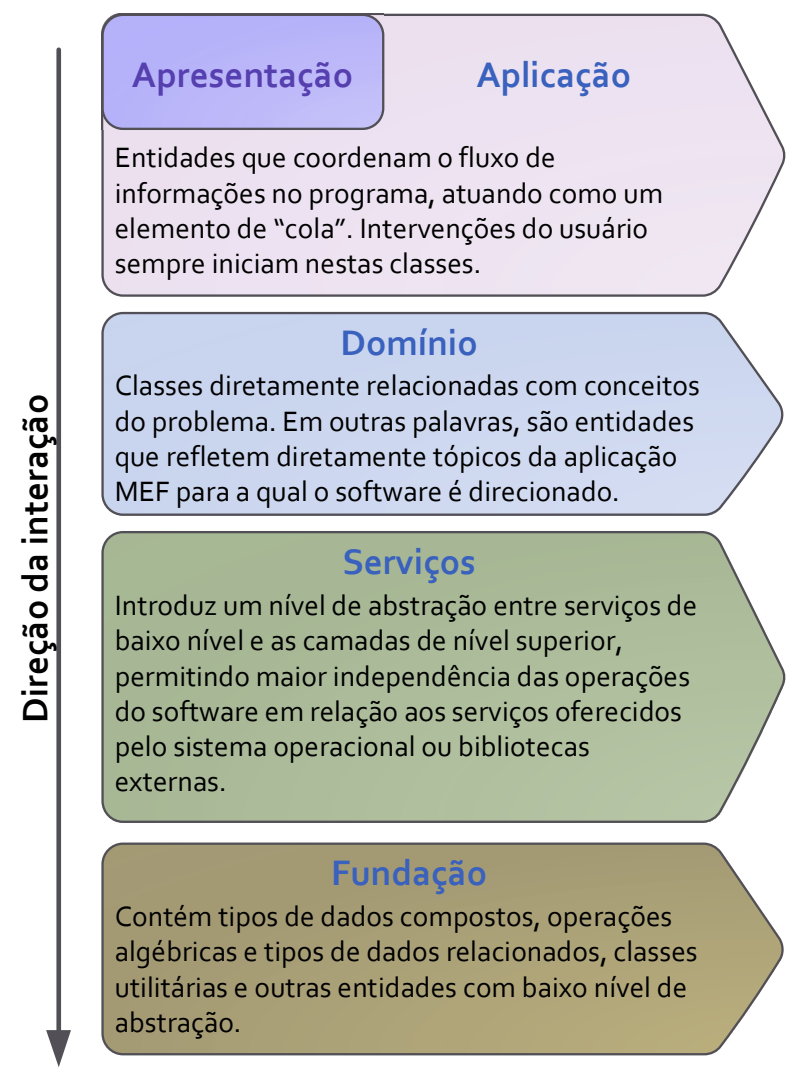

\section{Conteúdo}

- Fábricas de classes MEF

- Classes de localização e outras fábricas de recurso

- Sub-camada de Apresentação: todas as classes pertinentes à UI, como ConsoleWriter, WindowManager, etc.

- Classes de interpretação do arquivo de entrada

- FiniteElement, Node, DoF e outras classes MEF

- Algoritmos do solver, como ConjugateGradientSolver and LinearDynamicExplicitSolver

- Parser XML e classes de leitura do arquivo de configuração do programa

- Classes para leitura de tokens do arquivo de entrada ("tokenizer" - parser LL(1))

- Classes relacionadas a manipulação de plugins

- Date, Time, Timestamp, Uuid e outros tipos de dados compostos

- Biblioteca BLAS, e classes Matrix e Vector

- Classes para manipulação de arquivos

- Classes para manipulação de bibliotecas dinâmicas

Figura 5.3 Arquitetura lógica do programa em camadas.

de alta hierarquia, agrupados dentro do espaço de nome de primeiro nível, axis, conforme ilustra a Fig. 5.4. A tradução dos pacotes UML para o espaço de nomes $\mathrm{C}++$ é direta, facilitando a visualização da arquitetura lógica no código.

\subsubsection{Componentes do software}

O software Axis é dividido em componentes que, no escopo tecnológico, se manifestam em bibliotecas dinâmicas ${ }^{3}$. A divisão reduz a complexidade do sistema criando, no nível físico, limites bem-definidos para as classes que o compõem.

Cada um desses módulos pode ser compilado separadamente, mas possui conexão com outros módulos. As conexões são fracas e denomina-se assim porque não existe vínculo quanto à forma como a operação é executada, apenas quanto ao formato dos dados envolvidos. Como observado por Liskov [141], elas são apenas suposições feitas quanto a uma operação. A natureza fraca da ligação permite que

\footnotetext{
${ }^{3} \mathrm{Na}$ plataforma Windows, são referidas como bibliotecas de vínculo dinâmico (DLL); em Linux, objetos compartilhados (so) e em MacOS, bibliotecas dinâmicas (dylib).
} 
componentes possam ser substituídos, desde que o sucessor respeite as suposições feitas a respeito das operações em questão. A Figura 5.5 exemplifica esse tipo de interação.

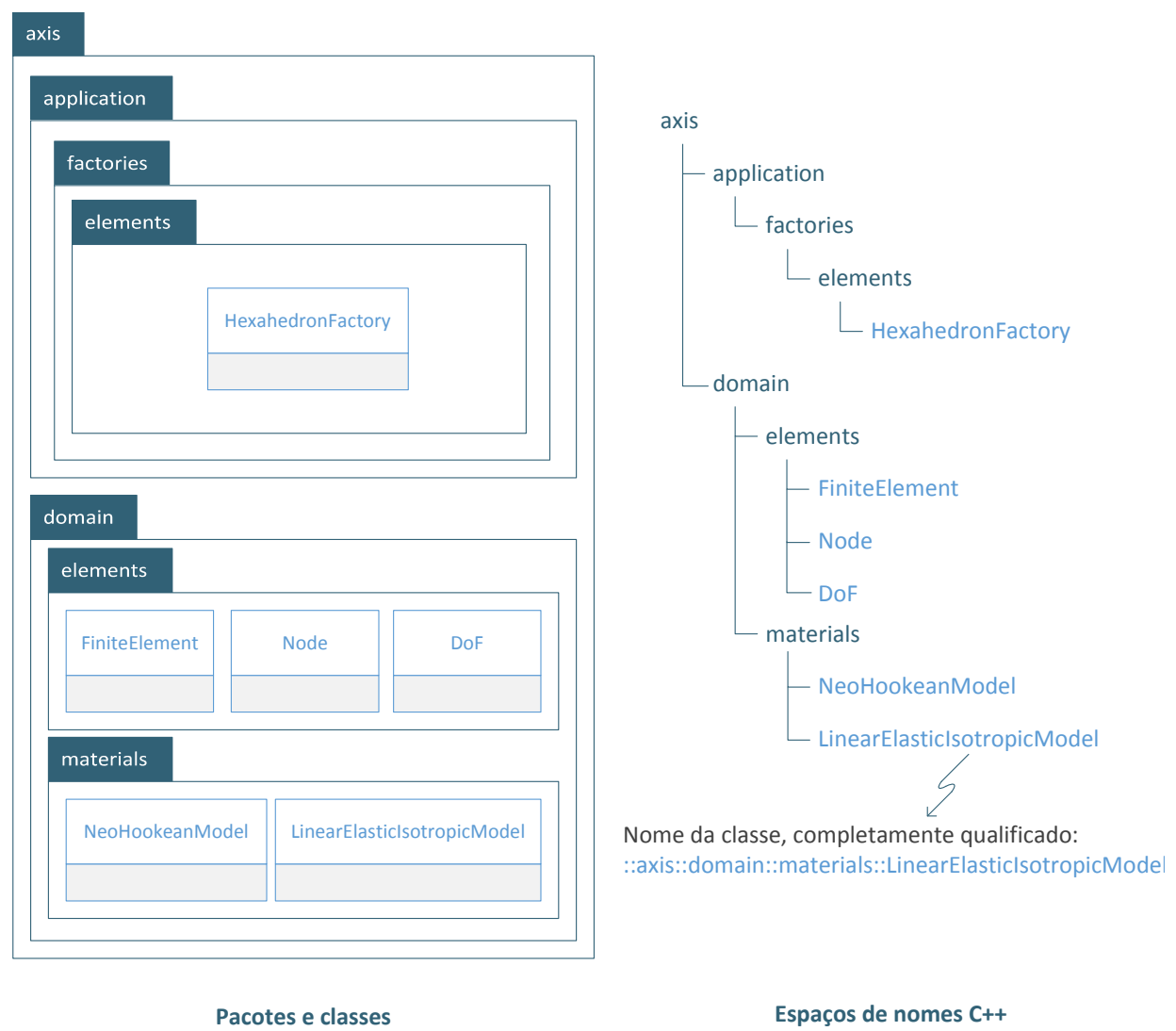

Figura 5.4 Tradução da arquitetura lógica em espaços de nomes no código do software.

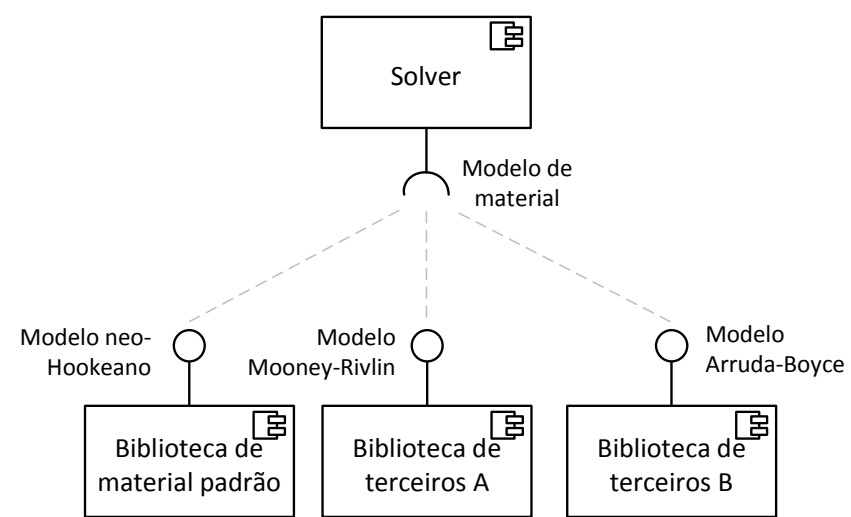

(a)

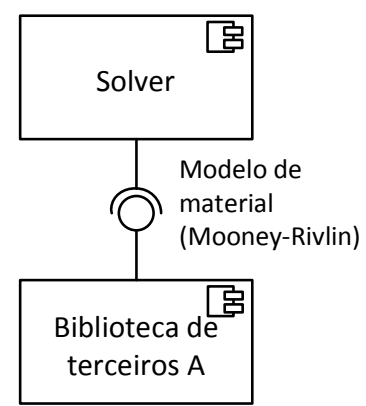

(b)

Figura 5.5 Relação entre componentes. Em (a), componentes implementam a interface esperada pelo Solver. A ligação, em UML, é representada em (b). 
Na Fig. 5.5a, o componente Solver requer a implementação da interface Modelo de material. Os componentes Biblioteca de material padrão, e Biblioteca de terceiros (A e B) implementam essa interface. Uma interface estabelece um "contrato", onde o contratante (Solver) faz uso dela para empregar os serviços do contratado (Modelo de Mooney-Rivlin, Fig. 5.5b), sem definir a forma como o serviço deve ser executado.

Os principais componentes que dividem o programa Axis são mostrados na Fig. 5.6 e explicados na sequência. Optou-se por não utilizar a notação UML no diagrama devido ao maior número de componentes e interações.

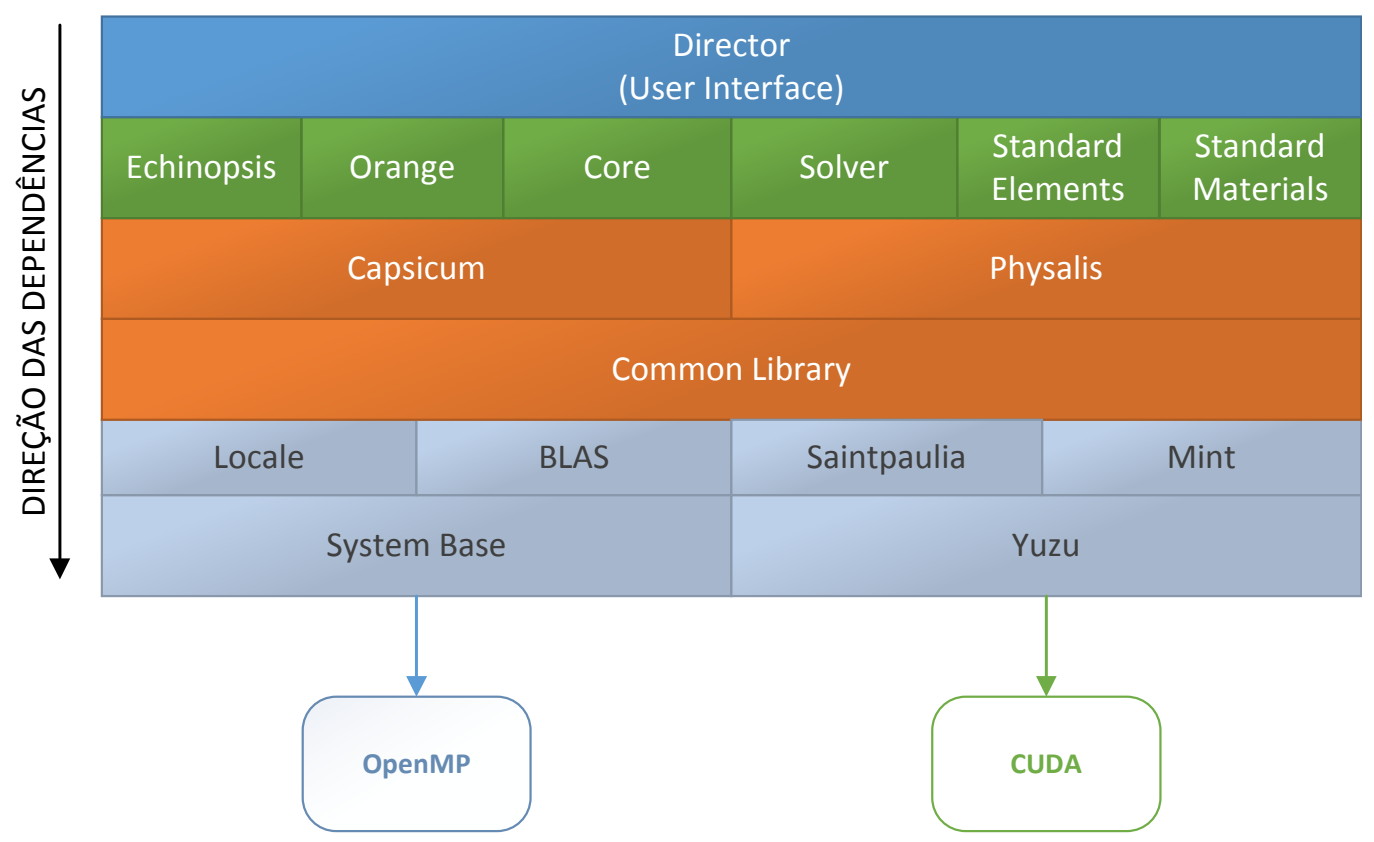

Figura 5.6 Componentes principais do Axis.

A organização segue o formato de uma pilha para evitar a criação de dependências cíclicas. A generalização e o número de componentes dependentes crescem na mesma direção das dependências. Cada componente define um conjunto de tarefas específicas ou oferece abstração, como forma de desacoplar dos aspectos tecnológicos dos níveis inferiores. Eles podem ser descritos segundo sua responsabilidade dentro do sistema:

Plataforma base do sistema Oferecem as primitivas básicas de dados que são utilizadas por todos os componentes do programa e também por componentes externos. O componente System Base oferece os mecanismos básicos para manipulação de plugins e localização de funcionalidades do sistema, conforme será explicado mais adiante. Também são disponibilizados os tipos de dados compostos de uso geral (literais, data, identificado- 
res, entre outros). O componente Yuzu expõe tipos de dados e operações para uso em GPU, sendo uma entidade essencial na elaboração de código em placas gráficas para o sistema.

Operações básicas Quatro tipos de operações são comuns em diversos pontos do programa e cada uma é encapsulada num componente. O componente Locale provê operações de localização ${ }^{4}$; BLAS ${ }^{5}$ oferece um conjunto mínimo de operações algébricas para manipulação de matrizes e vetores; Saintpaulia implementa funções algébricas mais elaboradas e comuns em Mecânica dos Sólidos, como o cálculo de auto-valores e auto-vetores e manipulação tensorial; finalmente, Mint oferece primitivas básicas para a interpretação textual em tokens, discutidas na Seção 5.5.3.

Serviços de uso comum no programa O componente Common Library expõe as classes bases para as entidades de domínio, isto é, os componentes diretamente relacionados com o problema. As classes-base para a solução pelo método dos elementos finitos são definidas aqui e utilizadas pelos componentes de nível superior. Estendendo as funcionalidades de uso comum, Capsicum oferece serviços para o gerenciamento das requisições de análise $(j o b)$. É de sua responsabilidade o despacho do job para o ambiente de processamento adequado (CPU ou GPU), processo discutido com maiores detalhes no Capítulo 7. Physalis oferece uma camada de abstração para os serviços de leitura do arquivo de entrada, vindos do Mint, expondo operações mais simples para a interpretação das informações no arquivo de entrada, no formato de leitura de parâmetros e valores.

Núcleo do programa $\mathrm{O}$ nível que contém as principais funcionalidades do programa é composto por seis componentes. Solver contém os algoritmos de solução de problemas, enumerados na Tab. 5.1. Standard Elements e Standard Materials oferecem as bibliotecas padrão de elementos e modelos de materiais, respectivamente. O componente Orange fornece outros objetos participantes da análise de elementos finitos, como as condições de contorno e classes que descrevem o seu comportamento ao longo do tempo. O componente Core contém as classes que são o ponto de partida para a execução da aplicação, coordenando o disparo dos diversos subsistemas da aplicação. Echinopsis oferece serviços para a gravação dos dados da análise para um programa de pós-processamento selecionado (MATLAB ou o pacote de programas Hyperworks, por exemplo).

\footnotetext{
${ }^{4}$ Do inglês locale, no que se refere a operações cuja apresentação do resultado varia de acordo com a localização regional configurada no sistema, tais como data, hora e valores numéricos.

${ }^{5}$ Acrônimo para Basic Linear Algebra Subprograms.
} 
Interface com o usuário Dado pelo componente Director, contém as classes que manipulam, atualizam a interface com o usuário e encaminham as solicitações para os componentes internos do programa.

\subsubsection{Distribuição das funcionalidades}

A Figura 5.7 mostra a fragmentação das funcionalidades (ou subsistemas) através dos componentes do programa. Essa divisão ocorre porque, para o cumprimento de uma determinada funcionalidade, é necessário o consumo de serviços oferecidos por diferentes componentes. Dentro de um componente, os serviços operam em diferentes camadas lógicas, de acordo com o nível de abstração apresentado.

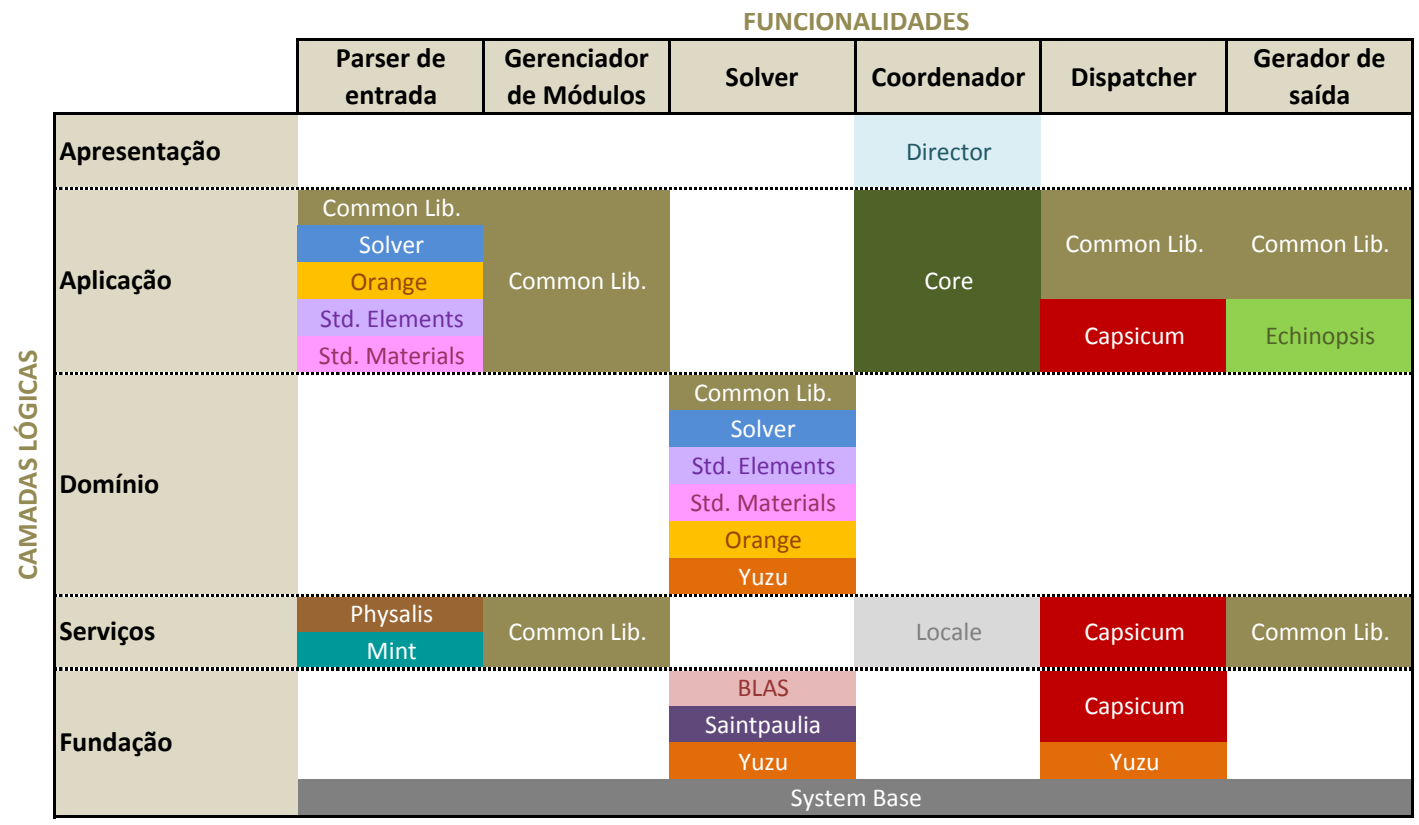

Figura 5.7 Distribuição das funcionalidades através das arquiteturas física e lógica.

No caso do subsistema Solver, por exemplo, nove componentes são necessários para compô-lo (Common Library, Solver, Standard Elements, Standard Materials, Orange, Yuzu, BLAS, Saintpaulia e System Base). As classes de domínio (vide seção 5.4) são declaradas nos componentes Common Library (estruturas básicas), Solver (algoritmos de solução padrão do programa), Standard Elements (tecnologias de elemento padrão), Standard Materials (modelos de material padrão) e Orange (condições de contorno e definições de comportamento das mesmas ao longo do tempo). O componente Yuzu oferece mecanismos de abstração para implementar essas classes em GPU. Para a implementação dos algoritmos, é necessário o uso de tipos de dados básicos, tais como vetores e matrizes, oferecidos pelos componentes System Base e BLAS. Saintpaulia e, novamente, Yuzu e BLAS, oferecem operações sobre 
esses tipos de dados. O nível de abstração das operações e dos dados é baixo, pois, isoladamente, pouco refletem os objetivos do software e, portanto, são localizados na camada de Fundação.

Também é possível fazer a leitura da importância de um componente a partir da Fig. 5.7. O componente System Base, por exemplo, participa na implementação de diversos subsistemas oferecendo serviços de baixo nível de abstração. Common Library tem importância similar, mas adquire valor ao participar de diferentes camadas da aplicação.

Algumas funcionalidades dependem de outras para concretizar sua operação. Tomando-se o subsistema Gerador de saída, para a transcrição dos resultados em um arquivo de saída, é necessária a leitura dos atributos nas entidades de domínio (elemento finito, carregamento, material, etc.), oferecidas pela funcionalidade Solver. Essa dependência é evidente através das relações ilustradas na Fig. 5.2.

A relevância desses três mecanismos de separação das operações e entidades do programa poderá ser melhor compreendida durante as discussões da elaboração do núcleo de elementos finitos.

\subsection{Modelo de domínio: construção básica do núcleo de elementos finitos}

O desenvolvimento inicial do núcleo MEF do programa consistiu na elaboração do modelo de domínio, cujas entidades principais encontram-se representadas nas Figuras 5.8 5.11. Sua construção partiu da análise das especificações do problema. A proposta dessa etapa é encontrar e descrever os conceitos principais (e essenciais) na definição do problema - tais como o elemento finito, o modelo numérico e o algoritmo de solução do problema. Esses elementos são descritos na forma de classes conceituais do programa, localizadas na camada de domínio.

Classes conceituais representam ideias oriundas da descrição do problema e que devem estar presentes durante o desenvolvimento. Em geral, isso implica no seu transporte para o conjunto de classes do programa final, mas, em alguns casos, o conceito pode ser desmembrado em múltiplas classes de produção, que desempenham papel equivalente.

Todas as entidades aqui discutidas, exceto suas especializações, são oferecidas pela biblioteca comum (componente Common Library). Nomes de componentes, classes, associações e atributos estão em inglês para melhor refletir a estrutura do programa. 


\subsubsection{Descrição de um elemento finito}

O elemento finito é, provavelmente, um dos conceitos que mais se relaciona com outras entidades do problema. Portanto, é importante a sua modelagem cuidadosa para que futuras intervenções neste conceito propaguem o menor número de modificações possível.

A proposta de modelagem da Figura 5.8 separa o conceito de elemento finito em uma face de dados e outra de operações. A face de dados, representada pela classe Element Geometry, é composta pela identificação dos nós associados ao elemento (e, consequentemente, os graus de liberdade, classe DoF) e dos pontos de integração, se houver. Operações sobre essas informações, tal como buscar o índice global de um nó local ou extrair o vetor local de uma quantia física a partir de sua versão global, também estão alocadas nessa entidade.

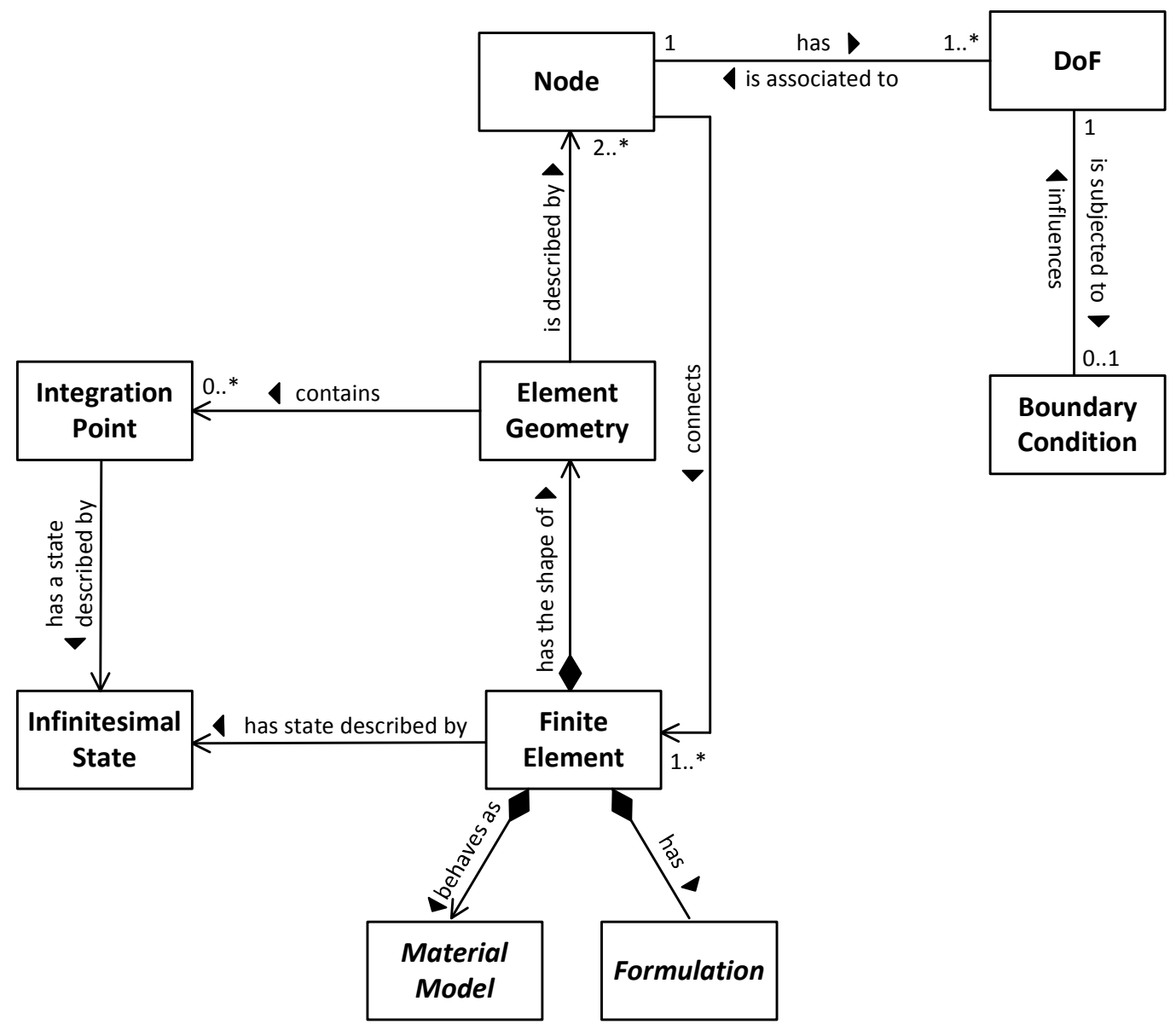

Figura 5.8 Modelo de domínio do software: descrição de um elemento finito.

A classe Finite Element é uma fachada para todo o sistema de classes que compõe o elemento finito. As principais operações são descritas na Figura 5.9. Ante 
ao acesso direto das operações, permite ocultar os detalhes de implementação do elemento. Ela também atua como uma classe de política [4], validando os parâmetros de entrada e de saída das operações e fornecendo uma estrutura básica para os algoritmos. Consequentemente, o código das especializações de Material Model e Formulation tem mais enfoque nas tarefas de sua responsabilidade. Essas classes têm a conotação de parte integrante do elemento, sendo visíveis apenas internamente. A classe Element Geometry, ao contrário, tem visibilidade pública através de um método de acesso.

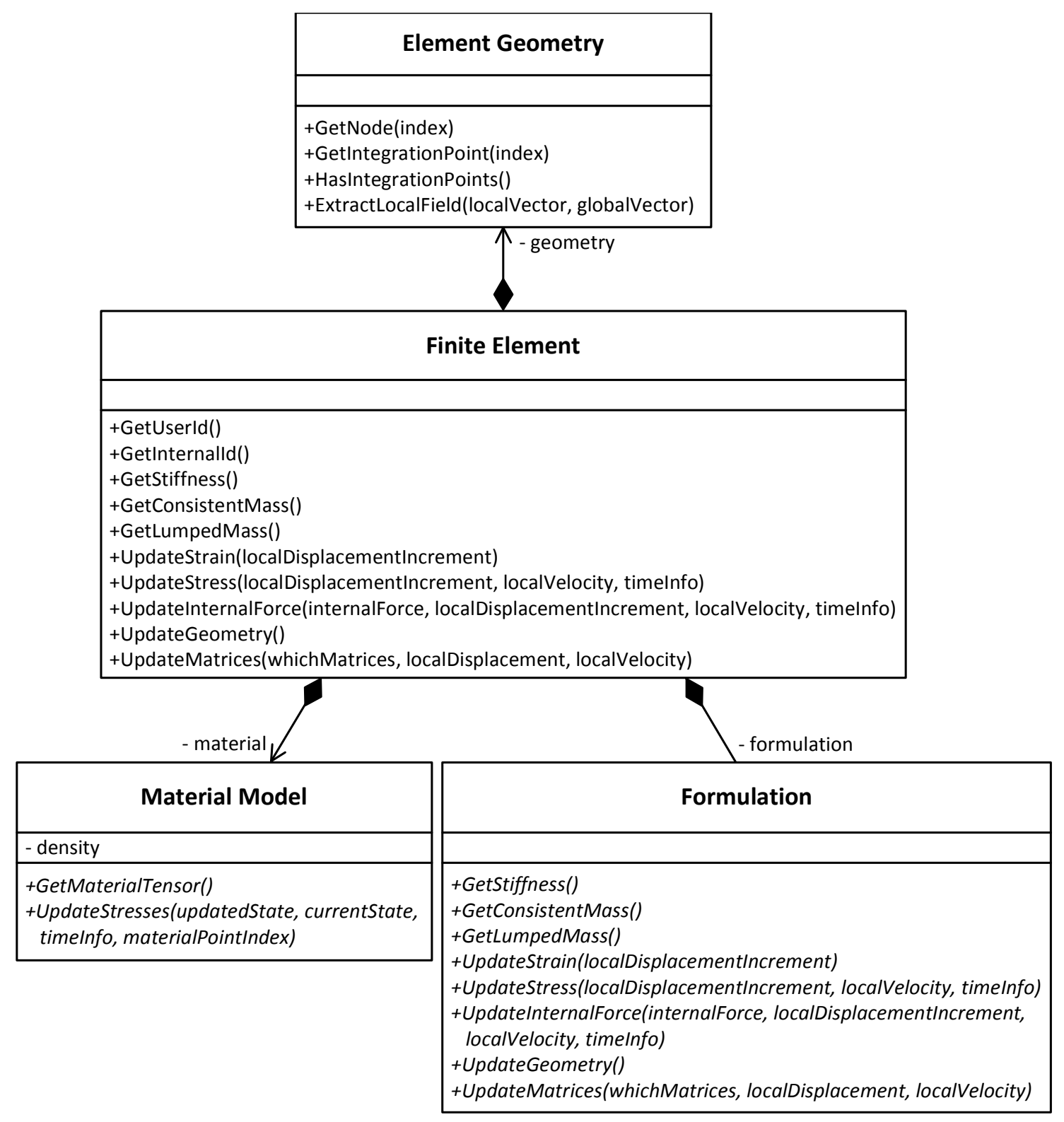

Figura 5.9 Principais operações do elemento finito. 
Os aspectos comportamentais do elemento, isto é, a descrição de suas operações, são oferecidos pelas especializações das classes Formulation (Fig. 5.10a) e Material Model (Fig. 5.10b). O método de interpolação das quantidades físicas (o que envolve métodos numéricos de integração, funções de interpolação, entre outros) e o cálculo das matrizes do elemento (rigidez e massa) são dados pela classe Formulation. Material Model implementa o cálculo de atualização do estado de tensão de um ponto segundo o modelo constitutivo.

Torna-se possível, portanto, a combinação de diferentes comportamentos de material para um mesmo elemento finito. Por questões de eficiência, sub-variantes de uma formulação de elemento (como o que ocorre ao variarem as funções de forma ou o método numérico de integração) são definidas como classes distintas.

A associação de uma condição de contorno (classe Boundary Condition) a um grau de liberdade (classe DoF), impõe um valor para uma grandeza física naquela direção (Fig. 5.10c). O comportamento dessa restrição é definido pela especialização da condição de contorno, podendo a variável estar associada a um histórico (classe Curve). A grandeza física na qual aquela condição de contorno atua é definida através da natureza da sua relação com o modelo numérico (Fig. 5.11), conforme será explicado na seção 5.4 .2 .

As demais classes da Fig. 5.8 atuam como classes de dados. Integration Point armazena informações sobre as coordenadas e peso dos pontos de integração, enquanto que Infinitesimal State detém informações sobre o estado de tensão e deformação do elemento. Node armazena a coordenada original (definida pela malha) e a atual (causada pela deformação) do nó.

\subsubsection{Modelo numérico}

O modelo numérico de uma análise é representado pela classe Numerical Model, ilustrado na Fig. 5.11, juntamente com as suas principais associações. A partir desta classe, é possível acessar a definição de todos os nós e elementos da malha e as condições de contorno aplicadas ao problema. Diferentes formas de associação entre uma condição de contorno e o modelo numérico (que são traduzidas em código como diferentes coleções de objetos) definem a natureza da condição de contorno. Estão exemplificadas na Fig. 5.11 a restrição do movimento de um grau de liberdade (associação is locked by) e a aplicação de cargas nodais (associação has applied loads described by). Outras condições, como deslocamento, velocidade e aceleração prescritos não foram representados em favor da clareza do diagrama.

As classes Model Kinematics e Model Dynamics detêm informações das quantias 


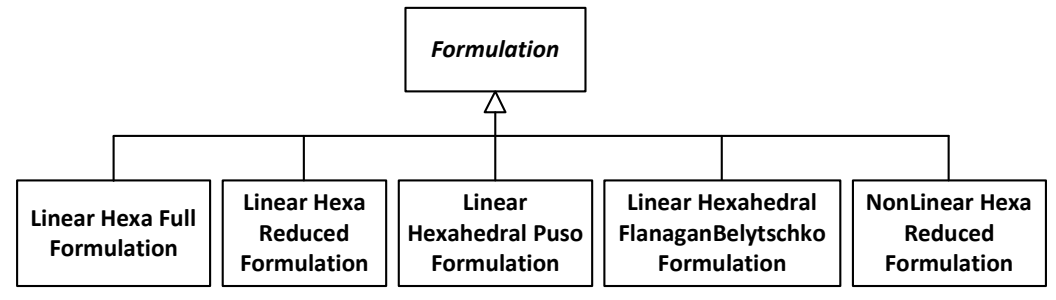

(a) Formulações de elemento (representação parcial)

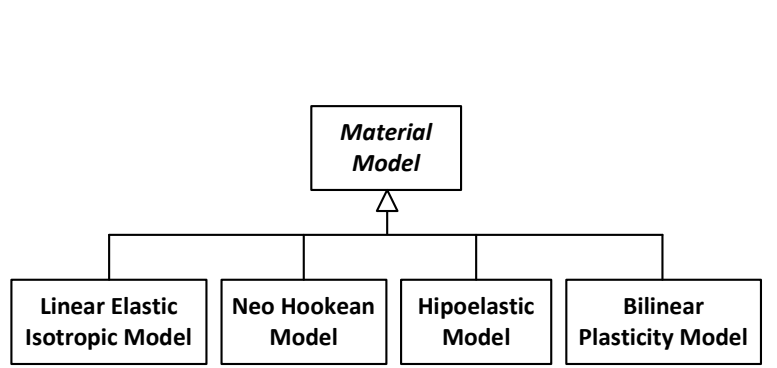

(b) Modelos de materiais

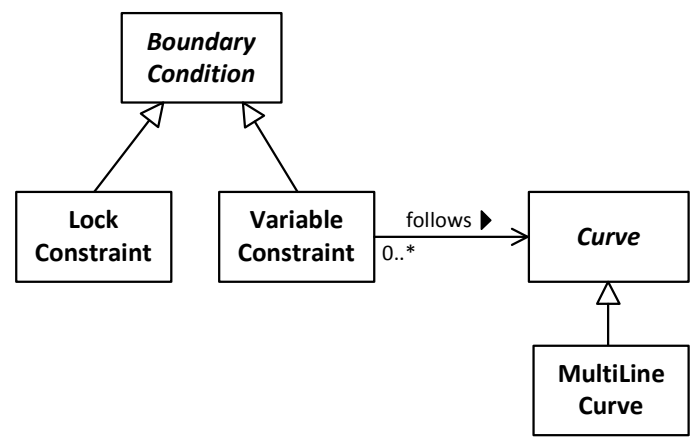

(c) Condições de contorno

Figura 5.10 Modelo de domínio do software: especializações de comportamento.

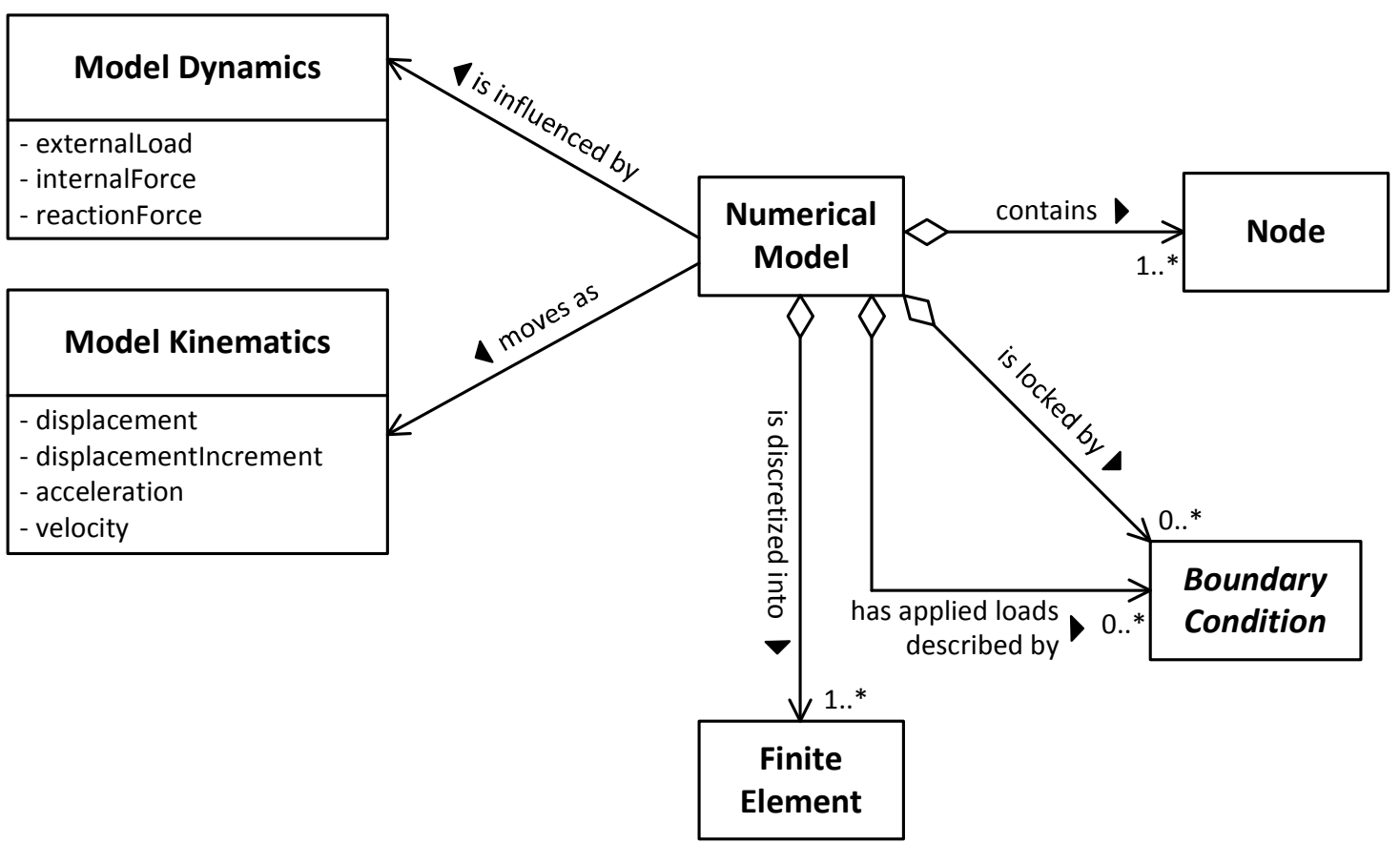

Figura 5.11 Modelo de domínio do software: representação básica de um modelo numérico. 
cinemáticas e dinâmicas do modelo, respectivamente. Em outras palavras, os vetores globais de deslocamento, aceleração, velocidade, forças internas, forças externas e reações de apoio são armazenados e controlados por essas classes. Ressalta-se, no entanto, que matrizes globais do problema, como a matriz de rigidez, não são responsabilidades dessas classes, pois são consideradas dependentes do tipo de análise e do algoritmo de solução sendo executado. Portanto, são gerenciadas pelo solver propriamente dito.

\subsubsection{Definição genérica do solver}

Todos os solvers suportados pelo núcleo são implementados sobre uma mesma estrutura lógica, ilustrada na Fig. 5.12.

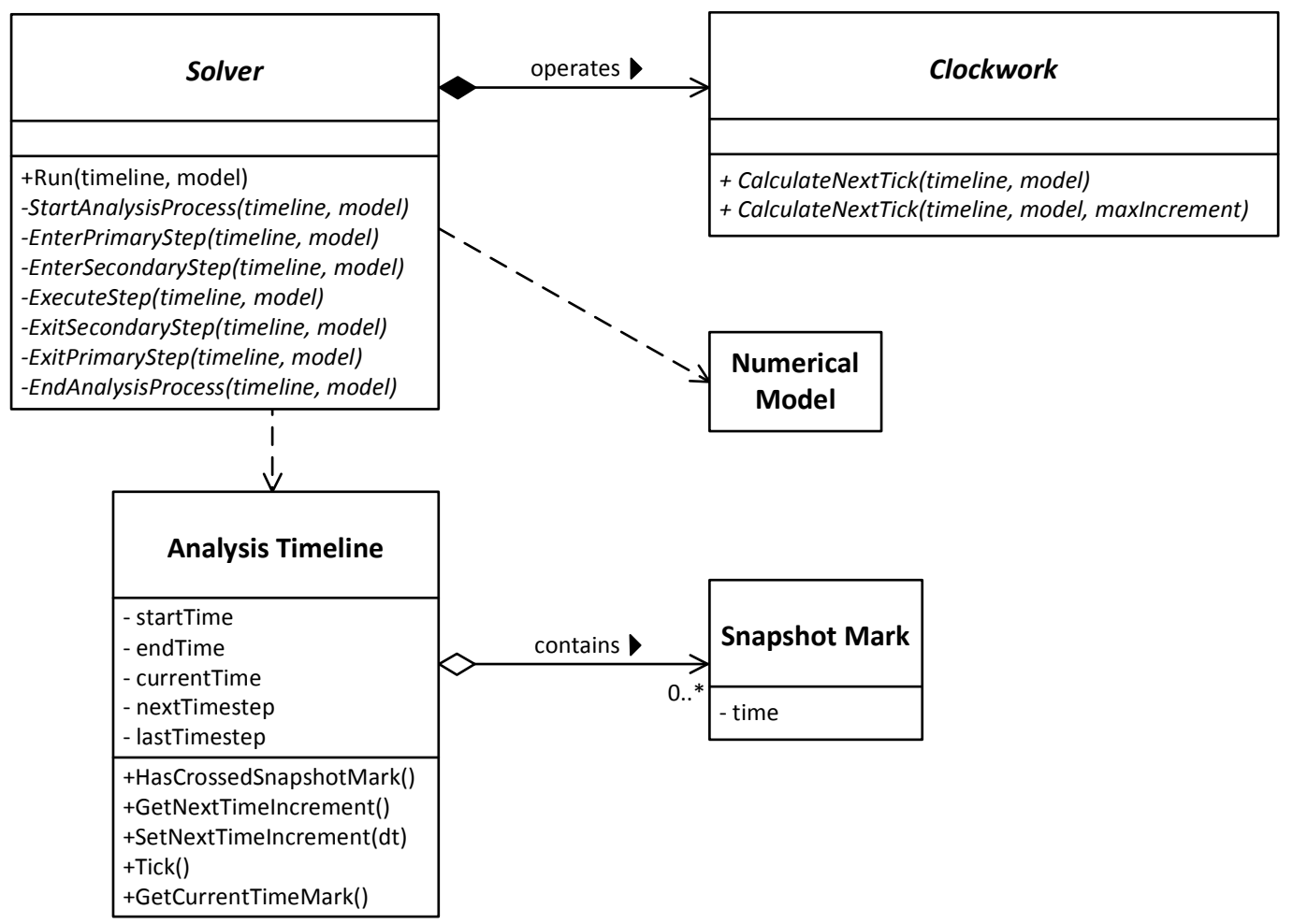

Figura 5.12 Modelo de domínio do software: solver genérico.

Na visão do programa, o Solver é uma classe que modifica o estado do par de objetos relacionados, o modelo numérico e a linha temporal. A duração da simulação numérica é dada pela linha temporal (instância de Analysis Timeline). Essa classe base oferece a lógica básica de iteração no tempo, herdada por todas as implementações especializadas.

A cada instante de tempo, um novo estado para o modelo numérico é calculado 
e, eventualmente, as informações são coletadas e gravadas nos arquivos de saída da análise. Em analogia ao mecanismo de um relógio, Clockwork é a classe especializada no cálculo do incremento de tempo, cujo valor pode ser estimado em função de aspectos do modelo numérico. A manipulação do Clockwork pela classe Solver é transparente para suas subclasses.

Definidos no arquivo de entrada, marcas de snapshot (instâncias de Snapshot Mark) identificam instantes de tempo sobre a linha temporal da análise (Fig. 5.13). As marcas identificam o momento em que o solver deverá obter o instantâneo (snapshot) do modelo numérico, isto é, efetuar o disparo da coleta de dados. O avanço sobre a linha temporal, dado pelo incremento de tempo calculado, e as marcas de snapshot, definem duas fases de execução do solver, identificadas na Fig. 5.13: a fase primária e a secundária.

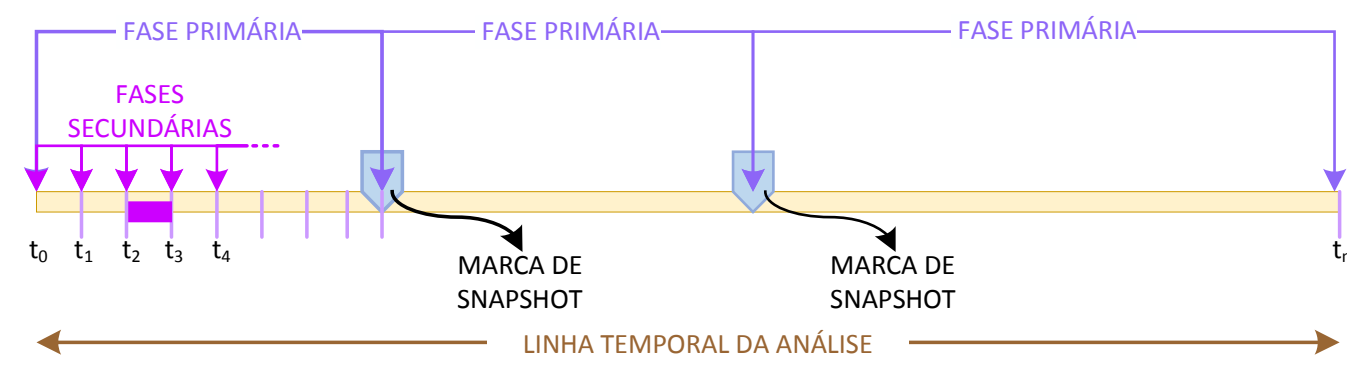

Figura 5.13 Segmentação da análise em fases discretas.

A fase primária é delimitada pelas marcas de snapshot. Normalmente, está relacionada com a preparação dos arquivos de saída para a gravação de um novo estado do modelo numérico (como, por exemplo, gravação de cabeçalhos e rodapés, abertura de registros num banco de dados, etc.).

Dentro da fase primária, as iterações definem fases secundárias, onde o algoritmo do solver é executado, calculando um novo estado intermediário do modelo a cada instante de tempo. Deve-se observar que não é obrigatória a regularidade do incremento de tempo ou das marcas de snapshot, tal como em análises dinâmicas não-lineares.

A partir da discretização do tempo, definem-se sete operações sobrecarregáveis para a descrição do algoritmo do solver, ilustradas na Fig. 5.14. Na implementação base, as operações são no-op, isto é, não executam qualquer instrução, retornando imediatamente o controle para a função chamadora e cabendo às classes derivadas a sua correta definição.

A execução do processo de solução tem início ao ser disparado o método concreto Run da classe Solver (Fig. 5.12). A lógica de execução iterativa ativa as ope- 
rações sobrecarregáveis em momentos distintos. O início e o final do processo de análise são marcados pelos métodos StartAnalysisProcess e EndAnalysisProcess, respectivamente. A entrada e saída das fases primárias e secundárias são identificadas pela execução de seus respectivos métodos Enter...Step e Exit...Step. A cada fase secundária, ExecuteStep é ativado entre as operações de entrada e saída da fase. Na Fig. 5.14, é sugerida uma lógica de implementação do solver nos métodos.

Essa estrutura mostrou-se suficiente para a construção dos diferentes solvers suportados pelo programa ${ }^{6}$. O detalhamento das computações implementadas sobre esse modelo é apresentada nos próximos capítulos.

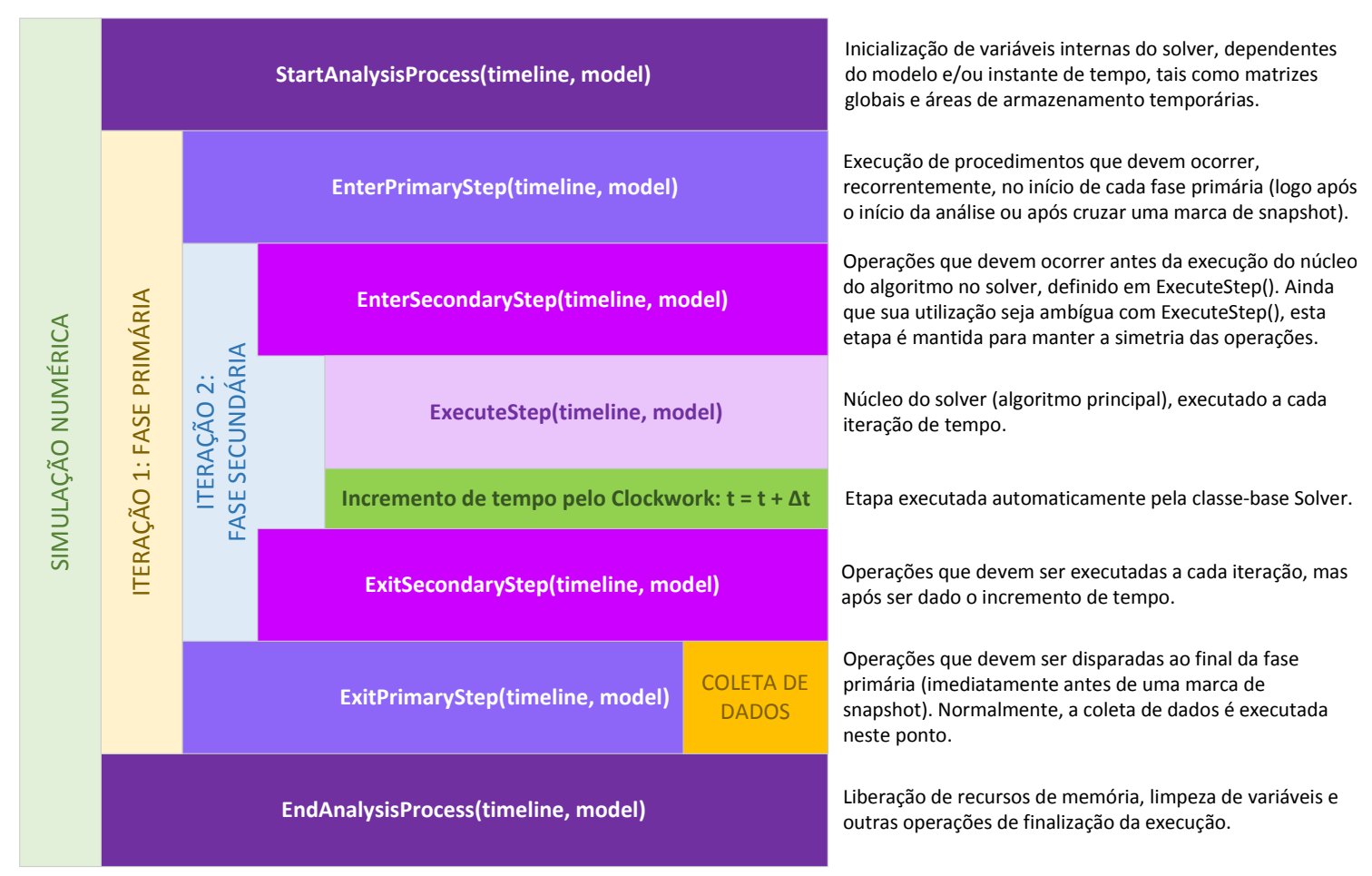

Figura 5.14 Operações sobrecarregáveis do solver.

\subsection{Extensibilidade e robustez do núcleo}

A extensibilidade e a robustez do núcleo implementado em Axis se revelam como as características mais importantes do código. Conforme foi apresentado na seção 5.1, o programa permite que as funcionalidades do programa sejam estendidas por meio de componentes carregados dinamicamente, em tempo de execução - os plugins. Para que novos recursos pudessem ser injetados na aplicação sem a necessidade de mo-

\footnotetext{
${ }^{6}$ Também foi observada a possibilidade de adaptação da estrutura para outros solvers. Numa análise modal, por exemplo, as marcas de snapshot definem os modos de vibrar a serem calculados. O incremento de tempo é regular e discreto. Em cada fase secundária, os modos são calculados e exportados para a saída do programa.
} 
dificar o código já existente, foi necessária a implementação de alguns mecanismos, discutidos a seguir.

\subsubsection{Carregamento dinâmico de plugins}

Todas as funcionalidades do programa, isto é, solvers, bibliotecas de elementos e materiais, tipos de condições de contorno, formatos de arquivo de saída e algoritmos de controle do passo de tempo, além das regras de sintaxe do arquivo de entrada para a correta leitura desses elementos, são oferecidas através de plugins - como os componentes Solver, Standard Elements, Standard Materials, Orange e Echinopis. Esses componentes são inseridos no programa através do gerenciador de módulos.

$\mathrm{Na}$ inicialização, o programa efetua a leitura de um script de configuração, onde são especificados os plugins a serem carregados. Para cada plugin especificado, a biblioteca dinâmica correspondente é carregada e se inicia a busca pela função de entrada do plugin, AxisPluginLoader_GetLoader. A finalidade dessa função é criar uma instância da classe utilitária (classe PluginLoader) que inicie o processo de registro de todas as funcionalidades oferecidas pelo plugin no programa. A Fig. 5.15 oferece um quadro resumo dessas operações. A descrição do arquivo de configuração do programa é dada no Apêndice $\mathrm{E}$.

As dependências tecnológicas causadas pelo uso de chamadas do sistema (no caso, LoadLibrary e GetProcAddress, da API do Windows) e padrões tecnológicos (XML) são isoladas em classes tecnológicas, como ilustrado na Fig. 5.16. Os objetos que fazem uso dessas funcionalidades passam a depender apenas da definição de uma classe abstrata, permitindo que alterações tecnológicas possam ocorrer sem prejuízo ao código específico do domínio do programa. A criação do objeto concreto é delegada para um objeto de nível superior, responsável por orquestrar todo o processo (não representado na figura).

Dentro do programa Axis, cada funcionalidade é representada por uma instância da classe Provider. Esses objetos são armazenados e organizados pela classe GlobalProviderCatalog, que atua como um índice para as funcionalidades disponíveis no programa. A instância de PluginLoader, fornecida pela função AxisPluginLoader_GetLoader do plugin, é responsável por registrar todos os provedores de recursos oferecidos assim que o método StartPlugin é invocado. A partir de então, tornam-se disponíveis as funcionalidades para o usuário. Ao final da execução do programa, todos os plugins são descarregados e tem início a operação de remoção dos registros de provedores. O procedimento é similar ao carregamento, ocorrendo em ordem inversa. 


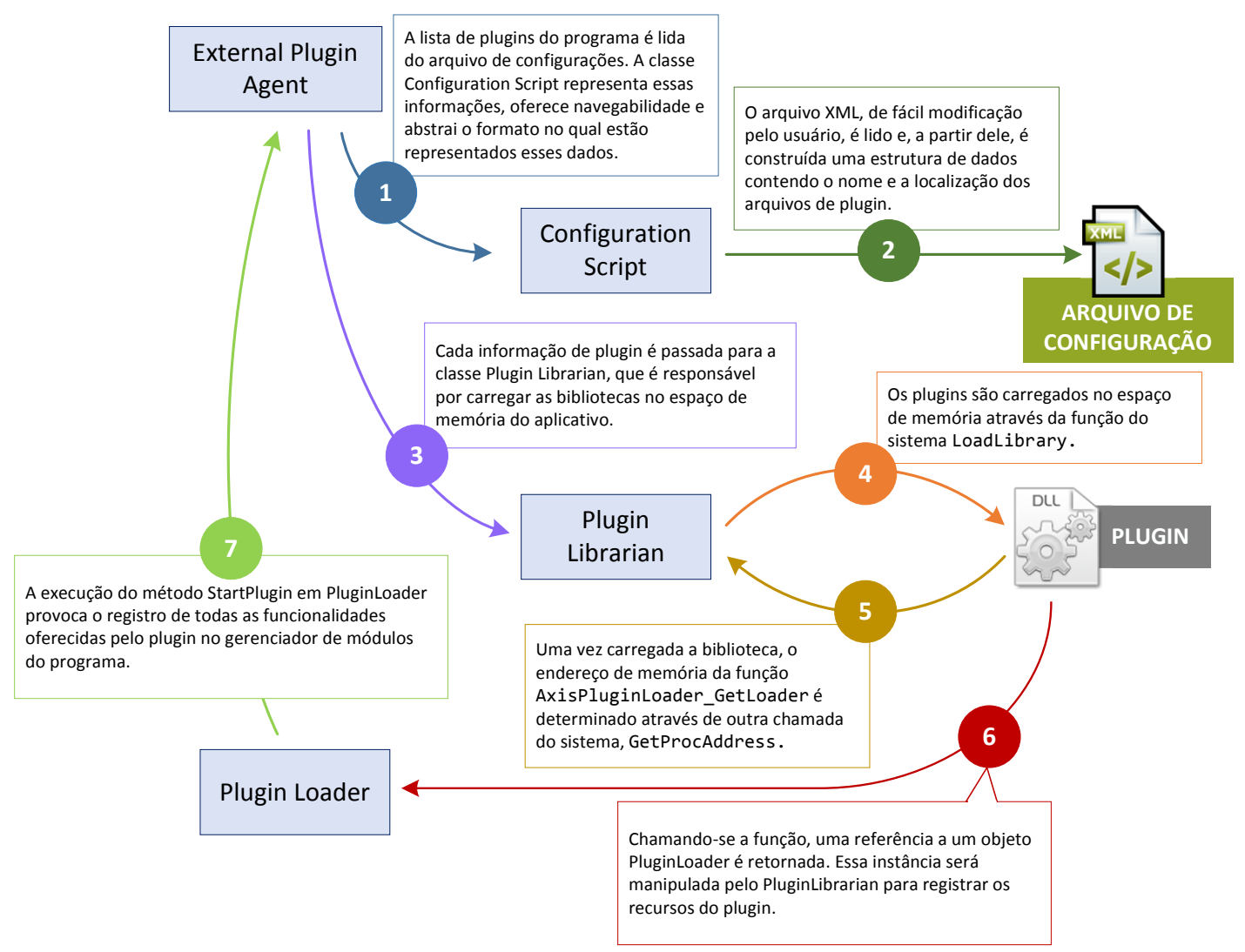

Figura 5.15 Esquema de carregamento de plugins no espaço de memória do programa.

Contudo, ainda é necessário estabelecer a relação das instruções do arquivo de entrada com as funcionalidades registradas pelo plugin. Para uma dada instrução, o programa deverá interpretar, identificar e construir em memória a funcionalidade referida. A ligação dos provedores com o parser de entrada é feita através dos objetos de localização (localizadores) e das fábricas de recursos.

\subsubsection{Provedores, localizadores e fábricas de recursos}

No Axis, todos os provedores de recursos são identificados exclusivamente por um nome completamente qualificado, dado pelo método GetFeaturePath da instância (Fig. 5.16). Conhecendo-se o nome completamente qualificado do provedor, é possível obtê-lo através do método GetProvider do catálogo global de provedores.

$\mathrm{Na}$ inicialização do programa, tipos especiais de provedores são definidos e registrados sob um nome conhecido. Os localizadores e as fábricas de recursos, inscritos no catálogo global, fornecem o ponto de partida para a detecção de novas funcionalidades pelo programa. 


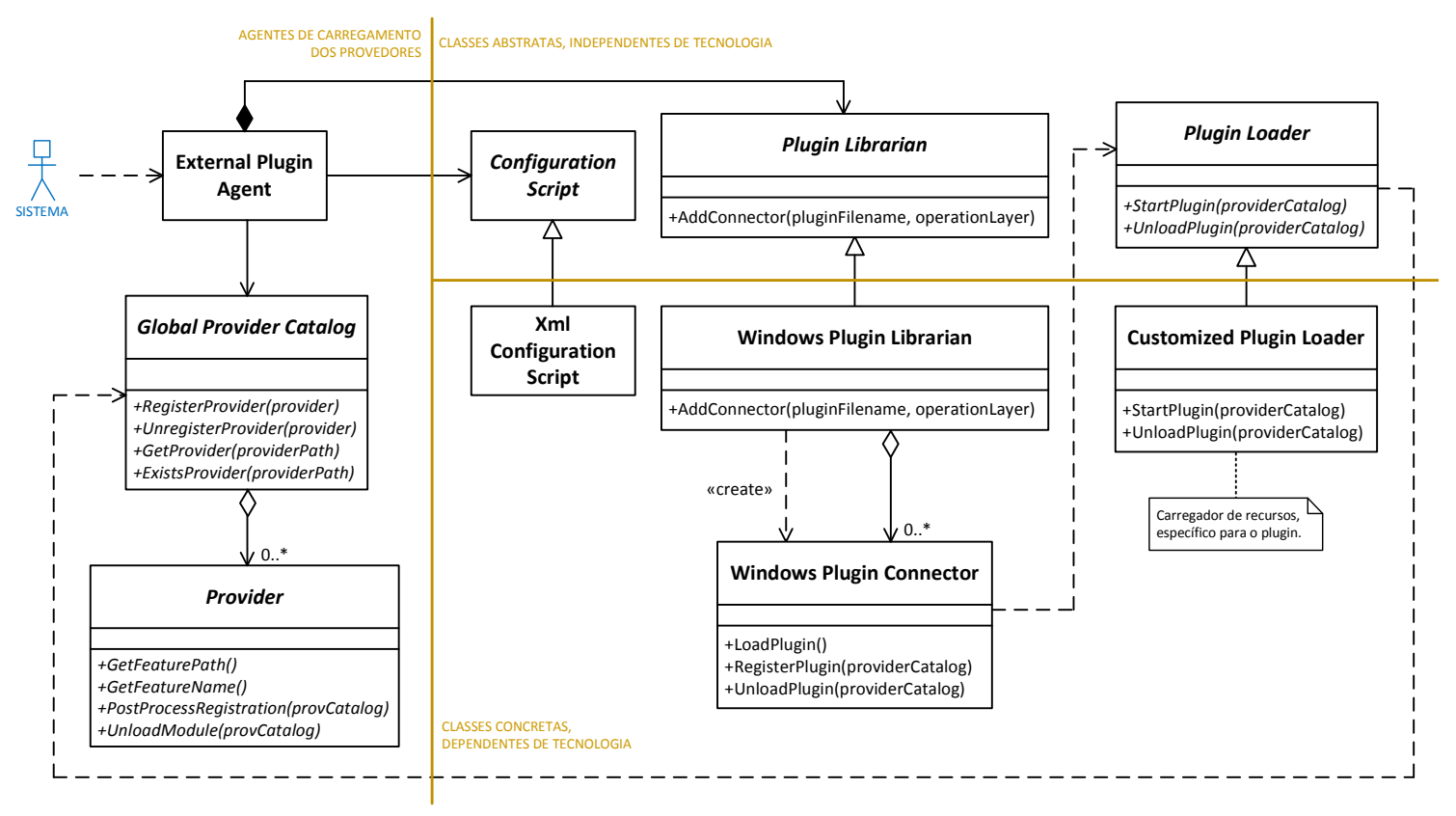

Figura 5.16 Principais classes e operações envolvidas no carregamento dinâmico de recursos do Axis.

Para ilustrar o funcionamento do processo, o sistema de localização e montagem para subclasses de Clockwork (vide Fig. 5.12) será tomado como exemplo e é ilustrado na Fig. 5.17.

Logo na inicialização do programa, o localizador de clockwork (classe ClockworkFactoryLocator), é registrado no catálogo global de provedores e identificado através de seu nome completamente qualificado, obtido através da consulta ao método GetFeaturePath da instância ${ }^{7}$. Esse nome é fixo e conhecido para o usuário e desenvolvedores de plugins.

O componente Solver é um plugin externo que implementa os algoritmos de solução do programa. Ao ser carregado, na solicitação do registro de suas funcionalidades, a instância da classe PluginLoader, implementada no componente, obtém referência ao localizador de clockwork (método GetProvider) para o registro de suas fábricas especializadas (no caso, RegularClockworkFactory).

A classe ClockworkFactory define a interface esperada para uma fábrica especializada na criação de um objeto Clockwork funcional. As instâncias especializadas dessa classe são registradas no localizador através do método RegisterFactory. O

\footnotetext{
${ }^{7}$ No Axis, os nomes dos provedores são organizados em uma árvore hierárquica de recursos. O nome da hierarquia mais geral (axis) mantém-se à esquerda e o recurso (clockwork_factory), mais específico, é colocado à direita do nome. Um ponto separa os nomes de cada nível da hierarquia. A organização em árvore facilita o entendimento da organização dos provedores e aumenta a eficiência na busca do recurso desejado.
} 


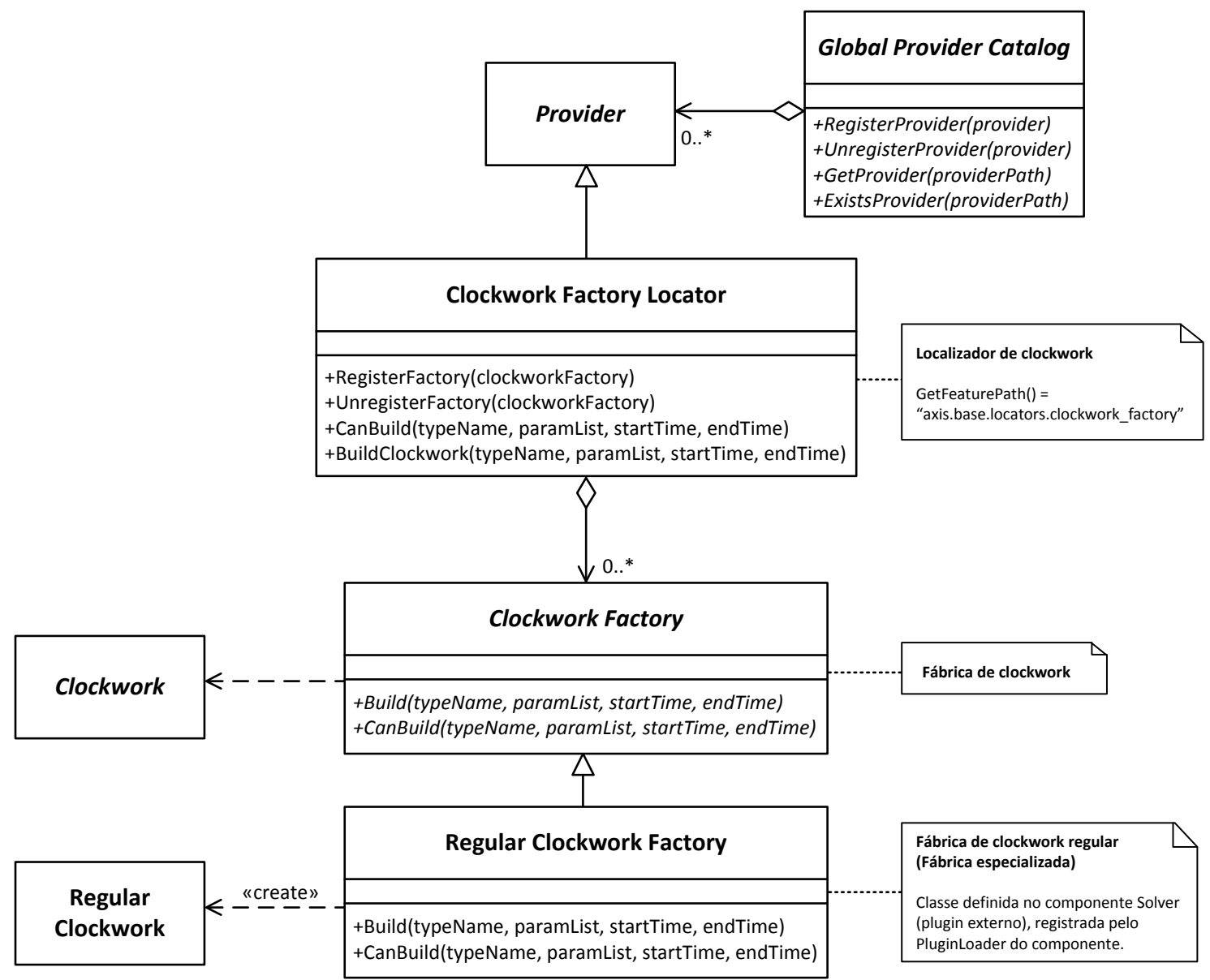

Figura 5.17 Exemplo de localizador e fábrica de recurso: montagem de clockworks.

desligamento de uma fábrica é feito pelo método UnregisterFactory.

Durante a leitura do arquivo de entrada, assim que é identificada a definição do solver da análise, a instrução é traduzida em uma lista de parâmetros da qual são extraídos os valores relevantes para a construção de um Clockwork. Com esse conjunto de valores, o método CanBuild do localizador é usado para detectar se algum provedor registrado demonstra ser capaz de construir a especialização especificado pelo usuário (o método CanBuild de cada fábrica é consultado até encontrar uma reclamante ou nenhuma se declarar). Em caso positivo, a fábrica que se manifestou é usada para criar a instância de Clockwork, através do método BuildClockwork.

Essa construção se repete para diversos tipos de funcionalidades do programa, tais como na identificação e construção de elementos, materiais e condições de contorno. A Fig. 5.18 oferece um outro exemplo do mecanismo, aplicado à identificação de provedores de modelos de materiais. 


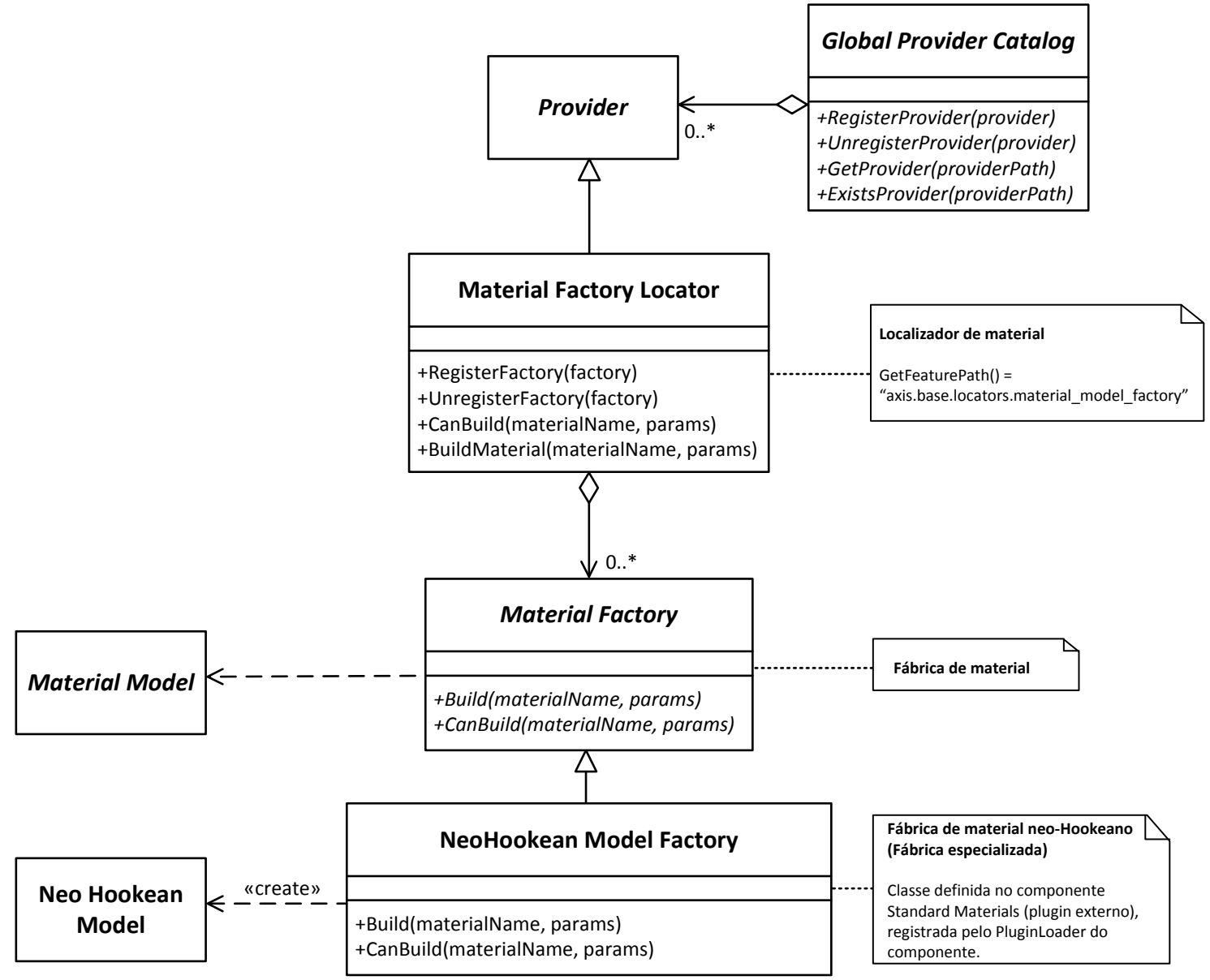

Figura 5.18 Exemplo de localizador e fábrica de recurso: montagem de materiais.

\subsubsection{Interpretador sintático do arquivo de entrada}

O programa Axis efetua a leitura do arquivo de entrada através de um analisador sintático LL $(1)^{8}$, baseado na biblioteca Boost [65]. Nesse sistema de leitura, primitivas básicas oferecidas pela biblioteca Mint - tais como parsers de identificadores, números, strings e vetores - são encadeadas para a construção de instruções sintaticamente mais complexas, definindo a declaração de uma funcionalidade do programa no arquivo de entrada. O formato geral da linguagem declarativa é apresentada no Apêndice C. O Apêndice D oferece alguns exemplos de entrada do programa.

O formato Axis do arquivo de entrada é dado em blocos aninhados, conforme ilustra a Listagem 5.1. A definição dos componentes da análise é delimitada em blocos que identificam a natureza da informação, isto é, cada bloco define um as-

\footnotetext{
${ }^{8} \mathrm{Em}$ um analisador sintático LL(1), a estrutura da frase (declaração), é identificada da esquerda para direita, observando-se, no máximo, um caractere após o atualmente lido para se diferenciar entre construções sintáticas similares [1].
} 
pecto específico da análise e é tratado por um único parser registrado no programa. Por exemplo, os nós da malha são definidos no bloco NODES. A interpretação de um bloco depende de seu aninhamento dentro de outros blocos, caracterizando o contexto da informação. No mesmo exemplo, o bloco NODES é corretamente intepretado apenas se não estiver aninhado dentro de outros blocos.

O componente Physalis define uma arquitetura básica de parsers de bloco, mostrada na Fig. 5.19. Usando um princípio de funcionamento similar ao comentado na seção 5.5.2, especializações da classe BlockParser detêm a responsabilidade de efetuar o parsing das informações contidas num determinado bloco. A instância do parser é fornecida pelo provedor de bloco correspondente, uma instância de BlockProvider. Os provedores de bloco mais relevantes para a aplicação, como o provedor do parser raiz, parser de elementos e o de materiais, são registrados no catálogo global de provedores para permitir a extensão da linguagem a partir desses pontos.

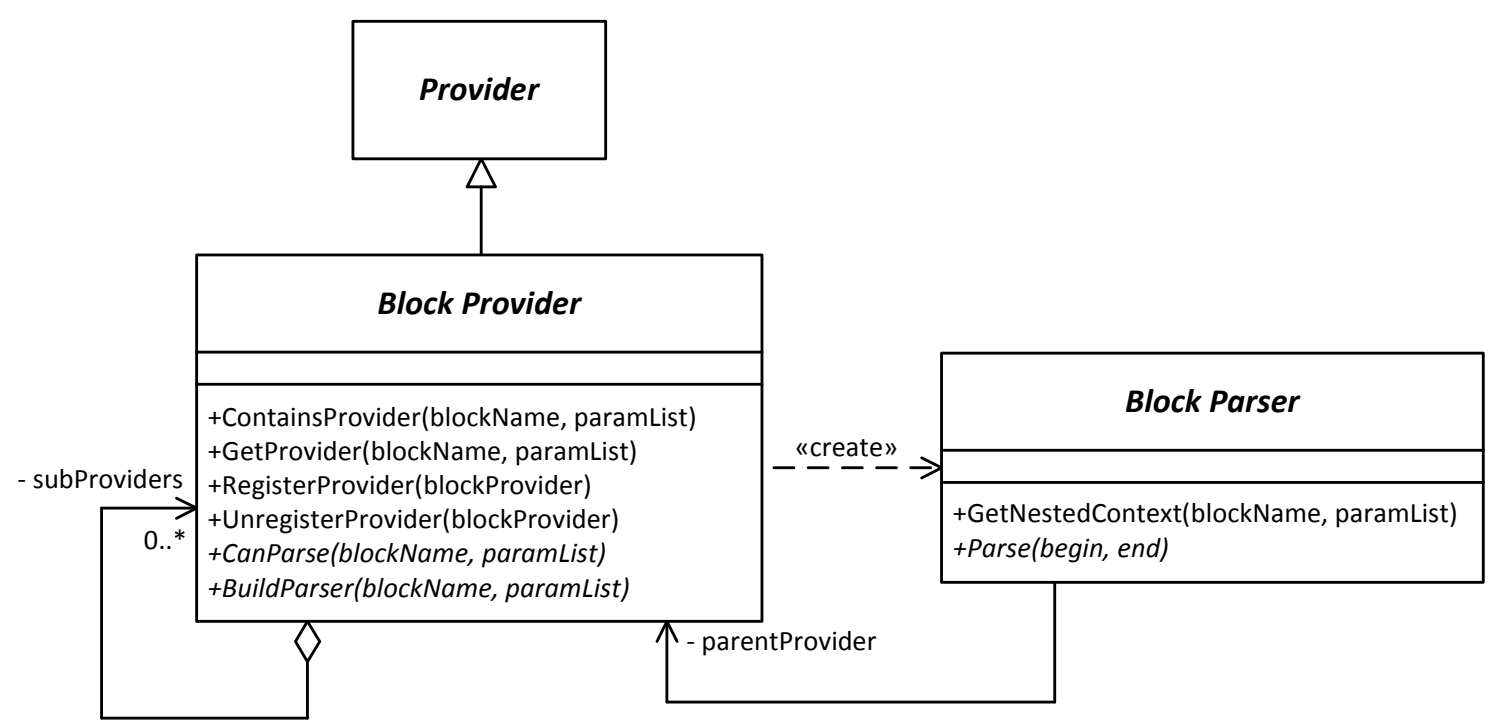

Figura 5.19 Organização básica dos parsers de bloco.

Todo provedor de blocos permite que outros provedores se registrem nele para a inclusão de subprovedores aninhados. O aninhamento é a indicação da relação hierárquica entre dois blocos e é registrada através do método RegisterProvider do bloco de nível superior.

O sistema de leitura do Axis captura todas as declarações de abertura e fechamento de blocos (instruções BEGIN...END na Listagem 5.1), impedindo que, de outra forma, sejam erroneamente processadas pelos parsers de bloco. Ao encontrar a instrução, consultando o provedor pai do parser de bloco atual (associação parentProvider da Fig. 5.19), é verificada a existência de algum sub-provedor (associação 
Listagem 5.1: Excerto de estrutura em bloco do arquivo de entrada do programa.

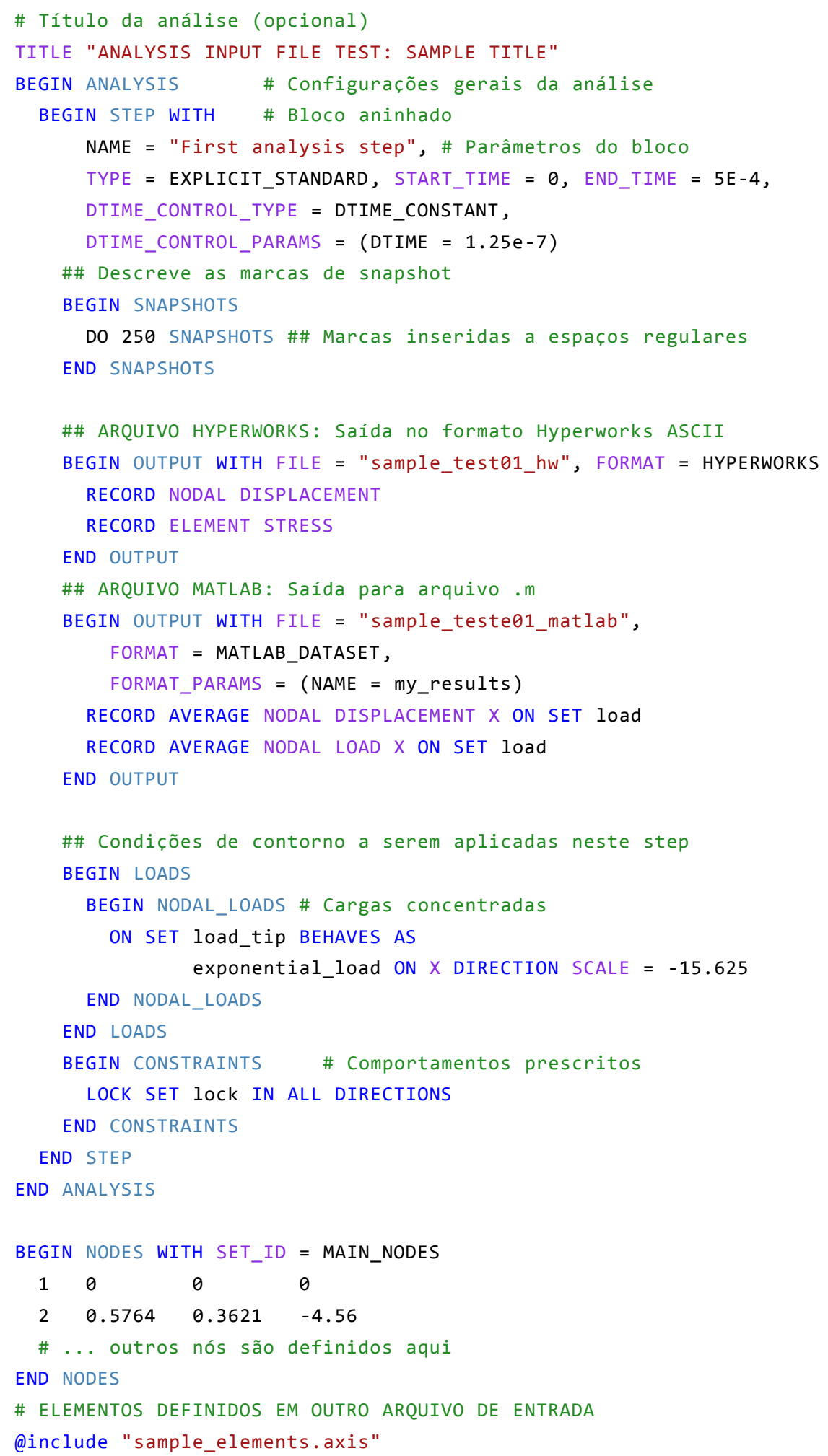


subProviders) que se identifique como capaz de interpretar o bloco declarado (método CanParse). Em caso positivo, o provedor é usado para criar o parser adequado. Parsers anteriores são mantidos em espera, organizados numa pilha, e são reativados à medida que os blocos aninhados são consumidos (isto é, lidos até o final).

O módulo do parser de entrada (Fig. 5.2) é composto de diversos outros mecanismos que promovem a sua escalabilidade e robustez. É importante enumerar algumas das características que elas conferem ao sistema:

- Comentários em bloco e em linha. Comentários podem ser adicionados ao arquivo de entrada, delimitados por separadores específicos ou por um indicador de comentário e o final da linha em que aparece. Isso promove a criação de arquivos de entrada mais legíveis e auto-explicativos.

- Insensibilidade à ordem de declaração. Elementos da análise que dependem de outros para a sua correta definição, tal como os nós para um elemento, podem ser declarados em qualquer ordem ou posição do arquivo de entrada, desde que o bloco seja declarado no contexto (aninhamento) correto.

- Insensibilidade à formatação. Instruções podem ser declaradas em uma ou múltiplas linhas, de acordo com a conveniência para o usuário. O sistema de parser automaticamente detecta o final de uma instrução que se estende por várias linhas e ignora espaços em branco adicionais e comentários inseridos no meio da instrução.

- API robusta. A biblioteca Mint já define parsers para primitivas básicas nas instruções do arquivo de entrada, como a identificação de tipos numéricos, identificadores, literais, e também complexas, como atribuições, listas e vetores. Para a criação de parsers de elementos e materiais, por exemplo, a biblioteca Physalis já oferece um conjunto de recursos que reduzem o trabalho na criação de um parser personalizado para o novo recurso, diminuindo a carga de trabalho necessária para estender o programa.

\subsubsection{Desacoplamento da saída de dados}

A flexibilidade oferecida na extensão das funcionalidades do programa Axis é garantida, entre outros aspectos, pela independência dos módulos do software. A redução dos vínculos entre atividades de naturezas distintas (por exemplo, simulação numérica e saída de dados) dá maior flexibilidade na manipulação dos componentes e diminui consideravelmente a propagação de mudanças no programa. 
O módulo gerador de saída é construído de tal forma que os demais subsistemas são completamente invisíveis para ele. A comunicação com o módulo é feita através de um mecanismo de distribuição de mensagens, definido pelas classes na Fig. 5.20 .

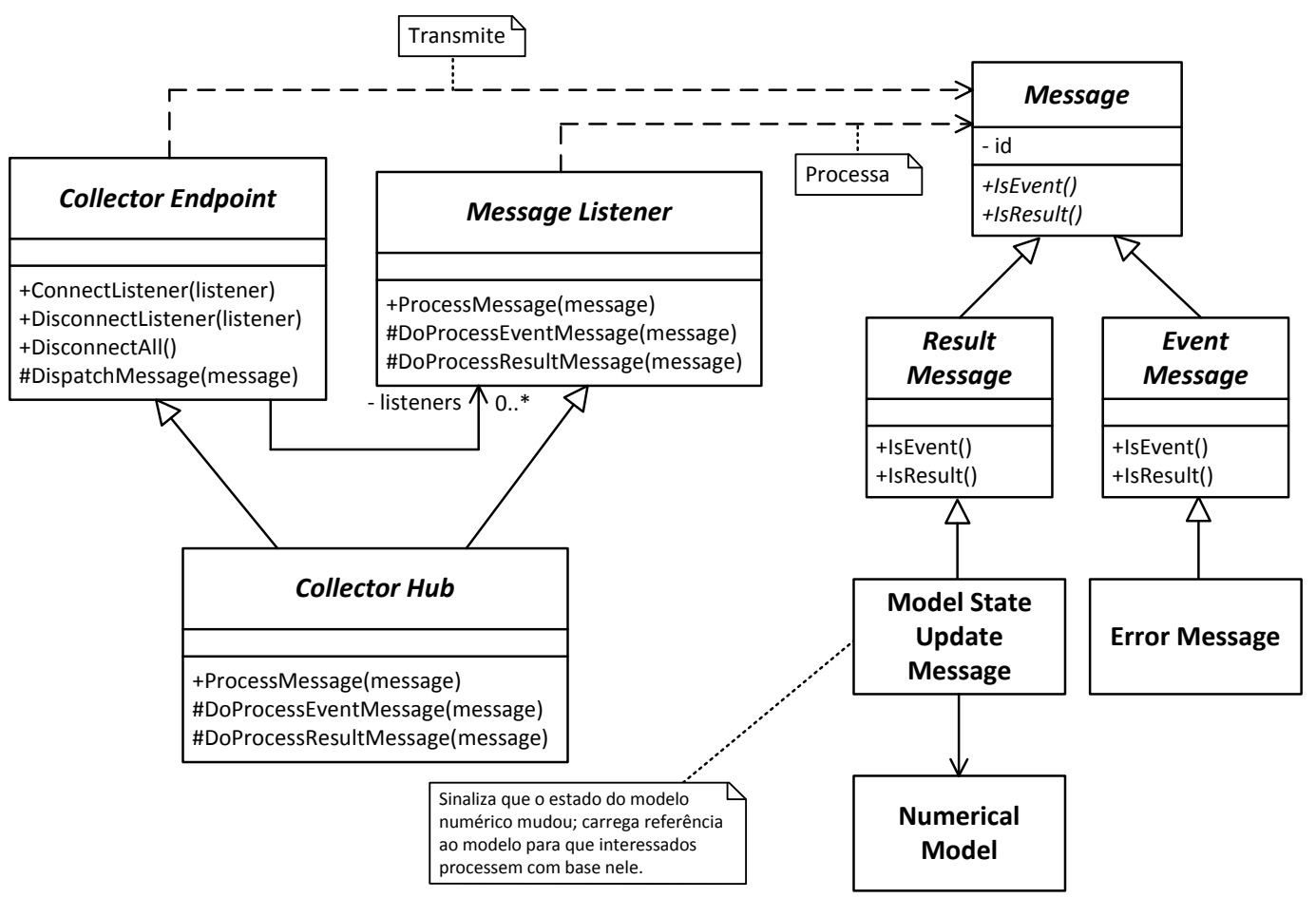

Figura 5.20 Entidades principais do sistema de transporte de mensagens.

O sistema de distribuição de mensagens é definido no componente System Base e constitui uma parte importante para o correto funcionamento do programa. Entidades importantes, como controles de interfaces com o usuário (UI), algoritmos de pós-processamento e coletores de dados, são interconectados através dele, promovendo o transporte de informações entre objetos de camadas ou responsabilidades distintas.

Eventos importantes no programa são sinalizados através do envio de mensagens que são transmitidas a todas as entidades interessadas, isto é, a todos os objetos que demonstram interesse no processamento das mensagens. Uma mensagem genérica é representada pela classe Message (Fig. 5.20), podendo se enquadrar em uma de duas categorias de informação distintas. Eventos gerais, que não carregam valor significativo para a simulação numérica em si, tais como mensagens de log, erros ou informações de depuração, são categorizados como mensagens de evento (classe EventMessage). Do contrário, outras mensagens, tais como indicação do término do cálculo da iteração de tempo ou indicação do término da simulação numérica, são definidas como mensagens de resultado (classe ResultMessage). 
O sistema de envio é construído a partir da ligação das entidades numa rede, cujos participantes são responsáveis por encaminhar as mensagens a todos os seus vizinhos próximos, comportamento similar ao padrão "cadeia de responsabilidade" e estruturalmente similar ao padrão "observador" [92].

Os objetos que apenas emitem as notificações de evento (mensagens) são instâncias da classe CollectorEndpoint, os terminais. As entidades que têm interesse no processamento das mensagens de uma fonte se registram nos terminais através do método ConnectListener. Esse papel é desempenhado pelas instâncias da classe MessageListener, os ouvintes.

O desacoplamento oferecido pelo sistema reside no fato de que não é requerido um ouvinte conhecer diretamente o terminal para que possa "escutar" suas mensagens. Na realidade, diversos ouvintes intermediários se conectam na rede de mensagens do Axis, os hubs, instâncias de CollectorHub.

Um hub é capaz de processar as mensagens recebidas e, então, retransmití-las para seus vizinhos imediatos, os ouvintes que se registraram através do método ConnectListener. Como é possível determinar pelo diagrama da Fig. 5.20, o hub também pode disparar mensagens, que serão retransmitidas a todos os pontos conectados a ele. A Fig. 5.21 esquematiza o processo de envio de mensagens.

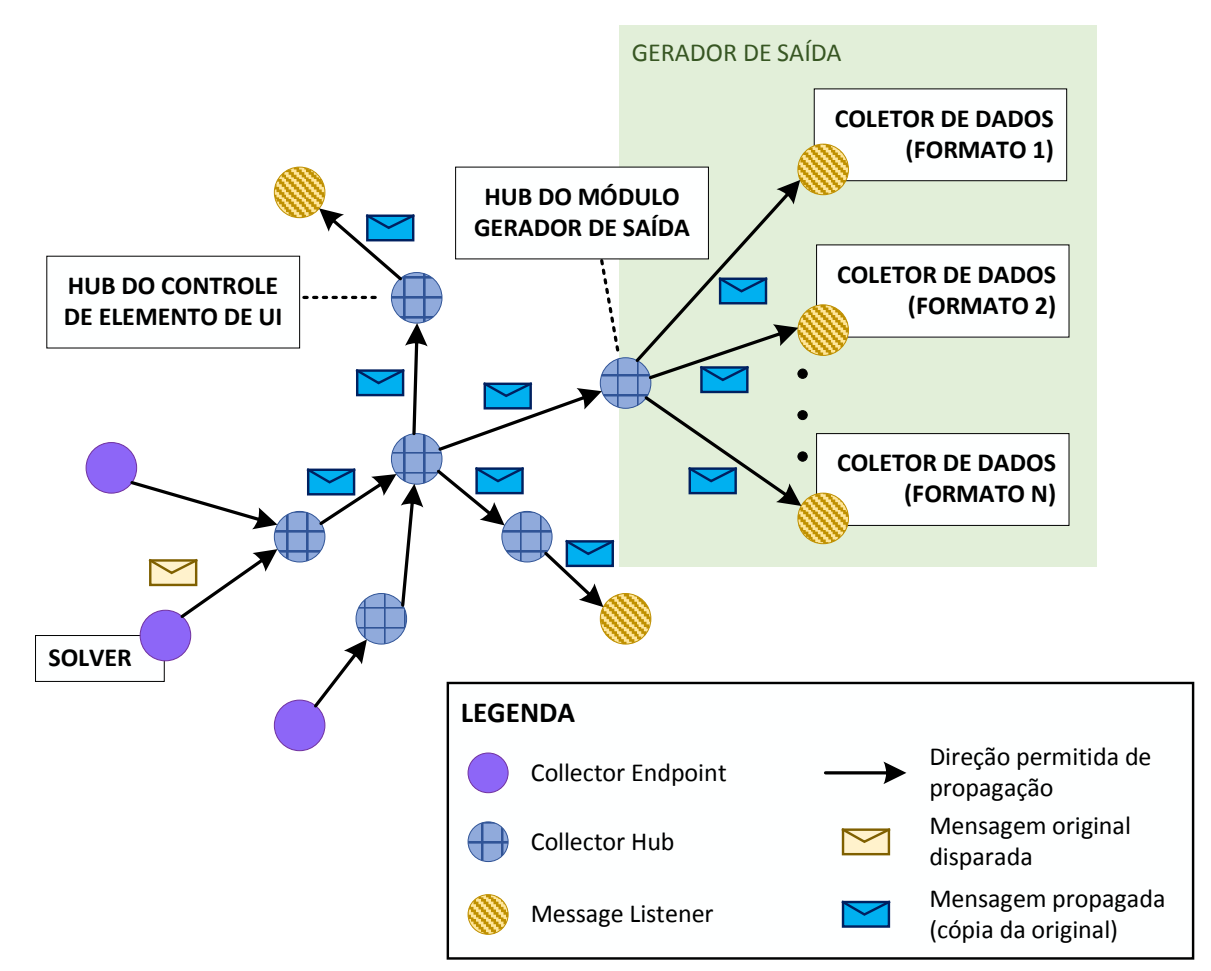

Figura 5.21 Esquema do transporte de mensagens entre as entidades do programa. 
Como todos os objetos conectados são definidos e conhecidos a partir de classes abstratas genéricas, não há acoplamentos em funções específicas, exercidas por qualquer entidade participante do processo. Para o caso do gerador de saída, por exemplo, é possível conectar múltiplas entidades que produzem saída para diversos formatos de aplicações de pós-processamento (os coletores de dados), sem que uma interfira na outra. Além disso, o solver é completamente transparente para os coletores, tendo eles acesso apenas ao modelo numérico, cuja estrutura é conhecida e única em todo o programa. De fato, essa flexibilidade permite, inclusive, que o solver seja totalmente desconectado do processo e, com a substituição por um objeto de teste (mock object), que os componentes do módulo gerador de saída sejam testados independentemente.

\subsection{Resumo}

A elaboração da arquitetura para o programa de elementos finitos contemplado neste trabalho mostra-se complexa à medida que se destacam as necessidades dos diversos pontos-chaves do software. Flexibilidade e robustez são aspectos importantes para o desenvolvimento sustentável do código. Ao mesmo tempo, perseguir estas qualidades ao longo do processo requer o acompanhamento de sua evolução. Para isso, é importante selecionar um conjunto de métricas que estimem a proximidade desses objetivos.

Foram apresentadas diversas vistas dos principais componentes do software e suas interações dentro do sistema, participando ativamente nas computações dos métodos de solução em CPU e em GPU. A compreensão de seu funcionamento é primordial para as dicussões que se seguem nos próximos capítulos. 


\section{Sistema de solução MEF-00 em CPU}

O programa de elementos finitos implementado neste trabalho contempla a solução de problemas quase estáticos lineares e dinâmicos, lineares ou não-lineares. Esses sistemas são executados e paralelizados nas CPUs locais, isto é, sem o uso de aceleradoras ou hardware especializado.

Este capítulo discute a implementação computacional dos sistemas de solução por elementos finitos de acordo com a arquitetura proposta para o programa. Além disso, ele também oferece a base para a compreensão do sistema de solução processado em GPU, a ser descrito no Capítulo 7 .

\subsection{Sistema de solução para problemas quase estáticos}

O procedimento de solução é implementado sobre a estrutura genérica definida na seção 5.4.3. O Algoritmo 2.1 foi adaptado para o funcionamento nessa estrutura, conforme mostra o comparativo na Tabela 6.1.

As classes participantes são apresentadas na Figura 6.1. As classes Solver e Clockwork declaram a interface básica para um sistema de solução e um algoritmo de controle do passo de tempo, respectivamente. Declaradas no componente Common Library, fazem parte da biblioteca base que define, de uma forma genérica, todas as entidades necessárias para o procedimento de solução do MEF. A classe Conjugate Gradient Solver é também localizada na biblioteca base, enquanto que CPU Linear Conjugate Gradient Solver e Regular Clockwork são definidas no componente Solver. 
O problema quase estático é definido num intervalo artificial de tempo, $t \in$ $[0,1]$. A especialização de Clockwork, Regular Clockwork, define um mecanismo de incremento de tempo regular e constante. Na montagem do sistema, a instância é devidamente configurada para que o solver execute uma única iteração de tempo. Assim, o procedimento descrito na Figura 5.14, normalmente iterativo em relação ao tempo, se resume a uma única execução das operações descritas na Tabela 6.1. A operação de incremento de tempo, disparado pelo algoritmo implementado na classe Solver, dispara a sequência de eventos ilustrada na Figura 6.2.

Tabela 6.1 Inserção do algoritmo gradiente conjugado dentro da arquitetura do programa.

\begin{tabular}{|c|c|c|}
\hline Nome da operação & Propósito geral & Implementação GC \\
\hline StartAnalysisProcess & $\begin{array}{c}\text { Inicialização de variáveis internas do } \\
\text { solver e preparação do modelo } \\
\text { numérico }\end{array}$ & (Operação nula) \\
\hline EnterPrimaryStep & $\begin{array}{l}\text { Execução de procedimentos que } \\
\text { devem ocorrer recorrentemente, no } \\
\text { início de cada fase primária }\end{array}$ & (Operação nula) \\
\hline EnterSecondaryStep & $\begin{array}{l}\text { Operações recorrentes no início de } \\
\text { cada fase secundária }\end{array}$ & $\begin{array}{c}\text { Inicializa os valores dos vetores de } \\
\text { solução e o estado das variáveis } \\
\text { internas }\end{array}$ \\
\hline ExecuteStep & Operações de núcleo do solver & $\begin{array}{l}\text { Executa o processo iterativo de } \\
\text { solução do sistema linear pelo GC }\end{array}$ \\
\hline ExitSecondaryStep & $\begin{array}{l}\text { Operações executadas após cada } \\
\text { incremento de tempo }\end{array}$ & $\begin{array}{l}\text { Calcula o estado do modelo a partir } \\
\text { do deslocamento obtido como } \\
\text { solução }\end{array}$ \\
\hline ExitPrimaryStep & $\begin{array}{c}\text { Operaç̃̃es de finalização da fase } \\
\text { primária }\end{array}$ & $\begin{array}{l}\text { Destroi todas as variáveis auxiliares } \\
\text { usadas no processo }\end{array}$ \\
\hline EndAnalysisProcess & $\begin{array}{l}\text { Finalização do processo de solução e } \\
\text { liberação de recursos alocados }\end{array}$ & (Operação nula) \\
\hline
\end{tabular}

O solver quase estático é implementado em dois níveis de hierarquia, como mostra a Figura 6.3. A classe de primeiro nível, Conjugate Gradient Solver, incorpora o algoritmo genérico do Gradiente Conjugado, GC, para a solução de qualquer sistema linear. Algumas operações são apenas declaradas como abstratas, deixando a cargo da subclasse a especialização do algoritmo para o MEF.

Esta separação permite que o algoritmo do solver e a montagem das matrizes (e vetores) de elementos finitos sejam testados e validados isoladamente, tornando mais simples o ambiente de testes. A Figura 6.3 exibe dois descendentes implementados, uma classe mock Beck [20], usada para simular o comportamento real do solver e verificar o algoritmo geral do GC através de unidades de testes, e a classe de 


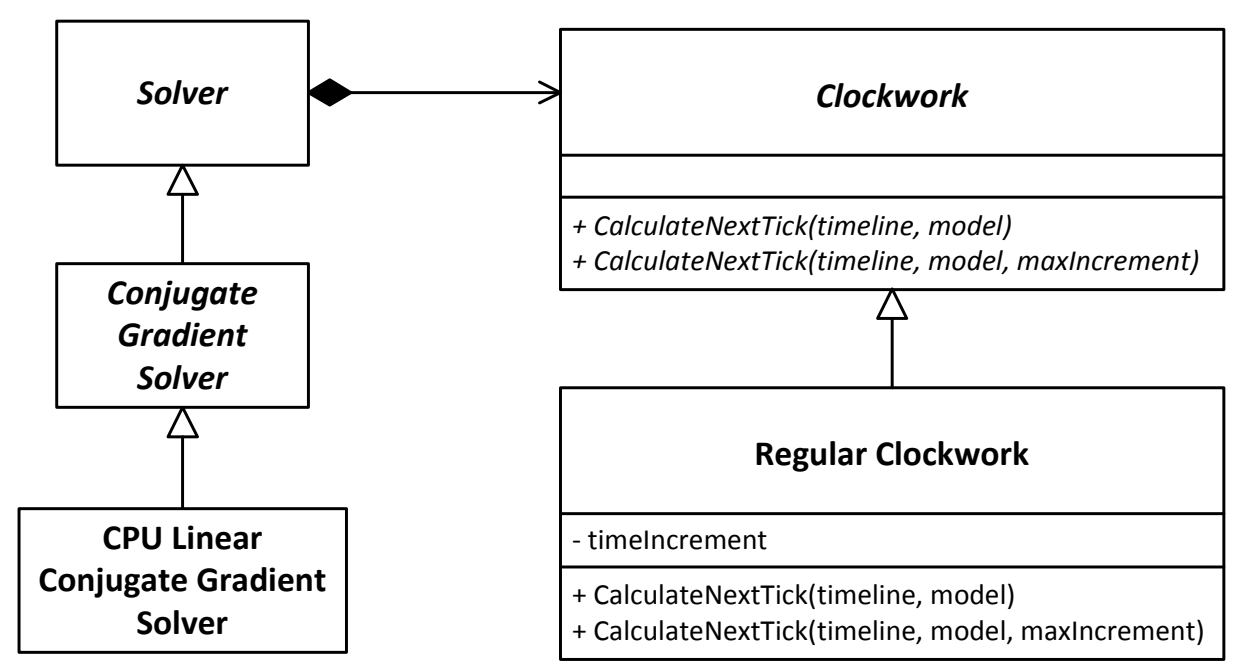

Figura 6.1 Principais classes para configuração do solver quase estático.

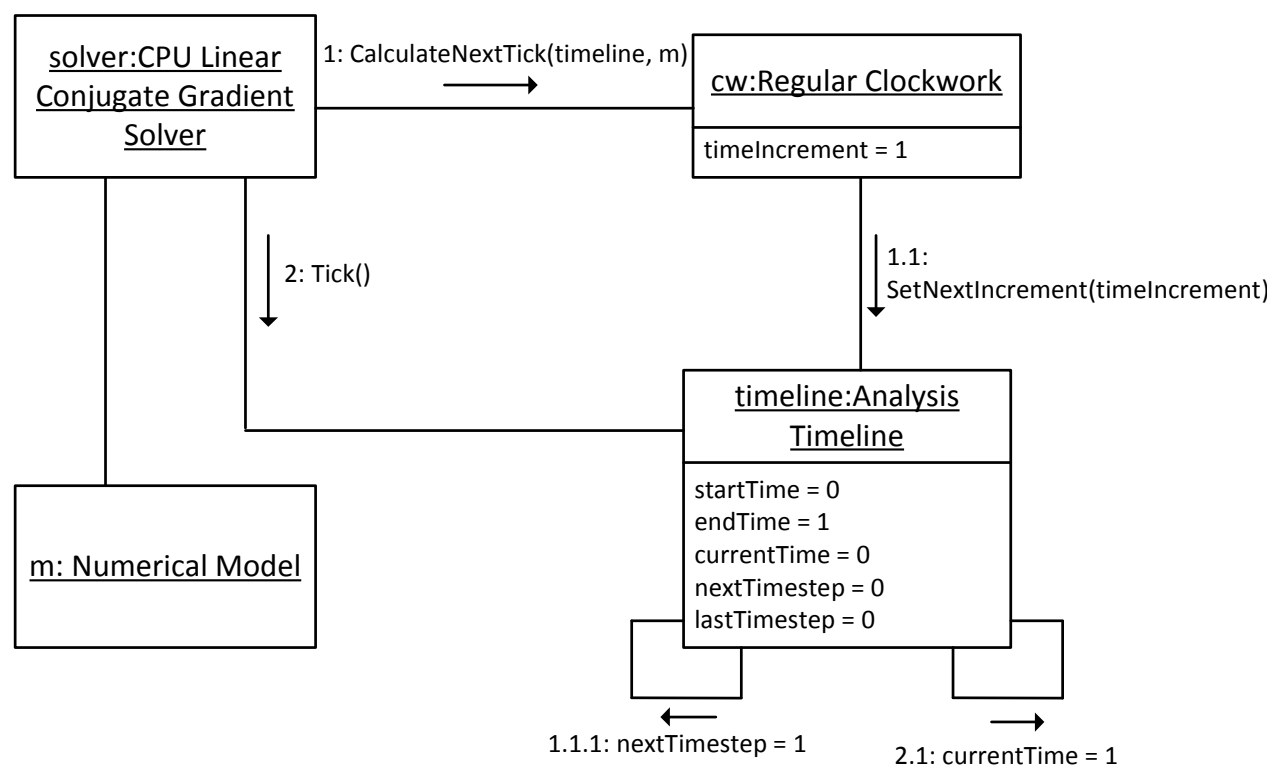

Figura 6.2 Encadeamento de mensagens em pseudo-iteração de tempo do solver quase estático.

produção, CPU Linear Conjugate Gradient Solver.

O modelo de algoritmo Gamma et al. [92], fornecido por Conjugate Gradient Solver, é estendido através de seus métodos abstratos. Para o objeto de testes, isso é feito para um sistema linear pré-definido e de resposta conhecida, a partir do qual é possível verificar as computações realizadas na iteração e depurar o solver sem a interferência de qualquer erro que possa haver no modelo numérico ou objetos associados.

Por outro lado, a classe de produção estende as funcionalidades em direção à 


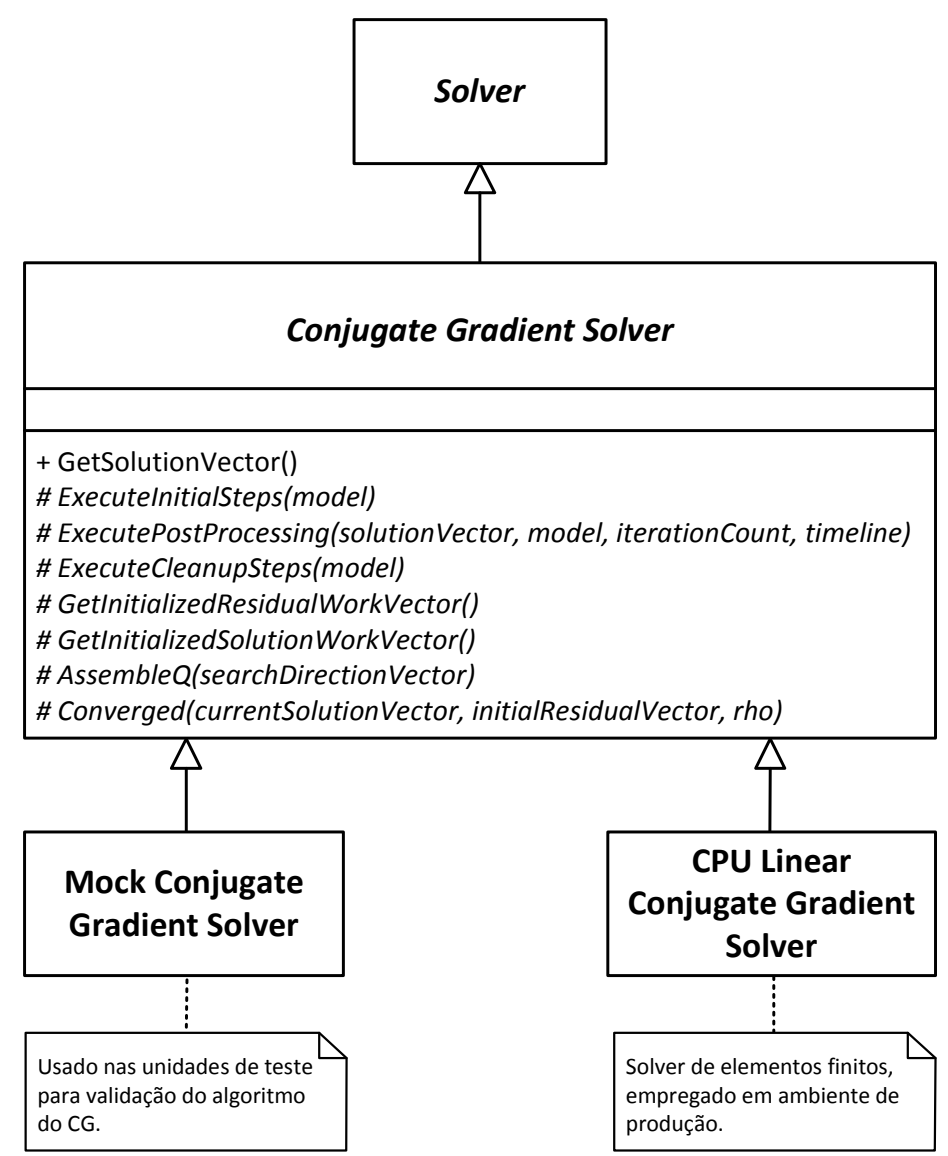

Figura 6.3 Implementação do solver quase estático em dois níveis.

aplicação em elementos finitos propriamente dita, onde o sistema linear é obtido a partir do modelo numérico. Dessa forma, as atividades descritas na Tabela 6.1 e as operações abstratas listadas na Figura 6.3 dão origem à sequência de operações pormenorizadas a seguir.

\subsubsection{Inicialização do solver}

A inicialização do solver ocorre no início da fase secundária, quando são então carregados os vetores iniciais de solução e de resíduo, obtidos através dos métodos abstratos, GetInitializedSolutionWorkVector() e GetInitializedResidualWorkVector(), respectivamente. Para a implementação em elementos finitos, isso corresponde ao vetor global de deslocamento, inicialmente nulo, com as condições de contorno iniciais aplicadas (deslocamentos prescritos), usado como vetor de solução, e o vetor global de forças externas, como residual. Na sequência, as matrizes de rigidez de todos os elementos são calculadas e armazenadas para uso posterior pelo algoritmo. 


\subsubsection{Execução principal}

O Algoritmo 2.1 é implementado como núcleo do solver, dentro do método ExecuteStep(), conforme mostra a Figura 6.4. Algumas operações são independentes entre si (como o cálculo de $\boldsymbol{\alpha}$, passo 5b.i do Algoritmo 2.1) e, portanto, facilmente paralelizáveis, ato identificado no diagrama pela bifurcação, com traço sólido mais espesso. Como o algoritmo é essencialmente um conjunto de operações vetoriais, estas também podem ser paralelizáveis no nível de suas componentes (não ilustrado no diagrama). Para a paralelização em CPU, conta-se com o suporte do compilador, para a otimização e paralelização das instruções via diretivas de pré-processamento do padrão OpenMP [46, 179].

A influência da matriz de coeficientes é dada pelo método implementado para a operação AssembleQ() da classe, através do qual é obtido $\mathbf{q}_{k}$. Para a versão final, ele é calculado elemento a elemento, de acordo com a Eq. (2.7), usando as matrizes de rigidez armazenadas na entrada da fase secundária.

\subsubsection{Pós-processamento}

A saída da fase secundária (operação ExitSecondaryStep()) é marcada pelo pósprocessamento do solver, através da operação ExecutePostProcessing(). O método consiste basicamente das seguintes atividades:

- processamento das estatísticas coletadas na execução do passo secundário, tais como tempo de execução do algoritmo, número de iterações, entre outros;

- cálculo do estado de tensão e de deformação dos elementos da estrutura;

- disparo da mensagem para coleta dos resultados solicitados pelo usuário através do arquivo de entrada.

\subsubsection{Limpeza}

Executada na saída da fase primária, a limpeza do algoritmo consiste em liberar todos os recursos de memória utilizados durante a execução do algoritmo. As variáveis internas usadas na versão base do GC são destruídas pela própria classe. Os objetos alocados pela implementação para elementos finitos (ou mesmo a mock) são liberados através do método ExecuteCleanupSteps(). 


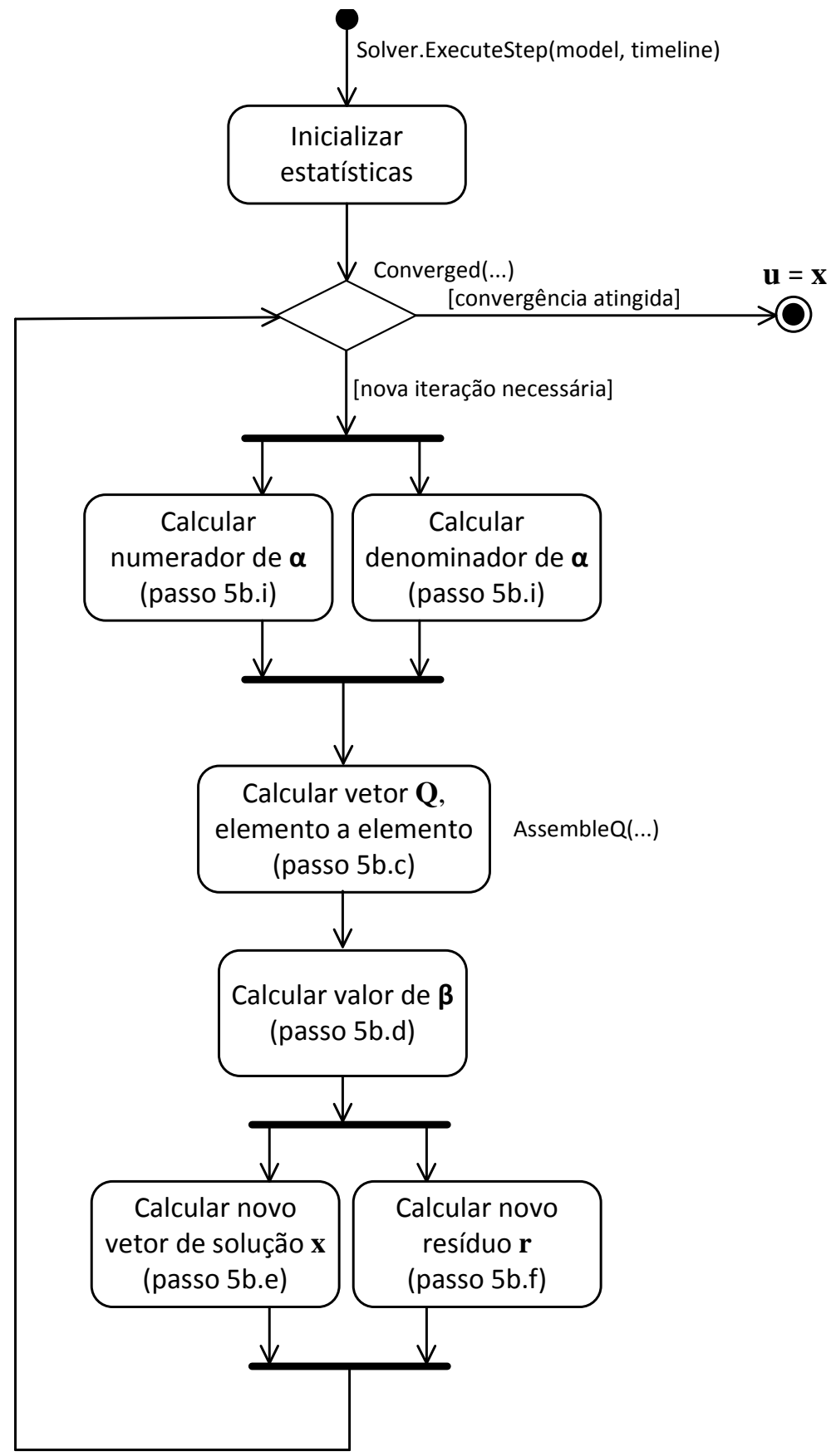

Figura 6.4 Implementação do algoritmo GC na classe Conjugate Gradient Solver 


\subsection{Sistema de solução para problemas dinâmicos}

A solução de problemas dinâmicos é dada pelo solver de integração explícita, definido na classe Explicit Dynamic Solver (Figura 6.5). A Tabela 6.2 mostra a abordagem usada para a concepção do solver na arquitetura do programa.

Tabela 6.2 Inserção do método de integração explícita dentro da arquitetura do programa.

\begin{tabular}{|c|c|c|}
\hline Nome da operação & Propósito geral & Implementação do método explícito \\
\hline StartAnalysisProcess & $\begin{array}{c}\text { Inicialização de variáveis internas do } \\
\text { solver e preparação do modelo } \\
\text { numérico }\end{array}$ & $\begin{array}{c}\text { Inicialização das variáveis internas; } \\
\text { aplicação das condições de contorno } \\
\text { iniciais; cálculo da matriz de massa } \\
\text { global }\end{array}$ \\
\hline EnterPrimaryStep & $\begin{array}{l}\text { Execução de procedimentos que } \\
\text { devem ocorrer recorrentemente, no } \\
\text { início de cada fase primária }\end{array}$ & (Operação nula) \\
\hline EnterSecondaryStep & $\begin{array}{l}\text { Operações recorrentes no início de } \\
\text { cada fase secundária }\end{array}$ & (Operação nula) \\
\hline ExecuteStep & Operações de núcleo do solver & $\begin{array}{l}\text { Execução de uma iteração de tempo } \\
\text { pelo método das diferenças centrais } \\
\quad(\dot{\mathbf{u}} \text { a meio passo de tempo) }\end{array}$ \\
\hline ExitSecondaryStep & $\begin{array}{l}\text { Operações executadas após cada } \\
\text { incremento de tempo }\end{array}$ & $\begin{array}{c}\text { Atualização das condições de } \\
\text { contorno para o novo instante de } \\
\text { tempo }\end{array}$ \\
\hline ExitPrimaryStep & $\begin{array}{c}\text { Operações de finalização da fase } \\
\text { primária }\end{array}$ & $\begin{array}{l}\text { Notificação dos coletores de dados } \\
\text { sobre a disponibilidade de resultados }\end{array}$ \\
\hline EndAnalysisProcess & $\begin{array}{l}\text { Finalização do processo de solução e } \\
\text { liberação de recursos alocados }\end{array}$ & $\begin{array}{c}\text { Finalização da execução e liberação } \\
\text { de recursos de memória }\end{array}$ \\
\hline
\end{tabular}

A arquitetura permite que o solver dinâmico aceite qualquer algoritmo de controle da iteração de tempo e, assim, opções mais robustas e eficientes possam ser implementadas e adotadas na forma de plugins. Na Figura 6.5, é exemplificado o emprego de passo de tempo constante, determinado pelo usuário (Regular Clockwork), ou um controle dinâmico, baseado na condição CFL, dado pela classe Wave Speed Proportional Clockwork.

Enquanto que em problemas quase estáticos a iteração de tempo promovida pela classe Solver não tem relevância no processo geral, para os casos dinâmicos, o mecanismo desempenha papel fundamental para o método. O diagrama de sequência mostrado na Figura 6.6 detalha como a execução do solver ocorre.

Destacadas em azul no diagrama, estão as operações sobrecarregáveis da classe Solver, cujo propósito foi apresentado na Figura 5.14 e suas especializações para o 


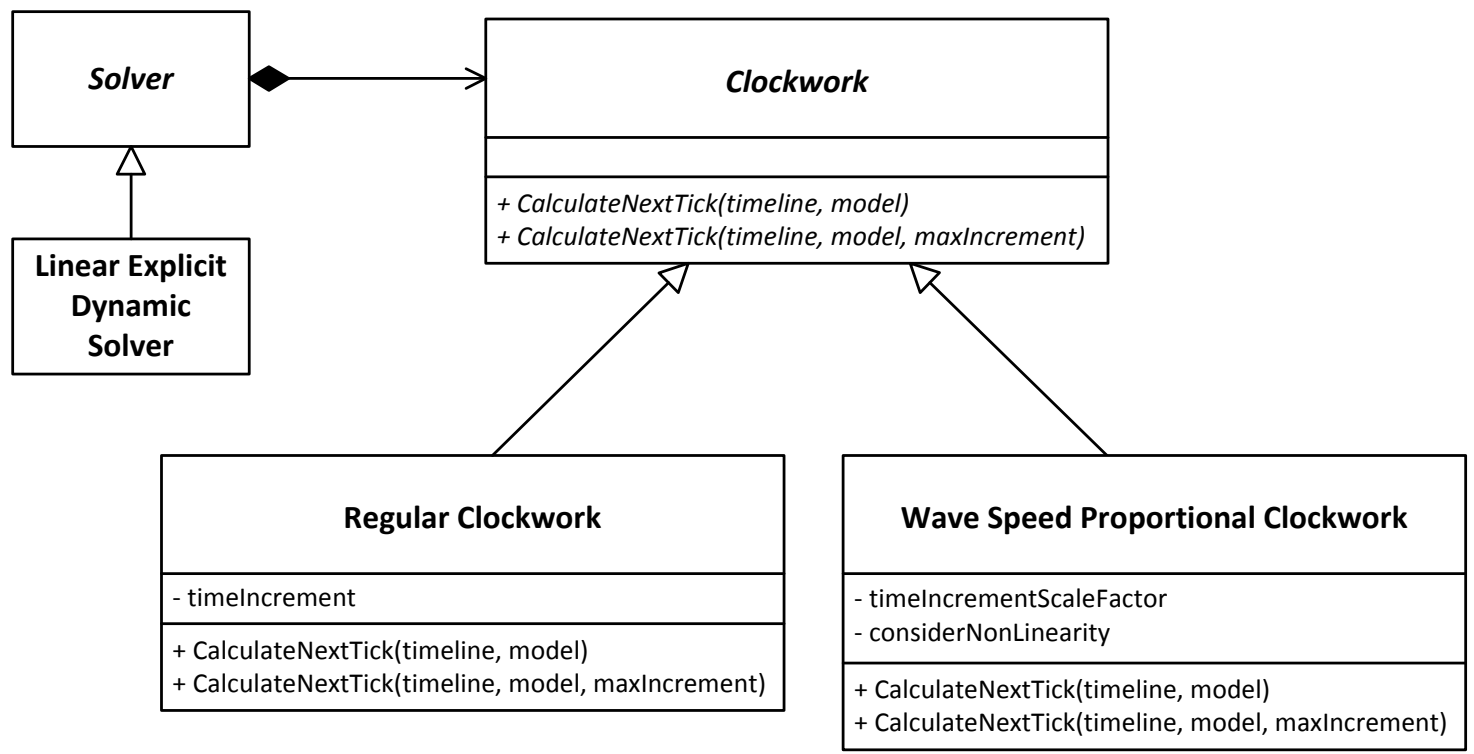

Figura 6.5 Principais participantes na solução de problemas dinâmicos explícitos.

sistema de solução dinâmico é informado na Tabela 6.2. O controle do passo de tempo é dado pelas operações destacadas em laranja.

A operação sobrecarregável CalculateNextTick() tem como objetivo estimar o passo de tempo máximo para garantir a estabilidade do algoritmo iterativo (no caso, o método explícito). O parâmetro model, correspondente ao modelo numérico, passado por referência na chamada do método Run(), pode ser usado pelo Clockwork para a calcular a estimativa.

A especialização Regular Clockwork simplesmente ignora este parâmetro e retorna imediatamente um valor constante para $\Delta t$, informado no arquivo de entrada da análise. Wave Speed Proportional Clockwork, por outro lado, itera pelos componentes da malha para obter o tempo máximo necessário para corretamente modelar a propagação de onda em todos os elementos da estrutura. A verificação para um único elemento hexaédrico é exemplificada na Figura 6.7.

Em problemas dinâmicos, o incremento de tempo tem que ser sempre atualizado. Contudo, em problemas lineares, as deformações envolvidas são muito pequenas e, portanto, não exige a atualização regular do incremento de tempo. Assim, Wave Speed Proportional Clockwork ignora chamadas posteriores à operação CalculateNextTick(). Um atributo interno da classe, considerNonLinearity, altera este comportamento conforme necessário. O incremento de tempo estimado pode ser alterado para uma proporção de seu valor, dado pelo atributo timelncrementScaleFactor. Para problemas lineares, seu valor é normalmente igual a 1. 


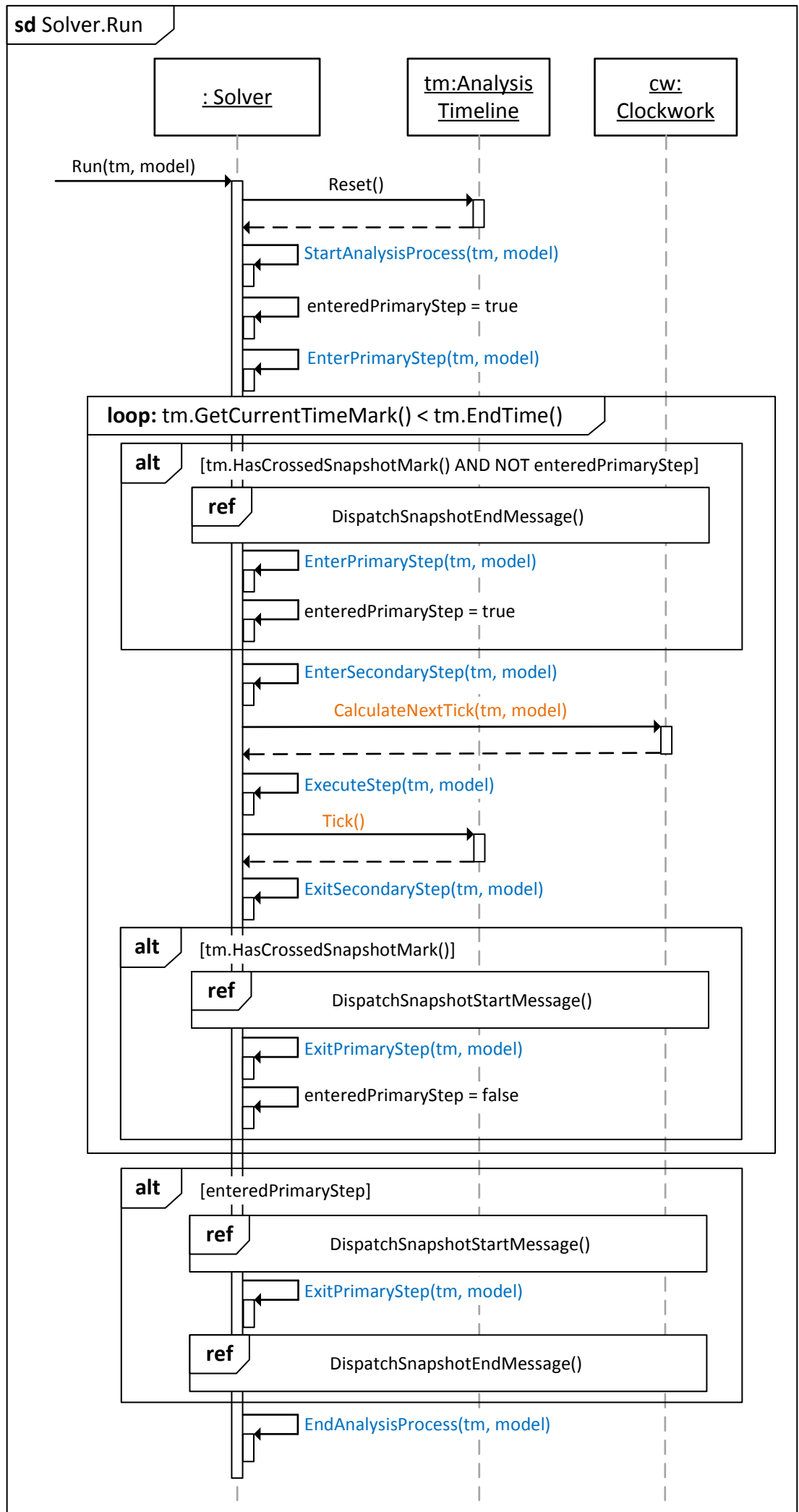

Figura 6.6 Algoritmo genérico de execução do solver, método Run(). 


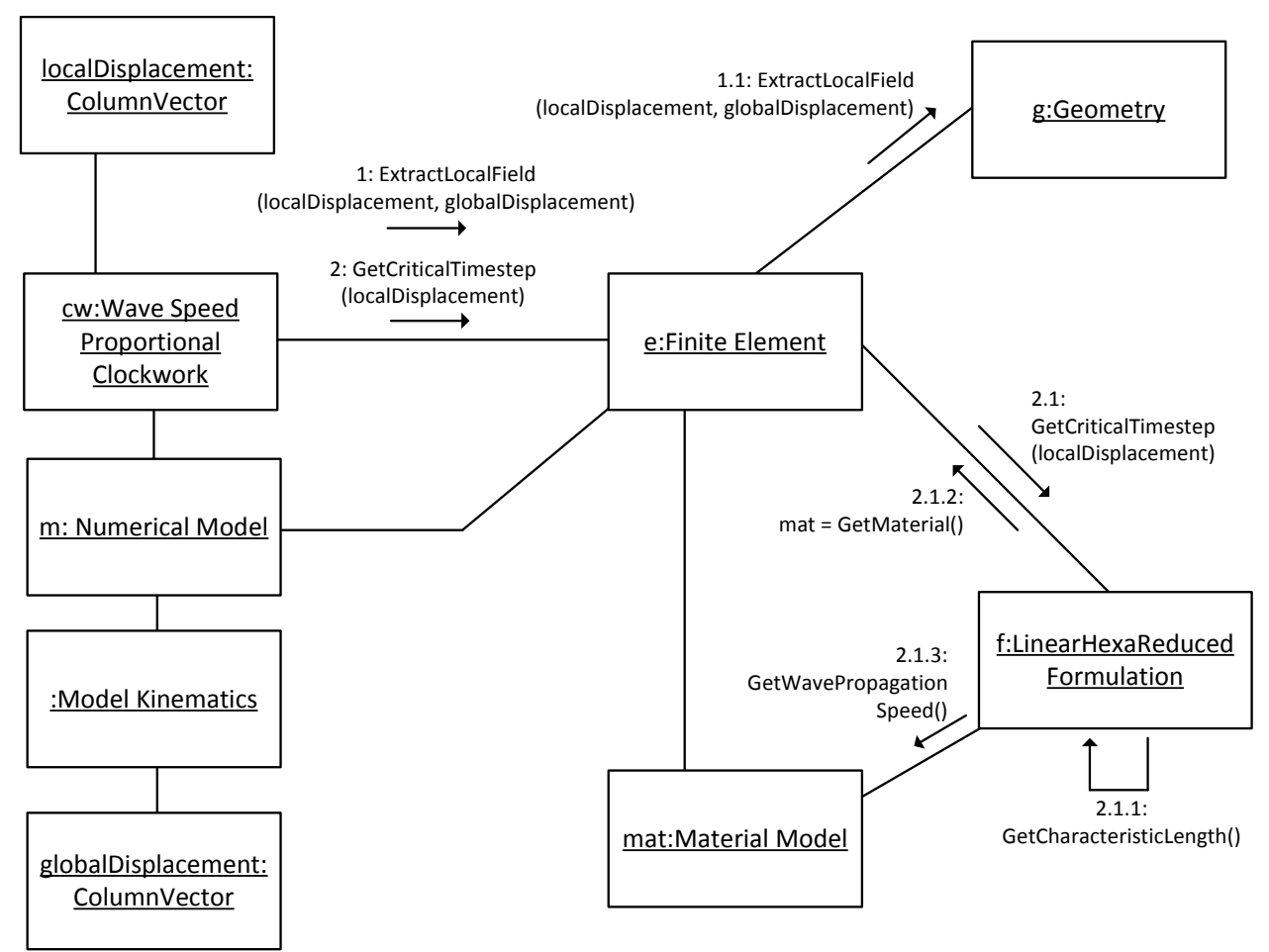

Figura 6.7 Sequência de comunicações para a verificação de $\Delta t_{c r}$ no elemento.

Uma vez calculada, a estimativa de tempo é armazenada na instância de Analysis Timeline (passada como parâmetro - timeline). O atributo nextTimelncrement da classe recebe o valor e será usado para avançar na linha temporal, quando a operação Tick() for invocada.

As operações descritas nos blocos de referência cruzada da Figura 6.6, DispatchSnapshotStartMessage e DispatchSnapshotEndMessage denotam o disparo de mensagens de notificação do início e final de um snapshot. A percepção desses eventos é importante para a coleta de resultados num problema dinâmico, conforme será discutido na seção 6.2.4.

Dessa forma, as operações para a construção do solver explícito, enumeradas na Tabela 6.2, são a seguir detalhadas.

\subsubsection{Inicialização do solver}

Na entrada do processo de solução (operação StartAnalysisProcess), a matriz de massa global é calculada, uma vez que se mantém constante ao longo do processo. Para o método explícito, é mais conveniente a adoção da matriz de massa diagonal. 
Nesta etapa, é também construído o vetor máscara que será usado para discernir entre as condições de contorno aplicadas no modelo. Para sua construção, leva-se em conta os métodos de identificação das condições de contorno, exibidos na Figura 6.8.

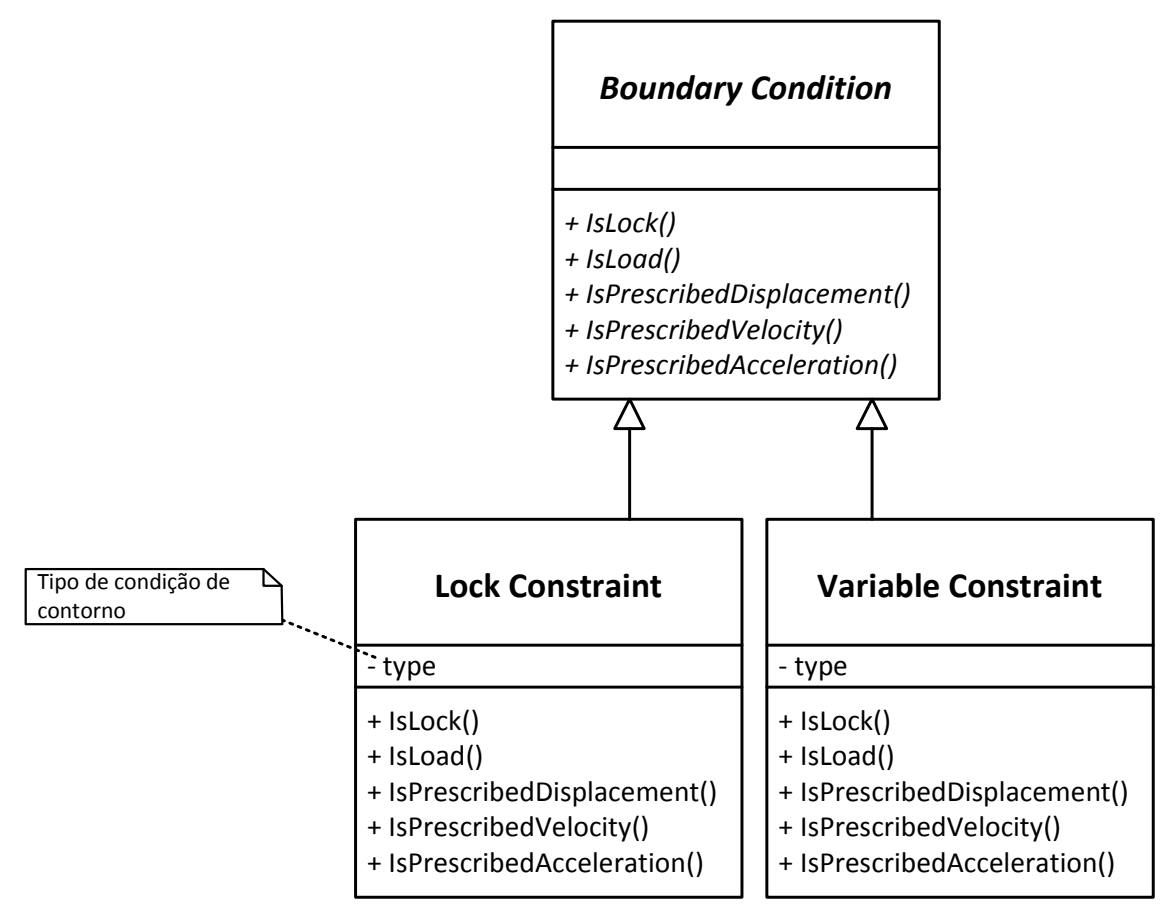

Figura 6.8 Operações de distinção da natureza das condições de contorno.

Cada uma das operações da classe abstrata Boundary Condition atua como uma pergunta de afirmativo ou negativo. Para uma dada instância, a diferenciação entre engastes da estrutura, prescrições ou cargas aplicadas é inferida a partir dos resultados retornados por essas operações.

Através da associação da condição de contorno com o grau de liberdade influenciado (vide Figura 5.8), determina-se a posição do vetor máscara que será marcada, como ilustra a Figura 6.9.

Cada posição marcada no vetor máscara identifica como serão efetuados os cálculos de deslocamento, velocidade e aceleração para aquele grau de liberdade. Por exemplo, com o deslocamento prescrito atribuído, as Eqs. (2.22) e (2.23) são ignoradas para o cálculo de $\mathbf{u}$, sendo obtido diretamente da prescrição estabelecida. 


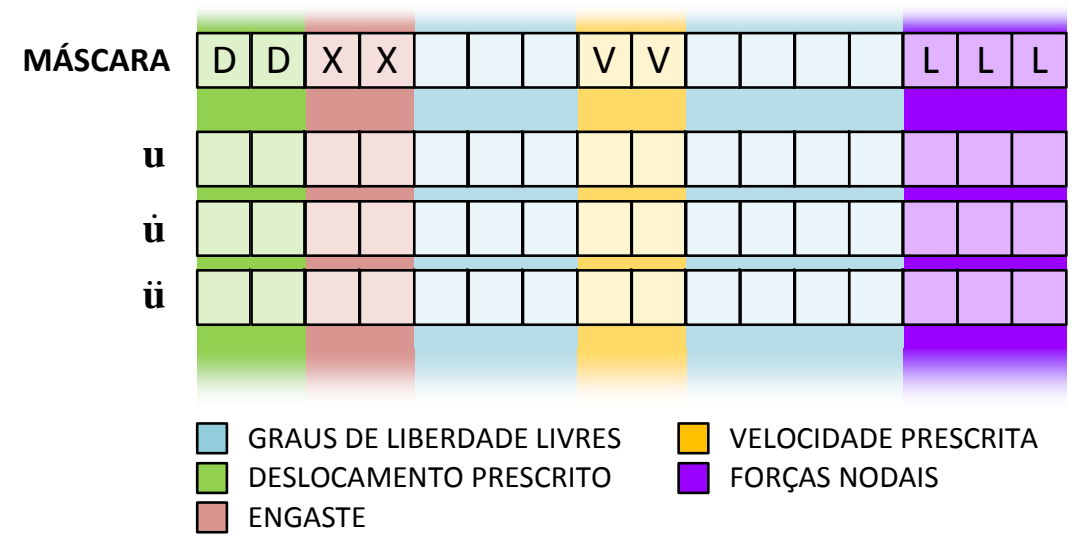

Figura 6.9 Construção do vetor máscara e sua influência sobre os vetores de solução.

\subsubsection{Execução principal}

O método das diferenças centrais, mostrado no Algoritmo 2.2, é implementado integralmente no método ExecuteStep(). Para um único grau de liberdade, o esquema de solução resultante é mostrado no Algoritmo 6.1 (amortecimento desprezado). A variável dofMask representa o vetor máscara, assumindo os estados descritos na Figura 6.9.

Algoritmo 6.1: Método ExecuteStep() usando diferenças centrais.

\section{Algoritmo Diferenças centrais (um único grau de liberdade)}

Condições iniciais: $m, u_{t}, \Delta u, \dot{u}_{t-\frac{1}{2} \Delta t}, r_{t+\Delta t}^{\text {ext }}$ e dofMask (vetor máscara)

Saída: $u_{t}, \dot{u}_{t}$ e $\ddot{u}_{t}$, a cada instante de tempo $t$

1. se dofMask $=$ 'DOF LIVRE' então $\Delta u=\Delta t \dot{u}_{t-\frac{1}{2} \Delta t}$

2. $u_{t+\Delta t}=u_{t}+\Delta u$

3. Calcular estado de tensão do modelo numérico

4. Calcular forças internas atuantes no modelo numérico $\left(r_{t+\Delta t}^{\mathrm{int}}\right)$

5. Calcular forças efetivas: $r_{t+\Delta t}^{\mathrm{R}}=r_{t+\Delta t}^{\mathrm{ext}}+r_{t+\Delta t}^{\mathrm{int}}$

6. se dofMask $\neq$ 'ENGASTE' então $\ddot{u}_{t+\Delta t}=r_{t+\Delta t}^{\mathrm{R}} / m$

7. se dofMask $=$ 'DOF LIVRE' então $\dot{u}_{t+\frac{1}{2} \Delta t}=\dot{u}_{t-\frac{1}{2} \Delta t}+\Delta t \ddot{u}_{t+\Delta t}$ 
O cálculo da tensão no passo 3 do algoritmo é dado pela sequência de comunicações apresentadas na Figura 6.10. A invocação da operação UpdateStress() (comunicação 1.5) na instância de Finite Element desencadeia uma série de operações que são mostradas no diagrama da Figura 6.11. O algoritmo implementado na classe de fachada atua de forma genérica para qualquer modelo de material acoplado ao elemento finito.

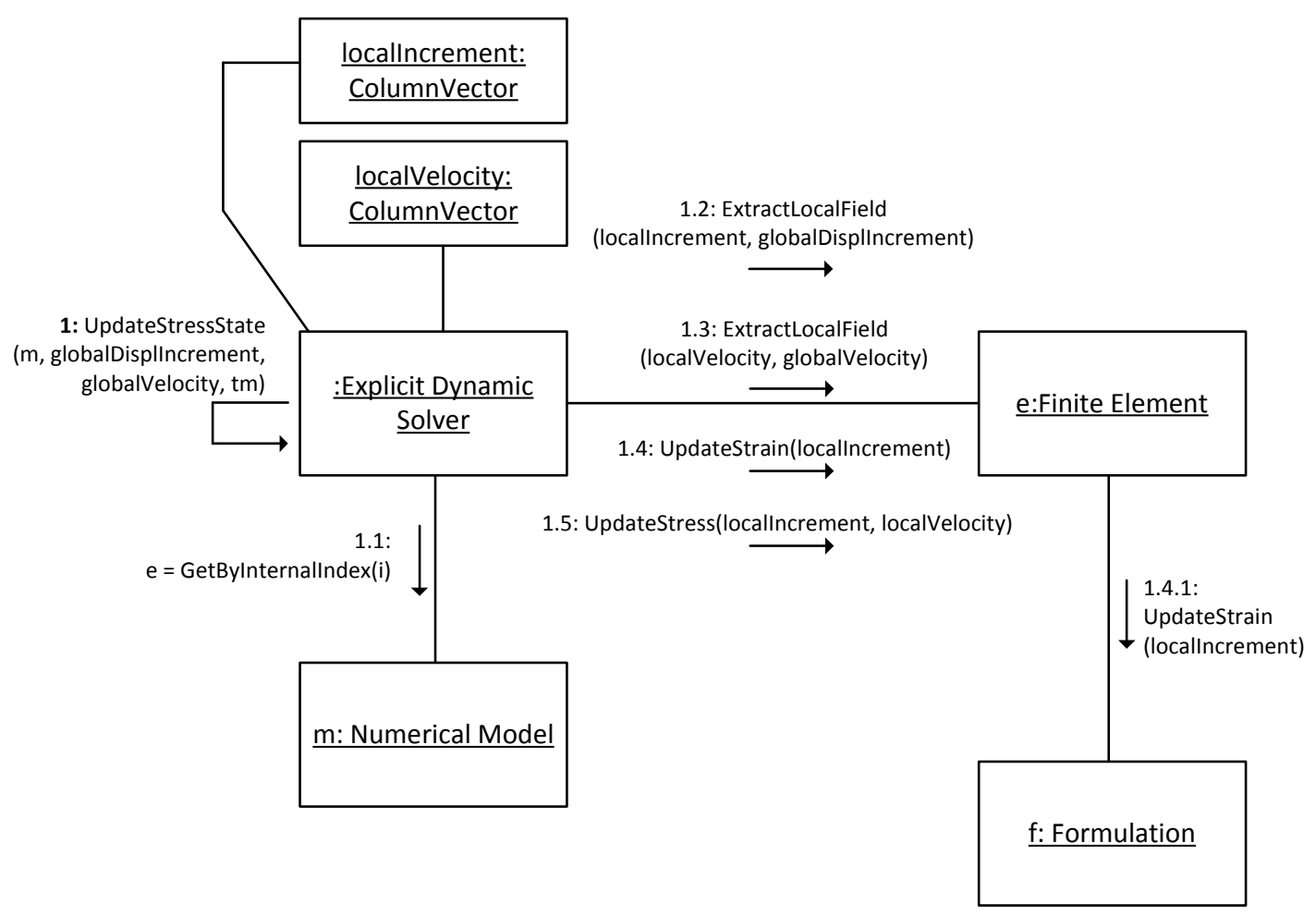

Figura 6.10 Cálculo do estado de tensão no solver explícito para um elemento finito.

A classe Infinitesimal State carrega o estado de tensão e de deformação de um ponto. A operação UpdateStress() de Material Model é capaz de acessar seus membros apenas em modo de leitura. A atualização da tensão só é possível por intermédio da classe Updated Physical State, que encapsula uma instância de Infinitesimal State, fornecendo acesso de leitura e escrita ao estado de tensão do ponto e protegendo os demais atributos (acesso somente leitura).

Uma vez calculadas as tensões da estrutura, a atualização das forças internas ocorre de maneira simples, executando-se, elemento a elemento, a operação UpdatelnternalForce, conforme mostra a Figura 6.12. Para uma formulação com controle de hourglass, a execução mantém-se praticamente idêntica, diferenciando-se apenas pela chamada reflexiva na formulação, que introduz a influência das forças de hourglass $\left({\underset{\sim}{\mathbf{r}}}^{\mathrm{HG}}\right)$, situação exemplificada na Figura 6.13 . 


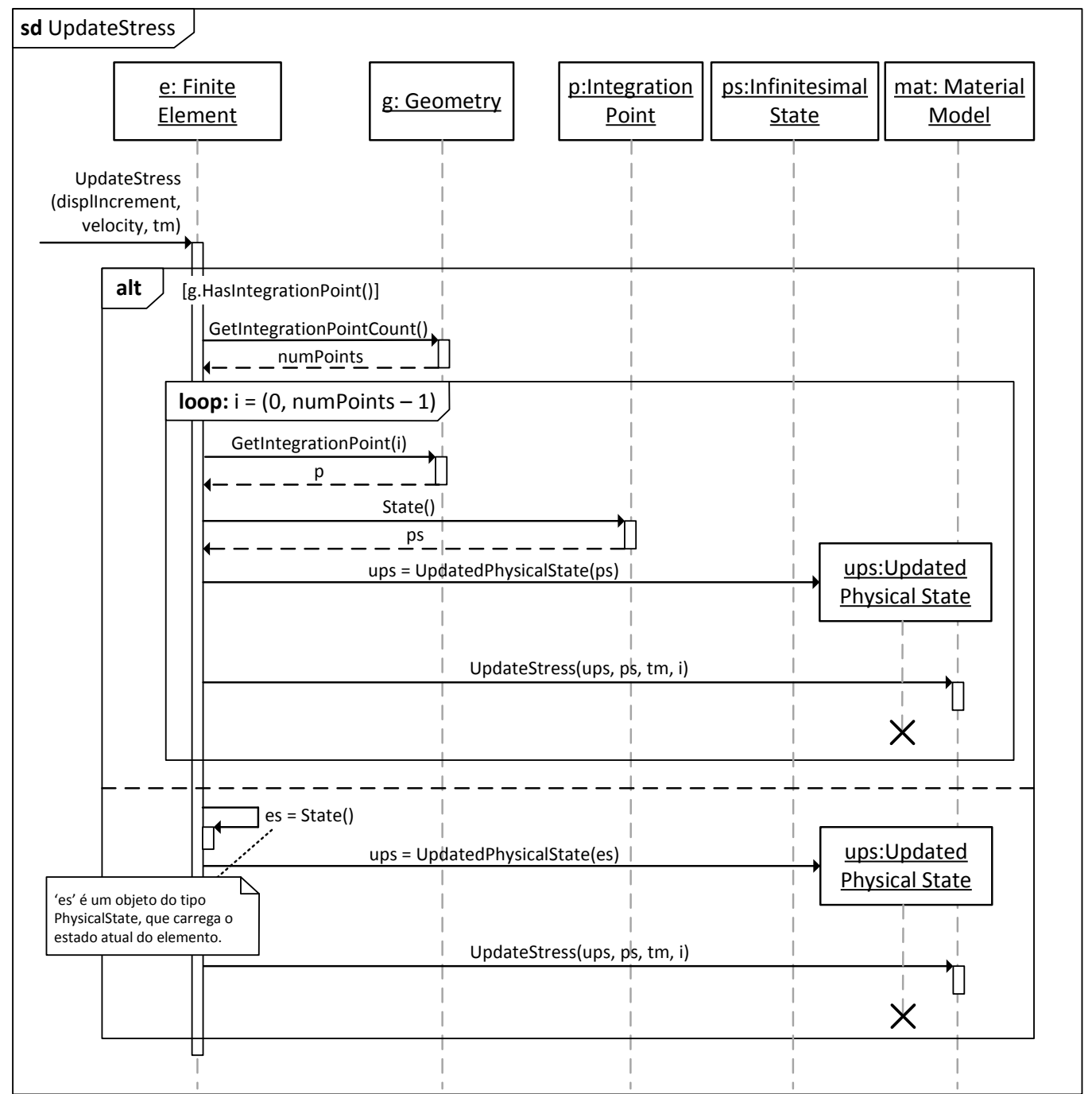

Figura 6.11 Algoritmo de atualização do estado de tensão na classe Finite Element.

\subsubsection{Atualização das condições de contorno}

Na saída da fase secundária, as condições de contorno são reaplicadas aos vetores de solução para o instante $t+\Delta t$ (pois o incremento de tempo foi realizado antes da entrada neste método, vide Figura 6.6).

A distinção dos tipos de condições de contorno se dá através das diferentes associações possíveis (Figura 5.11). A partir da lista de condições de contorno, o grau de liberdade e a posição correspondente nos vetores globais são facilmente recuperados através de suas relações, conforme ilustra a Figura 6.14 para uma única condição de contorno. 


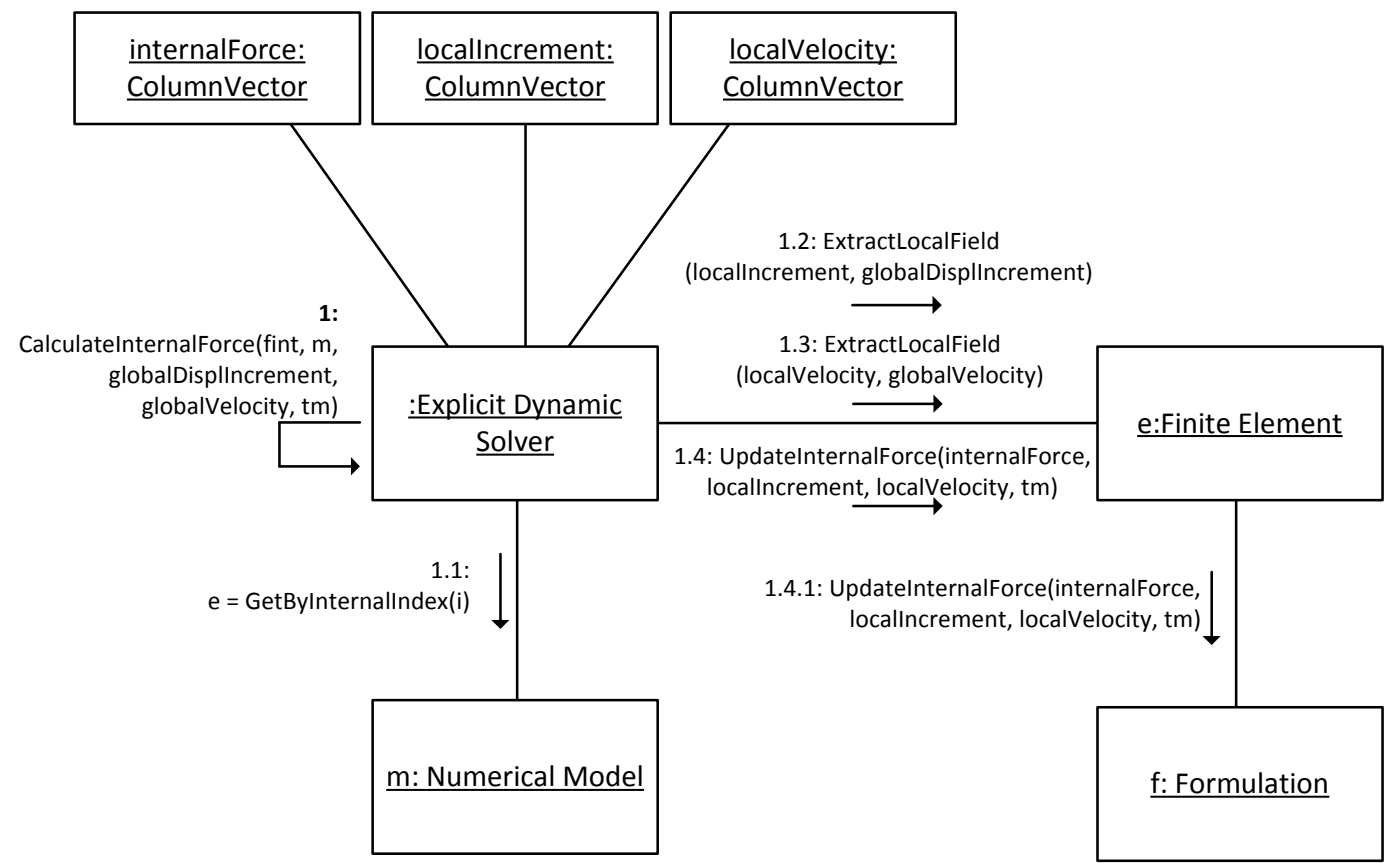

Figura 6.12 Cálculo das forças internas no solver explícito.

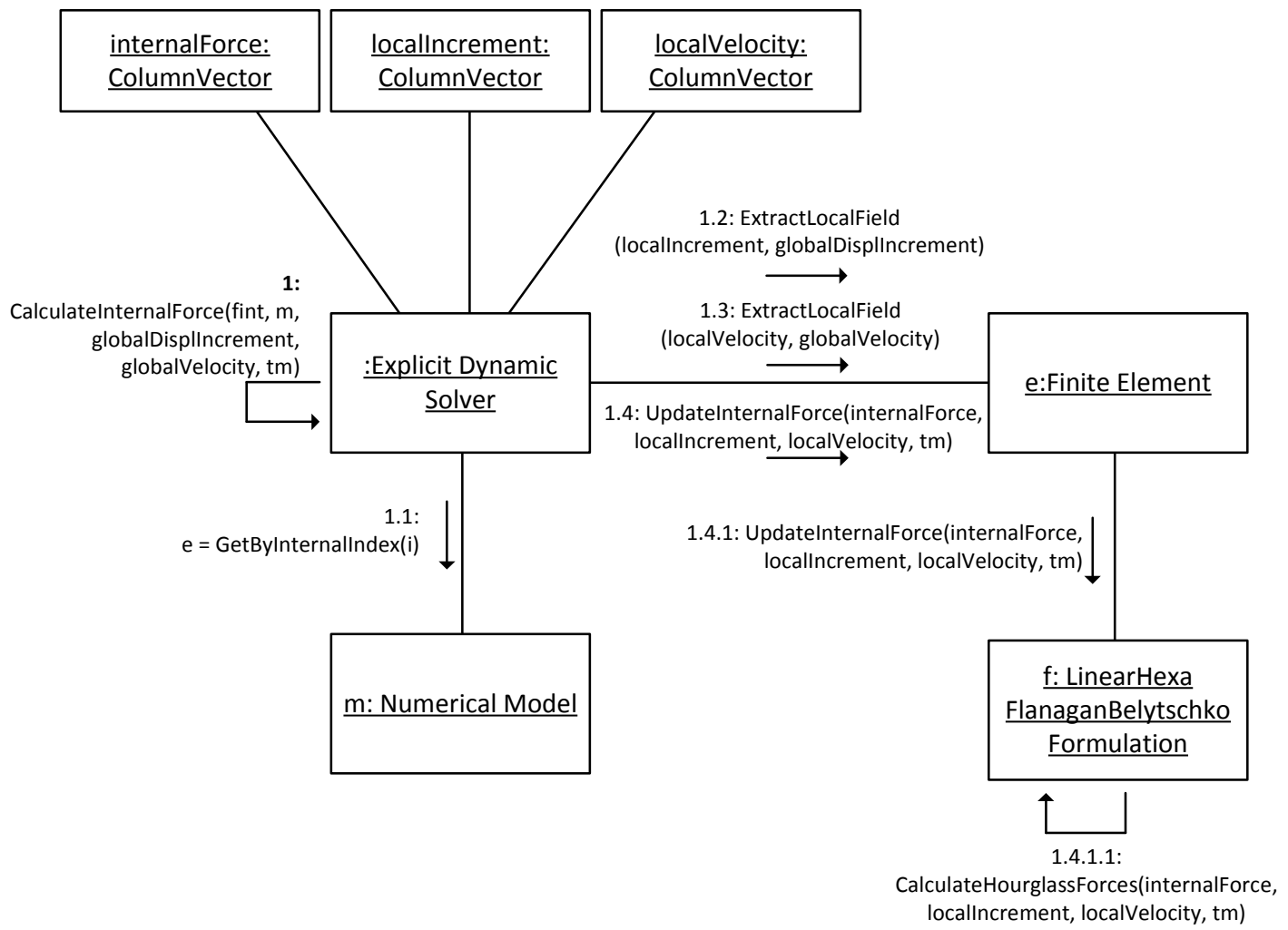

Figura 6.13 Cálculo das forças internas no solver explícito, com controle de hourglass. 


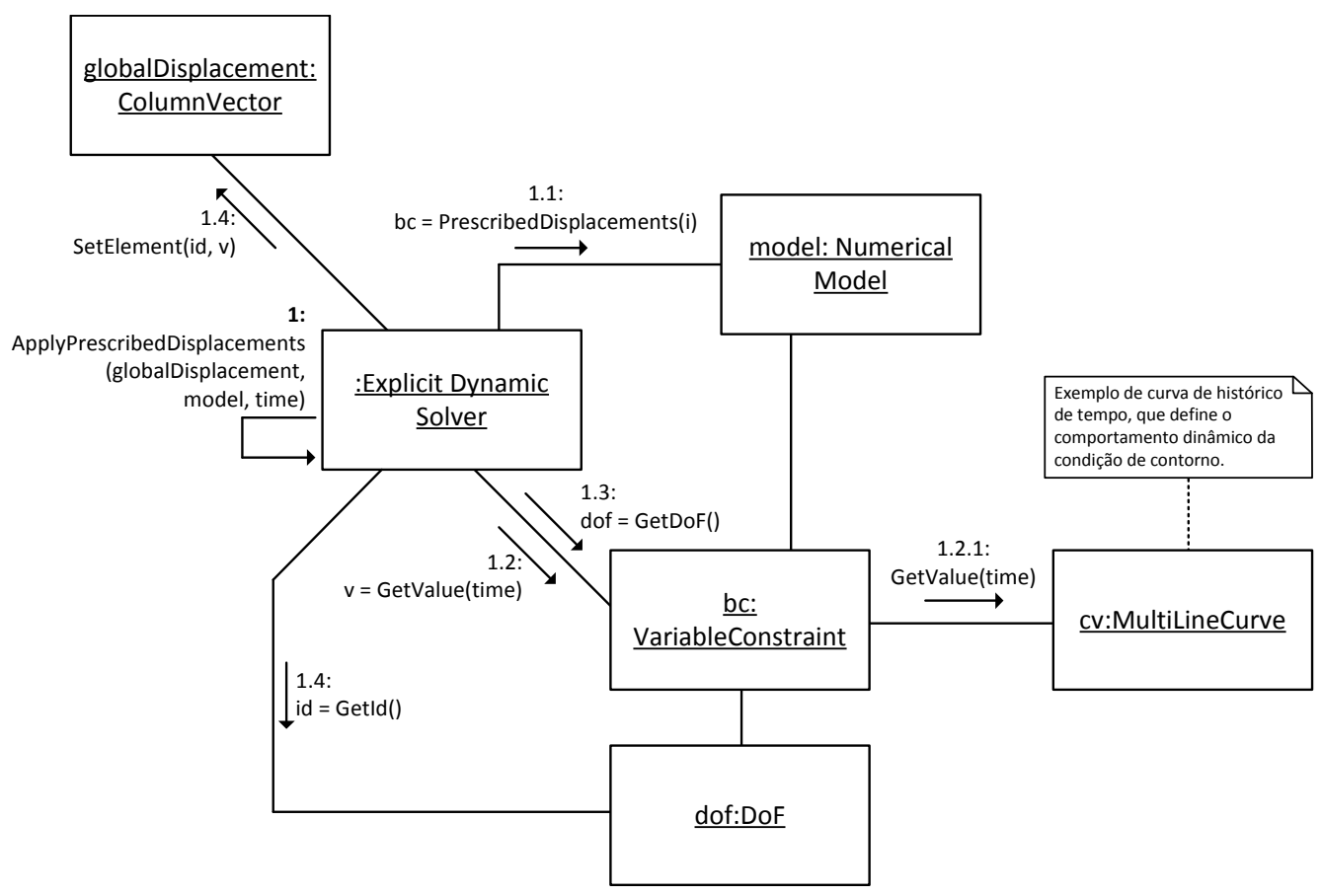

Figura 6.14 Interação entre objetos para aplicação da condições de contorno em um grau de liberdade.

\subsubsection{Coleta de resultados}

O final da fase primária é usado para disparar o mecanismo de coleta de dados. A invocação do sistema é feita através do despacho de uma mensagem encapsulada em um objeto (instância de Model State Update Message, uma especialização de Message). Os seus aspectos mais relevantes serão agora comentados.

As principais classes participantes do processo são representadas nos diagramas da Figura 6.15. O sistema de transporte de mensagens, discutido na seção 5.5.4, é usado pela classe Solver para se manter desacoplado do sistema de coleta de dados. O desconhecimento da outra parte envolvida é mútuo, tal que a classe Numerical Model é a única estrutura de dados de conhecimento comum a ambas. A mensagem propagada, por sua vez, proporciona uma forma de diferenciar os diversos eventos que ocorrem durante a etapa de solução do problema, sem se atrelar a aspectos construtivos dos sistemas. Os principais tipos são mostrados na Figura 6.15b.

O ponto de entrada para o sistema de coleta é a classe Result Bucket (Fig. 6.15a). As mensagens de Solver não são diretamente encaminhadas para suas instâncias, mas por intermédio da classe Finite Element Analysis, conforme ilustra a Figura 6.16.

Result Bucket é um elemento de fachada da camada de aplicação do software, 

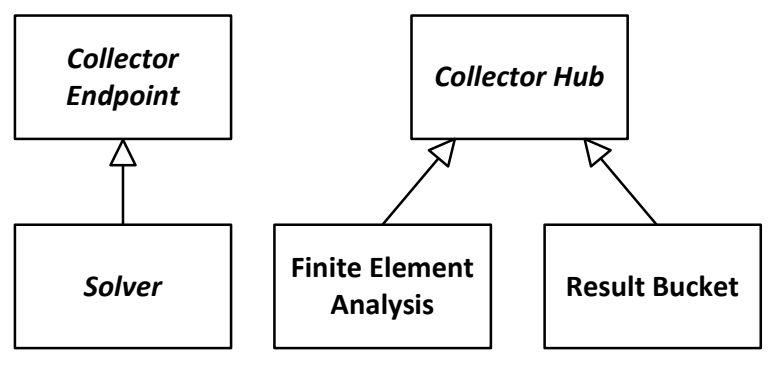

(a) Entidades da cadeia de transporte de mensagens

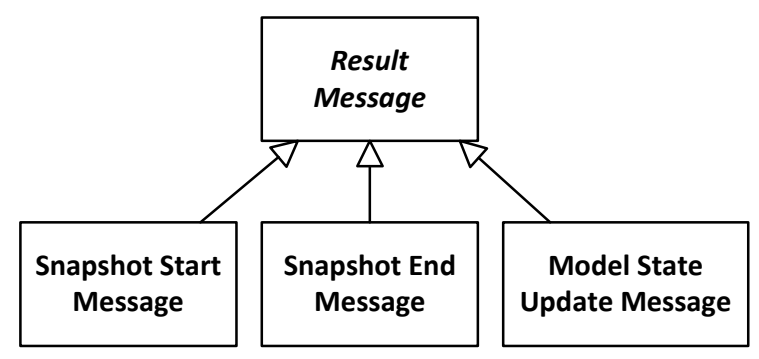

(b) Tipos de mensagens propagadas

Figura 6.15 Classes participantes do sistema de coleta de dados.

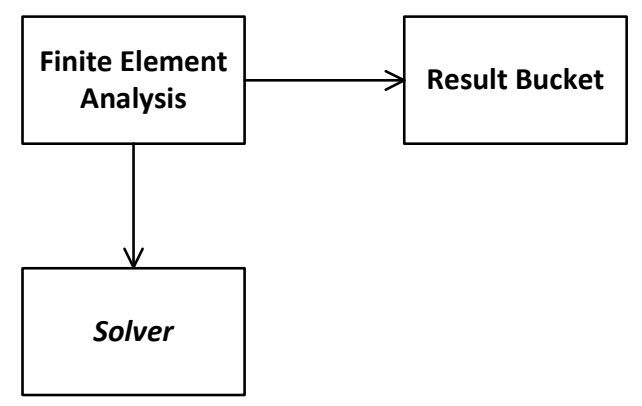

Figura 6.16 Classe Finite Element Analysis.

enquanto que todos os solvers (incluindo a definição Solver propriamente dita) são definidos na camada de domínio e lidam com problemas distintos. Portanto, o acoplamento direto pode não oferecer escalabilidade suficiente para o programa.

Com a finalidade de solucionar o problema, Finite Element Analysis atua como um elemento de junção entre os dois sistemas, nomeada segundo o padrão de pura fabricação do GRASP [134]. Todas as mensagens do solver atravessam o hub (vide herança da classe na Figura 6.15a) e são entregues ao sistema de coleta.

O sistema de coleta é composto por diversas classes, representadas na Figura 6.17. Todas as entidades do diagrama são definidas no componente Common Library, determinando a estrutura básica do sistema. 


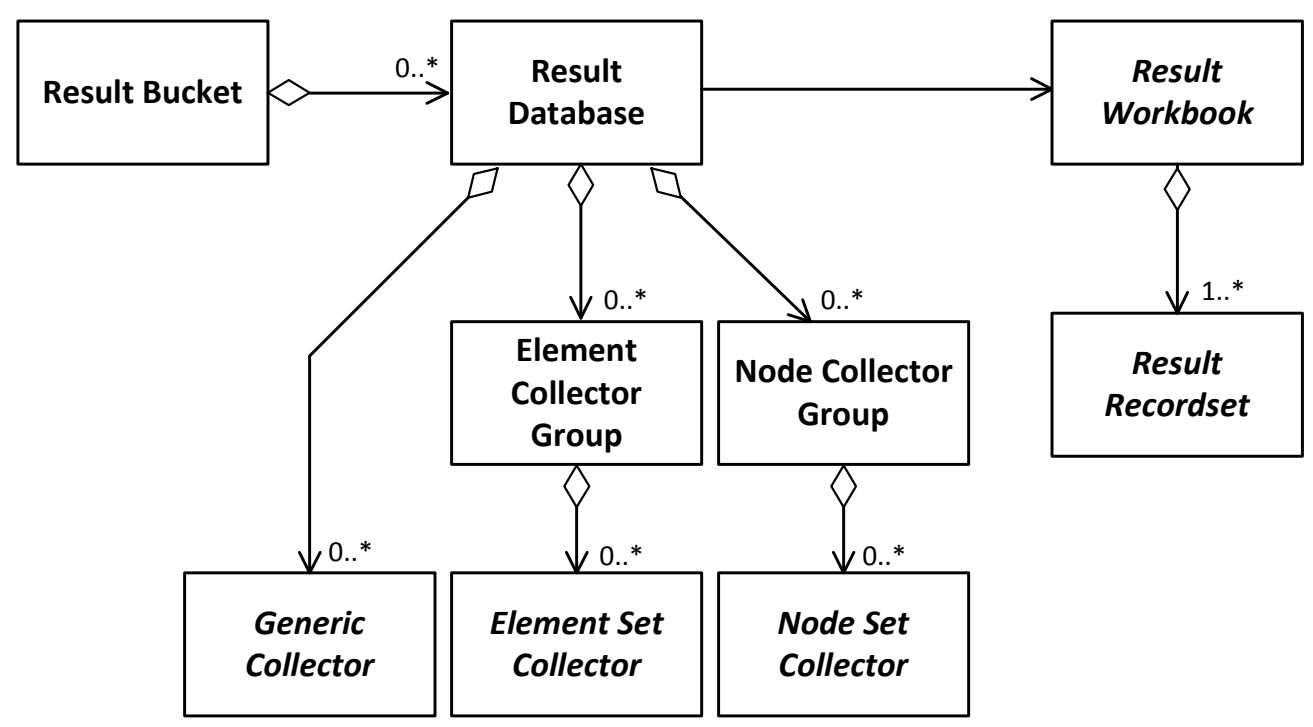

Figura 6.17 Sistema de coleta de dados do programa Axis.

Quando uma mensagem atinge Result Bucket, ela é propagada para todas os objetos internos, irradiando para as instâncias de Result Database, prosseguindo aos grupos de coletores e, finalmente, atingindo as entidades coletoras, Generic Collector, Element Set Collector e Node Set Collector.

A classe Result Database representa um arquivo de saída da análise, cujo formato é dado pelo par Result Workbook e Result Recordset. O primeiro coordena a gravação dos dados coletados entre os vários conjuntos de registros, isto é, a classe Result Recordset, que manipula os dados recebidos e os transforma para o formato nativo do tipo de arquivo de saída. A Figura 6.18 oferece alguns exemplos de formatos implementados no software.

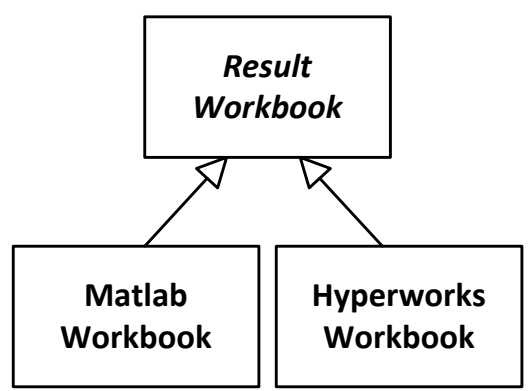

(a) Pastas de trabalho

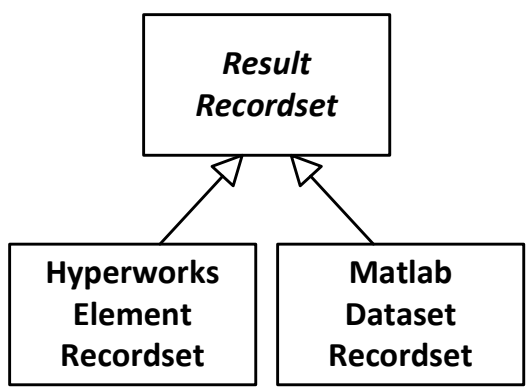

(b) Conjuntos de registros

Figura 6.18 Definição dos formato de saída Matlab e Hyperworks.

Para um arquivo de saída compatível com o software Matlab, são associados ao Result Database as classes Matlab Dataset Workbook e Matlab Dataset Recordset. 
Para o formato Hyperworks, o processo é análogo. Estas classes de formato são definidas no componente Echinopsis.

A coleta das informações solicitadas pelo usuário é efetuada pelas entidades coletoras, definidas sob uma mesma interface, conforme ilustra a Figura 6.19. Os grupos de coletores, apresentados na Figura 6.17, reúnem os coletores que atuam sobre um mesmo conjunto de elementos ou nós. Para um mesmo conjunto, os coletores podem extrair informações distintas (velocidade, aceleração, deformação ou tensão, por exemplo). Os coletores genéricos definem outras formas de coleta que não extraem informações entidade a entidade. É o caso de valores de sumário (eg. a maior tensão cisalhante), por exemplo.

A Figura 6.20 ilustra algumas possibilidades de coletores, implementados no componente Echinopsis.

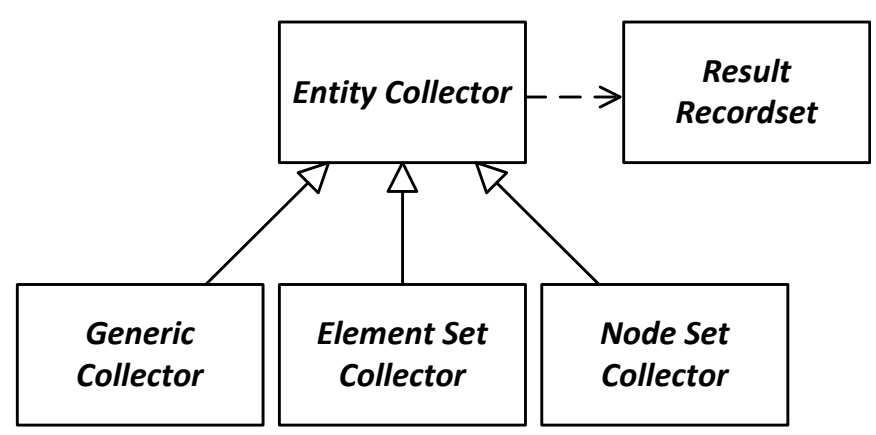

Figura 6.19 Tipos de entidades coletoras de dados.

As informações extraídas pelos coletores estão em seu estado bruto, isto é, nenhum tipo de formatação ou transformação dos dados é aplicado. Quando são encaminhados para o par de pasta de trabalho e conjunto de registros associados ao objeto de Result Database, as duas instâncias se encarregam da formatação e transformação dos dados convenientemente para o tipo de arquivo de saída que implementam.

O programa permite conectar diversos arquivos de saída para efetuar a coleta de dados em formatos distintos. O encapsulamento dos coletores e dos objetos de formatação, através de Result Database, impossibilita interferências na escrita e manipulação das diferentes saídas.

É comum a presença de metadados nos arquivos de saída para orientar um programa de pós-processamento na leitura dos dados. Isso pode incluir a gravação de cabeçalhos contendo informações sobre o instante de tempo a que se refere, título da análise, versão do formato, ou ainda, para formatos binários, bytes de identificação do tipo de dados, bytes de controle, identificação da codificação, entre outros. 


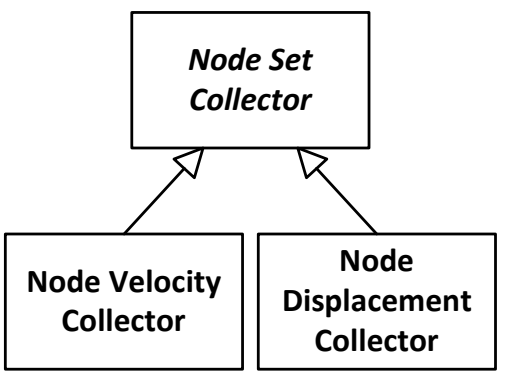

(a) Coletores de nós

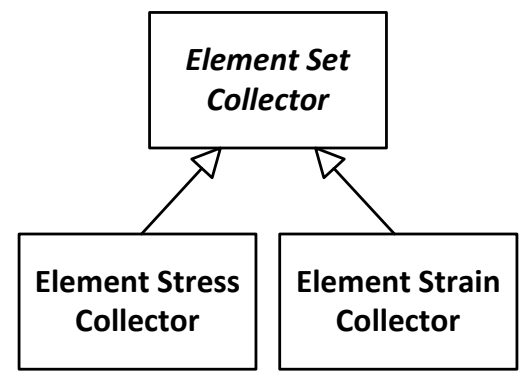

(b) Coletores de elementos

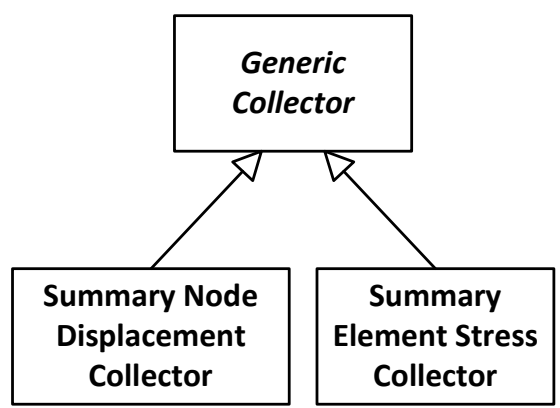

(c) Coletores genéricos

Figura 6.20 Algumas entidades coletoras implementadas no programa.

Gravar os metadados juntamente com os dados propriamente dito, numa única iteração da coleta, pode reduzir a legibilidade do código. É boa prática de programação lidar com as informações de naturezas distintas em diferentes etapas do processo, tornando mais clara a implementação da lógica de escrita no arquivo.

Dessa forma, optou-se pela diferenciação do processo geral de coleta em três etapas distintas, indicadas pela recepção de um dos tipos de mensagens definidos na Figura 6.15b. Cada um deles é resumido na Tabela 6.3.

A definição das pastas de trabalho, dos conjuntos de registros e das operações descritas na tabela definem um comportamento similar a um sistema gerenciador de banco de dados (SGBD). O sistema foi propositalmente elaborado desta forma para torná-lo compatível com formatos de base de dados binária ou em texto plano, como o Hyperworks ASCII [6], e sistemas mais sofisticados, nos quais o solver é conectado a um SGBD para o armazenamento das informações [185].

\subsubsection{Limpeza}

O final da análise, marcado pela operação EndAnalysisProcess, é dado pela liberação de recursos de memória usados pelo solver, como a matriz de massa global alocada, o vetor máscara e outras variáveis internas. 
Tabela 6.3 Operações da coleta de dados disparadas por mensagens.

\begin{tabular}{ll}
\hline Mensagem & Descrição \\
\hline Snapshot Start Message & $\begin{array}{l}\text { Abre um novo estado do modelo, requerendo que quaisquer } \\
\text { cabeçalhos ou metadados sejam gravados nos arquivos de } \\
\text { saída antes da escrita das informações do modelo. É tam- } \\
\text { bém requisitada a abertura de novos conjuntos de registros } \\
\text { que serão usados para a gravação desse novo estado. }\end{array}$ \\
Model State Update Message & $\begin{array}{l}\text { Inicia a coleta de dados propriamente dita, extraindo as in- } \\
\text { formações solicitadas do modelo e encaminhando para as } \\
\text { pastas de trabalho e conjuntos de registros de saída. }\end{array}$ \\
& $\begin{array}{l}\text { Solicita o fechamento dos conjuntos de registros utilizados } \\
\text { e a gravação de dados de rodapé ou metadados que sejam } \\
\text { requeridos para o formato do arquivo de saída. A mensagem } \\
\text { representa o fim da coleta de dados para o estado atual do } \\
\text { modelo numérico. }\end{array}$ \\
\hline
\end{tabular}

\subsection{Extensão do solver dinâmico para problemas não-lineares}

Como observado na seção 2.8.1, o método explícito requer poucas modificações para seu uso em problemas não-lineares. De fato, a maior parte dos cálculos para a consideração desse tipo de fenômeno é implementado na formulação do elemento e no modelo de material adotado.

O Algoritmo 6.2 apresenta o solver explícito para uso em problemas nãolineares, com as modificações em destaque. A atualização das coordenadas nodais consiste em armazenar a nova posição dos nós de acordo com a deformação sofrida pela estrutura. A atualização da geometria requisita a todos os elementos do modelo numérico que a matriz de gradientes, a matriz jacobiana e outras quantias relevantes sejam recalculadas para refletir a nova posição nodal. Com isso, algumas modificações estruturais nas classes de domínio são necessárias, sendo destacadas na Figura 6.21.

$\mathrm{Na}$ atualização do estado de deformação do modelo, da mesma forma que no caso linear, o método UpdateStrain() é chamado. Nisso, a formulação do elemento, que implementa os efeitos de não-linearidade, calcula o gradiente de deformação, necessário para as relações constitutivas, ao invés da deformação infinitesimal do caso linear. Modelos de materiais não-lineares requerem o armazenamento do estado de $\boldsymbol{F}$ no instante atual e na nova iteração de tempo sendo calculada, além de outras quantias específicas do modelo, como a deformação plástica equivalente. Essas variáveis são armazenadas na classe Infinitesimal State, cujas modificações necessárias estão destacadas na Figura 6.22. 
Os estados de $\boldsymbol{F}$ nos instantes $t$ e $t+\Delta t$ são armazenados nos atributos lastDeformationGradient e curDeformationGradient, respectivamente. Variáveis utilizadas por modelos elastoplásticos, como a deformação plástica acumulada, o último incremento de deformação plástica e a deformação plástica total equivalente, são representados pelos atributos plasticStrain, lastPlasticStrainIncrement e equivalentPlasticStrain, respectivamente. A classe Updated Physical State, utilizada no caso linear para proteger atributos de Infinitesimal State contra modificação acidental pelo modelo de material, também é atualizada para atender problemas não-lineares.

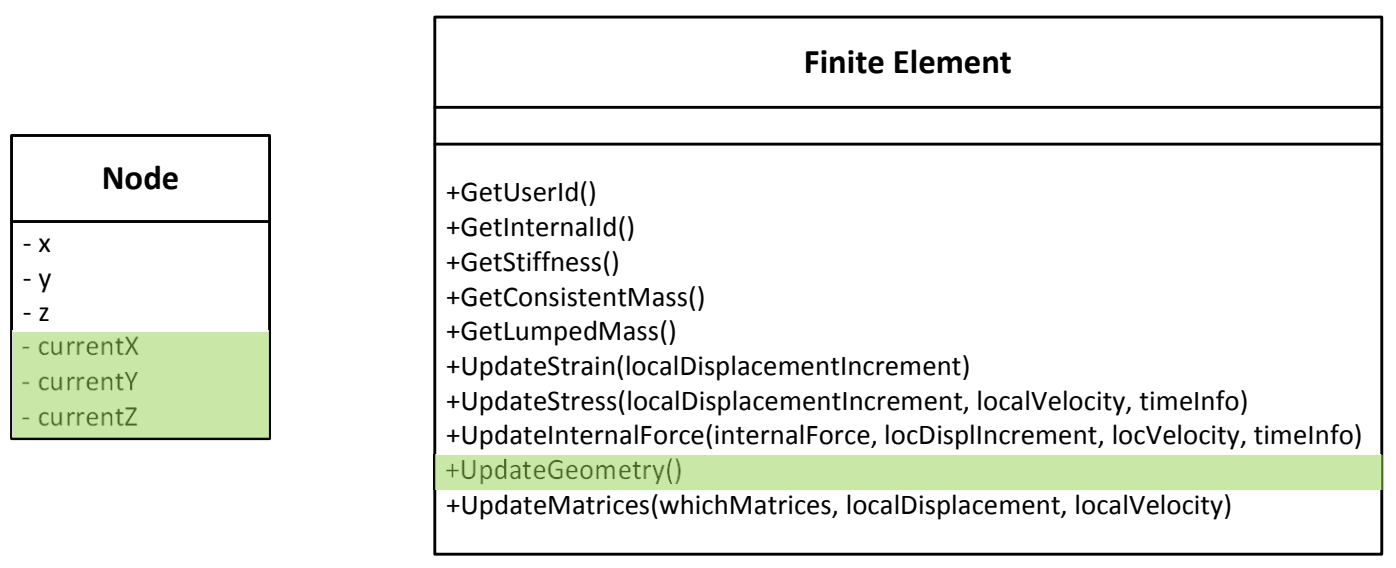

(a) Classe Node

(b) Classe Finite Element

\begin{tabular}{|l|}
\hline \multicolumn{1}{|c|}{ Formulation } \\
\hline \\
\hline +GetStiffness() \\
+GetConsistentMass() \\
+GetLumpedMass() \\
+UpdateStrain(localDisplacementIncrement) \\
+UpdateStress(localDisplacementIncrement, localVelocity, timelnfo) \\
+UpdateInternalForce(internalForce, locDisplIncrement, locVelocity, timelnfo) \\
+UpdateGeometry() \\
+UpdateMatrices(whichMatrices, localDisplacement, localVelocity) \\
\hline
\end{tabular}

(c) Classe Formulation

Figura 6.21 Modificações estruturais nas classes de domínio para o suporte a não-linearidade. 


\begin{tabular}{|l|}
\hline \multicolumn{1}{|c|}{ Infinitesimal State } \\
\hline - lastStrainIncrement \\
- strain \\
- lastStressIncrement \\
- stress \\
- lastDeformationGradient \\
- curDeformationGradient \\
- lastPlasticStrainIncrement \\
- plasticStrain \\
- equivalentPlasticStrain \\
\hline
\end{tabular}

Figura 6.22 Modificações estruturais na classe de domínio Infinitesimal State.

Algoritmo 6.2: Método ExecuteStep() usando diferenças centrais, com suporte a nãolinearidade.

\section{Algoritmo Diferenças centrais, não-linear (um único grau de liberdade)}

Condições iniciais: $m, u_{t}, \Delta u, \dot{u}_{0}, r_{t+\Delta t}^{\text {ext }}$ e dofMask (vetor máscara)

Saída: $u_{t}, \dot{u}_{t}$ e $\ddot{u}_{t}$, a cada instante de tempo $t$

1. se dofMask $=$ 'DOF LIVRE' então $\Delta u=\Delta t \dot{u}_{t-\frac{1}{2} \Delta t}$

2. $u_{t+\Delta t}=u_{t}+\Delta u$

3. Atualizar coordenadas dos nós

4. Calcular estado de deformação do modelo numérico

5. Calcular estado de tensão do modelo numérico

6. Calcular forças internas atuantes no modelo numérico $\left(r_{t+\Delta t}^{\mathrm{int}}\right)$

7. Calcular forças efetivas: $r_{t+\Delta t}^{\mathrm{R}}=r_{t+\Delta t}^{\mathrm{ext}}+r_{t+\Delta t}^{\mathrm{int}}$

8. se dofMask $\neq$ 'ENGASTE' então $\ddot{u}_{t+\Delta t}=r_{t+\Delta t}^{\mathrm{R}} / m$

9. se dofMask $=$ 'DOF LIVRE' então $\dot{u}_{t+\frac{1}{2} \Delta t}=\dot{u}_{t-\frac{1}{2} \Delta t}+\Delta t \ddot{u}_{t+\Delta t}$

10. Atualizar geometria do modelo

\subsection{Comentários}

O desenvolvimento dos sistemas de solução discutidos neste trabalho oferecem maiores esclarecimentos sobre como o framework de elementos finitos proposto atua para permitir a modelagem de um sistema flexível e robusto. A introdução dos fenômenos 
não-lineares aos procedimentos de solução causaram pouco impacto na estrutura já existente para problemas lineares.

A discussão apresentada também cabe como uma introdução para o processo de solução em GPU, uma vez que existem similaridades nos processos de ambos. Diversas entidades e seus relacionamentos relatados neste capítulo permanecerão válidos para a discussão que se segue. 


\section{Sistema de solução MEF-00 em GPU}

Recemente, o emprego de co-processadores para delegar o processamento de tarefas computacionais intensas vem sendo observado pela comunidade científica como uma solução para o desenvolvimento de sistemas de computação mais velozes e, em alguns casos, mais econômicos. Em particular, a GPU é o sistema preferido para métodos numéricos e estatísticos. Em MEF, alguns softwares já emprega o hardware para aliviar a carga de processamento, ainda que com algumas limitações [64.

O framework de elementos finitos proposto neste trabalho contempla o suporte a GPU para a solução numérica do problema, através da escrita de código orientado a objetos no hardware. É detalhado a seguir o sistema de solução por GPU.

\subsection{Visão geral da tecnologia}

Numa arquitetura de computador, duas formas principais de concorrência de processamento podem ser encontradas: a temporal e a espacial. Na concorrência temporal, as instruções são executadas sequencialmente, mas, sempre que possível, instruções independentes são alocadas em filas paralelas de execução (pipelining da CPU). Por outro lado, na concorrência espacial, vários elementos de processamento (EP) são alocados para executar, em paralelo, os componentes de uma tarefa. Neste caso, o ganho de desempenho está relacionado com o número de unidades alocadas para a computação.

A notação de Flynn discerne essas duas categorias, designando-as em sistemas SISD (Single Instruction, Single Data) e SIMD (Single Instruction, Multiple Data), 
respectivamente [68]. As CPUs tradicionais, que seguem a arquitetura de von Neumann convencional se encaixam no primeiro grupo, onde se tem um elemento de processamento que trabalha sobre um único conjunto de dados, executando as instruções fornecidas por uma unidade de controle. Processadores vetoriais são representantes da arquitetura SIMD, onde uma única unidade de controle alimenta com as mesmas instruções um grupo de elementos de processamentos, cada qual atuando sobre um conjunto distinto de dado, como o processador Cell, que equipa o console de video game Playstation 3 e alguns supercomputadores, além de EPs das CPUs x86, que implementam conjuntos de instruções vetoriais, como MMX, SSE e AVX.

As GPUs atuais são uma especialização da arquitetura SIMD. Os processadores gráficos são dispositivos altamente paralelos, especializados no processamento de grandes quantidades de dados submetidos a uma mesma execução de código. Isso se deve a sua natureza como co-processador para computação gráfica, onde os dados de múltiplos pixels estão sujeitos ao mesmo algoritmo como, por exemplo, num filtro de imagem, ilustrado na Figura 7.1. Neste tipo de hardware, milhares de threads são executadas simultaneamente e são agrupadas em conjuntos coordenados por uma única unidade de controle, que alimenta, com as mesmas instruções, os elementos de processamento do conjunto. A GPU dispõe de uma quantidade numerosa de EPs. Múltiplos elementos podem ser alocados para uma mesma tarefa (processamento coerente) ou para a realização de tarefas distintas, inclusive oriundas de diferentes processos. Devido a essa heterogeneidade, costuma-se referir à arquitetura do dispositibo como SIMT, isto é, Single Instruction, Multiple Threads (uma instrução, múltiplas threads), uma especialização do modelo SIMD.

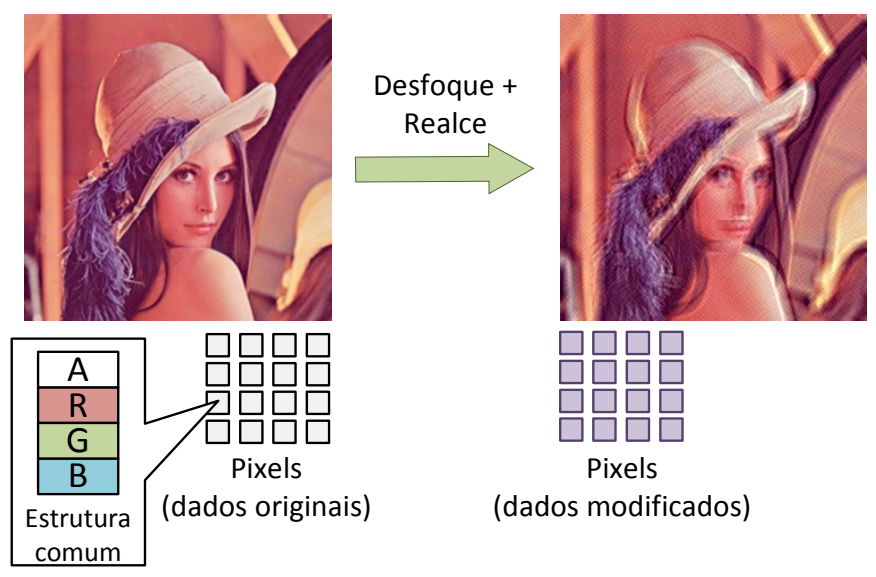

Figura 7.1 Processamento típico de GPU: em processamento de imagem, múltiplos pixels (mesma estrutura, dados distintos) são submetidos ao mesmo algoritmo de filtro para produzir o resultado de pós-processamento. 
CUDA é uma API para as linguagens de programação $\mathrm{C}$ e $\mathrm{C}++$ que permite desenvolvedores escreverem programas paralelos para execução em GPUs Nvidia. Basicamente, esses dispositivos são compostos pela unidade de processamento (a GPU, propriamente dita) e um banco de memória. GPUs com suporte ao CUDA são construídas numa matriz de unidades de processamento, chamada streaming multiprocessor (SM). Cada SM executa tarefas paralelas em um grupo de 32 threads denominado warp. O mesmo programa é executado em todas as threads, mas cada uma detém seu próprio contador de programa (PC) e estado de registradores (isto é, como se fossem pequenos processadores executando de forma coordenada). Em gerações modernas, é permitido o uso de instruções de desvio que causem divergências no fluxo de execução dentro do SM [175]. Uma visão geral da escrita de um programa usando a API é dada no Apêndice $\mathrm{F}$.

O subsistema gráfico, onde está localizada a GPU, está inserido dentro da arquitetura de hardware mostrada na Figura 7.2. O número de SMs e o máximo de threads paralelas permitidas dentro dele, possibilita que uma única GPU possa operar, simultaneamente, conjuntos de dados maiores que a CPU, levando a um processamento substancialmente maior.

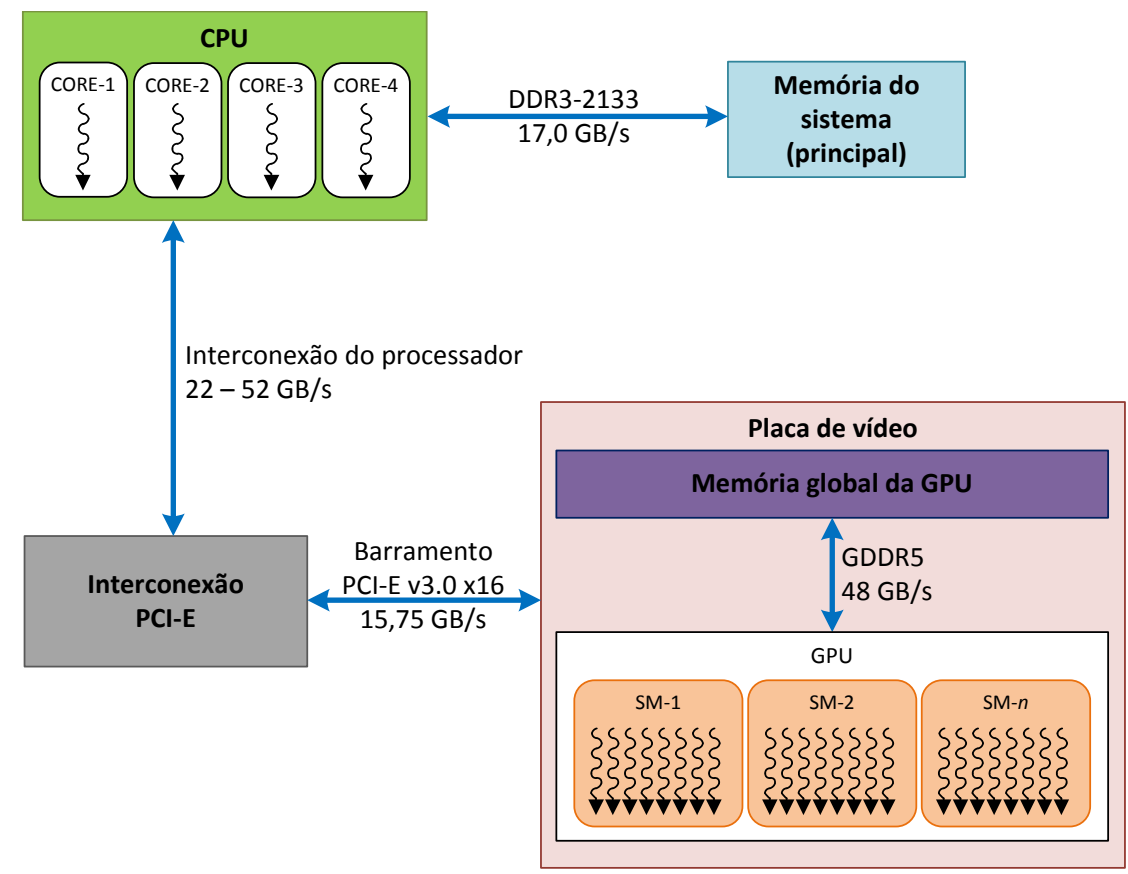

Figura 7.2 Configuração típica do subsistema de vídeo. 


\subsection{Limitações do processamento em GPU}

Devido à arquitetura distinta da GPU, códigos legados não são facilmente adaptados para o uso no dispositivo, além de que uma adaptação muito simples poderá não aproveitar ao máximo o hardware. Além disso, a tecnologia de compilação de código GPU, juntamente com o código de host é relativamente recente, tal que recursos encontrados para o código de host não estão completamente disponíveis para GPU, tornando mais difícil a implementação de um código flexível. Algumas dessas limitações são discutidas a seguir.

\subsubsection{Limitações do hardware}

Latência de comunicação. Na arquitetura atual dos computadores, a transferência de dados entre a CPU e a GPU é lenta em relação à velocidade interna do dispositivo gráfico, com vazão máxima de 15,75 GB/s [241] (vide Figura 7.2]). Transferências excessivas degradam rapidamente o desempenho do programa, conforme mostra a Figura 7.3 para um problema de 500 multiplicações de matrizes quadradas. Uma latência considerável é observada quando dados são transferidos a cada operação realizada (MT), em relação a apenas duas transferências (no início e no final).

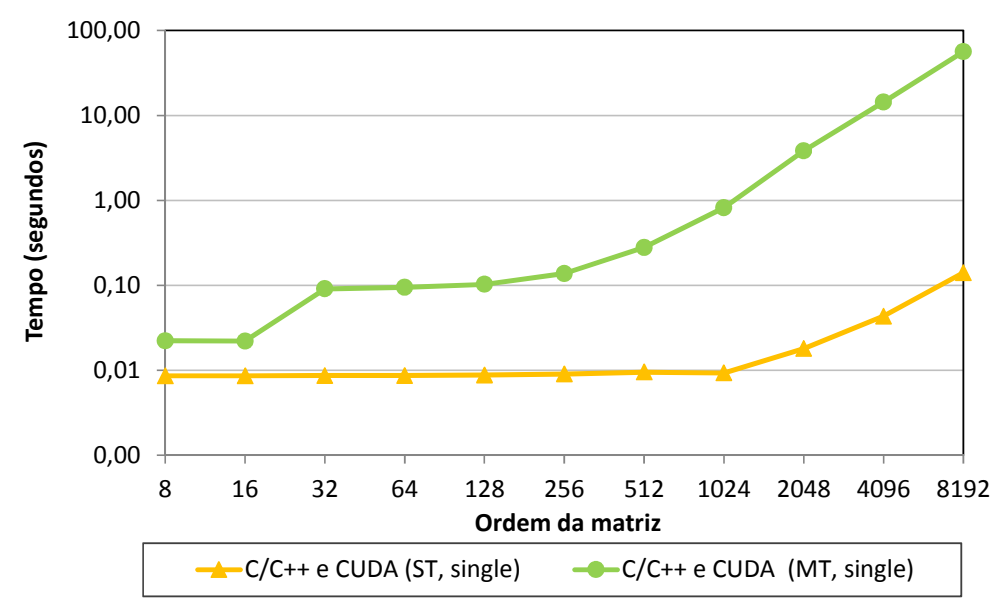

Figura 7.3 Latência da transferência de memória GPU-host num problema de multiplicação matricial, 500 repetições por teste.

Acesso limitado aos subsistemas do hardware. Ao contrário da CPU, a GPU não dispõe de acesso a todos os subsistemas do computador. Por exemplo, não é possível escrever um kernel (subrotina em GPU) que grave os resultados obtidos diretamente no arquivo de saída: é necessário transferir as informações para a memória principal do sistema e executar as operações a partir do código do host. 


\subsubsection{Limitações da API}

Endereços de memória distintos. Na arquitetura x86 e nos sistemas operacionais modernos, o endereçamento da memória de dispositivos distintos ocorre em intervalos diferentes, o que impossibilita, num kernel, usar ponteiros para regiões da memória do sistema (exceto áreas não-pagináveis ${ }^{1}$, acessíveis por canal $\mathrm{DMA}^{2}$ ).

Código não-trivial. A codificação de um kernel não é trivial. Devido à arquitetura distinta (SIMT), o modelo de programação pode exigir do desenvolvedor a reescrita do código e o aprendizado de novas primitivas de sincronização. Elementos como semáforos, barreiras e sinalizadores, próprios do modelo paralelo da CPU, não possuem contrapartes totalmente equivalentes na GPU.

Quebra da associação entre objetos. Em C++, a associação mostrada na Figura 7.4a é implementada como um ponteiro para o endereço base de memória do objeto Nó. Quando os objetos são criados no host, as referências são válidas apenas para a CPU (Fig. 7.4b). Ao copiá-los para a GPU, a associação é perdida, pois o endereço apontado não é válido para o dispositivo (Fig. 7.4b).

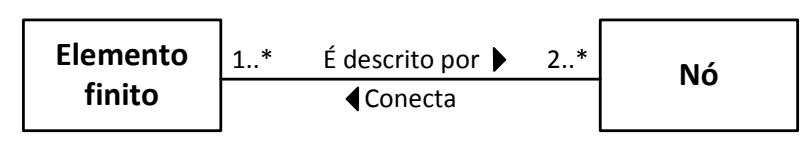

(a) Diagrama de classes

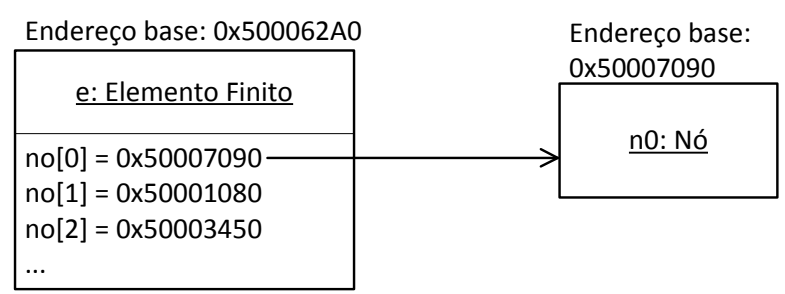

(b) Estado dos objetos na memória do host

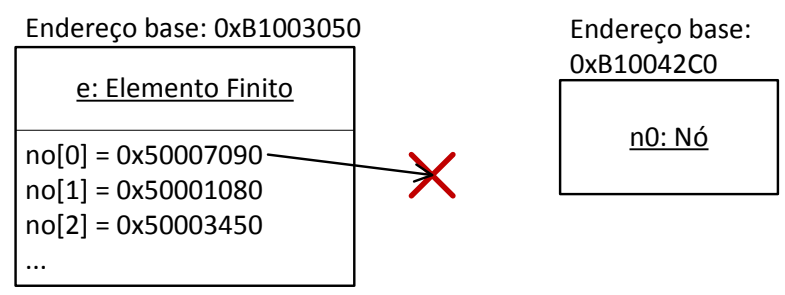

(c) Estado inconsistente dos objetos na memória da GPU

Figura 7.4 Exemplo de quebra da associação na GPU. Quando os objetos são transportados para a memória do dispositivo, o ponteiro que referencia n0 se torna inválido.

\footnotetext{
${ }^{1}$ Área não-paginável é o intervalo da memória virtual do sistema operacional sempre residente na memória física.

${ }^{2}$ Sigla inglesa para acesso direto à memória.
} 
Métodos virtuais não suportados. Em $\mathrm{C}++$, as operações sobrecarregáveis numa hierarquia de classes são implementadas através de métodos virtuais. A definição de qual implementação de método deve ser usado para um objeto, é dada pela tabela de métodos virtuais. Para a hierarquia da Figura 7.5a, cada subclasse define sua tabela, onde é especificada a localização do método AtualizarTensao() que implementam (Figura 7.5b). Os objetos derivados dessas classes são então associados à tabela correspondente. Esta funcionalidade não é totalmente suportada na GPU, pois as tabelas virtuais não são facilmente acessíveis pelo programador, o que impossibilita a sua cópia para a GPU. Além disso, análogo ao problema anterior, os ponteiros usados na tabela não são válidos para o dispositivo.

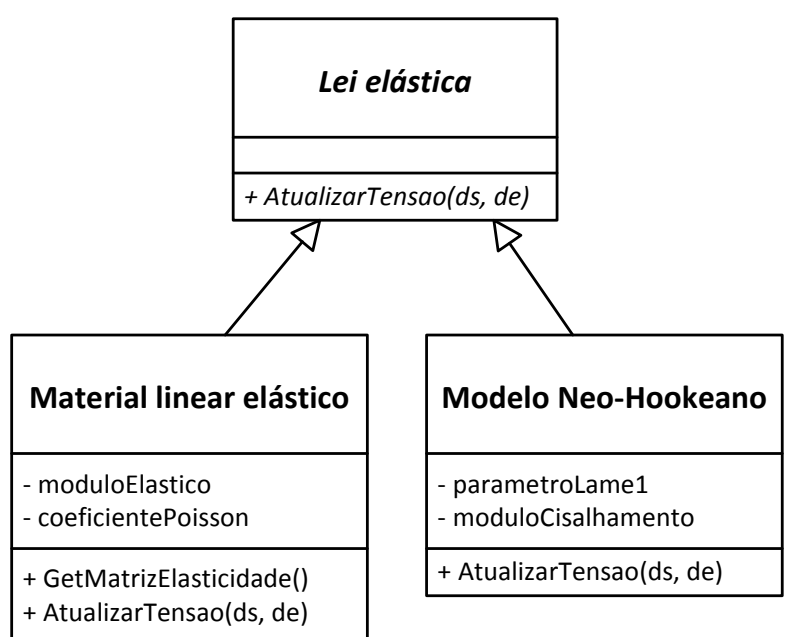

(a) Diagrama de classes

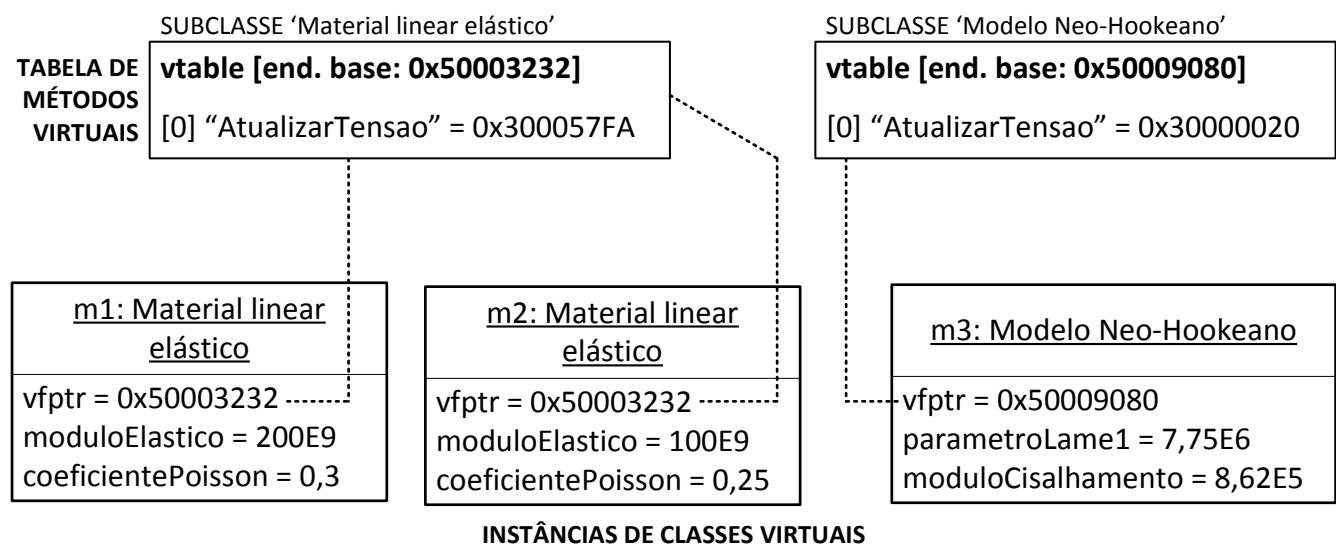

(b) Estado dos objetos na memória do host

Figura 7.5 Implementação de métodos virtuais em $\mathrm{C}++$. 
Símbolos do código de dispositivo não exportáveis. Na divisão do código de um programa em componentes, variáveis e funções são desmembrados em diferentes conjuntos alocados em bibliotecas compartilhadas. Para que seja trazida a unidade do programa, os símbolos (isto é, as definições das variáveis, funções globais e classes públicas) precisam ser exportados nas bibliotecas. Em códigos GPU CUDA, não é possíveis exportar símbolos definidos para a GPU e, mesmo que seja obtido o ponteiro de memória para a variável ou função de destino, não há garantia de que o código seja executado corretamente.

\subsection{Organização de memória do programa Axis}

As instâncias das classes $\mathrm{C}++$ são armazenadas em uma área de memória dinâmica, denominada free store [220]. O alocador, isto é, a rotina que reserva o espaço de memória na free store para um objeto, em geral não apresenta bom desempenho para um volume muito grande de objetos, além de que não há controle sobre qual região da memória será utilizada. Neste cenário, transferir os dados dos objetos para a GPU pode se transformar numa tarefa árdua, podendo significar milhares de pequenas transferências, provocando uma sobrecarga substancial no desempenho do programa. Uma possível solução para este problema é a adoção de arenas de memória.

\subsubsection{Sistema de arenas de memória}

Uma arena, também conhecida como pool, região ou zona de memória, é uma área de memória reservada onde um gerenciador de memória desenvolvido para o programa coordena as alocações e desalocações de objetos nesta região. Com o uso de arenas, apenas duas alocações de memória são efetivamente realizadas, a alocação e a desalocação da região, em contraste com as milhares ue seriam necessárias, por exemplo, para o armazenamento de uma malha de elementos finitos, o que provê um expressivo ganho de desempenho de até uma ordem de magnitude, segundo resultados obtidos neste estudo. Além disso, a alocação é determinística, pois o desenvolvedor tem total controle sobre a operação.

No programa Axis, a memória é configurada segundo o layout da Figura 7.6. O sistema de arena é definido na camada de fundação da arquitetura, dentro do componente System Base. Quatro arenas distintas são definidas para funcionalidades específicas do programa. Áreas potencialmente utilizadas concorrentemente implementam sistemas de sincronização de threads e são marcadas como thread-safe 
na figura. A área String é exclusivamente usada para alocar buffers do tipo de dados String, para a gravação de cadeias de caracteres. As áreas de memória de pilha são usadas para armazenar dados de objetos automáticos em $\mathrm{C}++$, como matrizes e vetores armazenados na pilha de execução do programa. Para maior desempenho, não implementam mecanismos de sincronização e, a fim de evitar condições de corrida, uma região é designada para cada thread paralela do programa.

A arena de memória do modelo e a arena global são áreas consideravelmente maiores que as demais. A arena modelo é usada para o armazenamento de objetos específicos da simulação numérica, como instâncias de elementos finitos, nós, materiais, condições de contorno, vetores de solução, entre outros. A área global é usada para propósitos gerais do programa, onde é requerido o armazenamento de informações ao longo do tempo de vida da análise. Para este estudo, a arena do modelo é a área de memória mais importante do programa, pois é nela que são armazenadas todas as informações que serão transportadas para a GPU.

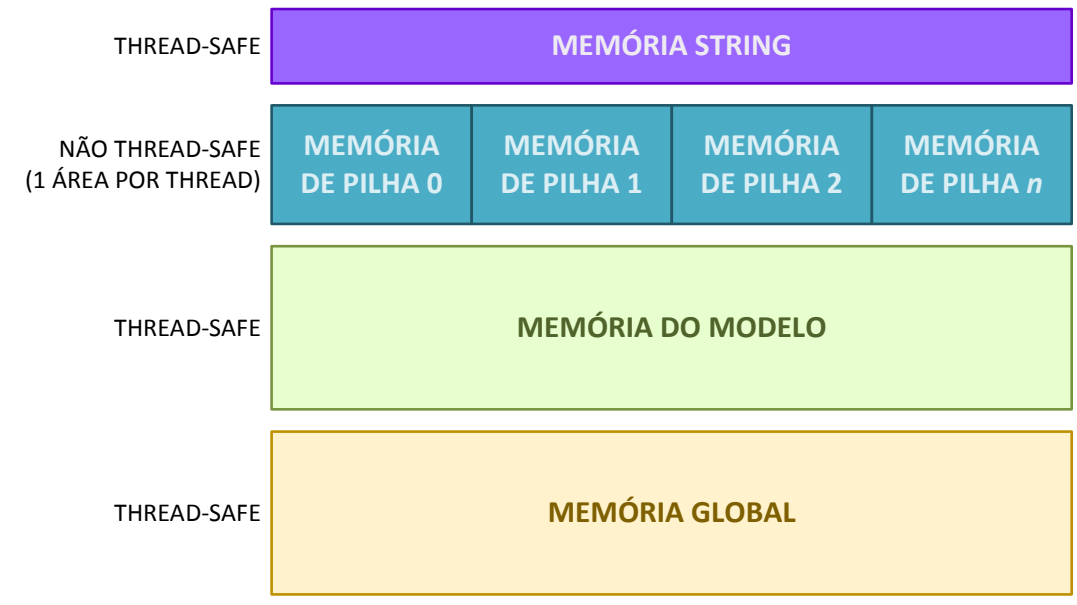

Figura 7.6 Regiões de arena do programa Axis.

A estruturação interna da arena do modelo é mostrada na Figura 7.7a. O seu funcionamento é coordenado pela classe Heap Block Arena. A natureza de alocação segue a lógica de uma estrutura de dados em pilhas, alocando sequencial e contiguamente (Fig. 7.7b). Não é definida a operação de desalocação neste região. Ao invés disso, a região inteira é desalocada no final da análise, praticamente eliminando o custo computacional envolvido na destruição individual dos objetos.

A arena é caracterizada como uma área redimensionável de acordo com o volume de alocação. Caso a região reservada, ou chunk, não possua espaço suficiente para alocar memória para um objeto, um novo chunk é reservado para suprir a demanda, conforme ilustra a Figura 7.8. Essas novas regiões são alocadas segundo um tamanho pré-definido pela configuração da classe de arena que coordena a operação. 


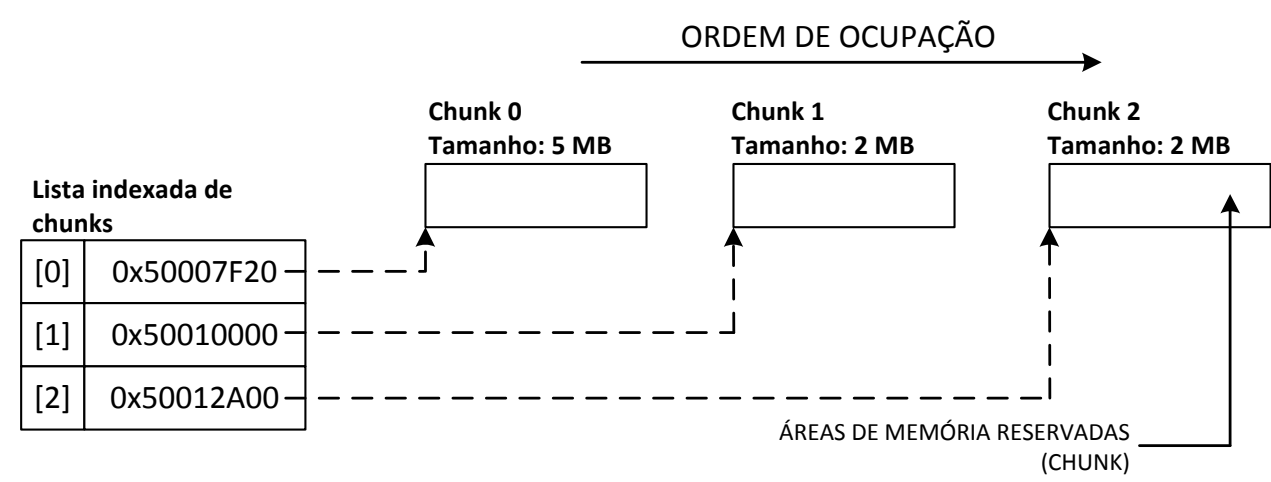

(a) Estruturas de dados internas

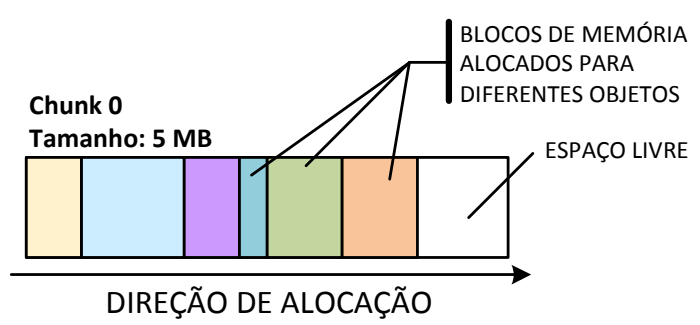

(b) Ordem de alocação dentro do chunk

Figura 7.7 Organização interna da arena de memória do modelo.

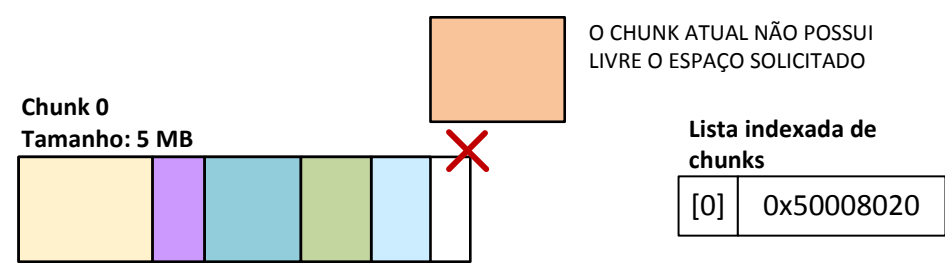

(a) Antes

CHUNK INICIAL

(SEM ESPAÇO LIVRE PARA ALOCAÇÃO)

Chunk 0

Tamanho: $5 \mathrm{MB}$

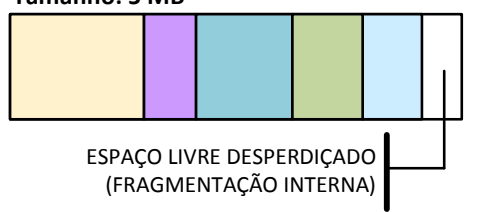

CHUNK NOVO RESERVADO (USADO PARA NOVAS ALOCAÇÕES)

Chunk 1

Tamanho: $2 \mathrm{MB}$

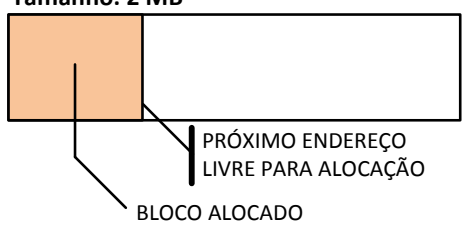

(b) Depois
Lista indexada de chunks

\begin{tabular}{|l|l|}
\hline$[0]$ & $0 \times 50008020$ \\
\hline$[1]$ & $0 \times 50020040$ \\
\hline
\end{tabular}

Figura 7.8 Elasticidade da arena do modelo para novas alocações. 
A Tabela 7.1 lista as configurações padrão das arenas do programa. Os valores adotados são ideais para problemas discretizados até cerca de 100000 elementos. Cenários menores ou muito maiores poderão exigir uma configuração específica, ajustável pelo usuário, para evitar desperdício de espaço ou fragmentação externa excessiva.

Tabela 7.1 Configurações padrão das arenas.

\begin{tabular}{lccc}
\hline \multirow{2}{*}{ Tipo de arena } & \multirow{2}{*}{ Expansível } & \multicolumn{2}{c}{ Tamanho (em MB) } \\
& & Tamanho inicial & Tamanho do incremento \\
\hline Memória string & Sim & 5,0 & 2,0 \\
Memória de pilha & Não & $10,0^{*}$ & - \\
Memória do modelo & Sim & 80,0 & 60,0 \\
Memória global & Sim & 40,0 & 40,0 \\
\hline
\end{tabular}

*Para cada thread.

\subsection{Referência independente de dispositivo: o ponteiro relativo}

O modelo de alocação em arenas, apresentado na seção anterior, permite concentrar os objetos em regiões de memória conhecidas, facilitando a localização e a transferência dessas informações para a GPU. Contudo, o problema da quebra de associação, discutido na seção 7.2.2, ainda persiste, e consiste num dos principais fatores que impedem a utilização da orientação a objetos no dispositivo.

No programa Axis, ao invés de usar o tipo nativo para ponteiros em $\mathrm{C}++$, referências a objetos da arena do modelo são feitas através do tipo Relative Pointer (Figura 7.9). O ponteiro relativo implementado pela classe possui o mesmo comportamento do tipo nativo. Contudo, a resolução do endereço é feita através de três parâmetros armazenados em seus atributos: pool ID, que identifica a arena em que o objeto está alocado (arena do modelo ou global); chunk ID, que é o índice do chunk da arena em que o objeto reside e; relative address, que é o endereço base do objeto dentro do chunk. Uma vez que as informações das arenas estão disponíveis globalmente, ponteiros relativos podem ser resolvidos verificando o endereço base do chunk através de pool ID e chunk ID e, então, somando o valor de relative address.

Se as informações da arena do modelo são mantidas atualizadas no host e na GPU e usando ponteiros relativos para estabelecer a associação entre objetos, referências de memória são preservadas no transporte dos dados para o dispositivo, sem que requerer a modificação individual e árdua de cada objeto sujeito ao processamento em GPU. 


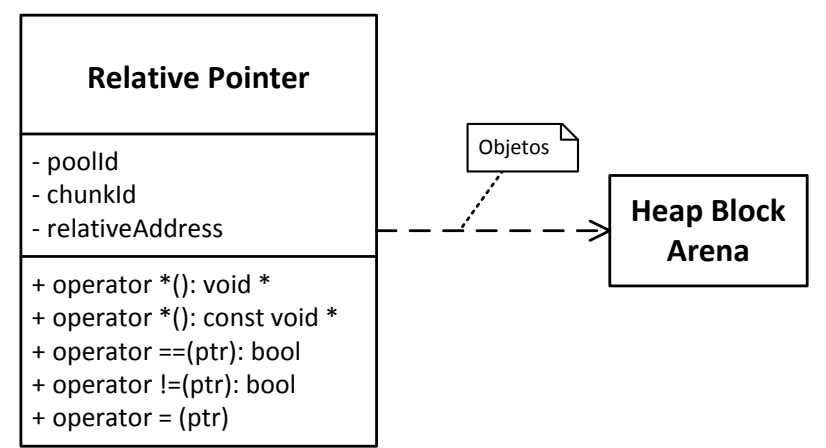

Figura 7.9 Ponteiro relativo.

\subsection{Yuzu: biblioteca estática para definição dos objetos em GPU}

A definição das classes de domínio básicas para uso em GPU estão localizadas na biblioteca estática Yuzu. Sendo a contraparte dos componentes para código de host, estão entre as classes que a biblioteca define:

- Finite Element, Node, DoF, Infinitesimal State, entre outras, compatíveis com as definições das mesmas classes de CPU em Common Library;

- Dense Matrix, Symmetric Matrix, Lower Triangular Matrix, Upper Triangular Matrix, Column Vector e Row Vector, compatíveis com as definições no componente BLAS;

- Relative Pointer, compatível com a mesma definição em System Base.

São também definidas na biblioteca funções globais auxiliares para a solução de problemas comuns na codificação de subprogramas em GPU.

A compatibilidade binária ${ }^{3}$ entre as definições de CPU e GPU é imprescindível para o correto funcionamento dos mecanismos da orientação a objetos e para a consistência dos dados. Bibliotecas estáticas, contudo, não dispõem de mecanismos automáticos para garanti-la.

Bibliotecas dinâmicas, ainda que sofram do mesmo problema, dispõem de alguns mecanismos que amenizam a questão da compatibilidade. Contudo, a API CUDA não suporta símbolos exportáveis definidos para o código de dispositivo, conforme foi discutido na seção 7.2.2. Dessa forma, fica a cargo do desenvolvedor manter a compatibilidade binária entre códigos (Figura 7.10).

\footnotetext{
${ }^{3} \mathrm{~A}$ compatibilide binária é aquela na qual o layout de memória de um objeto é preservado entre duas definições. Isso implica na preservação da ordem dos atributos, tipos de dados, espaçamentos devido ao alinhamento de memória requerido pela arquitetura do hardware, entre outros.
} 


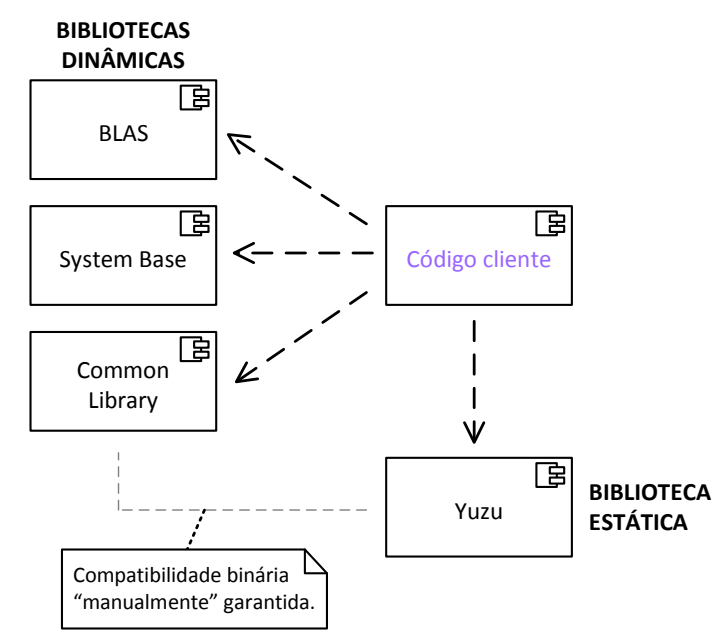

Figura 7.10 Cenário típico de emprego da biblioteca Yuzu.

\subsection{Capsicum: componente de gerenciamento e abstração das operações em GPU}

Para as operações de manipulação da GPU e suas primitivas de dados serem mantidas o mais desacoplado possível das classes de domínio, o componente Capsicum implementa sistemas de fachada que ofuscam a visualização desses objetos, tornando o algoritmo de elementos finitos implementado no dispositivo mais transparente e com melhor legibilidade.

Juntamente com o componente Common Library e a biblioteca estática Yuzu, o programa define um cenário com poucas dependências intercomponentes, tornando a implementação de plugins para a GPU mais simples, conforme ilustra a Figura 7.11.

Uma vez que plugins não dependem de Capsicum, eles estão livres de acoplamentos com as operações sobre o hardware gráfico. Isso é alcançado definindo classes abstratas de fachada dentro do componente Common Library. As interfaces definidas são usadas pelas entidades de MEF para o disparo dos cálculos na GPU. Capsicum, por sua vez, implementa subclasses concretas que coordenam a realização dessas computações no dispositivo.

São suportados no Axis os dispositivos gráficos que atendam aos requisitos mínimos listados na Tabela 7.2. Somente placas gráficas desenvolvidas na arquiteturaFermi ou compatível [175] são suportadas, devido às limitações mais severas na orientação a objetos que versões anteriores apresentam. Isso não representa um problema, pois todos os hardwares atuais usando GPU Nvidia possuem suporte.

Cada dispositivo gráfico, instalado no sistema e descoberto pelo componente 


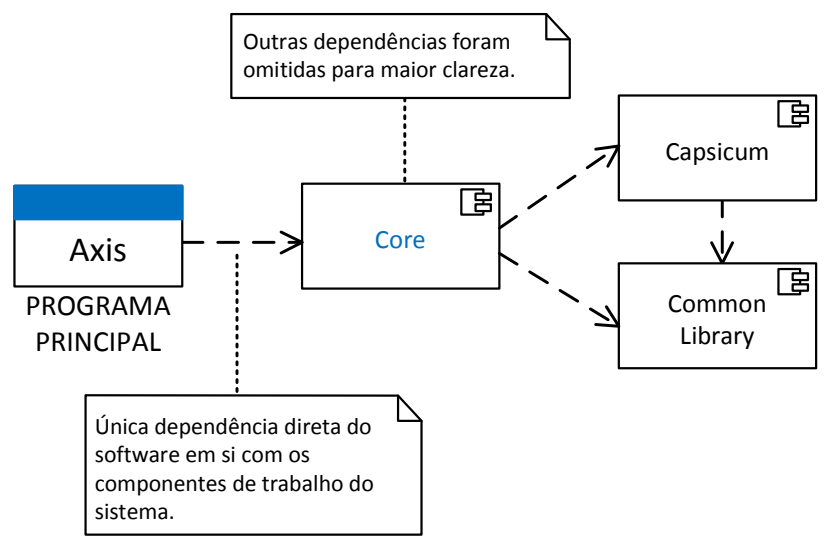

(a) Dependências mínimas para o software

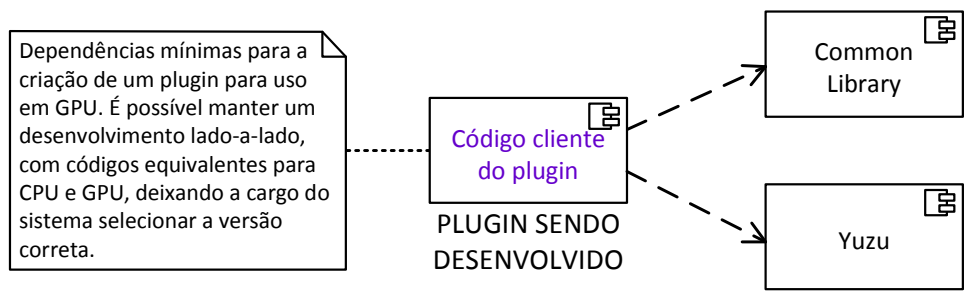

(b) Dependências mínimas para plugins

Figura 7.11 Dependências mínimas para um sistema com suporte a GPU.

Tabela 7.2 Requisitos mínimos da GPU para execução no Axis.

\begin{tabular}{lc}
\hline Parâmetro & Valor \\
\hline Versão mínima & 2.0 (Fermi) \\
Endereçamento unificado & Habilitado \\
Modo de computação & $\begin{array}{c}\text { Qualquer um diferente de cu- } \\
\text { daComputeModeProhibited }\end{array}$ \\
\hline
\end{tabular}

Capsicum, é identificado como um objeto da classe GPU Device, definida na camada de fundação. Poucas classes são acopladas a esta entidade, devido a sua forte ligação com aspectos tecnológicos. Neste sentido, sua área de atuação se limita apenas ao componente Capsicum. Esta abordagem se repete para diversas outras classes do componente, para não expor diretamente os elementos da API CUDA.

Capsicum executa quatro atividades relevantes para preparar uma análise para processamento em GPU: a validação do modelo numérico, em que todos os objetos da análise são verificados se possuem suporte para o hardware (isto é, implementam kernels de GPU); a seleção do ambiente de processamento, no qual propriedades da análise são consideradas no seu direcionamento para CPU ou GPU; a coalescência e escalonamento dos algoritmos, onde elementos, materiais e condições de contorno 
de formulação idêntica são devidamente agrupados para execução nos kernels e; despacho da análise, quando a simulação numérica é finalmente executada no hardware de destino. Cada uma delas será discutida a seguir.

\subsubsection{Validação do modelo numérico para execução em GPU}

Definido na camada de aplicação, a classe Job Inspector, mostrada na Figura 7.12a, é responsável pela inspeção do modelo numérico e solver adotado para a simulação numérica. Para que a simulação numérica possa ser executada na GPU, solver (classe Solver), elementos finitos (classes Formulation e Material Model), condições de contorno aplicadas no modelo (classe Boundary Condition) e histórico de tempo das condições de contorno (classe Curve) precisam definir algoritmos próprios para a execução no dispositivo (Figura 7.12b).

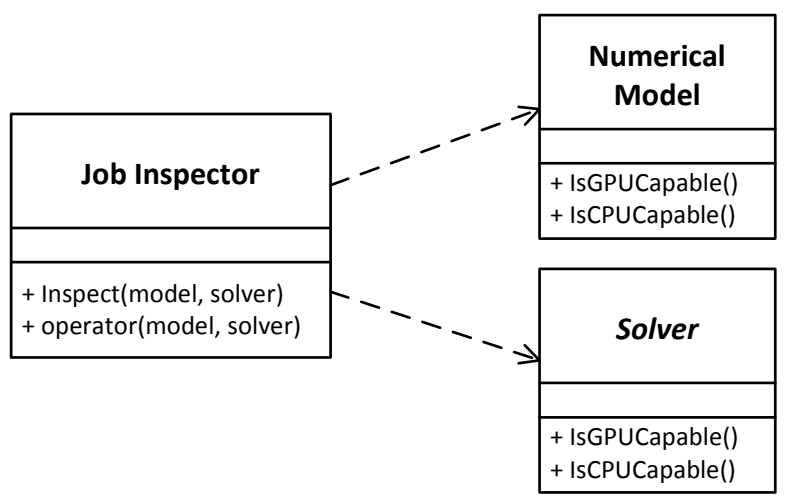

(a) Joblnspector e classes de primeiro nível da validação

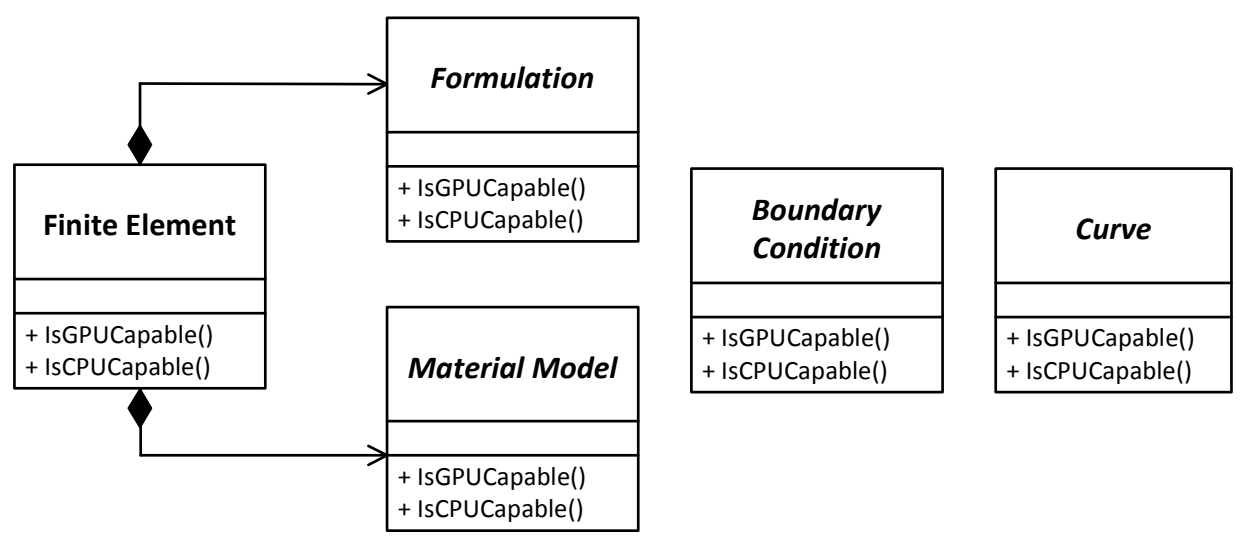

(b) Classes inspecionadas num modelo numérico

Figura 7.12 Classes para inspeção da simulação numérica. 
As classes anteriormente mencionadas definem a operação IsGPUCapable(), que retorna se a entidade possui código para execução em GPU. A implementação padrão retorna negativo. Subclasses que definem algoritmos para o dispositivo devem sobrecarregar o método para retornar o valor correto. De maneira análoga, IsCPUCapable() retorna se há código para execução em CPU que, na implementação padrão, retorna positivo. Por estes mecanismos, é possibilitado ao desenvolvedor especificar funcionalidades voltadas apenas para um dos ambientes de processamento ou ambos.

\subsubsection{Seleção do hardware de execução}

Uma vez que o solver e o modelo numérico concordam para execução em, pelo menos, um dos ambientes de processamento (isto é, todas as entidades envolvidas suportam um dos ambientes), cabe à classe Schedule Broker, definida na camada de aplicação, decidir em qual hardware a simulação numérica será executada. O sistema definido na camada de aplicação, e coordenado por ela, é mostrado na Figura 7.13.

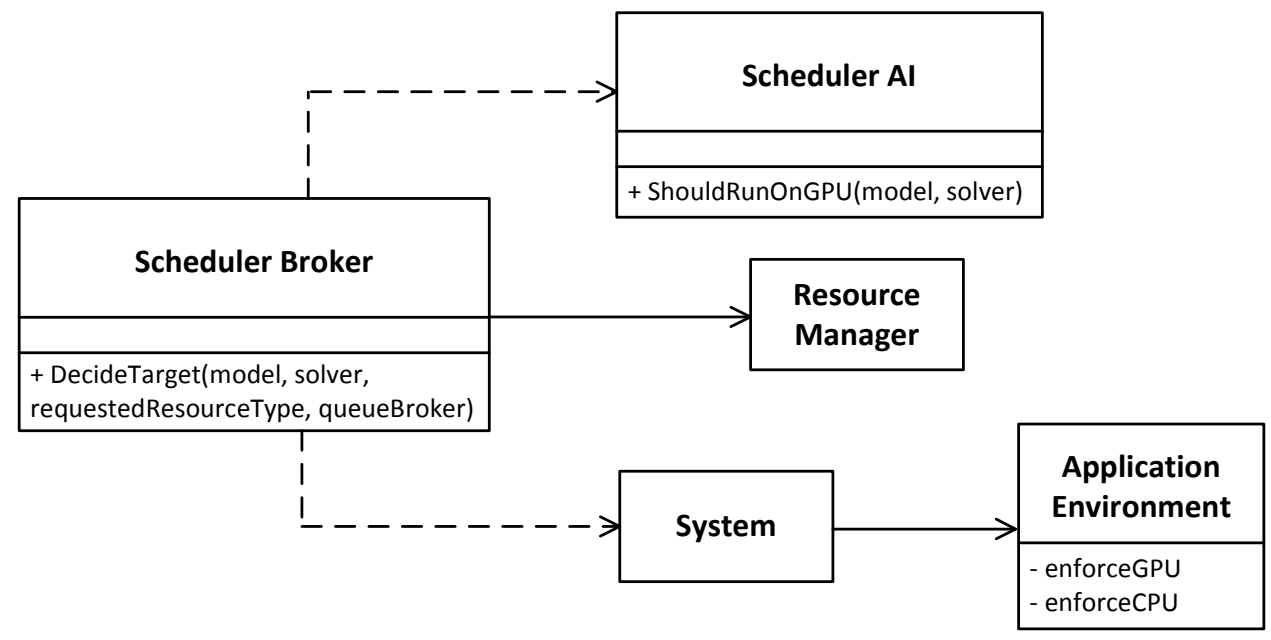

Figura 7.13 Sistema de seleção do ambiente de processamento.

Para a seleção do ambiente de processamento, são levados em consideração os seguintes critérios:

1. os tipos de ambientes suportados pela simulação numérica, segundo especificado pelas operações IsGPUCapable() e IsCPUCapable() e verificado pela classe Job Inspector;

2. os ambientes de processamentos nos quais o programa está compelido a executar, segundo a configuração retornada pela classe Application Environment, associada ao singleton System (Fig. 7.13). Definindo variáveis de 
ambiente no sistema operacional, o usuário pode obrigar a execução de simulações apenas em um dos tipos de hardware;

3. a disponibilidade de GPUs para a execução, conforme enumerado pela classe Resource Manager;

4. o algoritmo de decisão encapsulado na classe Scheduler AI, que pode levar em conta aspectos como a presença de não-linearidade e tamanho do modelo numérico. A implementação atual sugere execução na GPU para modelos com tamanho superior a 10000 elementos ou presença de nãolinearidade. Versões mais sofisticadas são possíveis, bastando substituir a definição atual da classe;

Caso ocorra um conflito dos critérios (eg. o modelo não suporta execução na GPU, mas o ambiente obriga a execução nesse tipo de hardware), considera-se que há uma discordância do ambiente com o job (a união do solver com o modelo numérico) e a execução é abortada. Deve-se observar, contudo, que a classe Scheduler Al oferece apenas uma sugestão do local de execução, não sendo, portanto, um critério capaz de causar conflito na resolução.

\subsubsection{Coalescência de algoritmos}

A classe Data Coalescer da camada de aplicação, mostrada na Figura 7.14, agrupa entidades semelhantes do modelo numérico em conjuntos distintos, que serão usados pelo sistema de escalonamento e agendamento para a definição das tarefas de processamento em GPU.

Para que um kernel de GPU possa ser disparado corretamente, é necessário que o algoritmo de uma formulação, por exemplo, atue somente nos dados de elementos que utilizem este código. No processo de coalescência, a diferenciação do código é dada pela operação GetTypeld() da classe (para o elemento finito, GetFormulationTypeld() e GetMaterialTypeld() são operações de fachada para a formulação e o modelo de material, respectivamente), que retorna um UUIDv4 ${ }^{4}$ que identifica exclusivamente aquele código. Se dois objetos possuem o mesmo UUID, então é assumido que são derivados da mesma classe e que, por consequência, implementam o mesmo código e trabalham sobre conjuntos de dados idênticos em estrutura e tamanho.

O agrupamentos das entidades é dado pelo UUID retornado pelo objeto, onde cada conjunto, definido pela classe Bucket, contém objetos de mesma definição

\footnotetext{
${ }^{4}$ UUIDv4 é a sigla inglesa para identificador único universal, versão 4, um padrão para identificar exclusivamente elementos, sem a necessidade de um ponto central de administração dos identificadores.
} 
(UUID iguais). Múltiplas definições são agrupadas em instâncias distintas da classe. O elemento finito é classificado segundo sua formulação e também de acordo com o modelo de material usado, conforme ilustra a Figura 7.14.

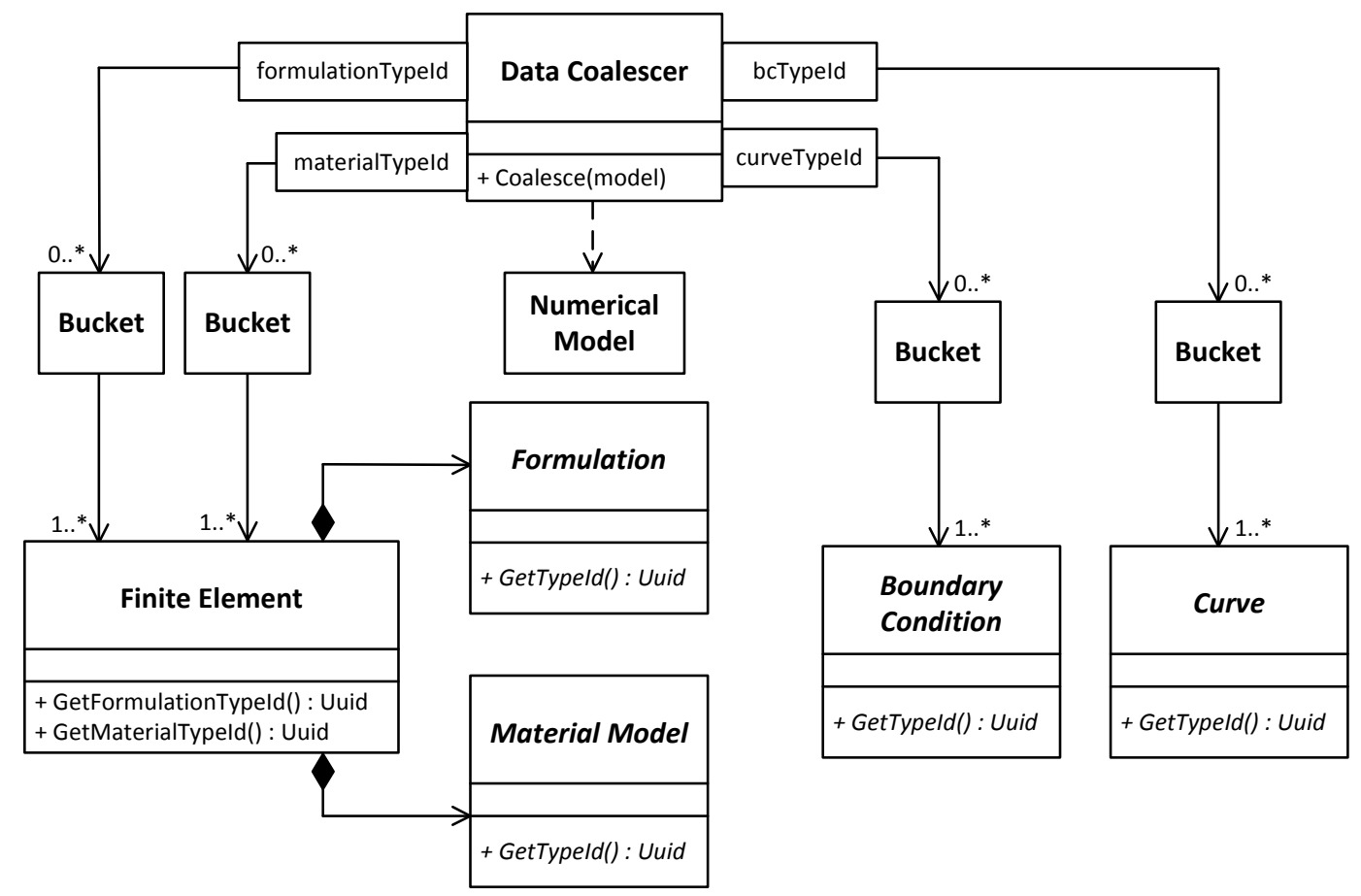

Figura 7.14 Sistema de coalescência de algoritmos.

\subsubsection{Escalonamento das tarefas de processamento}

Juntamente com o despacho, o escalonamento de tarefas é uma das tarefas mais importantes no sistema de gerenciamento da GPU. São definidas classes que denotam a divisão das tarefas entre as unidades gráficas e o gerenciamento dos dados residentes na memória do dispositivo. São explicados a seguir os principais componentes.

\section{A classe Kernel Scheduler}

Localizada na camada de serviço do programa, a classe Kernel Scheduler oferece serviços de escalonamento de tarefas para os dispositivos gráficos disponíveis no sistema. As operações disponíveis são listadas na Figura 7.15.

Uma sessão de agendamento de tarefas é delimitada pelas chamadas às operações BeginGPURound() e EndGPURound() da classe Kernel Scheduler. Dentro dela, as tarefas são escalonadas de acordo com a ocupação dos dispositivos existentes e espaço de memória global disponível no dispositivo, conforme informado pelas classes GPU Metadata, GPU Device e Resource Manager. 


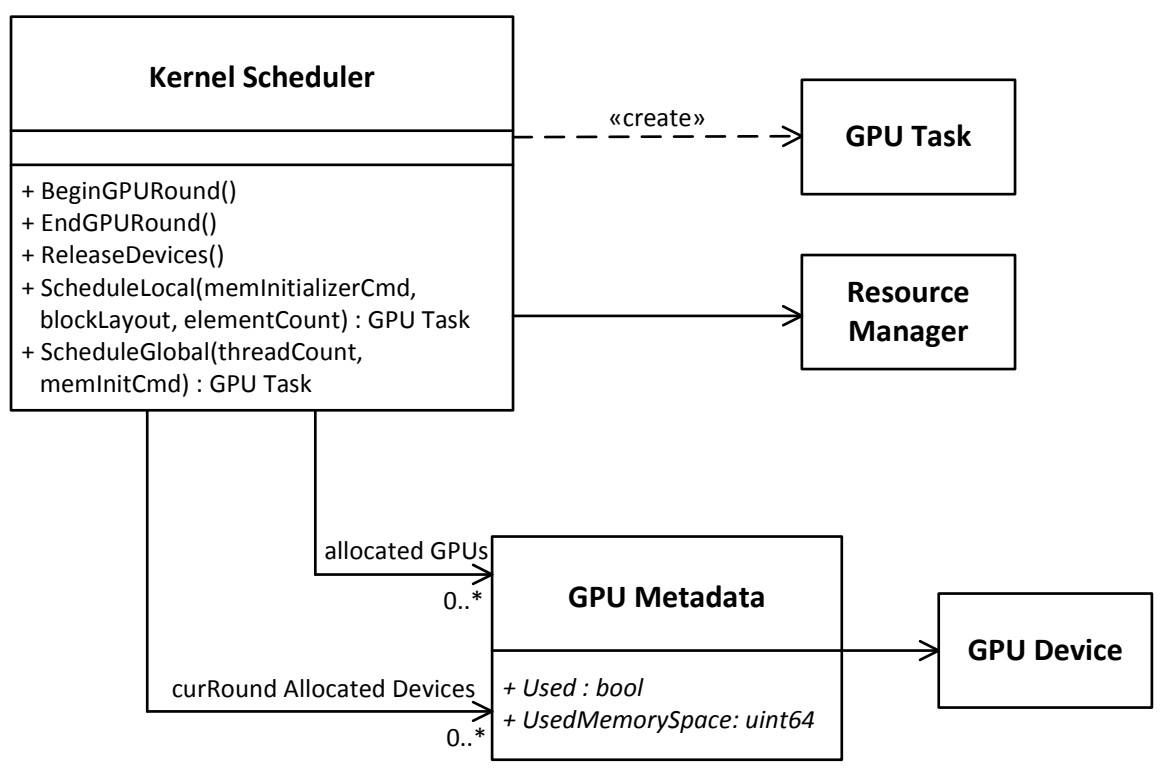

Figura 7.15 A classe Kernel Scheduler.

As tarefas de processamento, representadas pela classe GPU Task, são classificadas em locais ou globais. Na primeira, o código trabalha sobre informações num bloco de memória próprio, cujo espaço é automaticamente gerenciado pelo sistema para replicação dos dados entre host e GPU. São exemplos as atividades relacionadas com a manipulação de elementos finitos, modelos de materiais e condições de contorno.

Por outro lado, tarefas globais não possuem um bloco de memória próprio, desempenhando suas atividades dentro dos objetos contidos na memória de modelo, como os vetores de solução do problema. São mais utilizados pelos algoritmos de solução dos solvers. Cada um dos tipos é agendado pelas operações ScheduleLocal() e ScheduleGlobal(), respectivamente. Se, porventura, o escalonamento de alguma tarefa falhar (por falta de dispositivo ou memória insuficiente, por exemplo), a execução da simulação é abortada.

\section{Segmentação da tarefa: classes GPU Task e Kernel Configuration}

As tarefas criadas pelo escalonador Kernel Scheduler podem ser divididas entre múltiplos dispositivos, aos quais diferentes configurações de kernels são associadas, como ilustram as classes da Figura 7.16 (camada de serviço).

A classe Kernel Configuration gerencia os procedimentos de preparação para execução de um kernel no dispositivo de destino, tais como a alocação e inicialização de memória (operações Allocate e Deallocate, respecticamente), cópia dos dados do 


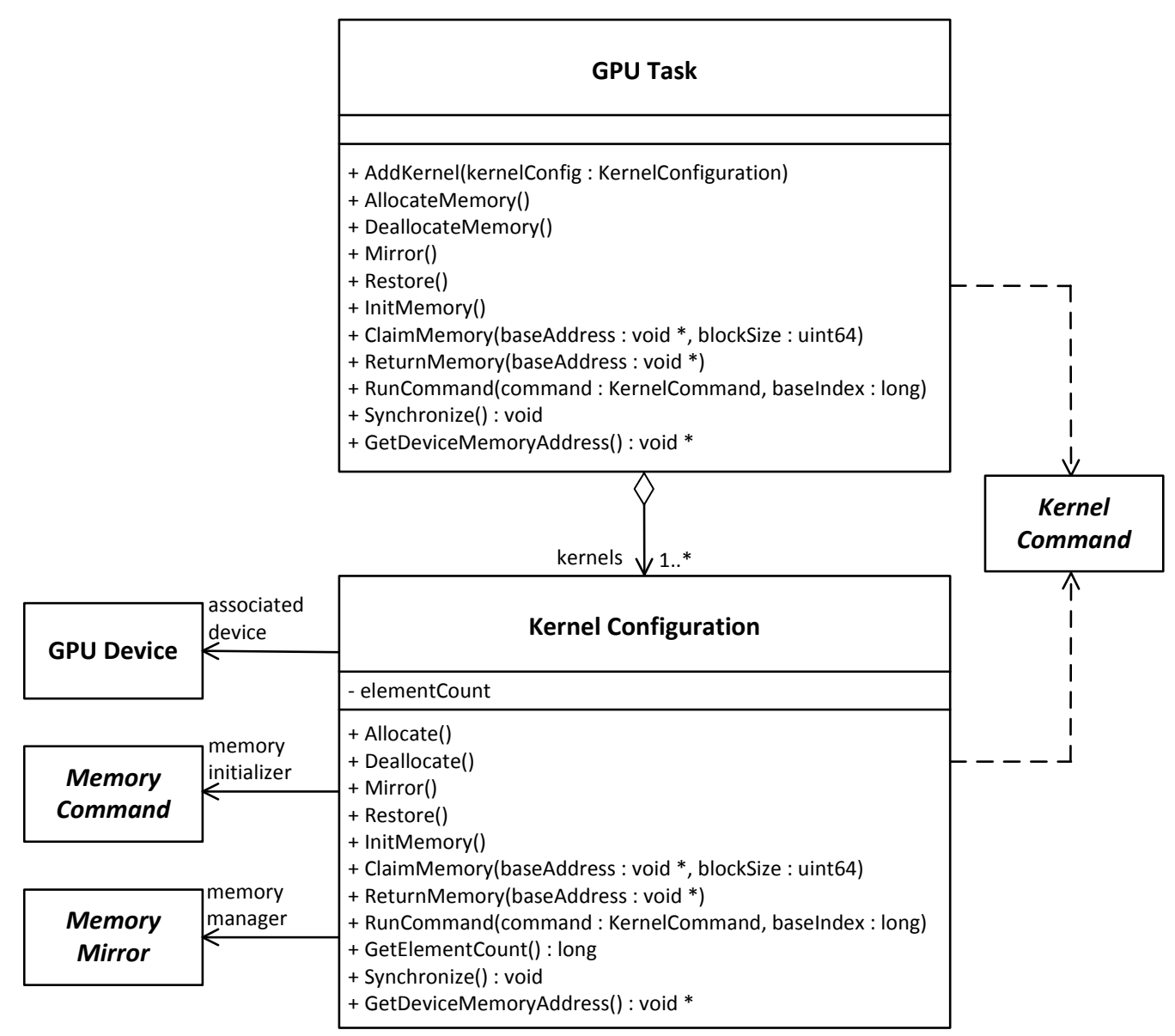

Figura 7.16 Decomposição de uma tarefa de GPU em múltiplas configurações de kernel.

host para a GPU e vice-versa (Mirror e Restore), inicialização dos dados na memória (InitMemory), entre outros. RunCommand e Synchronize são as duas operações mais relevantes da classe. RunCommand executa, na GPU associada, o kernel encapsulado em um objeto de comando (vide seção 7.6.5). Synchronize coloca a thread chamadora em espera até que o último comando executado termine. As operações de mesmo nome da classe GPU Task executam a atividade correspondente em todos as configurações de kernel associadas.

\section{Espelhamento de memória: classe Memory Mirror}

A classe Memory Mirror, definida na camada de fundação, descreve os serviços de espelhamento de blocos de memória do host e da GPU de destino, idênticos em tamanho. A atividade desempenhada pela classe é essencial na replicação dos dados da análise para a GPU e o host. Duas formas de espelhamento são possíveis e descritas pelas subclasses, apresentadas na Figura 7.17. 


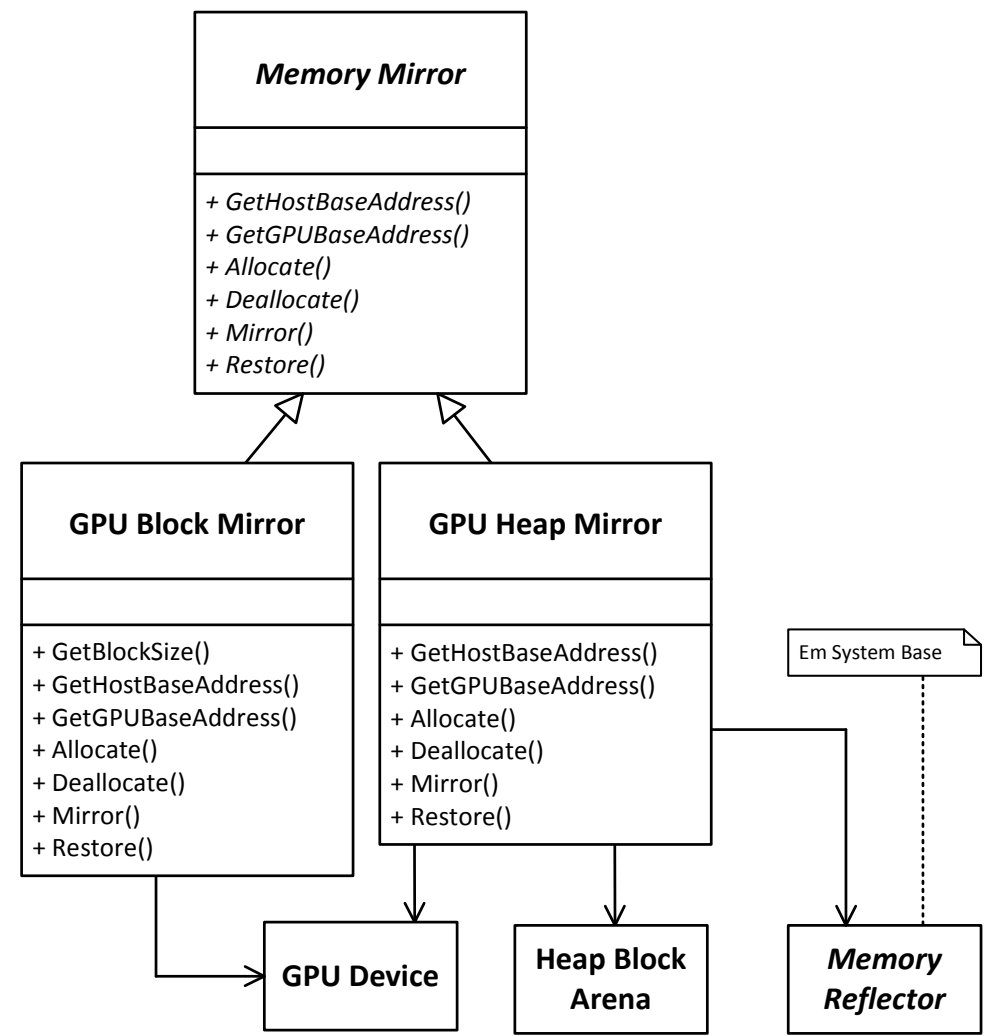

Figura 7.17 Classes de espelhamento de memória.

As quatro operações mais importantes das classes se referem à alocação, desalocação e movimentação de dados entre os ambientes (isto é, host e GPU). Allocate() e Deallocate() efetuam a alocação e a desalocação dos blocos espelhados nos ambientes, respectivamente. A sincronização da memória da GPU com o estado da memória do host é feita através da operação Mirror(). O sentido inverso é dado por Restore(). Essas operações são exemplificadas na Figura 7.18.

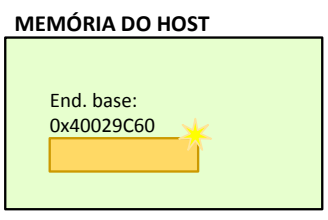

MEMÓRIA DA GPU

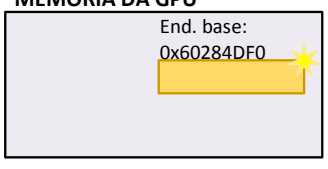

GetHostBaseAddress ()$=0 \times 40029$ C60 GetGPUBaseAddress ()$=0 \times 60284 \mathrm{DFO}$

(a) Allocate()

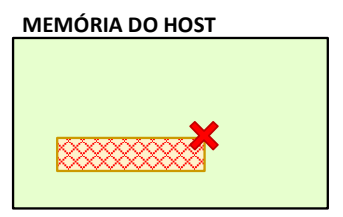

MEMÓRIA DA GPU

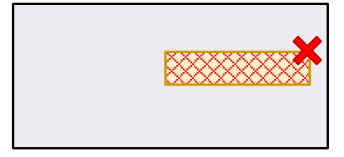

(b) Deallocate()
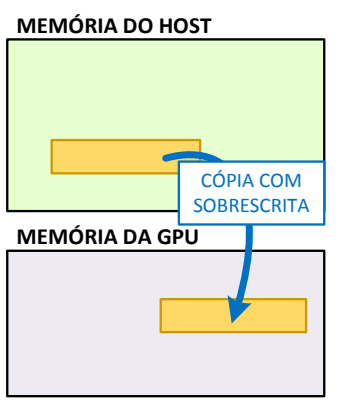

(c) Mirror()
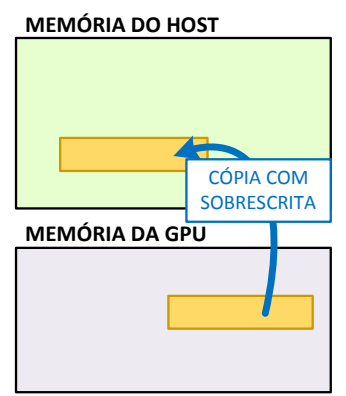

(d) Restore()

Figura 7.18 Operações de gerenciamento de par espelhado de memória. 
A classe GPU Block Mirror gerencia blocos de memória isolados, não associados à arena de memória do modelo. Durante a execução do programa, esses blocos são usados para agrupar os dados de formulações, modelos de materiais, condições de contorno e curvas similares. Enquanto isso, GPU Heap Mirror controla o espelhamento da arena de memória do modelo na GPU. A Figura 7.19 mostra a entidade e as principais classes com que colabora para a realização da tarefa.

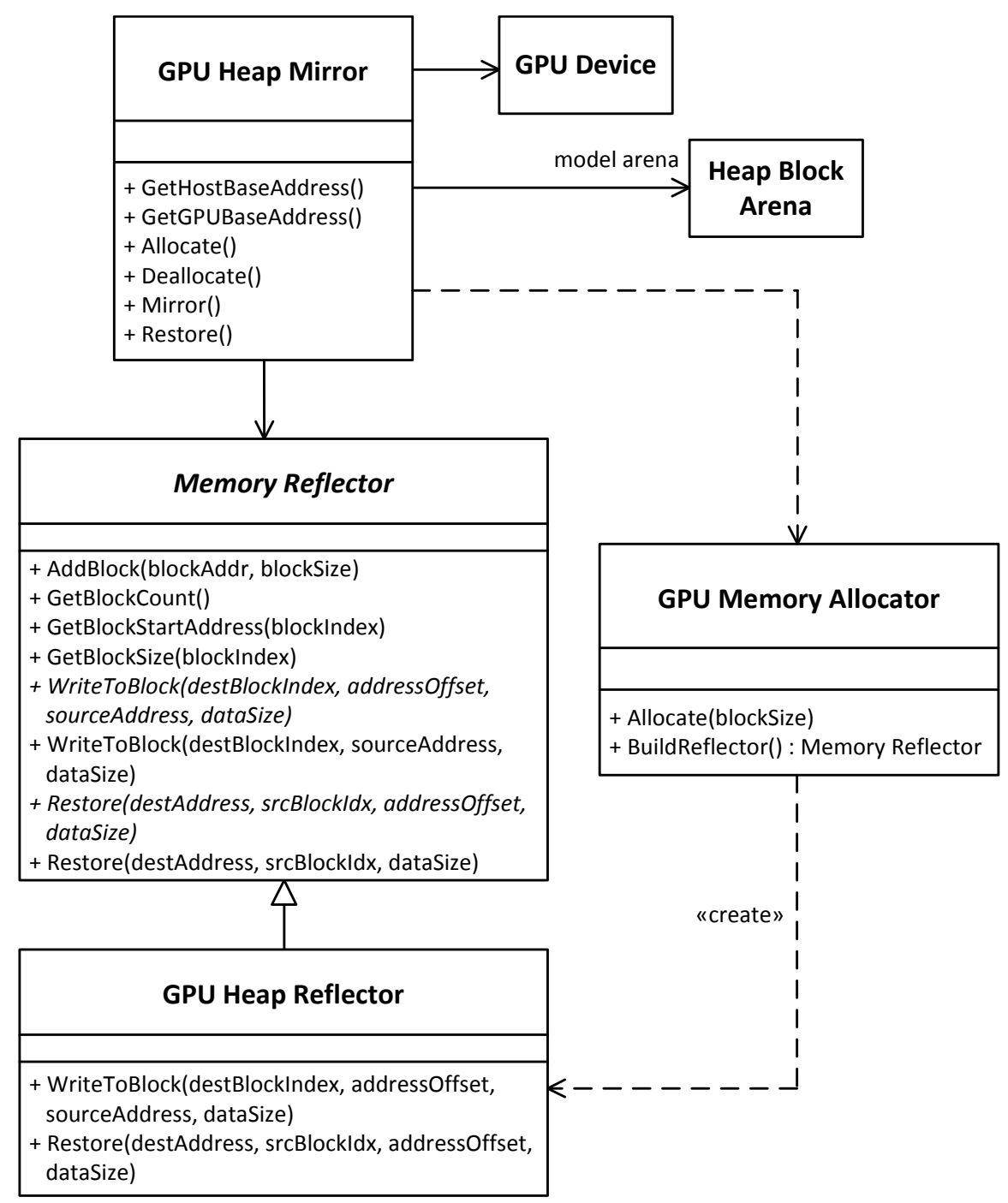

Figura 7.19 Sistema de espelhamento da arena de memória do modelo.

Para esta especialização, a operação Allocate() varre a arena do modelo copiando a estrutura de chunks de que é composta, através da classe GPU Memory Allocator, que armazena essas informações. Uma vez reconstruída a estrutura, o sistema de espelhamento de memória, representado por Memory Reflector, é construído através da operação BuildReflector() de GPU Memory Allocator. 
A subclasse de Memory Reflector, GPU Heap Reflector, é usada para o espelhamento das informações da arena construída no host para a GPU. As demais operações da classe GPU Heap Mirror executam de maneira similar a GPU Block Mirror, por intermédio do sistema de espelhamento associado.

Comandos de inicialização de memória: classe Memory Command

Os comandos de memória, representados pela classe Memory Command da camada de serviços, são usados para inicializar, no host, um bloco de memória antes de ser espelhado para a GPU. Os principais comandos são representados na Figura 7.20.

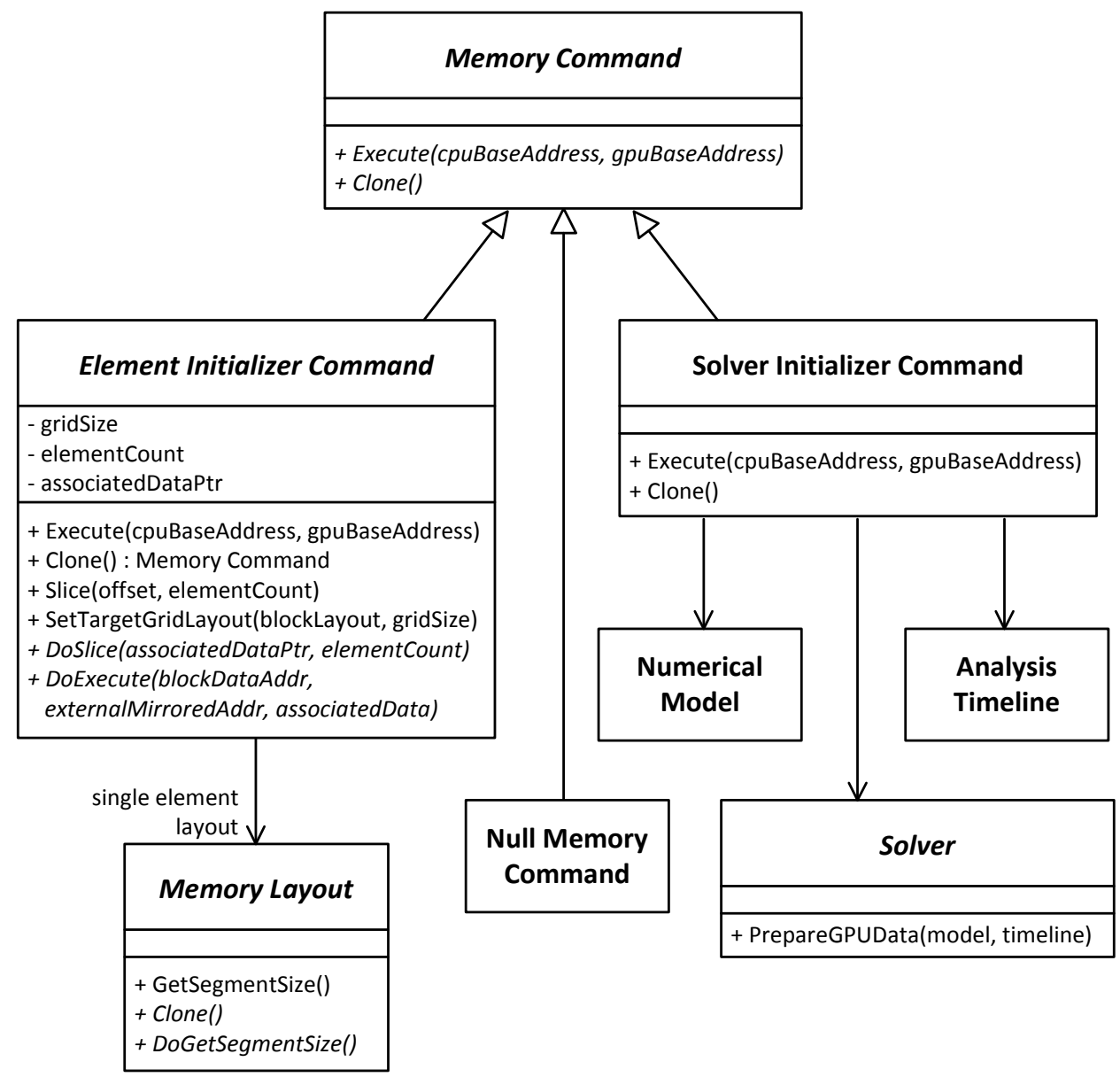

Figura 7.20 Comandos de memória.

O comando Solver Initializer Command encapsula a chamada para a operação PrepareGPUData() de Solver, na qual as subclasses definem a lógica apropriada, quando necessário, para preparar o modelo numérico, vetores de solução ou outras variáveis, situadas na arena do modelo, para a execução em GPU. Normalmente, este tipo de comando está associado ao espelhamento da arena do modelo. 
Os comandos de inicialização de elementos, mais complexos, atuam sobre blocos de memória não associados à arena de modelo e, portanto, são relacionados com o sistema de espelhamento da classe GPU Block Mirror. A inicialização do bloco de memória ocorre dividindo-o em segmentos, de acordo com a contagem de entidades que usarão esse espaço (atributo elementCount). O tamanho de cada segmento é determinado pela operação GetSegmentSize() da classe Memory Layout. O método concreto obtém o valor de retorno de DoGetSegmentSize() (que efetivamente calcula o tamanho do segmento) e o corrige para atender aos requisitos de alinhamento de memória do host e da GPU. De acordo com o tipo de informação que será armazenada nos segmentos, diferentes comandos (Figura 7.21) e layouts de memória (Figura 7.22) existem para operá-los corretamente.

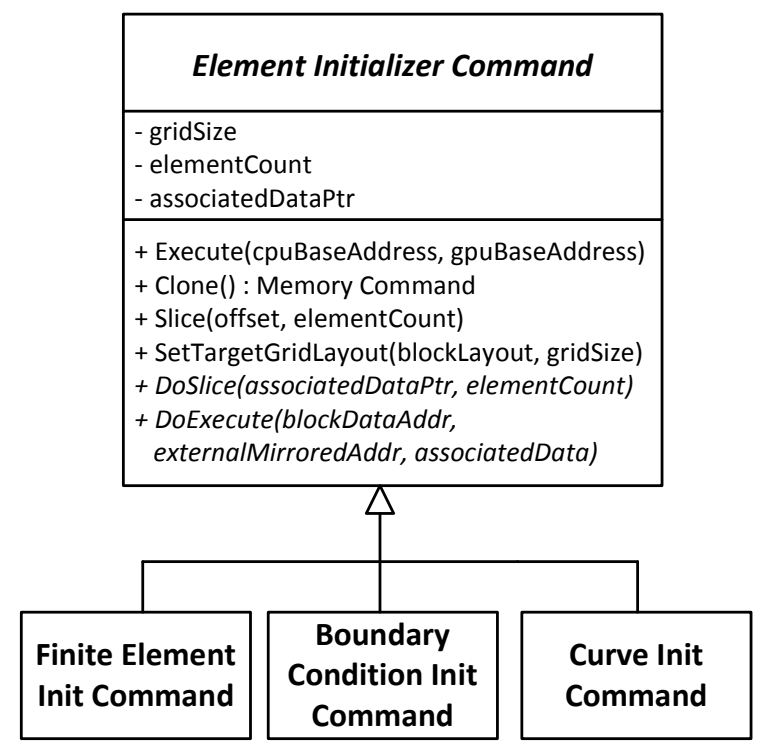

Figura 7.21 Comandos de inicialização de segmentos de bloco de memória.

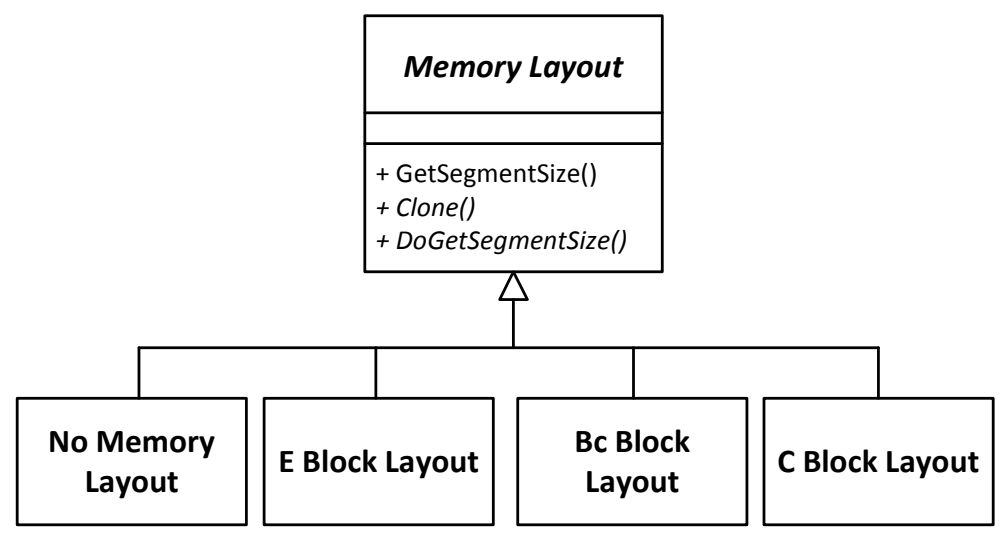

Figura 7.22 Layouts de segmentos de bloco de memória. 
As classes Finite Element Init Command, Boundary Condition Init Command e Curve Init Command inicializam os segmentos com dados de elementos finitos, condições de contorno e curvas do modelo numérico, respectivamente. Na mesma ordem, E Block Layout, Bc Block Layout e C Block Layout definem o tamanho necessário para armazenar as suas respectivas informações nos segmentos, além de definir a ordem de apresentação dos dados dentro dele. A classe No Memory Layout define um comando sem layout de memória próprio e é reservado para uso futuro.

\subsubsection{Operações em GPU para classes de domínio: classe Kernel Command}

Os kernels das classes de domínio são encapsulados em classes de comando (Figuras 7.23 e 7.24). O conjunto de comandos pertinentes a uma formulação é agrupado num singleton de estratégia, conforme ilustra a Figura 7.25. Quando não há suporte para GPU, a operação GetGPUStrategy() retorna uma estratégia nula.

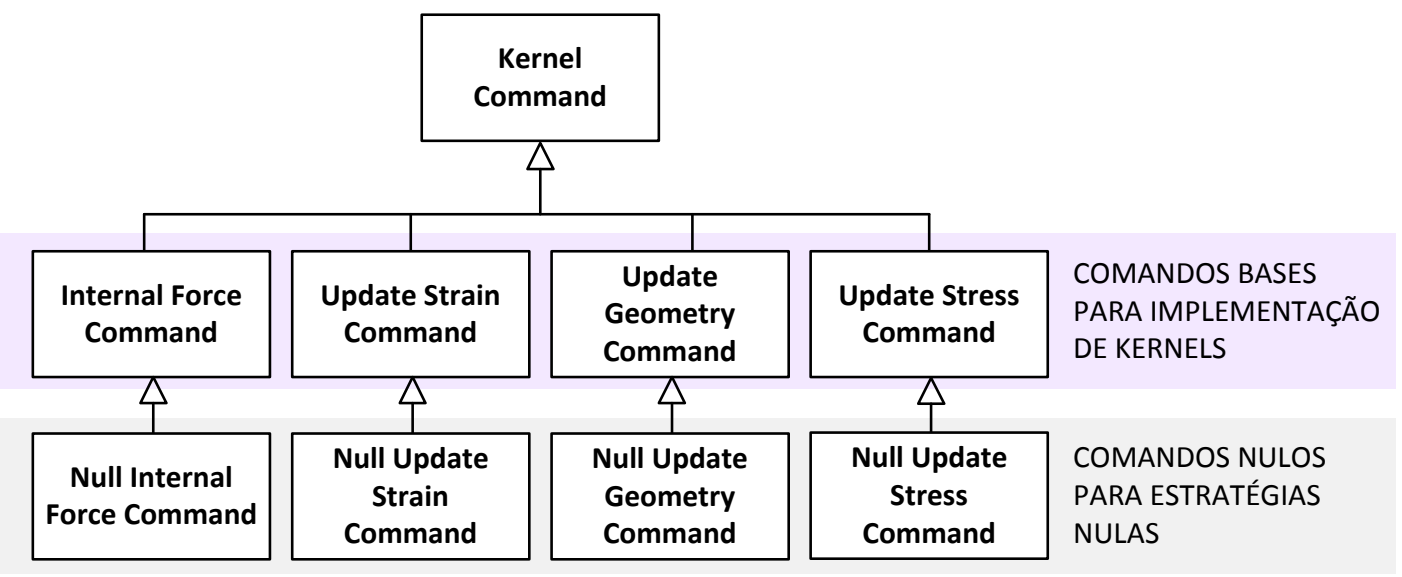

Figura 7.23 Classes de comando para kernels de um elemento finito.

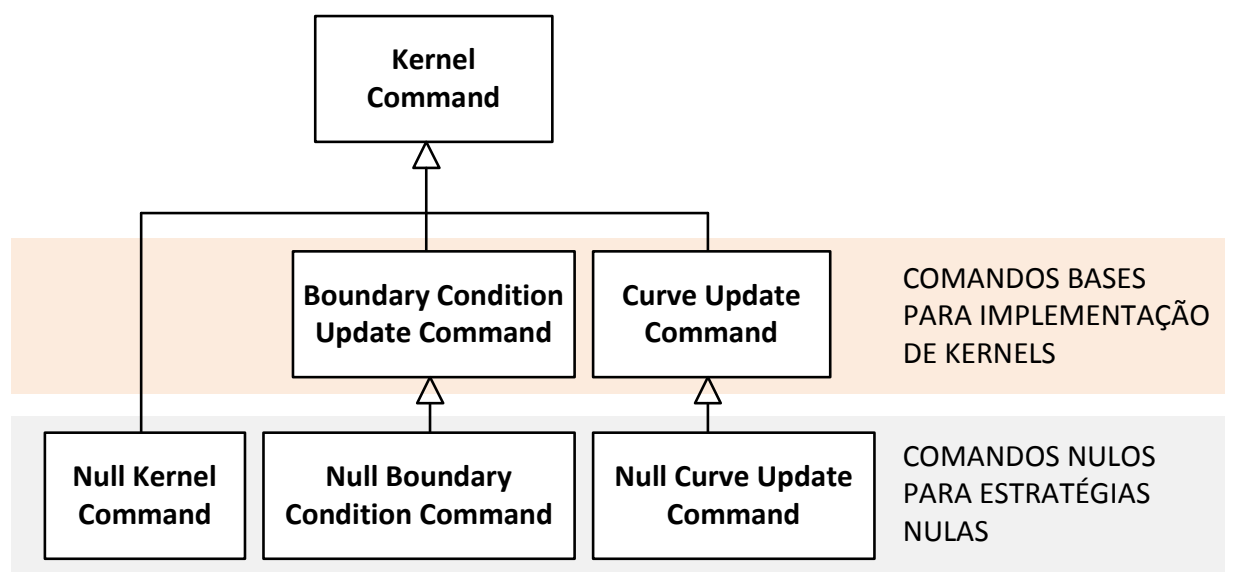

Figura 7.24 Classes de comando para kernels de condições de contorno e curvas. 


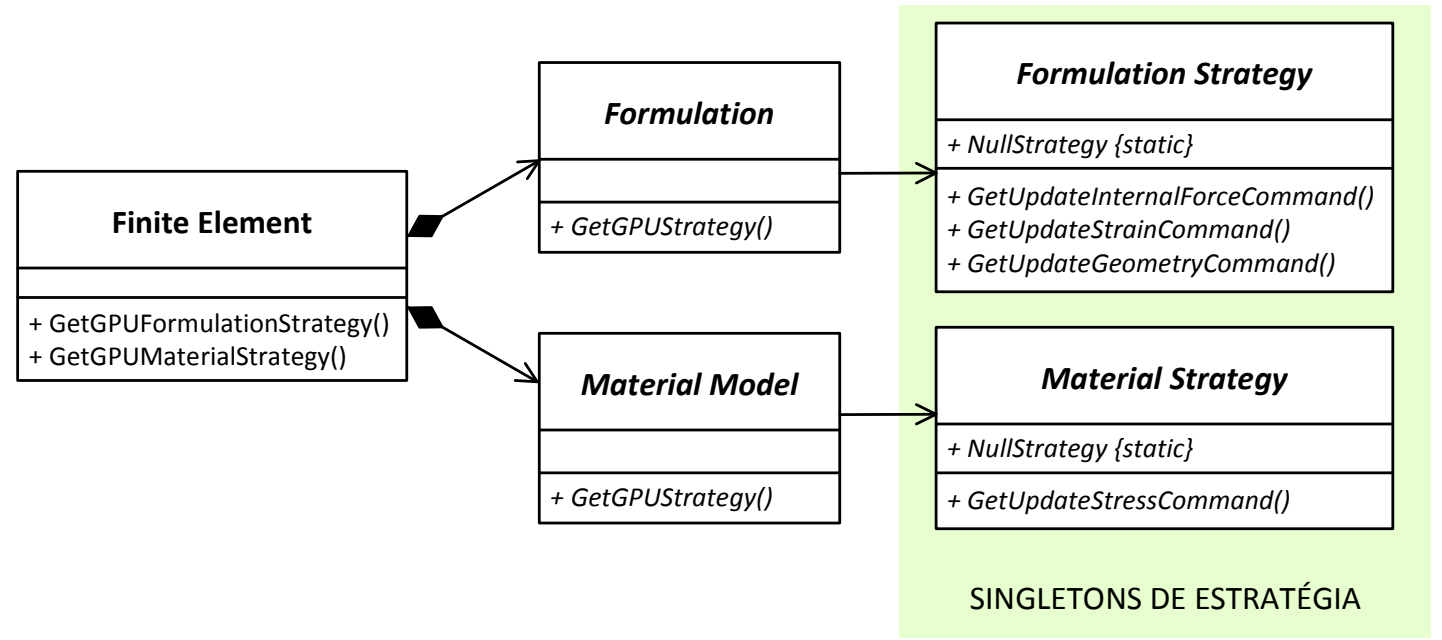

Figura 7.25 Formas de obtenção dos comandos para execução em GPU.

\subsubsection{Fachadas para as operações em GPU}

Conforme ilustra a Figura 7.26, são adicionadas à classe Solver operações equivalentes para a execução do sistema de solução em GPU. Executadas na CPU, elas oferecem o ponto de partida para a execução das operações no dispositivo gráfico.

\begin{tabular}{|c|c|c|}
\hline Solver & & Reduced \\
\hline $\begin{array}{l}\text { +RunOnGPU(timeline, reducedModel, solverFacade) } \\
\text {-StartAnalysisProcessOnGPU(timeline, reducedModel, solverFacade) } \\
\text {-EnterPrimaryStepOnGPU(timeline, reducedModel, solverFacade) }\end{array}$ & & Model \\
\hline $\begin{array}{l}\text {-EnterSecondaryStepOnGPU(timeline, reducedModel, solverFacade) } \\
\text {-ExecuteStepOnGPU(timeline, reducedModel, solverFacade) } \\
\text {-ExitSecondaryStepOnGPU(timeline, reducedModel, solverFacade) } \\
\text {-ExitPrimaryStepOnGPU(timeline, reducedModel, solverFacade) }\end{array}$ & $\geqslant$ & Solver Facade \\
\hline -EndAnalysisProcessOnGPU(timeline, reducedModel, solverFacade) & & \\
\hline
\end{tabular}

Figura 7.26 Modificações em Solver para execução em GPU.

Para a execução em GPU, a implementação de Solver deve utilizar classes de fachada para os sistemas de execução em GPU, Reduced Numerical Model e Solver Facade.

A fachada Reduced Numerical Model oferece recursos limitados para enumeração dos nós e elementos finitos, não sendo implementadas algumas formas de navegação possíveis na classe Numerical Model, a quem substitui. Contudo, para a maior parte dos algoritmos de um sistema de solução em elementos finitos, as operações implementadas são suficientes. A Figura 7.27 lista as operações disponíveis. 


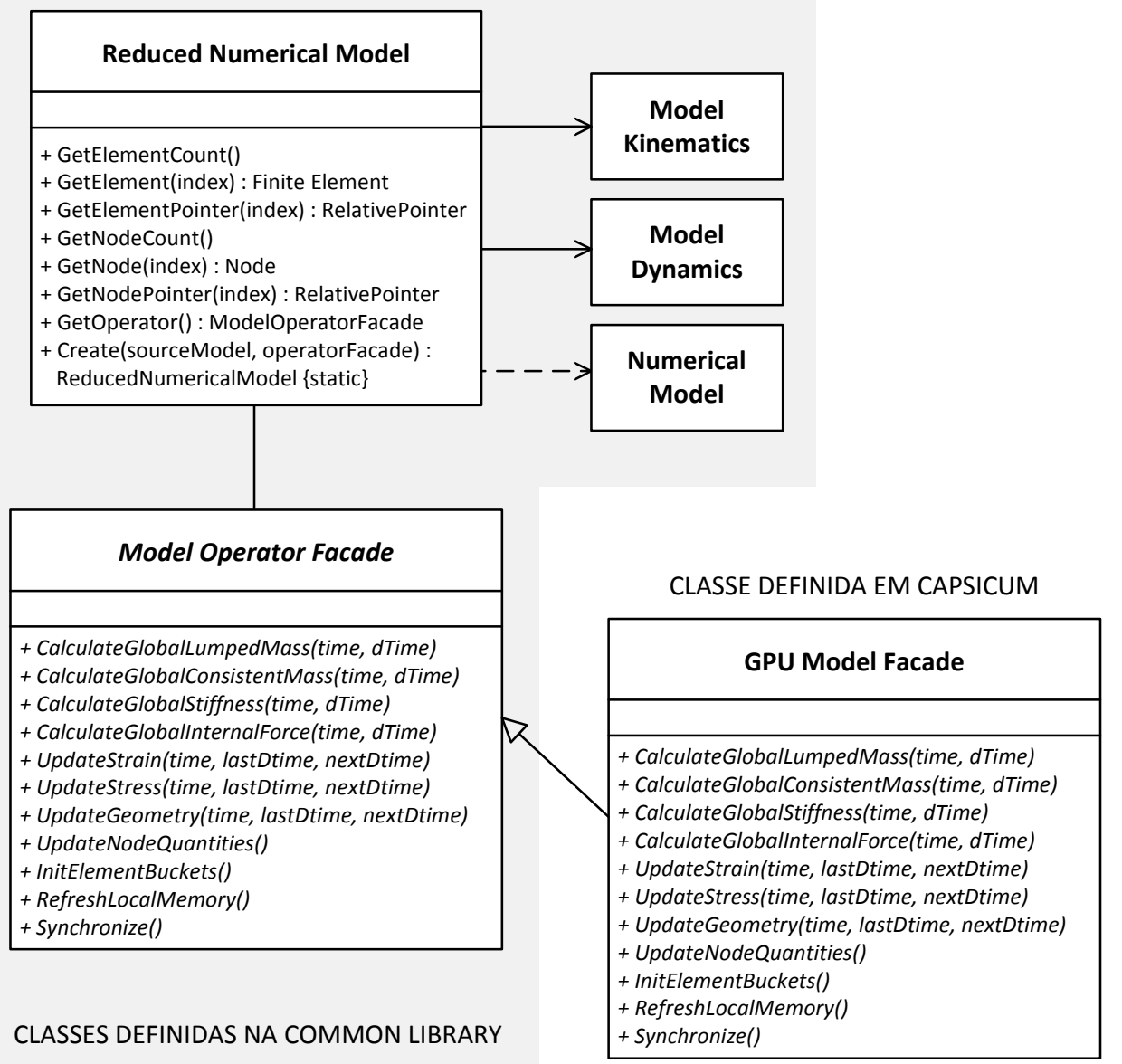

Figura 7.27 Classe Reduced Numerical Model e sistema de operador associado.

É definida uma fachada que atua como operador de GPU para o modelo numérico reduzido. A classe Model Operator Facade declara um conjunto de operações que executam sobre todos os elementos (ou nós) do modelo numérico. A especialização GPU Model Facade as implementa para execução em GPU. Construída pelo componente Capsicum, a fachada em GPU coordena as diversas tarefas de processamento (GPU Task) aglutinadas em códigos similares por Data Coalescer. Para cada implementação distinta, o comando correspondente da operação é obtido a partir de sua classe de estratégia.

De forma similar, a classe Solver Facade, mostrada na Figura 7.28, oferece um conjunto de operações utilitárias para uso no sistema de solução em GPU. Para a atualização das condições de contorno, são fornecidas as operações UpdateAccelerations(), UpdateVelocities(), UpdateDisplacements(), UpdateExternalLoads() e UpdateLocks(), responsáveis pela atualização das acelerações, velocidades, deslocamentos, carregamentos e engastes prescritos, respectivamente. Numa iteração de tempo, é 
necessário recalcular o valor das curvas (UpdateCurves()) para que as condições de contorno que delas dependam possam ser corretamente estimadas.

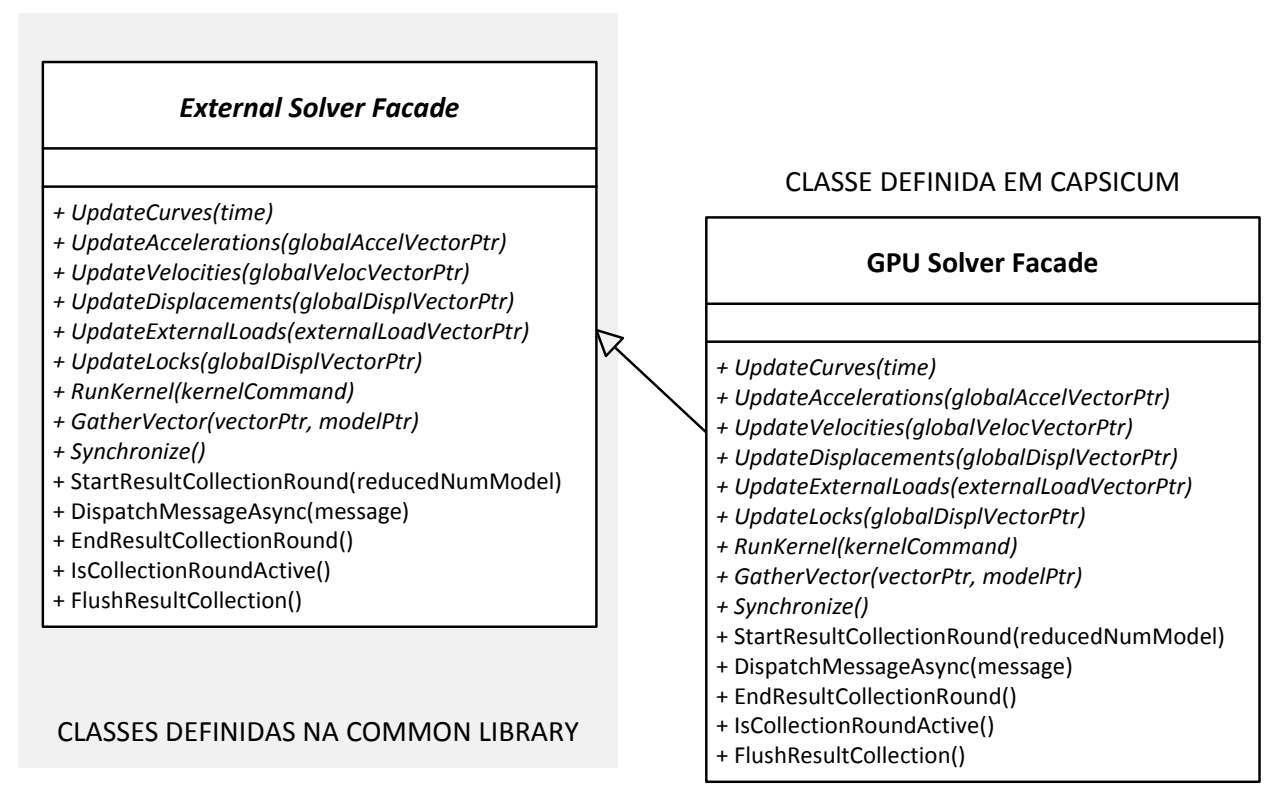

Figura 7.28 Solver Facade: fachada para operações do solver em GPU.

Kernels próprios da implementação do solver são executados através da operação RunKernel(), paralelizados para cada grau de liberdade do sistema. GatherVector() reúne os vetores de solução dos elementos (por exemplo, forças internas ou vetor de massa diagonal), previamente calculados, e os combina num vetor de solução global (operação scatter-gather). A operação Synchronize() bloqueia a thread chamadora enquanto o último pedido de execução na GPU não for concluído.

Quando é necessária a coleta de dados numa iteração, eles devem ser copiados de volta para a memória do sistema (host). O programa pode trabalhar assincronamente nesta cópia para produzir a saída de resultados, enquanto o laço principal de Solver continua a executar sobre os dados originais na GPU. Dependendo do problema e das condições de hardware, iterações do solver podem terminar mais rápido e uma nova coleta de dados pode se sobrepor a uma rodada anterior, ainda em progresso. Como resultado, o antigo estado da memória do host é sobrescrito com os novos dados da GPU, tornando inconsistente o estado sendo coletado pela primeira rodada. Para evitar essa condição, operações de semáforo binário são inseridas antes e depois da execução da coleta. A Figura 7.29 mostra uma possível execução do programa, demonstrando o mecanismo de sincronização.

A sincronização da coleta de dados é implementada na classe Solver Facade. Antes do disparo de mensagens de coleta, a operação StartResultCollectionRound() 
equivale à operação down(). Então, mensagens de coleta podem ser disparadas para serem executadas assincronamente, através de DispatchMessageAsync(). Por fim, a rodada de coleta é terminada chamando a operação EndResultCollectionRound().

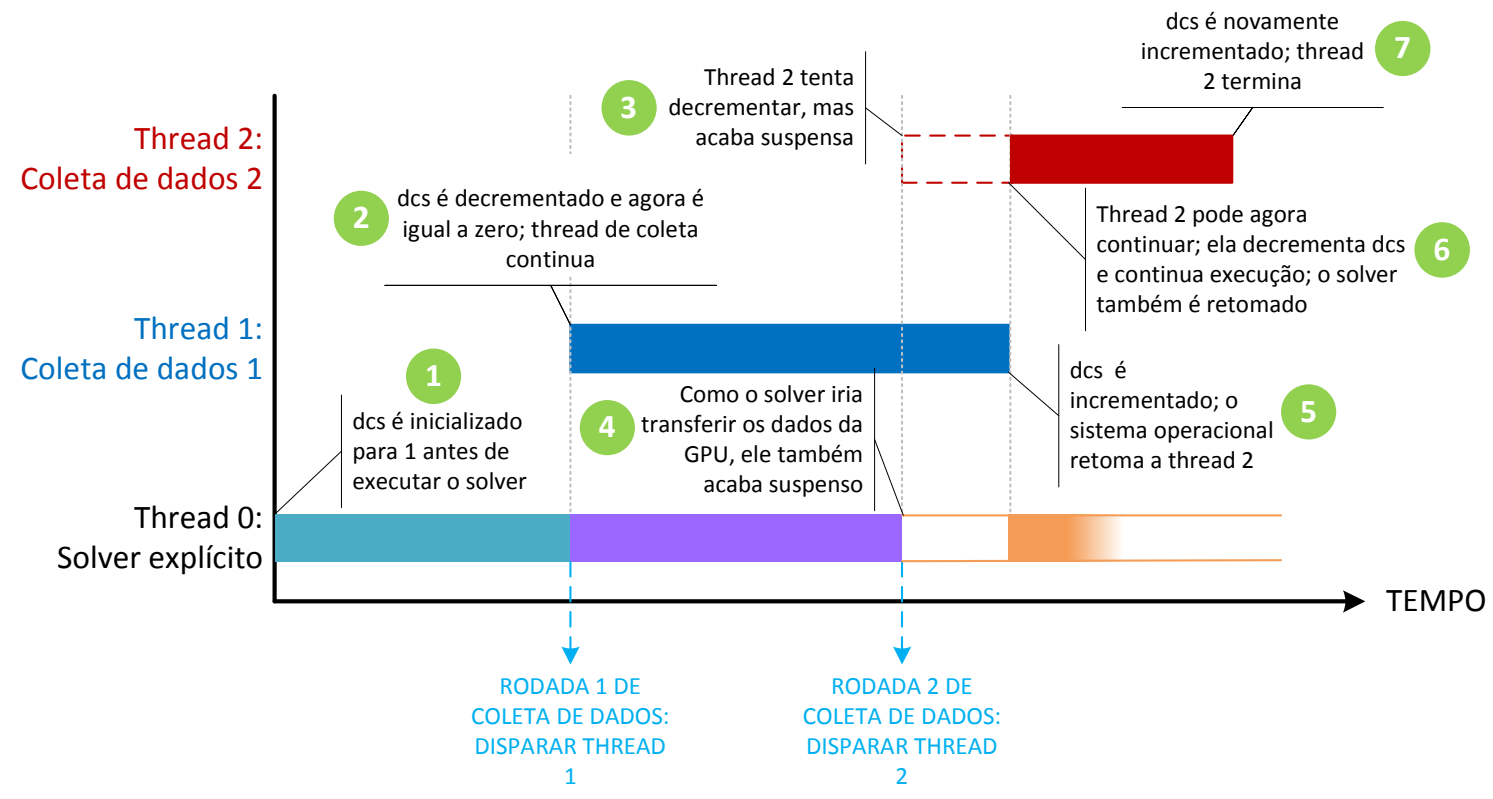

Figura 7.29 Exemplo de sincronização da coleta de dados usando semáforo.

\subsection{Execução do solver explícito não-linear em GPU}

Para demonstrar o funcionamento dos mecanismos de preparação, agendamento e execução em GPU, uma simulação numérica dada pelo arquivo de entrada da Listagem 7.1 será considerada. O exemplo apresenta as seguintes características:

- solver dinâmico explícito não-linear;

- malha de elementos hexaédricos com suporte a não-linearidade (10 elementos, 44 nós) e materiais hiper-elástico neo-Hookeano e plasticidade bilinear;

- carregamento dinâmico, descrito por uma curva de dois pontos (linear);

- gravação de 1000 pontos (estados) para os arquivos de saída;

- dois arquivos de saída definidos: ruber_results.hwascii (formato Hyperworks) e ruber_result_matrix.m (formato Matlab).

O arquivo de entrada não designa a GPU para o processamento. Como foi discutido anteriormente, o dispositivo será adotado apenas se o modelo numérico 
Listagem 7.1: Exemplo de arquivo de entrada para simulação numérica em GPU.

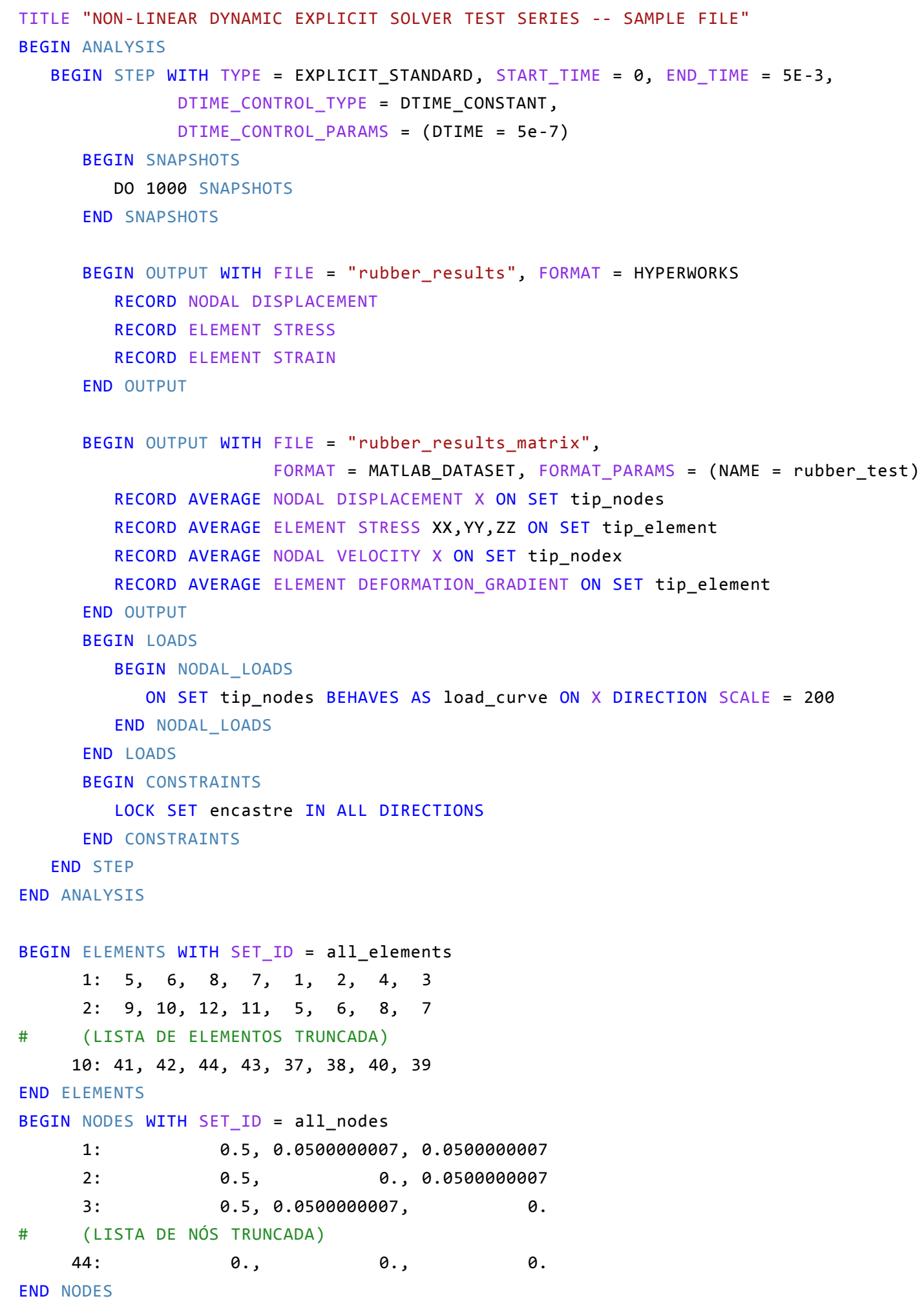


Listagem 7.1 (continuação).

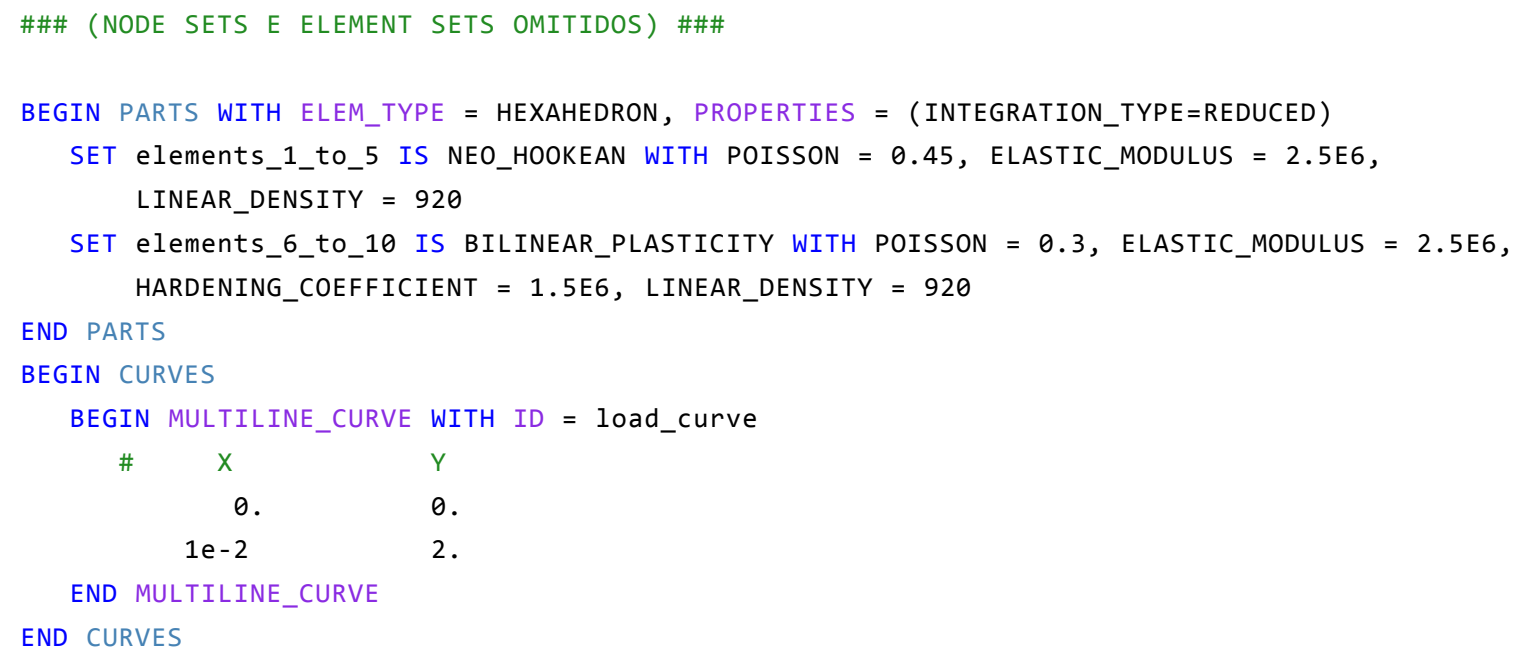

e o solver oferecem suporte e se a inteligência do programa determina ser mais vantajoso. Neste exemplo, é suposto que a execução em GPU é forçada por variável de ambiente. As atividades realizadas pelo software são explicadas a seguir.

\subsubsection{Inicialização do programa}

Durante a inicialização, os plugins contendo as funcionalidades do programa são carregados segundo o procedimento apresentado na seção 5.5.1. Durante o carregamento, um plugin que possui entidades executáveis em GPU deve se registrar no sistema para receber a notificação GPU_ARENA_MSG. Esse evento é disparado para todos os componentes do programa logo após a criação da arena de memória do modelo no dispositivo gráfico quando é fornecido o endereço base da arena, permitindo, então, que códigos clientes em GPU possam resolver corretamente as referências relativas no dispositivo, dadas pela versão da classe Relative Pointer implementada no componente Yuzu.

O registro para a notificação é feito estabelecendo-se um hook $k^{5}$ no singleton System, passando-se um objeto de callback apropriado (System Hook), conforme ilustra a Figura 7.30.

\footnotetext{
${ }^{5}$ Hooking é a técnica de se vincular uma função de callback ao componente de um sistema para alterar o seu comportamento ou reagir a eventos que ele dispara.
} 


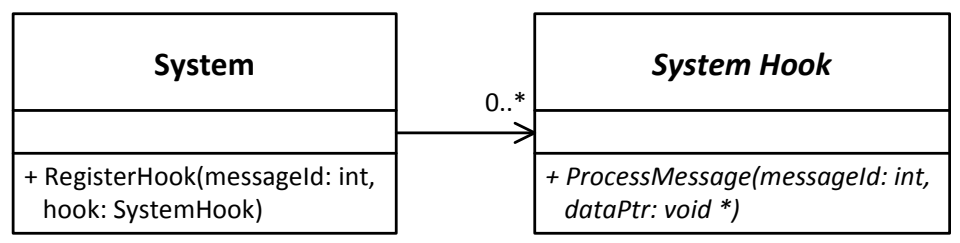

(a) Classe System Hook

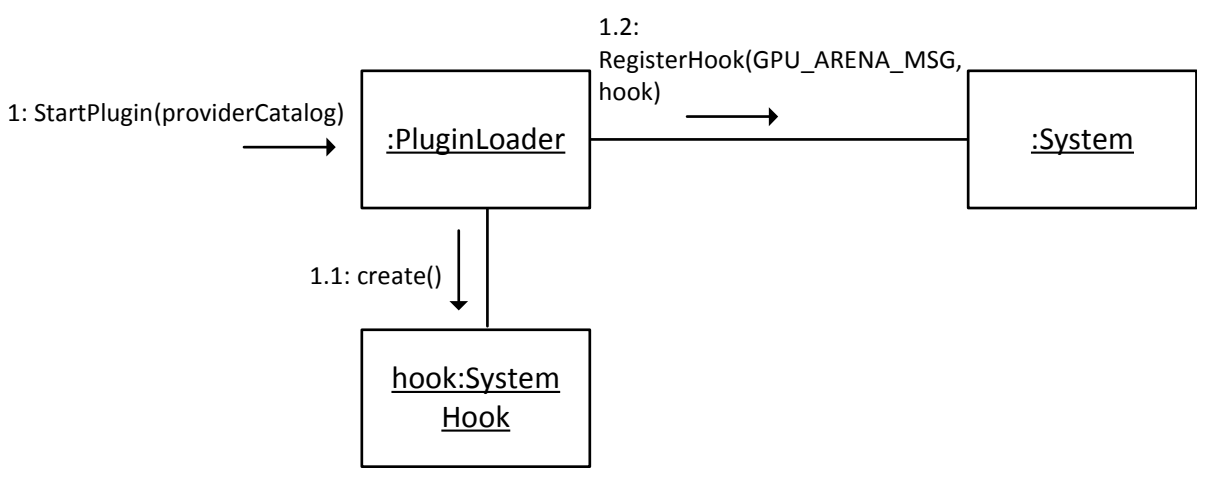

(b) Procedimento de registro

Figura 7.30 Hooking da mensagem GPU_ARENA_MSG.

\subsubsection{Carregamento do modelo númerico}

Após carregar todos os plugins no espaço de memória do programa, o arquivo de entrada é analisado pelo sistema de parsing, interpretando as declarações e as decompondo em árvores sintáticas para manipulação pelos diversos parsers implementados pelos plugins. A construção do modelo numérico é feita na memória do host, organizada em arenas, cujo estado final é mostrado na Figura 7.31.

\section{CONTEÚDO}

MEMÓRIA STRING

\begin{tabular}{|l|l|l|l|}
\hline MEMÓRIA & MEMÓRIA & MEMÓRIA & MEMÓRIA \\
DE PILHA 0 & DE PILHA 1 & DE PILHA 2 & DE PILHA $n$ \\
\hline
\end{tabular}

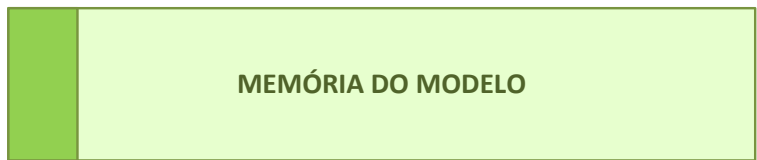

MEMÓRIA GLOBAL
Objetos String usados durante a leitura, análise e parsing do arquivo de entrada.

(Áreas vazias; usado somente durante o processamento da simulação em CPU)

Objetos Finite Element, Material Model, Formulation, Node, DoF, Boundary Condition, Numerical Model e outros relacionados ao modelo numérico

Objetos auxiliares criados durante o processamento do arquivo de entrada; sem relevância para o restante da execução do programa.

Figura 7.31 Estado das arenas de memória após a leitura do arquivo de entrada. 
Independente do ambiente de processamento que é adotado, as arenas de memória do host são sempre utilizadas. No processamento em CPU, os objetos são usados como estão, e as arena de pilha são empregadas durante a execução do solver. Por serem áreas pré-alocadas, maior desempenho é obtido na alocação e desalocação de vetores e matrizes temporárias. Para o processamento em GPU, conforme já foi discutido, apenas a arena do modelo é de interesse, sendo empregada no espelhamento de memória e preservando os objetos ali carregados.

\subsubsection{Escalonamento do trabalho}

Após construída, a análise de elementos é encaminhada para o sistema de escalonamento, mostrado na Figura 7.32. A classe Execution Request representa uma requisição para executar uma análise, dada pelo solver, modelo numérico e linha temporal. O pedido de requisição é encaminhado para a fachada Execution Scheduler, que coordena os subsistemas de enumeração de dispositivos, inspeção do modelo e seleção de ambiente de processamento.

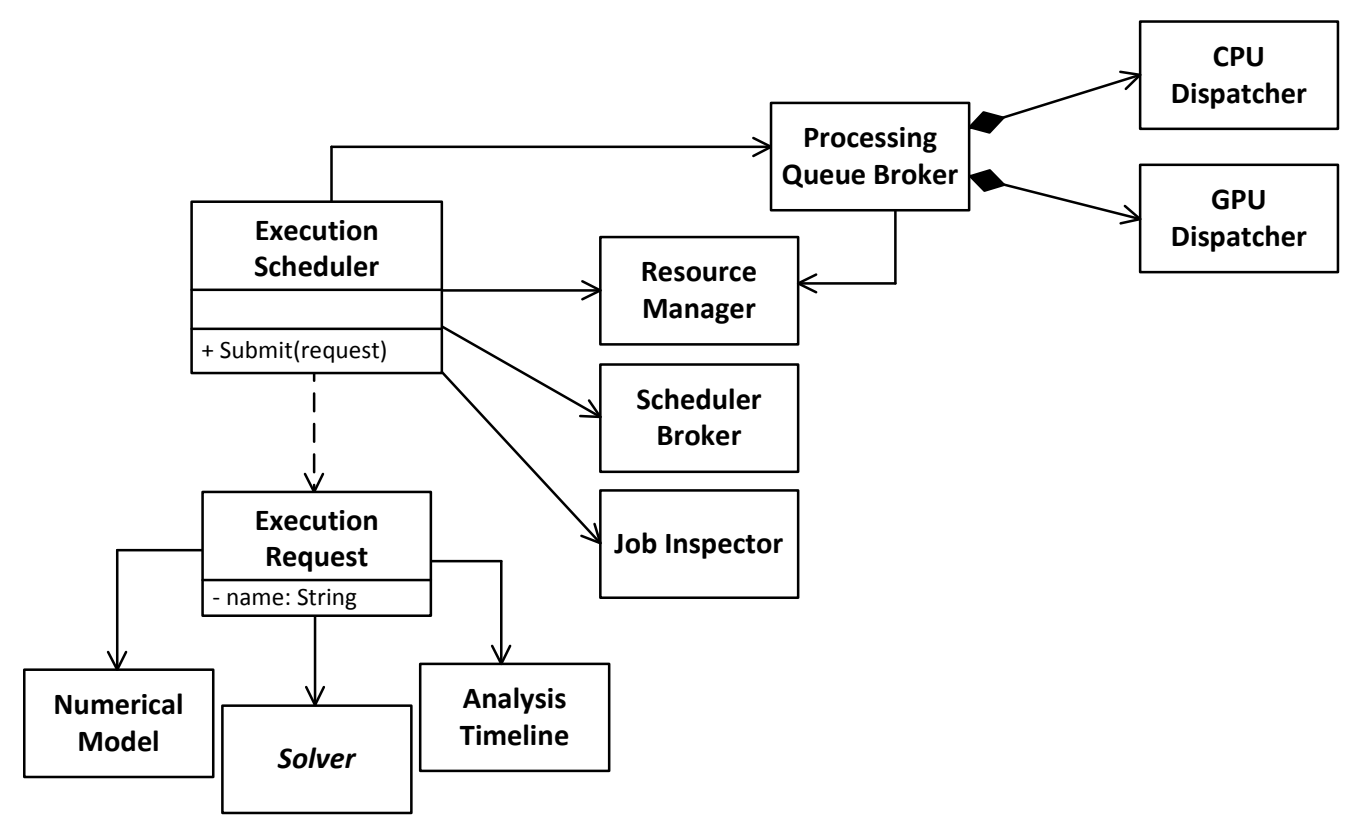

Figura 7.32 Sistema de escalonamento de trabalhos do Axis.

Após a validação da requisição pela classe Job Inspector e a decisão do ambiente de processamento que será adotado (Scheduler Broker), a requisição é encaminhada para o mediador das filas de processamento, Processing Queue Broker. De acordo com a decisão previamente tomada, o trabalho é encaminhado para despacho na CPU ou na GPU. 
Quando o trabalho atinge a fila de despacho para GPU, é requerido ao sistema construir os objetos e estruturas de dados para abstração do hardware. Isso é feito através da colaboração com os sistemas mostrados na Figura 7.33 .

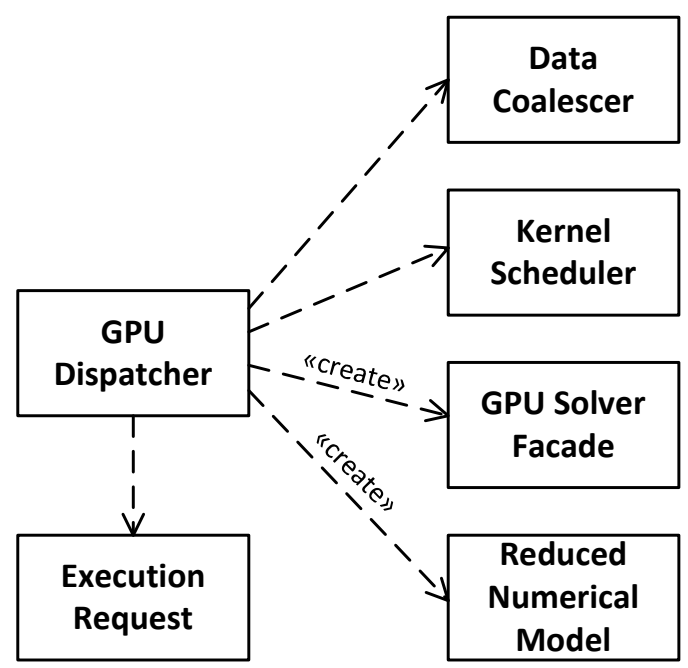

Figura 7.33 Sistemas de abstração da GPU.

Inicialmente, as entidades do modelo são agrupadas segundo seus algoritmos, através da classe Data Coalescer. Para os elementos finitos do exemplo, todos são descritos através da mesma formulação, contudo há divergência entre os modelos de materiais adotados nos componentes, conforme mostra a Figura 7.34.

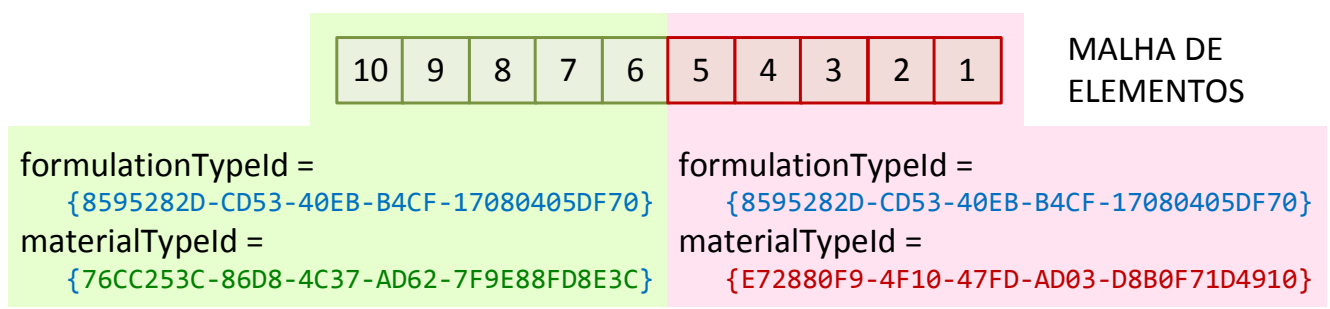

Figura 7.34 Composição da malha do exemplo.

De acordo com os UUIDs obtidos das operações GetFormulationTypeld() e GetMaterialTypeld(), os elementos finitos são classificados em um único grupo de formulação e em dois grupos de modelos de materiais pela classe Data Coalescer. Supondo que serão executados numa única GPU com capacidade de memória suficiente, cada grupo, traduzido numa GPU Task, é composto de apenas uma configuração de kernel (Kernel Configuration). A relação de uma GPU Task e sua respectiva classe de estratégia é armazenada na fachada GPU Model Facade, através de tuplas (Figuras 7.35 e 7.36). Condições de contorno e curvas são processadas de maneira similar. 


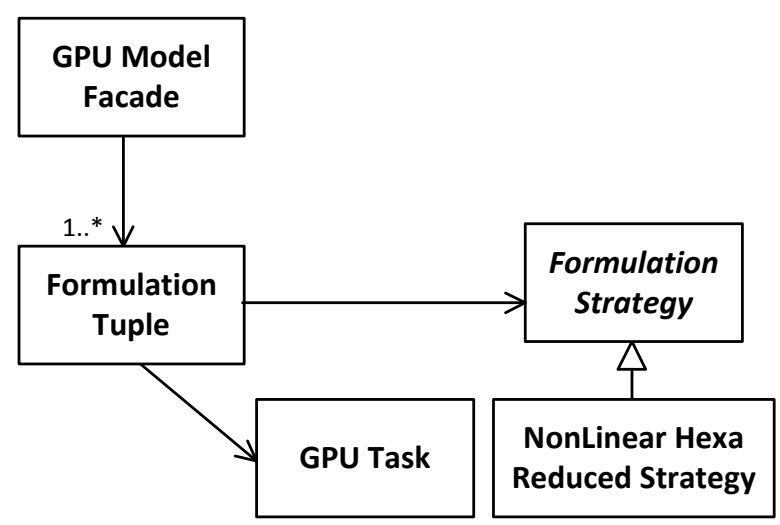

(a) Classes participantes

\section{AGRUPAMENTO DE FORMULAÇÃO}

\{8595282D-CD53-40EB-B4CF-17080405DF70\}

\begin{tabular}{|l|l|l|l|l|l|l|l|l|l|}
\hline 10 & 9 & 8 & 7 & 6 & 5 & 4 & 3 & 2 & 1 \\
\hline
\end{tabular}

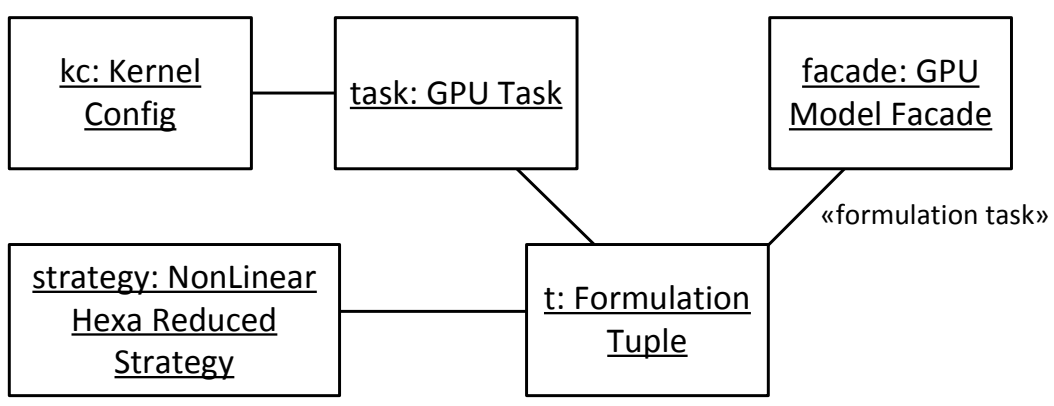

(b) Agrupamentos e objetos resultantes

Figura 7.35 Processo de coalescência de formulações de elementos.

É importante observar que o processo consiste apenas em agrupar elementos unicamente com base nos algoritmos que definem, para permitir que kernels de GPU possam ser disparados usando o código implementado e atuando sobre um conjunto de dados coerente (por exemplo, o código da formulação hexaédrica linear é aplicado apenas sobre os dados de elementos hexaédricos lineares, que são distinguidos de elementos tetraédricos de uma malha durante o processo de coalescência). O estado das entidades não é considerado para o processo (por exemplo, elementos em regime elástico e outros em regime plástico, mas que compartilham o mesmo modelo de material elastoplástico, são organizados em um único grupo - pois se trata do mesmo código implementado, mesmo que executando subconjuntos distintos de instruções). 


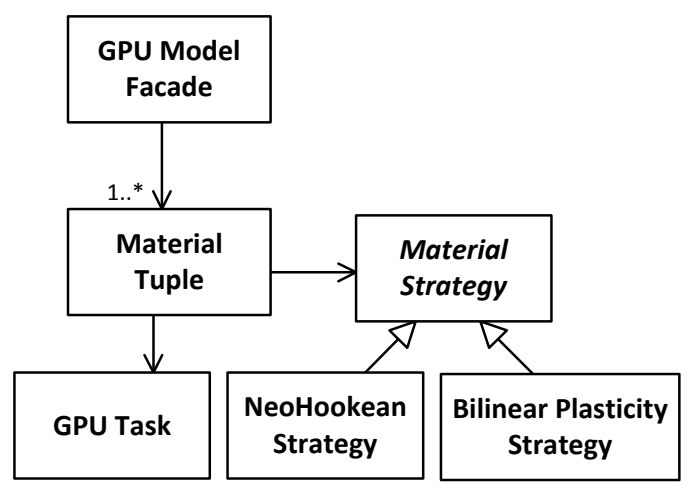

(a) Classes participantes

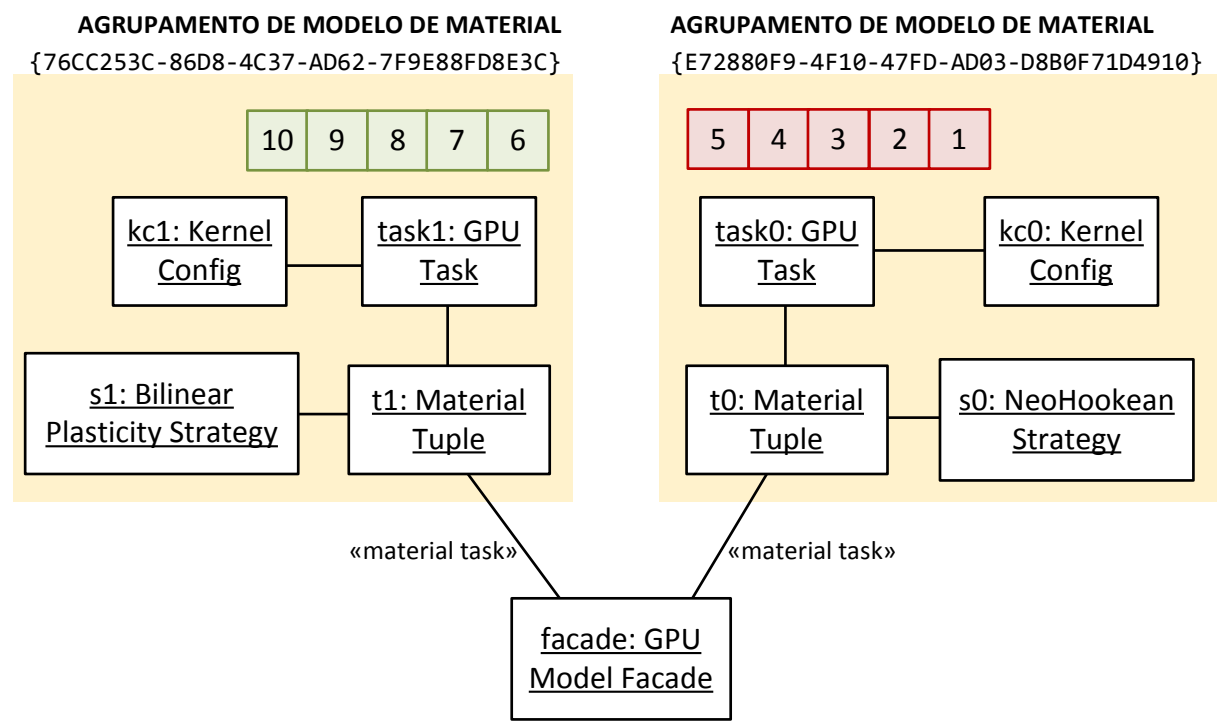

(b) Agrupamentos e objetos resultantes

Figura 7.36 Processo de coalescência de modelos de materiais.

A fachada GPU Solver Facade faz uso de uma tarefa agendada através da operação ScheduleGlobal() de Kernel Scheduler, conforme mostra a Figura 7.37. Supõe-se que tarefas do solver são executadas para vetores globais de solução e, portanto, são paralelizadas em número igual ao total de graus de liberdade do modelo.

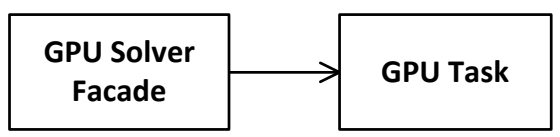

Figura 7.37 Tarefa de processamento associada a GPU Solver Facade. 


\subsubsection{Inicialização da memória}

Através da classe Kernel Scheduler, GPU Dispatcher configura o espelhamento de memória para as tarefas de GPU criadas. Como foram alocadas através de ScheduleLocal(), as tarefas associadas aos elementos finitos, condições de contorno e curvas operam sobre espaços de memória disjuntos do sistema de arena e são coordenados pela classe GPU Block Mirror. Informações como conectividade dos nós, pontos de integração e estado de deformação ainda são mantidos nas classes convencionais. Contudo, com o objetivo de adaptar o sistema ao modelo de processamento do hardware, esses blocos de memória abrigam as informações enumeradas na Figura 7.38.

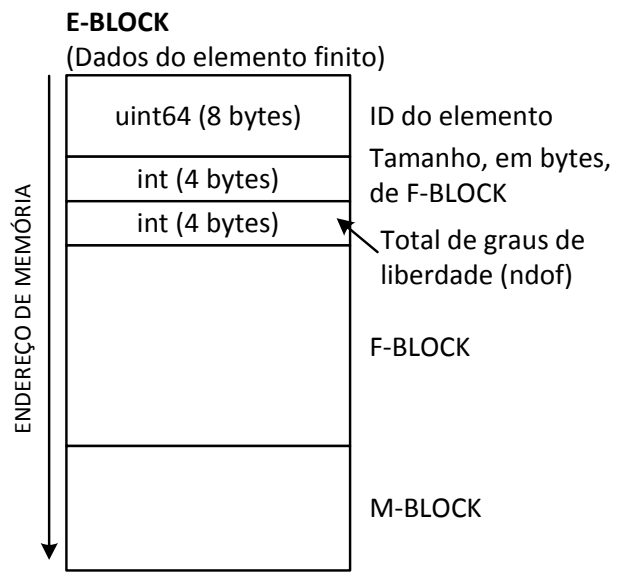

(a) Descritor de um elemento finito (GPU)

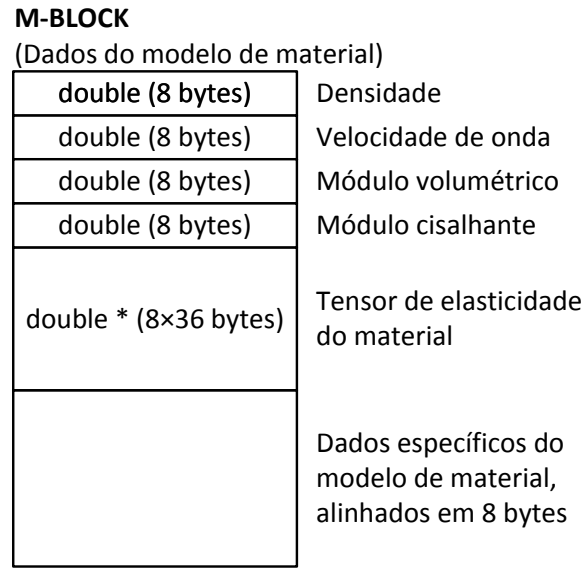

(b) Descritor do material do elemento

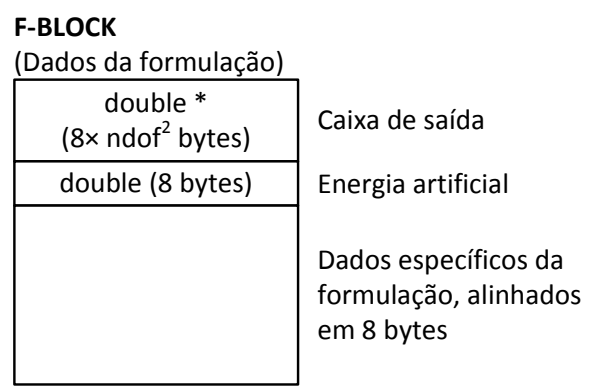

(c) Descritor da formulação do elemento

Figura 7.38 Layout de memória do bloco descritor de um elemento finito na GPU.

Devido à falta de suporte a métodos virtuais (vide seção 7.2.2), algumas informações do elemento na GPU não podem ser acessadas. Por exemplo, na CPU, o módulo cisalhante do modelo de material é obtido através de método virtual implementado pela classe (GetShearModulus()). Na GPU, essa informação precisa estar presente em um local bem-conhecido, isto é, pré-estabelecido pelo programa. Atra- 
vés do layout apresentado na Figura $7.38^{6}$, informações gerais das formulações e do modelo de material são dispostas no bloco de memória correspondente ao elemento. Dados específicos da formulação ou do material são também armazenadas nesses blocos (pois subclasses de Formulation e Material Model, por conter métodos virtuais, não são utilizáveis na GPU e, assim, seus atributos não são acessíveis).

\subsubsection{Execução do solver}

O Algoritmo 7.1 mostra a execução do método ExecuteStepOnGPU() para o solver dinâmico explícito não-linear.

Algoritmo 7.1: Execução do solver de GPU, dinâmico explícito não-linear: lado CPU.

\section{Algoritmo Método ExecuteStep()}

Condições iniciais: memória da GPU sincronizada; objetos de fachada da GPU inicializados

\section{Saída: -}

1. Executar comando de kernel: ExplicitSolverBeforeCommand através de GPU Solver Facade;

2. Sincronizar (aguardar término do comando na GPU);

3. Atualizar estado de deformação dos elementos: executar comando UpdateStrainCommand da estratégia da formulação (operação UpdateStrain() de GPU Model Facade);

4. Sincronizar;

5. Atualizar estado de tensão dos elementos: executar comando UpdateStressCommand da estratégia do material (operação UpdateStress() de GPU Model Facade);

6. Sincronizar;

7. Calcular forças internas dos elementos: executar comando UpdatelnternalForceCommand da estratégia da formulação (operação CalculateGloballnternalForce() de GPU Model Facade); os vetores locais são armazenados na caixa de saída dos elementos (vide Figura 7.38);

8. Sincronizar;

9. Reunir quantias no vetor global de forças internas: operação GatherVector() de GPU Solver Facade (vetores nas caixas de saída dos elementos são somados ao vetor global especificado);

10. Sincronizar;

11. Executar comando de kernel: ExplicitSolverAfterCommand através de GPU Solver Facade;

12. Sincronizar;

13. Atualizar geometria dos elementos: executar comando UpdateGeometryCommand da estratégia da formulação (operação UpdateGeometry() de GPU Model Facade);;

14. Sincronizar;

\footnotetext{
${ }^{6}$ No layout, o espaço "caixa de saída" em F-BLOCK é usado em operações scatter-gather para a montagem de vetores e matrizes globais.
} 
Todos os comandos executados na GPU são assíncronos e, por isso, operações interdependentes precisam ser sincronizadas antes de executar computações posteriores. O comando ExplicitSolverBeforeCommand corresponde aos passos 1 a 3 do Algoritmo 6.2, executados no dispositivo gráfico, enquanto que ExplicitSolverAfterCommand implementa os passos 6 a 8 .

\subsection{Comparação do código de elementos finitos em CPU e GPU}

Em virtude da arquitetura orientada a objetos na GPU e dos sistemas de abstração promovidos pelos componentes Capsicum e Yuzu, o código implementado no host e no dispositivo são, em geral, similares, o que favorece a legibilidade e clareza do programa, além de permitir, mais cedo, a adoção da GPU em tecnologias MEF.

A partir das Listagens 7.2 e 7.3 é possível comparar o código do modelo de material neo-Hookeano (classe Neo Hookean Model), implementado para ambos os ambientes de processamento suportados. O cálculo da deformação no elemento hexaédrico com suporte a não-linearidade é comparado nas Listagens 7.4 e 7.5 . 
Listagem 7.2: Código do modelo de material neo-Hookeano, versão CPU.

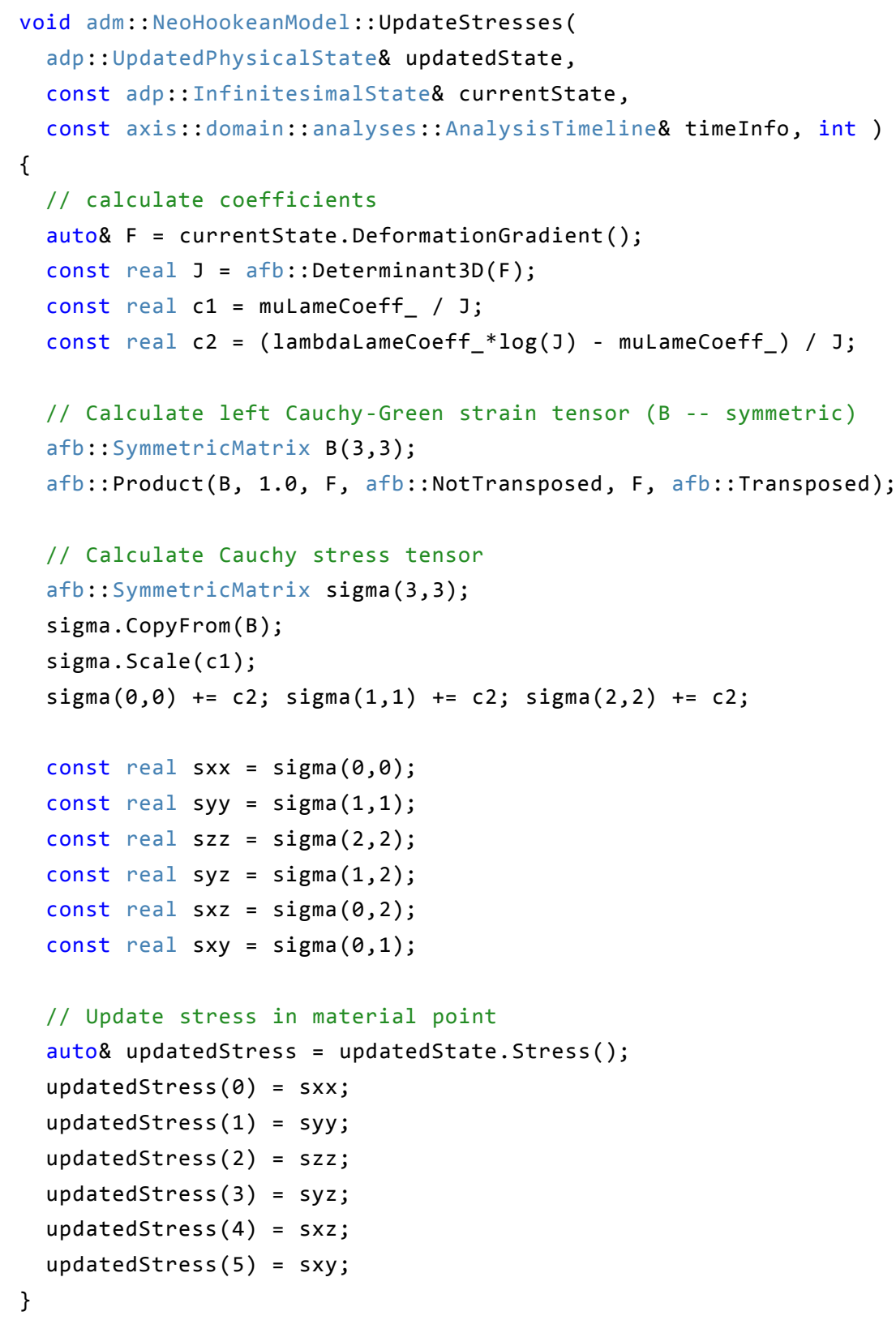


Listagem 7.3: Código do modelo de material neo-Hookeano, versão GPU.

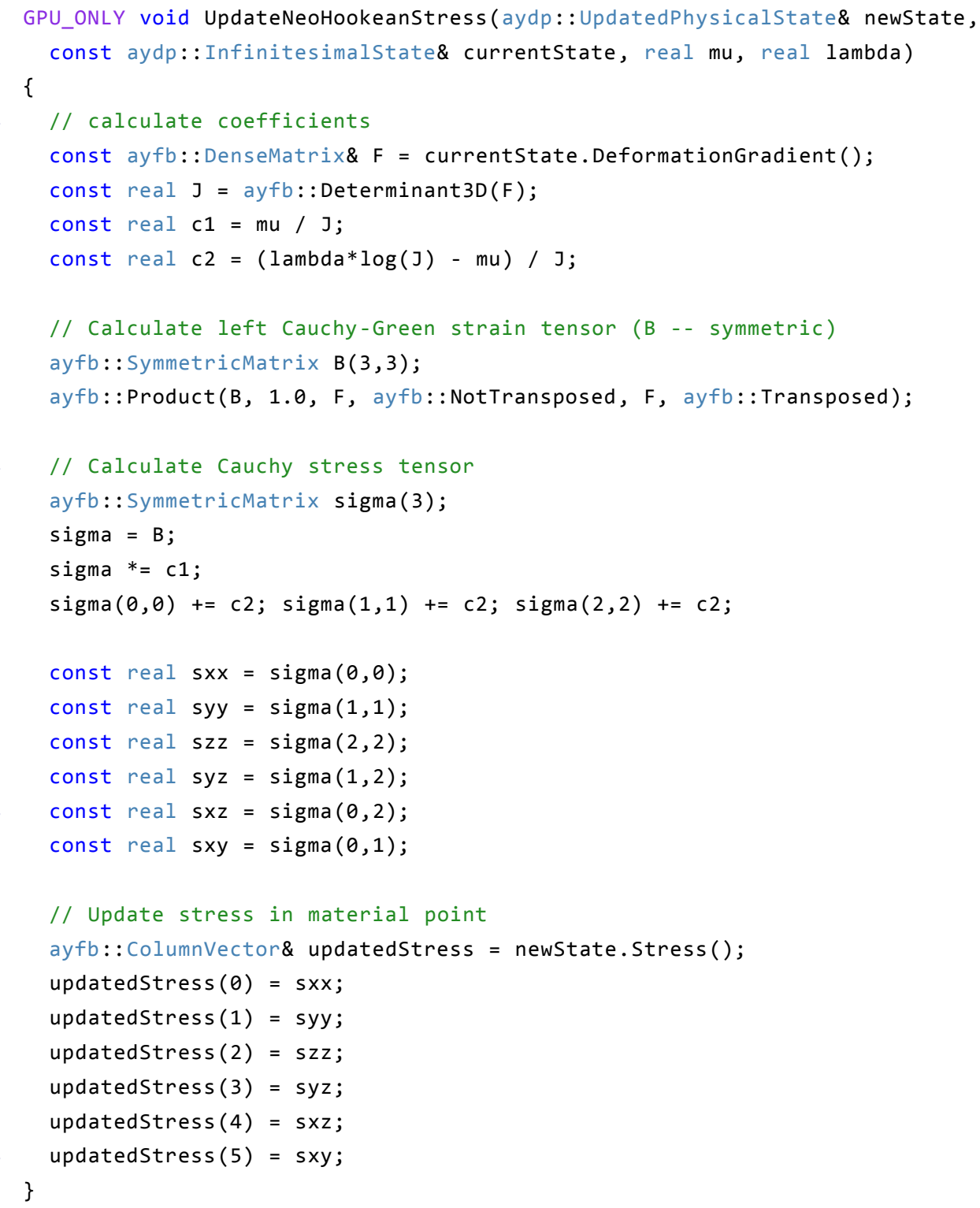


Listagem 7.4: Atualização do estado de deformação (elemento hexaédrico), versão CPU.

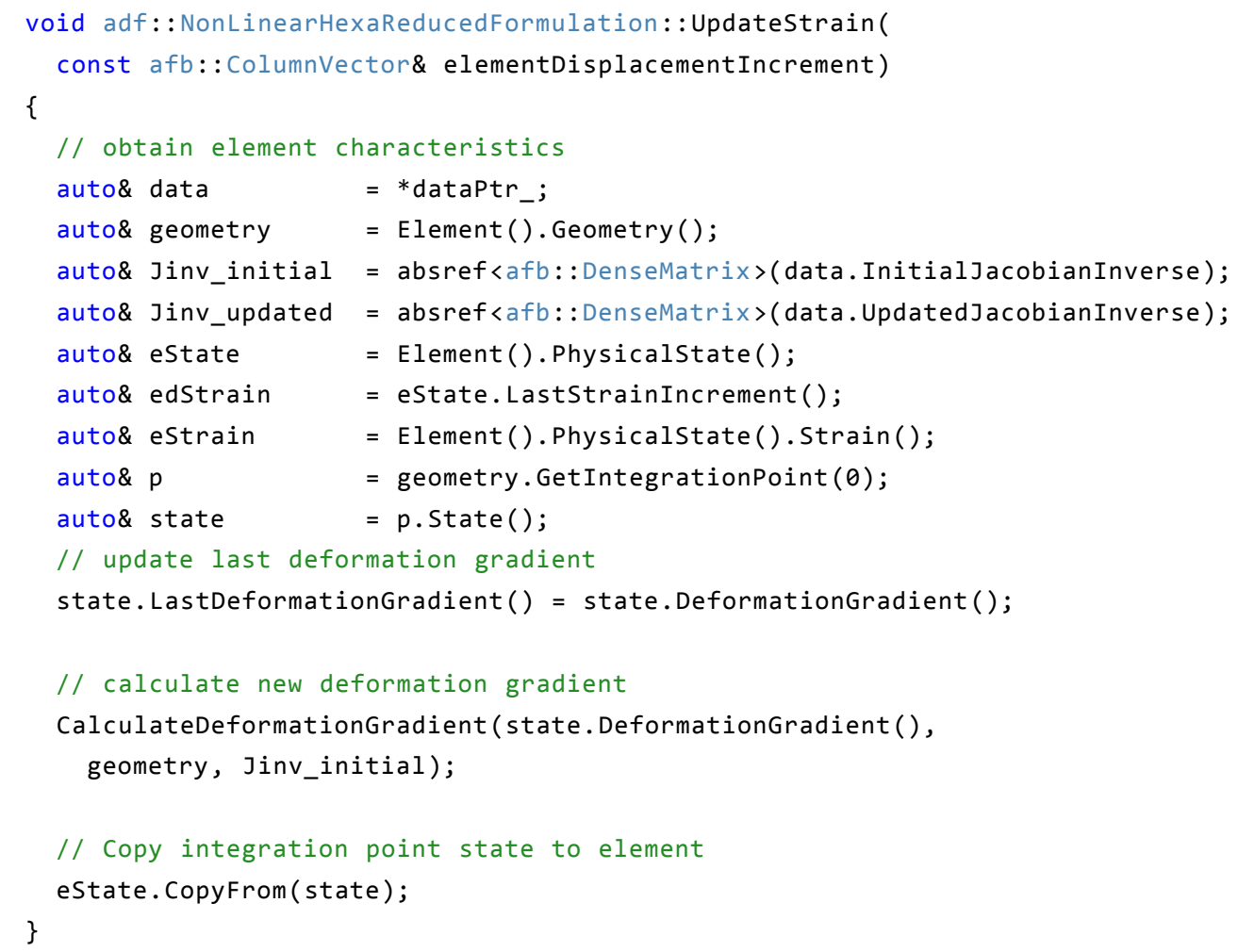


Listagem 7.5: Atualização do estado de deformação (elemento hexaédrico), versão GPU.

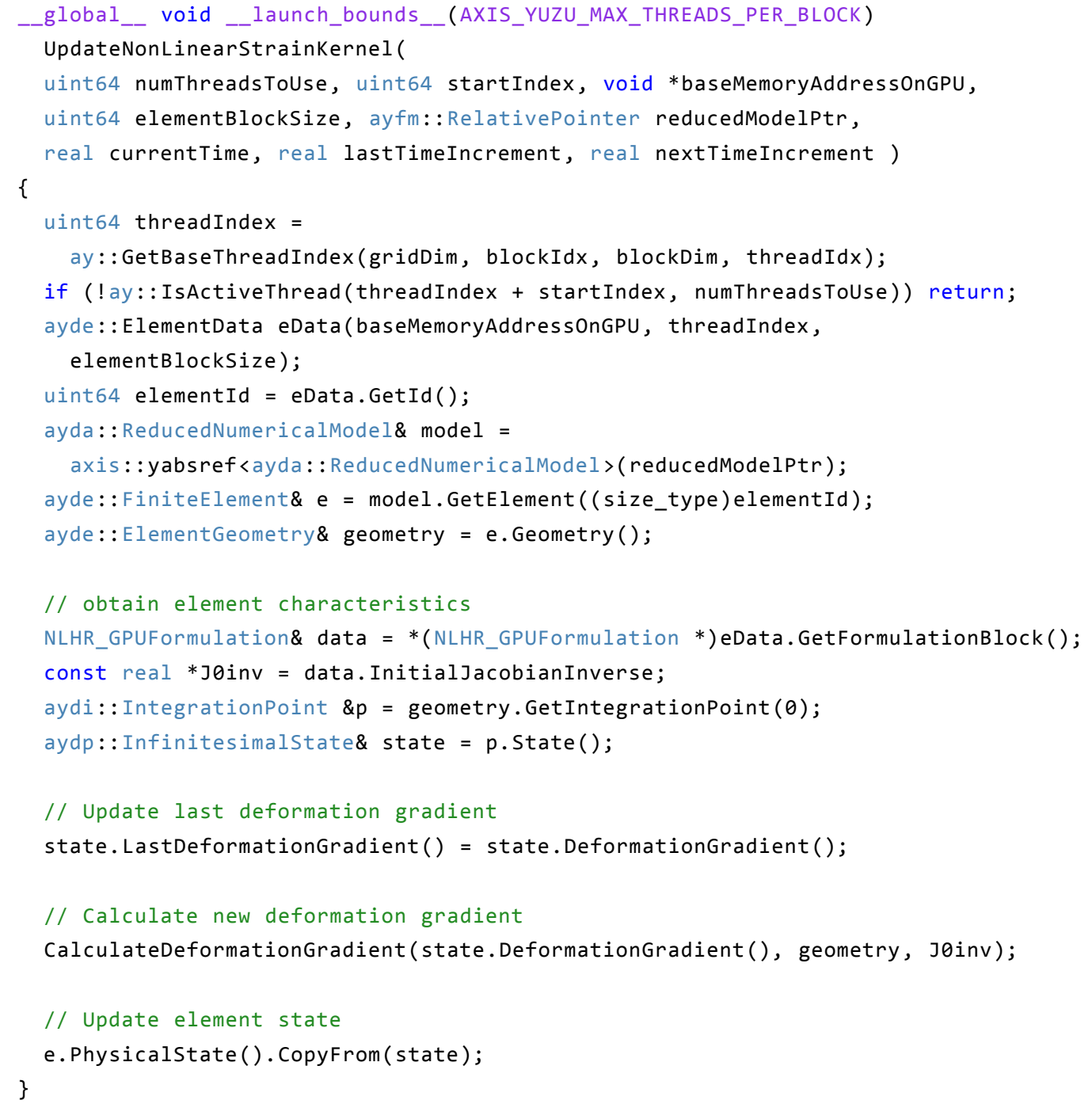




\subsection{Comentários}

A demanda por programas de elementos finitos capazes de usufruir dos benefícios trazidos pela evolução tecnológica cresceu nos últimos tempos, com a mudança de paradigmas trazida pela chamada revolução multi-core e o emprego de co-processadores, como a GPU. Contudo, o modelo de processamento do dispositivo, diferente do arquétipo tradicional, não é trivial e representa uma das barreiras para a adoção do hardware em programas MEF.

O modelo de abstração da GPU apresentado neste capítulo propõe um uso mais transparente do hardware sem a necessidade da escrita de longos códigos de configuração do dispositivo. Apectos como a manipulação e replicação de dados na GPU, a seleção do hardware apropriado e o despacho das tarefas para o dispositivo são realizados automaticamente pelo programa. Dessa forma, as atividades de desenvolvimento são mais focadas nos objetivos do problema de MEF, propriamente dito.

A escrita de códigos de elementos finitos orientados a objetos na GPU garante maior similaridade com a sua contraparte em CPU. Com isso, aumenta-se a legibilidade e clareza da implementação e permite a adoção do hardware mais cedo no desenvolvimento, simplificando a criação de protótipos rápidos para testes no hardware. 



\section{CAPÍTULO 8}

\section{Discussões e avaliação de desempenho}

Neste capítulo, são apresentados os resultados dos testes de validação e funcionalidade do programa desenvolvido. As primeiras verificações foram realizados a partir de unidades de testes dentro do ambiente de desenvolvimento, ainda com o código de elementos finitos em estágio anterior ao que lhe permite ser empregado efetivamente na execução de simulações numéricas.

Em seguida, testes de validação do elemento finito implementado são apresentados, demonstrando a conformidade do código através de testes de validação simples e outros, propostos na literatura, como os patch tests. Os sistema de solução são validados através da comparação com resultados obtidos do pacote comercial ABAQUS de elementos finitos. A precisão numérica do código é dada pelo tipo double, ponto flutuante de precisão dupla, segundo especificações da IEEE 754 [116].

São também apresentados os resultados do sistema de solução em GPU. Sua acurácia é medida através da comparação com os resultados obtidos para a mesma simulação numérica executada em CPU. A validação dos algoritmos é acompanhada de testes de desempenho, medindo o ganho de desempenho com o dispositivo para diferentes configuração de malha. Speedups obtidos são comparados e uma discussão é oferecida a respeito de possíveis limitantes para seu crescimento.

\subsection{Unidades de teste}

As unidades de teste promovem uma forma de testar pequenos trechos do códigofonte isoladamente, verificando se a funcionalidade e a semântica do bloco estão de 
acordo com o esperado. Normalmente, as unidades de teste são independentes e descritas através de classes, onde cada método verifica o comportamento do código num cenário específico.

Durante o ciclo de desenvolvimento, a validação isolada de partes do código permitiu a resolução antecipada de problemas e facilitou a depuração de sistemas maiores. Unidades de testes foram empregadas para verificar funcionalidades chaves do programa, tal como tipos de dados essenciais, como ColumnVector e DenseMatrix, impedindo que questões ocorridas nessas entidades desencadeassem problemas em níveis superiores do software (como em solver e outras classes de domínio), onde a depuração pode se tornar mais difícil.

Foram escritas 38 unidades de testes (classes de testes) que descrevem 490 cenários (métodos de testes). A intenção desta etapa é a validação das funcionalidades básicas do programa, responsáveis por manter unidos os diversos sistemas de que é composto, além de oferecer pré-testes para a realização das simulações numéricas. Dessa forma, as unidades de testes verificam apenas os aspectos técnicos do programa. Simulações numéricas e patch tests validam a coerência e precisão numérica dos algoritmos.

A Tabela 8.1 mostra a distribuição das unidades de teste para a verificação de diversas funcionalidades do programa. Por questões práticas, os testes não cobrem a totalidade do código desenvolvido, verificando apenas pontos importantes do software. Os esforços se concentram nas entidades e operações usadas mais constantemente durante uma análise de elementos finitos. Em seguida, o sistema de leitura do arquivo de entrada é validado, a fim de garantir a correta interpretação dos dados e a construção coerente do modelo numérico. Todos os testes apresentados executaram corretamente, dentro do comportamento esperado.

A verificação de funcionalidades específicas traz uma cobertura não-uniforme dos componentes do programa. Possivelmente, para a utilização efetiva da base de códigos, será necessária a realização de testes adicionais. Contudo, para o presente estudo, os pontos verificados do sistema são suficientes para demonstrar a sua usabilidade. A Tabela 8.2 detalha a cobertura do código dos componentes pelas unidades de teste.

Alguns componentes não puderam ser validados através de unidades de teste. Não há ainda disponível uma ferramenta de gerenciamento de unidades de teste para códigos em GPU. Por esta razão, os componentes Yuzu e Capsicum não foram cobertos. Código de dispositivo, presente em outros componentes, como Solver, Orange, Standard Elements e Standard Library, também não foram testados e por 
Tabela 8.1 Distribuição das unidades de teste.

\begin{tabular}{lc}
\hline Sistemas e funcionalidades & Total de cenários \\
\hline Fachada para o controle geral da aplicação & 4 \\
Classes de fachada (ponto de entrada do programa) & 4 \\
Tipos e operações básicas algébricas & $\mathbf{2 4 6}$ \\
Tipos algébricos básicos (matrizes, vetores, etc.) & 133 \\
Operações algébricas & 113 \\
Sistemas gerais de uso comum & 4 \\
Comportamento geral de um solver & 2 \\
Sistema de coleta de dados & 2 \\
Sistemas essenciais de fundação & 74 \\
Tipo de dados básicos (string, datas, etc.) & 30 \\
Sistemas de arena de memória & 23 \\
Sistema de carregamento de plugins & 21 \\
Leitura do arquivo de entrada (sistema de parsers) & $\mathbf{1 5 6}$ \\
Primitivas básicas & 25 \\
Tokenizers & 36 \\
Validação da gramática (sintaxe) & 14 \\
Fábricas de entidades do domínio & 81 \\
Testes básicos das classes domínio & $\mathbf{6}$ \\
Formulações de elementos & 1 \\
Modelos de materiais & 4 \\
Gradiente conjugado & 1 \\
\hline Total & 490 \\
\hline
\end{tabular}

Tabela 8.2 Cobertura dos componentes pelas unidades de teste.

\begin{tabular}{lrlr}
\hline Componente & $\begin{array}{c}\text { Cobertura de } \\
\text { código }(\%)\end{array}$ & Componente & $\begin{array}{r}\text { Cobertura de } \\
\text { código }(\%)\end{array}$ \\
\hline BLAS & 55,75 & Orange & 47,83 \\
Capsicum & 0,00 & Physalis & 20,05 \\
Common Library & 29,22 & Saintpaulia & 0,76 \\
Core & 77,90 & Solver & 13,80 \\
Director & 0,00 & Standard Elements & 15,01 \\
Echinopsis & 20,81 & Standard Materials & 9,75 \\
Locale & 12,25 & System Base & 21,39 \\
Mint & 52,45 & Yuzu & 0,00 \\
\hline
\end{tabular}


isso a cobertura é baixa. Assim, a verificação dessas funcionalidades foi postergada para os testes em simulações numéricas. O componente Director se trata apenas de entidades do programa para interface com o usuário e, por essa razão, não foi testado.

\subsection{Verificação do algoritmo GC do solver quase estático}

Como já foi apresentado na seção 6.1, o algoritmo principal do solver quase estático foi testado através de objetos mock. Nesse primeiro teste, o algoritmo base do sistema, o gradiente conjugado, foi validado para um sistema linear de solução conhecida, a saber

$$
\mathbf{A x}=\mathbf{b}
$$

onde

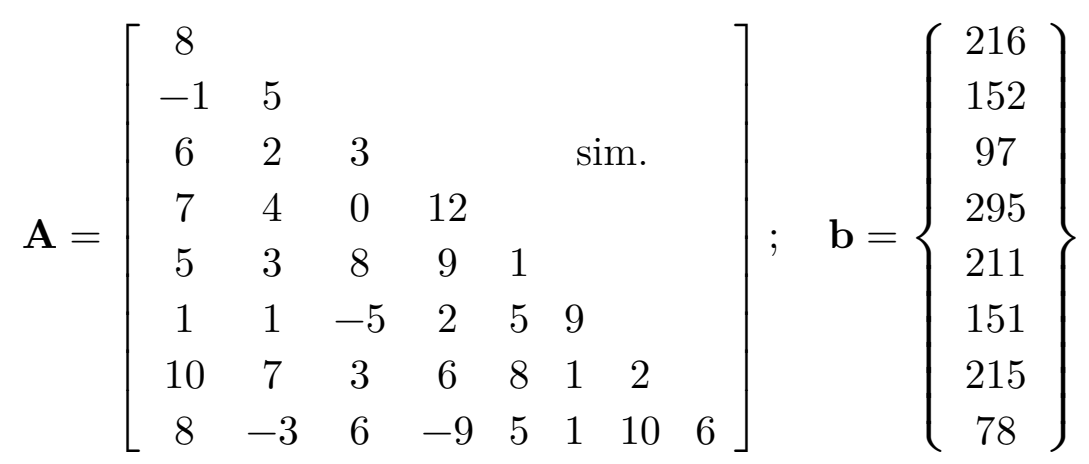

tendo a solução,

$$
\mathbf{x}=\left\{\begin{array}{llllllll}
3 & 5 & -1 & 8 & 10 & 7 & 9 & 0
\end{array}\right\}^{T} .
$$

Dentro do limite de precisão do programa (tipo double), a solução convergiu para o resultado esperado, dentro de uma tolerância máxima de $10^{-14}$. A verificação do solver, quando aplicado a problemas de elementos finitos, é feita conjuntamente com a validação da formulação do elemento linear hexaédrico e do modelo de material linear elástico.

\subsection{Validação do elemento finito linear}

O elemento linear hexaédrico, com integração numérica completa (C3D8FL, vide Tabela 5.2) foi validado juntamente com o modelo de material linear elástico isotrópico. Para tanto, foi realizada uma série de análises estáticas simples, envolvendo poucos elementos, para certificar o funcionamento e a acurária do elemento finito e do solver, seguidos de patch tests sugeridos na literatura. Cada um deles é apresentado a seguir. 


\subsubsection{Problema 1: compressão de um cubo unitário}

Foi usado como problema de validação um cubo de lado unitário, simplesmente apoiado e sujeito a uma carga estática de compressão em sua face superior, $\mathbf{r}^{\text {ext }}=$ $50 \mathrm{kN}$, conforme ilustra a Figura 8.1a. As propriedades do material linear elástico usado são $E=200 \mathrm{GPa}$ e $\nu=0,3$. Apenas um elemento finito hexaédrico linear (integração completa) é utilizado no modelo numérico (Figura 8.1b).

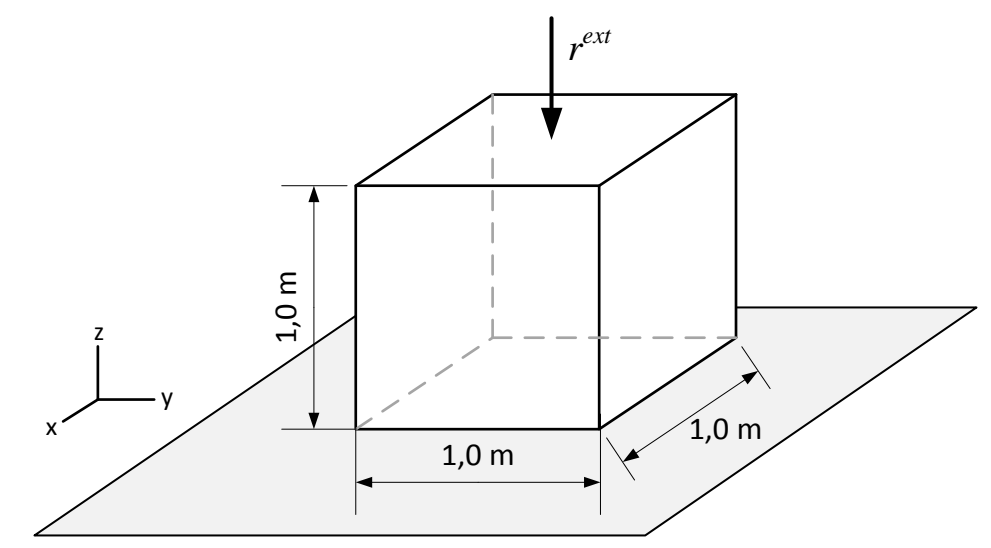

(a) Cubo unitário em compressão na face superior

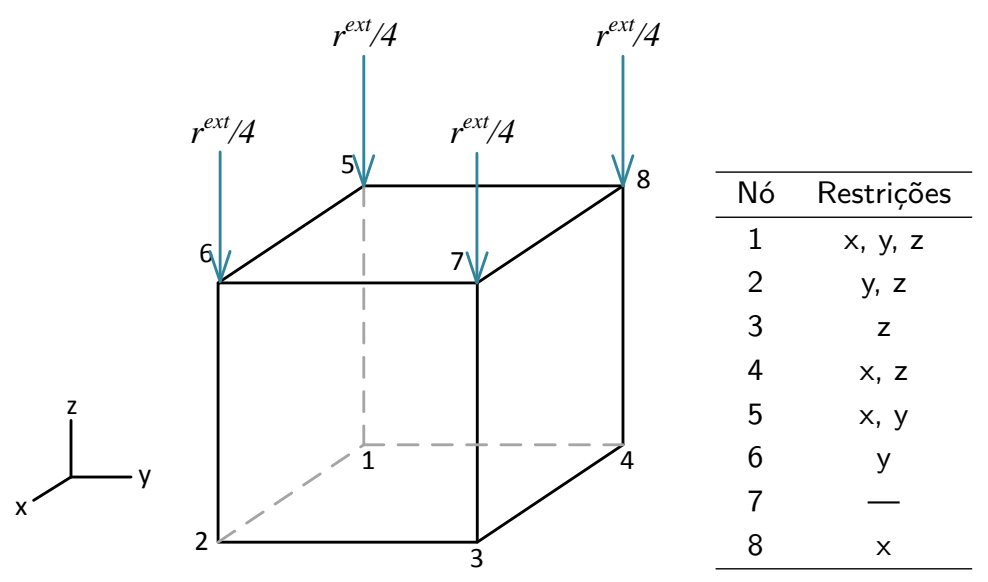

(b) Malha de elementos finitos com cargas nodais equivalentes

Figura 8.1 Modelo de cubo unitário usado no teste.

O objetivo deste problema é verificar as funcionalidades básicas do programa. A solução analítica pode facilmente ser obtida e, portanto, oferece uma maneira simples de averiguar a acurácia do resultado. A Tabela 8.3 mostra os deslocamentos nodais obtidos. O estado de tensão e de deformação do elemento são listados nas Tabelas 8.4 e 8.5, respectivamente. 
O deslocamento obtido convergiu satisfatoriamente para os valores esperados. Em algumas ocasiões, foram percebidos pequenos desvios nos resultados, não sendo representados na tabela devido a sua ordem de magnitude (inferior a $10^{-21}$ ). Essas pequenas pertubações no cálculo são causadas pela precisão finita do ponto flutuante. Variações similares foram percebidas para os resultados de tensão e deformação do elemento (magnitude máxima de $10^{-12}$ e $10^{-15}$, respectivamente).

Ao longo deste estudo, para a medida de imprecisão do algoritmo, causada por erros de truncamento e arredondamento do ponto flutuante e aproximações do processo de cálculo, é adotado o erro relativo $\epsilon$, dado por

$$
\epsilon=\left|\frac{x-v}{v}\right|
$$

onde $x$ é o valor obtido e $v$ é o valor esperado. Para $v=0$, adota-se $v= \pm 2,22 \times$ $10^{-16}$ (o que produz menor $\epsilon$ ), que é, aproximadamente, o épsilon de máquina para ponto flutuante de precisão dupla ${ }^{1}$.

Tabela 8.3 Deslocamento nodal do Problema 1.

\begin{tabular}{cccccccccc}
\hline \multirow{2}{*}{ Nó } & \multicolumn{3}{c}{$u_{x}\left(\times 10^{-7}\right)$} & \multicolumn{3}{c}{$u_{y}\left(\times 10^{-7}\right)$} & \multicolumn{3}{c}{$u_{z}\left(\times 10^{-7}\right)$} \\
\cline { 2 - 9 } & Obtido & Esperado & $\epsilon(\%)$ & Obtido & Esperado & $\epsilon(\%)$ & Obtido & Esperado & $\epsilon(\%)$ \\
\hline 1 & 0,00 & 0,00 & 0,00 & 0,00 & 0,00 & 0,00 & 0,00 & 0,00 & 0,00 \\
2 & 0,75 & 0,75 & 0,00 & 0,00 & 0,00 & 0,00 & 0,00 & 0,00 & 0,00 \\
3 & 0,75 & 0,75 & 0,00 & 0,75 & 0,75 & 0,00 & 0,00 & 0,00 & 0,00 \\
4 & 0,00 & 0,00 & 0,00 & 0,75 & 0,75 & 0,00 & 0,00 & 0,00 & 0,00 \\
5 & 0,00 & 0,00 & 0,00 & 0,00 & 0,00 & 0,00 & $-2,50$ & $-2,50$ & 0,00 \\
6 & 0,75 & 0,75 & 0,00 & 0,00 & 0,00 & 0,00 & $-2,50$ & $-2,50$ & 0,00 \\
7 & 0,75 & 0,75 & 0,00 & 0,75 & 0,75 & 0,00 & $-2,50$ & $-2,50$ & 0,00 \\
8 & 0,00 & 0,00 & 0,00 & 0,75 & 0,75 & 0,00 & $-2,50$ & $-2,50$ & 0,00 \\
\hline
\end{tabular}

Tabela 8.4 Estado de tensão do elemento no Problema 1.

\begin{tabular}{cccc}
\hline & Obtido (Pa) & Esperado (Pa) & $\epsilon(\%)$ \\
\hline$\sigma_{x x}$ & 0,000 & 0,000 & 0,00 \\
$\sigma_{y y}$ & 0,000 & 0,000 & 0,00 \\
$\sigma_{z z}$ & $-5,000 \times 10^{4}$ & $5,000 \times 10^{4}$ & 0,00 \\
$\sigma_{x y}$ & $-5,408 \times 10^{-13}$ & 0,000 & 0,00 \\
$\sigma_{y z}$ & $4,231 \times 10^{-12}$ & 0,000 & 0,00 \\
$\sigma_{x z}$ & $7,596 \times 10^{-13}$ & 0,000 & 0,00 \\
\hline
\end{tabular}

Tabela 8.5 Estado de deformação do elemento no Problema 1.

\begin{tabular}{cccc}
\hline & Obtido & Esperado & $\epsilon(\%)$ \\
\hline$\varepsilon_{x x}$ & $7,500 \times 10^{-8}$ & $7,500 \times 10^{-8}$ & 0,00 \\
$\varepsilon_{y y}$ & $7,500 \times 10^{-8}$ & $7,500 \times 10^{-8}$ & 0,00 \\
$\varepsilon_{z z}$ & $-2,500 \times 10^{-7}$ & $-2,500 \times 10^{-7}$ & 0,00 \\
$\varepsilon_{x y}$ & $-3,516 \times 10^{-24}$ & 0,000 & 0,00 \\
$\varepsilon_{y z}$ & $2,750 \times 10^{-23}$ & 0,000 & 0,00 \\
$\varepsilon_{x z}$ & $4,937 \times 10^{-24}$ & 0,000 & 0,00 \\
\hline
\end{tabular}

\footnotetext{
${ }^{1} \mathrm{O}$ épsilon de máquina, ou menor número representável, é o menor valor o qual, somado a 1, produza resultado diferente de 1, isto é, que não seja arredondado, dentro da forma de representação adotada.
} 
Num segundo teste, o mesmo modelo de elementos finitos foi usado, substituindo as cargas nodais pela prescrição dos deslocamentos obtidos na Tabela 8.3. Os mesmos resultados de tensão e deformação foram obtidos, como esperado.

\subsubsection{Problema 2: compressão de um cubo: modelo discretizado}

O segundo problema, mostrado na Figura 8.2a, busca verificar a consistência do sistema de montagem das matrizes e vetores globais. Para uma carga $\mathbf{r}^{\mathrm{ext}}=160$ kN, no modelo de elementos finitos da Figura 8.2b, são aplicadas cargas nodais equivalentes $r_{1}=40 \mathrm{kN}, r_{2}=10 \mathrm{kN}$ e $r_{3}=20 \mathrm{kN}$.

A mesma formulação de elemento e modelo de material do teste anterior são usados para a definição do modelo numérico deste problema. Alguns nós do modelo foram selecionados para verificar a concordância dos deslocamentos com o resultado analítico e são listados na Tabela 8.6. O erro absoluto nos valores obtidos é menor que $10^{-15}$. O estado de tensão e de deformação dos elementos 4,6 e 7 foram verificados e são apresentados nas Tabelas 8.7 e 8.8, respectivamente. Para esses casos, o erro absoluto é, na ordem, inferior a $10^{-5}$ e $10^{-16}$.

Tabela 8.6 Deslocamento nodal do Problema 2.

\begin{tabular}{lccccccccc}
\hline \multirow{2}{*}{ Nó } & \multicolumn{3}{c}{$u_{x}\left(\times 10^{-7}\right)$} & \multicolumn{3}{c}{$u_{y}\left(\times 10^{-7}\right)$} & \multicolumn{3}{c}{$u_{z}\left(\times 10^{-7}\right)$} \\
\cline { 2 - 9 } & Obtido & Esperado & $\epsilon(\%)$ & Obtido & Esperado & $\epsilon(\%)$ & Obtido & Esperado & $\epsilon(\%)$ \\
\hline 1 & 0,00 & 0,00 & 0,00 & 0,00 & 0,00 & 0,00 & 0,00 & 0,00 & 0,00 \\
7 & 0,60 & 0,60 & 0,00 & 0,75 & 0,60 & 0,60 & 0,00 & $-2,00$ & 0,00 \\
13 & 0,00 & 0,00 & 0,00 & 0,75 & 0,00 & 0,00 & 0,00 & $-4,00$ & 0,00 \\
21 & 1,20 & 1,20 & 0,00 & 1,20 & 1,20 & 0,00 & 0,00 & 0,00 & 0,00 \\
25 & 0,00 & 0,00 & 0,00 & 1,20 & 1,20 & 0,00 & $-2,50$ & $-4,00$ & 0,00 \\
27 & 1,20 & 1,20 & 0,00 & 1,20 & 1,20 & 0,00 & $-2,50$ & $-4,00$ & 0,00 \\
\hline
\end{tabular}

Tabela 8.7 Estado de tensão dos elementos 4, 6 e 7 no Problema 2.

\begin{tabular}{cccccccccc}
\hline & \multicolumn{3}{c}{ Elemento 4 $(\mathrm{kPa})$} & \multicolumn{3}{c}{ Elemento 6 $(\mathrm{kPa})$} & \multicolumn{3}{c}{ Elemento 7 (kPa) } \\
\cline { 2 - 9 } & Obtido & Esperado & $\epsilon(\%)$ & Obtido & Esperado & $\epsilon(\%)$ & Obtido & Esperado & $\epsilon(\%)$ \\
\hline$\sigma_{x x}$ & 0,000 & 0,000 & 0,00 & 0,000 & 0,000 & 0,00 & 0,000 & 0,000 & 0,00 \\
$\sigma_{y y}$ & 0,000 & 0,000 & 0,00 & 0,000 & 0,000 & 0,00 & 0,000 & 0,000 & 0,00 \\
$\sigma_{z z}$ & $-4,000$ & $-4,000$ & 0,00 & $-4,000$ & $-4,000$ & 0,00 & $-4,000$ & $-4,000$ & 0,00 \\
$\sigma_{x y}$ & 0,000 & 0,000 & 0,00 & 0,000 & 0,000 & 0,00 & 0,000 & 0,000 & 0,00 \\
$\sigma_{y z}$ & 0,000 & 0,000 & 0,00 & 0,000 & 0,000 & 0,00 & 0,000 & 0,000 & 0,00 \\
$\sigma_{x z}$ & 0,000 & 0,000 & 0,00 & 0,000 & 0,000 & 0,00 & 0,000 & 0,000 & 0,00 \\
\hline
\end{tabular}


Tabela 8.8 Estado de deformação dos elementos 4, 6 e 7 no Problema 2.

\begin{tabular}{cccccccccc}
\hline & \multicolumn{3}{c}{ Elemento $4\left(\times 10^{-7}\right)$} & \multicolumn{3}{c}{ Elemento $6\left(\times 10^{-7}\right)$} & \multicolumn{3}{c}{ Elemento $7\left(\times 10^{-7}\right)$} \\
\cline { 2 - 9 } & Obtido & Esperado & $\epsilon(\%)$ & Obtido & Esperado & $\epsilon(\%)$ & Obtido & Esperado & $\epsilon(\%)$ \\
\hline$\varepsilon_{x x}$ & 0,600 & 0,600 & 0,00 & 0,600 & 0,600 & 0,00 & 0,600 & 0,600 & 0,00 \\
$\varepsilon_{y y}$ & 0,600 & 0,600 & 0,00 & 0,600 & 0,600 & 0,00 & 0,600 & 0,600 & 0,00 \\
$\varepsilon_{z z}$ & $-2,000$ & $-2,000$ & 0,00 & $-2,000$ & $-2,000$ & 0,00 & $-2,000$ & $-2,000$ & 0,00 \\
$\varepsilon_{x y}$ & 0,000 & 0,000 & 0,00 & 0,000 & 0,000 & 0,00 & 0,000 & 0,000 & 0,00 \\
$\varepsilon_{y z}$ & 0,000 & 0,000 & 0,00 & 0,000 & 0,000 & 0,00 & 0,000 & 0,000 & 0,00 \\
$\varepsilon_{x z}$ & 0,000 & 0,000 & 0,00 & 0,000 & 0,000 & 0,00 & 0,000 & 0,000 & 0,00 \\
\hline
\end{tabular}

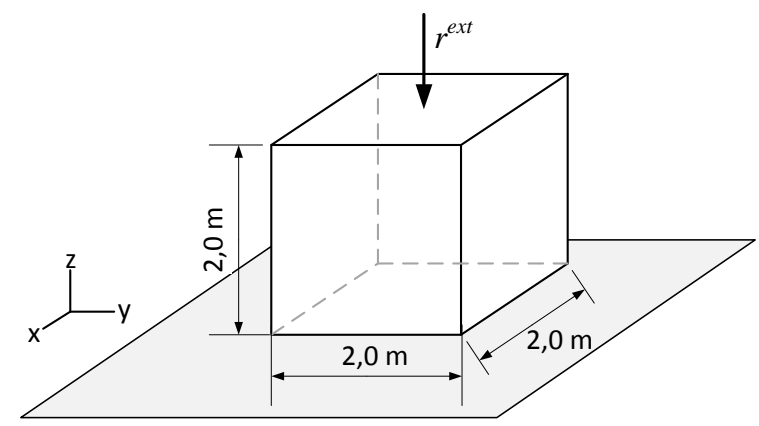

(a) Cubo em compressão na face superior

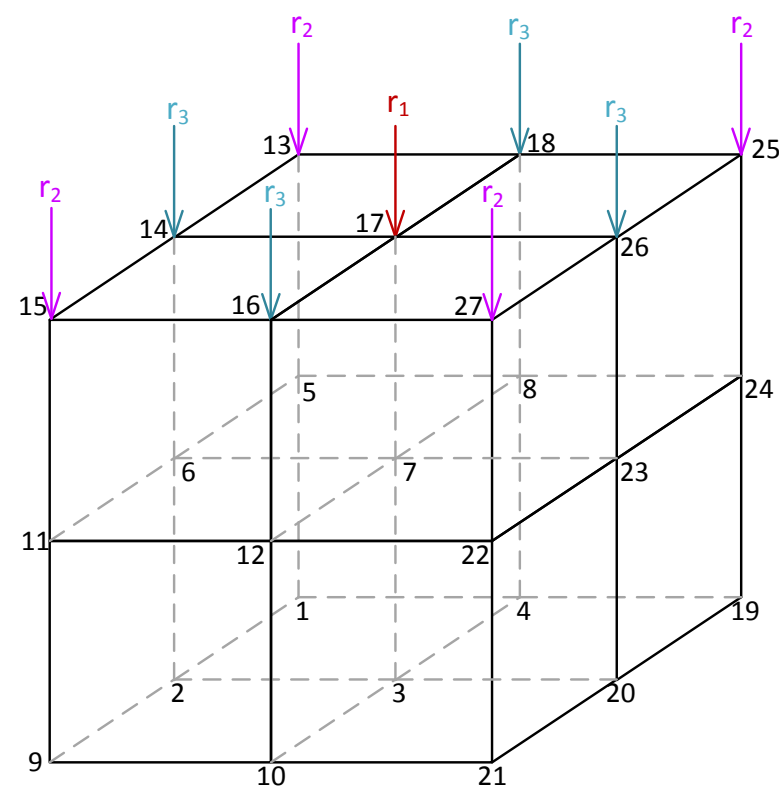

$L_{x}^{2} y$

\begin{tabular}{cc}
\hline Nós & Restrições \\
\hline 1 & $\mathrm{x}, \mathrm{y}, \mathrm{z}$ \\
$2,3,4$ & $\mathrm{z}$ \\
9 & $\mathrm{y}, \mathrm{z}$
\end{tabular}

10, 19, 20, $21 \quad z$

Demais nós -

\begin{tabular}{cc}
\hline Elemento & Conectividade nodal \\
\hline 1 & $1,2,3,4,5,6,7,8$ \\
2 & $2,9,10,3,6,11,12,7$ \\
3 & $5,6,7,8,13,14,17,18$ \\
4 & $6,11,12,7,14,15,16,17$ \\
5 & $4,3,20,19,8,7,23,24$ \\
6 & $3,10,21,20,7,12,22,23$ \\
7 & $8,7,23,24,18,17,26,25$ \\
8 & $7,12,22,23,17,16,27,26$
\end{tabular}

(b) Malha de elementos finitos com cargas nodais equivalentes

Figura 8.2 Modelo de cubo discretizado usado no teste. 


\subsubsection{Problema 3: paralelepípedo sob pressão}

Este problema foi extraído do manual de verificação do programa ABAQUS [62], onde um paralelepípedo $(2 \times 2 \times 1)$ é sujeito a uma pressão hidrostática constante de $1000 \mathrm{~Pa}$, ao mesmo tempo que forças concentradas são aplicadas, tal que as tensões cisalhantes no elemento são iguais a -1000, em todos os pontos de integração. Dessa forma, o modelo numérico apresentado na Figura 8.3 foi usado para descrever o problema. Os parâmetros do modelo de material linear elástico usado são $E=$ $30 \times 10^{6}$ e $\nu=0,3$. Os resultados obtidos de deslocamento, tensão e deformação são apresentados nas Tabelas 8.9, 8.10 e 8.11, respectivamente. O desvio máximo, causado pelos erros de aproximação e truncamento são inferiores a, na ordem, $10^{-19}$, $10^{-13}$ e $10^{-20}$.

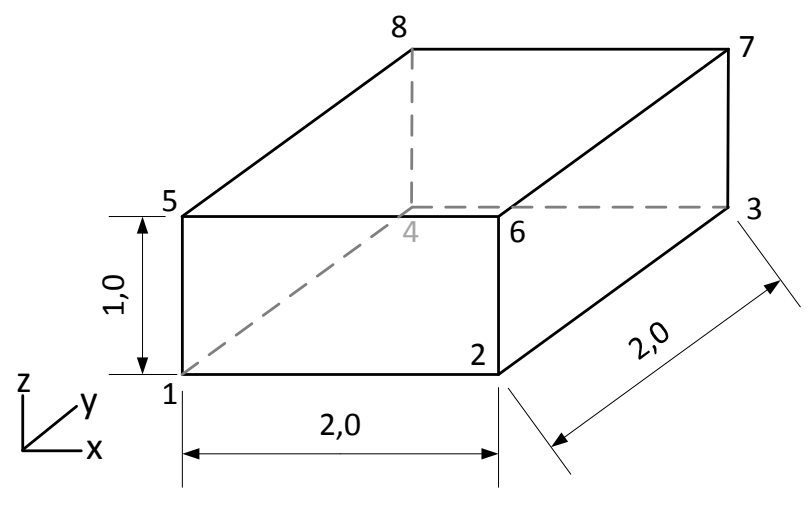

\begin{tabular}{|c|c|c|c|}
\hline & Nó & \multicolumn{2}{|c|}{ Restrições } \\
\hline & 1 & \multicolumn{2}{|c|}{$\mathrm{x}, \mathrm{y}, \mathrm{z}$} \\
\hline & 2 & \multicolumn{2}{|c|}{ y } \\
\hline & 4 & \multicolumn{2}{|c|}{ z } \\
\hline & 5 & \multicolumn{2}{|c|}{$x$} \\
\hline & emais $n$ & \multicolumn{2}{|c|}{ - } \\
\hline \multirow{2}{*}{ Nó } & \multicolumn{3}{|c|}{ Carregamentos aplicados } \\
\hline & $x$ & $\mathrm{y}$ & z \\
\hline 2 & 1000 & - & 1000 \\
\hline 4 & 1000 & 1000 & - \\
\hline 6 & -1000 & -1000 & -1000 \\
\hline 7 & -2000 & -2000 & -2000 \\
\hline 8 & -1000 & -1000 & -1000 \\
\hline
\end{tabular}

Figura 8.3 Descrição do Problema 3.

Tabela 8.9 Deslocamento nodal do Problema 3.

\begin{tabular}{cccccccccc}
\hline \multirow{2}{*}{ Nó } & \multicolumn{3}{c}{$u_{x}\left(\times 10^{-4}\right)$} & \multicolumn{3}{c}{$u_{y}\left(\times 10^{-4}\right)$} & \multicolumn{3}{c}{$u_{z}\left(\times 10^{-4}\right)$} \\
\cline { 2 - 9 } & Obtido & Esperado & $\epsilon(\%)$ & Obtido & Esperado & $\epsilon(\%)$ & Obtido & Esperado & $\epsilon(\%)$ \\
\hline 1 & 0,000 & 0,000 & 0,00 & 0,000 & 0,000 & 0,00 & 0,000 & 0,000 & 0,00 \\
2 & $-0,267$ & $-0,267$ & 0,00 & 0,000 & 0,000 & 0,00 & $-1,733$ & $-1,733$ & 0,00 \\
3 & $-2,000$ & $-2,000$ & 0,00 & $-0,267$ & $-0,267$ & 0,00 & $-1,733$ & $-1,733$ & 0,00 \\
4 & $-1,733$ & $-1,733$ & 0,00 & $-0,267$ & $-0,267$ & 0,00 & 0,000 & 0,000 & 0,00 \\
5 & 0,000 & 0,000 & 0,00 & $-0,867$ & $-0,867$ & 0,00 & $-0,133$ & $-0,133$ & 0,00 \\
6 & $-0,267$ & $-0,267$ & 0,00 & $-0,867$ & $-0,867$ & 0,00 & $-1,867$ & $-1,867$ & 0,00 \\
7 & $-2,000$ & $-2,000$ & 0,00 & $-1,133$ & $-1,133$ & 0,00 & $-1,867$ & $-1,867$ & 0,00 \\
8 & $-1,733$ & $-1,733$ & 0,00 & $-1,133$ & $-1,133$ & 0,00 & $-0,133$ & $-0,133$ & 0,00 \\
\hline
\end{tabular}


Tabela 8.10 Estado de tensão do elemento no Problema 3.

\begin{tabular}{cccc}
\hline & Obtido & Esperado & $\epsilon(\%)$ \\
\hline$\sigma_{x x}$ & $-1000,000$ & $-1000,000$ & 0,00 \\
$\sigma_{y y}$ & $-1000,000$ & $-1000,000$ & 0,00 \\
$\sigma_{z z}$ & $-1000,000$ & $-1000,000$ & 0,00 \\
$\sigma_{x y}$ & $-1000,000$ & $-1000,000$ & 0,00 \\
$\sigma_{y z}$ & $-1000,000$ & $-1000,000$ & 0,00 \\
$\sigma_{x z}$ & $-1000,000$ & $-1000,000$ & 0,00 \\
\hline
\end{tabular}

Tabela 8.11 Estado de deformação do elemento no Problema 3.

\begin{tabular}{cccc}
\hline & Obtido & Esperado & $\epsilon(\%)$ \\
\hline$\varepsilon_{x x}$ & $-1,333 \times 10^{-5}$ & $-1,333 \times 10^{-5}$ & 0,00 \\
$\varepsilon_{y y}$ & $-1,333 \times 10^{-5}$ & $-1,333 \times 10^{-5}$ & 0,00 \\
$\varepsilon_{z z}$ & $-1,333 \times 10^{-5}$ & $-1,333 \times 10^{-5}$ & 0,00 \\
$\varepsilon_{x y}$ & $-8,667 \times 10^{-5}$ & $-8,667 \times 10^{-5}$ & 0,00 \\
$\varepsilon_{y z}$ & $-8,667 \times 10^{-5}$ & $-8,667 \times 10^{-5}$ & 0,00 \\
$\varepsilon_{x z}$ & $-8,667 \times 10^{-5}$ & $-8,667 \times 10^{-5}$ & 0,00 \\
\hline
\end{tabular}

\subsubsection{Problema 4: patch test para sólidos}

Macneal e Harder [154 propõe um patch test para sólidos, que avalia a acurácia do elemento usado. É realizada a análise estática linear de um cubo unitário irregularmente discretizado, conforme mostra a Figura 8.4, com parâmetros do material linear elástico, $E=1,0 \times 10^{6}$ e $\nu=0,25$.

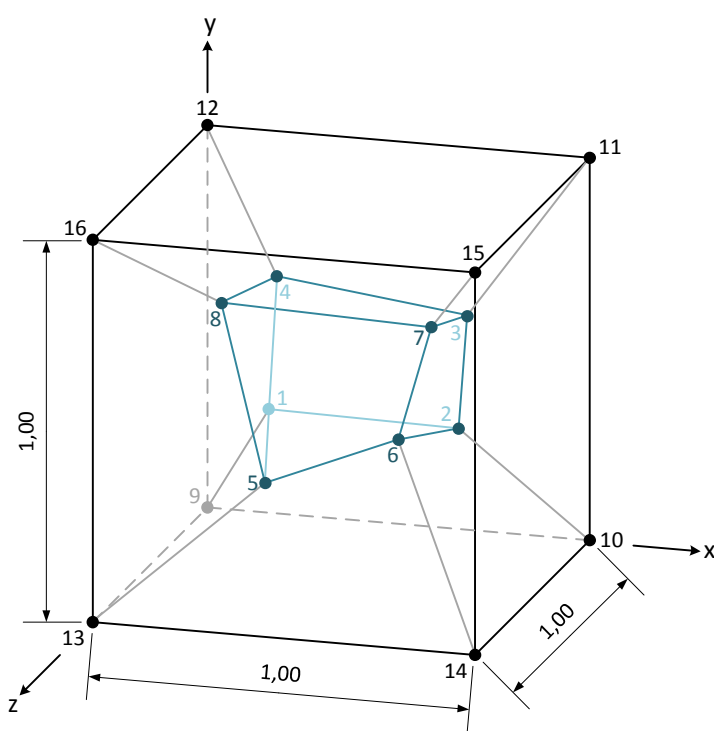

\begin{tabular}{cc}
\hline Elemento & Conectividade nodal \\
\hline 1 & $13,14,10,9,5,6,2,1$ \\
2 & $13,5,1,9,16,8,4,12$ \\
3 & $5,6,2,1,8,7,3,4$ \\
4 & $6,14,10,2,7,15,11,3$ \\
5 & $8,7,3,4,16,15,11,12$ \\
6 & $2,10,9,1,3,11,12,4$ \\
7 & $14,6,5,13,15,7,8,16$ \\
\hline
\end{tabular}

\begin{tabular}{cccc}
\hline \multirow{2}{*}{ Nó } & \multicolumn{3}{c}{ Prescrições de deslocamento } \\
\cline { 2 - 4 } & $u_{x}$ & $u_{y}$ & $u_{z}$ \\
\hline 9 & 0,0 & 0,0 & 0,0 \\
10 & 1,0 & 0,5 & 0,5 \\
11 & 1,5 & 1,5 & 1,0 \\
12 & 0,5 & 1,0 & 0,5 \\
13 & 0,5 & 0,5 & 1,0 \\
14 & 1,5 & 1,0 & 1,5 \\
15 & 2,0 & 2,0 & 2,0 \\
16 & 1,0 & 1,5 & 1,5 \\
\hline
\end{tabular}

\begin{tabular}{ccccccccc}
\hline \multicolumn{10}{c}{ Coordenadas nodais } \\
\hline $\mathrm{x}$ & 1 & 2 & 3 & 4 & 5 & 6 & 7 & 8 \\
$\mathrm{y}$ & 0,249 & 0,826 & 0,850 & 0,273 & 0,320 & 0,677 & 0,788 & 0,165 \\
$\mathrm{z}$ & 0,342 & 0,288 & 0,649 & 0,750 & 0,186 & 0,305 & 0,693 & 0,745 \\
& 0,192 & 0,288 & 0,263 & 0,230 & 0,643 & 0,683 & 0,644 & 0,702 \\
\hline & 9 & 10 & 11 & 12 & 13 & 14 & 15 & 16 \\
\hline $\mathrm{x}$ & 0,000 & 1,000 & 1,000 & 0,000 & 0,000 & 1,000 & 1,000 & 0,000 \\
$\mathrm{y}$ & 0,000 & 0,000 & 1,000 & 1,000 & 0,000 & 0,000 & 1,000 & 1,000 \\
$\mathrm{z}$ & 0,000 & 0,000 & 0,000 & 0,000 & 1,000 & 1,000 & 1,000 & 1,000 \\
\hline
\end{tabular}

Figura 8.4 Patch test para elemento hexaédrico [154]. 
Todos os elementos da malha devem apresentar o mesmo estado de deformação, ou seja, $\varepsilon_{x x}=\varepsilon_{y y}=\varepsilon_{z z}=0,001$ e $\gamma_{x y}=\gamma_{y z}=\gamma_{x z}=0$, 001. Similarmente, o estado de tensão em todos os elementos deve ser igual a $\sigma_{x x}=\sigma_{y y}=\sigma_{z z}=2000$ e $\sigma_{x y}=\sigma_{y z}=\sigma_{x z}=400$. Os resultados obtidos pelo pelo programa possuem erro absoluto não superior a $10^{-17}$ para deformação e $10^{-12}$ para tensão. Logo, o erro relativo da solução é praticamente nulo.

\subsection{Verificação do solver dinâmico explícito linear (CPU)}

Os resultados apresentados na seção 8.3 demonstram a conformidade e a acurácia da implementação base do elemento hexaédrico. Ainda não foram verificadas suas propriedades dinâmicas, sendo elas avaliadas juntamente com o solver dinâmico explícito, apropriado para esse tipo de problema. Para os testes que se seguem, é adotado o elemento C3D8RL do programa.

\subsubsection{Problema 5: barra em compressão constante (Cook et al. [57])}

O problema descrito por Cook et al. [57], ilustrado na Figura 8.5a, modela a propagação de ondas numa barra de aço com comprimento $L=20$ pol $(50,8 \mathrm{~cm})$ e seção quadrada. Inicialmente em repouso, é aplicada na estrutura, em $t=0$, uma carga constante de compressão de $100 \mathrm{lb}(444,822$ N). O modelo numérico é dado por 40 elementos cúbicos ao longo do comprimento, num total de 160 para a malha (Figura 8.5b). Cargas nodais equivalentes são aplicadas na extremidade livre da barra.

A solução exata e o resultado obtido pelo programa Axis são mostrados na Figura 8.6, com incremento de tempo constante de $\Delta t=1 \times 10^{-6}$ s. Neste exemplo, é demonstrado o fenômeno de propagação de ondas, calculado pelo método numérico. O nível de tensão no centro da barra é nulo até que a onda de compressão atravesse a seção no instante $t=0,05 \mathrm{~ms}$. O estado do ponto é novamente alterado em $t=0,15 \mathrm{~ms}$, devido à onda refletida pela outra extremidade da barra.

A oscilação presente no resultado é causada pelo método numérico devido à aproximação oferecida pelo algoritmo. Como não são implementados mecanismos dissipativos, como amortecimento rígido ou visco-elasticidade, o fenômeno permanece durante toda a análise. Neste caso, a pertubação não é causada por instabilidade numérica, mas, sim, devido a movimentos de alta frequência. A Figura 8.7 mostra os resultados obtidos pelo programa para a evolução do estado da estrutura em diferentes instantes de tempo. 


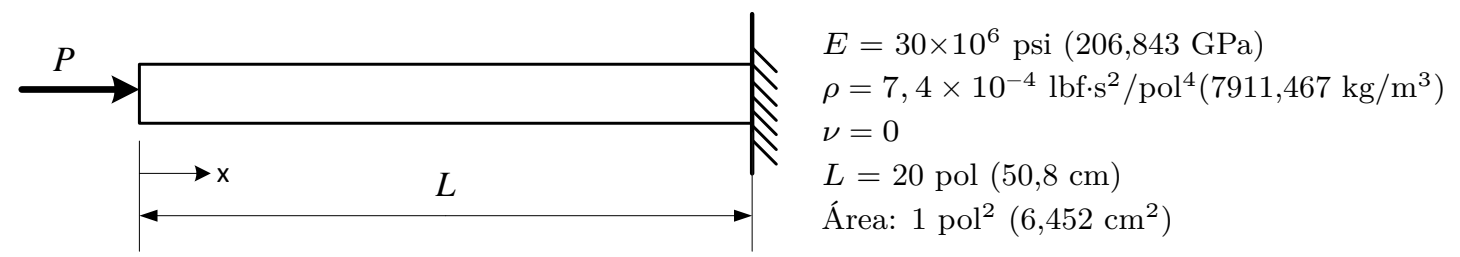

(a) Descrição do problema

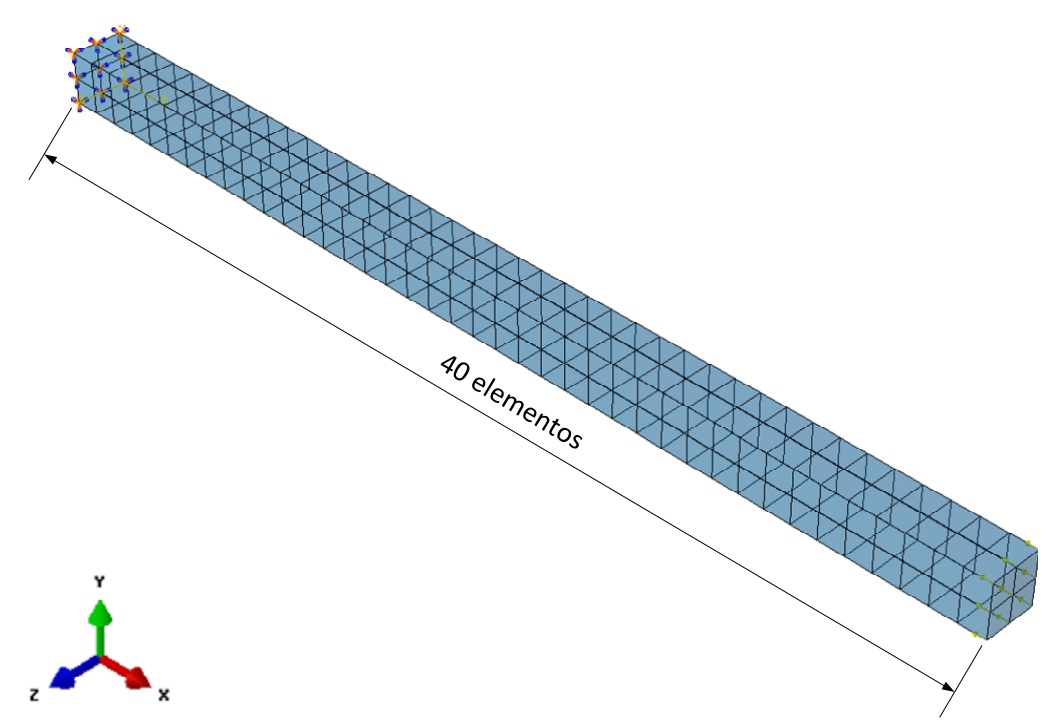

(b) Modelo de elementos finitos

Figura 8.5 Propagação de ondas numa barra de aço (baseado em Cook et al. [57]).

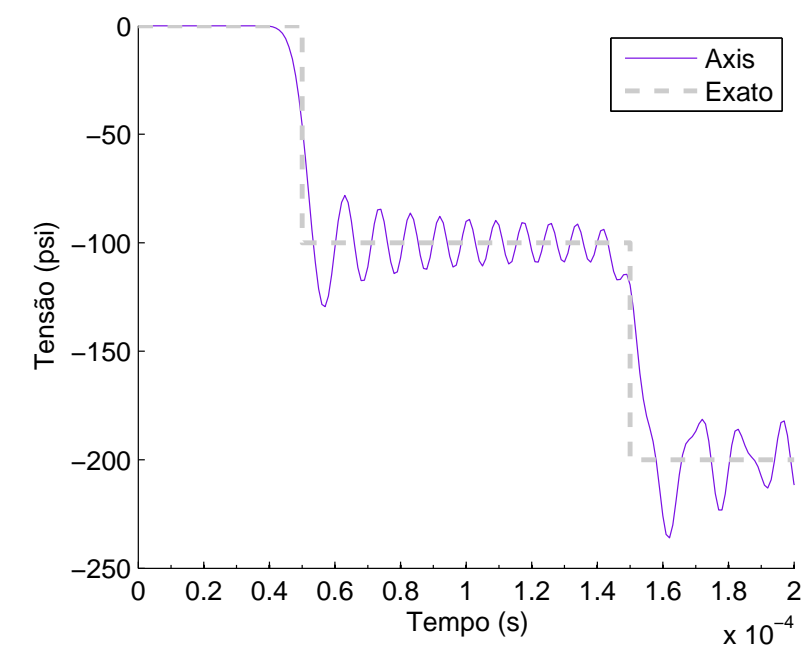

Figura 8.6 Histórico da tensão axial no ponto $x=9,75$ pol $(24,765 \mathrm{~cm})$ da barra. Resultado do programa obtido pela média das tensões dos elementos da seção que compreende o ponto. 


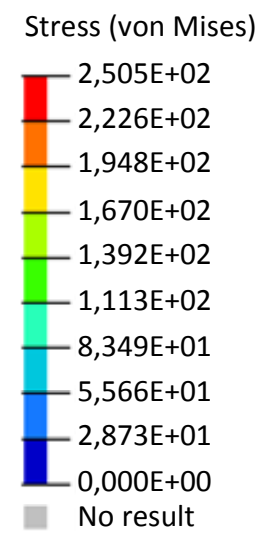

$\operatorname{Max}=2,505 \mathrm{E}+02$

PART-1-1 157

Min $=0,000 E+00$

PART-1-1 1

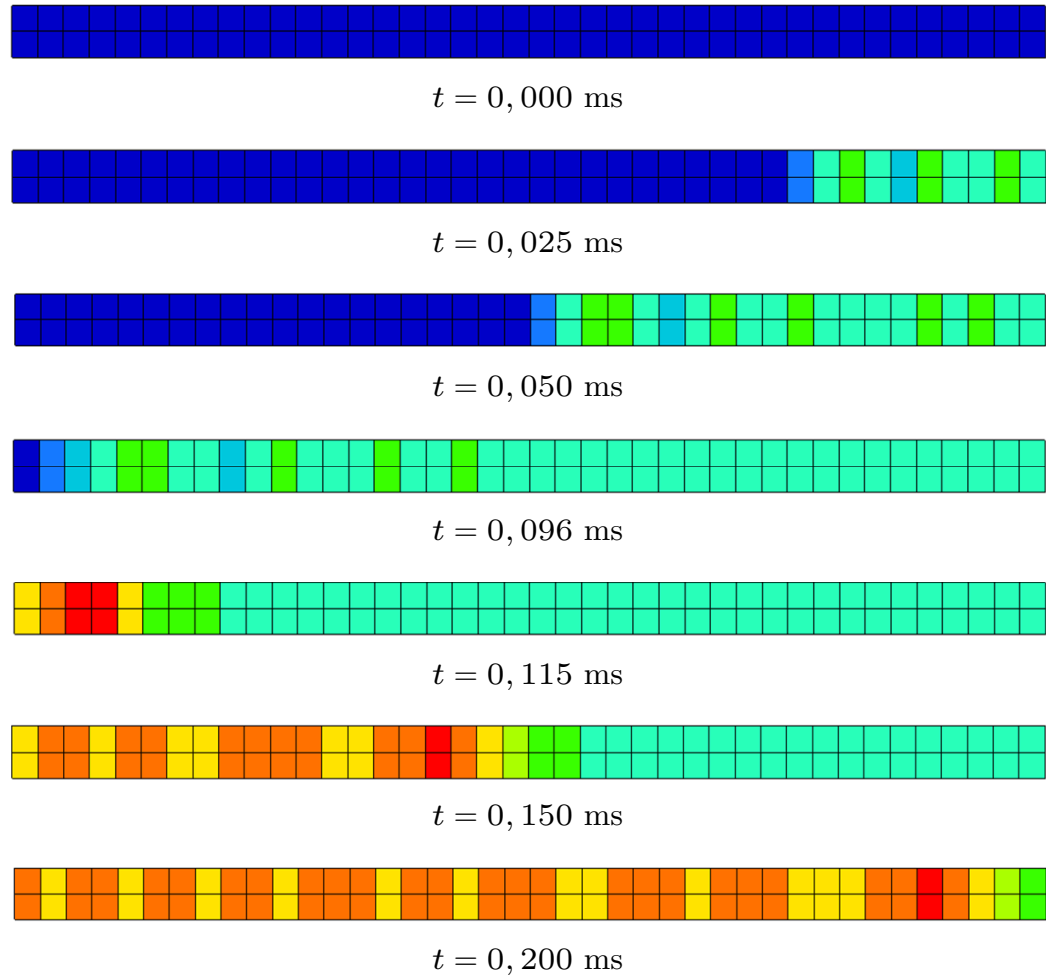

Figura 8.7 Estado da estrutura do Problema 5 em diferentes instantes de tempo. Pósprocessamento realizado no programa Altair Hyperworks.

\subsubsection{Problema 6: pulso de compressão}

Neste problema, uma barra engastada, discretizada por 10 elementos ao longo do comprimento (Figura 8.8), sofre um pulso de compressão na extremidade livre. O material é descrito pelo modelo linear elástico, cujos parâmetros são apresentados na figura. O método explícito é configurado para um incremento fixo de tempo, $\Delta t=1,0 \times 10^{-6} \mathrm{~s}$.

Os resultados são comparados contra a mesma simulação numérica executada no programa comercial ABAQUS [64], configurado para o uso dos métodos numéricos e formulações mais próximas das adotadas em Axis. A configuração utilizada é mostrada na Tabela 8.12 e é mantida para os demais problemas.

A Figura 8.9 mostra os resultados obtidos pelo programa Axis, comparados contra o resultado de referência do ABAQUS. A diferença relativa $\left(d_{R}\right)$ entre os valores é definida de maneira similar ao erro relativo, isto é, $d_{R}=\left(\left|\frac{x-v}{v}\right|\right)$. Na medição, foram desconsiderados intervalos onde a imprecisão numérica é dominante (ou seja, a magnitude do valor sendo medido é muito menor do que os erros de aproximação e truncamento). 


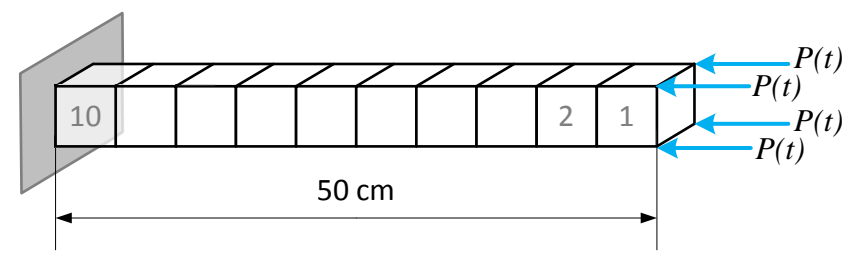

$$
\begin{aligned}
& E=200 \mathrm{GPa} \\
& \nu=0,3 \\
& \rho=7850 \mathrm{~kg} / \mathrm{m}^{3} \\
& \text { Área: } 25 \mathrm{~cm}^{2}(5 \times 5 \mathrm{~cm})
\end{aligned}
$$

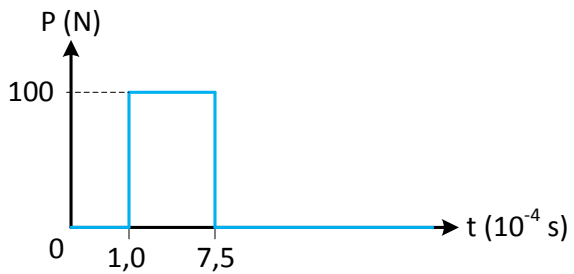

Figura 8.8 Descrição do Problema 6.

Tabela 8.12 Configurações gerais da simulação numérica executada no ABAQUS.

\begin{tabular}{lc}
\hline Parâmetro & Valor \\
\hline Configurações do elemento & C3D8R* \\
Tipo de elemento & Não \\
Controle de distorção & Rígido \\
Controle de hourglass & 0 (desativado) \\
Fator de escala do controle hourglass & 0,0 \\
Viscosidade volumétrica linear & 0,0 \\
Viscosidade volumétrica quadrática & \\
Configuraçães do passo & Desativado \\
Nigeom (não linearidade geométrica) & Fixo $\left(1 \times 10^{-6} \mathrm{~s}\right)$ \\
Incremento de tempo & 0 \\
Viscosidade volumétrica linear (global) & 0,0 \\
Viscosidade volumétrica quadrática (global) & \\
\hline *Hexaedro linear, integração reduzida &
\end{tabular}

Em relação ao pacote comercial, os valores para o deslocamento axial da extremidade livre e a tensão axial do elemento central da barra apresentaram boa convergência, com diferenças inferiores a $1 \%$.

Em algumas iterações de tempo, a velocidade e a aceleração calculadas pelo programa estão defasadas em relação à referência do ABAQUS. Com isso, a diferença entre os valores torna-se consideravelmente alta em casos isolados. Contudo, como é possível observar pelo histórico apresentado nos gráficos, essas discrepâncias não degradam significativamente a solução. 


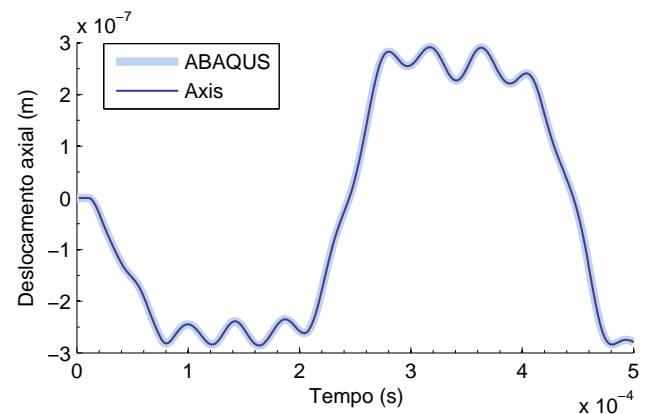

Diferença relativa

\begin{tabular}{ccc}
\hline Mínimo (\%) & Máximo (\%) & Médio (\%) \\
\hline 0,000 & 0,179 & 0,001
\end{tabular}

(a) Deslocamento axial na extremidade livre

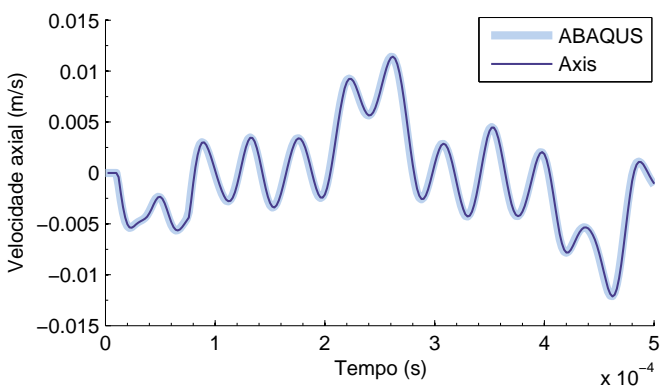

Diferença relativa

\begin{tabular}{ccc}
\hline Mínimo (\%) & Máximo (\%) & Médio (\%) \\
\hline 0,000 & 28,850 & 5,206 \\
\hline
\end{tabular}

(c) Velocidade axial na extremidade livre

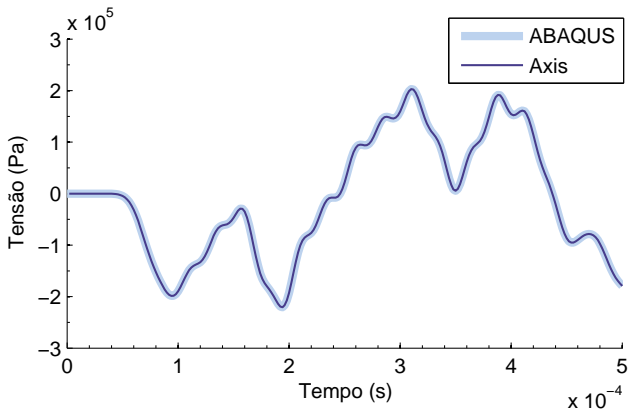

Diferença relativa

\begin{tabular}{ccc}
\hline Mínimo (\%) & Máximo (\%) & Médio (\%) \\
\hline 0,000 & 0,011 & 0,000 \\
\hline
\end{tabular}

(b) Tensão axial no elemento 6

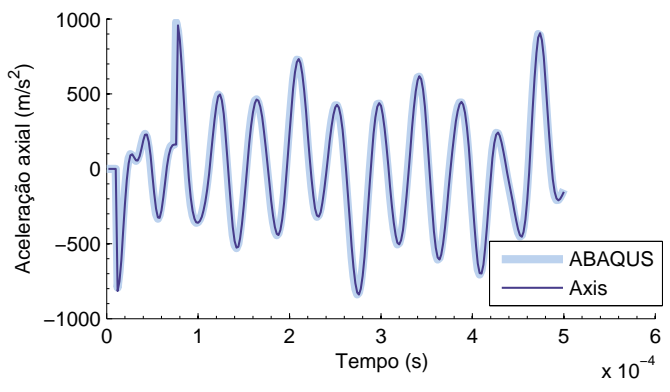

\begin{tabular}{ccc}
\multicolumn{3}{c}{ Diferença relativa } \\
\hline Mínimo (\%) & Máximo (\%) & Médio (\%) \\
\hline 0,000 & 37,751 & 8,959 \\
\hline
\end{tabular}

(d) Aceleração axial na extremidade livre

Figura 8.9 Comparação dos resultados obtidos no Problema 6.

\subsubsection{Problema 7: Prescrição de deslocamento}

Usando o modelo numérico do Problema 6, é prescrito o deslocamento axial da extremidade livre, em substituição à carga originalmente aplicada (Figura 8.10). Os resultados são comparados contra os obtidos pelo ABAQUS e mostrados na Figuras 8.11. Novamente, intervalos em que são predominantes erros de aproximação e de truncamento foram desconsiderados. 


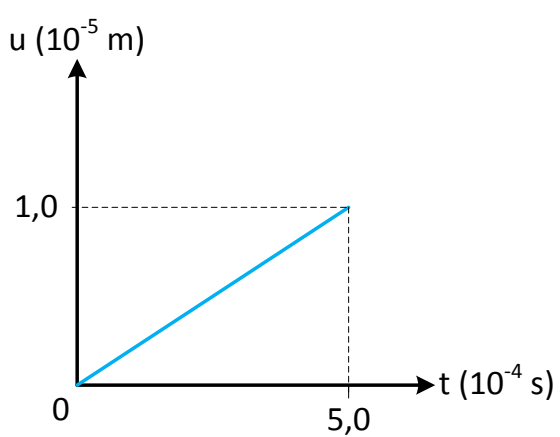

Figura 8.10 Deslocamento axial prescrito na extremidade livre da barra.

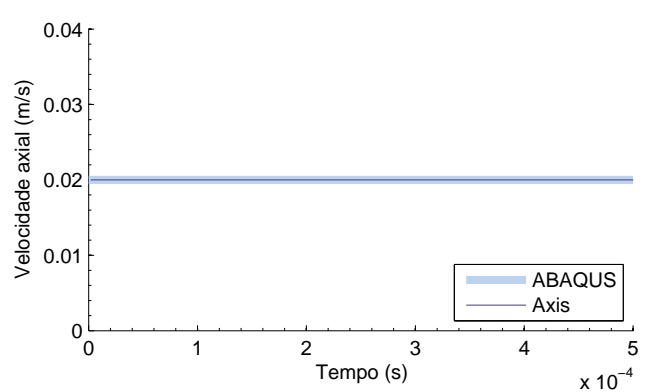

Diferença relativa

\begin{tabular}{ccc}
\hline Mínimo (\%) & Máximo (\%) & Médio (\%) \\
\hline 0,000 & 0,179 & 0,001 \\
\hline
\end{tabular}

(a) Velocidade axial na extremidade livre

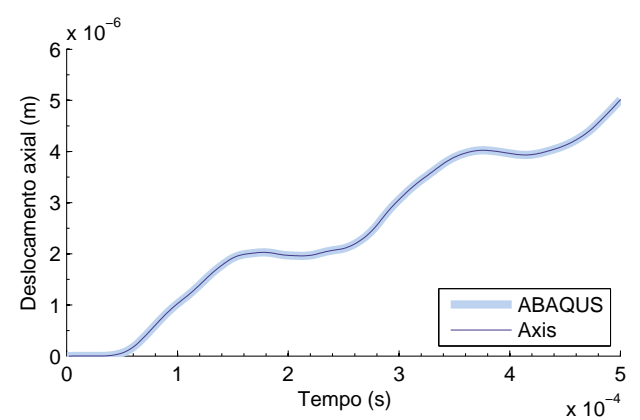

Diferença relativa

\begin{tabular}{ccc}
\hline Mínimo (\%) & Máximo (\%) & Médio (\%) \\
\hline 0,000 & 0,000 & 0,000
\end{tabular}

(c) Deslocamento axial na seção central do modelo

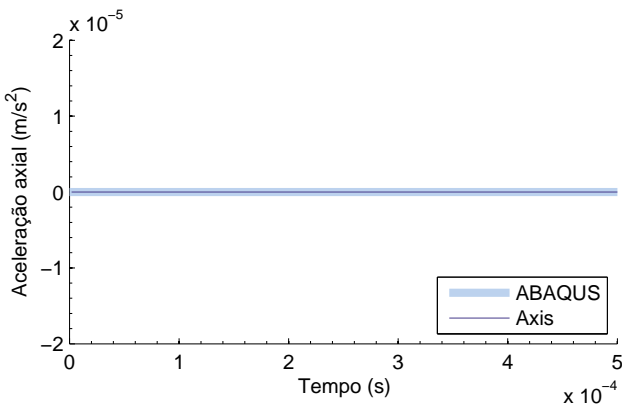

Diferença relativa

\begin{tabular}{ccc}
\hline Mínimo (\%) & Máximo (\%) & Médio (\%) \\
\hline 0,000 & 0,011 & 0,000 \\
\hline
\end{tabular}

(b) Aceleração axial na extremidade livre

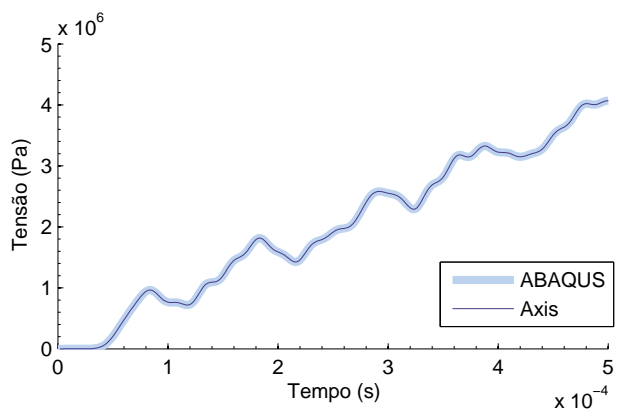

Diferença relativa

\begin{tabular}{ccc}
\hline Mínimo (\%) & Máximo (\%) & Médio (\%) \\
\hline 0,000 & 0,000 & 0,000 \\
\hline
\end{tabular}

(d) Tensão axial no elemento 6

Figura 8.11 Comparação dos resultados obtidos no Problema 7. 


\subsubsection{Problema 8: Prescrição de velocidade}

Num cenário alternativo ao problema anterior, a velocidade axial é prescrita nos nós da extremidade livre. A curva de velocidade é dada na Figura 8.12. A comparação dos resultados contra a solução comercial adotada é apresentada na Figura 8.13. Intervalos com predominância de erros numéricos foram desconsiderados.

\subsection{Formulação não-linear: validação do gradiente de deformação}

O gradiente de deformação é a medida principal para formulações não-lineares em elementos finitos. Por esta razão, é necessário verificar a acurácia de seu cálculo para minimamente validar a formulação do elemento e impedir a propagação de erros causados pela sua computação incorreta.

Bhatti [28] oferece um exemplo para o cálculo do gradiente de deformação a partir de valores conhecidos. O algoritmo para determinação de $\boldsymbol{F}$, incorporado no elemento C3D8RN, foi testado por meio de unidade de teste. Para este cenário, um elemento hexaédrico sofre uma translação rígida de $\left(u_{x}, u_{y}, u_{z}\right)=(2,1,2)$, uma rotação rígida de $30^{\circ}$ em torno do eixo $z$ e uma expansão volumétrica de razão 1,2. A configuração inicial e a atual do elemento são:

$$
\text { Config. inicial: }\left[\begin{array}{ccc}
0 & 0 & 0 \\
1 & 0 & 0 \\
1 & 1 & 0 \\
0 & 1 & 0 \\
0 & 0 & 1 \\
1 & 0 & 1 \\
1 & 1 & 1 \\
0 & 1 & 1
\end{array}\right] \text { Config. atual: }\left[\begin{array}{ccc}
2 & 1 & 2 \\
2+\frac{3 \sqrt{3}}{5} & \frac{2}{5} & 2 \\
\frac{13}{5}+\frac{3 \sqrt{3}}{5} & \frac{2}{5}+\frac{3 \sqrt{3}}{5} & 2 \\
\frac{13}{5} & 1+\frac{3 \sqrt{3}}{5} & 2 \\
2 & 1 & \frac{16}{5} \\
2+\frac{3 \sqrt{3}}{5} & \frac{2}{5} & \frac{16}{5} \\
\frac{13}{5}+\frac{3 \sqrt{3}}{5} & \frac{2}{5}+\frac{3 \sqrt{3}}{5} & \frac{16}{5} \\
\frac{13}{5} & 1+\frac{3 \sqrt{3}}{5} & \frac{16}{5}
\end{array}\right]
$$

O gradiente de deformação esperado é

$$
\boldsymbol{F}=\left[\begin{array}{ccc}
1,03923 & 0,6 & 0 \\
-0,6 & 1,03923 & 0 \\
0 & 0 & 1,2
\end{array}\right]
$$




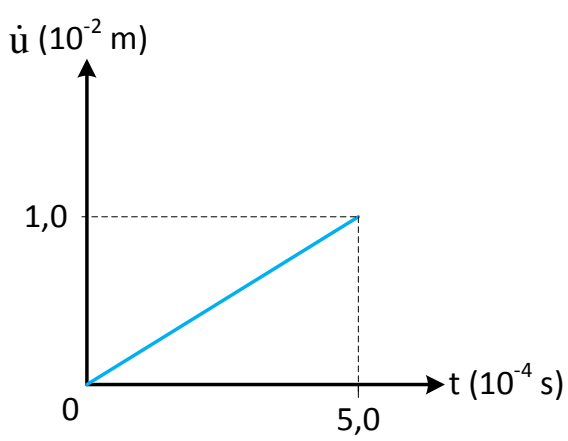

Figura 8.12 Velocidade axial prescrita na extremidade livre da barra.

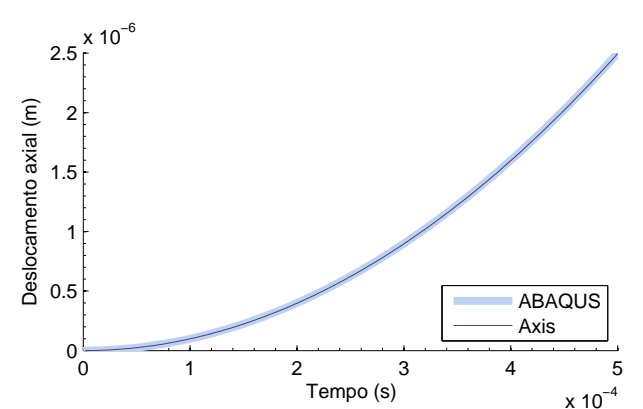

Diferença relativa

\begin{tabular}{ccc}
\hline Mínimo (\%) & Máximo (\%) & Médio (\%) \\
\hline 0,000 & 2,500 & 0,509
\end{tabular}

(a) Deslocamento axial na extremidade livre

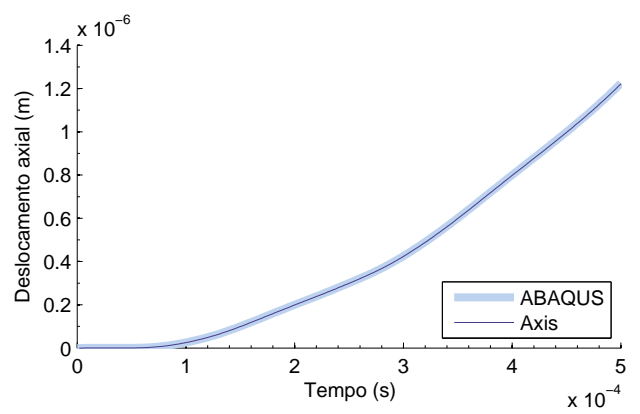

Diferença relativa

\begin{tabular}{ccc}
\hline Mínimo (\%) & Máximo (\%) & Médio (\%) \\
\hline 0,000 & 4,463 & 0,575 \\
\hline
\end{tabular}

(c) Deslocamento axial na seção central do modelo

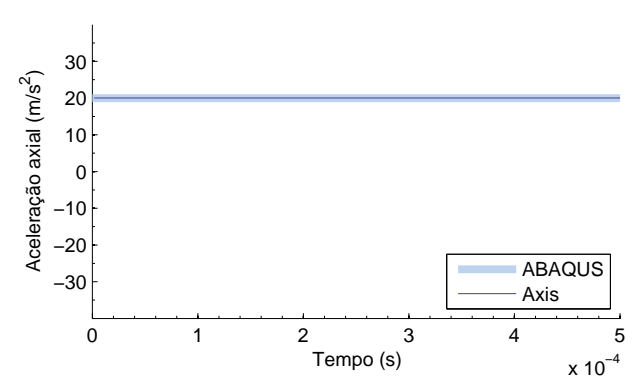

Diferença relativa

\begin{tabular}{ccc}
\hline Mínimo (\%) & Máximo (\%) & Médio (\%) \\
\hline 0,000 & 0,000 & 0,000 \\
\hline
\end{tabular}

(b) Aceleração axial na extremidade livre

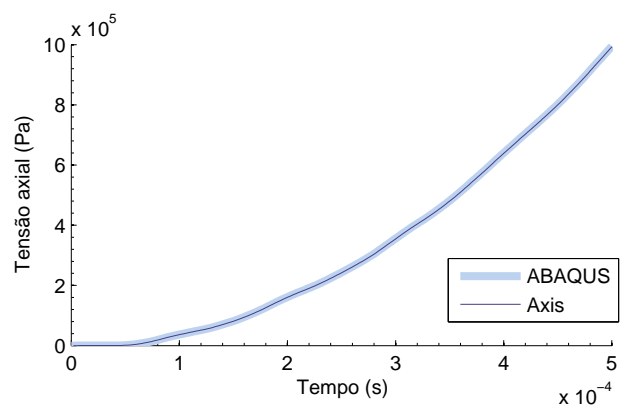

Diferença relativa

\begin{tabular}{ccc}
\hline Mínimo (\%) & Máximo (\%) & Médio (\%) \\
\hline 0,000 & 3,421 & 0,459 \\
\hline
\end{tabular}

(d) Tensão axial no elemento 6

Figura 8.13 Comparação dos resultados obtidos no Problema 8. 
A translação rígida não deve inteferir no valor de $\boldsymbol{F}$. Em contrapartida, a rotação rígida é sempre contabilizada e, dessa forma, o exemplo fornece uma maneira de verificar essas características no valor calculado pelo algoritmo. Para o programa Axis, $\boldsymbol{F}$ foi calculado corretamente, com erro absoluto inferior a $10^{-5}$ em cada componente, satisfatório para o teste (pois o valor das componentes de $\boldsymbol{F}$ na Eq. (8.3) estão truncados).

\subsection{Problemas não-lineares}

Da mesma forma que o solver dinâmico explícito, o suporte do programa à nãolinearidade do problema foi verificado a partir de pequenos testes, utilizando a formulação C3D8RN e um dos modelos de material não-linear. Os testes realizados são apresentados a seguir.

\subsubsection{Problema 9: Barra de borracha em tensão}

Neste teste, uma barra de borracha engastada, inicialmente em repouso, é tensionada axialmente por uma força com crescimento em rampa, com valor máximo de 800 N. A modelagem em elementos finito é mostrada na Figura 8.14. O modelo neoHookeano compressível é usado para a caracterização do material.
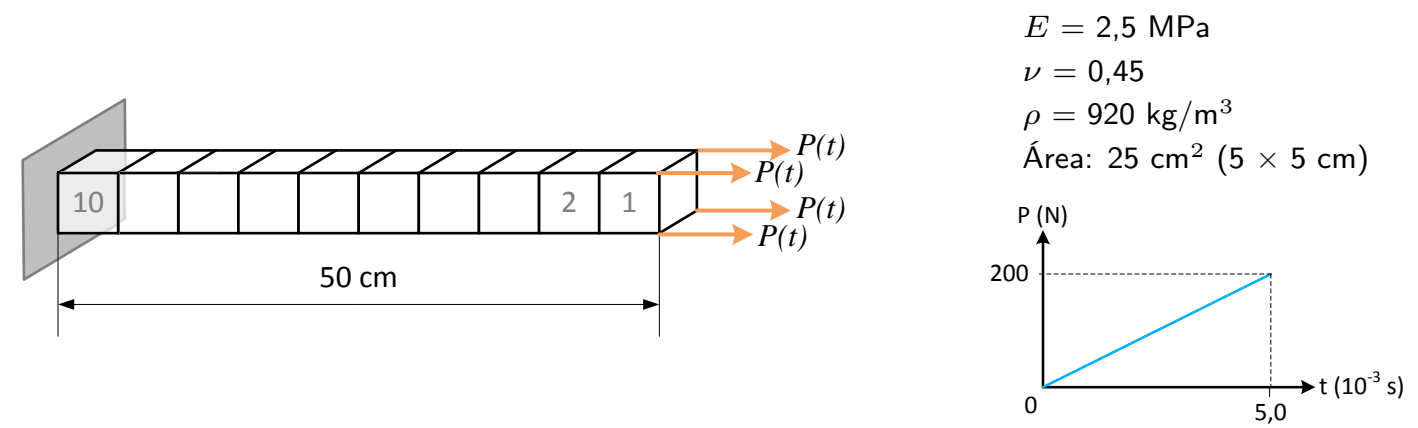

Figura 8.14 Modelo de elementos finitos para o Problema 9.

No ABAQUS, a opção NLGEOM foi ativada para a modelagem dos fenômenos não lineares geométricos. O sistema de controle do passo de tempo do programa é mais robusto e precisou ser substituído pela iteração fixa de tempo $\left(2,5 \times 10^{-6} \mathrm{~s}\right)$ para permitir uma comparação direta com o software em desenvolvimento. Por não haver detalhes suficientes sobre os métodos numéricos usados no pacote comercial na literatura, discrepâncias no comportamento ou valores obtidos pelos algoritmos são esperados. 


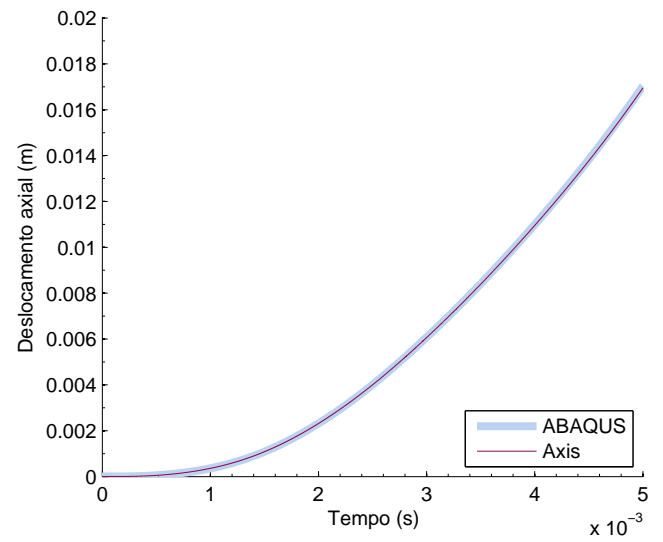

Diferença relativa

\begin{tabular}{ccc}
\hline Mínimo (\%) & Máximo (\%) & Médio (\%) \\
\hline 0,000 & 2,039 & 0,384
\end{tabular}

(a) Deslocamento axial na extremidade livre

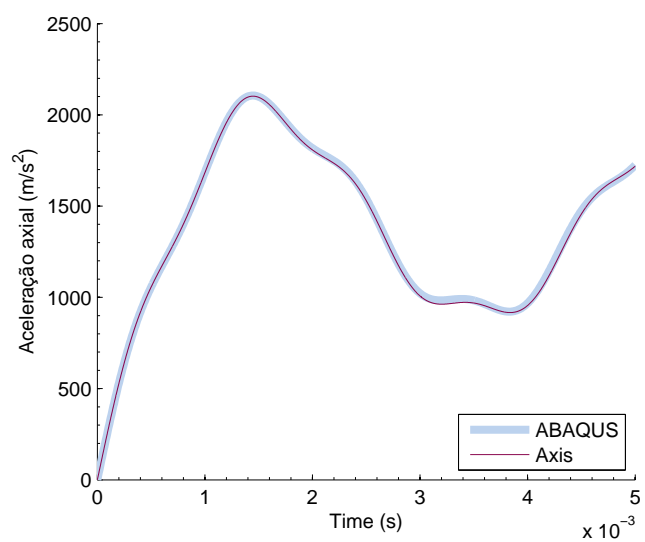

Diferença relativa

\begin{tabular}{ccc}
\hline Mínimo (\%) & Máximo (\%) & Médio (\%) \\
\hline 0,000 & 4,111 & 0,871
\end{tabular}

(c) Aceleração axial na extremidade livre

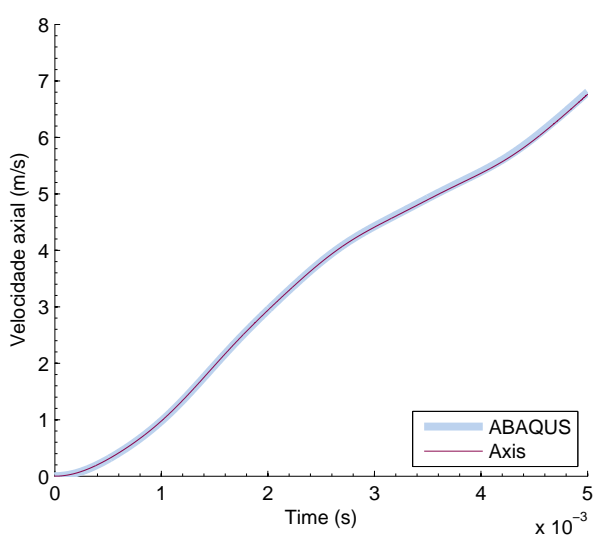

Diferença relativa

\begin{tabular}{ccc}
\hline Mínimo (\%) & Máximo (\%) & Médio (\%) \\
\hline 0,000 & 4,415 & 0,557 \\
\hline
\end{tabular}

(b) Velocidade axial na extremidade livre

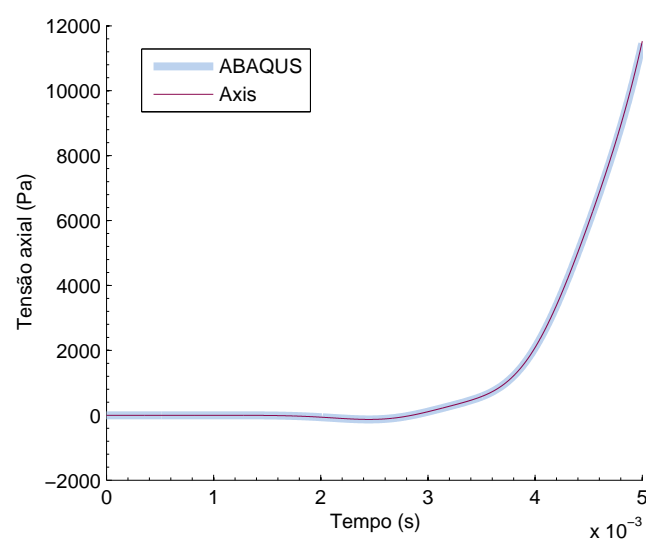

\begin{tabular}{ccc}
\multicolumn{3}{c}{ Diferença relativa } \\
\hline Mínimo (\%) & Máximo (\%) & Médio (\%) \\
\hline 0,000 & 0,934 & 0,240 \\
\hline
\end{tabular}

(d) Tensão axial no elemento 6

Figura 8.15 Comparação dos resultados obtidos no Problema 9.

Os resultados obtidos pelo programa, comparados contra o ABAQUS, são mostrados na Figura 8.15. Intervalos de dados cujos erros de aproximação e truncamento são inerentemente dominantes foram desconsiderados na medição. Para todos os casos, a diferença relativa se manteve abaixo de $1 \%$ na média.

Devido à baixa discretização, a tensão axial do elemento 6 sofre uma pequena instabilidade numérica no intervalo de tempo $0 \leq t \leq 3 \times 10^{-3} \mathrm{~s}$, sendo percebida em 
ambas as execuções da simulação, com diferentes amplitudes e variações no tempo. Por esta razão, valores compreendidos no intervalo não são contabilizados para a avaliação do algoritmo.

\subsubsection{Problema 10: Viga sob deformação plástica}

O problema da Figura 8.16 foi usado para a verificação do algoritmo de plasticidade, implementado na classe BiLinear Plasticity Model. Através deste teste, são validados os modelos hipo-elástico e o hipo-elasto-plástico, uma vez que o último faz uso da definição do primeiro. No modelo, uma parte simétrica de uma viga biengastada é discretizada por 10 elementos ao longo de seu comprimento. Uma carga dinâmica transversal é aplicada em seu centro, cujo comportamento é mostrado na figura, juntamente com os parâmetros do modelo de material.

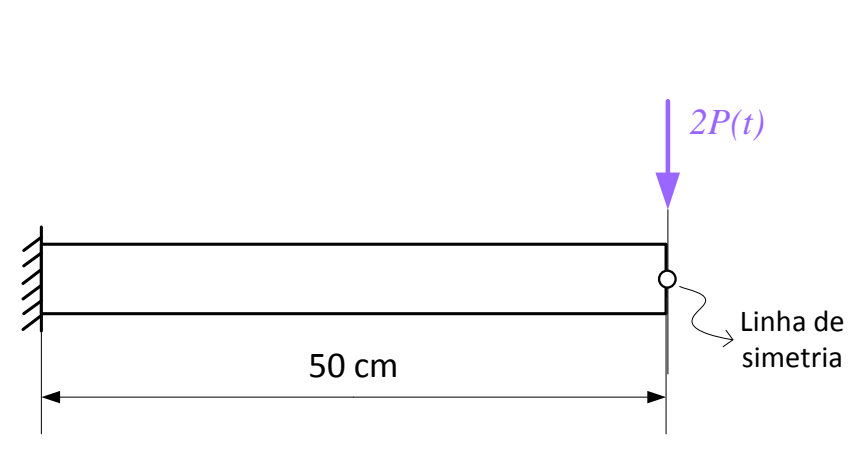

(a) Definição do problema
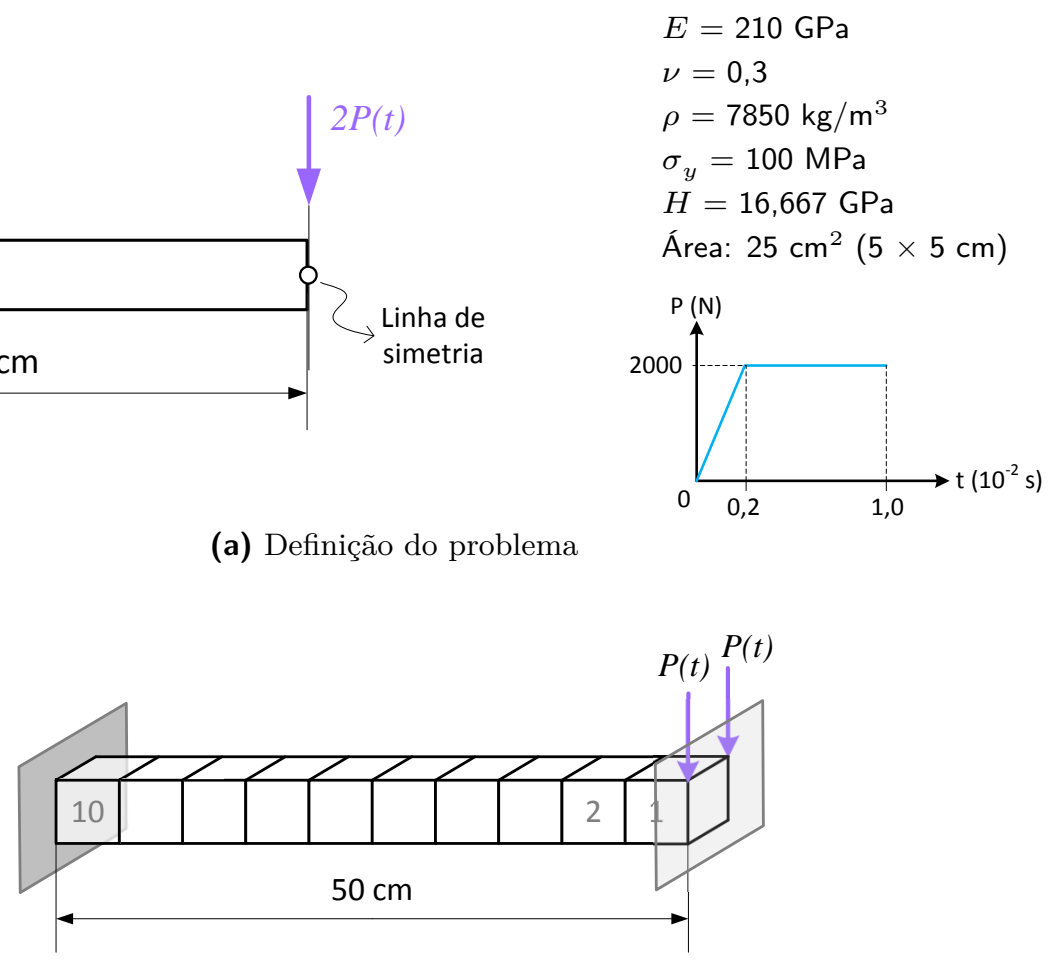

(b) Modelo numérico

Figura 8.16 Modelo de elementos finitos para o Problema 10.

Os resultados obtidos são mostrados na Figura 8.17. Como em todos os testes anteriores, intervalos com predominância de erros de aproximação foram desconsiderados. A aceleração apresentou maiores pertubações com no resultado, aumentando o valor da diferença relativa. Contudo, essas discrepâncias são localizadas, não inteferindo significativamente no comportamento geral da simulação. 


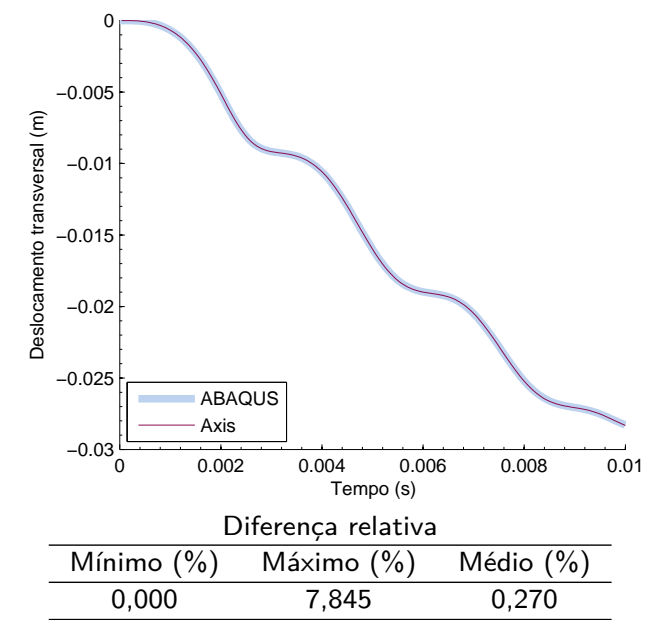

(a) Deslocamento transversal na extremidade livre

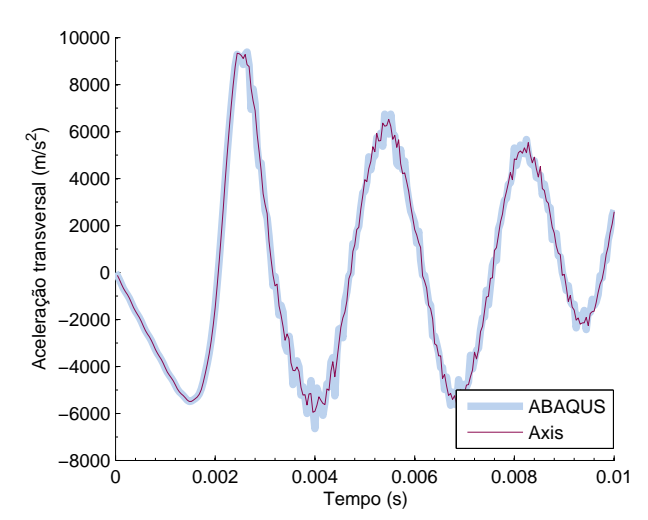

\begin{tabular}{ccc}
\multicolumn{3}{c}{ Diferença relativa } \\
\hline Mínimo (\%) & Máximo (\%) & Médio (\%) \\
\hline 0,000 & 48,813 & 8,025 \\
\hline
\end{tabular}

(c) Aceleração transversal na extremidade livre

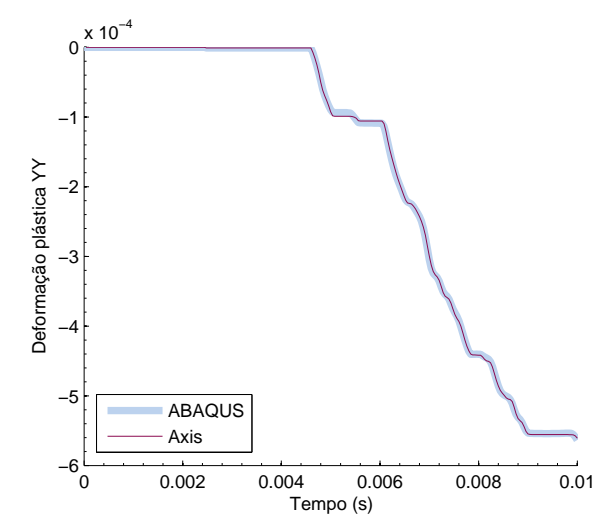

\begin{tabular}{ccc}
\multicolumn{3}{c}{ Diferença relativa } \\
\hline Mínimo (\%) & Máximo (\%) & Médio (\%) \\
\hline 0,000 & 8,884 & 1,312 \\
\hline
\end{tabular}

(e) Deformação plástica YY no elemento 1

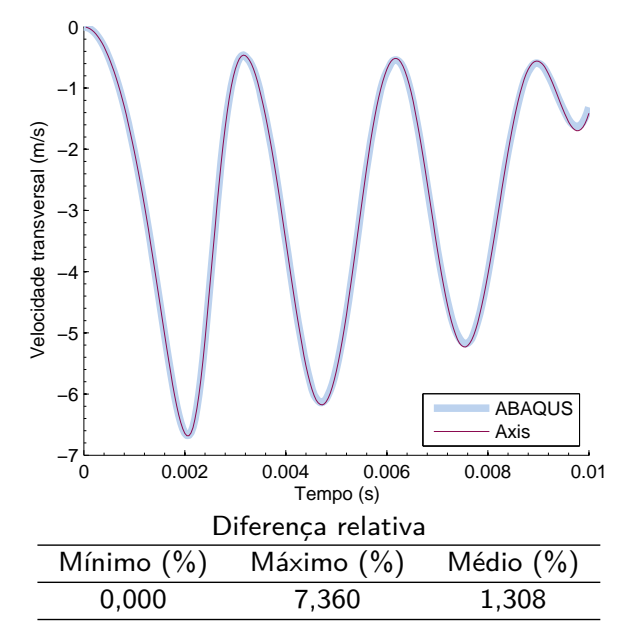

(b) Velocidade transversal na extremidade livre

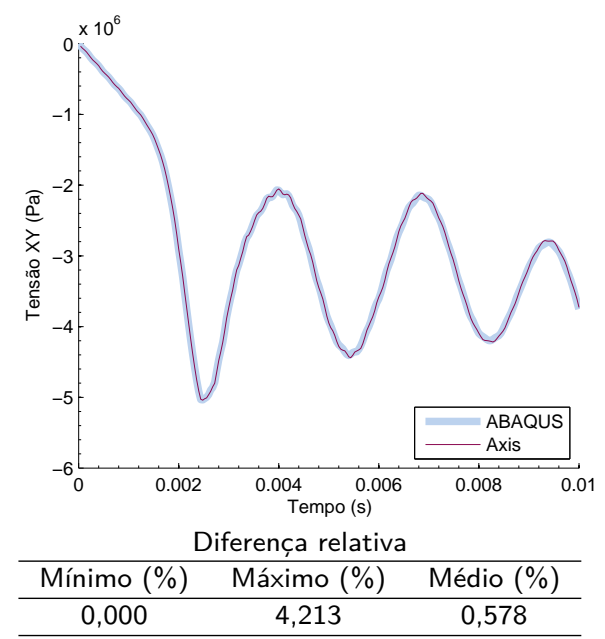

(d) Tensão cisalhante XY no elemento 1

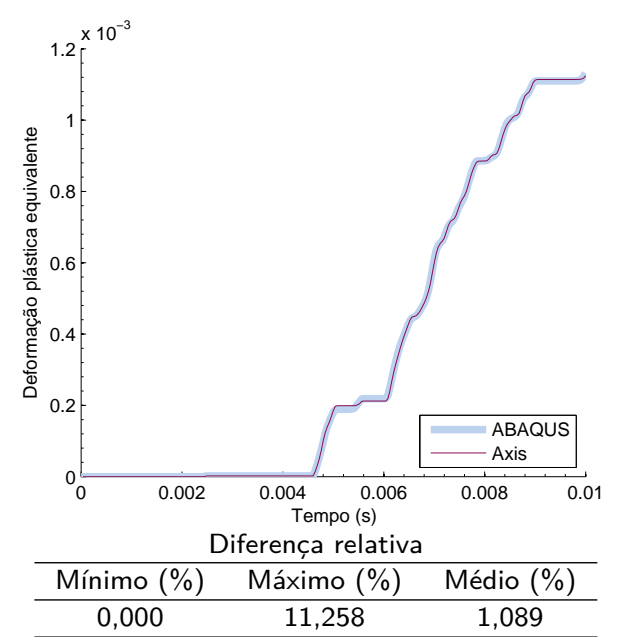

(f) Deformação plástica equivalente no elemento 1

Figura 8.17 Comparação dos resultados obtidos no Problema 10. 


\subsection{Simulações numéricas em GPU}

Para a medida de desempenho do programa, foram propostos dois cenários de testes. Nestas análises, não é ojetivo demonstrar as funcionalidades do programa, cabendo a discussão apenas sobre o comportamento do programa na utilização dos recursos computacionais. Comentários são feitos a partir dos resultados obtidos para o tempo de execução, padrão de ocupação da memória e utilização do dispositivo de processamento (CPU ou GPU), a partir do qual é traçado o speedup da GPU.

\subsubsection{Cenário A: Problema dinâmico linear}

Neste cenário, é proposto um problema dinâmico linear, cuja configuração é mostrada na Figura 8.18. A viga de seção quadrada é discretizada em cinco densidades de malha distintas, listadas na Tabela 8.13. Por se tratar de um problema linear, o incremento de tempo foi afixado em cada uma das configurações. Devido ao aumento da densidade de elementos e consequente redução do menor comprimento característico, o valor de $\Delta t$ foi reduzido para manter a estabilidade do algoritmo. Para o modelo, foi utilizada a formulação de elemento C3D8RL e o modelo de material linear elástico.
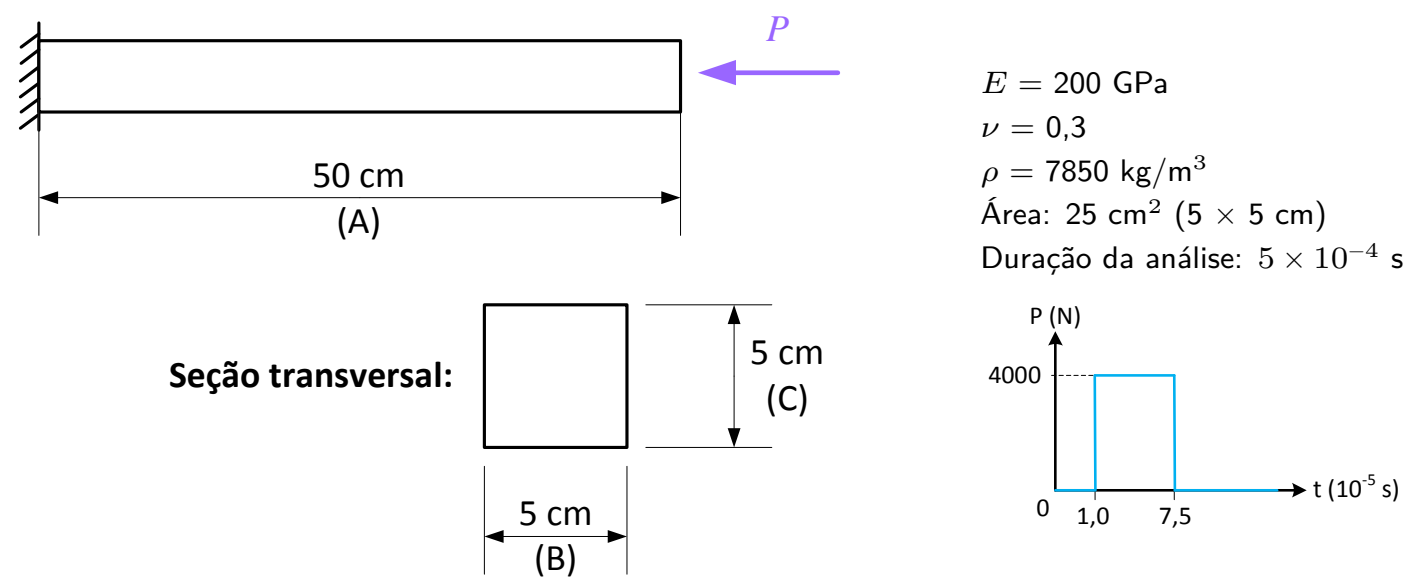

Figura 8.18 Problema dinâmico linear usado para avaliação de desempenho do Axis.

Antes de comparar o desempenho, os resultados produzidos na GPU foram comparados contra a mesma execução na CPU, a fim de certificar a acurácia dos cálculos realizados no dispositivo. A Figura 8.19 mostra o deslocamento axial de um dos nós da extremidade livre para o teste 3. Como é possível observar na figura, há uma boa concordância dos resultados, o que se manteve em todos os demais testes. 
Tabela 8.13 Configurações dos testes para o problema linear (Cenário A).

\begin{tabular}{|c|c|c|c|c|c|}
\hline \multirow{2}{*}{ Teste } & \multicolumn{3}{|c|}{ Densidade da malha em cada dimensão } & \multirow{2}{*}{$\begin{array}{l}\text { Número de } \\
\text { elementos }\end{array}$} & \multirow{2}{*}{$\Delta t\left(\times 10^{-7} \mathrm{~s}\right)$} \\
\hline & $\mathrm{A}$ & $\mathrm{B}$ & $\mathrm{C}$ & & \\
\hline 1 & 10 & 1 & 1 & 10 & 10,000 \\
\hline 2 & 40 & 4 & 4 & 640 & 2,500 \\
\hline 3 & 80 & 8 & 8 & 5120 & 1,250 \\
\hline 4 & 160 & 16 & 16 & 40960 & 0,625 \\
\hline 5 & 200 & 20 & 20 & 80000 & 0,500 \\
\hline
\end{tabular}

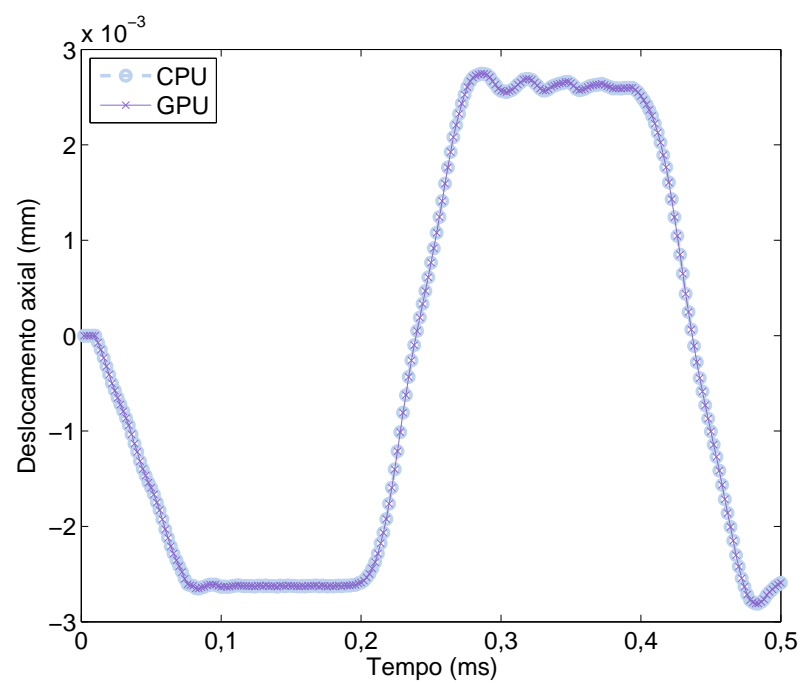

Figura 8.19 Deslocamento axial de nó da extremidade livre no Cenário A, Teste 3 (CPU e GPU).

Os testes de desempenho foram executados nos equipamentos cujas configurações foram mostradas nas Tabelas 4.2 e 4.3 na seção 4.6.4. O melhor desempenho de CPU foi medido na configuração S1 e é usada como referência na comparação de speedup da GPU. Detalhes dos hardwares gráficos envolvidos são mostrados na Tabela 8.14 .

A Figura 8.20 compara o tempo de execução das GPUs em relação à CPU de referência. Os valores são a média de três execuções para cada um dos testes enumerados na Tabela 8.13. Nota-se um ganho de desempenho pela GPU a partir de configurações de malha mais densas. Em cargas de trabalho menos intensas, a latência na transferência de dados para a memória da GPU se torna mais evidente. Além disso, a organização das estruturas de dados (coalescência) nas etapas anteriores ao despacho para o dispositivo gráfico é outro fator que penaliza o desempenho do programa nessas ocasiões. 
Tabela 8.14 Detalhes dos hardwares gráficos empregados nos testes.

\begin{tabular}{lccc}
\hline Parâmetros & D1 & D2 & S1 \\
\hline Processador & & & \\
Núcleos CUDA & 384 & 2304 & 448 \\
Frequência do núcleo gráfico $(\mathrm{MHz})$ & 822 & 863 & 1147 \\
Memória & & & \\
$\quad$ Capacidade (GB) & 1,0 & 3,0 & 3,0 \\
Frequência (MHz) & 2100 & 3004 & 1550 \\
Interface & GDDR5 & GDDR5 & GDDR5 \\
Largura da interface (bits) & 256 & 384 & 384 \\
Largura de banda (GB/s) & 128,0 & 288,4 & 148,0 \\
Arquitetura & & & \\
Tipo de arquitetura & Fermi & Kepler & Fermi \\
Versão de computação CUDA & 2.1 & 3.5 & 2.0 \\
Suporte a endereçamento unificado & Sim & Sim & Sim \\
Suporte a ECC & Não & Não & Sim \\
Modos de computação suportados & WDDM & WDDM & TCC \\
Interface de comunicação & PCI-E v2.0 & PCI-E v2.0 & PCI-E v2.0 \\
Características térmicas & & & \\
Potência de pico consumida $(\mathrm{W})$ & 170 & 250 & 225 \\
Temperatura máxima do núcleo $\left({ }^{\circ} \mathrm{C}\right)$ & 99 & 95 & $-{ }^{b}$ \\
\hline
\end{tabular}

${ }^{a}$ Apesar da placa gráfica suportar a interface PCI-E v3.0, a versão do barramento foi rebaixada devido a limitações da placa-mãe do sistema.

${ }^{b}$ Valor não fornecido pelo fabricante.

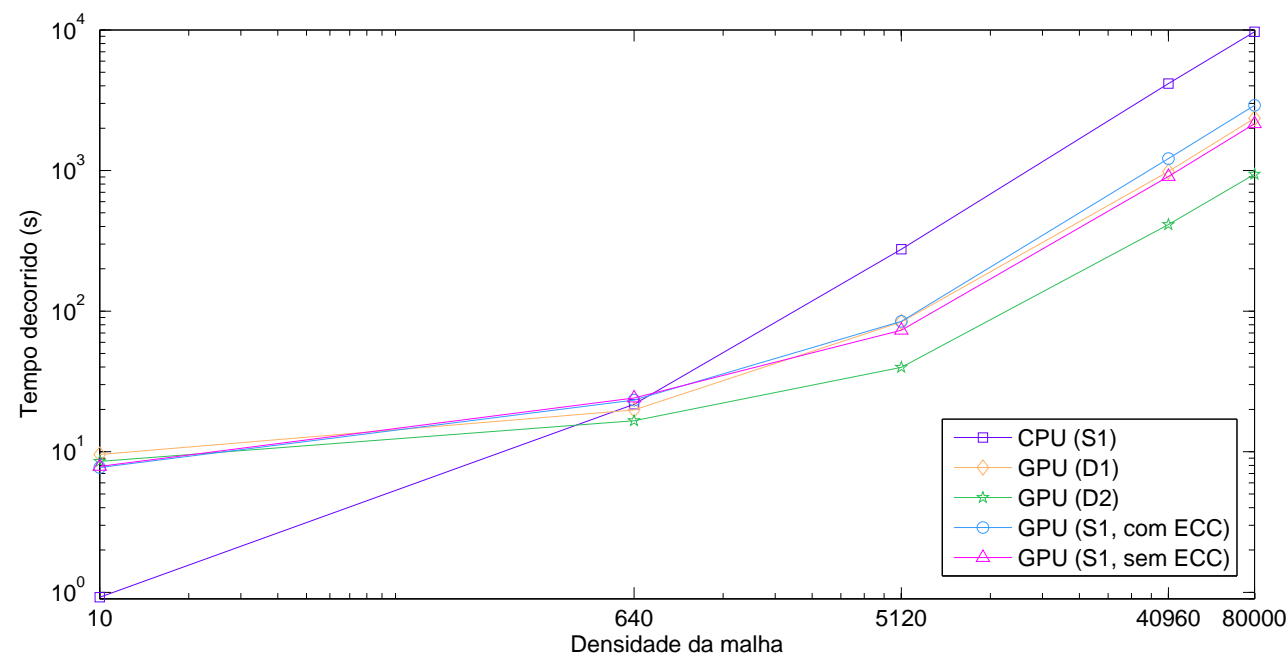

Figura 8.20 Cenário A: tempo de execução das GPUs em relação à configuração de referência. 
A placa gráfica usada na configuração S1 possui suporte à ECC (sigla inglesa para verificação e correção de erros). Essa tecnologia adiciona maior confiabilidade ao dispositivo, principalmente em situações de computação intensa. Contudo, a sua adoção implica em redução no desempenho geral do dispositivo, uma vez que bits de paridade precisam ser calculados em todas as transações da memória.

Com a finalidade de verificar o poder computacional máximo da GPU, as medidas de tempo foram feitas na presença e na ausência de ECC, conforme mostra a Figura 8.20. Desabilitando-a, a redução no tempo de execução é perceptível em malhas densas (a partir de 5120 elementos). Para o teste 3, obteve uma redução de $13,4 \%$. Nos testes 4 e 5 , a redução foi praticamente constante, com valores de $25,3 \%$ e 26,0\%, respectivamente. Não foram detectados erros na solução durante as execuções. Dessa forma, para manter maior clareza das discussões, optou-se por utilizar a configuração S1 apenas sem ECC.

O desempenho de D1 e S1 é bastante similar, o que é esperado, uma vez que utilizam a mesma arquitetura de GPU (Fermi) e são dispositivos de épocas de lançamento próximas (janeiro/2011 e julho/2011, respectivamente), o que implica em maior similaridade tecnológica. O hardware mais recente de D2 lhe permite obter maior velocidade de execução, sendo mais rápido que um sistema duplo processado de geração tecnológica anterior (S1). Até o momento da escrita deste documento, o laboratório em que foram desenvolvidos os testes não dispunha de CPU de geração equiparável para comparar o desempenho nesse sentido.

O speedup das placas gráficas, em relação à CPU de referência, é mostrado na Figura 8.21. Obteve-se um ganho máximo aproximado de 10 vezes para a configuração de malha mais densa no dispositivo mais recente. A redução no tempo é considerável, porém o speedup obtido é inferior ao relatado em outros trabalhos, onde o hardware é empregado para problemas de outra natureza [54, 143, 194, 226]. Uma das razões mais notórias é a falta de otimização do código de GPU. A redução no uso de registradores do multiprocessador, adoção de funções atômicas, além da própria melhoria geral do código são fatores que podem melhorar sensivelmente o ganho.

Por outro lado, o maior speedup possível pode ser limitado pelos aspectos inerentes do MEF, como o número de variáveis envolvidas e o acoplamento entre elas. Essas características podem reduzir as possibilidades de otimização do código. Verificar qual seria esse limite requer testes mais aprofundados e foge do escopo deste trabalho. Contudo, os resultados obtidos para análises não-lineares, mostrados na seção 8.7.2, podem fornecer maiores indicações de potenciais fatores limitantes. 


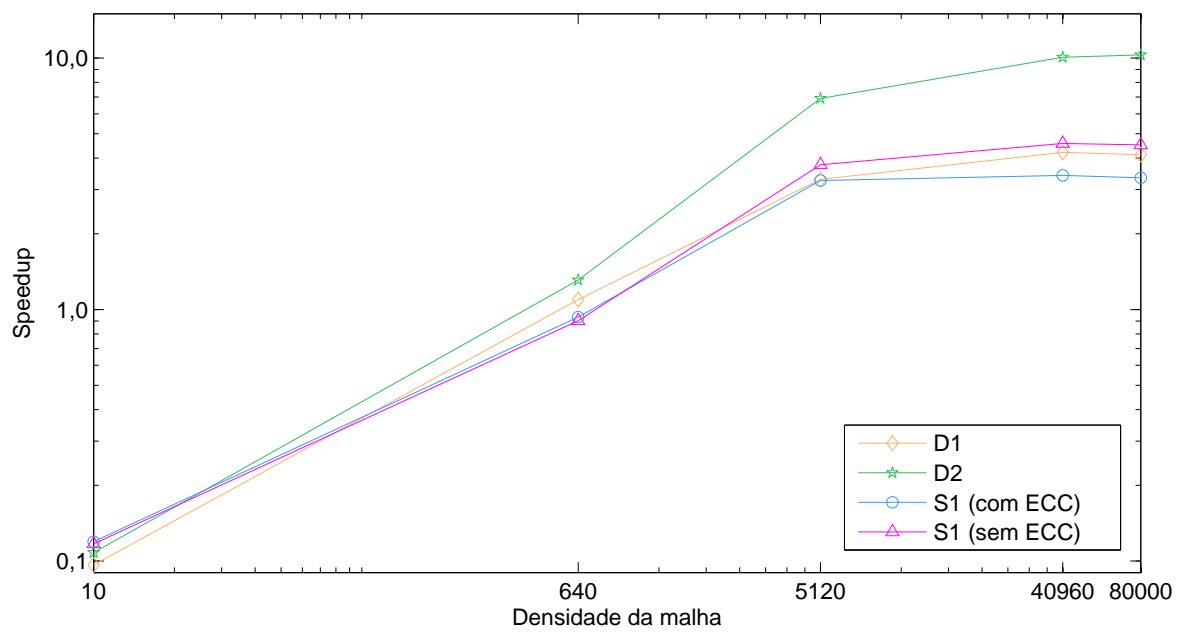

Figura 8.21 Speedup obtido para o Cenário A.

A configuração padrão das arenas de memória (Tabela 7.1) se mostrou apropriada para a resolução de todos os problemas. A Tabela 8.15 apresenta algumas estatísticas que sumarizam a utilização do recurso pelo programa, obtidas após a execução da análise e antes do início dos procedimentos de limpeza (liberação de recursos).

Foram detectados problemas na alocação de memória para tipos String (cadeias de caractere). Identificadores de entidades do modelo numérico, como o nome de conjuntos de nós e de elementos, são também alocados nesta arena de memória. Durante a leitura do arquivo de entrada, a alocação dos identificadores na arena causam todo o espaço anteriormente usado pelo analisadores sintáticos estar sujeito à liberação após o término da análise (pois este é o tempo de vida do identificador). Dessa forma, o espaço não é reciclado e a saturação da arena é iminente. Para resolver o problema, é possível alocar os identificadores na arena global ou transformá-lo em uma tipo de dados interno e alternativo (um UUID, por exemplo) e descartá-lo após sua leitura no arquivo de entrada.

A arena global apresente baixa utilização em todos os testes. Ainda assim, acredita-se que o espaço mínimo estipulado seja suficiente para as execuções. Como se trata de uma área de alocação de propósito geral, funcionalidades que possam ser adicionadas ao programa poderão aumentar o volume de objetos alocados na arena. Em grandes quantidades de elementos, como mostra o Teste 5, há a possibilidade da exaustão do espaço caso o valor padrão seja reduzido. O tamanho da área global representa uma parcela muito pequena do que há disponível em computadores desktop atuais (1\% dum total de 4 GB) e insignificante em relação à capacidade 
Tabela 8.15 Estatísticas de uso da arena de memória para o Cenário A.

\begin{tabular}{|c|c|c|c|c|c|}
\hline \multirow{2}{*}{ Estatística } & \multicolumn{5}{|c|}{ Teste } \\
\hline & $\# 1$ & $\# 2$ & $\# 3$ & $\# 4$ & $\# 5$ \\
\hline \multicolumn{6}{|l|}{ Arena String } \\
\hline Total alocado (KB) & 5000 & 11000 & 63000 & 449000 & 887000 \\
\hline Número de fragmentos (chunks) & 1 & 4 & 30 & 223 & 442 \\
\hline Maior espaço livre contíguo (KB) & 4113 & 1252 & 1775 & 1567 & 1576 \\
\hline Total de espaço livre (KB) & 4113 & 1252 & 1776 & 1571 & 1582 \\
\hline Espaço utilizado (KB) & 886 & 9744 & 61223 & 447428 & 885416 \\
\hline Percentual de ocupação (\%) & 17,72 & 88,58 & 97,18 & 99,64 & 99,82 \\
\hline \multicolumn{6}{|l|}{ Arena Modelo } \\
\hline Total alocado (KB) & 80000 & 80000 & 80000 & 200000 & 380000 \\
\hline Número de fragmentos (chunks) & 1 & 1 & 1 & 3 & 6 \\
\hline Maior espaço livre contíguo (KB) & 79934 & 76940 & 56468 & 15161 & 19328 \\
\hline Total de espaço livre (KB) & 79934 & 76940 & 56468 & 15161 & 20264 \\
\hline Espaço utilizado (KB) & 65 & 3059 & 23531 & 184838 & 359735 \\
\hline Percentual de ocupação (\%) & 0,08 & 3,82 & 29,41 & 92,41 & 94,66 \\
\hline \multicolumn{6}{|l|}{ Arena Global } \\
\hline Total alocado (KB) & 40000 & 40000 & 40000 & 40000 & 40000 \\
\hline Número de fragmentos (chunks) & 1 & 1 & 1 & 1 & 1 \\
\hline Maior espaço livre contíguo (KB) & 39998 & 39928 & 39426 & 35412 & 31039 \\
\hline Total de espaço livre (KB) & 39998 & 39928 & 39426 & 35412 & 31039 \\
\hline Espaço utilizado (KB) & 1 & 71 & 573 & 4587 & 8960 \\
\hline Percentual de ocupação (\%) & 0,00 & 0,17 & 1,43 & 11,46 & 22,40 \\
\hline
\end{tabular}

máxima em sistemas desse porte $(0,12 \%$ de 32 GB possíveis). Para servidores e clusters HPC, esse percentual é ainda menor.

Para a arena do modelo, é importante que haja pouca fragmentação interna, para evitar desperdício de memória na GPU, uma vez que esse dispositivo normalmente dispõe de quantidades inferiores do que há disponível no sistema. O maior espaço livre contíguo e o total de espaço disponível indicam a intensidade da fragmentação - ela é alta para valores bastante distantes. A fragmentação externa, isto é, o grau de dispersão da arena pela memória do sistema, deve ser mantido ao mínimo para evitar que transferências de memória excessivas ocorram entre CPU e GPU.

Nos testes realizados, a arena do modelo sofreu pouca fragmentação interna, se tornando evidente apenas em grandes quantidades de elementos (Teste 5). Ao mesmo tempo, a fragmentação externa é mínima ao considerar o volume de elementos e nós alocados em cada teste. Nas primeiras execuções, houve grande desperdício de espaço, com ocupação inferior a 50\%. Contudo, para aplicações reais, representadas pelos testes 4 e 5 , o tamanho da arena é adequada para a carga de trabalho. 
A imagem do programa representa uma parcela pequena do total de memória ocupado pelo Axis. Desconsiderando o espaço das arenas, código, metadados e estruturas de dados do software ocupam aproximadamente de 9309 KB. Pequenas variações podem ocorrer decorrentes da plataforma em que o programa é executado.

Durante a execução dos testes de GPU na configuração S1, foram coletadas estatísticas de desempenho no dispositivo e utilização da CPU do sistema, para verificar o correto direcionamento do processamento. Os resultados para alguns dos testes são mostrados na Figura 8.22. As leituras foram obtidas a intervalos de 5 segundos a partir de contadores de desempenho disponibilizados pelo driver do dispositivo. Não foi possível coletar estas informações nas outras configurações devido a limitações do driver dos respectivos dispositivos.

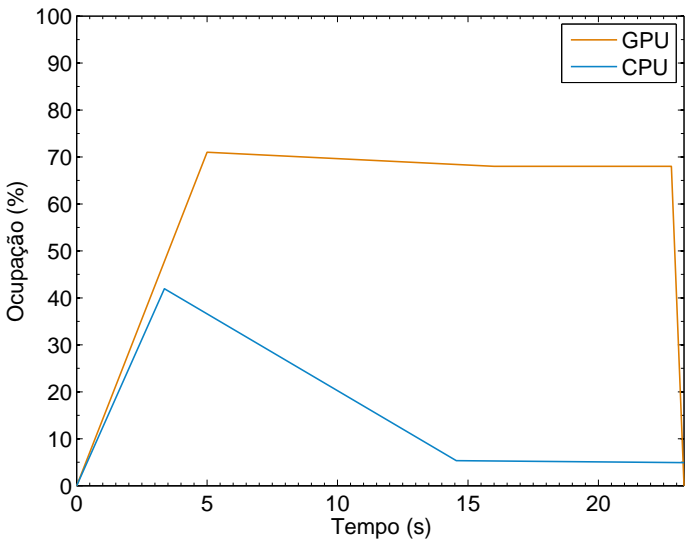

(a) Teste 2

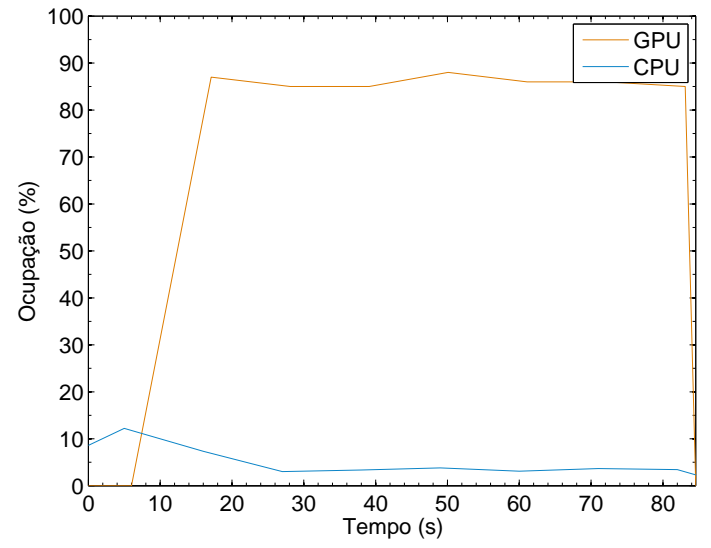

(b) Teste 3

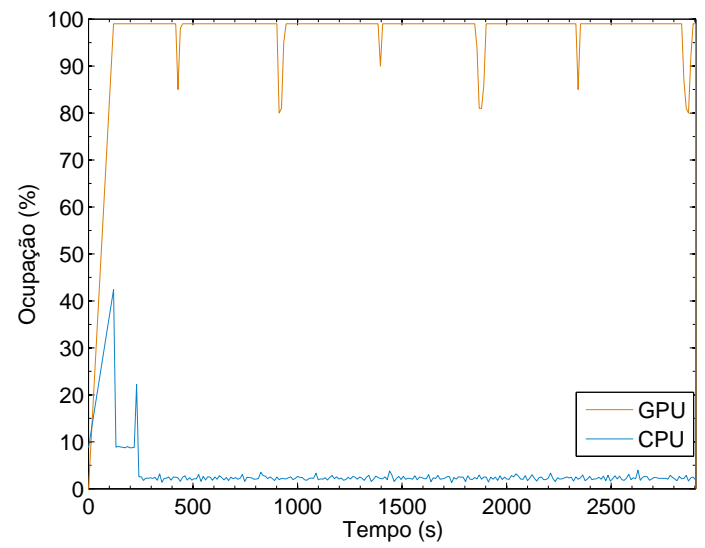

(c) Teste 5

Figura 8.22 Cenário A: ocupação dos dispositivos de processamento nos testes de GPU na configuração S1. 
No início da análise, há um maior uso da CPU, causado pela organização das estruturas de dados que serão usadas para gerenciar a GPU. A partir de então, o processador é praticamente mantido ocioso. O pouco posterior se limita apenas ao gerenciamento das tarefas no hardware gráfico, ao laço principal da análise (iteração de tempo), à coleta de resultados, entre outros.

Uma vez que é iniciada a ocupação da GPU, seu uso se mantém praticamente constante em todos os testes. É possível notar que em malhas pouco densas (Figuras $8.22 \mathrm{a}$ e $8.22 \mathrm{~b}$ ) a carga de trabalho não é suficiente para saturar o dispositivo, situação que só ocorreu nos testes 4 e 5.

\subsubsection{Cenário B: Problema dinâmico não-linear}

O problema dinâmico não-linear é dado por uma viga de borracha sob tração, cuja configuração é mostrada na Figura 8.23. Da mesma forma que no cenário anterior, a estrutura é discretizada em cinco densidades de malha distintas, listadas na Tabela 8.16. Por questões de tempo, o controle do passo de tempo foi implementado apenas para execução em CPU. Dessa forma, o valor de $\Delta t$ foi mantido constante em todas as execuções (em CPU e em GPU), conforme mostra a tabela. Para o modelo, foi utilizada a formulação de elemento C3D8RN e o modelo de material neo-Hookeano.

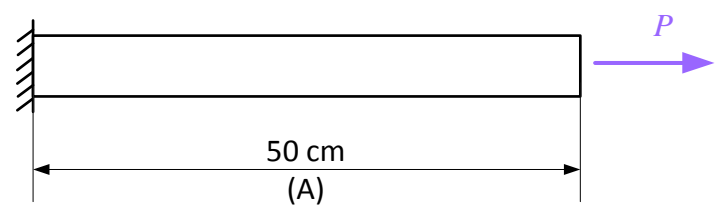

$$
\begin{aligned}
& E=2,5 \mathrm{MPa} \\
& \nu=0,45 \\
& \rho=920 \mathrm{~kg} / \mathrm{m}^{3} \\
& \text { Área: } 25 \mathrm{~cm}^{2}(5 \times 5 \mathrm{~cm})
\end{aligned}
$$$$
\text { Duração da análise: } 5 \times 10^{-3} \mathrm{~s}
$$
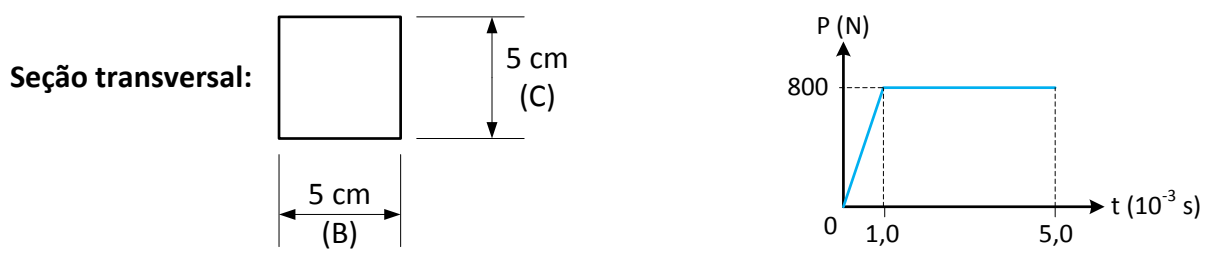

Figura 8.23 Problema dinâmico não-linear usado para avaliação de desempenho do Axis.

Neste cenário, foram utilizados os mesmos equipamentos e configurações apresentadas na seção 8.7.1. Para validar o código em GPU, o teste 3 foi executado em ambos os ambientes de processamento. O resultado do deslocamento axial de um dos nós da extremidade livre, obtido em ambas as execuções, é comparado na Figura 8.24. Em relação à CPU, os resultados da GPU apresentam boa concordância, com erros numéricos desprezíveis, ocorrendo em poucas ocasiões e apenas nos dois últimos dígitos menos significativos da mantissa do ponto flutuante. 
Tabela 8.16 Configurações dos testes para o problema não-linear (Cenário B).

\begin{tabular}{ccccccc}
\hline \multirow{2}{*}{ Teste } & \multicolumn{2}{c}{ Densidade da malha em cada dimensão } & & Número de & \multirow{2}{*}{ elementos } & $\Delta t\left(\times 10^{-8} \mathrm{~s}\right)$ \\
\cline { 2 - 4 } & $\mathrm{A}$ & $\mathrm{B}$ & $\mathrm{C}$ & 1 & 10 & 25,000 \\
1 & 10 & 1 & 4 & 640 & 12,500 \\
2 & 40 & 8 & 8 & 5120 & 6,250 \\
3 & 80 & 16 & 16 & 40960 & 3,125 \\
4 & 160 & 20 & 20 & 80000 & 1,000 \\
5 & 200 & & & & \\
\hline
\end{tabular}

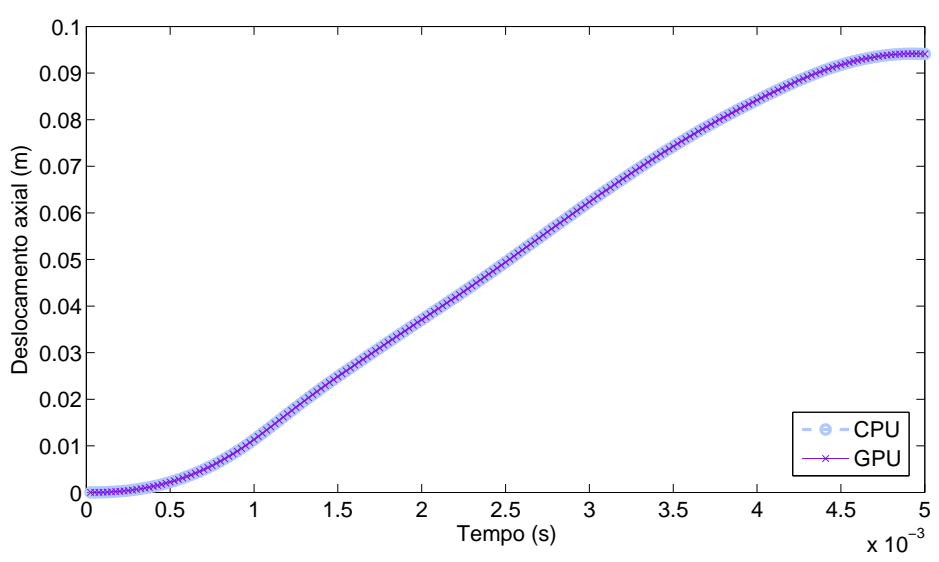

Figura 8.24 Deslocamento axial do nó da extremidade livre no Cenário B, Teste 3 (CPU e GPU).

O tempo de execução obtido nos testes é mostrado na Figura 8.25. Novamente, o tempo de execução em CPU na configuração S1 é apresentado para referência. Os valores são a média de três execuções para cada um dos testes.

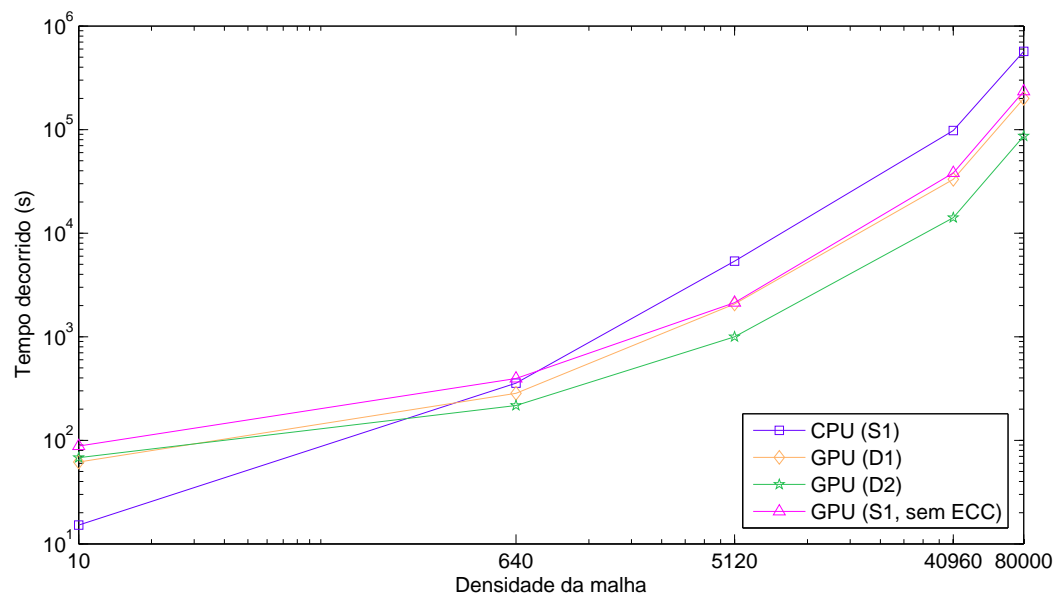

Figura 8.25 Cenário B: tempo de execução das GPUs em relação à configuração de referência. 
Devido ao maior número de iterações e ao número de computações em cada uma delas, o tempo de execução neste cenário é expressivamente maior. Repetindo o ocorrido no cenário anterior, em cargas menores de tabalho, a latência da transferência de dados e da preparação das estruturas de dados para coordenação da GPU torna-se mais evidente, degradando o desempenho do programa nesses casos.

Para o problema não-linear proposto, notou-se uma queda do speedup da GPU, como mostra a Figura 8.26. A configuração D2 apresenta o melhor speedup, com valor máximo de 6.93 para o teste 4 e patamar similar para o teste 5 (6.58). Contudo, é importante ressaltar que D2 (GPU) e S1 (CPU) são dispositivos de gerações tecnológicas distintas. Por outro lado, D1 (GPU) e S1 (GPU), de mesma geração, não obtiveram ganhos expressivos, alcançando valores máximos entre 2.51 a 2.85 .

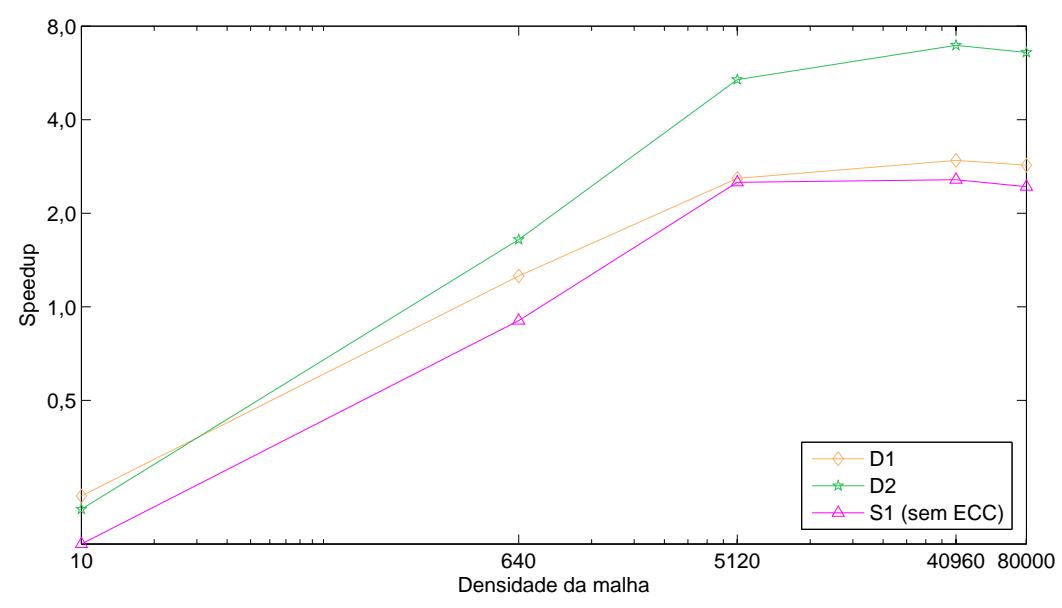

Figura 8.26 Speedup obtido para o Cenário B.

Em problemas de grandes deformações, o número de variáveis envolvidas é maior, requerendo maior quantidade de registradores e memória local por thread do dispositivo. Consequentemente, devido à arquitetura do dispositivo, a capacidade de paralelização da GPU diminui em favor da disponibilidade de espaço de memória por thread.

Além disso, a falta de otimização do código tem um impacto mais severo neste problema, pois a falta de localidade das informações numa thread (isto é, a cópia de informações na memória global para a a área local da thread) e a ausência de reciclagem dos registradores reduzem significativamente o desempenho do código.

O número de variáveis envolvidas neste tipo de problema pode reduzir a efetividade da otimização do código. Se, por exemplo, fosse levado em conta fenômenos mecânicos adicionais, como falha e contato, melhorias significativas no programa po- 
derão não trazer grandes benefícios, pois o acoplamento de informações localizadas em outras entidade do MEF, como modelo de material e dependência da formulação utilizada, impedem uma maior redução no consumo de registradores e tornam a localidade dos dados mais difícil.

O consumo de memória para o Cenário B é apresentado na Tabela 8.17. O problema de vazamento de memória no sistema de leitura do arquivo de entrada se torna evidente com estes testes, uma vez que são utilizados analisadores sintáticos diferentes para este caso (pois a formulação do elemento e o modelo de material são distintos).

Tabela 8.17 Estatísticas de uso da arena de memória para o Cenário B.

\begin{tabular}{lccccc}
\hline \multirow{2}{*}{ Estatística } & \multicolumn{5}{c}{ Teste } \\
\cline { 2 - 6 } & $\# 1$ & $\# 2$ & $\# 3$ & $\# 4$ & $\# 5$ \\
\hline Arena String & 5000 & 11000 & 63000 & 449000 & 887000 \\
$\quad$ Total alocado (KB) & 1 & 4 & 30 & 223 & 442 \\
Número de fragmentos (chunks) & 4103 & 1244 & 1621 & 1557 & 1565 \\
Maior espaço livre contíguo (KB) & 4103 & 1245 & 1623 & 1562 & 1572 \\
Total de espaço livre (KB) & 896 & 9754 & 61376 & 447437 & 885427 \\
Espaço utilizado (KB) & 17,92 & 88,68 & 97,42 & 99,65 & 99,82 \\
Percentual de ocupação (\%) & & & & & \\
Arena Modelo & 80000 & 80000 & 80000 & 200000 & 380000 \\
Total alocado (KB) & 1 & 1 & 1 & 3 & 6 \\
Número de fragmentos (chunks) & 79932 & 76756 & 54994 & 3364 & 4264 \\
Maior espaço livre contíguo (KB) & 79932 & 76756 & 54994 & 3364 & 4264 \\
Total de espaço livre (KB) & 67 & 3243 & 25005 & 196635 & 375735 \\
Espaço utilizado (KB) & 0,08 & 4,05 & 31,25 & 98,31 & 98,88 \\
Percentual de ocupação (\%) & & & & & \\
Arena Global & 40000 & 40000 & 40000 & 40000 & 40000 \\
Total alocado (KB) & 1 & 1 & 1 & 1 & 1 \\
Número de fragmentos (chunks) & 39998 & 39917 & 39344 & 34756 & 30452 \\
Maior espaço livre contíguo (KB) & 39998 & 39917 & 39344 & 34756 & 30452 \\
Total de espaço livre (KB) & 1 & 82 & 655 & 5243 & 9547 \\
Espaço utilizado (KB) & 0,00 & 0,20 & 1,63 & 13,10 & 23,87 \\
Percentual de ocupação (\%) & & & & &
\end{tabular}

Praticamente, o nível de fragmentação interna e externa nas arenas foi preservado em relação ao Cenário A. Como se trata de um problema com elemento e modelo de material simples, nota-se que a implementação de não-linearidade não aumenta significamente o consumo de memória. 
A Figura 8.27 mostra a ocupação dos dispositivos de processamento na execução em GPU dos testes deste cenário. Os valores foram coletados para a configuração S1. O método de coleta e as limitações encontradas no Cenário A também se aplicam.

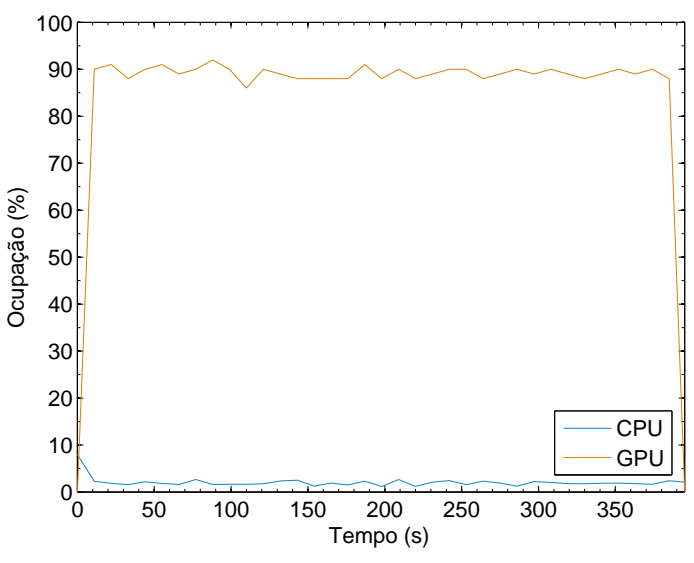

(a) Teste 2

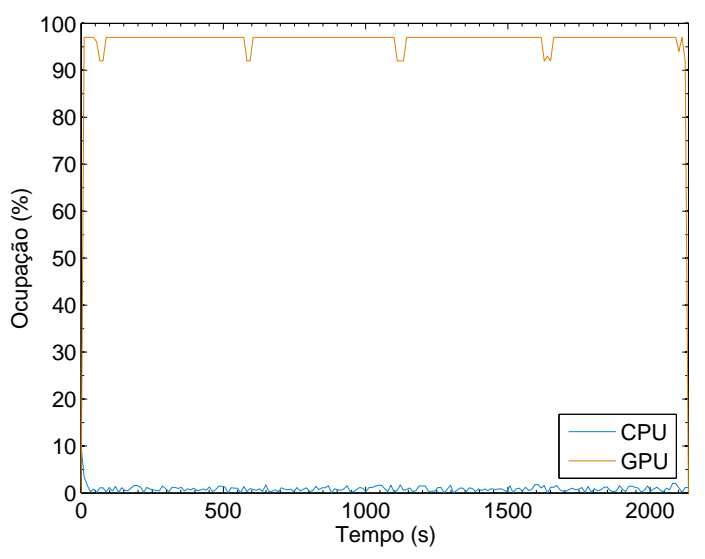

(b) Teste 3

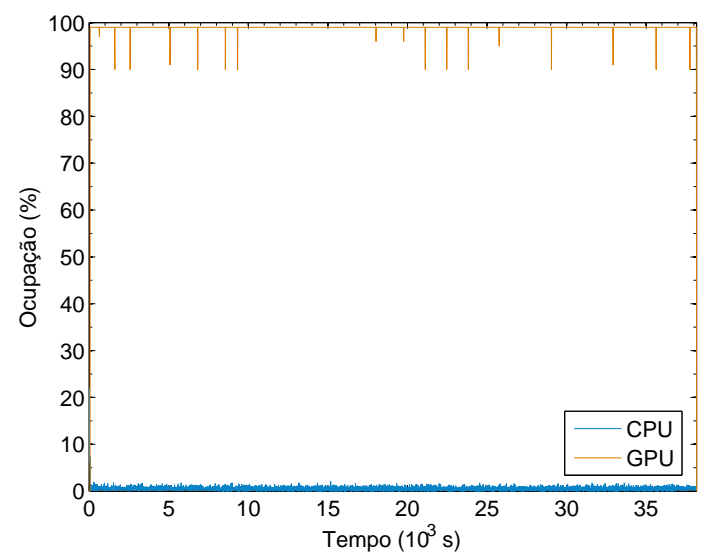

(c) Teste 4

Figura 8.27 Cenário 2: ocupação dos dispositivos de processamento nos testes de GPU na configuração S1.

Nota-se a ocupação quase que completa do dispositivo logo em densidades de malha mais baixas. Ainda que, para não-linearidade, exista um maior número de cálculos a serem realizados, na implementação do Axis, eles não influenciam na ocupação do dispositivo, isto porque o número de threads é determinado unicamente pelo número de elementos (para tarefas da classe Model Facade) ou o total de graus de liberdade no modelo (para tarefas da classe Solver Facade). O maior número de computações exigidas pelas classes não-lineares apenas aumentam o volume de trabalho das threads (isto é, o tempo gasto para executar a thread). 
A ocupação mais rápida da GPU pode ser explicada pelo maior consumo da memória local dos multiprocessadores pelas threads. Com a maior necessidade de memória das threads, cada multiprocessador passa a ser capaz de executar um menor número de threads, reduzindo a vazão de processamento máximo da GPU. É possível observar que o dispositivo é saturado em configurações de malha menores e, com isso, a aceleração adquirida com a adoção do hardware passa a ser menor.

\subsubsection{Comparação de desempenho com software comercial}

Os melhores tempos de execução para os Cenários A e B são comparados contra a execução dos mesmos problemas no software comercial ABAQUS. Os resultados são mostrados na Figura 8.28 .

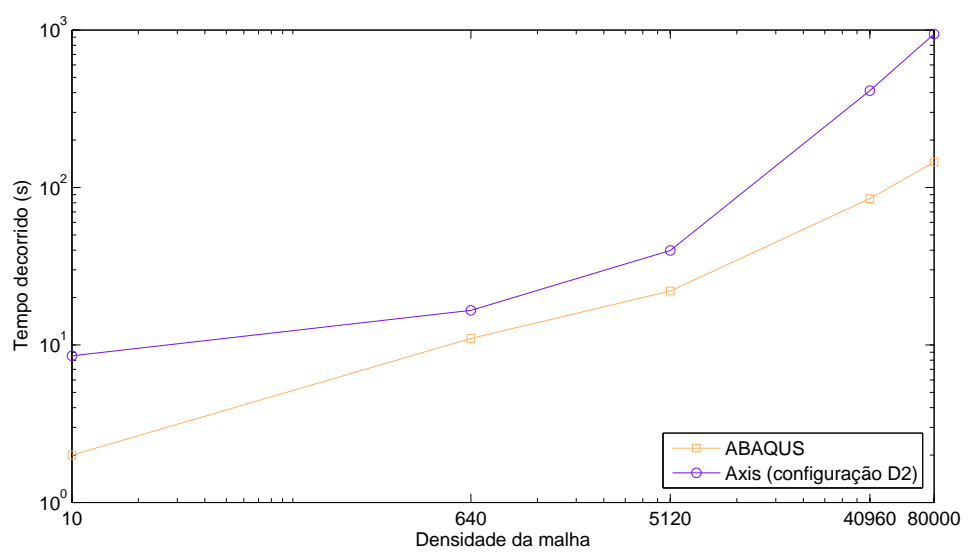

(a) Caso linear (Cenário A)

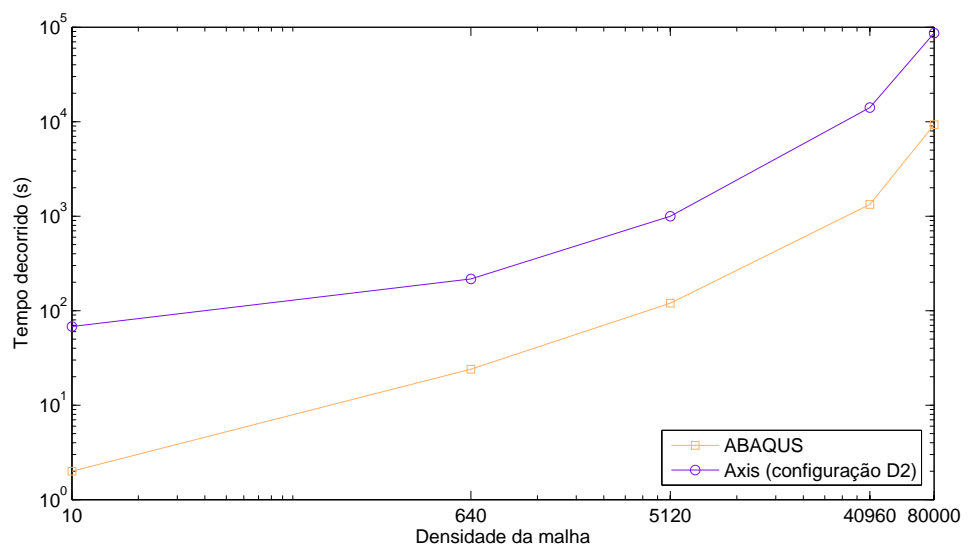

(b) Caso não-linear (Cenário B)

Figura 8.28 Comparação de desempenho do programa Axis (GPU) e o ABAQUS (CPU). 
Observa-se uma considerável diferença de desempenho da solução GPU em relação ao ABAQUS. Contudo, esta situação era esperada, pois não é foco deste trabalho a otimização do código. Tratando-se de um programa estabelecido no mercado há vários anos, é provável que no ABAQUS existam rotinas que usam mais eficientemente os recursos de processamento disponíveis na máquina.

Além disso, o código Axis testado possui instrumentações de depuração, isto é, pequenos trechos de código introduzidos pelo compilador para facilitar o acompanhamento do estado do programa em tempo de execução. Essas instruções facilitam o processo de depuração, mas penalizam o desempenho geral do software.

\subsection{Outras observações}

Os algoritmos implementados no programa mostraram boa concordância com os resultados esperados em testes bem conhecidos da literatura e na comparação com um programa MEF comercial reconhecido. Com erros expressivamente pequenos e, na maioria dos casos, causados por limitações da matemática discreta do computador, a acurácia do programa é suficiente para a resolução de problemas reais.

O uso da GPU em problemas lineares demonstrou potencial benefício para a aceleração de simulações deste caso, apresentando, pelo menos, a redução em 3 vezes no tempo de execução para densidades de malha consideráveis, numa comparação com dispositivos de mesma geração tecnológica. Para casos não-lineares, a queda de desempenho põe em questão a aplicabilidade da GPU neste tipo de problema. Com o maior consumo de memória local das threads, exigido em problemas de grandes deformações, a capacidade de paralelização do dispositivo diminui, saturando mais rapidamente em configurações de malha menores.

Considera-se que as informações apresentadas neste estudo não são suficientes para definir a empregabilidade da GPU em elementos finitos. Outros fenômenos, como contato, dano e falha, aqui não considerados, podem interferir no grau de paralelização do código MEF para o dispositivo. Por outro lado, não foram exploradas as características de paralelização entre dispositivos instalados numa mesma máquina e entre sistemas interligados por rede (computação distribuída).

Outro aspecto relevante a ser verificado é o consumo energético por gigaflop oferecido pela placa, quando comparado contra o valor da CPU. Em alguns casos relatados na literatura [98], observa-se ganhos de desempenho e de consumo energético na adoção do hardware gráfico. Esta comparação pode também ser estendida para outros dispositivos aceleradores, como o Xeon Phi [120]. 


\section{CAPÍTULO 9}

\section{Conclusão}

Com a rápida evolução do hardware, softwares de aplicação científica precisam cada vez mais ser robustos e bem estruturados para incorporar os benefícios trazidos pela tecnologia o mais cedo possível. Essas mudanças fazem parte do ciclo de vida do software, mais especificamente na manutenção pós-lançamento do programa, fase em que os custos de manutenção superam os gastos da produção. Em bases de código monolíticas ou de arquitetura fragmentada, pouco escalável, ou intervenções mal planejadas denotam a morte do software, onde os custos para estender o seu tempo de vida tornam-se impraticáveis.

Neste trabalho, foi desenvolvida uma arquitetura de programa de elementos finitos voltado para a análise de estruturas. Para a demonstração de suas características, a ferramenta desenvolvida sobre essas estrutura é aplicada para o estudo de impacto. O fenômeno engloba uma variedade de aspectos de mecânica dos sólidos, o que o torna ideal para a verificação da escalabilidade do código.

A complexidade do desenvolvimento do código reside, principalmente, na compreensão dos fenômenos que cercam o problema abordado pelo programa aliada à correta modelagem do software. Considerável percepção do domínio do problema atrelada a pouca familiaridade no projeto e desenvolvimento de softwares podem resultar em códigos altamente focados num tipo de problema e pouco escaláveis. Do contrário, o pouco domínio sobre os aspectos de elementos finitos e mecânica dos sólidos, fatalmente, resultam num código distante dos objetivos estabelecidos.

Os conceitos apresentados nos Capítulos 2 e 3 buscam apresentar o mínimo desses conceitos, que foram necessários para o desenvolvimento de Axis. O Capítulo 2 
apresenta os conceitos de elementos finitos aplicados à ferramenta, abordando-os como um conjunto de tarefas estanques, que colaboram entre si dentro de um modelo abstrato de dados. Orientando a discussão nesse sentido, buscou-se destacar a forma simples e direta de implementa de um software MEF: através de entidades abstratas, que estabelecem especificações gerais para as computações realizadas, independente da forma como são implementadas - ou seja, a generalidade do método enquanto seu aspecto principal. As ferramentas de Engenharia de Software, apresentadas no Capítulo 3, foram discutidas à luz dos conceitos de elementos finitos, para facilitar sua compreensão e demonstrar sua aplicabilidade e importância para o desenvolvimento da ferramenta em questão.

É importante o estabelecimento de um "ecossistema" saudável de desenvolvimento, no qual o programa possa crescer à medida que eses conceitos são melhor compreendidos. Os principais problemas que impedem a adoção desse ambiente foram apresentados no Capítulo 4, ressaltando a importância da adoção de um método coordenado e iterativo para a produção do código, permitindo que o programa cresça à medida que conceitos do domínio do problema são melhor compreendidos. Dessa forma, na escolha de equipes de desenvolvimento, profissionais com diferentes níveis de aptidão sobre os conceitos que cercam o software podem igualmente colaborar na sua elaboração, em diferentes etapas do processo, para diferentes segmentos do sistema.

Sendo assim, a robustez e a escalabilidade do código são características que desempenham papel fundamental para a manutenção e longevidade do sistema. Aproveitando-se da generalidade do MEF e das ferramentas de abstração oferecidas pela orientação a objetos, a arquitetura do programa é consolidada no Capítulo 5, entendida como um conjunto de módulos consistentes, apresentados sob diversas perspectivas. O programa apresenta diferentes níveis de organização, permitindo sua fragmentação no desenvolvimento e alocação de tarefas independentes para diferentes integrantes de uma equipe de produção.

A plataforma-base, oferecida para a elaboração dos diferentes sistemas de solução do MEF, tem sua versatilidade demonstrada no Capítulo 6, comportando dois diferentes solvers implementados (estático e dinâmico) e permitindo a extensão do último para problemas não-lineares. A robustez do programa é também explorada ao estender seu suporte para o ambiente de processamento em GPU, no Capítulo 7, construindo um sistema abstrato para a manipulação e controle do dispositivo, removendo do desenvolvedor essas responsabilidades na codificação, permitindo maior concentração dos esforços nas tarefas pertinentes do domínio do problema.

A implementação dos algoritmos de elementos finitos foi validada no Capí- 
tulo 8. Verificado contra testes simples e outros fornecidos na literatura, o programa demonstrou boa acurácia nos resultados. Contudo, principalmente para problemas não-lineares, foram medidos desvios maiores nos valores obtidos, causados principalmente por pequenas instabilidades numéricas e erros de aproximação.

Quando comparados contra uma solução comercial (ABAQUS), as diferenças encontradas demonstram pequenas discrepâncias na implementação adotada pela referência. Não há, na literatura, informações suficientes para identificar tais divergências nas soluções. Entretanto, estipula-se, como uma das principais causas, as estratégias de otimização do código comercial, onde processos algébricos são simplificados para maior desempenho, sob o acréscimo de erro numérico, contudo, executados de forma controlada. Outra possível causa é a adoção de código otimizado, como instruções vetoriais, que permitem reduzir erros de truncamento do ponto flutuante e obter melhor tempo de execução.

Verificado contra o ABAQUS, o programa Axis não obteve boas marcas de desempenho. Todavia, esse cenário era esperado, pois, além das otimizações presentes do código comercial, a solução desenvolvida não contempla técnicas de otimização dos cálculos, apresentando os conceitos da ferramenta de MEF em seu formato mais simples. Certamente, maior refinamento do código é necessário, para se identificar pontos críticos para seu desempenho e substituir as computações mais frequentes por versões mais eficientes. Otimizar o sistema após a construção de sua versão inicial pode representar uma vantagem para o processo. Segundo Fowler [88], nesta abordagem, otimizações globais são mais facilmente identificadas, garantindo melhores marcas de tempo a um custo menor de produção, ao contrário das otimizações locais. Não é objetivo deste trabalho a otimização computacional das técnicas de MEF, pois se trata de um estudo considerável sobre os aspectos numéricos dos algoritmos e conhecimento sobre os mecanismos de otimização dos compiladores e de execução das instruções de máquina, tornando inviável sua abrangência nesta pesquisa.

Através da arquitetura apresentada, diferentes aspectos do desenvolvimento da ferramenta de MEF puderam ser identificados, principalmente no tocante ao desenvolvimento colaborativo e multidisciplinar, requerido para um sistema saudável de produção. Descrevendo computações através de termos próprios da linguagem do domínio, a codificação dos algoritmos de elementos finitos se torna mais clara, removendo a necessidade de extensos dicionários de dados e promovendo a autodocumentação do programa, isto é, o código é estruturado o suficiente para permitir uma leitura direta de suas intenções, consequentemente reduzindo a carga de documentação. 
O software oferece um ambiente adequado para o desenvolvimento de novas pesquisas na área. Oferecendo uma base pronta, novas tecnologias de elementos finitos podem ser implementadas e testadas, tais como formulações de elementos, modelos de materiais, algoritmos de controle de iteração no tempo, sistemas de solução, entre outros. A estruturação em componentes facilita a reutilização do código, diminui as dependências de bibliotecas necessárias para a funcionalidade e diminui o rastro de imagem gerado pelo compilador. A plataforma de MEF desenvolvida destaca-se como uma das poucas a oferecer suporte à GPU, com o uso de orientação e objetos, além de permitir que extensões elaboradas por terceiros também usufruam do poder de processamento do hardware, características ausentes mesmo nos programas comerciais disponíveis até então.

A existência de bases de código de MEF promovem a disseminação e aprofundamento das técnicas envolvidas no método numérico, extensivamente utilizado por diversas indústrias de substancial importância econômica para o país. O impulsionamento de pesquisas nessa área, atreladas ao uso de tecnologias recentes, como a GPU, fornece um mecanismo para a capacitação de mão-de-obra especializada e a formação de uma base de conhecimento mais sólida, fundamental para o desenvolvimento tecnológico nacional.

\subsection{Perspectivas futuras}

A partir deste trabalho, diversas linhas de pesquisa podem ser estabelecidas. Em diversas delas, a multidisciplinaridade da tarefa deve ser considerada, dadas as tecnologias envolvidas. Tratando-se de uma estrutura base para o desenvolvimento, o código do Axis é adotado como ponto de partida para a definição de sistemas mais robustos, conforme serão discutidos a seguir.

\section{Otimizações do código}

O código de MEF apresentado pode ser otimizado para melhores marcas de desempenho. O melhor aproveitamento dos níveis de cache do processador, localidade da informação, alinhamento da memória, uso de instruções otimizadas e a otimização dos procedimentos numéricos estão entre as possíveis melhorias do código em CPU. Para a GPU, o correto alinhamento de memória, o aproveitamento das áreas de memória de alta velocidade e a redução do uso de registradores por multiprocessador são possíveis otimizações. 
Implementação de tecnologias de elementos finitos

Outras tecnologias de elementos finitos podem ser introduzidas no programa para estender suas funcionalidades. Outros elementos de fundamental importância para a análise de estruturas podem ser codificados. Para análises tridimensionais, elementos de casca são constantemente usados para a modelagem de placas e sóilidos com pequena espessura. Elementos de viga são usados para a análise de estruturas mais simples, como pórticos e apoios, além de atuar como elemento auxiliar para a representação de torções e afixações no modelo numérico. Similarmente, uma maior biblioteca de materiais permite a modelagem de estruturas com diferentes comportamentos, como sensibilidade à taxa de deformação, efeito Mullins, histerese ou anisotropia.

A introdução de outros aspectos, como dano e contato, não cobertos pelo presente estudo, são outras possíveis linhas de pesquisa neste escopo. Opcionalmente, esses recursos podem ser considerados na execução em GPU, para simetria das funcionalidades em ambos os ambientes de processamento.

\section{Distribuição do processamento}

Bibliotecas consolidadas para o processamento distribuído, como MPI, fornecem as ferramentas básicas para a adaptação do programa para ambientes distribuídos. O desenvolvimento de um código eficiente para este cenário requer um estudo detalhado dos algoritmos envolvidos e correta seleção dos dados para distribuição entre os nós de trabalho, uma vez que os canais de comunicação que os interligam representam alta latência para a execução da análise.

Num ambiente heterogêneo, com a co-existência de nós CPU e GPU, a divisão da carga se torna uma tarefa ainda mais complexa, onde um algoritmo de seleção deve ser capaz de eleger unidades de processamento adequadas para a execução eficiente da simulação.

\section{Maior usabilidade na interface com o usuário}

Do ponto de vista de usabilidade, a interface com o usuário (analista ou desenvolvedor) é uma preocupação recente e tardia para softwares de elementos finitos. Tecnologias recentes para a construção de UI permitem a elaboração de janelas gráficas mais intuitivas, iconografia consistente e com linguagem visual apelativa.

É também possível a implementação de dispositivos mais sofisticados para o 
monitoramento de uma análise, por exemplo, exibindo-se gráficos-resumos de quantias físicas como energia cinética do modelo e energia artificial (de anti-hourglass e outras correções), para a validação dos resultados em tempo real.

\section{Armazenamento de resultados em SGBD}

Recentemente, sistemas de gerenciamento de banco de dados (SGBD) são explorados para o armazenamento dos resultados de uma análise de elementos finitos. Os sistemas SGBD são mais eficientes para a armazenagem massiva de dados do que a gravação em bases de dados locais.

O sistema de coleta de dados implementado no Axis é preparado para a introdução de tecnologias SGBD no despacho dos resultados. A partir da implementação de um plugin, dados da simulação podem ser encaminhados para um sistema intermediário, que enfileira os estados do modelo a serem gravados no banco de dados, hospedado num outro sistema remoto. O uso de um sistema intermediário permite a execução completamente paralelizada do solver com o sistema de coleta de dados, similar ao mecanismo de semáforos implementado para o solver de GPU, mostrado no Capítulo 7 .

Além disso, o mecanismo de consulta de dados dos SGBDs fornecem métodos robustos para o tratamento das informações de uma análise. A tensão máxima de uma seção, os elementos que iniciaram uma trinca e a maior tensão cisalhante das seções que sofreram plastificação são algumas das estatísticas possíveis de se obter pelo sistema, sem a necessidade de que sejam previamente computadas pelo solver. Além disso, análises mais complexas, como por exemplo a análise simultânea de dados de simulações num processo de otimização, tornam-se mais ágeis e flexíveis. Em ambientes de computação remota ou por nuvem, ou na preparação de um ambiente para o big data, a tecnologia é fundamental para a implantação desses cenários.

\section{Análise de elementos finitos na nuvem}

Computação em nuvem é um dos tópicos de computação mais discutidos para a utilização transparente de serviços remotos. Ari e Muhtaroglu [12] discute aspectos para a elaboração e implantação do ambiente. Uma vez que a arquitetura do Axis é desacoplada do sistema de interface com o usuário, o núcleo do programa pode ser implementado como um sistema remoto de análise, aliado a um armazém de dados, eliminando os altos custos de manutenção do ambiente computacional para empresas, reduzindo-o a taxas de processamento por hora, por exemplo. A terceirização 
e compra de serviços HPC é uma tendência recente e que certamente merece maior aprofundamento das pesquisas sobre seus benefícios num ambiente MEF. 



\section{Referências Bibliográficas}

[1] Aho, A. V., Lam, M. S., Sethi, R., \& Ullman, J. D. (2006). Compilers: Principles, Techniques, and Tools. Prentice Hall, 2a. edição.

[2] Akin, J. \& Singh, M. (2002). Object-oriented fortran 90 P-adaptive finite element method. Advances in Engineering Software, 33:461-468.

[3] Alain, C. \& Ute, R. (2013). Pitfalls in the finite element modeling of the buckling of sandwich shells of revolution. Thin-Walled Structures, 63:91-97.

[4] Alexandrescu, A. (2001). Modern C++ Design - Generic Programming and Design Patterns Applied. Addison-Wesley, EUA.

[5] Altair Engineering Inc. (2009). RADIOSS theory manual, Part 1.

[6] Altair Engineering Inc. (2013). HyperWorks Desktop Reference Guide: Generic ASCII Reader.

[7] Alves Filho, A. (2005). Elementos finitos - a base da tecnologia CAE. Érica, São Paulo, Brasil.

[8] Amazon Web Services Inc. Computação de alta performance (HPC) na AWS. Disponível em < http://aws.amazon.com/pt/hpc-applications/> (acesso em dez. 2013).

[9] AnandTech. OpenCL 1.0: The road to pervasive GPU computing. Disponível em <http://www.anandtech.com/video/showdoc.aspx?i=3488> (acesso em jul. 2009). 
[10] ANSYS, Inc. ANSYS Mechanical. Disponível em < http://www.ansys.com/Products/ Simulation+Technology/Structural+Mechanics/ANSYS+Mechanical $>$ (acesso em set. 2011).

[11] Archer, G., Fenves, G., \& Thewalt, C. (1999). A new object-oriented finite element analysis program architecture. Computer \& Structures, 70:63-75.

[12] Ari, I. \& Muhtaroglu, N. (2013). Design and implementation of a cloud computing service for finite element analysis. Advances in Engineering Software, 60-61:122-135.

[13] Augusto, R. A. (2012). Arquitetura orientada a objetos para o MEF de alta ordem com aplicações em mecânica estrutural. Tese de doutorado, Faculdade de Engenharia Mecânica, Universidade de Campinas, Campinas, Brasil.

[14] Balieu, R., Lauro, F., Bennani, B., Delille, R., Matsumoto, T., \& Mottola, E. (2013). A fully coupled elastoviscoplastic damage model at finite strains for mineral filled semi-crystalline polymer. International Journal of Plasticity, 51:241 -270 .

[15] Basar, Y. \& Weichert, D. (2000). Nonlinear continuum mechanics of solids. Springer.

[16] Bathe, K.-J. (2006). Finite Element Procedures. Prentice Hall, EUA.

[17] Bathe, K.-J., Ramm, E., \& Wilson, E. L. (1975). Finite element formulations for large deformation dynamic analysis. International Journal for Numerical Methods in Engineering, 9:353-386.

[18] Bathe, K. J. \& Wilson, E. L. (1976). Numerical Methods in Finite Element Analysis. Prentice-Hall.

[19] Bažant, Z. P. (1998). Easy-to-compute tensors with symmetric inverse approximating Hencky finite strain and its rate. Journal of Engineering Materials and Technology, 120:131-136.

[20] Beck, K. (2010). TDD - Desenvolvimento guiado por testets. Bookman, Porto Alegre, Brasil.

[21] Belytschko, T. (1983). Correction of article by D.P. Flanagan and T. Belytschko - A uniform strain hexahedron and quadrilateral with orthogonal hourglass control. International Journal for Numerical Methods in Engineering, 19:467-468.

[22] Belytschko, T. \& Bindeman, L. P. (1993). Assumed strain stabilization of the eight node hexahedral element. Computer Methods in Applied Mechanics and Engineering, 105:225-260. 
[23] Belytschko, T., Liu, W. K., \& Moran, B. (2007). Nonlinear Finite Elements for Continua and Structures. Wiley, EUA.

[24] Besson, J. \& Foerch, R. (1997). Large scale object-oriented finite element code design. Computer Methods in Applied Mechanics and Engineering, 142:165-187.

[25] Betram, A. (2008). Elasticity and plasticity of large deformations - an introduction. Springer, 2a. edição.

[26] Bezerra, A. C. \& Rade, D. A. (2004). Análise térmica do processo de soldagem TIG via elementos finitos. Em 14 POSMEC - Simpósio do Programa de pósgraduação em Engenharia Mecânica, Minas Gerais, Brasil. Universidade Federal de Uberlândia.

[27] Bhatti, M. A. (2005). Fundamental Finite Element Analysis and Applications. Wiley, EUA.

[28] Bhatti, M. A. (2006). Advanced Topics in Finite Element Analysis of Structures. Wiley, EUA.

[29] Bitencourt Júnior, L. A. G. (2009). Desenvolvimento de uma plataforma computacional para análise via método dos elementos finitos de estruturas de concreto armado convencional e reforçado com fibras de aço. Dissertação de mestrado, Escola Politécnica da Universidade de São Paulo, São Paulo, Brasil.

[30] Bittencourt, M. L. (2010). Análise computacional de estruturas: com aplicação do Método de Elementos Finitos. Editora Unicamp.

[31] Bittencourt, M. L., Borges, E. G., Carvalho, E. F., \& Augusto, R. A. (2008). An application service provider for finite element analysis. Advances in Engineering Software, 39:899-910.

[32] Bonet, J. \& Wood, R. D. (1997). Nonlinear continuum mechanics for finite element analysis. Cambridge.

[33] Booch, G., Maksimchuk, R. A., Engle, M. W., Young, B. J., Conallen, J., \& Houston, K. A. (2007). Object-oriented analysis and design with applications. Addison-Wesley, 3a. edição.

[34] Bouaanani, N. \& Lu, F. Y. (2009). Assessment of potential-based fluid finite elements for seismic analysis of dam-reservoir systems. Computers $\&$ Structures, 87(3-4):206-224.

[35] Bower, A. F. (2010). Applied Mechanics of Solids. CRC Press, EUA.

[36] Boyer, C. B. (2010). História da Matemática. Blucher, 3a.a. edição. 
[37] Brinson, H. F. \& Brinson, L. C. (2008). Polymer Engineering Science and Viscoelasticity. Springer.

[38] Brooks Jr., F. P. (2009). O Mítico Homem-Mês. Campus, Elsevier, Rio de Janeiro, Brasil.

[39] Buck, I. Data parallel computing on graphics hardware. Disponível em < http: T/www.graphics.stanford.edu/projects/brookgpu/GHO3-Brook.ppt > (acesso em jul. 2009).

[40] Buck, I., Foley, T., Horn, D., et al. BrookGPU. Disponível em < http://www. graphics.stanford.edu/projects/brookgpu/index.html > (acesso em jun. 2009).

[41] Bueno, R. Unicamp usa PlayStation 3 para realizar pesquisas. Disponível em <http://g1.globo.com/Noticias/Tecnologia/0, MUL146410-6174,00-UNICAMP+USA+ PLAYSTATION+PARA+REALIZAR+PESQUISAS.htmI > (acesso em jul. 2009).

[42] Bueno, R. C. S. (1994). Metodologia para análise da interação coluna de perfuração/riser/poço por elementos finitos. Dissertação de mestrado, Universidade de Campinas, São Paulo, Brasil.

[43] Castaño-Díez, D., Moser, D., Schoenegger, A., Pruggnaller, S., \& Fragakis, A. S. (2008). Performance evaluation of image processing algorithms on the GPU. Journal of Structural Biology, 164:153-160.

[44] Cerrolaza, M. \& Osorio, J. (2012). Relations among stiffness coefficients of hexahedral 8-noded finite elements: A simple and efficient way to reduce the integration time. Finite Elements in Analysis and Design, 55:1 - 6.

[45] Cesa, T. R. \& de Oliveira, B. F. (2010). Aplicação do método de elementos finitos na simulação de uma estrutura de proteção contra capotamento. Em Dvorkin, E., Goldschmit, M., \& Storti, M., eds., Mecánica Computacional Vol XXIX, p. 319-342, Argentina. Asociación Argentina de Mecánica Computacional.

[46] Chapman, B., Jost, G., \& van der Pas, R. (2007). Using OpenMP: Portable Shared Memory Parallel Programming. MIT Press.

[47] Chatzi, E. The finite element method for the analysis of non-linear and dynamic systems. Disponível em < http://www.ibk.ethz.ch/ch/education/femII/education/index_ EN/Lecture11new.pdf $>$ (acesso em jan. 2014).

[48] Chen, H.-M. \& Lin, Y.-C. (2008). Web-FEM: An internet-based finite-element analysis framework with $3 \mathrm{D}$ graphics and parallel computing environment. Advances in Engineering Software, 39:55-68.

[49] Clough, R. W. (1960). The finite element method in plane stress analysis. Em Proc. ASCE Conf. Electron. Computat., p. 345-378. 
[50] Clough, R. W. (1980). The Finite Element Method after twenty-five years: a personal view. Computer \& Structures, 12:361-370.

[51] Clough, R. W. \& Wilson, E. L. (1999). Early finite element research at Berkeley. Em 5th U.S. National Conference on Computational Mechanics.

[52] CNN. Pan am flight 103 fast facts. Disponível em <http://edition.cnn.com/2013/09/ 26/world/pan-am-flight-103-fast-facts/> (acesso em dez. 2013).

[53] Cocchetti, G., Pagani, M., \& Perego, U. (2013). Selective mass scaling and critical time-step estimate for explicit dynamics analyses with solid-shell elements. Computers \& Structures, 127:39 - 52.

[54] Cohen, J. M. \& Molemaker, M. J. (2009). A fast double precision CFD code using CUDA. CUDA Zone. Disponível em <http: //www.nvidia.com/content/cudazone/CUDABrowser/downloads/papers/ DoublePrecision-CFD-Cohen-parCFD09.pdf $>$.

[55] COMSOL. COMSOL Multiphysics Modeling, Finite Element Analysis, and Engineering Simulation Software. Disponível em <http://www.comsol.com/ $>$ (acesso em fev. 2013).

[56] Cook, R. (1994). Finite element modeling for stress analysis. Wiley.

[57] Cook, R. D., Malkus, D. S., \& Plesha, M. E. (1989). Concepts and applications of Finite Element Analysis. Wiley, EUA.

[58] Courant, R. (1943). Variational methods for the solution of problems of equilibrium and vibrations. Bull. Amer. Math. Soc., 49:1-23. DOI: http://dx.doi.org/10.1090/S0002-9904-1943-07818-4.

[59] Courant, R., Friedrichs, K., \& Lewy, H. (1967). On the partial difference equations on mathematical physics. IBM Journal, p. 215-234. Republicação da tradução do alemão, a partir do original AEC Report NYO-7689, AEC Computing Facility da Universidade de Nova York.

[60] Cunha, M. C. C. (2000). Métodos numéricos. Editora Unicamp, São Paulo, Brasil.

[61] da Silva, E. P. (2013). Elementos finitos como ferramenta auxiliar na análise estrutural estática de uma colhedora de café do tipo automotriz. Dissertação de mestrado, Universidade Federal de Lavras, Minas Gerais, Brasil.

[62] Dassault Systèmes (2011). ABAQUS 6.11-3 Verification Manual.

[63] Dassault Systèmes (2011). Abaqus 6.11 Theory Manual. 
[64] Dassault Systèmes. Abaqus unified FEA. Disponível em <http://www.3ds.com// products-services/simulia/portfolio/abaqus/latest-release/> (acesso em jan. 2014).

[65] Dawes, B., Abrahams, D., \& Rivera, R. Boost C++ Libraries. Disponível em $<$ http://www.boost.org/> (acesso em set. 2013).

[66] de Cerqueira, F. A. (2004). Modelagem por elementos finitos da associação fluxo e equilíbrio em problemas de engenheria geotécnica. Dissertação de mestrado, Universidade de Fortaleza, Fortaleza, Brasil.

[67] de Moura, M. \& Chousal, J. (2006). Cohesive and continuum damage models applied to fracture characterization of bonded joints. International Journal of Mechanical Sciences, 48(5):493 - 503.

[68] De Rose, C. A. F. \& Navaux, P. O. A. (2008). Arquiteturas Paralelas. Bookman.

[69] de Souza Neto, E., Perić, D., \& Owen, D. (2008). Computational Methods for Plasticity. Wiley, Reino Unido.

[70] Demerjian, C. Nvidia downgrades Tesla again. Disponível em < http:// semiaccurate.com/2010/05/05/nvidia-downgrades-tesla-again/> (acesso em dez. 2013).

[71] D'herbe, D. R. Airliners.net. Disponível em < <ttp://www.airliners.net $>$ (acesso em dez. 2013).

[72] Dijkstra, E. W. (1970). Notes on structured programming. Relatório Técnico 70WSK-03, Department of Mathematics, Tehnological University Eindhoven, The Netherlands. Second edition.

[73] Dodds Jr., R. H. \& Lopez, L. A. (1980). A generalized software system for non-linear analysis. Advances in Engineering Software, 2(4):161-168.

[74] Dolenc, M. (2004). Developing extendible component-oriented finite element software. Advances in Engineering Software, 35:703-714.

[75] Donald, B. (2007). Practical Stress Analysis With Finite Elements. Glasnevin.

[76] Dubois-Pèlerin, Y. \& Zimmermann, T. (1993). Object-oriented finite element programming: III. An efficient implementation in $\mathrm{C}++$. Computer Methods in Applied Mechanics and Engineering, 108:165-183.

[77] Dunbar, B. NASA Technology. Disponível em < http://www.nasa.gov/centers/dryden/ news/X-Press/stories/2008/10_08_technology.html > (acesso em dez. 2013).

[78] Dunne, F. \& Petrinic, N. (2005). Introduction to Computational Plasticity. Oxford. 
[79] Edem, I. \& Gosling, P. (2013). Physically stabilised displacement-based ANS solid-shell element. Finite Elements in Analysis and Design, 74:30 - 40.

[80] Eriksson, H.-E., Penker, M., Lyons, B., \& Fado, D. (2003). UML 2 Toolkit. Wiley.

[81] Farber, R. (2013). Preserving sanity in the face of rampant technology change. Scientific Computing. Disponível em <http://www.scientificcomputing.com/ articles/2013/12/preserving-sanity-face-rampant-technology-change?et_ cid=3723729\&et_rid=332626633\&type=headline $>$.

[82] Fernandes, B. Grave acidente com vítima fatal na avenida Senador Fernandes Távora. Disponível em <http://sobralnoticias.zip.net/arch2011-06-05_2011-06-11.html > (acesso em dez. 2013).

[83] Filgueiras, W. H., de Queiroz, D. M., Dias, G. P., \& Della Lucia, R. M. (2000). Modelagem da planta de café por elementos finitos para estudos de colheita por vibraÇão. Em I Simpósio de Pesquisa dos Cafés do Brasil, p. 1095-1098, Minas Gerais, Brasil. Embrapa.

[84] Flanagan, D. P. \& Belytschko, T. (1981). A uniform strain hexahedron and quadrilateral with orthogonal hourglass control. International Journal for Numerical Methods in Engineering, 17:679-706.

[85] Flood, R. \& Carson, E. (1993). Dealing with complexity: an introduction to the theory and application of systems science. Springer, 2a. edição.

[86] Flores, F. G. \& Oñate, E. (2006). Rotation-free finite element for the nonlinear analysis of beams and axisymmetric shells. Computer Methods in Applied Mechanics and Engineering, 195(41-43):5297 - 5315.

[87] Forde, B. W., Foschi, R. O., \& Stiemer, S. F. (1990). Objecdt-oriented finite element analysis. Computer \& Structures, 34(3):355-374.

[88] Fowler, M. (1999). Refactoring: improving the design of existing code. AddisonWesley.

[89] Frischkorn, J. \& Reese, S. (2013). A solid-beam finite element and non-linear constitutive modelling. Computer Methods in Applied Mechanics and Engineering, $265: 195-212$.

[90] Fulgham, B. The computer language benchmark game. Disponível em < http: 7/shootout.alioth.debian.org/> (acesso em set. 2011). 
[91] Galoppo, N., Govindaraju, N. K., Henson, M., \& Manocha, D. (2005). LUGPU: Efficient algorithms for solving dense linear systems on graphics hardware. Em SC '05: Proceedings of the 2005 ACM/IEEE conference on Supercomputing, p. 3, Washington, DC, EUA. IEEE Computer Society.

[92] Gamma, E., Helm, R., Johnson, R., \& Vlissides, J. (1995). Design patterns: elements of reusable object-oriented software. Addison-Wesley.

[93] Garshol, L. M. Bnf and ebnf: What are they and how do they work? Disponível em <http://www.garshol.priv.no/download/text/bnf.html $>$ (acesso em fev. 2014).

[94] Geys, I. \& Van Gool, L. (2007). View synthesis by the parallel use of GPU and CPU. Image and Vision Computing, 25:1154-1164.

[95] Gil, L. \& Bugeda, G. (2001). A c++ object-oriented programming strategy for the implementation of the finite element sensitivity analysis for a non-linear structural material model. Advances in Engineering Software, 32:927-935.

[96] Göddeke, D. (2010). Fast and accurate finite-element multigrid solvers for PDE simulations on GPU clusters. Tese de doutorado, Technischen Universität Dortmund.

[97] Göddeke, D. \& Strzodka, R. (2007). Performance and accuracy of hardwareoriented native-, emulated- and mixed-precision solvers in FEM simulations (Part 2: Double precision GPUs). International Journal of Parallel, Emergent and Distributed Systems, 22(4):221-256.

[98] Göddeke, D., Strzodka, R., Mohd-Yusof, J., McCormick, P., Buijssen, S. H. M., Grajewski, M., \& Turek, S. (2007). Exploring weak scalability for FEM calculations on a GPU-enhanced cluster. Parallel Computing, 33:685-699.

[99] Golub, G. H. \& Van Loan, C. F. (1996). Matrix Computations. Johns Hopkins University Press, EUA, 3a. edição.

[100] Gomaa, H. (2000). Designing concurrent, distributed, and real-time applications with UML. Addison-Wesley.

[101] Greenbaum, A. \& Chartier, T. P. (2012). Numerical methods: design, analysis and computer implementation of algorithms. Princeton University Press.

[102] Gregory, K. \& Miller, A. (2012). C++ AMP. Microsoft Press, EUA.

[103] Hallquist, J. O. (2006). LS-DYNA Theory Manual. Livermore Software Technology Corporation, EUA. 
[104] Hamming, R. W. (1987). Numerical Methods for Scientists and Engineers. Dover, 2a. edição.

[105] Hansbo, P. \& Larson, M. G. (2014). Finite element modeling of a linear membrane shell problem using tangential differential calculus. Computer Methods in Applied Mechanics and Engineering, 270:1 - 14.

[106] Heng, B. C. P. \& Mackie, R. I. (2009). Using design patterns in object-oriented finite element programming. Computer and Structures, 87:952-961.

[107] Hibbitt, H. (1984). ABAQUS/EPGEN - a general purpose Finite Element code with emphasis on nonlinear applications. Nuclear Engineering and Design, $77: 271-297$.

[108] Hibbitt, H. D., Marcak, P. V., \& Rice, J. R. (1970). A finite element formulation for problems of large strain and large displacement. International Journal of Solids and Structures, 6:1069-1086.

[109] Hoger, A. (1986). The material time derivative of logarithmic strain. International Journal of Solid Structures, 22(9):1019-1032.

[110] Hoger, A. (1987). The stress conjugate to logarithmic strain. International Journal of Solids and Structures, 23(12):1645-1656.

[111] Holtsnider, B., Wheeler, T., Stragand, G., \& Gee, J. (2010). Agile Development and Business Goals: the six week solution. Morgan Kaufmann.

[112] Hopcroft, J. E., Ullman, J. D., \& Motwani, R. (2003). Introdução à Teoria de Autômatos, Linguagens e Computação. Campus, 2a. edição.

[113] Hruska, J. Intel's Haswell is an unprecedented threat to Nvidia, AMD. Disponível em <http://www.extremetech.com/computing/ 136219-intels-haswell-is-an-unprecedented-threat-to-nvidia-amd $>$ (acesso em dez. 2013).

[114] Hu, Y.-K. \& Nagy, L. I. (1997). A one-point quadrature eight-node brick element with hourglass control. Computers \&3 Structures, 65(6):893-902.

[115] Hughes, T. J. R. (1987). The Finite Element Method. Prentice Hall.

[116] IEEE (2008). IEEE standard for floating-point arithmetic. Relatório Técnico 754-2008, IEEE.

[117] Intel Corporation. Intel math kernel library (intel mkl) 10.3. Disponível em $<$ http://software.intel.com/en-us/articles/intel-mk1/> (acesso em set. 2011).

[118] Intel Corporation. Processors. Disponível em < http://www.intel.com/support/ processors/sb/cs-030123.htm > (acesso em dez. 2013). 
[119] Intel Corporation. Intel instruction set architecture extensions. Disponível em $<$ http://software.intel.com/intel-isa-extensions $>$ (acesso em dez. 2013).

[120] Intel Corporation. Coprocessador Intel Xeon Phi. Disponível em < http: //software.intel.com/pt-br/mic-developer?gclid=CL2ny7yK5LWCFW9p7AodK08AjA $>$ (acesso em fev. 2014).

[121] Intel Corportation. Intel Xeon processor E7 family. Disponível em <http: //ark.intel.com/pt-br/products/family/59139> (acesso em dez. 2013).

[122] ISO/IEC. JTC1/SC22/WG21 - The C++ standards committee. Disponível em $<$ http://www.open-std.org/jtc1/sc22/wg21/ $>$ (acesso em jan. 2014).

[123] Jacobson, I., Booch, G., \& Rumbaugh, J. (1999). The Unified Software Development Process. Addison-Wesley.

[124] Joldes, G. R., Wittek, A., \& Miller, K. (2007). An efficient hourglass control implementation for the uniform strain hexahedron using the Total Lagrangian formulation. Communications in numerical methods in engineering, 24:1315-1323.

[125] Jones, N. (1997). Structural Impact. Cambridge.

[126] Josuttis, N. M. (2012). The C++ Standard Library: a tutorial and reference. Addison-Wesley, 2a. edição.

[127] Kabas, O., Celik, H. K., Ozmerzi, A., \& Akinci, I. (2008). Drop test simulation of a sample tomato with finite element method. Journal of the Science of Food and Agriculture, 88:1537-1541.

[128] Kawahara, M. \& Takeuchi, N. (1977). Mixed finite element method for analysis of viscoelastic fluid flow. Computers \& Fluids, 5(1):33-45.

[129] Khronos Group. OpenCL - the open standard for parallel programming of heterogeneous systems. Disponível em <http://www.khronos.org/openc1/ $>$ (acesso em jul. 2009).

[130] Klir, G. J. (1985). Complexity: Some general observations. Systems Research, 2(2):131-140.

[131] Komatitsch, D., Michéa, D., \& Erlebacher, G. (2009). Porting a high-order finite-element earthquake modeling application to NVIDIA graphics cards using CUDA. J. Parallel Distrib. Comput., 69:451-460.

[132] Kot Engenharia. Kotchergenko engenharia. Disponível em <http://www.kot.com. br/elementos_finitos.php $>$ (acesso em jan. 2014).

[133] Lakos, J. (2009). Large-scale C++ software design. Addison-Wesley, EUA. 
[134] Larman, C. (2005). Applying UML and Patterns: An introduction to objectoriented analysis and design and iterative development. Prentice Hall, 3a. edição.

[135] Lee, Y., Yoon, K., \& Lee, P.-S. (2012). Improving the MITC3 shell finite element by using the hellinger-reissner principle. Computers \& Structures, 110-111:93-106.

[136] Li, K. P. \& Cescotto, S. (1997). An 8-node brick element with mixed formulation for large deformation analysis. Computational Methods in Applied Mechanics and Engineering, 141:157-204.

[137] Li, L. M., Peng, Y. H., \& Li, D. Y. (2011). A stabilized underintegrated enhanced assumed strain solid-shell element for geometrically nonlinear plate/shell analysis. Finite Elements in Analysis and Design, 47:511-518.

[138] Lientz, B. P. \& Swanson, E. B. (1980). Software maintenance management. Addison-Wesley.

[139] Lima, G. V. F. (2013). Análise dinâmica via método dos elementos finitos do estádio nacional de Brasília. Dissertação de mestrado, Universidade de Brasília, Brasília, Brasil.

[140] Lischner, R. (2013). Exploring $C++11$. Apress, 2a. edição.

[141] Liskov, B. (1980). A design methodology for reliable software systems. Em Tutorial on software design techniques, p. 66. IEEE Computer Society, Nova Iorque, EUA, 3a. edição.

[142] Liu, J.-L., Lin, I.-J., Shih, M.-C., Chen, R.-C., \& Hsieh, M.-C. (1996). Objectoriented programming of adaptive finite element and finite volume methods. $A p$ plied Numerical Mathematics, 21:439-467.

[143] Liu, W., Schmidt, B., Voss, G., \& Müller-Wittig, W. (2008). Accelerating molecular dynamics simulations using Graphics Processing Units with CUDA. Computer Physics Communications, 179:634-641.

[144] Livermore Software Technology Corp. LS-DYNA. Disponível em < http://www. 1stc.com/node/16> (acesso em set. 2011).

[145] Lotti, R. S., Machado, A. W., Mazzieiro, E. T., \& Júnior, J. L. (2006). Aplicabilidade científica do método dos elementos finitos. Revista Dentral Press de Ortodontia e Ortopedia Facial, 11(2):35-43.

[146] Mackerle, J. (1986). Finite Element codes for microcomputers - a review. Computer \& Structures, 24(4):657-682. 
[147] Mackerle, J. (1994). Finite and boundary element techniques in acoustics - a bibliography (1990-1992). Finite Elements in Analysis and Design, 15(3):263-272.

[148] Mackerle, J. (1995). Some remarks on progress with finite elements. Computers E Structures, 55:1101-1106.

[149] Mackerle, J. (2000). Object-oriented techniques in FEM and BEM: A bibliography (1996-1999). Finite Elements in Analysis and Design, 36:189-196.

[150] Mackerle, J. (2004). Object-oriented programming in fem and bem: a bibliography (1990-2003). Advances in Engineering Software, 35:325-336.

[151] Mackie, R. I. (2002). Using objects to handle calculation control in finite element modeling. Computer \&6 Structures, 80:2001-2009.

[152] MacNeal, R. H. (1974). Some organizational aspects of NASTRAN. Nuclear Engineering and design, 29:254-265.

[153] MacNeal, R. H. (1987). Zen and the art of finite element design. Finite Element in Analysis and Design, 3:85-91.

[154] Macneal, R. H. \& Harder, R. L. (1985). A proposed standard set of problems to test finite element accuracy. Finite Elements in Analysis and Design, 1:3-20.

[155] Marante, M., Suárez, L., Quero, A., Redondo, J., Vera, B., Uzcategui, M., et al. (2005). Portal of damage: a web-based finite element program for the analysis of framed structures subjected to overloads. Advances in Engineering Software, 36:346-358.

[156] Matsumoto, A. T. (2010). Estudo do desempenho de reforços poliméricos em estruturas veiculares submetidas a impacto. Dissertação de mestrado, Escola Politécnica da Universidade de São Paulo, São Paulo, Brasil.

[157] Mazzariol, L. M. (2012). Escalonamento de paineis reforçados sujeitos à cargas de impacto. Dissertação de mestrado, Escola Politécnica da Universidade de São Paulo, São Paulo, Brasil.

[158] McConnell, S. (2004). Code Complete: A Practical Handbook of Software Construction. Microsoft Press, 2a. edição.

[159] McGinty, B. Finite deformation continuum mechanics. Disponível em < http: //www.continuummechanics.org/cm/index.htmI > (acesso em jan. 2014).

[160] Micheli, G. B. (2008). Análise numérico-experimental do impacto em chapas de alumínio aeronáutico. Tese de doutorado, Escola Politécnica da Universidade de São Paulo, São Paulo. 
[161] Microsoft Corporation. 4-Gigabyte tuning. Disponível em $<$ http://msdn.microsoft. com/en-us/library/windows/desktop/bb613473(v=vs.85).aspx > (acesso em dez. 2013).

[162] Mo, O., Klem, H. F., Pahle, E., \& Harwiss, T. (1977). Finite element programs based on general programming systems. Computers \& Structures, 8:703-715.

[163] Mohammadi, H., Bahramian, F., \& Wan, W. (2009). Advanced modeling strategy for the analysis of heart valve leaflet tissue mechanics using high-order finite element method. Medical Engineering \& Physics, 31(9):1110-1117.

[164] Mohr, G. A. (1984). Finite element analysis of viscous fluid flow. Computers E) Fluids, 12(3):217-233.

[165] Moura, R. T. (2013). Modelagem e ensaios mecânicos de polímeros termoplásticos sob carregamentos quase-estático e dinâmico. Tese de doutorado, Escola Politécnica da Universidade de São Paulo.

[166] MSC Software. MSC Nastran. Disponível em < http://www.mscsoftware.com/Products/ CAE-Tools/MSC-Nastran.aspx $>$ (acesso em set. 2011).

[167] Mueller, F. Sony PS3 Cluster (IBM Cell BE). Disponível em < http://moss.csc. ncsu.edu/ mueller/cluster/ps3/> (acesso em ago. 2011).

[168] Naghdabadi, R., Baghani, M., \& Arghavani, J. (2012). A viscoelastic constitutive model for compressible polymers based on logarithmic strain and its finite element implementation. Finite Elements in Analysis and Design, 62:18 - 27.

[169] Newmark, N. M. (1959). A method of computation for structural dynamics. Journal of the Engineering Mechanics Division / Proceedings of ASCE, 85(EM 3):67-94.

[170] Nimbix Inc. Nvidia - nimbix accelerated compute cloud. Disponível em $<$ http: 7/www.nimbix.net/nvidia/> (acesso em dez. 2013).

[171] Noh, G. \& Bathe, K.-J. (2013). An explicit time integration scheme for the analysis of wave propagations. Computers \& Structures, 129:178-193.

[172] Nokia Corporation. Qt. Disponível em < http://at.nokia.com/ $>$ (acesso em set. 2011).

[173] Nunes Dias, C., Driemeier, L., Bittencourt, M., \& Alves, M. (2009). FEMSYS - an explicit finite element code for non-linear dynamic structural analysis: a time integration strategy. Em da Costa Mattos, H. \& Alves, M., eds., Mechanics of Solids in Brazil 2009, p. 411-423. Brazilian Society of Mechanical Sciences and Engineering. 
[174] Nvidia Corporation. CUDA zone. Disponível em <http://developer.nvidia.com/ category/zone/cuda-zone $>$ (acesso em set. 2011).

[175] Nvidia Corporation. NVIDIA CUDA C programming guide. Disponível em $<$ http://docs.nvidia.com/cuda/index.html $>$ (acesso em jul. 2013).

[176] Oh, K.-S. \& Jung, K. (2004). GPU implementation of neural networks. Pattern Recognition, 37:1311-1314.

[177] Open Channel Software. Open Channel Foundation: Request NASTRAN. Disponível em <http://www.openchannelsoftware.org/orders/index.php?group_id=112 $>$ (acesso em dez. 2013).

[178] OpenACC. OpenACC - directives for accelerators. Disponível em < http://www. openacc-standard.org/> (acesso em dez. 2013).

[179] OpenMP ARB. The OpenMP API specification for parallel programming. Disponível em <http://openmp.org/wp/> (acesso em jan. 2014).

[180] Ozpetek, S. (1988). A nonlinear finite element stress analysis of the leaflets of a prosthetic heart valve. Mathematical and Computer Modeling, 11:152-157.

[181] Pagani, M., Reese, S., \& Perego, U. (2014). Computationally efficient explicit nonlinear analyses using reduced integration-based solid-shell finite elements. Computer Methods in Applied Mechanics and Engineering, 268:141 - 159.

[182] Pascon, J. \& Coda, H. (2013). Large deformation analysis of elastoplastic homogeneous materials via high order tetrahedral finite elements. Finite Elements in Analysis and Design, 76:21 - 38 .

[183] Patzák, B. \& Bittnar, Z. (2001). Design of object oriented finite element code. Advances in Engineering Software, 32:759-767.

[184] Peng, J. \& Law, K. H. (2004). Building finite element analysis programs in distributed services environment. Computers \& Structures, 82:1813-1833.

[185] Peng, J., Liu, D., \& Law, K. H. (2003). An engineering data access system for a finite element program. Advances in Engineering Software, 34:163-181.

[186] Pennycook, S. J., Hammond, S. D., Wright, S. A., Herdman, J. A., Miller, I., \& Jarvis, S. A. (2013). An investigation of the performance portability of OpenCL. Journal of Parallel and Distributed Computing, 73:1439-1450.

[187] Phongthanapanich, S. \& Dechaumphai, P. (2006). EasyFEM - an objectoriented graphics interface finite element/finite volume software. Advances in Engineering Software, 37:797-804. 
[188] Plešek, J. \& Korouš, J. (2002). Explicit integration method with time step control for viscoplasticity and creep. Advances in Engineering Software, 33(7-10):621 -630 .

[189] Pop, S. Intel Ivy Bridge-E/EP CPUs will have up to 12 cores. Disponível em $<$ http://news. softpedia.com/news/Intel-Ivy-Bridge-E-EP-CPUs-Will-Have-Up-to-12-Cores-295703. shtml > (acesso em dez. 2013).

[190] Pöschl, W., Vretenar, D., Rummel, A., \& Ring, P. (1997). Application of finite element methods in relativistic mean-field theory: spherical nucleus. Computer Physics Communications, 101(1-2):75-107.

[191] Prado, F. S. (2013). Modelagem do comportamento dinâmico não linear de risers pelo método dos elementos finitos. Dissertação de mestrado, Escola Polit'ecnica da Universidade de São Paulo, São Paulo, Brasil.

[192] Prathap, G. (1994a). The displacement-type finite element approach - from art to science. Prog. Aerospace Sci., 30:295-405.

[193] Prathap, G. (1994b). Locking, rank and singularity of penalty-linked stiffness matrix and consistency of strain-field. Computer \& Structures, 52(1):35-39.

[194] Preis, T., Virnau, P., Paul, W., \& Schneider, J. J. (2009). GPU accelerated Monte Carlo simulation of the 2D and 3D Ising model. Journal of Computational Physics, 228:4468-4477.

[195] Puso, M. A. (2000). A highly efficient enhanced assumed strain physically stabilized hexahedral element. International Journal for Numerical Methods in Engineering, 49:1029-1064.

[196] Ramakrishna, S., Mayer, J., Wintermantel, E., \& Leong, K. W. (2001). Biomedical applications of polymer-composite materials: a review. Composites Science and Technology, 61(9):1189-1224.

[197] Rank, E., Düster, A., Nübel, V., Preusch, K., \& Bruhns, O. (2005). High order finite elements for shells. Computer Methods in Applied Mechanics and Engineering, 194(21-24):2494 - 2512.

[198] Rao, A. R. M., Rao, T. A., \& Dattaguru, B. (2003). A new parallel overlapped domain decomposition method for nonlinear dynamic finite element analysis. Computer \&5 Structures, 81(26-27):2441-2454.

[199] Rao, S. S. (2011). The finite element method in engineering. ButterworthHeinemann, EUA, 5a. edição. 
[200] Rathod, H. \& Karim, M. S. (2002). An explicit integration scheme based on recursion for the curved triangular finite elements. Computers \& Structures, $80(1): 43-76$.

[201] Reese, S. (2005). On a physically stabilized one point finite element formulation for three-dimensional finite elasto-plasticity. Computer methods in Applied Mechanics and Engineering, 194:4685-4715.

[202] Reese, S., Wriggers, R., \& Reddy, B. D. (2000). A new locking-free brick element technique for large deformation problems in elasticity. Computer and Structures, 75:291-304.

[203] Rigobello, R., Coda, H. B., \& Neto, J. M. (2013). Inelastic analysis of steel frames with a solid-like finite element. Journal of Constructional Steel Research, $86: 140-152$.

[204] Rodrigues, E. \& Amaro, L. Universidade federal de sergipe: Professor desenvolve projeto para dar suporte a estudos de elementos finitos. Disponível em <http://www.ufs.br/conteudo/ professor-desenvolve-projeto-para-dar-suporte-estudos-elementos-finitos-8087.html> (acesso em jan. 2014).

[205] Rosenberg, D., Stephens, M., \& Collins-Cope, M. (2005). Agile development with ICONIX Process: People, process, and pragmatism. Apress.

[206] Sadowski, A. J. \& Rotter, J. M. (2013). Solid or shell finite elements to model thick cylindrical tubes and shells under global bending. International Journal of Mechanical Sciences, 74:143 - 153.

[207] Sanders, J. \& Kandrot, E. (2011). CUDA by example. Addison-Wesley, EUA.

[208] Schenk, O., Christen, M., \& Burkart, H. (2008). Algorithmic performance studies on graphics processing units. J. Parallel Distrib. Comput., 68:1360-1369.

[209] Schrem, E. (1979). Trends and aspects of the development of large finite element software systems. Computer \& Structures, 10:419-425.

[210] Sebesta, R. W. (2010). Concepts of Programming Language. Addison-Wesley, EUA, 9a. edição.

[211] Shi, B.-J., Shu, D.-W., Wang, S., Luo, J., Meng, H., Ng, Q., Lau, J. H. T., \& Zambri, R. (2007). Drop test simulation and power spectrum analysis of a head actuator assembly in a hard disk drive. International Journal of Impact Engineering, 34:120-133. 
[212] Sintorn, E. \& Assarsson, U. (2008). Fast parallel GPU-sorting using a hybrid algorithm. J. Parallel Distrib. Comput., 68:1381-1388.

[213] Smith, I. \& Griffiths, D. (2004). Programming the Finite Element Method. Wiley, EUA, 4a. edição.

[214] Smith, R. NVIDIA launches Tesla K20 \& K20X: GK110 arrives at last. Disponível em <http://www.anandtech.com/show/6446/ nvidia-launches-tesla-k20-k20x-gk110-arrives-at-last/3 > (acesso em dez. 2013).

[215] Softlayer Technologies Inc. High performance computing servers. Disponível em <http://www.softlayer.com/dedicated-servers/high-performance-computing $>$ (acesso em dez. 2013).

[216] Soriano, H. L. (2003). Método de Elementos finitos em análise de estruturas. Edusp.

[217] Stallings, W. (2004). Arquitetura e Organização de Computadores. Prentice Hall, São Paulo, Brasil, 5a. edição.

[218] Stewart, J. (2005). Cálculo, volume II. Pioneira, Thomson Learning, São Paulo, 4a. edição.

[219] Stroustrup, B. (2013). The C++ programming language. Addison-Wesley, 4a. edição.

[220] Sutter, H. (1999). Exceptional $C++$ : 47 engineering puzzles, programming problems, and solutions. $\mathrm{C}++$ In-Depth. Addison-Wesley.

[221] Sze, K. Y. \& Fan, H. (1996). An economical assumed stress brick element and its implementation. Finite Elements in Analysis and Design, 21:179-200.

[222] Takahashi, A. G. (2004). GPU contra CPU. Revista PCs, (46):10-11.

[223] Taylor, R. L. (2008). My fifty years with Finite Elements. Em WCCM8/ECCOMAS 2008 Congress.

[224] TOP500.Org. TOP500 supercomputing sites. Disponível em < http://www.top500. org/ $>$ (acesso em dez. 2013).

[225] Torii, A. J. \& Machado, R. D. (2012). Structural dynamic analyses for time response of bars and trusses using the Generalized Finite Element Method. Latin American Journal of Solids and Structures, 9(3):309-337.

[226] Trapnell, C. \& Schatz, M. C. (2009). Optimizing data intensive GPGPU computations for DNA sequence alignment. Parallel Computing, 35(8-9):429-440. 
[227] Turek, S., Göddeke, D., Buijssen, S. H., \& Wobker, H. (2011). Hardwareoriented multigrid finite element solvers on GPU-accelerated clusters. Em Kurzak, J., Bader, D. A., \& Dongarra, J., eds., Scientific Computing with Multicore Accelerators, p. 113-130. CRC Press.

[228] University of Colorado. Introduction to finite element methods (asen 5007). Disponível em <http://www.colorado.edu/engineering/cas/courses.d/IFEM.d/ $>$ (acesso em dez. 2013).

[229] University of Waterloo Computer Graphics Lab. Sh: A high-level metaprogramming language for modern GPUs. Disponível em $<$ http://libsh.org/ $>$ (acesso em jun. 2009).

[230] Vaz, L. E. (2011). Método dos elementos finitos em análise de estruturas. Campus, Brasil.

[231] Venkatesh, D. N. \& Shrinivasa, U. (1994). Solid finite elements through three decades. Sadhana, 19(2):271-287.

[232] Vidal, P., Gallimard, L., \& Polit, O. (2014). Shell finite element based on the proper generalized decomposition for the modeling of cylindrical composite structures. Computers \& Structures, 132:1 - 11.

[233] Weng, W.-C. (2011). Web-based post-processing visualization system for finite element analysis. Advances in Engineering Software, 42:398-407.

[234] Wikipedia. Assembly language. Disponível em <http://en.wikipedia.org/wiki// Assembly_language $>$ (acesso em fev. 2013).

[235] Wikipedia. GeForce 700 series. Disponível em <http://en.wikipedia.org/wiki// GeForce_700_Series $>$ (acesso em dez. 2013).

[236] Wikipedia. Ivy bridge (microarchitecture). Disponível em < http://en.wikipedia. org/wiki/Ivy_Bridge_(microarchitecture) $>$ (acesso em dez. 2013).

[237] Wikipedia. Nastran. Disponível em <http://en.wikipedia.org/wiki/Nastran $>$ (acesso em dez. 2013).

[238] Wikipedia. Nvidia tesla. Disponível em <http://en.wikipedia.org/wiki/Nvidia_Tesla $>$ (acesso em dez. 2013).

[239] Wikipedia. Pentium 4. Disponível em <http://en.wikipedia.org/wiki/Pentium_4 $>$ (acesso em dez. 2013).

[240] Wikipedia. Extended backus-naur form. Disponível em <http://en.wikipedia.org/ wiki/Extended_Backus\%E2\%80\%93Naur_Form $>$ (acesso em jan. 2014). 
[241] Wikipedia. PCI Express. Disponível em < http://en.wikipedia.org/wiki/PCI_Express $>$ (acesso em jan. 2014).

[242] Williams, S., Oliker, L., Vuduc, R., Shalf, J., Yelick, K., \& Demmel, J. (2007). Optimization of sparse matrix-vector multiplication on emerging multicore platforms. Em SC '0\%: Proceedings of the 2007 ACM/IEEE conference on Supercomputing, p. 1-12, New York, NY, EUA. ACM.

[243] Wills, C. M. R. \& Roe, D. (1972). NASTRAN - a finite element program for structural analysis. Computer-Aided Design, 4(4):172-175.

[244] Wu, S. R. (2006). Lumped mass matrix in explicit finite element method for transient dynamics of elasticity. Computer Methods in Applied Mechanics and Engineering, 195:5983-5994.

[245] Wu, S. R. \& Gu, L. (2012). Introduction to the Explicit Finite Element Method for Nonlinear Transient Dynamics. Wiley, EUA.

[246] Wu, T.-Y. (2013). Dynamic nonlinear analysis of shell structures using a vector form intrinsic finite element. Engineering Structures, 56:2028 - 2040.

[247] Xiao, H., Bruhns, O. T., \& Meyers, A. (1997). Logarithmic strain, logarithmic spin and logarithmic rate. Acta Mechanica, 124:89-105.

[248] Xingjian, Y. (1991). A database design technique for finite element analysis. Computer Methods in Applied Mechanics and Engineering, 91(1-3):1357-1364.

[249] Xingjian, Y. (1992). A database design method for finite element analysis. Computer \& Structures, 44(4):911-914.

[250] Yu, N., Polycarpou, A. A., \& Hanchi, J. V. (2010). Thermomechanical finite element analysis of slider-disk impact in magnetic storage thin film disks. Tribology International, 43:737-745.

[251] Zhang, S. (2007). Numerical integration with Taylor truncations for the quadrilateral and hexahedral finite elements. Journal of Computational and Applied Mathematics, 205(1):325 - 342 .

[252] Zienkiewicz, O., Taylor, R., \& Zhu, J. (2005). The Finite Element Method: Its Basis and Fundamentals. Butterworth-Heinemann, 6a. edição.

[253] Zienkiewicz, O. C. (1971). The Finite Element Method in Engineering Science. McGraw-Hill, New York.

[254] Zwillinger, D. (2011). CRC Standard Mathematical Tables and Formulae. Discrete Mathematics and Its Applications. CRC Press, 32a. edição. 



\section{APÊNDICE A}

\section{Fundamentos de não-linearidade em elementos finitos}

Provavelmente, análises lineares são predominantes na resolução dos problemas em Engenharia. Por outro lado, cada vez mais se exploram aplicações governadas por relações não-lineares, sejam de caráter:

- Geométrico, onde as quantidades cinemáticas em estudo são não-lineares, tais como grandes deslocamentos, deformações, rotações, entre outros.

- Material, quando a relação tensão-deformação ou força-deslocamento não são lineares.

- Condições de contorno, nos quais o conjunto inicial de condições de contorno não é preservado ao longo da análise. Refere-se principalmente a fenômenos de contato, não contemplados neste trabalho.

Em diversos casos, opta-se pela análise não-linear de estruturas quando se tem, pelo menos, um dos seguintes motivos:

- desenvolvimento de componentes de alto desempenho;

- estudo detalhado de um fenômeno;

- investigar as causas da falha de um componente; ou

- simular com precisão o comportamento de um material. 
Análises não-lineares são computacionalmente intensas e fazem uso de algoritmos mais sofisticados e complexos. Este é o caso de impacto estrutural, que é um fenômeno predominantemente não-linear. Para habilitar o MEF a representá-lo precisamente, torna-se necessária a incorporação das relações governantes pertinentes, que serão apresentadas a seguir de uma forma objetiva. As equações governantes apresentadas neste trabalho leva em consideração a formulação Lagrangiana Total. Outras formas de descrição das equações, como as formulações Lagrangiana Atualizada e a Euleriana, e maiores detalhes acerca de não linearidade em elementos finitos podem ser encontrados, respectivamente em Belytschko et al. [23] e Bathe [16], de Souza Neto et al. [69], Wu e Gu [245].

\section{A.1 Gradiente de deformação}

Dado um corpo que se move, é chamado de configuração o mapeamento da posição do corpo no espaço em dado instante de tempo. Por ser possível mapear o deslocamento do corpo em todos os instantes, diz-se que o mapeamento é diferenciável.

Na Figura A.1, considere o ponto $P$, cuja posição é representada pelo vetor X em relação a um referencial fixo. Quando o corpo, em sua configuração de referência (ou inicial) sofre deformação, o mesmo ponto se desloca para a posição de $P^{\prime}$, representada pelo vetor $\mathbf{x}$, resultando na configuração deformada (ou atual) do contínuo. Para cada ponto do corpo, existe uma função de mapeamento, $\phi$, que associa um ponto $P$ da configuração de referência com o seu estado deformado $P^{\prime}$ (isso não necessariamente implica em uma única função de mapeamento para todos os pontos do corpo). Considera-se que essa função mapeia a posição de um ponto em todos os instantes de tempo o que, portanto, a torna diferenciável.

Agora, considerando um infinitesimal do corpo em sua configuração de referência, dado pelo segmento $P Q$, também representado pelo vetor $d \mathbf{X}$, ao sofrer deformação, os pontos do segmento são mapeados para $P^{\prime}$ e $Q^{\prime}$, respectivamente. Os pontos em ambas as configurações são relacionadas através do deslocamento sofrido, $\underset{\sim}{\mathbf{u}}$, tal que

$$
\mathbf{x}=\mathbf{X}+\underset{\sim}{\mathbf{u}}
$$

A transformação do vetor infinitesimal $d \mathbf{X}$ para a sua configuração deformada, $d \mathbf{x}$ (segmento $P^{\prime} Q^{\prime}$ ), é dada pelo gradiente de deformação $\boldsymbol{F}$, em que

$$
d \mathbf{x}=\boldsymbol{F} d \mathbf{X}
$$




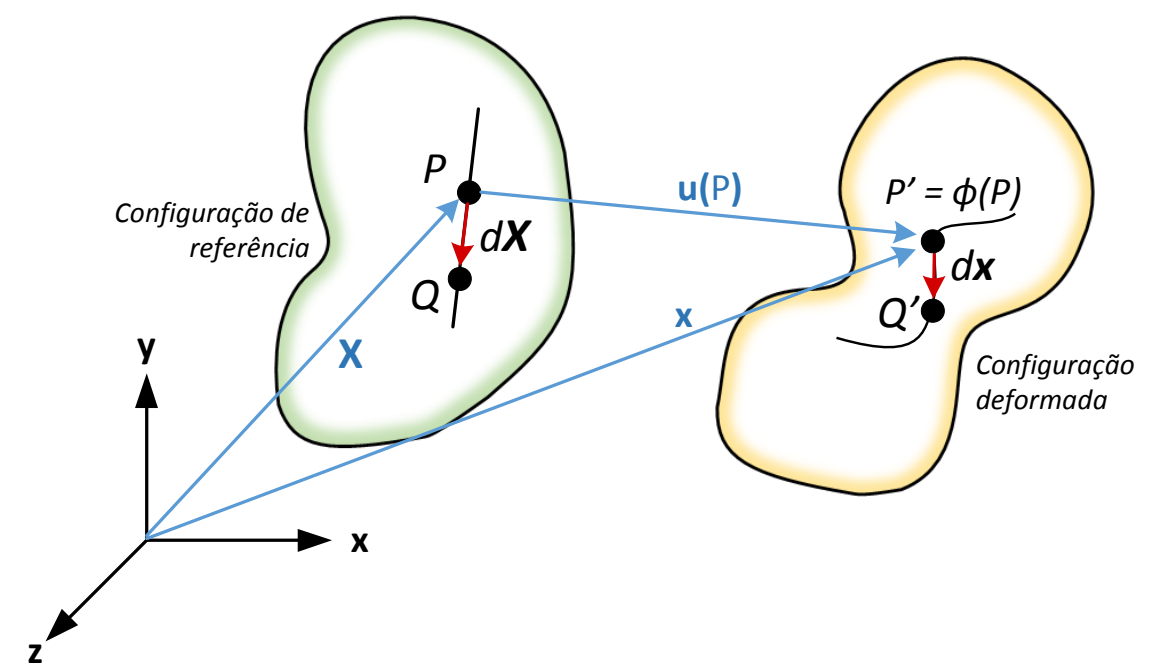

Figura A.1 Um infinitesimal de um corpo em sua configuração de referência sofrendo deformação e se deslocando para sua configuração deformada.

que possui as componentes

$$
\left\{\begin{array}{l}
d x \\
d y \\
d z
\end{array}\right\}=\left[\begin{array}{ccc}
\frac{\partial x}{\partial X} & \frac{\partial x}{\partial Y} & \frac{\partial x}{\partial Z} \\
\frac{\partial y}{\partial X} & \frac{\partial y}{\partial Y} & \frac{\partial y}{\partial Z} \\
\frac{\partial z}{\partial X} & \frac{\partial z}{\partial Y} & \frac{\partial z}{\partial Z}
\end{array}\right]\left\{\begin{array}{c}
d X \\
d Y \\
d Z
\end{array}\right\}
$$

Alternativamente, $\boldsymbol{F}$ é escrito simplesmente como

$$
\boldsymbol{F}=\frac{\partial \mathbf{x}}{\partial \mathbf{X}}
$$

Substituindo a Eq. (A.1) em (A.4), temos

$$
\boldsymbol{F}=\frac{d(\underline{\mathbf{u}}+\mathbf{X})}{d \mathbf{X}}=\frac{d \underline{\mathbf{u}}}{d X}+\boldsymbol{I}
$$

Se o corpo sofre translação rígida, então u independe de $\mathbf{X}$ e, portanto, $\boldsymbol{F}=\boldsymbol{I}$. Logo, o gradiente de deformação não contabiliza o movimento, todavia, rotações rígidas são consideradas (vide seção A.4).

Assume-se que $\boldsymbol{F}$ mapeia um infinitesimal de um corpo em todos os instantes de tempo e, portanto, é diferenciável. Ao mesmo tempo, esse mapeamento é único, logo, o gradiente de deformação é invertível, o que nos permite dizer que, pela Eq. (A.2):

$$
d \mathbf{X}=\boldsymbol{F}^{-1} d \mathbf{x}
$$




\section{A.2 Determinante do gradiente de deformação}

O determinante de $\boldsymbol{F}$ (que, confusamente, é algumas vezes chamado de jacobiano na literatura) mensura a mudança de volume produzida pela deformação correspondente (vide prova em de Souza Neto et al. [69]). É definido por:

$$
J=\operatorname{det}(\boldsymbol{F})=\frac{d v}{d v_{0}}
$$

onde $d v_{0}$ e $d v$ são os volumes inicial e final do infinitesimal, respectivamente.

A condição $J \leq 0$ nunca ocorre, pois é uma situação fisicamente inadmissível, na qual o volume colapsa em um único ponto (igual a zero) ou que o espaço fosse "virado pelo avesso" (menor que zero). Essa desigualdade é usada em algumas implementações para verificar a estabilidade da solução de elementos finitos.

É também possível estabelecer a razão de mudança da densidade do material em um ponto através de $J$, tal que

$$
\rho=\frac{\rho_{0}}{J}
$$

onde $\rho_{0}$ e $\rho$ são as densidades inicial e final do infinitesimal, respectivamente.

\section{A.3 Decomposição multiplicativa do gradiente de deformação}

Qualquer deformação pode ser dividida em componentes multiplicativas de deformação puramente isocórica e puramente volumétrica, tal que

$$
\boldsymbol{F}=\boldsymbol{F}^{\text {iso }} \boldsymbol{F}^{\mathrm{vol}}=\boldsymbol{F}^{\mathrm{vol}} \boldsymbol{F}^{\text {iso }}
$$

onde a componente volumétrica, $\boldsymbol{F}^{\mathrm{vol}}$, vale

$$
\boldsymbol{F}^{\mathrm{vol}}=J^{1 / 3} \boldsymbol{I}
$$

e a parte isocórica, $\boldsymbol{F}^{\text {iso }}$, é

$$
\boldsymbol{F}^{\text {iso }}=J^{-1 / 3} \boldsymbol{F}
$$

\section{A.4 Decomposição polar}

O gradiente de deformação é invertível e positivo-definido [25]. Portanto, admite decomposição polar, o que significa que é possível descrever a deformação do infinitesimal em uma componente de rotação rígida e outra de alongamento puro, isto é,

$$
\boldsymbol{F}=\boldsymbol{R} \boldsymbol{U}=\boldsymbol{V} \boldsymbol{R}
$$


onde $\boldsymbol{R}$ é o tensor de rotação rígida e $\boldsymbol{U}$ e $\boldsymbol{V}$ são, respectivamente, os tensores de alongamento direito e esquerdo, positivos-definidos e simétricos, tal que

$$
\begin{aligned}
& \boldsymbol{U}=\sqrt{\boldsymbol{F}^{T} \boldsymbol{F}} \\
& \boldsymbol{V}=\sqrt{\boldsymbol{F}^{T}}
\end{aligned}
$$

e $\sqrt{(\cdot)}$ é a raiz quadrada do tensor $(\cdot)$.

\section{A.5 Medidas de deformação}

Em deformações finitas, diferentes medidas de deformação são definidas. Cada uma apresenta maior importância no estudo de um fenômeno específico, guardando propriedades matemáticas que auxiliam na formulação do modelo numérico. Nesta seção, são abordadas algumas dessas medidas.

\section{A.5.1 Tensores de deformação de Cauchy-Green}

Seja a linha infinitesimal $d \mathbf{X}$, na configuração de referência, mapeada para $d \mathbf{x}$ na configuração deformada. Considerando o comprimento $d l$ de $d \mathbf{x}$, É possível estabelecer a seguinte relação usando a Eq. (A.4) [78]:

$$
d l^{2}=d \mathbf{x} \cdot \boldsymbol{l} \cdot d \mathbf{x}=(\boldsymbol{F} d \mathbf{X}) \cdot(\boldsymbol{F} d \mathbf{X})=d \mathbf{X} \boldsymbol{F}^{T} \boldsymbol{F} d \mathbf{X}=d \mathbf{X} \boldsymbol{C} d \mathbf{X}=d \mathbf{X} \cdot \boldsymbol{C} \cdot d \mathbf{X}
$$

onde $\boldsymbol{C}=\boldsymbol{F}^{T} \boldsymbol{F}$ é, por definição, o tensor direito de Cauchy-Green. Assim como $d \mathbf{X}, \boldsymbol{C}$ está definido na configuração de referência e, portanto, é classificado como um tensor material (ou Lagrangiano).

Fazendo uso da ortogonalidade de $\boldsymbol{R}, \boldsymbol{C}$ também pode ser definido através da decomposição polar de $\boldsymbol{F}[165]$ :

$$
\boldsymbol{C}=\boldsymbol{F}^{T} \boldsymbol{F}=(\boldsymbol{R} \boldsymbol{U})^{T}(\boldsymbol{R} \boldsymbol{U})=\boldsymbol{U}^{T} \boldsymbol{R}^{T} \boldsymbol{R} \boldsymbol{U}=\boldsymbol{U}^{2}
$$

Agora, considerando o comprimento $d L$ da linha infinitesimal $d \mathbf{X}$, na configuração de referência, e a Eq. (A.6), temos:

$d L^{2}=d \mathbf{X} \cdot \boldsymbol{l} \cdot d \mathbf{X}=\left(\boldsymbol{F}^{-1} d \mathbf{x}\right) \cdot\left(\boldsymbol{F}^{-1} d \mathbf{x}\right)=d \mathbf{x} \boldsymbol{F}^{-T} \boldsymbol{F}^{-1} d \mathbf{x}=d \mathbf{x} \boldsymbol{B}^{-1} d \mathbf{x}=d \mathbf{x} \cdot \boldsymbol{B}^{-1} \cdot d \mathbf{x}$

onde $\boldsymbol{B}^{-1}=\boldsymbol{F}^{-T} \boldsymbol{F}^{-1}$ e $\boldsymbol{B}=\boldsymbol{F} \boldsymbol{F}^{T}$ é o tensor esquerdo de Cauchy-Green, também denominado tensor de Finger. Por estar definido na configuração deformada, é classificado como um tensor espacial (ou Euleriano). 
Analogamente, $\boldsymbol{B}$ pode ser definido através da decomposição polar de $\boldsymbol{F}$ :

$$
\boldsymbol{B}=\boldsymbol{F} \boldsymbol{F}^{T}=(\boldsymbol{V} \boldsymbol{R})(\boldsymbol{V} \boldsymbol{R})^{T}=\boldsymbol{V} \boldsymbol{R} \boldsymbol{R}^{T} \boldsymbol{V}=\boldsymbol{V}^{2}
$$

Através das Eqs. (A.16) e (A.18), é notório que os tensores de Cauchy-Green são insensíveis à rotação rígida e, portanto, modelos de materiais que fazem uso dessa medida não requerem a correção das tensões devido ao movimento. No entanto, se não há deformação, $\boldsymbol{F}=\boldsymbol{I}$, então $\boldsymbol{U}=\boldsymbol{V}=\boldsymbol{I}$ e $\boldsymbol{C}=\boldsymbol{B}=\boldsymbol{I}$. Logo, os tensores não são nulos sob deformação zero. Para modelos de materiais que requeiram esta condição, outras medidas de deformação podem ser apropriadas [25, 69, 165].

\section{A.5.2 Tensor de deformação de Green-Lagrange}

O tensor de Green-Lagrange, $\boldsymbol{E}_{\boldsymbol{E}}$, é definido por

$$
\stackrel{\mathrm{GL}}{\boldsymbol{E}}=\frac{1}{2}\left(\boldsymbol{F}^{T} \boldsymbol{F}-\boldsymbol{I}\right)=\frac{1}{2}(\boldsymbol{C}-\boldsymbol{I})
$$

O tensor material $\stackrel{G L}{\boldsymbol{E}}$ oferece uma maneira alternativa de mensurar a deformação, onde, para ausência de deformação, o tensor é nulo. Como está em função de $\boldsymbol{C}$, ele também é insensível a rotações rígidas.

\section{A.5.3 Tensor de deformação de Hencky ou logarítmico}

O tensor material de Hencky, $\boldsymbol{H}^{(M)}$, é definido por

$$
\boldsymbol{H}^{(M)}=\ln (\boldsymbol{U})=\frac{1}{2} \ln (\boldsymbol{C})
$$

onde $\ln (\cdot)$ é o logaritmo natural do tensor $(\cdot)$.

A versão espacial do tensor é dada por

$$
\boldsymbol{H}^{(E)}=\ln (\boldsymbol{V})=\frac{1}{2} \ln (\boldsymbol{B})
$$

onde $\boldsymbol{H}^{(E)}$, ou simplesmente $\boldsymbol{H}$, é o tensor espacial de Hencky, sendo esta a medida adotada pelo programa Axis.

Novamente, $\boldsymbol{H}$ é insensível a rotações rígidas. Esta medida de deformação é bastante conhecida por apresentar propriedades similares ao tensor de deformação infinitesimal $\boldsymbol{\varepsilon}$ do caso linear e, por vezes, é conhecida como a deformação natural ou verdadeira. Contudo, ele dificilmente é calculado diretamente devido à dificuldade 
de se obter $\ln (\boldsymbol{B})$, o que envolve a custosa decomposição espectral de $\boldsymbol{B}$. Quando necessário, o tensor é geralmente obtido por aproximações, como, por exemplo, mostra Bažant [19].

\section{A.6 Gradiente de velocidade, taxa de deformação e giro}

Define-se como gradiente de velocidade $(\boldsymbol{L})$ a variação espacial da velocidade $(d \underset{\sim}{\dot{\mathbf{u}}})$ para um incremento de posição $d \mathbf{x}$ na configuração deformada [78], isto é,

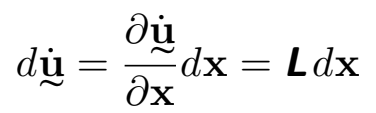

É mais interessante definir o gradiente de velocidade em função de $\boldsymbol{F}$, ou seja, segundo Moura [165],

$$
\boldsymbol{L}=\frac{\partial \underset{\sim}{\dot{\mathbf{u}}}}{\partial \mathbf{x}}=\frac{\partial \underset{\mathbf{u}}{\partial}}{\partial \mathbf{X}} \frac{\partial \mathbf{X}}{\partial \mathbf{x}}=\frac{\partial}{\partial t}\left(\frac{\partial \mathbf{x}}{\partial \mathbf{X}}\right) \frac{\partial \mathbf{X}}{\partial \mathbf{x}}=\dot{\boldsymbol{F}} \boldsymbol{F}^{-1}
$$

o que nos permite dizer que $\boldsymbol{L}$ relaciona o gradiente de deformação com a sua taxa.

O gradiente de velocidade pode ser decomposto em partes simétrica e antisimétrica:

$$
\begin{gathered}
\boldsymbol{L}=\boldsymbol{D}+\boldsymbol{W} \\
\boldsymbol{D}=\frac{1}{2}\left(\boldsymbol{L}+\boldsymbol{L}^{T}\right) \\
\boldsymbol{W}=\frac{1}{2}\left(\boldsymbol{L}-\boldsymbol{L}^{T}\right)
\end{gathered}
$$

onde $\boldsymbol{D}$ é o tensor de taxa de deformação e $\boldsymbol{W}$ é o tensor de giro. Ambas as parcelas representam quantias importantes para diversos modelos constitutivos.

O tensor de taxa de deformação $\boldsymbol{D}$ é uma quantia cinemática que oferece uma forma de mensurar a taxa de mudança do comprimento de uma linha infinitesimal e a taxa de mudança de ângulo entre dois elementos infinitesimais do corpo em deformação [247]. Contudo, segundo Hoger [109], o tensor também oferece uma aproximação para taxas co-rotacionais (ou objetivas) da deformação logarítmica espacial (tal como a taxa de Jaumann) para incrementos de tempo pequenos, onde a deformação é pequena e evolui lentamente, como é o caso em métodos explícitos de integração temporal.

Xiao et al. [247] também oferece uma prova mais generalizada para a relação, na qual se demonstra que, mantendo-se a restrição do passo de tempo,

$$
D \equiv \dot{H}
$$


o que significa que $\boldsymbol{D}$ é uma medida mais simples e direta da taxa de deformação, usufruindo das propriedades do tensor Euleriano $\boldsymbol{H}$. $\boldsymbol{D}$ é a taxa co-rotacional mais simples, usada principalmente nos modelos de materiais hipo-elástico e nos sensíveis à taxa de deformação. Além disso, a elaboração de modelos através de $\boldsymbol{D}$ permite o uso das tensões de Cauchy como o par energeticamente conjugado (este tópico será abordado mais adiante) [110, 247].

O tensor de giro $\boldsymbol{W}$ é importante na medida da velocidade angular de um ponto material do corpo e é dado por [78]

$$
\boldsymbol{W}=\boldsymbol{\Omega}+\boldsymbol{R} \text { antissim }\left(\dot{\boldsymbol{U}} \boldsymbol{U}^{-1}\right) \boldsymbol{R}^{T}
$$

onde $\operatorname{antissim}(\cdot)$ é a parte anti-simétrica do tensor $(\cdot)$ e $\boldsymbol{\Omega}$ é o tensor de velocidade angular,

$$
\boldsymbol{\Omega}=\dot{R} \boldsymbol{R}^{T}
$$

Quando o corpo está sujeito apenas a rotações rígidas ou, então, as deformações são consideravelmente pequenas no intervalo de tempo, temos que

$$
\boldsymbol{\Omega}=\boldsymbol{W}=\dot{R} \boldsymbol{R}^{T}
$$

Esta relação é importante para a elaboração de taxas de tensão objetivas, conforme será visto mais adiante.

\section{A.7 Medidas de tensão}

Nas equações constitutivas, é importante que sejam corretamente selecionadas as medidas de deformação e tensão, para que a taxa de energia interna do corpo, $\dot{\psi}$, seja corretamente representada. Em processos puramente mecânicos e não dissipativos, a conservação de energia do corpo é dada pela relação,

$$
\dot{\psi}=(\cdot)_{\sigma}:(\cdot)_{\varepsilon}
$$

$(\cdot)_{\boldsymbol{\sigma}}$ e $(\dot{\cdot})_{\boldsymbol{\varepsilon}}$ são, respectivamente, medidas de tensão e de taxa de deformação, cujo par é capaz de descrever a taxa de energia interna do corpo. Diz-se, então, que o par de medidas é conjugado em potência (também chamado de conjugado energético ou, ainda, de trabalho). A escolha de uma par conjugado adequado é importante para a correta construção das equações do Princípio da Potência Virtual, importantes para a formulação de elementos finitos.

Diversas medidas de tensão existem e, assim como com as medidas de deformação, cada uma apresenta vantagens para o estudo de um fenômeno específico devido 
as suas propriedades. As medidas de tensão mais relevantes para este trabalho serão apresentadas a seguir.

\section{A.7.1 Tensor de tensão de Cauchy}

O tensor de tensão de Cauchy $(\boldsymbol{T}$ ) relaciona a força sobre unidade de área na configuração deformada e, por isso, é também conhecido como a tensão verdadeira. Por definição, suas componentes normais são positivas em tração e negativas em compressão e, devido à conservação de momento angular, é um tensor simétrico.

Por definir o estado do corpo em sua configuração deformada, ele é um dos mais aceitos para a formulação de equilíbrio da estrutura, sendo a medida padrão em diversos pacotes comerciais de elementos finitos.

O tensor de Cauchy é conjugado em potência ao tensor de taxa de deformção $\boldsymbol{D}$, tal que 15

$$
\dot{\psi}=J \boldsymbol{T}: \boldsymbol{D}
$$

\section{A.7.2 Tensor de tensão de Kirchhoff}

Define-se o tensor de tensão de Kirchhoff, $\boldsymbol{\tau}$, por

$$
\tau=J \boldsymbol{T}
$$

Isto é, a medida de tensão escalona as tensões de Cauchy pela variação de volume do ponto. Se o movimento do corpo é isocórico, $J=1$, logo as medidas de tensão são equivalentes. Em alguns modelos de materiais, principalmente em algoritmos de plasticidade, ambas as medidas se confundem.

O tensor $\tau$ é usado em modelos constitutivos hiper-elásticos e hipo-elastoplásticos, pois leva à simetria do módulo tangente do material [165]. Das Eqs. A.32 e (A.33), determina-se o seu conjugado em potência,

$$
\dot{\psi}=\boldsymbol{\tau}: \boldsymbol{D}
$$

\section{A.7.3 Primeiro tensor de tensão de Piola-Kirchhoff}

O primeiro tensor de Piola-Kirchhoff, $\boldsymbol{P}$, expressa as tensões como uma relação das forças, na configuração deformada, com a área, na configuração de referência. Ele se relaciona com o tensor de Cauchy através da fórmula:

$$
\boldsymbol{P}=J \boldsymbol{T} \boldsymbol{F}^{-T}
$$


Devido à relação entre diferentes configurações, o tensor não é simétrico. A medida é conjugada em potência com a taxa do gradiente de deformação,

$$
\dot{\psi}=\boldsymbol{P}: \dot{\boldsymbol{F}}
$$

\section{A.7.4 Segundo tensor de tensão de Piola-Kirchhoff}

Diferentemente do primeiro tensor, o segundo tensor de Piola-Kirchhoff, $\boldsymbol{S}$, relaciona as forças e a área de aplicação na configuração de referência. Esta medida é bastante utilizada na definição de materiais hiper-elásticos [32, 165] e sua relação com a tensão de Cauchy é dada por

$$
\boldsymbol{S}=J \boldsymbol{F}^{-1} \boldsymbol{T} \boldsymbol{F}^{-T}=\boldsymbol{F}^{-1} \boldsymbol{P}
$$

A pré-multiplicação pelo gradiente de deformação o torna simétrico. O seu conjugado em potência é o tensor de Green-Lagrange, tal que

$$
\dot{\psi}=\boldsymbol{S}: \dot{\mathrm{GL}}
$$

\section{A.8 Princípio da objetividade do material ou da indiferênça do referencial}

Quando as relações constitutivas são aplicadas no contexto de elasticidade linear, as deformações e deslocamentos sofridos pelo corpo são muito pequenos, a ponto de as rotações serem desprezíveis e, portanto, negligenciadas no modelo numérico. Contudo, no contexto geral de deformações finitas, um dado ponto material pode sofrer grandes deslcamentos e rotações, tal que os princípios adotados na formulação do modelo não são mais válidos, conforme ilustra o exemplo a seguir, baseado em Dunne e Petrinic [78], McGinty [159] e [165].

Considere uma barra no instante $t=0$, mostrado na Figura A.2, modelada com a seguinte relação constitutiva hipo-elástica:

$$
\dot{\boldsymbol{T}}=\mathrm{E}: \boldsymbol{D}
$$

onde $\mathbf{E}$ é o tensor do módulo do material que relaciona a taxa de tensão de Cauchy com o tensor de taxa de deformação.

Em $t=0$, a barra é sujeita a um carregamento axial, tal que seu estado de tensão se altera para $\left\{\sigma_{1} \sigma_{2}\right\}=\left\{\sigma_{0} 0\right\}$. A partir de então, a barra é induzida a uma rotação rígida, tal que em $t=t_{1}, \sigma_{1} \neq 0$ e $\sigma_{2} \neq 0 \mathrm{e}$, em $t=t_{2}$, o seu estado de tensão passa a ser $\left\{\sigma_{1} \sigma_{2}\right\}=\left\{0 ; \sigma_{0}\right\}$. Contudo, observe que a relação constitutiva não modela corretamente o evento, pois $\boldsymbol{D}$ é desacoplado das rotações sofridas pelo 

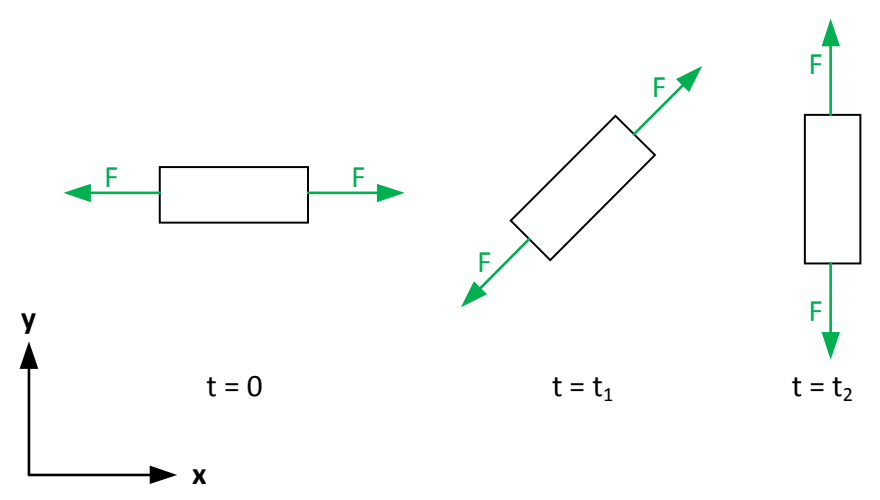

Figura A.2 Barra sujeita a uma rotação rígida, alterando seu estado de tensão.

corpo e, portanto, durante todo o processo, a taxa de tensão permaneceu nula. Isto é, do ponto de vista do modelo, as tensões não se alteraram.

Define-se então a objetividade ou indiferência de referencial de um tensor $(\cdot)$ como aquele no qual pode ser rotacionado para sua configuração $(\cdot)^{\prime}$ através da relação

$$
(\cdot)^{\prime}=\boldsymbol{R}(\cdot) \boldsymbol{R}^{T}
$$

Dessa forma, torna-se necessária a definição de taxas de tensão que alterem o estado de tensão do corpo, tal que os efeitos de rotação rígida sejam contabilizados. Ainda que algumas medidas de tensão sejam objetivas, como o tensor de Cauchy [78], isso pode não ser o caso de sua taxa temporal. São definidas na literatura diversas taxas de tensão, com o objetivo de corrigir essa deficiência. Uma medida em específico é foco deste estudo, a taxa de tensão de Jaumann.

\section{A.8.1 Taxa de tensão de Jaumann}

A taxa de tensão de Jaumann para o tensor de tensão de Cauchy é dada por

$$
\stackrel{\nabla J}{\boldsymbol{T}}=\dot{\boldsymbol{T}}-\boldsymbol{W} \boldsymbol{T}-\boldsymbol{T} \boldsymbol{W}^{T}
$$

$\nabla$

onde $(\cdot)$ denota uma taxa de tensão objetiva do tensor $(\cdot)$ e o superscrito $J$ denota a taxa de Jaumann. A prova da objetividade de $\underset{\boldsymbol{T}}{\nabla J}$ pode ser encontrada em de Souza Neto et al. [69], Dunne e Petrinic [78].

Numa relação constitutiva hipo-elástica, a correção da taxa de tensão de Cauchy, considerando as Eqs. A.39) e (A.41), pode ser dada por [165],

$$
\dot{\boldsymbol{T}}=\stackrel{\nabla J}{\boldsymbol{T}}+\boldsymbol{W} \boldsymbol{T}+\boldsymbol{T} \boldsymbol{W}^{T}=\mathbf{E}: \boldsymbol{D}+\boldsymbol{W} \boldsymbol{T}+\boldsymbol{T} \boldsymbol{W}^{T}
$$


onde a mudança do estado de tensão causado por rotações rígidas é dado pelos dois últimos termos da equação. Contudo, é importante observar que a objetividade somente é mantida para incrementos de deslocamento suficientemente pequenos. Esse é o caso para métodos de integração explícita no tempo, onde os incrementos de tempo são restritamente pequenos e garantem a objetividade da taxa [69]. 


\section{APÊNDICE B}

\section{Controle de hourglass}

Conforme apresentado na seção 2.6.2, a integração reduzida, utilizada para a redução do travamento e melhorar o desempenho computacional do elemento linear, introduz instabilidades numéricas que se manifestam como deformações não-físicas no modelo numérico, denominadas hourglassing. Neste apêndice, são apresentadas duas formas de controle que reduzem os efeitos de hourglassing, o controle viscoso de FlanaganBelytschko e o controle rígido de Puso.

\section{B.1 Estabilização de Flanagan-Belytschko}

Flanagan e Belytschko [84] define um controle de hourglass para o hexaedro linear usando integração reduzida. Nessa formulação, o deslocamento é descrito através de uma base ortogonal de oito vetores,

$\mathcal{N}_{i}=\frac{1}{8} \mathbf{s}+\frac{1}{4} \xi\left(\boldsymbol{\Lambda}_{1}\right)_{i}+\frac{1}{4} \eta\left(\boldsymbol{\Lambda}_{2}\right)_{i}+\frac{1}{4} \zeta\left(\boldsymbol{\Lambda}_{3}\right)_{i}+\frac{1}{2} \eta \zeta\left(\boldsymbol{\Gamma}_{1}\right)_{i}+\frac{1}{2} \zeta \xi\left(\boldsymbol{\Gamma}_{2}\right)_{i}+\frac{1}{2} \xi \eta\left(\boldsymbol{\Gamma}_{3}\right)_{i}+\xi \eta \zeta\left(\boldsymbol{\Gamma}_{4}\right)_{i}$

tal que

$$
\begin{aligned}
\mathbf{s} & =\left\{\begin{array}{llllllll}
1 & 1 & 1 & 1 & 1 & 1 & 1 & 1
\end{array}\right\}^{T} \\
\boldsymbol{\Lambda}_{1} & =\left\{\begin{array}{lllllllll}
-1 & 1 & 1 & -1 & -1 & 1 & 1 & -1
\end{array}\right\}^{T} \\
\boldsymbol{\Lambda}_{2} & =\left\{\begin{array}{llllllll}
-1 & -1 & 1 & 1 & -1 & -1 & 1 & 1
\end{array}\right\}^{T} \\
\boldsymbol{\Lambda}_{3} & =\left\{\begin{array}{llllllll}
-1 & -1 & -1 & -1 & 1 & 1 & 1 & 1
\end{array}\right\}^{T}
\end{aligned}
$$




$$
\begin{array}{lllllllll}
\boldsymbol{\Gamma}_{1} & =\left\{\begin{array}{llllllll}
1 & 1 & -1 & -1 & -1 & -1 & 1 & 1
\end{array}\right\}^{T} & \boldsymbol{\Gamma}_{2} & =\left\{\begin{array}{llllllllll}
1 & -1 & -1 & 1 & -1 & 1 & 1 & -1
\end{array}\right\}^{T} \\
\boldsymbol{\Gamma}_{3} & =\left\{\begin{array}{lllllllllllll}
1 & -1 & 1 & -1 & 1 & -1 & 1 & -1
\end{array}\right\}^{T} & \boldsymbol{\Gamma}_{4} & =\left\{\begin{array}{lllllllll}
-1 & 1 & -1 & 1 & 1 & -1 & 1 & -1
\end{array}\right\}^{T}
\end{array}
$$

$\mathrm{e}$

$$
\begin{gathered}
\boldsymbol{\Lambda}=\left[\begin{array}{lll}
\boldsymbol{\Lambda}_{1} & \boldsymbol{\Lambda}_{2} & \boldsymbol{\Lambda}_{3}
\end{array}\right] \\
\boldsymbol{\Gamma}=\left[\begin{array}{llll}
\boldsymbol{\Gamma}_{1} & \boldsymbol{\Gamma}_{2} & \boldsymbol{\Gamma}_{3} & \boldsymbol{\Gamma}_{4}
\end{array}\right]
\end{gathered}
$$

com o subscrito $i$ definindo o i-ésimo componente de um vetor, correspondente ao nó de mesmo número. O vetor s representa movimentos de corpo rígido. Os vetores $\boldsymbol{\Lambda}_{j}$ $(j=1 \ldots 3)$ são a base de vetores volumétricos que define os modos de deformação constantes e $\boldsymbol{\Gamma}_{k}(k=1 \ldots 4)$ determinam os modos de deformação lineares que denotam os padrões de deformação mostrados na Figura 2.7 e, por isso, compõem os vetores base de hourglass. Por formarem uma base, os vetores são ortogonais entre si, isto é,

$$
\boldsymbol{\Lambda}_{i} \bullet \boldsymbol{\Gamma}_{j}=0, \quad \mathbf{s} \bullet \boldsymbol{\Lambda}_{i}=0, \quad \mathbf{s} \bullet \boldsymbol{\Lambda}_{j}=0 \quad i=1 \ldots 3, j=1 \ldots 4
$$

Na formulação, a matriz de gradientes $\mathbf{B}$ é avaliada no centroide do elemento, de tal forma que as quantidades cinemáticas são integradas no volume, o que resulta na deformação depender apenas de componentes lineares. A matriz de gradiente média, $\tilde{\mathbf{B}}$, é calculada integrando-se a Eq. (B.1) no volume do elemento,

$$
\tilde{\mathbf{B}}=\int_{v} \mathcal{N} d v
$$

A dedução e o desenvolvimento desta integral foge do escopo deste trabalho e não serão apresentados. Detalhes são fornecidos em Flanagan e Belytschko [84]. Por questões práticas, os componentes da matriz $\tilde{\mathbf{B}}$ são dados segundo a seguinte organização:

$$
\tilde{\mathbf{B}}=\left[\begin{array}{lll}
\tilde{\mathbf{B}}_{1} & \tilde{\mathbf{B}}_{2} & \tilde{\mathbf{B}}_{3}
\end{array}\right]
$$

onde

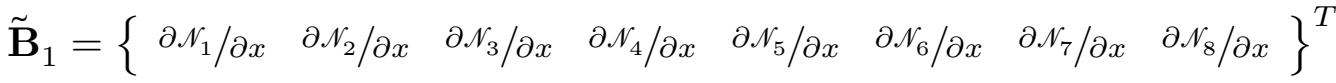

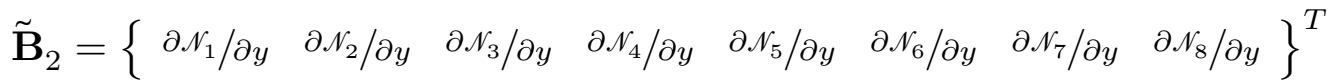

$$
\begin{aligned}
& \tilde{\mathbf{B}}_{3}=\left\{\begin{array}{llllllll}
\partial \mathscr{N}_{1} / \partial z & \partial \mathscr{N}_{2} / \partial z & \partial \mathcal{N}_{3} / \partial z & \partial \mathcal{N}_{4} / \partial z & \partial \mathscr{N}_{5} / \partial z & \partial \mathscr{N}_{6} / \partial z & \partial \mathscr{N}_{7} / \partial z & \partial \mathscr{N}_{8} / \partial z
\end{array}\right\}^{T}
\end{aligned}
$$

Na formulação, são consideradas as quantias médias das variáveis cinemáticas. O vetor médio de velocidade é dado por

$$
\dot{\overline{\mathbf{u}}}=\left\{\begin{array}{c}
\dot{\bar{u}}_{1} \\
\dot{\bar{u}}_{2} \\
\dot{\bar{u}}_{3}
\end{array}\right\}=\frac{1}{8} \tilde{\dot{\mathbf{u}}}^{T} \mathbf{s}
$$


onde $\underset{\sim}{\tilde{\mathbf{u}}}$ é o vetor de velocidades reescrito no formato,

$$
\tilde{\dot{\mathrm{u}}}=\left[\begin{array}{lll}
\tilde{\dot{\mathrm{u}}}_{x} & \tilde{\dot{\mathrm{u}}}_{y} & \tilde{\dot{\mathrm{u}}}_{z}
\end{array}\right]
$$

tal que ${\underset{\sim}{\dot{\mathbf{u}}}}_{x},{\underset{\sim}{\dot{\mathbf{u}}}}_{y} \mathrm{e}{\underset{\sim}{\tilde{\dot{\mathbf{u}}}}}_{z}$ são os vetores-coluna das velocidades nodais nas direções $x, y$ e $z$, respectivamente.

O centroide do elemento, $\bar{\chi}$, usado no desenvolvimento de algumas relações, é obtido por um equacionamento similar,

$$
\bar{\chi}=\left\{\begin{array}{l}
\chi_{x} \\
\chi_{y} \\
\chi_{z}
\end{array}\right\}=\frac{1}{8} \chi^{T} \mathbf{s}
$$

onde $\chi$ é a matriz de coordenadas dos nós,

$$
\chi=\left[\begin{array}{lll}
\chi_{1} & \chi_{2} & \chi_{3}
\end{array}\right]
$$

em que $\chi_{1}, \chi_{2}$ e $\chi_{3}$ são os vetores-colunas contendo as componentes $x, y$ e $z$ das coordenadas nodais, respectivamente.

O controle viscoso definido no algoritmo separa o campo de velocidades do elemento $(\underset{\dot{\mathbf{u}}}{)})$ em parcelas linear $\left(\stackrel{\dot{\mathbf{u}}}{ }^{\mathrm{LIN}}\right)$ e de hourglass $\left(\stackrel{\dot{\mathbf{u}}}{ }^{\mathrm{HG}}\right)$, tal que

$$
\underset{\tilde{\mathbf{u}}}{=} \stackrel{\dot{\mathbf{u}}}{ }^{\mathrm{LIN}}+\stackrel{\dot{\mathrm{u}}}{ }^{\mathrm{HG}}
$$

com ${\underset{\dot{\mathbf{u}}}{ }}^{\text {LIN }}$ sendo calculado a partir da expansão de Taylor avaliada no centroide $\overline{\boldsymbol{\chi}}$,

$$
\stackrel{\dot{\mathbf{u}}}{ }^{\mathrm{LIN}}=\mathbf{s} \dot{\overline{\mathbf{u}}}^{T}+\left(\chi-\mathbf{s} \bar{\chi}^{T}\right) \frac{\partial \dot{\overline{\mathbf{u}}}}{\partial \chi}
$$

onde $\partial \dot{\mathrm{u}} / \partial \chi$ é dado por

$$
\frac{\partial \dot{\overline{\mathbf{u}}}}{\partial \chi}=\frac{1}{v} \tilde{\mathbf{B}}^{T} \stackrel{\tilde{\mathbf{u}}}{\sim}
$$

Devido às condições de ortogonalidade da Eq. (B.6), a parcela de velocidade que induz o hourglass pode ser escrita como combinação linear de $\boldsymbol{\Gamma}$, ou seja,

$$
\dot{\mathbf{u}}^{\mathrm{HG}}=\frac{1}{\sqrt{8}} \boldsymbol{\Gamma} \dot{\mathbf{q}}
$$

onde $\mathbf{q}$ contém as velocidades modais de hourglass, dadas pela projeção escalar da velocidade sobre os vetores de forma do hourglass, $\boldsymbol{\Xi}$ :

$$
\dot{\mathbf{q}}=\frac{1}{\sqrt{8}} \tilde{\mathbf{u}}^{T} \Xi
$$


Substituindo as Eqs. (B.15), (B.17) e (B.18) em (B.14) e pré-multiplicando por $\boldsymbol{\Gamma}^{T}$, tem-se

$$
\boldsymbol{\Gamma}^{T} \underset{\sim}{\tilde{\mathbf{u}}}-\boldsymbol{\Gamma}^{T} \dot{\mathbf{s}}_{\stackrel{\overline{\mathbf{u}}}{T}}^{T}-\boldsymbol{\Gamma}^{T}\left(\boldsymbol{\chi}-\mathbf{s} \bar{\chi}^{T}\right) \frac{\partial \dot{\overline{\mathbf{u}}}}{\partial \boldsymbol{\chi}}=\frac{1}{8} \boldsymbol{\Gamma}^{T} \boldsymbol{\Gamma} \boldsymbol{\Xi}^{T} \underset{\dot{\mathbf{u}}}{ }
$$

Aproveitando-se das condições de ortogonalidade, Eq. (B.6), da relação (B.16) e da identidade $\boldsymbol{\Gamma}^{T} \boldsymbol{\Gamma}=8 \mathbf{I}_{4 \times 4}$, a partir da expressão em (B.19), define-se $\boldsymbol{\Xi}$ como

$$
\boldsymbol{\Xi}=\boldsymbol{\Gamma}-\frac{1}{v} \tilde{\mathbf{B}} \chi^{T} \boldsymbol{\Gamma}
$$

Definem-se também forças generalizadas $\mathbf{Q}$, formando, juntamente com $\dot{\mathbf{q}}$, um par energeticamente conjugado, tal que a taxa de trabalho é dada por

$$
\underset{\sim}{\tilde{\mathbf{u}}} \stackrel{F}{:}{\underset{\sim}{\mathbf{r}}}^{\mathrm{HG}}=\mathbf{Q} \stackrel{F}{:} \dot{\mathbf{q}}
$$

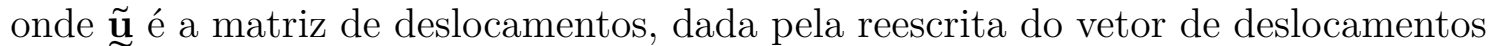
do elemento no formato apresentado na Eq. (B.11), ${\underset{\sim}{\mathrm{r}}}^{\mathrm{HG}}$ é a matriz de forças de hourglass, dada no mesmo formato, e o operador $\stackrel{F}{:}$ denota o produto interno de Frobenius, tal que $\mathbf{A} \stackrel{F}{:} \mathbf{B}=\operatorname{tr}\left(\mathbf{A B}^{T}\right)$.

Substituindo (B.18) em (B.21) e simplificando, tem-se

$$
\stackrel{\sim}{\mathbf{r}}^{\mathrm{HG}}=\frac{1}{\sqrt{8}} \mathbf{\Xi Q}^{T}
$$

Flanagan e Belytschko [84] define a natureza e a intensidade da atenuação dos efeitos de hourglassing determinando $\mathbf{Q}$ como

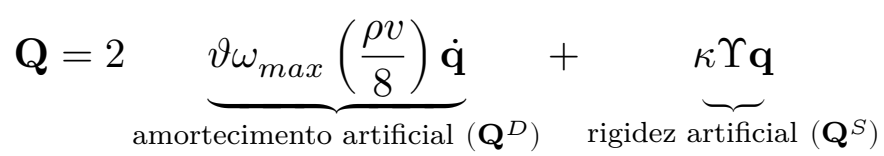

onde $\vartheta$ e $\kappa$ são parâmetros de entrada do controle. A resistência de amortecimento, $\mathbf{Q}^{D}$, é dada por

$$
\mathbf{Q}^{D}=\vartheta \sqrt{\frac{\rho(\lambda+2 G)\left(\tilde{\mathbf{B}}^{F}: \tilde{\mathbf{B}}\right)}{6}} \dot{\mathbf{q}}
$$

e a taxa de resistência de rigidez, $\dot{\mathbf{Q}}^{S}$,

$$
\dot{\mathbf{Q}}^{S}=\kappa \frac{\lambda+2 G}{3} \frac{\tilde{\mathbf{B}} \stackrel{F}{:} \tilde{\mathbf{B}}}{v} \dot{\mathbf{q}}
$$

$\mathbf{Q}^{S}$ é definido através de sua taxa porque assim se adequa melhor a problemas de grandes deformações (vide seção A). No método explícito, a taxa pode ser integrada 
usando a aproximação

$$
\int_{t} \frac{\partial(\cdot)}{\partial t} d t=\frac{\partial(\cdot)}{\partial t} \Delta t
$$

onde $\partial(\cdot) / \partial t$ é uma expressão qualquer dependente de $t$. Logo,

$$
\mathbf{Q}^{S}=\kappa \Delta t \frac{\lambda+2 G}{3} \frac{\tilde{\mathbf{B}}^{F}: \tilde{\mathbf{B}}}{v} \dot{\mathbf{q}}
$$

Assim, as forças de hourglass são dadas por

$$
\begin{aligned}
& \stackrel{\sim}{\mathbf{r}}^{\mathrm{HG}}={\underset{\sim}{\mathbf{r}}}^{\mathrm{HG} D}+\left({\underset{\sim}{\mathbf{r}}}^{\mathrm{HG}}\right)^{S} \\
& \left(\stackrel{\sim}{\mathbf{r}}^{\mathrm{HG}}\right)^{D}=\frac{1}{\sqrt{8}} \mathbf{\Xi}\left(\mathbf{Q}^{D}\right)^{T} \\
& \left({\underset{\sim}{\mathbf{r G}}}^{\mathrm{HG}}\right)^{S}=\frac{1}{\sqrt{8}} \mathbf{\Xi}\left(\mathbf{Q}^{S}\right)^{T}
\end{aligned}
$$

Na prática, apenas um dos modos de controle é implementado no elemento (isto é, $\mathbf{Q}^{D}$ ou $\mathbf{Q}^{S}$ ), pois, como relatado por Flanagan e Belytschko [84], há poucas evidências de melhora no controle simultâneo. Para aliviar a sobrecarga computacional que o algoritmo oferece, é possível reduzir estrategicamente o cálculo e atualização de $\boldsymbol{\Xi}$ a um número menor de iterações no tempo. Numa outra abordagem, pode-se assumir que $\boldsymbol{\Xi} \approx \boldsymbol{\Gamma}$, ignorando completamente o cálculo de $\boldsymbol{\Xi}$. Logicamente que, nesses dois métodos, a acurácia é reduzida.

Os valores de $\vartheta$ e $\kappa$ devem ser escolhidos de tal forma que sejam suficientes para estabilizar a solução. Números altos demais podem atenuar modos de deformação da estrutura e afetar negativamente na resposta, enquanto que baixos demais reduzem a capacidade de estabilização. Valores como $\kappa=0,125$ e $\vartheta=0,5$ já oferecem resultados significativos para alguns tipos de problema [84].

\section{B.2 Estabilização por deformação assumida de Puso}

Puso [195] oferece um algoritmo de controle rígido baseado no método das deformações melhoradas assumidas (EAS - enhanced assumed strain, em inglês). Assim como o controle de Flanagan e Belytschko [84], o procedimento aqui disctudio pode ser utilizado também em problemas não-lineares e, até certo ponto, independe do modelo de material adotado, o que dá à técnica um diferencial.

Para os cálculos que seguem, assume-se que a matriz de gradientes, B, é calculada no centroide do elemento, usando o procedimento de Flanagan e Belytschko [84] e tomando seu valor médio no volume. No entanto, ao contrário do mostrado 
na seção anterior, a organização dos coeficientes da matriz é dado de maneira usual, isto é,

$$
\mathbf{B}=\left[\begin{array}{ccc}
\tilde{\mathbf{B}}_{1} & \mathbf{0} & \mathbf{0} \\
\mathbf{0} & \tilde{\mathbf{B}}_{2} & \mathbf{0} \\
\mathbf{0} & \mathbf{0} & \tilde{\mathbf{B}}_{3} \\
\tilde{\mathbf{B}}_{2} & \tilde{\mathbf{B}}_{1} & \mathbf{0} \\
\mathbf{0} & \tilde{\mathbf{B}}_{3} & \tilde{\mathbf{B}}_{2} \\
\tilde{\mathbf{B}}_{3} & \mathbf{0} & \tilde{\mathbf{B}}_{1}
\end{array}\right]
$$

e, por consequência, os vetores de deslocamento, velocidade e força são arranjados em formato compatível.

Considerando a forma alternativa para a descrição das funções de interpolação, apresentada nas Eqs. (B.1), (B.2), (B.3) e (B.4), a matriz jacobiana calculada no centroide do elemento, $\mathbf{J}_{0}$, é dada por

$$
\mathbf{J}_{0}=\chi^{T} \boldsymbol{\Lambda}
$$

onde $\chi$ é a matriz de coordenadas nodais, apresentada na Eq. (B.13).

Define-se as funções de forma de hourglass como

$$
\boldsymbol{\Xi}_{i}=\frac{1}{8}\left[\boldsymbol{\Gamma}_{i}-\sum_{j=1}^{3}\left(\boldsymbol{\Gamma}_{i} \bullet \boldsymbol{\chi}_{j}\right) \tilde{\mathbf{B}}_{j}\right]
$$

Usando $\boldsymbol{\Xi}$, é possível extrair os deslocamentos de hourglass, $\mathbf{h}$, usando a relação

$$
\mathbf{h}_{i}=\boldsymbol{\Pi}_{i}^{T} \Delta \underline{\mathbf{u}}, \quad 1 \leq i \leq 4
$$

onde

$$
\boldsymbol{\Pi}_{i}=\left[\begin{array}{ccc}
\boldsymbol{\Xi}_{i} & \mathbf{0} & \mathbf{0} \\
\mathbf{0} & \boldsymbol{\Xi}_{i} & \mathbf{0} \\
\mathbf{0} & \mathbf{0} & \boldsymbol{\Xi}_{i}
\end{array}\right]
$$

Para definir as forças de hourglass, é preciso transportar $\mathbf{h}$ para o domínio isoparamétrico. Esse procedimento é feito pela relação,

$$
\boldsymbol{h}_{i}=\mathbf{J}_{0}^{T} \mathbf{h}_{i}, \quad 1 \leq i \leq 4
$$

onde $\boldsymbol{h}_{i}$ é são os incrementos de deslocamento de hourglass descritos em coordenadas isoparamétricas.

É requerido que a matriz de elasticidade do material seja transportada para o domínio isoparamétrico. A matriz mapeada, $\mathscr{E}$, é dada por

$$
\mathscr{E}=\hat{\mathbf{J}}_{0}^{-T} \mathbf{E} \hat{\mathbf{J}}_{0}^{-1}
$$


sendo que $\hat{\mathbf{J}}_{0}^{-1}$ é a matriz diagonal:

$$
\hat{\mathbf{J}}_{0}^{-1}=\left[\begin{array}{cccc}
\left\|\mathbf{J}_{1}\right\|^{-2} & & & \\
& \left\|\mathbf{J}_{2}\right\|^{-2} & & \\
& & \left\|\mathbf{J}_{3}\right\|^{-2} & \\
& & \left\|\mathbf{J}_{1}\right\|^{-1}\left\|\mathbf{J}_{2}\right\|^{-1} & \\
& & & \left\|\mathbf{J}_{2}\right\|^{-1}\left\|\mathbf{J}_{3}\right\|^{-1}
\end{array}\right.
$$

tal que

$$
\mathbf{J}_{0}=\left[\begin{array}{lll}
\left(\mathbf{J}_{1}\right)_{3 \times 1} & \left(\mathbf{J}_{2}\right)_{3 \times 1} & \left(\mathbf{J}_{3}\right)_{3 \times 1}
\end{array}\right]
$$

Seis variáveis internas do algoritmo, $\Delta \alpha_{i}$, definem os graus de liberdade de deformação assumida para estabilização do elemento. São elas:

$$
\begin{gathered}
\Delta \alpha_{1}=\frac{1}{c_{11}}\left(c_{12} h_{21}+c_{15} h_{22}+c_{13} h_{32}+c_{15} h_{31}\right) \\
\Delta \alpha_{2}=\frac{1}{c_{22}}\left(c_{21} h_{11}+c_{26} h_{13}+c_{23} h_{33}\right) \\
\Delta \alpha_{3}=\frac{1}{c_{33}}\left(c_{31} h_{12}+c_{34} h_{13}+c_{32} h_{23}+c_{34} h_{22}\right) \\
\Delta \alpha_{4}=\frac{h_{34}}{q}\left(c_{13}+c_{23}+c_{33}\right) \\
\Delta \alpha_{5}=\frac{h_{14}}{q}\left(c_{11}+c_{21}+c_{31}\right) \\
\Delta \alpha_{6}=\frac{h_{24}}{q}\left(c_{12}+c_{22}+c_{32}\right)
\end{gathered}
$$

onde $q=c_{11}+c_{22}+c_{33}+2\left(c_{12}+c_{23}+c_{13}\right), c_{i j}$ são as componentes de $\mathscr{E}$ e $h_{i j}$ são as componentes de $\boldsymbol{h}_{j}$. 
Assim, as forças generalizadas são dadas pelas seguintes equações:

$$
\begin{gathered}
\Delta \tilde{\mathbf{r}}_{1}=\frac{8 v}{3}\left\{\begin{array}{c}
c_{11} h_{11}+c_{13} h_{33}+c_{16}\left(h_{13}+h_{31}\right)-c_{21} \Delta \alpha_{2} \\
c_{22} h_{21}+c_{23} h_{32}+c_{25}\left(h_{22}+h_{3} 1\right)-c_{12} \Delta \alpha_{1} \\
c_{55}\left(h_{22}+h_{31}\right)+c_{66}\left(h_{13}+h_{31}\right)+c_{61} h_{11}+ \\
+c_{52} h_{21}+c_{53} h_{32}+c_{53} h_{32}+c_{63} h_{33}-c_{15} \Delta \alpha_{1}
\end{array}\right\} \\
\Delta \tilde{\mathbf{r}}_{2}=\frac{8 v}{3}\left\{\begin{array}{c}
c_{11} h_{12}+c_{12} h_{23}+c_{14}\left(h_{13}+h_{22}\right)-c_{31} \Delta \alpha_{3} \\
c_{44}\left(\begin{array}{c}
\left.h_{13}+h 22\right)+c_{55}\left(h_{22}+h_{31}\right)+c_{41} h_{12}+c_{42} h_{23}+ \\
+c_{52} h_{21}+c_{53} h_{32}-c_{15} \Delta \alpha_{1}-c_{34} \Delta \alpha_{3} \\
c_{32} h_{21}+c_{33} h_{32}+c_{35}\left(h_{22}+h_{31}\right)-c_{13} \Delta \alpha_{1} \\
c_{44}\left(h_{13}+h_{22}\right)+c_{66}\left(h_{13}+h_{31}\right)+c_{41} h_{12}+ \\
+c_{42} h_{23}+c_{61} h_{11}+c_{63} h_{33}-c_{26} \Delta \alpha_{2}-c_{34} \Delta \alpha_{3} \\
c_{21} h_{12}+c_{22} h_{23}+c_{24}\left(h_{13}+h_{22}\right)-c_{32} \Delta \alpha_{3} \\
c_{31} h_{11}+c_{33} h_{33}+c_{36}\left(h_{13}+h_{31}\right)-c_{23} \Delta \alpha_{2}
\end{array}\right\} \\
\Delta \tilde{\mathbf{r}}_{3}=\frac{8 v}{3}\left\{\begin{array}{c}
c_{11} h_{14}-\left(c_{11}+c_{21}+c_{31}\right) \Delta \alpha_{5} \\
c_{22} h_{24}-\left(c_{12}+c_{22}+c_{32}\right) \Delta \alpha_{6} \\
c_{33} h_{34}-\left(c_{13}+c_{23}+c_{33}\right) \Delta \alpha_{4}
\end{array}\right\}
\end{array}\right\}
\end{gathered}
$$

Para materiais isotrópicos, observe que as expressões (B.38) e (B.39) podem ser simplificadas consideravelmente.

Finalmente, as forças de hourglass são calculadas incrementalmente, isto é,

$$
\begin{aligned}
\left(\tilde{\mathbf{r}}_{i}\right)_{t} & =\left(\tilde{\mathbf{r}}_{i}\right)_{t-\Delta t}+\Delta \tilde{\mathbf{r}}_{i} \\
{\underset{\sim}{\mathrm{r}}}_{t}^{\mathrm{HG}} & =\sum_{i=1}^{4} \boldsymbol{\Pi}_{i} \mathbf{J}_{0}\left(\tilde{\mathbf{r}}_{i}\right)_{t}
\end{aligned}
$$




\section{APÊNDICE}

\section{Construção sintática do arquivo de}

entrada

O sistema de leitura do arquivo de entrada tem suas primitivas básicas implementadas no componente Mint. Com o auxílio do sistema de parsing Spirit da biblioteca Boost [65], um sistema de análise sintática é elaborado para interpretar uma linguagem em blocos aninhados, a partir da qual são definidas as diversas instruções declarativas no arquivo de simulação. Ao longo deste apêndice, a notação estendida do formalismo de Backus-Naur (EBNF) é usada para descrever os elementos sintáticos da linguagem interpretada pelo programa - a AIL (Axis Input Language). Informações sobre a EBNF podem ser encontradas em diversos sítios hospedados on line [93, 240] (para informações gerais) e em literaturas sobre compiladores e linguagens formais [1, 112] (para maiores detalhes).

\section{C.1 Introdução rápida à EBNF}

A EBNF é usada para descrever linguagens livres de contexto que, basicamente, são linguagens que podem ser descritas através de regras de produções, que obedecem o seguinte formato

$$
\text { producao } \rightarrow \text { 'terminal' }
$$

onde producao é um símbolo não-terminal e o conteúdo das aspas simples é denominado símbolo terminal. Normalmente, uma linguagem é definida pela recursão de regras de produção: 


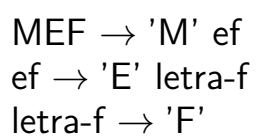

Neste exemplo, a regra MEF define uma linguagem que identifica apenas a cadeia de caracteres 'MEF', descrita recursivamente através de outras duas regras de produção. Símbolos não-terminais podem ser derivados para expandir a definição da regra de produção original. Símbolos terminais, como o próprio nome diz, são caracteres que a produção aceita, não sendo deriváveis adiante. Em algumas regras de produção, a aceitação de espaços em branco é omitida para maior clareza.

Uma regra de produção pode aceitar, alternativamente, múltiplas regras de produção ou terminais:

$$
\mathrm{MEF} \rightarrow \text { 'MEF' | 'mef' }
$$

Aqui, a regra MEF aceita duas cadeias de caracteres, 'MEF' ou 'mef', conforme indicado pelo operador de alternância (|) (alternância exclusiva).

Em determinadas ocasiões, a definição de uma regra optativa pode facilitar a escrita de regras de produção, sem necessitar recorrer ao operador de alternância. Por exemplo,

$$
\begin{aligned}
& \text { digito } \rightarrow \text { '0' | '1' | '2' | '3' | '4' | '5' | '6' | '7' | '8' | '9' } \\
& \text { sinal } \rightarrow \text { '+' |'-' } \\
& \text { numero } \rightarrow \text { sinal? digito }
\end{aligned}
$$

Neste exemplo, um número é dado pelas produções sinal e digito, em sequência. sinal é uma produção opcional, indicada pelo operador ? a sua direita. Isso é equivalente a usar o operador de alternância:

$$
\text { numero } \rightarrow \text { (sinal digito) } \mid \text { digito }
$$

Os parênteses são delimitadores que agrupam um conjunto de regras de produção (isto é, a sequência sinal digito é indivisível e pode ser considerada como se fosse uma única produção).

Pode-se indicar a multiplicidade de uma regra de produção usando o operador de de Kleene $\left(^{*}\right)$ ou o operador +, conforme ilustra o exemplo abaixo:

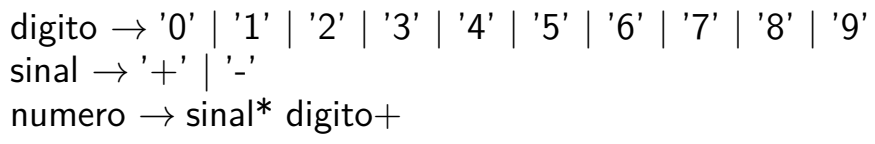

Neste caso, um número é definido por uma sequência de zero ou mais sinais ('+' ou '-'), seguidos por uma cadeia de um ou mais algarismos, como em '123', '+-25', '-269', mas não em '+', '_' ou " (cadeia vazia), por exemplo. 


\section{C.2 Primitivas básicas}

Inicialmente, são definidas as produções básicas da linguagem:

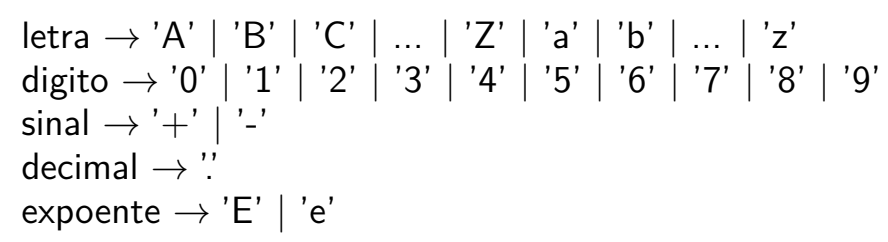

A partir delas, são definidas as primitivas básicas da linguagem, cujas produções estão marcadas em destaque:

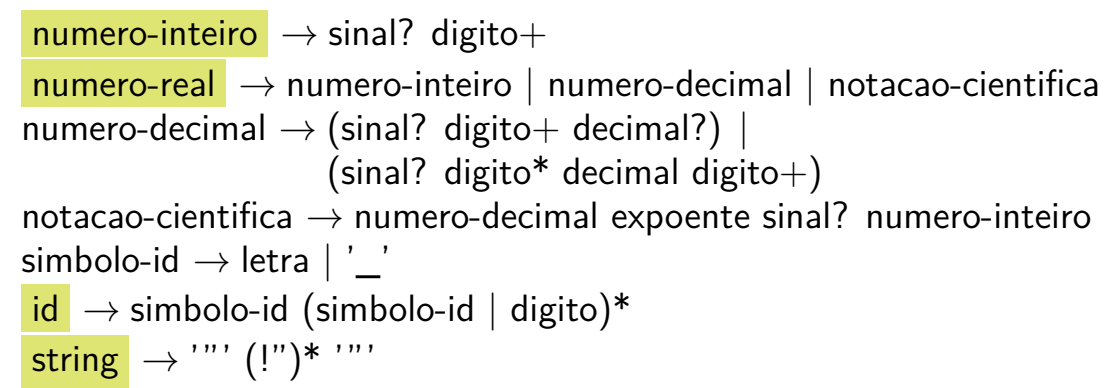

onde o agrupamento (!") indica "qualquer caractere diferente de aspas duplas".

Identificadores (produção id), tipos numéricos (numero-inteiro e numero-real) e cadeias de caracteres (string) são usados para definir elementos gramaticais mais complexos:

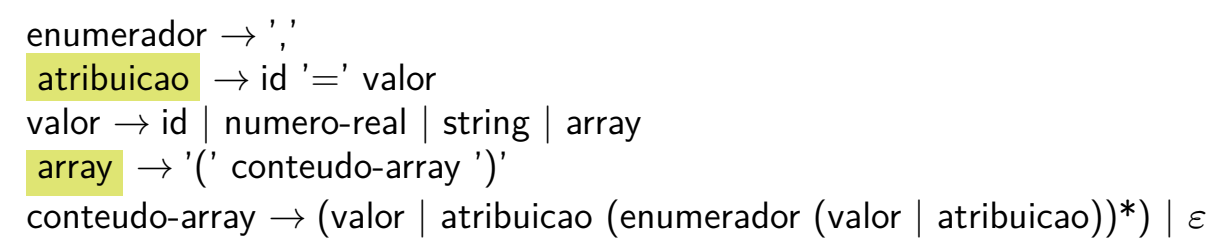

onde $\varepsilon$ é uma produção que aceita uma cadeia vazia de caracteres.

\section{C.3 Blocos de contexto}

Blocos de contexto constituem a definição principal da AIL. Cada bloco delimita um contexto distinto, onde as instruções declarativas contidas são analisadas pelo respectivo parser de bloco. Dessa forma, cada plugin pode definir a sintaxe de entrada para seus elementos, usando as primitivas básicas da AIL.

Um bloco é delimitado por um cabeçalho (produção bloco-cabecalho) e um rodapé (produção bloco-rodape): 


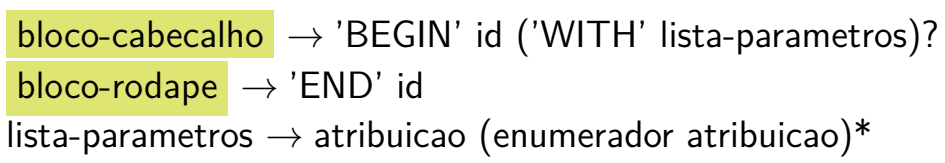

O contexto iniciado pelo bloco é declarado pelo identificador mencionado no seu cabeçalho. Opcionalmente, uma lista de parâmetros pode ser fornecida, que será usado pelo parser, modificando seu comportamento ao interpretar as instruções dentro do bloco. Observe que a lista de parâmetros é, na verdade, uma lista exaustiva de atribuições, cujos valores podem ser encadeamentos complexos de valores, enumerações de valores, atribuições ou de outras enumerações. Ou seja, os cabeçalhos de bloco abaixo, por exemplo, são válidos:

BEGIN NODES

BEGIN NODES WITH id = todos_nos

BEGIN PARTS WITH ELEMENT_TYPE $=$ LINEAR_HEXAHEDRON, PROPERTIES $=\overline{(I N T E G R A T I O N} \_$TYPE $=$REDUCED, HOURGLASS_CONTROL_TYPE $=$ VISCUOUS, STABILIZATION_COEFFICIENT $=0.01$ )

O término do bloco, indicado pelo rodapé, deve ser declarado com o mesmo identificador, para fins de consistência. Múltiplos blocos podem ser aninhados, com a intenção de apontar relação entre os contextos. A Listagem C.1 oferece um exemplo.

Listagem C.1: Exemplo de aninhamento de blocos.

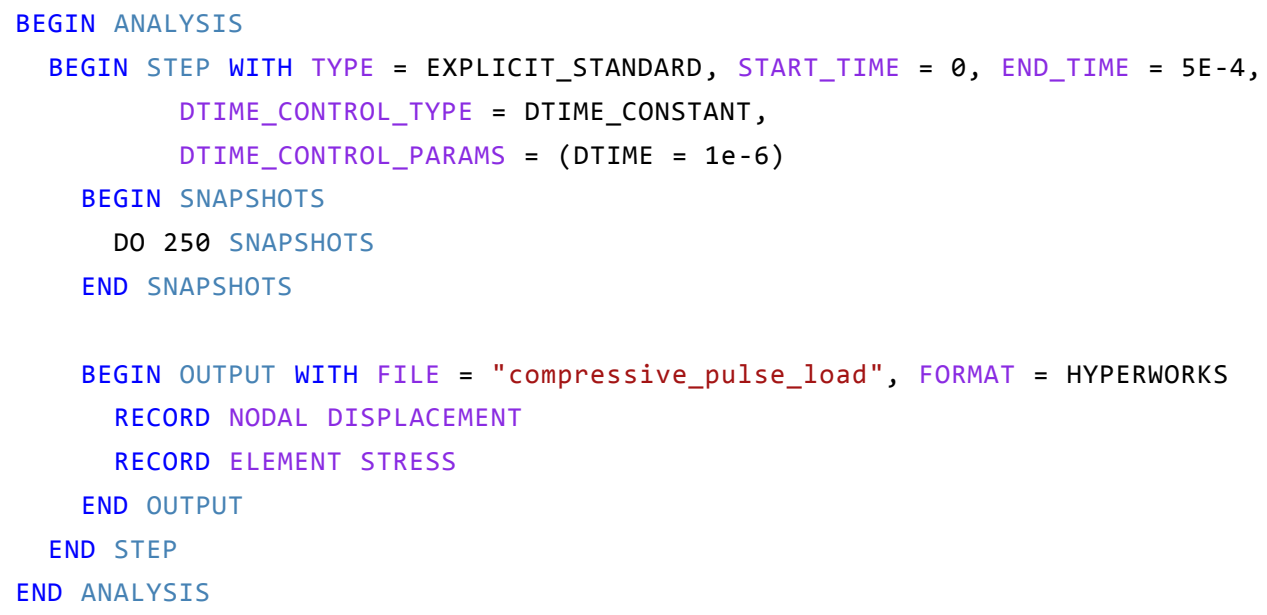

Cada bloco aninhado define um novo contexto que é analisado por um parser distinto. No exemplo da Listagem C.1, a relação é hierárquica, indicando um tipo de saída de dados (bloco OUTPUT) associada a um passo da análise (bloco 
STEP). As configurações de coleta de dados no passo é indicado pelo bloco aninhado SNAPSHOTS. Múltiplos passos de análise são configurados dentro de um bloco ANALYSIS.

O aninhamento precisa ser respeitado para que os blocos possam ser interpretados pelo parser correspondente. Por exemplo, o bloco SNAPSHOTS pode ser definido apenas dentro do bloco STEP. Ainda que seja possível definir múltiplos aninhamento de um bloco na AIL, esse comportamento não é recomendável, pois reduz a legibilidade do arquivo.

\section{C.4 Extensão da sintaxe}

A sintaxe definida pelos plugins denota a estrutura do conteúdo dos blocos correspondentes às funcionalidades que implementam. O plugin Echinopsis, por exemplo, implementa dois formatos de saída de dados, o conjunto de dados Matlab e o arquivo de pós-processamento do Hyperworks. Cada tipo adota uma sintaxe própria, mas similar, para manter a coerência dos blocos, conforme mostra a Listagem C.2.

Listagem C.2: Sintaxes distintas para um mesmo tipo de bloco por influência dos parâmetros do bloco.

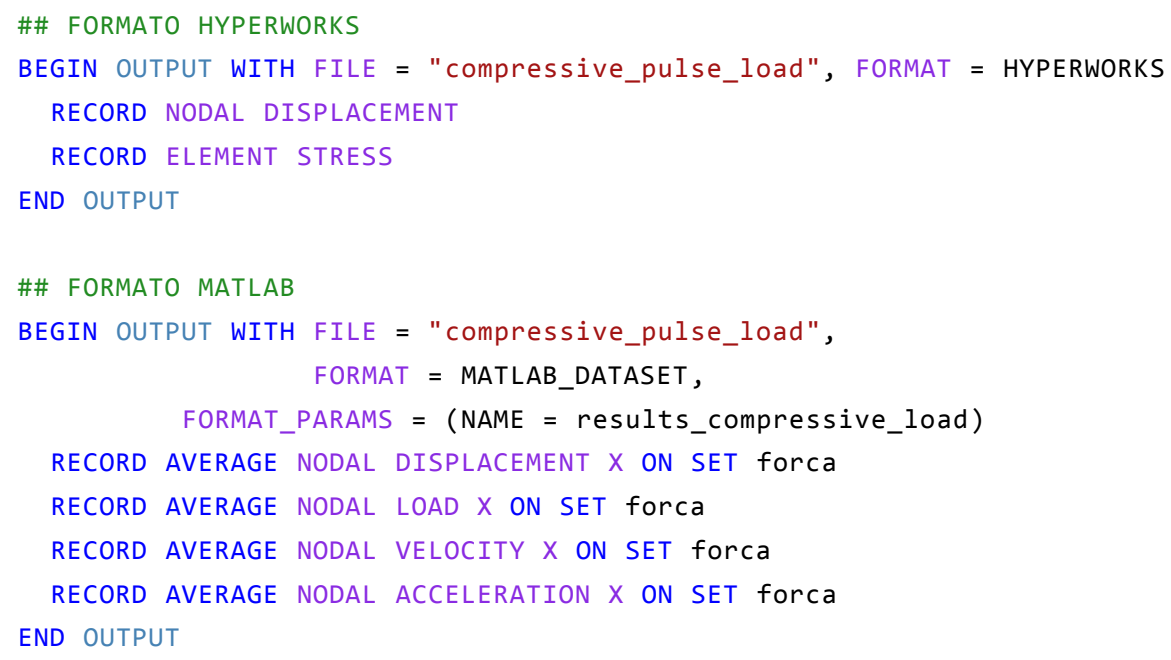

O plugin Orange define curvas usadas para descrever o comportamento de uma condição de contorno ao longo do tempo. Na sintaxe que define, uma curva multilinear é declarada informando as coordenadas $(X, Y)$ dos pontos em sequência, dentro do bloco MULTILINE_CURVE, aninhado a CURVES (Listagem C.3). 
Listagem C.3: Exemplo de bloco MULTILINE_CURVE.

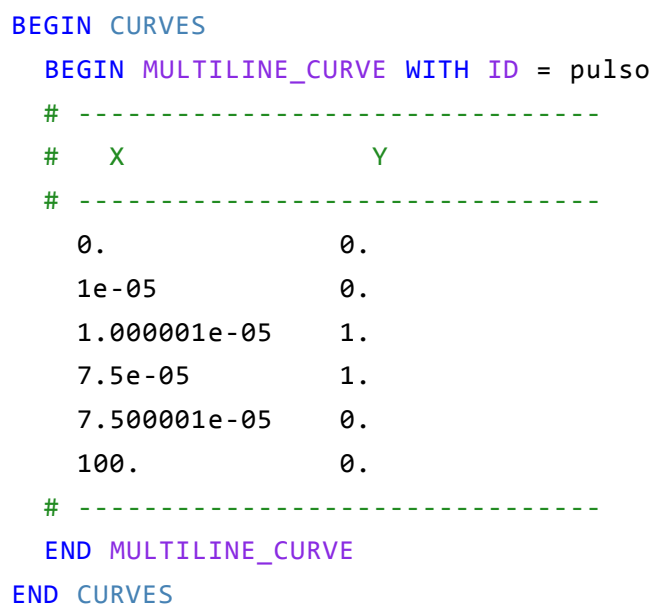

O Apêndice D lista os arquivos de entrada usados nos testes, onde é possível verificar a sintaxe definida por outros plugins do programa, estendendo a linguagem AIL original. 


\section{APÊNDICE}

\section{Arquivos de entrada dos casos de teste}

Para ilustrar a sintaxe definida pelos plugins do programa Axis, neste apêndice são listados os arquivos de entrada usados em alguns dos casos de teste do Capítulo 8 . Um breve resumo da configuração da análise numérica, declarada no arquivo, é fornecido a cada exemplo, para auxiliar na compreensão dos elementos sintáticos.

\section{D.1 Problema 1: compressão de um cubo unitário}

Além do modelo numérico, cujas descrições foram enumeradas na seção 8.3.1, o arquivo de entrada usado no teste, apresentado na Listagem D.1, configura os seguintes elementos:

- Título da análise, uma descrição "amigável", usada para identificar os resultados da análise no pós-processamento;

- Passos de análise, que, no caso, apenas uma é definida (bloco STEP);

- Configuração do solver, que, neste exemplo, trata-se de uma análise quase estática linear, com iteração no tempo unitária (conforme discutido na seção 6.1);

- Regularidade da coleta de resultados, definida apenas para a última iteração de tempo (bloco SNAPSHOTS);

- Arquivo de saída, usando o formato de relatório em texto plano (bloco OUTPUT, formato AXIS); 
- Discriminação da saída, onde, para o arquivo "test_1", são gravados, na ordem:

— Deslocamentos em todas as direções no conjunto de nós all_nodes;

- Todas as componentes de deformação do conjunto de nós all_nodes;

- Todas as componentes de deformação do conjunto de elementos all_elements;

- Todas as componentes de tensão do conjunto de nós all_nodes; e

— Todas as componentes de tensão do conjunto de elementos all_elements.

- cargas (bloco LOADS) nodais (bloco NODAL_LOADS) aplicadas, onde, no exemplo, apenas uma é definida para o conjunto de nós top_face e o comportamento é dado pela curva constant_curve;

- restrições no movimento, como engastes, suportes e prescrições (bloco CONSTRAINTS). No exemplo, são aplicadas restrições no deslocamento de três conjuntos de nós:

- Conjunto bottom_face: $u_{z}=0$;

- Conjunto setx: $u_{x}=0$;

- Conjunto sety: $u_{y}=0$;

- nós e elementos, para a discretização da estrutura (blocos NODES e ELEMENTS). Cada bloco pode, opcionalmente, definir um conjunto de nós ou elementos, respectivamente;

- partes (bloco PARTS), que define a formulação e propriedades do elemento finito e o modelo de material adotado em um conjunto de elementos. No exemplo, o conjunto de elementos all_elements usa a formulação LINEAR_HEXAHEDRON, com suas propriedades padrão (hexaedro linear, integração completa), e o modelo de material LINEAR_ISO_ELASTIC (linear elástico isotrópico);

- conjuntos de nós (bloco NODE_SET), usados para aplicar restrições ou coletar resultados;

- curvas (bloco CURVES), usadas para modificar o comportamento de condições de contorno. No exemplo, apenas uma é definida (bloco MULTILINE_CURVE - curva linear ponto a ponto).

Não há restrição quanto à ordem em que os elementos da análise são apresentados. Em outras palavras, os blocos do arquivo de entrada podem ser declarados em qualquer posição, de acordo com a preferência do usuário. 
Listagem D.1: Arquivo de entrada do Problema 1.

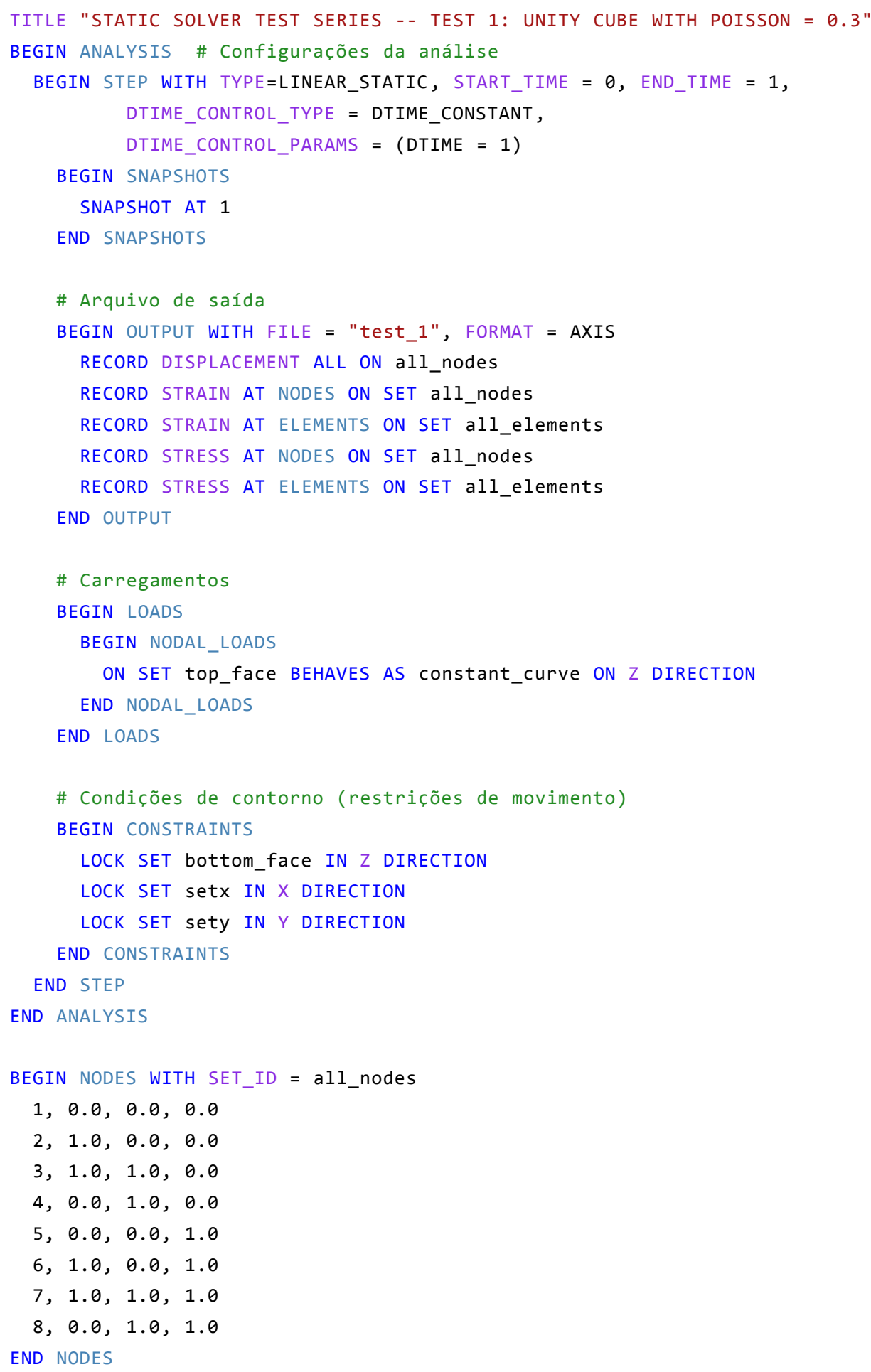




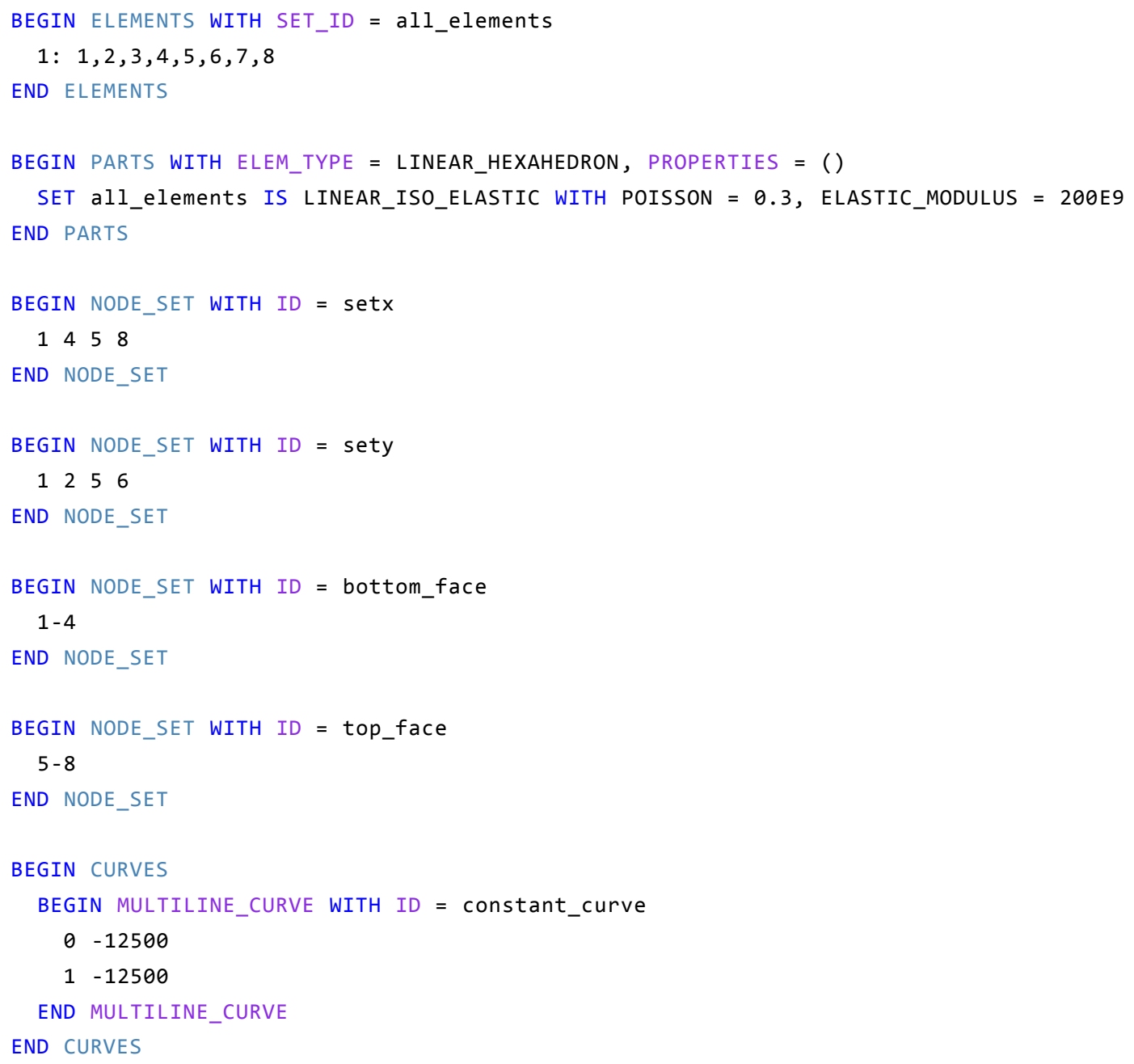

\section{D.2 Problema 4: patch test}

Além do modelo numérico, definido na seção 8.3.4, em relação ao arquivo anterior, poucos elementos sintáticos são novos neste exemplo. O patch test prescreve o deslocamento dos nós externos do cubo, aplicados através de instruções declarativas no bloco CONSTRAINTS. Na Listagem D.2, três prescrições são ilustradas, aplicadas em conjuntos de nós distintos (uz1d5, ux1d5 e uz1d0) e possuem o mesmo comportamento (curva constante). A magnitude do deslocamento é dada pela amplitude da curva e o fator de escala da prescrição. Para maior objetividade, alguns elementos declarados no arquivo de entrada foram omitidos. 
Listagem D.2: Arquivo de entrada do Problema 4.

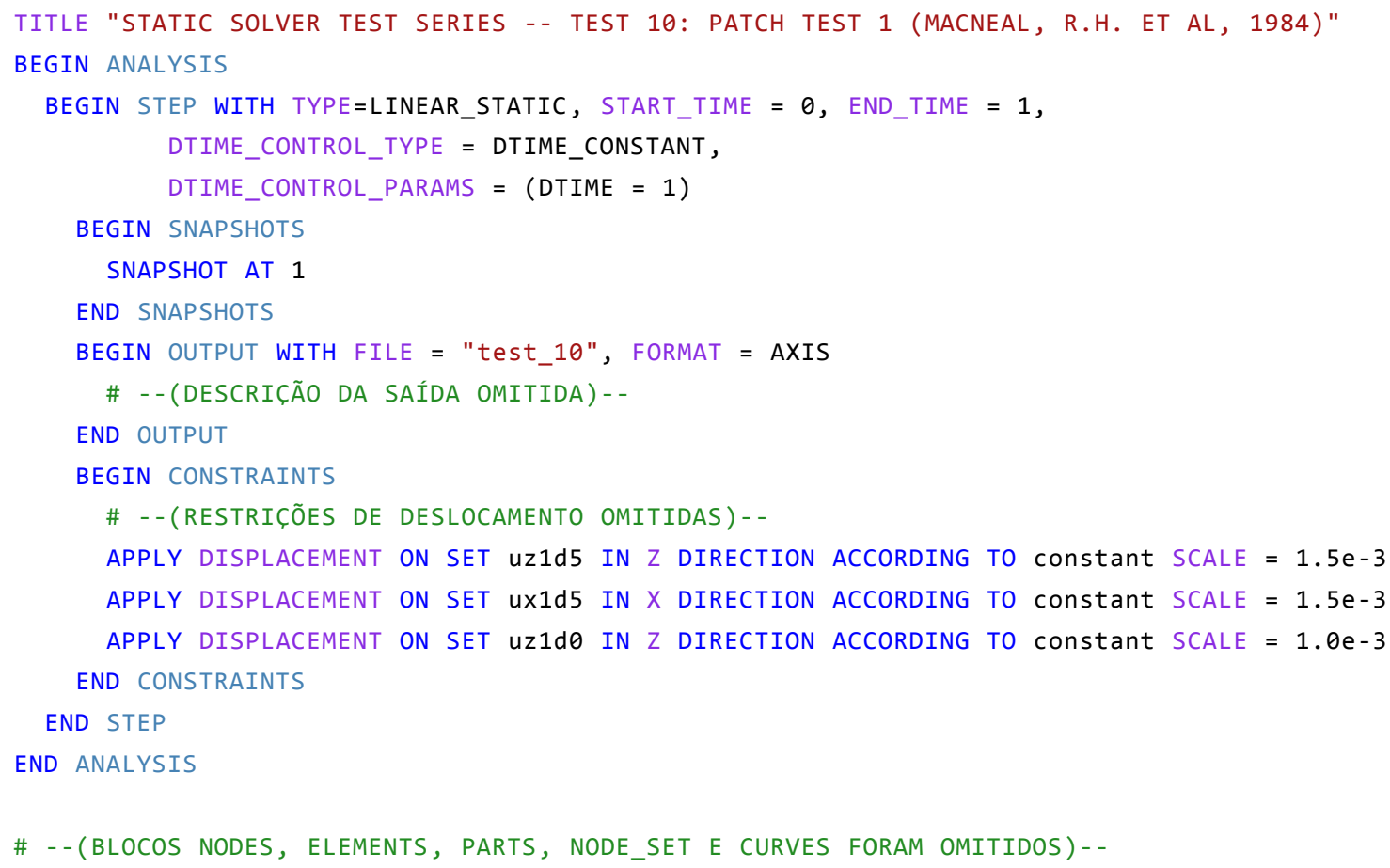

\section{D.3 Problema 5: barra em compressão constante}

No problema da seção 8.4.1, o solver dinâmico explícito é utilizado para a análise. Na Listagem D.3, é apresentada a sua seleção e configuração, dentro dos parâmetros do bloco STEP. Os arquivos de saída contêm o estado do modelo em 200 instantes distintos, regularmente espaçados, conforme descreve o bloco SNAPSHOTS.

Para esta análise, dois arquivos de saída são gerados, um no formato MATLAB (cook_exercise.m, bloco OUTPUT e formato selecionado MATLAB_DATASET) e outro no formato Hyperworks (cook_exercise.hwascii, formato HYPERWORKS). A declaração dos dados coletados possui uma sintaxe única em cada arquivo, definida pelo plugin responsável.

O elemento C3D8RL é selecionado alterando as propriedades da formulação hexaédrica linear, através do atributo PROPERTIES do bloco PARTS. A propriedade INTEGRATION_TYPE regula o número de pontos usados no método de integração numérica (completa ou reduzida). 
Listagem D.3: Arquivo de entrada do Problema 5.

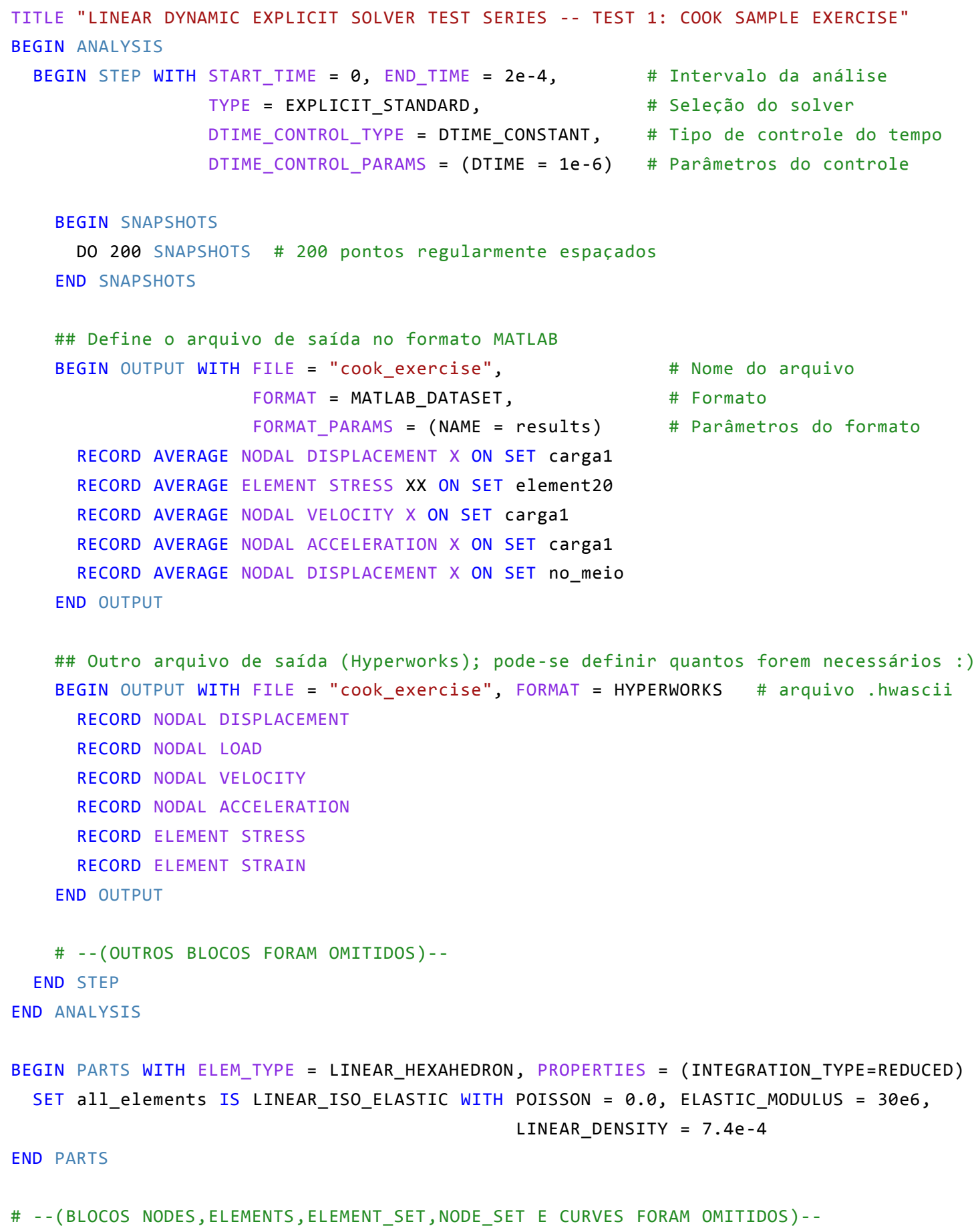




\section{D.4 Problema 8: prescrição de velocidade}

Na seção 8.4.4, é prescrita a velocidade dos nós do modelo. Na Listagem D.3, é apresentada a configuração desta restrição, cujo comportamento é dado pela curva associada.

Listagem D.4: Arquivo de entrada do Problema 8.

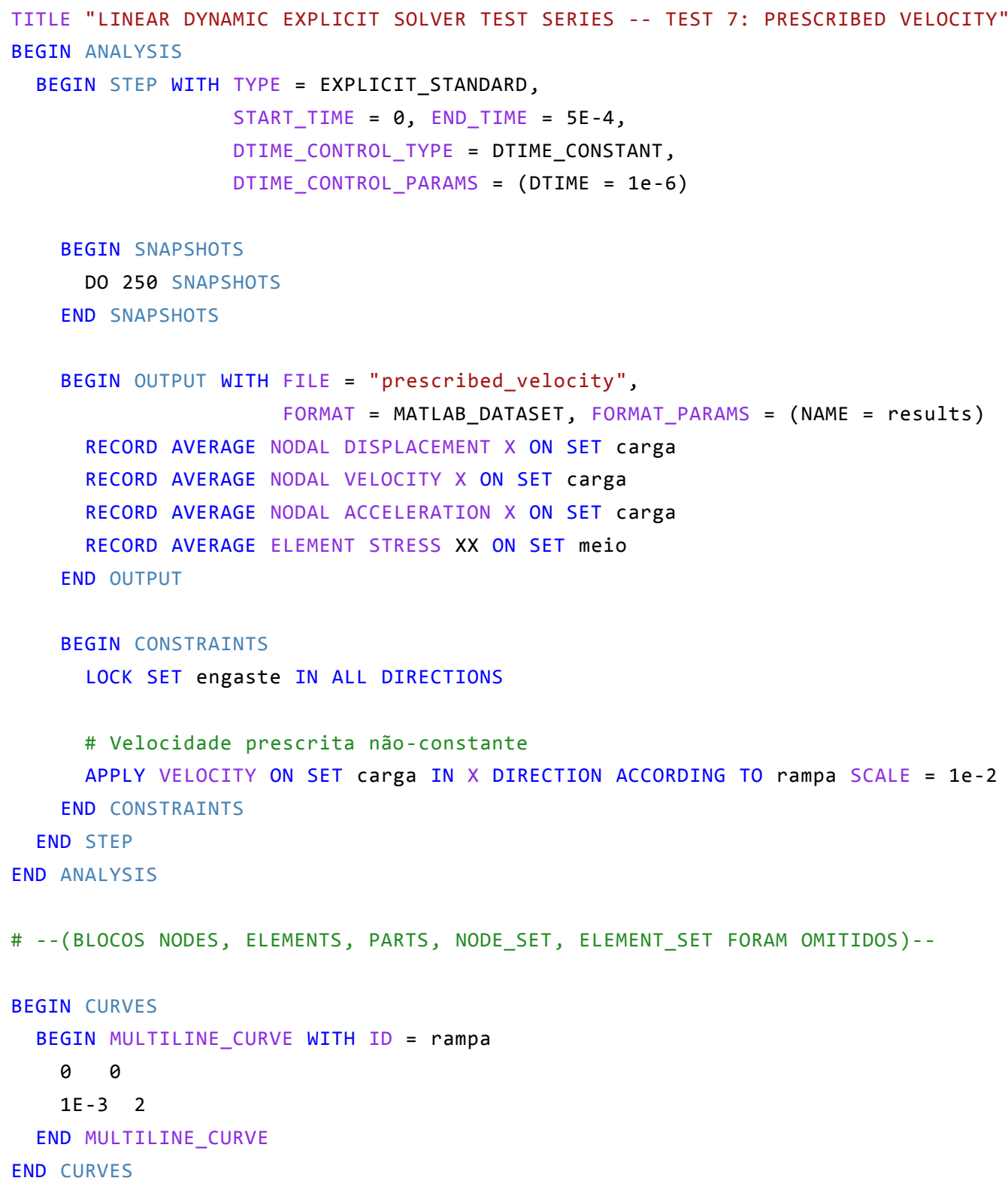




\section{D.5 Teste não-linear 1: barra de borracha em tensão}

No problema da seção 8.6.1, é usado o modelo de material hiper-elástico neoHookeano. A seleção da relação constitutiva é feita dentro do bloco PARTS, conforme ilustra a Listagem D.5. Para a correta solução do problema, ao empregar modelos de material não-lineares, é necessário alternar para formulações não-lineares dos elementos finitos. Neste exemplo, o elemento C3D8RN é selecionado alterando o valor do parâmetro ELEM_TYPE do bloco PARTS para HEXAHEDRON e selecionando o método de integração reduzida pelo parâmetro PROPERTIES.

Listagem D.5: Arquivo de entrada do Teste não-linear 1.

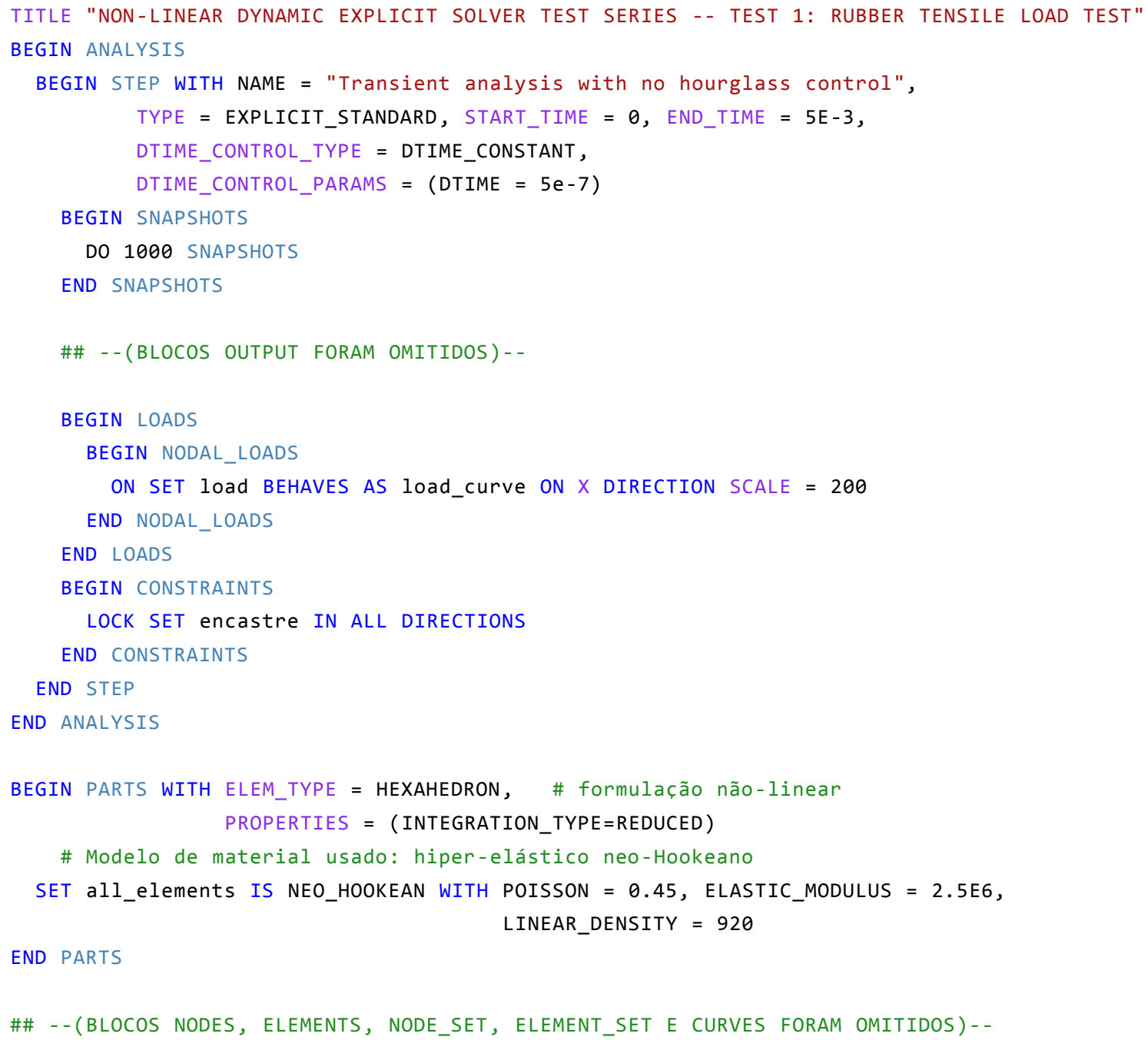




\section{D.6 Teste não-linear 2: viga sob deformação plástica}

O problema da seção 8.6.2 descreve uma viga sujeita a um carregamento transversal intenso, colocando-a sob o regime de plasticidade. Para utilização do modelo bilinear plástico, o modelo de material BILINEAR_PLASTICITY é empregado, sendo especificado dentro do bloco PARTS. Diferentemente dos outros modelos, são necessários parâmetros adicionais para especificar o comportamento do material. A lista de valores requeridos e os tipos de dados esperados são dados pelo plugin que implementa a relação constitutiva. A Listagem D.6 ilustra como isso é feito.

Neste exemplo, o modelo numérico (nós, elementos, conjuntos e curvas) é declarado num arquivo em separado, incluído através da diretiva de pré-processamento @include. Como esse tipo de instrução é processada antes da avaliação dos blocos, qualquer trecho do arquivo de entrada pode ser transportado para outros arquivos, com a possibilidade de encadear múltiplas inclusões. Para o programa, a inclusão de um arquivo equivale ao que, para o usuário, seria a inserção direta de seu conteúdo no ponto especificado. O programa também define outras diretivas de pré-processamento que influenciam quais partes de um arquivo de entrada são processadas, similarmente aos pré-processadores de linguagens de programação, como $\mathrm{C} / \mathrm{C}++$. Contudo, elas não cabem na discussão deste trabalho. 
Listagem D.6: Arquivo de entrada do Teste não-linear 2.

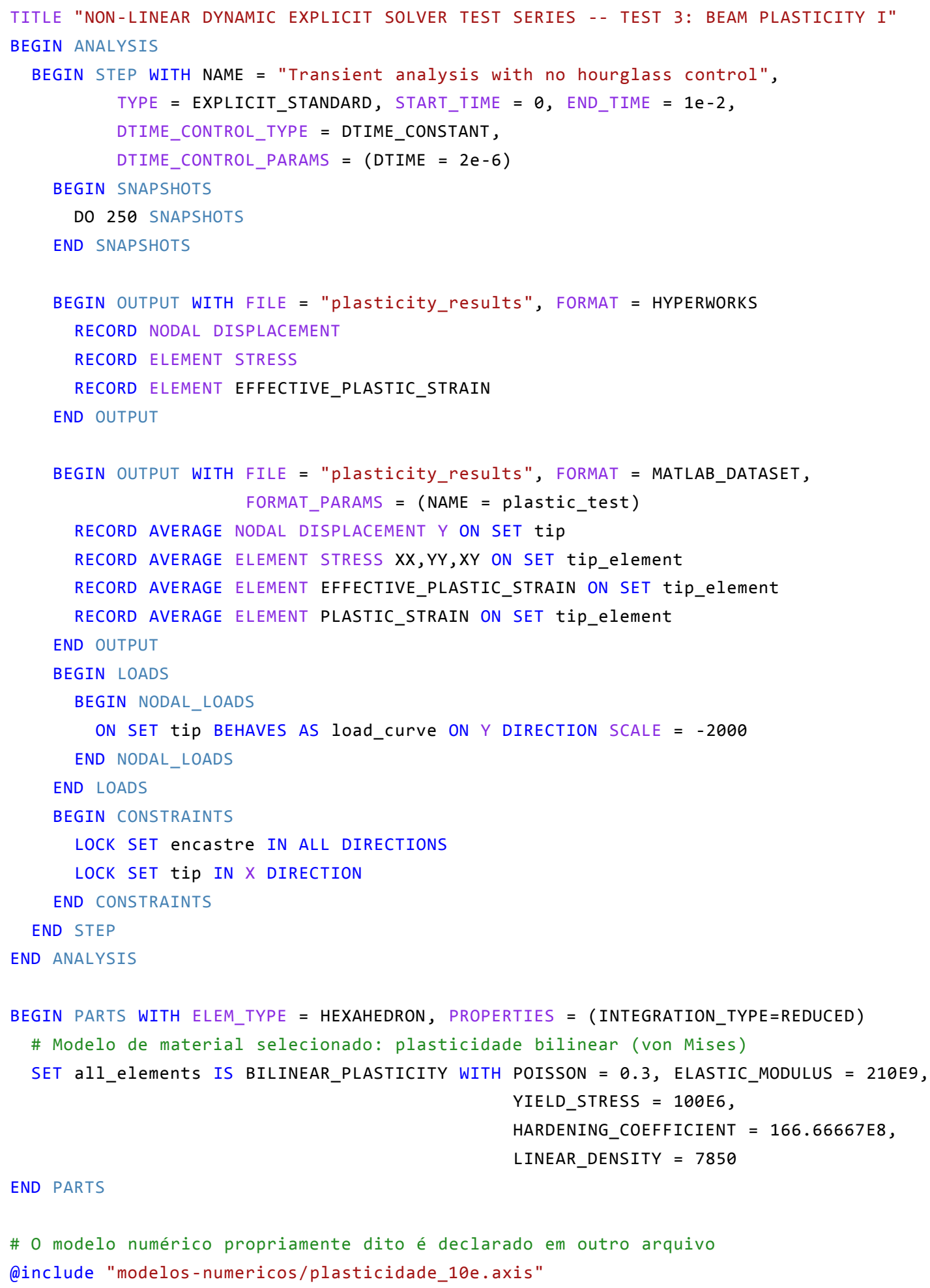




\section{APÊNDICE E}

\section{Arquivo de configuração do programa}

O arquivo de configuração do Axis é descrito em linguagem XML, um padrão aberto, amplamente utilizado para a codificação estruturada de dados. Os plugins carregados pelo programa são enumerados no arquivo e classificados em níveis de privilégios.

As funcionalidades oferecidas por um plugin, através de classes provedoras, podem ser substituídas por outras equivalentes. Por exemplo, o plugin Standard Material oferece o modelo de material hipo-elasto-plástico bilinear. Um outro componente pode, ao ser carregado, sobrescrever esse modelo de material, oferecendo uma versão melhorada (eg. encruamento linear ponto a ponto), sem a necessidade de reescrever arquivos de entrada que utilizam o modelo, tornando a atualização transparente.

Três níveis de privilégios são definidos, a saber:

- Plugins do sistema. São os componentes que podem sobrescrever funcionalidades padrão do programa. É identificado pelo elemento XML system_plugins;

- Plugins estáveis. Plugins deste nível não podem sobrescrever funcionalidades padrão do sistema ou aquelas definidas no nível de privilégio anterior. É identificado pelo elemento XML stable_plugins;

- Plugins voláteis. Componentes deste nível podem sobrescrever apenas funcionalidades de plugins estáveis. É identificado pelo elemento XML volatile_plugins. 
Os níveis de privilégios protegem as funcionalidades de serem sobrescritas por acidente. Quando mais de um plugin define o mesmo recurso dentro de um nível de privilégio, isso denota uma configuração incorreta e a inicialização do programa falha.

A Listagem E.1 mostra um exemplo de arquivo de configuração do Axis. Todos os elementos de configuração são organizados dentro da raiz principal do arquivo, axis.settings. Configurações de plugins são inseridas dentro do elemento plugins, no momento o único aspecto do programa configurável pelo arquivo. Futuras capacidades do programa serão configuradas por outros elementos localizados imediatamente abaixo da raiz principal.

Cada nível de privilégio é definido dentro de plugins. Um único arquivo de plugin é especificado pelo elemento XML plugin (linhas 5 a 9 da Listagem E.1). O atributo location especifica o caminho e nome do arquivo. Todos os plugins válidos dentro de uma pasta podem ser carregados através do elemento library. O atributo location identifica a pasta que contém os arquivos. Opcionalmente, toda a estrutura de subpastas pode ser verificada, definindo o atributo recursive do elemento para o valor "yes" (por padrão, subpastas não são verificadas).

Listagem E.1: Exemplo de arquivo de configuração do Axis.

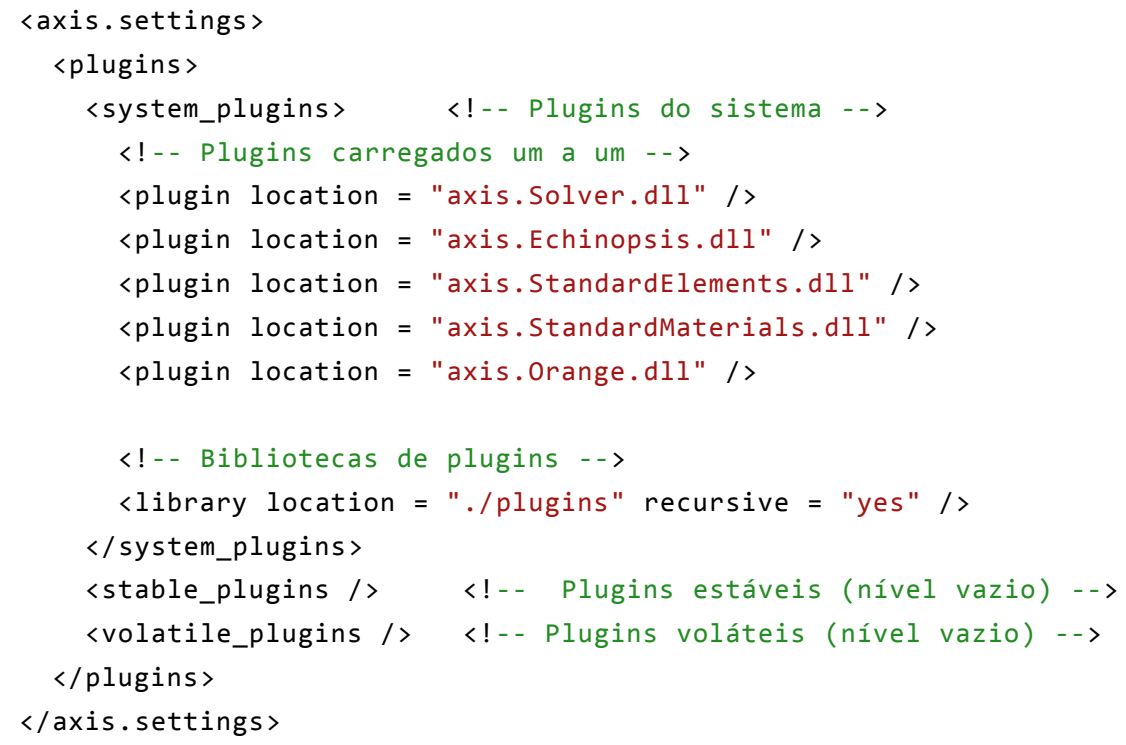




\section{APÊNDICE $F$}

\section{Codificação de kernels para a GPU}

O código de um kernel CUDA - os subprogramas que serão executados em GPU, é descrito em uma linguagem de programação convencional. Extensões são adicionadas para indicar aspectos particulares da execução, como o número de threads a alocar, quantidade de memória compartilhada, dispositivo em que será executado o subprograma, entre outros. A compilação do código resulta em duas partes distintas:

- código executável em CPU, presente na seção principal da imagem do aplicativo. A API de GPGPU insere, automaticamente, instruções para o preparo e despacho das atividades na GPU;

- código executável em GPU, anexado à imagem do aplicativo, copiado para o dispositivo antes da execução da atividade.

Definem-se três tipos de subprogramas que executam em partes do hardware distintas: os códigos de host, que são executados exclusivamente na CPU (o host), cujos dados estão presentes na memória do sistema; o código global, que, assim como o anterior, executa na CPU, mas é habilitado para disparar códigos de dispositivo, que executam exclusivamente no hardware gráfico, cujos dados estão presentes na memória da GPU (o dispositivo).

Para que as instruções do código sejam corretamente interpretadas e traduzidas em código binário (ou de montagem) do hardware de destino, num processo similar ao bootstrapping, a API CUDA modifica o sistema de compilação, conforme mostra

o diagrama da Figura F.1. 


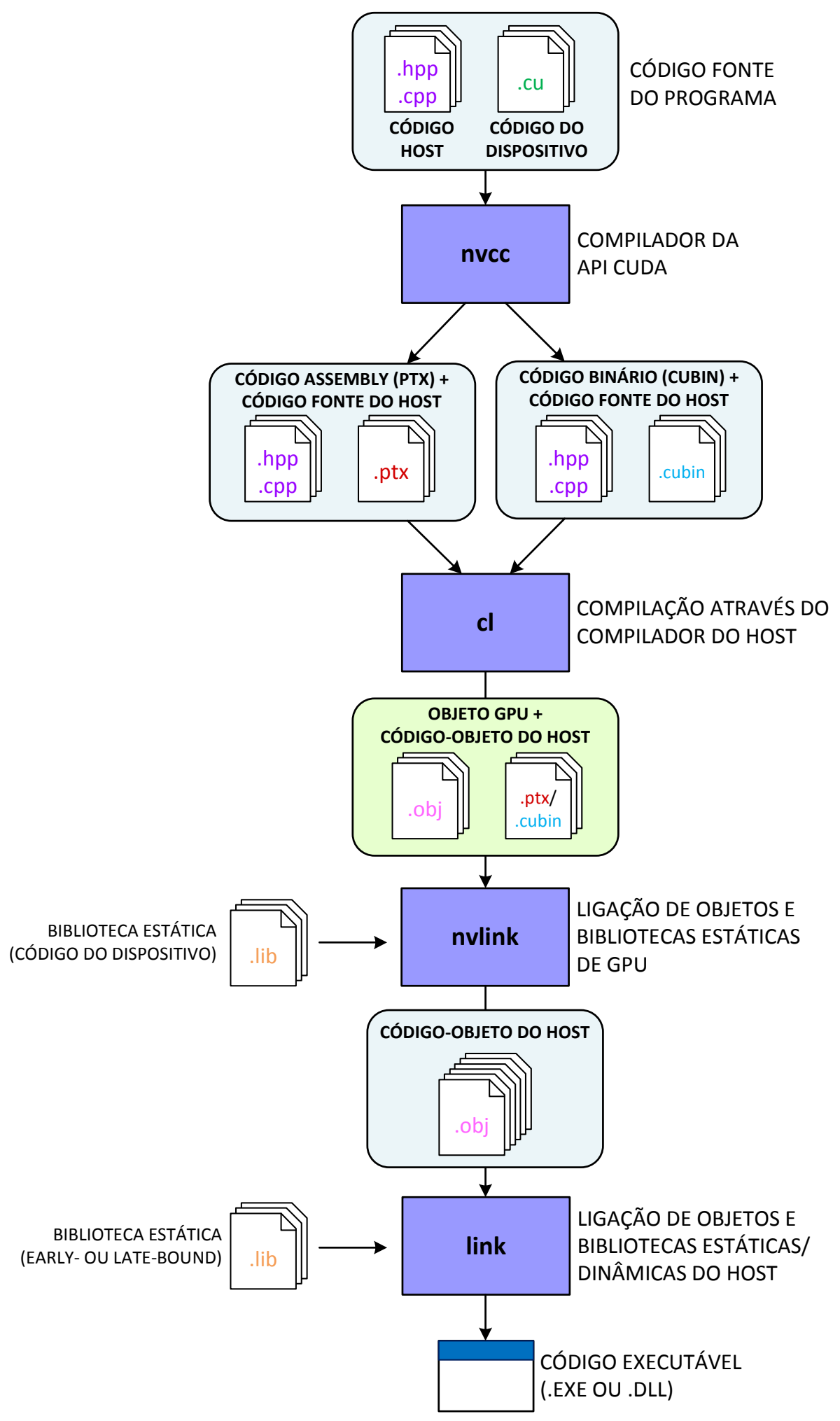

Figura F.1 Processo de compilação usando a plataforma CUDA. 
O código-fonte do programa é dividido em unidades de tradução distintas. Códigos que são exclusivamente executados no host (.cpp) e no dispositivo (.cu) são encaminhados para o compilador CUDA (nvcc), que produz, para o código de dispositivo, o código binário (.cubin) ou descrito em linguagem de montagem (.ptx), para compilação $\mathrm{JIT}^{1}$. O código do host é modificado nos locais indicados pela sintaxe estendida, inserindo as funções da API para a manipulação do dispositivo. As unidades de tradução do host são então encaminhadas para o compilador do código de host $(\mathrm{cl})$, produzindo o código-objeto correspondente.

A ferramenta de ligação do código de dispositivo (nvlink), recebe os artefatos produzidos pelo compilador associado e, juntamente com quaisquer bibliotecas estáticas usadas no código, são produzidos os códigos-objetos, onde as referências às funções de dispositivos já foram resolvidas e aptas para serem compiladas juntamente com o código de host.

Por fim, o ligador do código de host (link) interpreta os códigos-objetos gerados nas etapas anteriores, resolvendo referências a bibliotecas estáticas (early bound) ou dinâmicas (late bound) e poduzindo o código executável.

Com isso, num programa típico, para a execução de um kernel, o código produzido conjuntamente pelo desenvolvedor e pelo compilador possui os seguintes procedimentos:

1. O código de host aloca um bloco de memória que conterá as informações a serem transferidas para a GPU;

2. Ainda no host, os dados para a tarefa são inicializados no bloco alocado na memória principal do sistema;

3. Entre os dispositivos existentes no sistema atual, com suporte a CUDA, o host escolhe um para o qual serão enviadas as tarefas;

4. Uma quantidade igual de memória é alocada no dispositivo de destino, para onde serão transferidas as informações de trabalho;

5. Uma função global, executada no host, dispara a execução do kernel. A configuração do kernel, informada no ato, descreve quantas threads e como elas serão organizadas entre os SMs da GPU;

6. A menos que configurado do contrário, a execução na GPU é assíncrona; sendo assim, o host está livre para executar outras operações;

\footnotetext{
${ }^{1}$ Sigla para just-in-time, isto é, o código binário final é compilado durante a execução do programa pelo driver do dispositivo.
} 
7. Enquanto for necessário, o host pode lançar outros kernels para trabalhar sobre os dados transmitidos, pois a alocação de memória é permanente enquanto o processo do programa durar;

8. Com a tarefa concluída, o código de CPU transfere os dados da GPU de volta para a memória principal do sistema;

9. A memória da GPU é desalocada pelo host.

Para que se obtenha a vantagem na vazão de dados que a GPU proporciona em relação a CPU, é importante que algoritmos do programa sejam corretamente adaptados para o novo modelo de programação, podendo melhor usufruir das capacidades intrínsecas do hardware. Isso envolve, principalmente, a presença dos seguintes aspectos [81]:

- Modelo de execução escalável. Para que o programa possa se beneficiar do poder de paralelismo da GPU, as tarefas disparadas devem, sempre que possível, saturar o sistema de processamento. Comunicações e primitivas de sincronização entre threads devem ser mantidas ao mínimo. Dessa forma, o desempenho do programa acompanhará atualizações do dispositivo por hardware mais potente, desde que o problema permita a ocupação completa do sistema;

- Otimização do uso de memória. A arquitetura de memória da GPU é diferente da empregada na memória do sistema. Colocado de uma forma simples, acessos aleatórios das threads a endereços de memória, de uma forma não padronizada, e a duplicidade excessiva das informações (threads se referem à mesma informação, cada qual referenciando uma cópia em endereços de memória distintos) dificultam a coalescência dos acessos ao recurso, degradando substancialmente o desempenho; 